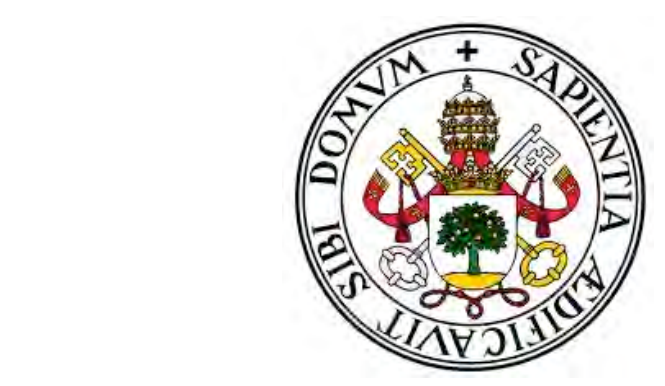

Universidad de Valladolid

FACULTAD DE MEDICINA

DEPARTAMENTO DE MEDICINA, DERMATOLOGÍA Y TOXICOLOGÍA

TESIS DOCTORAL

\title{
EFECTOS METABÓLICOS DE LA GASTRECTOMÍA VERTICAL EN UN MODELO DE RATA DIABÉTICA NO OBESA.
}

Presentada por MARIO ALBERTO MONTES MANRIQUE para optar al grado de doctor por la Universidad de Valladolid.

Dirigida por:

Dr. Daniel A. De Luis Román

Dr. David Pacheco Sánchez 



\section{Universidad deValladolid}

\section{AUTORIZACIÓN DEL DIRECTOR DE TESIS}

(Art. 2.1. c de la Normativa para la presentación y defensa de la Tesis Doctoral en la UVa)

D. Daniel Antonio de Luis Román, con D.N.I. n ${ }^{\circ}$ 12378804-C profesor del departamento de Medicina, Dermatología y Toxicología como Director de la Tesis Doctoral titulada Efectos metabólicos de la gastrectomía vertical en un modelo de rata diabética no obesa, presentada por Mario Alberto Montes Manrique, autoriza la presentación de la misma, considerando que la estructura y ejecución de este trabajo se ajusta a los objetivos propuestos inicialmente en su redacción y por ello puede ser presentada como trabajo original para la obtención del Titulo de Doctor.

Valladolid, 18 de febrero de 2013

El Director de la Tesis,

Fdo.: Daniel A. de Luis Román

ILMO. SR. PRESIDENTE DE LA COMISIÓN DE DOCTORADO 



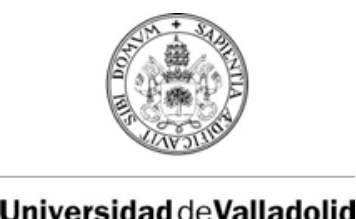

\section{AUTORIZACIÓN DEL DIRECTOR DE TESIS}

(Art. 2.1. c de la Normativa para la presentación y defensa de la Tesis Doctoral en la UVa)

D. David Pacheco Sánchez, con D.N.I. n DNI: 07481413I, profesor del departamento de Cirugía, como Director de la Tesis Doctoral titulada Efectos metabólicos de la gastrectomía vertical en un modelo de rata diabética no obesa, presentada por Mario Alberto Montes Manrique, autoriza la presentación de la misma, considerando que la estructura y ejecución de este trabajo se ajusta a los objetivos propuestos inicialmente en su redacción y por ello puede ser presentada como trabajo original para la obtención del Titulo de Doctor.

Valladolid, 18 de febrero de 2013

El Director de la Tesis,

Fdo.: David Pacheco Sánchez. 

Un poco de ciencia aleja de Dios, pero mucha ciencia devuelve a Él. 

AGRADECIMIENTOS. 

La realización de este trabajo habría sido imposible sin la colaboración de muchas personas. Quiero agradecer especialmente:

Al Dr. Daniel de Luis y al Dr. David Pacheco por permitirme participar en su grupo de investigación y poner a mi disposición sus valiosos conocimientos, experiencia y recursos para la realización de este proyecto tan interesante.

Al Dr. Manuel González Sagrado por su invaluable colaboración en la realización del análisis estadístico y otros aspectos de este trabajo.

Al Dr. Ciro Casadiego. Espero que en un futuro podamos tener nuevos proyectos en común.

A mis compañeros y amigos del Servicio de Cirugía General del Hospital del Río Hortega en especial a Alejandro Romero, Enrique Asensio y Fernando Labarga.

Al Dr. Angel Barcia del animalario de la Facultad de Medicina de la Universidad de Valladolid, por su apoyo y consejos para el cuidado y el bienestar de los animales utilizados en el experimento.

Al personal de la Unidad de Investigación, en especial a David Primo por su inestimable colaboración en el desarrollo del trabajo realizado.

A Ma. Luz de Andrés de la Biblioteca del Hospital Río Hortega por su disposición a ayudar y buen ánimo.

El agradecimiento más profundo es a las personas a las que dedico este trabajo:

A mis padres y a mi hermano porque aún en la distancia siento su cariño cada día con más fuerza.

Gracias por acompañarme en cada momento de este duro camino.

Especialmente a mis tres chicas, Azucena, María Alejandra y Lucía, los motores de mi vida. Soy un hombre afortunado por tenerlas.

Las adoro y esto es por ustedes. 

ÍNDICE. 



\section{INDICE}

1. DIABETES MELLITUS

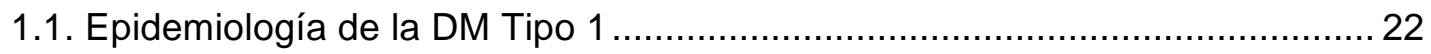

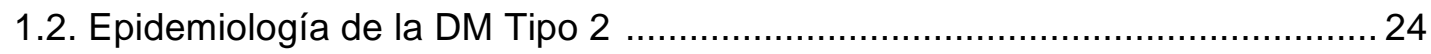

1.2.1. Prevalencia de la DM Tipo 2 en España,........................................ 25

1.3. Etiopatogenia y Clasificación de la Diabetes Mellitus.

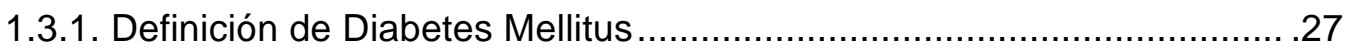

1.3.2. Clasificación de la Diabetes Mellitus ….............................................. 28

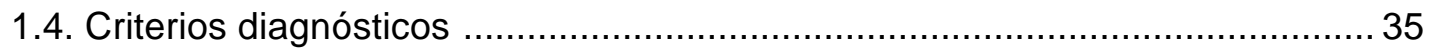

1.5. Manifestaciones Clínicas de la Diabetes Mellitus

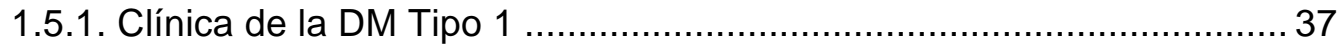

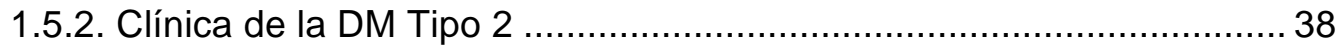

1.6. Tratamiento

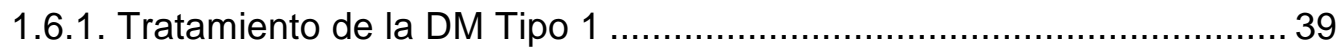

1.6.2. Tratamiento de la DM Tipo 2 ........................................................ 40

1.6.3. Nuevos tratamientos en Diabetes........................................................ 44

1.7. Complicaciones de la Diabetes Mellitus.

1.7.1. Complicaciones agudas de la Diabetes Mellitus ..............................51

1.7.2. Complicaciones crónicas de la Diabetes Mellitus ...............................52

2. FISIOLOGÍA DEL ISLOTE PANCREÁTICO. INSULINA Y GLUCAGÓN.

2.1. Estructura y Función del páncreas endocrino .............................................. 58

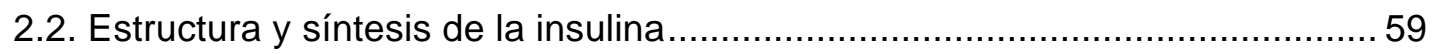

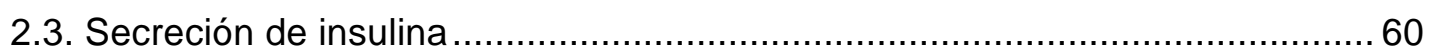

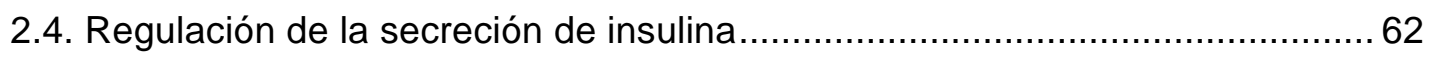

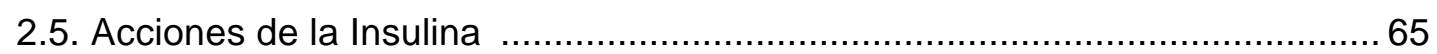

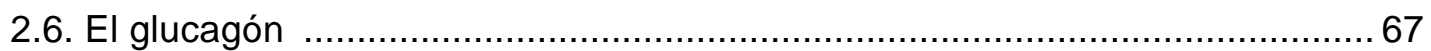

3. REVISIÓN DE LA OBESIDAD.

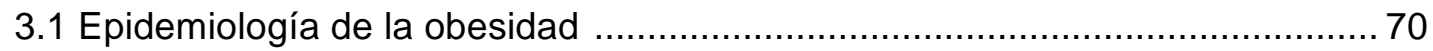

3.1.1. Prevalencia de la obesidad en España ............................................ 71 


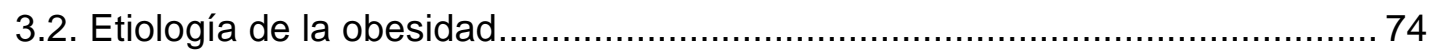

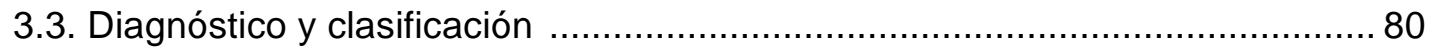

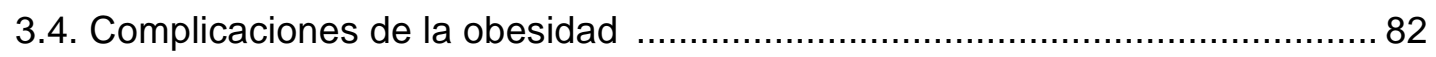

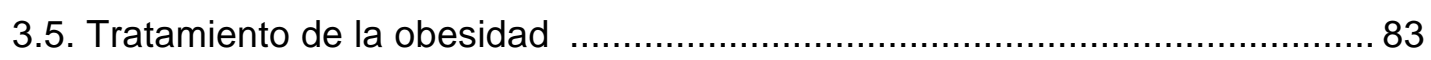

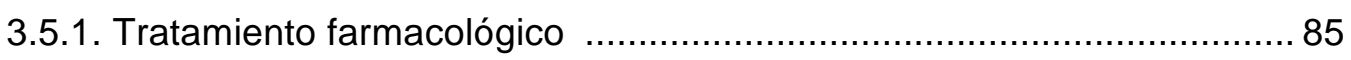

3.5.2. Tratamiento quirúrgico. Cirugía bariátrica ......................................... 89

4. SINDROME METABÓLICO.

4.1. Criterios para el diagnóstico del Síndrome Metabólico ................................. 91

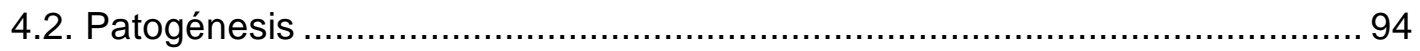

5. CIRUGÍA BARIÁTRICA Y METABÓLICA.

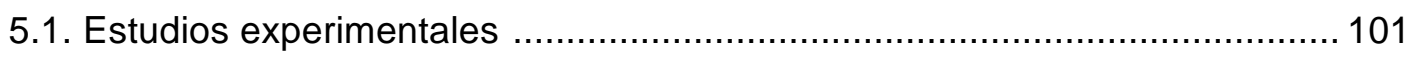

5.2. Procedimientos malabsortivos .......................................................... 103

5.2.1. Bypass yeyuno-ileal y derivación yeyuno-cólica. ............................ 103

5.3. Procedimientos combinados ............................................................... 104

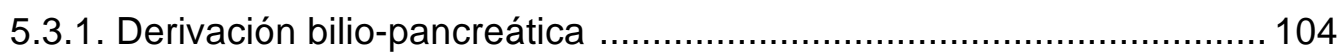

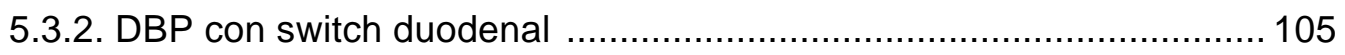

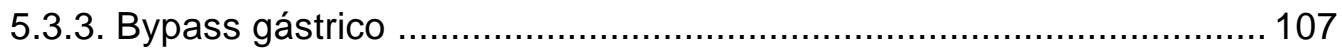

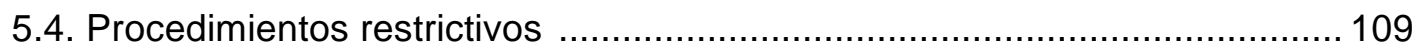

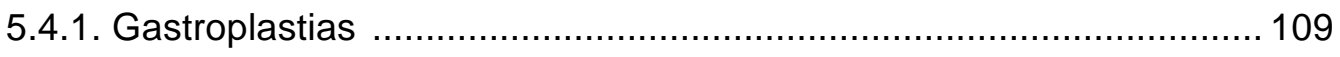

5.4.2. Banda gástrica ajustable ..................................................... 111

5.4.3. Gastrectomía en banda o vertical ............................................... 113

5.5. Laparoscopia en cirugía bariátrica ...................................................... 114

5.6. Fisiología de la pérdida de peso tras cirugía bariátrica.

5.6.1. El eje endocrino-entero-encefálico, obesidad y CB ....................... 116

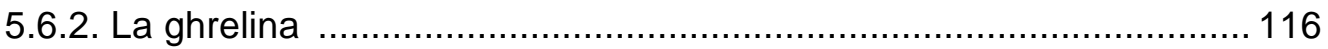

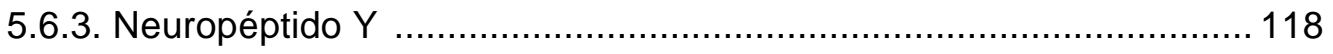

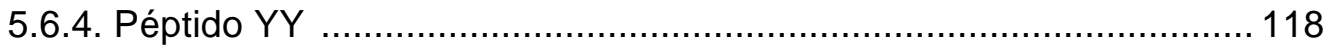

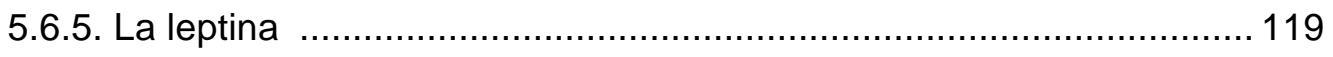

5.7. Impacto de la cirugía bariátrica en la morbilidad asociada a la obesidad.

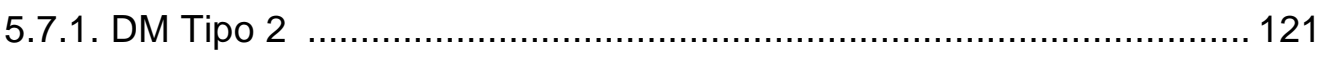

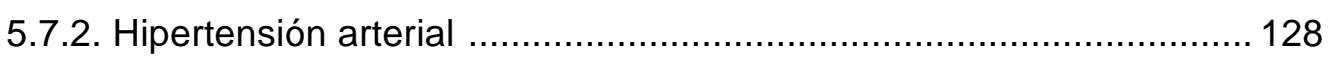

5.7.3. Hiperlipidemia .................................................................... 129

5.7.4. Trastornos cardio-vasculares .................................................... 130

5.7.5. Apnea obstructiva del sueño y asma ............................................ 131

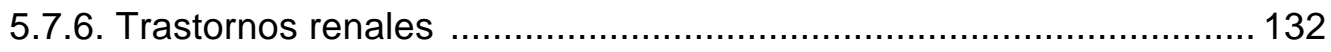

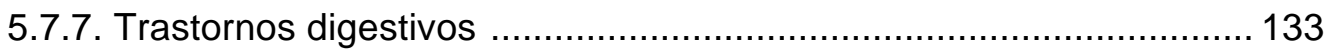

5.7.8. Trastornos musculo-esqueléticos ............................................ 134 
5.7.9. Trastornos psicológicos, neurológicos y sexuales 135

5.7.10. Cáncer

5.8. El futuro cercano

5.8.1. Algunas intervenciones quirúrgicas en evolución 138

5.8.2. Nuevas indicaciones en CB: La cirugía metabólica 140

5.8.3. Nuevas técnicas quirúrgicas 141

5.8.4. Endoscopia en procedimientos bariátricos 142

5.8.5. La electroestimulación gástrica 144

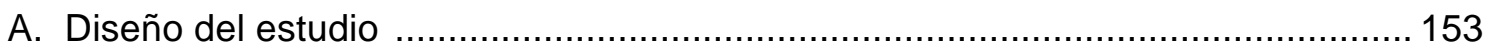

B. Protocolo experimental y variables recogidas .................................................. 153

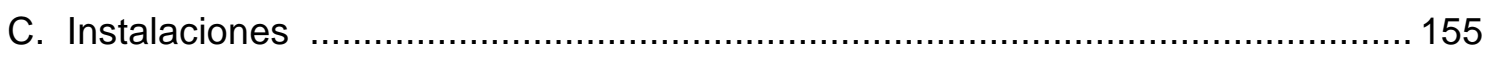

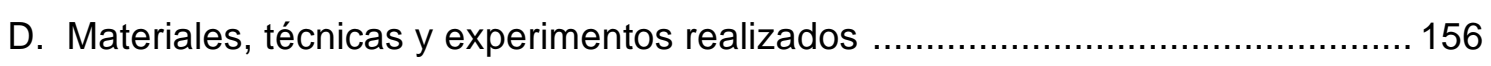

E. Experimentos in vivo

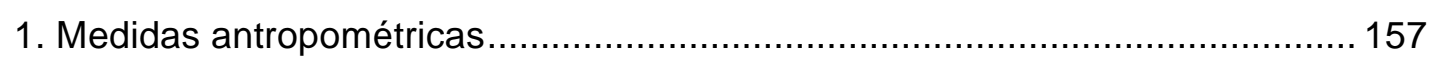

2. Test de tolerancia oral a la glucosa ........................................................ 158

3. Obtención de muestras para determinaciones hormonales ........................... 160

4. Técnica quirúrgica: Gastrectomía vertical ............................................... 161

F. Experimentos in vitro.

I. Estudios en islotes pancreáticos aislados.

1. Preparación de disoluciones para islotes pancreáticos aislados ................. 168

2. Preparación y microdisección del tejido pancreático .................................... 169

3. Aislamiento de los islotes ............................................................. 171

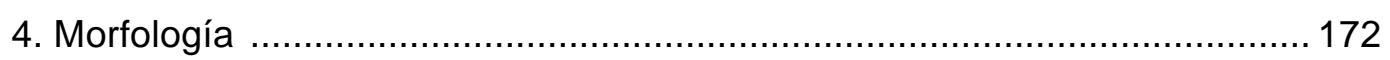

5. Incubación y medida de la secreción de los islotes .................................. 172

6. Sonicado. Medida del contenido de insulina en el islote ............................ 173

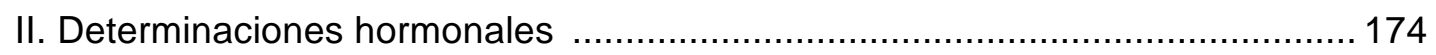

III. Reacción en Cadena de la Polimerasa (RCP) .......................................... 182

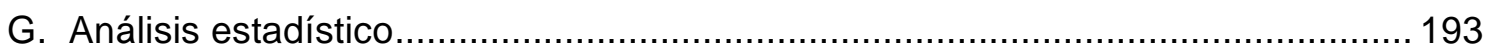

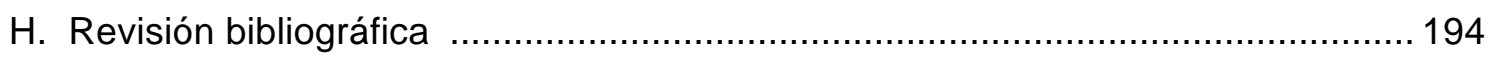

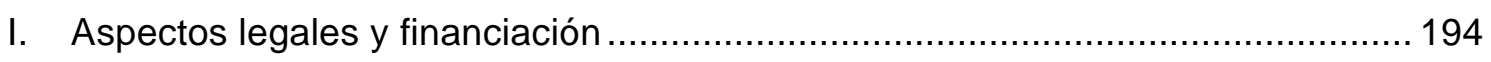


SECCION 1. RESULTADOS DE LOS ENSAYOS IN VIVO.

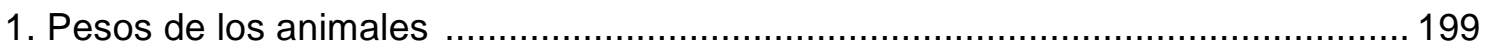

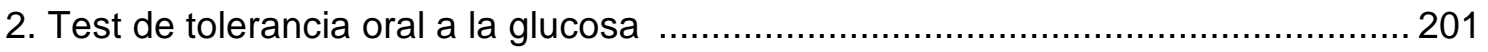

3. Resultados de los péptidos entero-insulares.

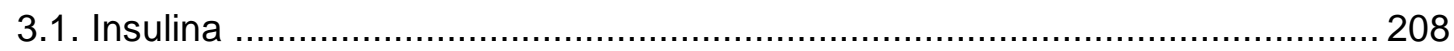

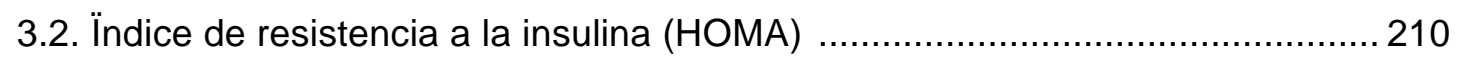

3.3. Ïndice de sensibiidad a la insulina (QUICKi) ……...................................... 212

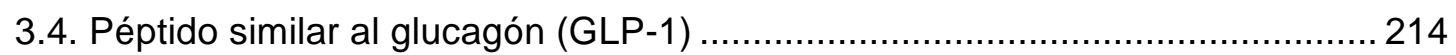

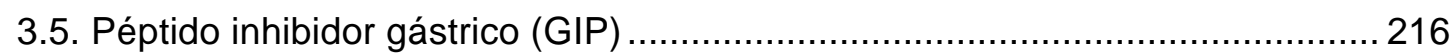

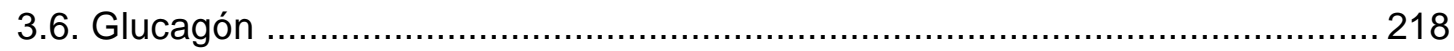

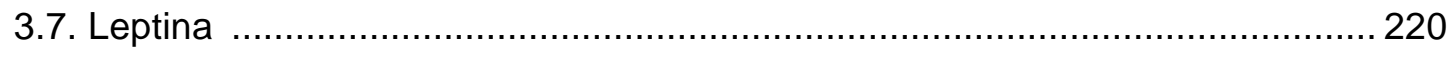

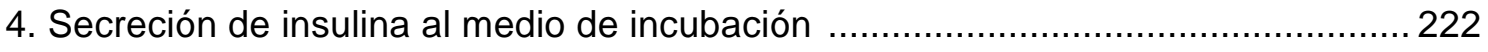

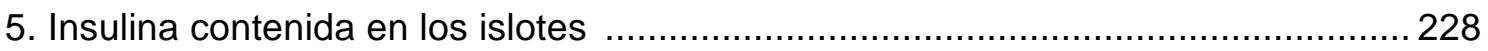

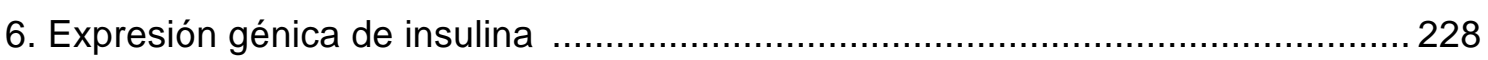

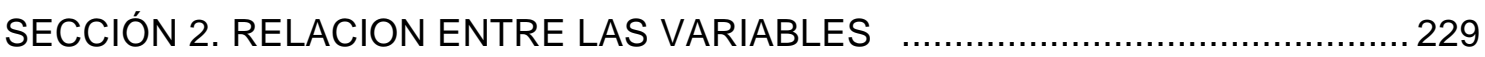

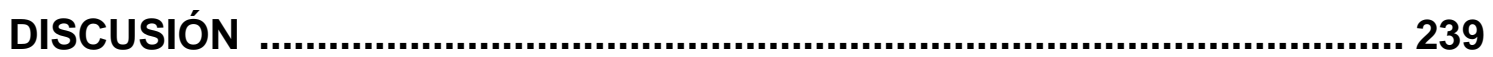

1. Elección del modelo y de la técnica quirúrgica ...................................................... 241

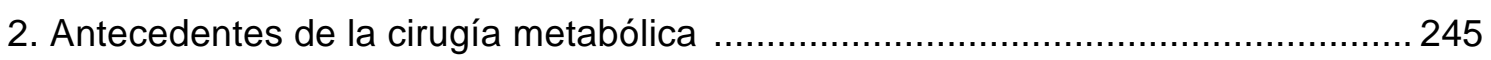

3. Resultados sobre el peso y el control glucémico tras la GV ................................. 251

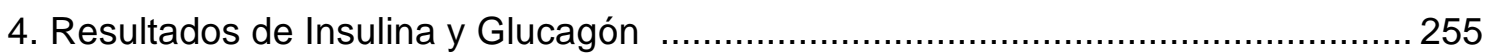

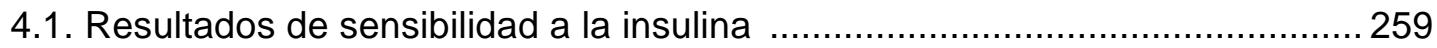

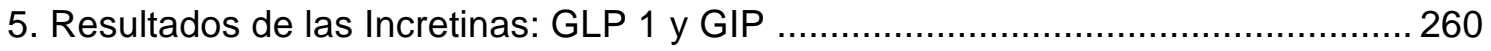

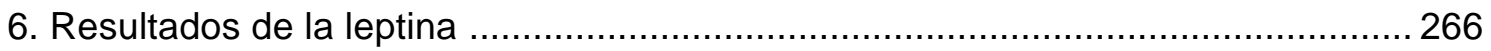

7. Resultados del contenido de insulina en el islote ............................................... 270

8. Resultados de secreción de insulina al medio por los islotes ............................... 272

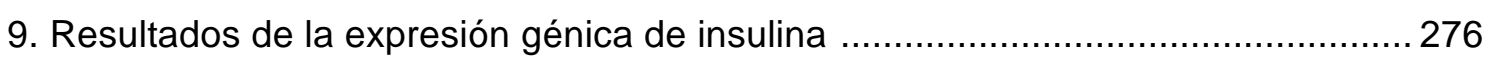

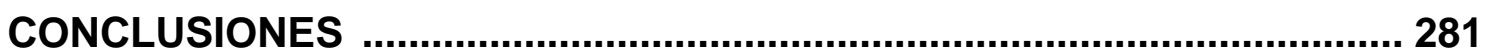

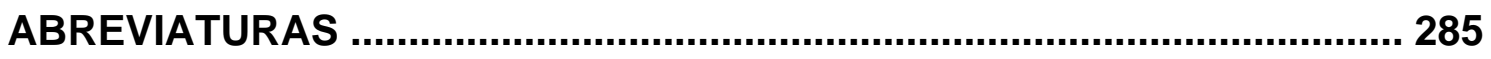

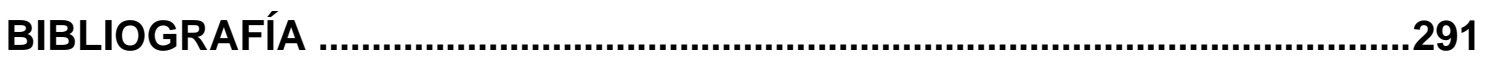


INTRODUCCIÓN. 





\section{DIABETES MELLITUS}

La diabetes mellitus (DM) es una de las principales enfermedades a nivel mundial teniendo en cuenta su prevalencia y repercusión sociosanitaria, no sólo por su elevada frecuencia, sino también por el impacto de las complicaciones crónicas de la enfermedad. La prevalencia de la diabetes en el mundo en el año 2000 fue de 171 millones de personas y se calcula que en 2030 podría llegar a los 366 millones (Roglic G, et al, 2005). La prevalencia de la Diabetes en los Estados Unidos se calcula entre un 4.4 y un $17.9 \%$ (media 8.2\%) (Cory, et al, 2010) Sin embargo debido a la enfermedad macro y microvascular asociada, la DM produce cerca del $14 \%$ del gasto sanitario del Sistema de Salud de los Estados Unidos, siendo complicaciones importantes el Infarto del Miocardio, Insuficiencia renal terminal, retinopatía y pie diabético. (Mokdad AH, et al, 2003)

Según los datos de la Hoja Nacional de Registro de Datos en diabetes de los Estados Unidos de la Asociación Americana de la Diabetes (ADA) en 2011 hay una prevalencia total de 25,8 millones de niños y adultos ( $8,3 \%$ de la población) con cerca de un tercio de casos sin diagnosticar y otras 79 millones de personas con intolerancia a la glucosa.

En 2010 fueron diagnosticados 1,9 millones de nuevos casos de diabetes en personas de más de 20 años de edad. A nivel mundial se estima que se pasaran de los 171 millones de diabéticos en el año 2000 a 366 millones en el año 2030 (Wild S, et al, 2004). En la población de menores de 20 años de edad, se estima la cifra en 215.000 , o un $0,26 \%$ de todas las personas de este grupo de edad tienen diabetes. (Datos de la Asociación Americana de la Diabetes)

En la mayoría de los países europeos la prevalencia de la DM es superior al 5\%, aunque existen notables diferencias entre determinadas zonas geográficas y, sobre todo, entre individuos de ciertos grupos étnicos (Roglic G, et al, 2005). Aumenta claramente con la edad, de manera que en Estados Unidos, por cada 1000 habitantes existen 17 diabéticos en el grupo de edad comprendido entre 20 y 39 años, 64 en el de 40 a 49 años, 126 en el de 50 a 59 años, 188 entre 60 y 74 años y 189 en los mayores de 75 años. En Latinoamérica se pasa de menos del 5\% en menores de 30 años a más del $20 \%$ en mayores de 60 años y en Europa se sitúa entre el 10 y el $20 \%$ en personas entre 60 y 79 años (Roglic G, et al, 2005). 
Numerosos factores, en adición a los relacionados directamente con las complicaciones médicas, contribuyen al impacto de la diabetes en aspectos como la calidad de vida o el gasto sanitario. La diabetes, así mismo está asociada con una alta prevalencia de desordenes afectivos y a un impacto en el absentismo y la disminución de la productividad laboral (Tuncelli K, et al, 2005).

\subsection{EPIDEMIOLOGÍA DE LA DIABETES MELLITUS TIPO 1.}

Los informes preliminares del proyecto DIAMOND en el año 2000 describen la incidencia de DM 1 en niños menores de 14 años de edad o menos en 50 países en todo el mundo, con un total de 19.164 casos de una población de 75,1 millones de niños (un 4,5\% de la población mundial en este rango de edad) desde 1990 a 1994.

Se ha encontrado una diferencia de más de 350 veces en la incidencia de DM1 entre diversas poblaciones. Por ejemplo, se encontraron incidencias que van desde un mínimo de 0.1/100.000 al año en China y Venezuela hasta un máximo de $36.5 / 100.000$ en Finlandia y 36.8/100.000 por año en Cerdeña.

La incidencia más baja (<1/100.000 al año) se registró en las poblaciones de China y América del Sur y las incidencias más altas (> 20/100.000 por año) se detectaron en Cerdeña, Finlandia, Suecia, Noruega, Portugal, el Reino Unido, Canadá y Nueva Zelanda. Las poblaciones de los EE.UU incluidas en el estudio DIAMOND procedentes de los estados de Pennsylvania, Alabama e Illinois, tuvieron una incidencia entre 10 a 20/100, 000 por año.

Aproximadamente en la mitad de la población europea se encontró una incidencia moderada entre el 5 y 10/100.000 por año, encontrando tasas más altas en la mitad restante (Karvonen M, et al, 2000). La incidencia de DM1 aumenta con la edad en la mayoría de las poblaciones con mayor incidencia, en niños de 10 a 14 años.

Se observa también una variación geográfica dentro del mismo país como es el caso de Italia continental y Cerdeña con tasas en esta última 3 a 5 veces superiores, encontrando similares variaciones en Portugal, Nueva Zelanda y China (Maahs DM, et al, 2010). 
Se piensa que buena parte del aumento del riesgo de DM de tipo 1 es el reflejo de la frecuencia de alelos del antígeno leucocitario humano (human leukocyte antigen, HLA) de alto riesgo en grupos étnicos de diferentes zonas geográficas.

La edad es un factor condicionante en la aparición de DM tipo 1, el pico más acusado es alrededor de los 12 a los 14 años de edad. Aunque se trata de una enfermedad que aparece clásicamente en niños y adolescentes, la aparición de casos nuevos a partir de los 20 años ha aumentado en numerosos países, entre ellos en España.

La incidencia observada en Cataluña (Goday A., 2002) en un estudio entre 1987-1990 para el grupo de edad de 0-14 años fue de 11,3/100.000 habitantes año, siendo para el grupo de 15-29 años de 9,9/100.000 habitantes/año. La incidencia es mínima entre los 0 y 5 años, y máxima a los 13-14 años. En el grupo de 0 a 14 años no existen diferencias en la incidencia por sexos, mientras que entre 15 y 30 años se observa un claro predominio de varones. Como en otros países, la incidencia de DM1 sigue un patrón estacional, con picos de incidencia en los meses fríos del año. El estudio de la Comunidad Autónoma de Madrid incluye todos los casos de edad inferior a 15 años sobre una población de riesgo (menores de 15 años) de 1.105.243 habitantes en el periodo 1985-1988. La incidencia estimada fue de 11,3/100.000 habitantes año.

Otros estudios realizados en Málaga, Navarra, Extremadura y Canarias, incluyendo los grupos de edad 0-14 años obtuvieron resultados muy similares a los anteriormente expuestos. La comparación de los estudios realizados ha permitido estimar la incidencia absoluta para toda España, por provincias y comunidades autónomas.

Los datos más recientes del registro de diabetes mellitus tipo 1 (DM1) de Málaga demuestran un evidente aumento en la incidencia de la enfermedad, de forma que si en las publicaciones iniciales la tasa inicial durante el periodo 1982-1988 se fijaba en 11 casos por 100.000 habitantes y año, la investigación de periodos más recientes sitúa esta tasa en valores muy superiores, próximos a 18 casos por 100.000 habitantes y año. Una situación similar se ha observado en Navarra. Por el contrario, el registro catalán de DM1, desarrollado de forma prospectiva desde 1987, sobre una base poblacional de dos millones y medio de personas menores de 30 años, ha demostrado una tasa de incidencia relativamente constante. Tampoco se han podido detectar cambios importantes en la incidencia de la enfermedad en Badajoz durante el periodo 1992-1996. 


\subsection{EPIDEMIOLOGÍA DE LA DIABETES MELLITUS TIPO 2.}

La distribución mundial de la prevalencia de la diabetes tipo 2 sugieren que el origen de este trastorno está en una interacción compleja entre la susceptibilidad genética, el desarrollo temprano y los hábitos de vida del individuo (Franks PW et al, 2007)

En muchas zonas del mundo la diabetes mellitus tipo 2 (DM 2) aparece en proporciones epidémicas, a pesar de la resistencia de algunas autoridades en utilizar este término. Tiene amplias variaciones de prevalencia a nivel mundial y su prevalencia es influida por, entre otros factores, el envejecimiento de la población en la mayoría de las regiones, el incremento de la obesidad y el sedentarismo. (Wareham NJ, 2009).

A pesar del desarrollo de nuevos fármacos, las investigaciones en las vías moleculares y los esfuerzos en educación pública, desarrollados en los últimos años, el número de estadounidenses diagnosticados de DM2 se triplicó de 1980 a 2007, aumentando de 5,6 millones a 17,4 millones de casos. Las estimaciones de casos no diagnosticados de DM2 en los Estados Unidos siguen aumentando constantemente. La Organización Mundial de la Salud estima que en 2030 los Estados Unidos tendrán 30,3 millones de los casos (Pories WJ, et al, 2011).

Dentro de los Estados Unidos, 1 de cada 10 personas mayores de 20 años de edad y 1 de cada 4 personas mayores de 60 años actualmente sufren de diabetes tipo 2.

La epidemia de diabetes parece estar empeorando. Un estudio reciente estima que uno de cada tres estadounidenses nacidos en el año 2000 desarrollará diabetes durante el curso de su vida. Los afroamericanos, los hispanos o latinos, indios americanos, y los nativos hawaianos y otros isleños del Pacífico están particularmente en alto riesgo de desarrollar DM2 y sus complicaciones. Los afroamericanos tienen una probabilidad $70 \%$ mayor de desarrollar diabetes durante toda su vida en comparación con los estadounidenses blancos. (Pories WJ, et al, 2011).

En el estudio DECODE, que incluye 13 estudios de 9 países europeos entre los cuales hay 3 españoles, concluye que en la mayoría de países europeos la incidencia de DM 2 es de baja a moderada $(<10 \%$ en menores de 60 años y del $10-20 \%$ en personas de 60 a 80 años) (DECODE Study Group, 2003) 
En general, las poblaciones más afectadas son aquellas donde el estilo de vida tradicional ha dejado paso al estilo occidental, como ocurre en muchos países de Latinoamérica.

La DM tipo 2 afecta también a niños y jóvenes; se ha visto un incremento en la prevalencia en estos grupos de edad coincidiendo con aumentos en las tasas de obesidad (Pinhas-Hamiel O, et al, 2005). Un estudio realizado en Ohio (EE.UU.), resalta la incidencia entre los 10 y 19 años que pasó de 0,7/100.000 en 1982 a 7,2/100.000 en 1994 (Pinhas-Hamiel O, et al, 1996). Esta incidencia creciente en DM 2 en los jóvenes se confirma en estudios realizados en otros países como Argentina, Tailandia y Japón, con una incidencia que cambio en este último de 1.73/100.000 antes de 1981 a 2.73/100.000 en años posteriores (Urakami T, et al, 2005). En cuanto al sexo existen prevalencias semejantes entre hombres y mujeres.

\subsubsection{Prevalencia de la Diabetes Tipo 2 en España}

Según los datos de del Ministerio de Sanidad de España: Estrategia en Diabetes del Sistema Nacional de Salud (2006), basados en diferentes estudios realizados en la pasada década, la prevalencia de DM en España se sitúa en torno a un 6,5\% para la población entre los 30 y 65 años, oscilando en diferentes estudios entre el 6 y el 12\% (Goday A, et al, 2006).

Sin embargo los datos del estudio di@bet.es (Soringer F, et al, 2012) reportan cifras cercanas al $30 \%$ de la población con alguna alteración en el control de la glucosa. La prevalencia total de diabetes mellitus en el estudio fue de un $13.8 \%$, de los cuales la mitad de los pacientes no sabían que tenían la enfermedad. A su vez el estudio reporta una tasa de tolerancia anormal a la glucosa del $9.2 \%$ de la población, con una glucemia basal alterada en el $3.4 \%$ de los individuos analizados.

Entre 1984 y 1985 se realizó en Lejona (Vizcaya) un estudio transversal para conocer la prevalencia de la DM 2 a partir de una muestra de 862 habitantes mayores de 30 años seleccionados aleatoriamente de una población censada de 11.515 habitantes (Bayo J. et al, 1993). La prevalencia observada de DM fue de un 6,4\%, de la que el $3,6 \%$ correspondía a DM no conocida y un $2,8 \%$ a DM conocida (Bayo J, 1996).

La prevalencia de la DM 2 en Cataluña en 2005 fue de 3.839 individuos de 30 a 89 años de edad con los criterios de la Organización Mundial de la Salud (OMS) en 1985. La prevalencia total de diabetes para el grupo de 30-89 años fue de un 10,3\%, con 
unas tasas de DM conocida e ignorada del 6,4 y 3,4 en varones, y del 6,9 y 3.4 en mujeres, respectivamente. La prevalencia ajustada para el grupo de edad 30-64 años fue del $6,1 \%$ (7,1\% en varones y $5,2 \%$ en mujeres). En relación con la edad, la prevalencia es mínima en el grupo de edad de 30 a 49 años, con una tasa del 2,5\% y máxima en el grupo de 70 a 89 años, con una tasa del 24\% (Roglic G. et al, 2005).

En el estudio de Guía (Gran Canaria) la mayoría de la población es de origen canario. El municipio tiene 12.383 habitantes y la prevalencia de DM fue del 15,9\% (criterios de 1997 de la ADA). La prevalencia de DM ajustada a la población mundial de Segi fue del $12,4 \%$ (Criterios de la OMS de 1985). Esto representa la prevalencia más elevada de toda Europa (De Pablos et al., 2001).

Los estudios de prevalencia más recientes detectan tasas más altas. Así, en el estudio realizado en Asturias (Botas P., 2008), la prevalencia de DM2 global fue del 9,9\%, moderadamente elevada y similar a la observada previamente en nuestro país y en otras poblaciones de raza blanca en el mundo.

En la comunidad Valenciana las prevalencias fueron del $12,8 \%$, en Málaga del $12 \%$ y en Murcia del $12,6 \%$. Por lo tanto, se observa un aumento en la prevalencia de DM2 en España, de forma que en la década de los 80 era cerca del 5,5\%, al final de los 90 era del $10 \%$ y en la actualidad es de más del $13 \%$. (Soringer $F$, et al, 2012)

\begin{tabular}{|l|l|l|l|l|}
\hline Área & Edad & Muestra & Prevalencia DM (\%) & Año \\
\hline León & $>18$ & 572 & 5,6 & 1992 \\
\hline Lejona (Vizcaya) & $>30$ & 862 & 6,4 & 1993 \\
\hline Cerdaña (Cataluña) & $>6$ & 692 & 5,5 & 1994 \\
\hline Galicia & $40-69$ & 1.275 & 7,5 & 1995 \\
\hline Aragón & $10-74$ & 995 & 6,1 & 1997 \\
\hline Cataluña & $30-89$ & 3.839 & 10,3 & 1999 \\
\hline Asturias & $30-75$ & 1.034 & 9,9 & 2001 \\
\hline Guía (Canarias) & $>30$ & 691 & 15,9 & 2001 \\
\hline Pizarra (Málaga) & $>18$ & 1.226 & 14,7 & 2002 \\
\hline Girona & $25-74$ & 1.748 & 13,0 & 2004 \\
\hline Telde (Canarias) & $>30$ & 1.030 & 13,2 & 2005 \\
\hline Burriana (Valencia) & $30-80$ & 375 & 12,8 & 2005 \\
\hline
\end{tabular}

Tabla 1: Prevalencia de la Diabetes Tipo 2 en España. 


\subsection{ETIOPATOGENIA Y CLASIFICACION DE LA DIABETES MELLITUS}

\subsubsection{Definición de Diabetes Mellitus.}

El término Diabetes mellitus (DM) se refiere a un grupo de desórdenes metabólicos que tienen como característica común la hiperglucemia. Existen diferentes tipos de DM y son producidos por una compleja interacción de factores genéticos y ambientales.

Dependiendo de la etiología de la DM, los factores que contribuyen a la hiperglucemia pueden ser una reducción en la secreción de insulina, la disminución de la utilización de glucosa a nivel celular y un aumento de la producción de glucosa. La desregulación metabólica asociada provoca alteraciones en el metabolismo de lípidos y proteínas, produciendo a su vez cambios fisiopatológicos secundarios en múltiples órganos y sistemas que imponen una enorme carga para la persona diabética y el sistema de salud. En países desarrollados, la DM es la principal causa de enfermedad renal terminal, amputaciones de extremidades inferiores y ceguera en adultos asociando una predisposición a enfermedades cardiovasculares. (Conget el al., 2002; ADA, 2008).

Son varios los procesos patogénicos implicados en el desarrollo de la diabetes, desde la destrucción autoinmune de las células $\beta$ del páncreas con la consiguiente deficiencia de insulina, hasta alteraciones que dan lugar a la resistencia a la insulina.

La deficiente acción de la insulina sobre los tejidos diana da lugar a una inadecuada secreción de insulina y/o a una disminución de la respuesta tisular a la insulina en uno o más puntos de las complejas vías de acción de la hormona.

Los síntomas de una hiperglucemia marcada son poliuria, polidipsia, pérdida de peso, en ocasiones con polifagia, y visión borrosa. Además, puede afectar al crecimiento y aumentar la susceptibilidad a determinadas infecciones. Las consecuencias más graves de la diabetes incontrolada son la hiperglucemia con cetoacidosis o el síndrome hiperosmolar no cetósico.

Entre las complicaciones a largo plazo de la diabetes se encuentran la retinopatía con potencial pérdida de visión, la nefropatía que conduce a la insuficiencia renal, la neuropatía periférica con riesgo de úlceras en el pie, amputaciones y articulaciones de Charcot, y la neuropatía autonómica que produce síntomas gastrointestinales, genitourinarios, cardiovasculares, y disfunción sexual. Los pacientes con diabetes tienen una mayor incidencia de enfermedades cardiovasculares y enfermedad 
vascular cerebral y con frecuencia hipertensión y alteraciones en el metabolismo de lipoproteínas.

\subsubsection{Clasificación de la diabetes mellitus.}

La clasificación que se sigue en la actualidad es la propuesta en 1997 por la Asociación de Diabetes Americana, basada en la etiología de la enfermedad y se detalla en la Tabla 2. (ADA, 1997)

\section{Diabetes mellitus tipo 1}

Esta forma de DM corresponde a la anteriormente denominada diabetes mellitus juvenil o DM Tipo I. En la clasificación actual la DM1 se subdivide en dos subtipos, la DM1 A o autoinmune y DM1 B o idiopática.

\section{A. Diabetes mellitus tipo $1 \mathrm{~A}$}

La DM tipo 1 se caracteriza por la falta absoluta de insulina debida a la destrucción inmunológica de la células $\beta$ pancreáticas. Su inicio es generalmente agudo y se desarrolla en periodos de días a semanas y el 95\% de los pacientes la desarrollan antes de los 25 años (Mayfield J, 1998).

Los mecanismos relacionados con la destrucción selectiva de la célula $\beta$ son: predisposición genética, factores ambientales desencadenantes y respuesta autoinmune.

La existencia de un componente genético en la DM tipo 1 se apoya en estudios epidemiológicos que muestran una distribución geográfica característica (afectando sobre todo a áreas del norte de Europa), una agregación familiar (afectando a un 6\% de los hijos de padres con DM tipo 1) y una concordancia de un $30-40 \%$ entre gemelos homocigóticos.

Existen datos que sugieren una herencia de la DM tipo 1 de carácter poligénico y se asocia a ciertos alelos del complejo mayor de histocompatibilidad (HMC). Alrededor de un $30 \%$ de riesgo para padecer la enfermedad se asocia a la presencia de determinados haplotipos en la región que codifica para los genes antígeno leucocitario humano (HLA) y en especial con los alelos HLA DR y DQ. Además son necesarios factores ambientales que den lugar a la respuesta autoinmune en individuos predispuestos genéticamente. 
Se han señalado como agentes externos capaces de desencadenar una respuesta inmunológica específica contra la célula $\beta$ pancreática, los virus de la parotiditis, rubéola, citomegalovirus, coxsackie B4 y B5, retrovirus, reovirus y virus de la encefalomiocarditis. Determinados péptidos víricos presentan homología con proteínas propias de la célula $\beta$, es lo que se conoce como mimetismo molecular, que determinaría una respuesta inmune frente a una proteína vírica que tiene una secuencia de aminoácidos homóloga a una proteína de la célula $\beta$, desencadene también una respuesta inmune dirigida contra la célula $\beta$. Sin embargo el mimetismo molecular no se limita a infecciones víricas, existen también diversos factores nutricionales que se han relacionado con el desarrollo de DM tipo 1.

Otro posible mecanismo patogénico de la DM tipo 1 sugiere que superantígenos de origen microbiano podrían activar subpoblaciones de linfocitos T (CD8 positivos) autorreactivos contra la célula $\beta$ pancreática.

Finalmente señalar que entre los factores ambientales que pueden producir DM tipo 1 se encuentran diversos tóxicos (Tabla 2).

Existen evidencias que apoyan el carácter autoinmune de la DM tipo 1: asociación con alelos específicos del sistema HLA clase II, asociación con otras endocrinopatías de base autoinmune, infiltración linfocítica de los islotes de Langerhans, y desarrollo de anticuerpos específicos contra proteínas citoplasmáticas y de la membrana de los islotes (Redondo et al., 2002).

En el $80-85 \%$ de los pacientes con DM 1 A se detectan algún marcador serológico en forma de autoanticuerpos contra el islote pancreático, contra la insulina, contra la descarboxilasa del ácido glutámico y contra la tirosinfosfatasa (Aguilera et al., 2000).

Frente a esta forma clásica de presentación más frecuente cuanto menor es la edad en el momento del diagnóstico, cabe señalar otro tipo de DM que se conoce como LADA (Latent Autoimmune Diabetes of the Adult), que puede diagnosticarse en personas de más de 35-40 años que también presenta características autoinmunes (Tuomi, 1999). Estos pacientes generalmente son etiquetados como diabéticos Tipo 2 , presentando pobre respuesta a los antidiabéticos orales y alto riesgo de cetoacidosis. Existen estudios en marcha que buscan determinar si se puede actuar sobre la progresión de la enfermedad con el uso precoz de insulina o agentes inmunomoduladores. (Leslie RD, et al, 2006) 


\section{B. Diabetes mellitus tipo 1B o idiopática}

Algunos pacientes, usualmente de origen africano o asiático, presentan insulinopenia inicial y tendencia a la cetosis o cetoacidosis, sin encontrarse evidencia de autoinmunidad ni ninguna asociación con HLA (National Diabetes Data Group, 1995).

\section{Diabetes mellitus tipo 2}

Esta forma de DM se corresponde con la llamada diabetes del adulto o Tipo II de la anterior clasificación, sin embargo, cada vez son más frecuentes los casos de DM2 diagnosticados en jóvenes, adolescentes y niños. La DM2 supone entre el 90\% al 95\% de todos los casos de DM, afecta a un 6 - 13\% de la población española y constituye un problema sociosanitario que ha adquirido en los últimos años características epidémicas, sobre todo en los países occidentales (Conget, 2002; Soriguer F, et al, 2012).

Es un síndrome hiperglucémico heterogéneo fenogenotípicamente que se acompaña con una prevalencia que aumenta de forma paralela con la obesidad y que puede permanecer sin diagnosticar durante años. (Sullivan PW, et al, 2005)

Se encuentra determinada por componentes genéticos y ambientales (estilo de vida occidental, dieta, sedentarismo entre otros) y su herencia es claramente poligénica.

Los rasgos fisiopatológicos básicos de la DM2 son grados variables de resistencia a la insulina y un defecto de la secreción de insulina. Existe una íntima relación entre la secreción de insulina y la sensibilidad a la acción de la hormona en el control de la homeostasis de la glucosa. Ambos fenómenos suelen coexistir y participan en una proporción diferente en la fisiopatología de la enfermedad, no sólo según la población estudiada, sino también según el período evolutivo de la misma (De Fronzo, 1999).

En las situaciones en las que predomina la resistencia a la insulina, la masa de células $\beta$ sufre una trasformación capaz de aumentar su oferta de insulina, pero la hiperglucemia por si misma puede afectar el funcionamiento de las células $\beta$ y la resistencia periférica a la insulina creando un circulo vicioso que empeora el ya afectado estado metabólico. (Li Y, et al, 2004).

El riesgo de desarrollar esta forma de diabetes aumenta con la edad, la obesidad y la inactividad física. Es más frecuente en mujeres especialmente en las que tienen historia de diabetes mellitus gestacional (DMG) previa y en individuos con hipertensión 
o dislipemia y su frecuencia varía entre grupos raciales, siendo más frecuente en negros, hispánicos y nativos americanos (Mayfield, 1998).

La resistencia a la Insulina usualmente empieza muchos años antes del inicio de la DM2. Los genes claves son PPARG, CAPN10, KCNJ11, TCF7L2, HHEXIIDE, KCNQ1, FTO y MC4R, y actúan en conjunción con factores ambientales como el embarazo, inactividad física, cambios en la cantidad y calidad de nutrientes, pubertad, adiposidad entre otros, perjudicando la secreción y función de la insulina (Tahrani A, et al, 2011)

Una gran proporción de los pacientes con DM2 son obesos (80\%) y la obesidad, especialmente la de localización abdominal, genera per se resistencia a la insulina. Sin embargo, la DM2 también puede diagnosticarse en sujetos no obesos.

La prevalencia de complicaciones macro y microvasculares y neuropatía en DM2 es elevada: retinopatía en el $21 \%$, neuropatías en el 66\%, hipertensión arterial en el $65 \%$, infarto agudo de miocardio en el 34\% y vasculopatía periférica en el 37\% (Grupo UKPDS, 2000).

La obesidad ha demostrado ser un factor de riesgo independiente para el desarrollo de DM2. El mecanismo exacto por el cual la obesidad causa resistencia a la insulina es desconocido. Una teoría es que las concentraciones plasmáticas elevadas de ácidos grasos libres observados en la obesidad ayudaría a impulsar la resistencia a la insulina. Los altos niveles de ácidos grasos libres son un factor conocido en la predisposición a la inhibición de la secreción de insulina y la disminución de la absorción de glucosa en tejidos periféricos

Otra explicación podría consistir en la adiponectina, una citoquina que es liberada por el tejido adiposo que disminuye la resistencia a la insulina. Los niveles de adiponectina están disminuidos en la obesidad y esto puede conducir a un aumento de la resistencia a la insulina. Otras sustancias producidas por los adipocitos que pueden estar relacionados con el desarrollo de resistencia a la insulina en la obesidad incluyen el factor de necrosis tumoral a (TNF-a), el inhibidor del activador del plasminógeno 1, la proteína fijadora de retinol 4 y la resistina. El aumento en la cantidad de ácidos grasos libres que aparece en la obesidad aumenta los niveles de TNF-alfa, que puede conducir a un aumento de la resistencia a la insulina. Además de su asociación con un mayor riesgo de enfermedad cardiovascular, el inhibidor del activador del plasminógeno se ha identificado en varios estudios como un factor predictor 
independiente para el desarrollo de DM2. (Mc Kenney et al, 2011). La resistina es secretada por los adipocitos y disminuye la captación de glucosa mediada por los adipocitos. Aumenta de forma proporcional al incremento de masa grasa y sus niveles están relacionados con otros marcadores inflamatorios, triglicéridos, colesterol y variables antropométricas en pacientes obesos mórbidos pero se ha visto que sus niveles no están asociados a la presencia de factores relacionados o al diagnóstico de síndrome metabólico en subpoblaciones de pacientes obesos (De Luis DA, et al, 2011, 2)

\section{Otros tipos específicos}

En este apartado se engloban diversos tipos de diabetes; se incluyen desde defectos genéticos en la célula $\beta$ (diabetes MODY) o en la acción de la insulina, enfermedades del páncreas exocrino y distintos tipos de endocrinopatías hasta fármacos e infecciones involucrados en el desarrollo de la enfermedad, etc. (Tabla 2).

En su conjunto suponen menos del $10 \%$ de casos y algunas formas son muy poco frecuentes, por ello destacamos en este grupo la DM tipo MODY.

La diabetes tipo MODY (maturity onset diabetes of the young), es una forma de diabetes caracterizada por una transmisión autosómica dominante, por presentar un inicio temprano y por asociarse diferentes grados de defectos de la célula $\beta$ que limitan la secreción de insulina y de resistencia a la misma. La diabetes tipo MODY afecta, aproximadamente, al 5\% del total de pacientes con DM.

Las complicaciones crónicas asociadas a la diabetes tipo MODY, en algunos casos, pueden asemejarse a las observadas en los pacientes con diabetes tipo 1 y 2 .

Actualmente se han descrito 5 tipos de diabetes tipo MODY (Tabla 2), asociadas a mutaciones en diferentes localizaciones cromosómicas: en el gen que codifica para la enzima glucoquinasa (MODY 2), factor nuclear hepático 1a (MODY 3), factor nuclear hepático 4a (MODY 1), factor nuclear hepático 1b (MODY 5) y en el factor promotor de la insulina 1 (MODY 4). Las formas más frecuentes son MODY 2 y 3 . Los pacientes con MODY 2 presentan desde edades tempranas una hiperglucemia discreta que se mantiene estable a lo largo de la vida y que raramente requiere tratamiento farmacológico. En el caso de MODY 3 existe un progresivo deterioro de la tolerancia a la glucosa desde la pubertad, muchas veces sintomático y que en los dos tercios de los casos requiere el uso de antidiabéticos orales o insulina para el control metabólico 
de la enfermedad. En los pacientes con este tipo de diabetes se presentan con frecuencia complicaciones crónicas asociadas a la diabetes, que en algunos casos, se asemejan a la observada en los pacientes con diabetes tipos 1 y 2 (Conget et al., 2002)

\section{Diabetes mellitus gestacional}

El término diabetes gestacional se ha utilizado para definir a las mujeres con tolerancia anormal a la glucosa detectada durante el embarazo. Sin embargo, en 2010, la Asociación Internacional de Diabetes y Embarazo (IADPSG), recomienda un cambio en la terminología (Metzger BE, et al, 2010) En este sistema, la diabetes diagnosticada durante el embarazo se clasifica en dos clases: Diabetes manifiesta, que se rige por los mismos parámetros que la DM en pacientes no gestantes y DM gestacional. En enero de 2011, la Asociación Americana de la Diabetes (ADA) hizo suya esta recomendación (ADA, 2011).

Aproximadamente el 7\% de todos los embarazos (de 1 a 14\%, dependiendo de la población estudiada y las pruebas de diagnóstico empleadas) son complicados por DMG, resultando en más de 200.000 casos al año (ADA, 2010). 
I. Diabetes tipo 1. Destrucción de células $\beta$, que generalmente conduce a una deficiencia absoluta de insulina
A. Immune
B. Idiopática

II. Diabetes tipo 2. Puede variar entre predominantemente por resistencia a la insulina hasta predominantemente por déficit de secrección con resistencia a insulina.

\section{Otros tipos específicos}

A. Anomalías genéticas de la función de la célula $\beta$ :

Cromosoma 12, HNF-1a (MODY3), cromosoma 7, glucocinasa (MODY2), cromosoma 20, HNF-4a (MODY1), cromosoma 13, factor promotor de la insulina (IPF-1; MODY4), cromosoma 17, HNF-1b (MODY5), cromosoma 2, NeuroD1 (MODY6), ADN Mitocondrial, y otros (diabetes tipo LADA).

\section{B. Alteraciones genéticas en la acción de la insulina:}

Resistencia a la insulina tipo 2, leprechaunismo, síndrome de Rabson-Mendenhall, diabetes lipoatrófica y otros.

\section{Enfermedades del páncreas exocrino:}

Pancreatitis, traumatismo/pancreatectomía, neoplasia, fibrosis quística, hemocromatosis, pancreatopatía fibrocalculosa, y otras.

\section{Endocrinopatías:}

Acromegalia, síndrome de Cushing, glucagonoma, feochromocitoma, hipertiroidismo, somatostatinoma, aldosteronoma y otras.

\section{E. Inducida por fármacos o agentes químicos:}

Vacor, pentamidina, acido nicotínico, glucocorticoides, hormona tiroidea, diazóxido, agonistas $\beta$-adrenérgicos, tiazidas, dilantin, interferón $\alpha$ y otros.

\section{F. Secundaria a infecciones:}

Rubeola congénita, citomegalovirus y otras.

G. Formas poco frecuentes de diabetes inmunomediada:

Síndrome del hombre rígido ("Stiff-man"), anticuerpos antirreceptor de la insulina y otros.

\section{H. Otros síndromes genéticos a veces asociados con diabetes}

Síndrome de Down, síndrome de Klinefelter, síndrome de Turner, síndrome de Wolfram, ataxia de Friedreich, corea de Huntington, síndrome de Laurence-Moon-Biedl, distrofia miotónica, porfiria, síndrome de Prader-Willi, y otros. 


\subsection{CRITERIOS DIAGNÓSTICOS.}

La diabetes mellitus puede presentarse con un cuadro clínico típico de polidipsia, poliuria y pérdida de peso o, en los casos más graves, como situación hiperosmolar o cetoacidosis, típicamente en la diabetes tipo 1. Sin embargo, en la mayoría de los casos, la diabetes mellitus tiene una fase, que puede durar años, que cursa asintomática, con niveles de glucemia prácticamente normales o ligeramente elevados. Es precisamente en estos individuos en los que es importante realizar un diagnóstico precoz, ya que el tratamiento adecuado puede evitar o retrasar la aparición de complicaciones a largo plazo.

Los criterios para el diagnóstico de la diabetes en adultos:

1. Hemoglobina glicosilada $(\mathrm{HbA} 1 \mathrm{C}) \geq 6.5 \%$ ( $\mathrm{ADA}, 2011$ ), realizada en un laboratorio estandarizado. El comité de expertos de la Asociación Americana de la Diabetes, dicta esta recomendación basándose en la relación en la prevalencia de retinopatía y el aumento de la $\mathrm{HbA} 1 \mathrm{C}$, que se correlaciona mejor que los niveles de glucosa basal, además de la baja inestabilidad que tiene la $\mathrm{HbA1C}$ en situaciones agudas y la baja variabilidad en sus niveles en periodos cortos de tiempo. (Olson DE, et al. 2010)

2. Glucosa plasmática en ayunas $\geq 126 \mathrm{mg} / \mathrm{dL}$, definiendo ayunas como ninguna ingesta calórica en las últimas 8 horas. La glucosa plasmática en ayunas o glucemia basal, es la prueba preferida para detectar y diagnosticar la diabetes en niños y en adultos no gestantes.

Respecto a los valores de glucemia basal, la ADA en 1997 y la OMS en 1999 establecieron que una cifra inferior a $110 \mathrm{mg} / \mathrm{dL}$ es glucemia normal, mientras que valores iguales o superiores a $126 \mathrm{mg} / \mathrm{dL}$ establecen el diagnóstico de diabetes mellitus.

Para aquellas personas que presentan cifras comprendidas entre $110-125 \mathrm{mg} / \mathrm{dL}$ (valores de la OMS) se ha acuñado el término de glucemia basal alterada (GBA), considerando que se trata de un estado intermedio entre un metabolismo normal de la glucosa y la diabetes mellitus. Su importancia radica en que estas personas tienen un riesgo mayor de diabetes y complicaciones vasculares. En 2003, la ADA modifica el criterio de normalidad de la glucemia basal, lo establece en cifras inferiores a 100 $\mathrm{mg} / \mathrm{dL}$, la OMS mantiene los valores previos (ADA, 2010). 
3. Síntomas clásicos de diabetes (polidipsia, polifagia, poliuria y pérdida de peso inexplicable) y una glucosa plasmática al azar de $\geq 200 \mathrm{mg} / \mathrm{dL}$. Al azar se define como cualquier momento del día e independientemente del momento de la última ingesta.

4. Cuando para el diagnóstico de diabetes se utiliza el test de tolerancia oral de glucosa (TTOG), los valores de glucemia utilizados son los obtenidos a las 2 horas de realizar la sobrecarga de glucosa, con 75 gramos de glucosa anhidra disuelta en agua.

Se establecen los puntos de corte: metabolismo normal de la glucosa para cifras $<140$ $\mathrm{mg} / \mathrm{dL}$, diabetes mellitus si $\geq 200 \mathrm{mg} / \mathrm{dL}$ confirmados en dos determinaciones y cuando se obtienen valores intermedios a estas cifras se habla de intolerancia a la glucosa que, como en el caso de la GBA, indica una regulación alterada de la glucosa, que puede progresar con el tiempo a diabetes.

5. Para detectar la diabetes en el embarazo se emplea el análisis de los factores de riesgo, tales como obesidad, antecedentes personales de DM gestacional o parto de un hijo grande para su edad gestacional, antecedentes familiares, etc., y si es apropiado realizar el TTOG.

En nuestro medio para el diagnóstico de la diabetes gestacional se realiza una detección inicial midiendo concentraciones plasmáticas de la glucosa 1 hora tras

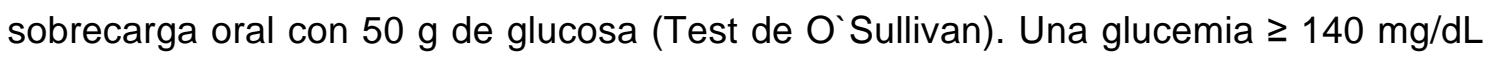
identifica el $80 \%$ de las mujeres con DMG y el $90 \%$ cuando se emplea el punto de corte de $\geq 130 \mathrm{mg} / \mathrm{dL}$.

Se hace un TTOG de $100 \mathrm{~g}$ en otro día en las mujeres que superan el umbral elegido en la sobrecarga de $50 \mathrm{~g}$, o se realiza directamente un TTOG de $100 \mathrm{~g}$ diagnóstico en todas las mujeres a las $24-28$ semanas de embarazo.

En 2010, la ADA ha cambiado los criterios para el diagnostico de diabetes gestacional, acoplándolos a los criterios generales para mujeres no gestantes. Según esto los criterios de Diabetes Gestacional son:

1. Glucosa basal mayor o igual a $92 \mathrm{mg} / \mathrm{dL}$, pero menor a $<126 \mathrm{mg} / \mathrm{dL}$ en cualquier edad gestacional. Glucosa basal mayor o igual a $126 \mathrm{mg} / \mathrm{dL}$ es compatible con DM manifiesta. 
2. A las 24 a 28 semanas de gestación, se realiza un test de tolerancia a la glucosa con al menos un resultado anormal entre los siguientes. Glucosa basal mayor a $\geq 92$ $\mathrm{mg} / \mathrm{dL}$, pero menor a $126 \mathrm{mg} / \mathrm{dL}$ o mayor a $180 \mathrm{mg} / \mathrm{dL}$ tras una hora o mayor a 153 $\mathrm{mg} / \mathrm{dL}$ tras dos horas. (ADA, 2011).

En las mujeres con diabetes gestacional se hace un seguimiento de 6 a 12 semanas después del parto con las pruebas de detección habituales para el desarrollo de prediabetes o diabetes.

\subsection{MANIFESTACIONES CLÍNICAS DE LA DIABETES MELLITUS.}

\subsubsection{Clínica de la diabetes tipo 1}

El síndrome clínico de la DM1 se inicia cuando la destrucción de las células $\beta$ alcanzan el $80-90 \%$ de la masa total, haciendo necesaria la instauración de tratamiento de forma indefinida. La destrucción celular puede desarrollarse en unos individuos de forma rápida (generalmente en niños y adolescentes) y lenta en adultos. En niños y adolescentes la primera manifestación suele ser el cuadro de cetoacidosis. Otros pacientes comienzan con leves hiperglucemias que pueden rápidamente variar a hiperglucemias severas y/o cetoacidosis en presencia de estrés o infecciones. En adultos, el cuadro clínico suele imitar al de la DM tipo 2 y pueden mantener una función de células $\beta$ suficiente para prevenir la cetoacidosis durante varios años. $Y$ aunque los pacientes son raramente obesos, la presencia de obesidad no es incompatible con el diagnóstico.

La deficiencia absoluta de insulina, produce hiperglucemia y aumento de lipolisis con acumulación excesiva de ácidos grasos en plasma, dando lugar a hiperosmolaridad plasmática e hipercetonemia.

Cuando la glucosa en plasma es mayor de $180 \mathrm{mg} / \mathrm{dL}$, se produce glucosuria y diuresis osmótica, con pérdida de glucosa, agua libre y electrolitos por la orina. Por otro lado la hiperosmolaridad plasmática pone en marcha el mecanismo de la sed, y aumenta la ingesta hídrica, produciéndose de esta forma poliuria y polidipsia. La deshidratación con disminución del volumen plasmático puede provocar mareos, debilidad e hipotensión postural. 
La pérdida ponderal, a pesar del aumento de apetito y de la ingesta, es una de las características de la DM1 y refleja el estado catabólico de la enfermedad. Se desarrolla generalmente de forma subaguda durante un periodo de semanas o meses. La pérdida de masa muscular se relaciona con la utilización de aminoácidos para la producción de glucosa en el hígado por la vía de la neoglucogénesis. Los cambios en el metabolismo proteico contribuyen al retraso en el crecimiento observado en niños con DM1 con mal control metabólico.

Las complicaciones agudas de la diabetes mellitus pueden ocurrir tanto en situación de hipoglucemia como de hiperglucemia. Las causas del coma en relación directa con la DM1 o con su tratamiento son el coma hipoglucémico y la cetoacidosis diabética.

Las complicaciones crónicas micro (retinopatía, neuropatía y nefropatía) y macrovasculares (ateroesclerosis y sus complicaciones asociadas) se derivan del daño tisular producido por la hiperglucemia mantenida de forma habitual.

\subsubsection{Clínica de la diabetes tipo 2}

La presentación clínica de la DM2 difiere de la DM 1 en varios aspectos. La mayoría son mayores de 60 años y el comienzo suele ser después de los 30-40 años, dos tercios padecen sobrepeso y el $40 \%$ presenta historia familiar de diabetes.

Aproximadamente el $50 \%$ de los casos presentan poliuria, polidipsia y polifagia. Los síntomas de cetoacidosis suelen estar ausentes. La alteración de la conciencia se asocia al coma hiperosmolar.

Muchos pacientes con DM2 no presentan síntomas obvios de hiperglucemia y la enfermedad se detecta de forma casual. Se estima que la hiperglucemia está presente de 5 a 7 años antes de que se haga el diagnóstico y cerca del $50 \%$ de la DM 2 es desconocida.

La obesidad es el mayor factor que predispone a la insulinorresistencia. En los países industrializados el $50 \%$ de los hombres y el $70 \%$ de las mujeres presentan sobrepeso en el momento del diagnóstico.

Los pacientes con DM2 tienen el riesgo de complicaciones diabéticas a largo plazo, que incluyen la enfermedad microvascular (retinopatía, nefropatía y neuropatía) y problemas macrovasculares no específicos como la enfermedad arterioesclerótica oclusiva que afecta principalmente al corazón, cerebro y extremidades inferiores. 
Las complicaciones microvasculares son menos prominentes en la DM2 que en la DM1. Sin embargo, estos pacientes tienen mayor tendencia a la enfermedad macrovascular, de manera que cerca del $60 \%$ mueren por enfermedad isquémica coronaria.

\subsection{TRATAMIENTO.}

\subsubsection{Tratamiento de la diabetes tipo 1}

El descubrimiento de la insulina por Banting y Best en 1921, su posterior extracción y purificación (en la década de los 60-70) y su disponibilidad comercial, representa el mayor avance terapéutico hasta la actualidad en el tratamiento de diabetes mellitus y constituye el único tratamiento eficaz para la diabetes tipo 1.

Hasta la década de los 80 los preparados de insulina obtenidos de la extracción del páncreas bovino o porcino, o sus mezclas, tenían un papel primordial en el tratamiento del diabético, pero posteriormente, han ido desapareciendo hasta apenas usarse en países desarrollados, a favor de la insulina sintética humana (obtenida por la técnica del ADN recombinante) que tiene la misma secuencia de aminoácidos de la insulina humana y es menos inmunógenica. En la última década, el mayor progreso ha estado en relación a la obtención de análogos de insulina con perfiles de acción más adecuados, mediante la modificación de la secuencia de aminoácidos.

Las insulinas de uso clínico pueden clasificarse según su perfil farmacocinético en ultrarrápidas (análogos de insulina: lispro y aspart), rápidas y basales (NPH: neutral protamine Hagedorn insulin, detemir y glargina). Los diferentes perfiles tiempo-acción posibilitan la utilización de cada una de ellas según el patrón alimentario y ejercicio del paciente para intentar simular la secreción fisiológica de la insulina.

Así clasificamos las insulinas comercializadas en postprandiales (análogos de acción rápida, insulina rápida e insulina inhalada) por su rápido inicio de acción y corta duración, como el pico de secreción de insulina que se produce en una persona no diabética tras la ingesta, para controlar la glucemia posprandial. $\mathrm{Y}$ las insulinas basales (NPH, detemir y glargina), que simulan la concentración basal de insulina que se produce entre comidas, durante la noche y en el ayuno. 
Los análogos de insulina de acción rápida (lispro y aspart) presentan un inicio de acción muy rápido con concentraciones plasmáticas muy altas, de forma que reducen eficazmente la glucemia postprandial con tasas de hipoglucemia bajas (Siebenhofer et al, 2006; Owens, 2006). Además, otorgan más flexibilidad al paciente en el horario de comidas porque no requieren de su administración 30 minutos antes.

La insulina rápida humana por vía subcutánea tiene una velocidad de absorción menor que los análogos de absorción rápida, por lo que se utilizan menos para controlar la glucemia postprandial. Pero sigue siendo la única que se puede administrar por vía intravenosa.

La insulina inhalada de reciente retirada del mercado mundial, presenta una farmacocinética muy especial para controlar la glucemia postprandial, ya que se absorbe a una rapidez mayor que ninguna otra, pero duración de acción muy corta, además de variabilidad, dosis escasas y limitaciones en pacientes con afectación respiratoria, hace que su uso en la práctica diaria sea muy difícil.

La insulina NPH ha sido la utilizada durante décadas como insulinización basal, pero desde la aparición de los análogos de insulina de acción prolongada está siendo relegada por su pico máximo de acción, que puede producir hipoglucemias (Rosenstock J, 2000, Vague P, 2003).

En el caso del análogo glargina, tiene una duración de un día en la mayoría de los pacientes, sin pico máximo, por lo que imita teóricamente mejor la insulinización basal fisiológica (Gough et al, 2006).

Por otra parte el análogo determir se asocia a una menor ganancia de peso y variabilidad que con otras insulinas (Ackermann et al, 2006; Heise et al, 2004).

\subsubsection{Tratamiento de la diabetes tipo 2}

La diabetes tipo 2 presenta una serie de transformaciones en su fisiopatología, por lo que el tratamiento farmacológico, se debe adaptar al curso evolutivo.

El tratamiento dietético y el ejercicio físico deben ir encaminados a mantener el estado nutricional adecuado, a combatir la obesidad y a favorecer la utilización de la glucosa. Actualmente, está demostrado que cambios en el estilo de vida pueden interrumpir la 
progresión de la historia natural de la diabetes, además de disminuir considerablemente el riesgo cardiovascular (De Luis et al, 2008; Vázquez et al, 2008; Tuomilehto et al, 2001).

Con el tratamiento farmacológico en la diabetes 2 , el objetivo, a veces muy difícil, es descender o evitar el aumento de la hemoglobina glicosilada; para ello se utiliza la selección y la asociación más adecuada de fármacos.

En la actualidad se puede actuar con tratamiento farmacológico preventivamente sobre casi todas las alteraciones que concurren en este tipo de diabetes.

Las Sulfonilureas, (Gliclazida, Gliplizida, Glimepirida y Glibenclamida) aprobadas para uso clínico en 1946, incrementan la secreción de insulina mediante la estimulación del receptor 1 de las sulfonilureas, su vía de administración es oral y tienen como ventajas su seguridad a largo plazo y bajo coste. Como desventajas presentan riesgo de hipoglucemia con el tratamiento, ganancia de peso y la necesidad de una cuidadosa dosificación (Philippe J, et al, 2009).

Las biguanidas, aprobadas en 1957 siendo su principal ejemplo la Metformina, suprimen la liberación hepática de glucosa, incrementan la sensibilidad muscular a la insulina, interfieren con el metabolismo de la glucosa y el lactato en el intestino, pueden incrementar las concentraciones del GLP1 endógeno. Se administran de forma oral y su uso ha sido muy extendido por su seguridad a largo plazo, estabilidad en el peso del paciente, bajo riesgo de hipoglucemia y bajo coste. Pueden tener efectos adversos gastrointestinales, y se deben evitar en pacientes con alteración renal o respiratoria (Bailey CJ, et al, 1996).

En 1997 se aprueban para uso clínico las Meglitinidas (Nateglinida y Repaglinida), que actúan como las sulfonilureas pero estimulando el receptor en un sitio diferente a estas, produciendo una respuesta insulínica más rápida y corta. Son ventajosas por su rápida acción que las hace adecuadas para el uso con las comidas. Hay pocos datos respecto a su seguridad a largo plazo, y al igual que las sulfonilureas pueden producir ganancia de peso e hipoglucemia (Black C, et al, 2007).

Los inhibidores de la alfa-glucosidasa como la Acarbosa o el Miglitol, inhiben la degradación de los carbohidratos en el intestino, son de administración oral, tienen 
bajo coste y no producen cambios de peso relevantes. Pueden presentar efectos adversos gastrointestinales (Tahrani AA, et al, 2011).

Las Glitazonas, aprobadas en 1997, (Pioglitazona y Rosiglitazona, esta última retirada del mercado europeo en 2010) estimulan la adipogénesis subcutánea reduciendo la liberación de ácidos grasos libres. También incrementan la sensibilidad del músculo y el hígado a la insulina. Son ventajosas por tener moderados efectos sobre la hipertensión arterial y bajo riesgo de hipoglucemia, pero tienen riesgo de producir incrementos importantes en el peso corporal, edemas, fallo cardiaco y fracturas (YkiJarvinen H. 2004).

Los análogos del GLP 1 (aprobados para uso clínico en 2005) como Exenatide o Liraglutide, activan el receptor GLP 1 causando un incremento en la secreción de insulina dependiente de glucosa, supresión del glucagón, retardo del vaciamiento gástrico y supresión del apetito. Pueden producir pérdida de peso, bajo riesgo de hipoglucemia a menos que se utilicen con sulfonilureas y estudios en animales reportan un posible efecto positivo en la supervivencia y disminución de las células beta. Por otra parte no se pueden utilizar en fallo renal y hay reportes de posibles asociaciones con pancreatitis y algunos tipos de cáncer. (Tahrani AA, et al, 2011).

Los Inhibidores de la dipeptidil peptidasa 4 (DPP4), introducidos en 2006, son la Sitagliptina, Vildagliptina y Saxagliptina; este año se ha introducido la linagliptina. Incrementan las concentraciones de incretinas endógenas, sin cambios en el peso ni riesgo importante de hipoglucemias. Como los análogos del GLP 1 pueden tener un efecto beneficioso en la conservación de las células beta pancreáticas, pero su uso se ha asociado con pancreatitis en algunos reportes. (Tahrani AA, et al, 2011). Se hablará de ellas

Los análogos de la amilina cuyo representante es el Pramlintide (No comercializado en Europa), actúan disminuyendo los niveles de glucosa postprandial produciendo saciedad central, disminuyendo la secreción de glucagón y retardando el vaciado gástrico. Produce pérdida de peso, pero puede producir hipoglucemias al tenerse que usar siempre asociado a insulina. (Kruger DF, et al, 2004)

Por último, la Insulina cuyas características ya se han comentado en la sección anterior. 
La monoterapia oral inicial de la diabetes mellitus tipo 2 debe centrarse en el uso de metformina. Las sulfonilureas también son fármacos eficaces en su tratamiento, siempre que se utilicen precozmente cuando aún existe función de la célula beta y, fundamentalmente, en terapia combinada con otros fármacos orales (metformina, glitazonas). Las sulfonilureas no protegen el deterioro progresivo de la célula beta y, por lo que se refiere a efectos secundarios, es evidente la propensión a la hipoglucemia y al aumento de peso (Pallardo Sánchez, 2008).

Con los fármacos de acción incretina (derivados de GLP-1, principalmente), además de estimular la secreción de insulina e inhibir la de glucagón, se reduce la producción hepática de glucosa, tienen un efecto positivo o neutro sobre la reducción del peso corporal, una posible protección de las células beta junto con la ausencia de hipoglucemias y otros efectos beneficiosos para la homeostasis de la glucosa, por lo que se consideran en la actualidad una importante opción terapéutica (Pallardo Sánchez, 2008).

Por último, entre un tercio y la mitad de los pacientes diabéticos tipo 2, la administración exógena de insulina o análogos de insulina será necesaria por la situación de disfunción de la célula $\beta$, o ante la ausencia de cumplimiento de los objetivos con otros tipos de tratamiento (Ampudia-Blasco FJ, Rosenstock J, 2008)

En 2008 se publica una declaración de consenso de la ADA y la Asociación Europea para el estudio de la Diabetes sobre la estrategia terapéutica de la hiperglucemia en individuos con diabetes tipo 2. La intervención precoz con modificaciones en el estilo de vida (terapia médica nutricional y ejercicio) en combinación con metformina, seguida de la selección y asociación más adecuada de fármacos, incluyendo el inicio temprano de la terapia con insulina. Con ello se persigue alcanzar y mantener los niveles de glucemia recomendados, y una hemoglobina glicosilada $(\mathrm{HbA} 1 \mathrm{c})<7 \%$.

El inicio temprano de la insulina podría ser la estrategia más segura en los individuos que presentan pérdida de peso, síntomas más graves y unos valores de glucemia mayores a 250-300 mg/dL. La terapia con insulina consiste en una dosis basal de insulina intermedia o retardada en combinación con una dosis de insulina de acción rápida o corta antes de cada ingesta. 


\subsubsection{Nuevos tratamientos en diabetes}

El tratamiento de la diabetes con múltiples dosis de insulina no es capaz de reproducir de manera estricta la secreción fisiológica de la misma a pesar de la introducción en la terapéutica de los análogos de insulina de acción lenta y rápida.

Aunque los objetivos del tratamiento intensivo pueden ser alcanzados con múltiples dosis de insulina, en numerosas ocasiones no llegan a conseguirse y la terapia con infusores de insulina puede ser una buena alternativa terapéutica.

El tratamiento con infusión subcutánea continua de insulina (bombas de insulina) es actualmente la vía más fisiológica para reemplazar tanto el componente basal de la secreción de insulina, al poderla ajustar a los diferentes requerimientos fisiológicos existentes a lo largo del día, como los picos de secreción insulínica en respuesta a los alimentos conseguido mediante la administración de "bolus" antes de cada ingesta.

En el momento actual este tipo de terapia es valorada como segura y resulta una buena alternativa de tratamiento tanto en adultos como en adolescentes y en niños con diabetes.

Los tratamientos hipoglucemiantes en desarrollo se pueden clasificar como los que se dirigen a la función del páncreas o el hígado, a mejorar la acción de la insulina, los que actúan con independencia de la insulina o los que actúan en las características del síndrome metabólico. Adicionalmente, la cirugía metabólica está ganando impulso como un potencial tratamiento para la DM2.

Los fármacos que se dirigen al páncreas puede actuar directa o indirectamente sobre las células beta (insulina, péptido $\mathrm{C}$, y amilina), a las células alfa (glucagón), o células delta (somatostatina). (Tahrani A, et al, 2011)

\section{Fármacos que actúan en la disfunción de la célula Beta}

Nuevos tratamientos basados en las incretinas.

Desde principios del siglo 20, la evidencia sugiere que existen factores intestinales llamados incretinas que mejoran la respuesta hipoglucemiante de la insulina. Las incretinas principales son el péptido insulino-trópico glucosa dependiente (GIP) y el péptido similar al glucagón 1 (GLP-1). (Green BD, et al, 2007) 
En los últimos años han aparecido en el mercado tratamientos que actúan principalmente sobre la acción y la inactivación del GLP-1, pero su desarrollo continua en la actualidad.

Las incretinas son rápidamente inactivadas por la dipeptidil peptidasa 4 (DPP-4). Para alargar la vida media del GLP 1 se han desarrollado análogos resistentes a la acción del DPP-4 con propiedades agonistas al receptor del GLP (GLP-1R) como liraglutida y exenatida. Otra estrategia ha sido el aumento de GLP-1 endógeno por antagonistas altamente específicos del DPP-4 como son la sitagliptina, vildagliptina y saxagliptina.

Linagliptina y alogliptina, ambos inhibidores de la DPP-4, han sido evaluados en estudios de fase 3 . En estudios previos la linagliptina mejoró de forma importante la tolerancia a la glucosa después de su administración durante 12 días. La monoterapia con linagliptina mejoró el control glucémico en pacientes que eran intolerantes a la metformina. A su vez, la linagliptina en combinación con sulfonilureas o metformina no se asoció con aumento del riesgo de hipoglicemia. (Barnett $\mathrm{AH}$, et al, 2010)

La alogliptina, como monoterapia o en combinación con metformina o glibenclamida mejora los niveles de glucemia en ayunas y reduce las concentraciones de $\mathrm{HbA} 1 \mathrm{c}$ en 26 semanas y se asoció con una buena tolerabilidad gastrointestinal y una baja incidencia de hipoglicemia. Cuando se utiliza con la misma dosis de insulina, mejora el control glucémico sin episodios de hipoglucemia y sin aumento de peso. Características similares se han descrito para otros inhibidores de DPP-4 que están en primeras fases de desarrollo con eficacias similares en el control de la glucemia pero diferencias farmacocinéticas que podrían ser útiles en subpoblaciones de pacientes, por ejemplo, la linagliptina se metaboliza casi en su totalidad por el hígado, siendo potencialmente útil en pacientes con insuficiencia renal. (Bailey CJ, 2009).

\section{Estimulantes de las células Beta sin acción incretina}

La fosforilación de la glucosa por la glucoquinasa después de la entrada en la célula beta, afecta la tasa de metabolismo de la glucosa y la posterior producción de ATP. Para mejorar la acción de la glucoquinasa en las células beta, varios activadores de la glucoquinasa se han desarrollado, incluyendo piragliatin, compuesto 14, R1511, AZD1656, AZD6370, compuesto 6 y ID1101. Los activadores de la glucoquinasa aumentan las concentraciones de insulina y reducen las concentraciones de glucosa 
en sangre en modelos animales de diabetes tipo 2. Adicionalmente pueden reducir las concentraciones de glucosa a través de efectos en el metabolismo de glucosa hepática. La activación de la glucoquinasa está asociada con mayores concentraciones de triglicéridos en sangre y riesgo aumentado de hipoglucemia. (Kozian DH, et al, 2010).

Varios receptores asociados a Proteinas $G$ se expresan en las células beta. Algunos agonistas sintéticos activos por vía oral aumentan las concentraciones intracelulares de AMPc y potencian la secreción de insulina inducida por la glucosa, mejorando la tolerancia a la misma en modelos animales. Receptores similares también se expresan en las células $\mathrm{K}$ y $\mathrm{L}$ intestinales produciendo una mejora en los niveles de incretinas. (Tahrani A, et al, 2011)

Aunque la reducción de la masa celular beta en el páncreas en la DM2 se conoce desde hace tiempo, no hay un tratamiento disponible que evite o retrase este efecto.

Después del trasplante de islotes pancreáticos en DM 1 se ha visto que la exenatida puede reducir la necesidad de insulina o prolongar la independencia de la insulina, lo que sugiere un efecto positivo en la supervivencia y la función del injerto.

Algunos compuestos que reducen el estrés oxidativo, han mostrado que reducen la apoptosis en células de islotes aislados de pacientes con DM2. En estudios preclínicos anti-inflamatorios como los antagonistas del receptor de Interleukina 1 mejoran la secreción de insulina, la hiperglucemia y los infiltrados inflamatorios y la fibrosis a nivel de los islotes, pudiendo tener algún efecto en la supervivencia de las células beta. (Lupi R, et al, 2007)

\section{Fármacos que actúan en la disfunción de las células Alfa.}

Los pacientes con DM2 por lo general tienen elevadas concentraciones de glucagón en ayunas y no tienen capacidad de suprimir el glucagón postprandial. Se están estudiando mecanismos para contrarrestar el exceso de glucagón bloqueando su receptor o su señalización post-receptor.

Otro mecanismo para contrarrestar el exceso de glucagón es bloquear el receptor de glucagón o su señalización intracelular después de unirse con la hormona. Los modelos animales con una mutación nula del receptor de glucagón o una reducción de 
su expresión con nucleótidos antisentido muestran una significativa reducción de la glucemia basal mejorando la tolerancia a la glucosa, pero con significativos incrementos en los niveles de glucagón e hiperplasia de células alfa. (Agius L, 2007)

\section{Medicamentos dirigidos a la disfunción de células Alfa y Beta.}

Un posible enfoque para hacer frente a la hiperglucagonemia de rebote después de la administración de antagonistas del receptor de glucagón podría ser suprimir la secreción de glucagón con GLP-1. Algunos péptidos híbridos han sido desarrollados; son agonistas de la secuencia nativa para el GLP-1R que se unen al receptor de glucagón sin activarlo. Un ejemplo es el péptido de acción dual para la diabetes (DAPD) diseñado para una acción de duración prolongada, mejorando la secreción de insulina y la tolerancia a la glucosa en ratones (Claus TH, et al, 2007).

Otro péptido de la familia preproglucagón es la oxintomodulina, secretada por las células $L$ junto con el GLP1. Es un agonista del receptor GLP-1R y del receptor de glucagón. En ratas obesas indujo pérdida de peso, reducción de la ingesta y de los niveles de glucosa. La administración subcutánea en individuos obesos redujo la ingesta de alimentos, y produjo el aumento del gasto energético y pérdida de peso.

\section{Potenciadores de la acción de la insulina.}

Varias sustancias han sido evaluadas buscando activar el receptor de insulina o algunas señales post-receptor. Estas aproximaciones son complicadas debido a que muchas de las señales intermedias post-receptor son también parte de otras vías regulatorias que pueden incluir señales de diferenciación celular y apoptosis. En 1999 se observó que un metabolito no peptídico del hongo Pseudomassaria activa el receptor tirosina-kinasa de la insulina, reduciendo la glucosa en sangre en roedores diabéticos cuando se administraba oralmente. Esta molécula (denominada L-783281) interactuaba selectivamente con la subunidad beta del receptor de la Insulina. A pesar que esta molécula probablemente no pueda ser utilizada en humanos por su inestabilidad, es una prueba del concepto en cuestión.

La acción de la insulina puede ser potenciada por la fosforilación prolongada de la subunidad Beta del receptor de insulina después de la unión de la Insulina con la subunidad alfa. Hay varias clases de moléculas que pueden hacer esta función, no teniendo efecto en el receptor sin la presencia de Insulina en el mismo. 
Los inhibidores de la tirosina fosfatasa 1B reducen la desfosforilación de la subunidad beta del receptor de la insulina potenciando la acción de la insulina reduciendo la concentración de glucosa en modelos animales hiperglucémicos y podrían ayudar a la pérdida de peso y a mejorar la función endotelial. (Tahrani A, et al, 2011).

\section{Fármacos dirigidos a vías no insulin-dependientes}

Inhibidores del co-trasportador 2 de sodio-glucosa (SGLT-2).

Los riñones contribuyen a la homeostasis de glucosa a través de la gluconeogénesis, el uso de la glucosa y la reabsorción de la misma del filtrado glomerular. La glucosa se reabsorbe principalmente a través de SGLT2, que se encuentra predominantemente en el borde en cepillo del túbulo proximal

En la DM2 la enfermedad renal aumenta la gluconeogénesis y la reabsorción de glucosa. A pesar de la hiperglucemia a menudo excede el umbral de función renal en la DM2, la inhibición de SGLT2 puede aumentar la glucosuria lo suficiente para reducir la hiperglucemia. Los pacientes con glucosuria renal familiar (Causada por mutaciones específicas del gen que codifica el SGLT2) tienen glucosuria y no presentan alteraciones de salud importantes. Debido a que la inhibición de SGLT2 es insulin independiente y es compensado por la reabsorción de glucosa a través de SGLT1 a bajas concentraciones de glucosa, el riesgo de hipoglucemia es bajo. Además, el efecto glucosúrico y la diuresis osmótica pueden ayudar a perder peso y reducir la tensión arterial. (Santer R, et al, 2010).

\section{Objetivos hepáticos.}

El hígado contribuye a la homeostasis de glucosa a través del aclaramiento postprandial en la circulación portal, la glucogenogénesis, la glucogenólisis y la gluconeogénesis según las necesidades y el ratio insulina - glucagón. El reto es la creación de compuestos que intervengan en las vías intracelulares que intervienen en la glucogenogénesis como por ejemplo la glucoquinasa o en la glucogenólisis con la glucosa 6 fosfatasa, que actúen estimulando la primera vía o inhibiendo la segunda con el fin de disminuir los niveles de glucosa circulante. Otras vías estudiadas como objetivo de actuaciones terapéuticas son las de la Fructosa 1-6 bifosfatasa y la 
glucógeno fosforilasa, pero diversos problemas como la hipoglucemia o la producción de esteatosis o fibrosis hepática deben ser superados. (Agius L, 2007)

\section{Medicamentos que actúan sobre el síndrome metabólico.}

Antagonistas del GIP

El GIP, como el GLP-1 potencia la secreción de insulina, pero promueve la adipogénesis, no inhibe la secreción de glucagón y tiene un pequeño efecto en el hambre, saciedad, vaciado gástrico y el peso corporal.

Algunos modelos animales han mostrado que el bloqueo en la acción del GIP incrementa el gasto energético, teniendo un efecto favorable en la homeostasis de la glucosa, potenciando la glucogenogénesis muscular, reduciendo la secreción hepática de glucosa y mejorando la función de la célula beta, planteando una diana terapéutica en pacientes diabéticos.

Inhibidores de la 11ß-hidroxiesteroide-deshidrogenasa-1

Las similaridades fenotípicas y metabólicas entre el Síndrome de Cushing y el Síndrome Metabólico han despertado el interés en el potencial terapéutico de la inhibición de la 11ß-hidroxiesteroide deshidrogenasa 1 reduciendo la formación de cortisol en el hígado y el tejido adiposo. El bloqueo de esta enzima en roedores reduce la resistencia a la insulina, mejora la tolerancia a la glucosa y mejora la respuesta a la secreción de insulina.

La administración del compuesto denominado INCB13739 (200 mg) junto con Metformina en pacientes con DM 2 durante 12 semanas mejora la glucosa basal en sangre y la $\mathrm{Hb} \mathrm{A} 1 \mathrm{C}$. También se han visto reducciones en las cifras de colesterol total y LDL y trigliceridos en pacientes con dislipemia. (Rosenstock L, et al, 2010)

Moduladores de los receptores del proliferador activado de los peroxisomas. (PPAR)

Estos compuestos forman heterodímeros con el receptor retinoide $X$, que modulan una amplia variedad de genes que afectan el metabolismo de los nutrientes y la inflamación. Los agonistas PPAR-y (por ejemplo, pioglitazone) mejoran la sensibilidad a la insulina y son un tratamiento establecido para la DM 2, mientras que los agonistas 
PPAR- $\alpha$ agonistas (fibratos) lo son para la dislipidemia. Se han desarrollado agonistas mixtos como el aleglitazar, con un perfil de efectos secundarios tolerable que ha mostrado mejorías dosis dependientes en los niveles de glucosa basal, resistencia a la insulina y en variables lipídicas. Estudios en marcha (ALECARDIO) tratan de determinar la incidencia de efectos adversos cardiovasculares y mortalidad en pacientes con DM 2 y síndrome coronario agudo reciente.

\section{Otros tratamientos con mecanismos desconocidos.}

La Bromocriptina es un ergot - alcaloide de la Dopamina que ha sido usado en el tratamiento de prolactinomas y la Enfermedad de Parkinson. Aunque la Bromocriptina solo ha sido aprobada en 2010 para el tratamiento de la DM2 por la FDA como agente coadyuvante a los cambios en el estilo de vida, sus efectos en las variables glucémicas han sido descritos desde la década de los 80 . La bromocriptina produce sus efectos sin aumentar las concentraciones de insulina posiblemente por la alteración de las neuronas hipotalámicas que reducen la gluconeogénesis hepática a través de una ruta vagal. En un estudio aleatorizado con 3095 pacientes, la Bromocriptina sola o en monoterapia redujo el riesgo cardiovascular comparado con placebo. No está aprobada en Europa para el tratamiento de la DM2. (Gaziano JM, et al, 2010)

Las resinas de intercambio iónico son un tratamiento conocido para la dislipidemia. También reducen los niveles de glucosa en pacientes diabéticos Tipo 2 por un mecanismo no bien conocido. En 2009, la FDA ha aprobado el Colesevelam como coadyuvante en el tratamiento de la DM Tipo 2 asociado a cambios en el estilo de vida, metformina, sulfonilureas o insulina mejorando los niveles de $\mathrm{Hb}$ A1C sin aumentar el riesgo de hipoglucemia, mejorando a su vez los niveles de colesterol HDH y LDL. El Colesevelam no está aprobado en Europa para el tratamiento de la DM2. (Fonseca VA, et al, 2010).

\section{Trasplante de páncreas y de islotes pancreáticos.}

El trasplante de páncreas es el único tratamiento que en la actualidad consigue restaurar la masa de células $\beta$ y mantener la normoglucemia a largo plazo en la mayoría de los pacientes (Larsen JL., 2005). Sin embargo, debido a la toxicidad del tratamiento inmunosupresor y a la escasez de órganos para el trasplante, este tratamiento puede ofrecerse sólo a un número limitado de pacientes. La mejora en los 
criterios aceptación de donantes y los avances en la fisiología y farmacología de la inmunosupresión hacen que los resultados a largo plazo en el control metabólico y supervivencia del injerto sean cada vez mejores (Gruessner AC, et al, 2012).

El trasplante de islotes tiene los mismos objetivos metabólicos del trasplante vascularizado pero sin los riesgos de una cirugía abdominal mayor, ya que los islotes son implantados en el hígado con cirugía de mínima invasión o mediante radiología intervencionista a través de un catéter.

En 2000 se publicó un ensayo clínico, el protocolo de Edmonton (Shapiro, et al, 2000), que mejoraba los resultados tras el trasplante insular obteniendo periodos de normoglucemia de más de 1 año en una serie consecutiva de pacientes con diabetes mellitus tipo 1 mediante un régimen sin corticoides y que en un plazo de cinco años el $80 \%$ mantuviera un injerto funcionante que les permitía, aunque con el requerimiento de dosis generalmente bajas de insulina, un control metabólico óptimo sin hipoglucemias graves. Ese protocolo ha sido refrendado en más de 50 centros en diferentes ensayos (Noguchi H., et al 2008).

De todas formas, la indicación de trasplante en pacientes diabéticos tipo 1 debe ser analizada cuidadosamente y debe ser restringida a subgrupos de pacientes con extrema labilidad en el control metabólico, con frecuentes hipoglucemias a pesar de un tratamiento médico óptimo. (Ludwig B, et al, 2010).

\subsection{COMPLICACIONES DE LA DIABETES}

\subsubsection{Complicaciones agudas de la diabetes}

A continuación se resumen las tres complicaciones agudas más frecuentes y graves:

1.- La cetoacidosis diabética se manifiesta con una situación de hiperglucemia marcada con cetosis. Los criterios diagnósticos vienen definidos por una glucemia mayor de $250 \mathrm{mg} / \mathrm{dL}$, acompañados de cetonuria y/o cetonemia. El tratamiento urgente está basado en una administración endovenosa de líquidos y la administración de insulina regular. 
2.- La situación de hiperglucemia hiperosmolar no cetósica, manifestada como un estado de hiperosmolaridad aunque sin cetosis con glucemias mayores de $600 \mathrm{mg} / \mathrm{dL}$. El tratamiento urgente se basa en la administración de suero fisiológico y de insulina.

3.- La hipoglucemia es la complicación más frecuente del tratamiento con insulina o sulfonilureas. La glucemia será $<50 \mathrm{mg} / \mathrm{dL}$ pero pueden observarse pacientes con glucemias menores que no presentan síntomas u otros que sí los presentan con glucemias mayores. Como tratamiento se aportarán alimentos que contengan de 5 a $15 \mathrm{~g}$ de glucosa fácilmente absorbibles, siempre que el paciente esté consciente o en los casos más graves por vía intravenosa.

\subsubsection{Complicaciones crónicas de la diabetes}

La intervención está basada en el desarrollo de un programa estructurado y continuado de la educación diabetológica y el tratamiento. En la prevención es prioritario el estricto control glucémico y de otros factores de riesgo: obesidad, circunferencia de la cintura, consumo de grasas, sendentarismo, etnia, DMG, hipertensión, HDL colesterol, niveles de triglicéridos, tabaquismo, etc.

La enfermedad cardiovascular (ECV) es la principal causa de mortalidad en las personas con diabetes. También es uno de los principales factores que contribuyen a la morbilidad y a los costes directos e indirectos de la diabetes. La diabetes tipo 2 es un factor de riesgo independiente de la enfermedad macrovascular y sus enfermedades coexistentes, hipertensión y dislipemia, son también factores de riesgo.

La hipertensión, definida como una presión arterial $\geq 140 / 90 \mathrm{mmHg}$, es una comorbilidad extremadamente común en la diabetes, afectando a la mayoría de las personas con diabetes, dependiendo de la obesidad, la etnia y la edad. La HTA también es un factor de riesgo principal para la ECV y las complicaciones microvasculares como la retinopatía y la nefropatía. En la diabetes tipo 1, la hipertensión es con frecuencia el resultado de una nefropatía subyacente. En la diabetes tipo 2, la HTA se presenta como parte del síndrome metabólico, que incluye obesidad, hiperglucemia y dislipemia, y que se acompaña de tasas elevadas de ECV.

Los estudios clínicos randomizados han demostrado el beneficio de la reducción de la presión arterial sistólica a $<130 \mathrm{mmHg}$ y diastólica $\mathrm{a}<80 \mathrm{mmHg}$ en los individuos con diabetes, gracias a la reducción de eventos de cardiopatía isquémica, ictus cerebral y 
nefropatía (UKPDS, 2000). Los pacientes con una presión arterial sistólica de 130-139 $\mathrm{mmHg}$ o una presión arterial diastólica de $80-90 \mathrm{mmHg}$ hay que recomendar solamente modificaciones del estilo de vida durante 3 meses, y si no se alcanzan los objetivos, deben ser tratados con farmacoterapia.

Los pacientes con diabetes tipo 2 tienen una mayor prevalencia de alteraciones de los lípidos, que contribuyen a un aumento de las tasa de ECV. El tratamiento de los lípidos tiene como objetivos la reducción de los niveles de LDL colesterol ( $\leq 100 \mathrm{mg} / \mathrm{dL}$ ), la elevación del HDL colesterol (> $50 \mathrm{mg} / \mathrm{dL}$ ) y la reducción de los triglicéridos $(<150$ $\mathrm{mg} / \mathrm{dL}$ ), lo que ha demostrado reducir la tasa de ECV y su mortalidad en pacientes con diabetes tipo 2 , en particular en los que habían tenido eventos cardiovasulares previos.

Las estatinas (inhibidores de la hidroximetilglutaril-coenzima $A$ reductasa) reducen significativamente los eventos coronarios y cerebrovasculares.

Se recomienda ácido acetilsalicílico como agente antiagregante plaquetario para la prevención de eventos cardiovasculares, incluidos el ictus y el infarto de miocardio en individuos con y sin diabetes (Hansson et al., 1998). Algunos estudios han demostrado una reducción del alrededor del $30 \%$ en el infarto de miocardio y del $20 \%$ en el ictus en una variedad de pacientes. La dosis empleadas varían entre 75 y $325 \mathrm{mg} / \mathrm{dL}$ (Velasco et al., 2000).

En la prevención es prioritario el estricto control glucémico y de otros factores de riesgo cardiovascular, que incluyen la dislipemia, la hipertensión arterial, el tabaquismo, IMC, la circunferencia de la cintura y el consumo de grasa. Se aconseja a todos los pacientes que dejen de fumar, los riesgos del tabaquismo para los pacientes con diabetes son al menos equivalentes a los de la población general.

Los factores de riesgo de cardiopatía coronaria son, además de la diabetes en sí misma, dislipemia, hipertensión, tabaquismo, antecedentes familiares de cardiopatía coronaria prematura y presencia de micro o macroalbuminuria.

En pacientes con ECV conocida, hay que emplear un inhibidor de la enzima convertidora de angiotensina (IECA), aspirina y estatinas, para reducir el riesgo de eventos cardiovasculares como primer escalón terapeútico. 
La presencia de complicaciones microvasculares específicas de la DM (retinopatía, neuropatía, nefropatía) se encuentra estrechamente relacionada con el grado de control metabólico, y está influenciada por el tiempo de evolución de la enfermedad.

La retinopatía diabética es una complicación vascular altamente específica tanto de la diabetes tipo 1 como de la tipo 2. La prevalencia de la retinopatía está muy relacionada con la duración de la diabetes y por el adecuado o inadecuado control de la enfermedad y es la causa más frecuente de nuevos casos de ceguera entre los adultos de 20 - 74 años.

El alcance de la retinopatía diabética en nuestro país está referenciado por 2 estudios recientes en los que se demuestra que tras 20 años de evolución de la enfermedad, prácticamente el $100 \%$ de los pacientes con DM tipo 1 y el $60 \%$ de los pacientes con DM tipo 2 presentan retinopatía diabética (15\% al momento del diagnóstico) (Teruel Maicas C., 2005, Santos Bueso E., 2005). Esta situación alcanza el grado de problema sanitario cuando el riesgo de pérdida de visión es 11 veces superior al de la población no diabética y casi 30 veces superior ante la presencia de retinopatía diabética proliferativa (Hernández Mira G, 1996).

La retinopatía diabética es la principal causa de ceguera en población de edad laboral en los países industrializados. La fotocoagulación con láser continúa siendo la principal arma terapéutica para evitar la progresión de la retinopatía, pero pierde efectividad cuando se indica demasiado tarde y no está exenta de efectos secundarios. Se están ensayando fármacos para bloquear tanto las vías metabólicas relacionadas con la hiperglucemia (p. ej., inhibidores de la proteína kinasa C o PKC), como la angiogénesis inducida por la hipoxia (p. ej., agentes anti-VEGF o anti factor de crecimiento vascular endotelial) que, proporcionarán una nueva perspectiva en el tratamiento de la retinopatía diabética (Hernández Pascual et al., 2008).

Alrededor de $50 \%$ de los sujetos con DM de tipos 1 y 2 de larga evolución presentan neuropatía diabética. Puede manifestarse en forma de polineuropatía, mononeuropatía, neuropatía vegetativa (autónoma) o combinaciones de ellas.

La forma más frecuente de neuropatía diabética es la polineuropatía simétrica distal. Los síntomas consisten en pérdida de la sensibilidad, sensación de adormecimiento, hormigueo, pinchazos o ardor quemante que se inicia en los pies y se extiende en sentido proximal. El dolor afecta de manera característica las extremidades inferiores, 
suele percibirse en reposo y empeora durante la noche. Se han descrito formas tanto aguda (que dura menos de 12 meses) como crónica de la neuropatía diabética dolorosa. Conforme avanza este trastorno neurológico, el dolor va cediendo, pero persiste un déficit de la sensibilidad en las extremidades inferiores.

La polirradiculopatía diabética es un síndrome caracterizado por dolor incapacitante situado en el territorio de distribución de una o más raíces nerviosas. Puede ir acompañado de debilidad motora. Las polirradiculopatías diabéticas pueden resolverse espontáneamente en 6-12 meses.

La mononeuropatía (disfunción de pares craneales o nervios periféricos aislados) es menos frecuente que la polineuropatía en la DM y se presenta en forma de dolor o debilidad motora en el territorio de un solo nervio. Su pronóstico es bueno y al cabo de varios meses se recuperan a veces de forma parcial.

La neuropatía vegetativa (autónoma): Los pacientes con DM de tipo 1 o 2 de larga evolución pueden presentar signos de disfunción vegetativa que afectan los sistemas colinérgico, noradrenérgico y peptidérgico (péptidos como polipéptido pancreático, sustancia $P$, etc.). Es posible que la neuropatía vegetativa relacionada con la DM afecte numerosos aparatos y sistemas, como el cardiovascular, el digestivo, el genitourinario, el psicomotor y el metabólico. La disfunción del sistema nervioso simpático puede producir hiperhidrosis de las extremidades superiores y anhidrosis de las inferiores. En este último caso es posible que ocurran sequedad de piel y grietas, de modo que aumenta el riesgo de úlceras en los pies. La neuropatía autónoma puede reducir la liberación de hormonas de contrarregulación, lo que conlleva incapacidad para detectar adecuadamente la hipoglucemia.

En el tratamiento se debe perseguir un mejor control de la glucemia, que mejorará la velocidad de conducción nerviosa, pero no necesariamente los síntomas de neuropatía diabética. La clave del tratamiento es evitar las neurotoxinas (alcohol), administrar suplementos vitamínicos contra posibles deficiencias y dar apoyo sintomático. La pérdida de sensibilidad en el pie pone al paciente en peligro de ulceración y de sus secuelas; por ello reviste importancia capital la prevención de estos problemas. Como el dolor de la neuropatía diabética puede resolverse en el transcurso del primer año, es posible suspender los analgésicos paulatinamente (Mendell et al, 2003). La neuropatía diabética dolorosa crónica es difícil de tratar pero 
puede responder a fármacos de la familia de los antidepresivos tricíclicos, gabapentina, antiinflamatorios no esteroideos y otros agentes como la capsaicina.

Complicaciones de las extremidades inferiores: Las úlceras, infecciones del pie y las amputaciones no traumáticas de los pies son las principales causas de morbilidad, discapacidad, así como de costes emocionales y físicos para personas con diabetes. Alrededor de $15 \%$ de los diabéticos presenta una úlcera en el pie, y una fracción importante de ellos sufrirá en algún momento una amputación (riesgo del 14 al 24\% con esa úlcera u otras úlceras posteriores) (Apelqvist et al, 1993).

Las razones del aumento de la incidencia de estos trastornos en la DM son complejas y suponen la interacción de varios factores patogénicos: neuropatía, biomecánica anormal del pie, enfermedad vascular periférica y cicatrización deficiente de las heridas. La neuropatía sensitiva periférica interfiere en los mecanismos normales de protección y produce que el paciente sufra traumatismos importantes o leves repetidos, que a menudo pasan inadvertidos. Los trastornos de la sensibilidad propioceptiva causan un soporte anormal del peso durante la marcha, con la consiguiente formación de callosidades o úlceras. La neuropatía motora y sensitiva conduce a una mecánica anormal de los músculos del pie y a alteraciones estructurales del pie. La neuropatía vegetativa provoca anhidrosis y altera el flujo sanguíneo superficial del pie, lo que promueve la desecación de la piel y la formación de fisuras. La enfermedad vascular periférica y la cicatrización deficiente impiden la resolución de pequeñas heridas de la piel, permitiendo que aumenten de tamaño y se infecten.

El reconocimiento temprano y el tratamiento de los factores de riesgo pueden prevenir o retrasar la aparición de procesos adversos (Martin P. et al, 2006). Se ha demostrado en diferentes estudios que más del $50 \%$ de las amputaciones pueden evitarse reduciendo los factores de riesgo (Patout et al, 2000). Las estrategias preventivas para reducir la aparición de úlceras en los pies y amputaciones de miembros inferiores están dirigidas al diagnóstico precoz de la úlcera en el pie del diabético. Además se educará al paciente para extremar las condiciones higiénicas del pie (Pérez Freirre y Calle Pascual, 2008).

La presencia de nefropatía diabética demostrada por microalbuminuria es del $13 \%$ en diabéticos tipo 1 y del $23 \%$ en diabéticos de tipo 2 , y el riesgo relativo de presentar 
insuficiencia renal es 25 veces superior en los pacientes diabéticos (Esmatjes et al., 1997). Los pacientes con microalbuminuria que evolucionan a macroalbuminuria suelen progresar a una insuficiencia renal terminal después de varios años. En el tratamiento tanto de micro como de macroalbuminuria, deben emplearse IECAs o antagonistas del receptor angiotensinógeno (ARA II). Para enlentecer su progresión se debe efectuar un abordaje multifactorial en el que será fundamental el control de la hiperglucemia y de la hipertensión, también será importante evitar el consumo de tabaco, controlar la dislipemia y evitar un consumo proteico excesivo. 


\section{FISIOLOGÍA DEL ISLOTE PANCREÁTICO. INSULINA Y GLUCAGÓN.}

\subsection{ESTRUCTURA Y FUNCIÓN DEL PÁNCREAS ENDOCRINO.}

El páncreas, es un órgano retroperitoneal compuesto por una estructura interna similar a la de las glándulas salivales. Las enzimas digestivas pancreáticas son secretadas por acinos pancreáticos, junto con grandes volúmenes de solución de bicarbonato sódico. El producto fluye entonces a través de un conducto pancreático que normalmente se une al conducto hepático inmediatamente antes de su desembocadura en el duodeno a través de la papila de Vater, rodeado por el esfínter de Oddi.

El páncreas endocrino está formado por acumulaciones de células dispuestas desordenadamente en la cabeza, el cuerpo y la cola del páncreas, denominadas islotes de Langerhans o pancreáticos, los cuales constituyen una unidad anátomofuncional y cuya masa corresponde al $1 \%$ del peso total del órgano. El páncreas humano tiene de 1 a 2 millones de islotes de Langerhans, cada uno sólo alrededor de 0,3 milímetro de diámetro y están organizados alrededor de pequeños capilares. Los islotes contienen tres tipos principales de células, alfa, beta y delta, que se distinguen entre sí por sus características morfológicas y de tinción. Los islotes no se distribuyen uniformemente, siendo más numerosos en el cuerpo y en la cola que en la cabeza (Berne et al, 2005). Estos islotes son denominados porción endocrina debido a que tienen la capacidad de introducir directamente en la sangre los productos de su secreción; en ellos se sintetizan la insulina y la amilina (células beta), el glucagón y el péptido ghrelina (células alfa), la somatostatina (células delta), el péptido PP (células PP) y el péptido ghrelina (células epsilon) (Edlund H., 2001). Los islotes tienen una fina red vascular, estando dotados de un sistema venoso de tipo portal orientado desde las células $\beta$, situadas en el centro, hacia las alfa, delta, PP, épsilon, localizadas en la periferia. Las pequeñas arteriolas entran en el corazón de los islotes y se dividen en un sistema de capilares sinusoides de endotelio fenestrado que convergen en vénulas, las cuales llevan la sangre a las capas celulares de los islotes; de este modo, reciben un flujo sanguíneo desproporcionado en relación a su masa. Cada célula $\beta$ y a tiene una cara basal (arterial) y una apical (venosa). En las caras laterales de dos células vecinas existe un canalículo al que se vierte la insulina y donde el fluido intersticial se dirige hacia el lado venoso, lo que permite la exposición de las caras laterales a la 
acción de moléculas que permite que la insulina tenga efectos paracrinos sobre las células situadas en la periferia de los islotes.

Los islotes están inervados por el sistema nervioso autónomo y existen comunicaciones intercelulares. Además, las propias células delta son de tipo dendrítico y envían gránulos de secreción a las células $\beta$, lo que indica la existencia de una vía neurocrina de regulación entre islotes mediada por somatostatina.

Dentro de los islotes, las hormonas son almacenadas en los gránulos secretores rodeados por una membrana. Estos gránulos se distribuyen en la cara apical venosa (secretora) de las células. Dentro de cada célula hay un sistema de microtúbulos que separa las líneas paralelas de gránulos secretores. Además, existe una red de filamentos de actina y de miosina en asociación con microtúbulos, que, probablemente facilita el movimiento activo de los gránulos secretores hacia la membrana plasmática (Langin, 2001).

\subsection{ESTRUCTURA Y SINTESIS DE LA INSULINA.}

La insulina es un polipétido de peso molecular $6000 \mathrm{D}$, constituido por dos cadenas peptídicas denominadas A (21 aminoácidos) y B (30 aminoácidos), unidas entre sí por dos puentes de disulfuro. Además, la cadena $A$ tiene un puente de sulfuro intracatenario. La estructura espacial de la insulina es crítica para su actividad y está determinada por los extremos amino y carboxilo terminales de la cadena $A$ y el carácter hidrofóbico de los aminoácidos del extremo $\mathrm{C}$ terminal de la cadena $\mathrm{B}$. Los monómeros de insulina forman una estructura hexamérica con dos átomos de zinc (Berne et al, 2005).

El gen de la insulina es un miembro ancestral de una familia de genes que codifican para una serie de factores de crecimiento análogos a la insulina. Está compuesto de cuatro exones y dos intrones y dirige la síntesis de preproinsulina, un precursor de la insulina de peso molecular 11.500, que contiene cuatro péptidos en orden secuencial: el péptido señal $N$ terminal, la cadena $B$, un péptido de conexión entre cadenas (péptido $\mathrm{C}$ ) y la cadena $\mathrm{A}$ de la insulina. El péptido $\mathrm{N}$ terminal es eliminado de la 
molécula en el retículo endoplasmático de la célula $\beta$, mientras que la proinsulina, que contiene las cadenas A y B y el péptido C, está completando su síntesis. La proinsulina es dirigida hacia el aparato de Golgi, se forman los puentes de disulfuro y sufre un proceso de plegamiento. Durante su empaquetamiento en forma de gránulos en el Golgi, la proinsulina es rota lentamente por las enzimas proconvertasa-1 y carboxipeptidasa-H. Las moléculas resultantes con la insulina y el péptido C (PC-1), las cuales son liberadas por exocitosis al espacio extracelular.

\subsection{SECRECIÓN DE INSULINA}

La secreción de insulina puede simplificarse en dos estadios: 1) captación y metabolismo de la glucosa en la célula $\beta$ y 2) entrada de calcio y fusión de los gránulos de secreción con la membrana plasmática (exocitosis). En general, la síntesis y secreción de la insulina están íntimamente ligadas, siendo estimulados por la glucosa e inhibidos por el ayuno. La glucosa es el principal nutriente que regula la liberación de insulina, aunque algunos aminoácidos, como la arginina, la leucina y la glutamina, también inducen la secreción. La secreción mediada por nutrientes implica dos vías de transducción de señales. Una de ellas es independiente de la modulación de un canal de $\mathrm{K}^{+} \mathrm{ATP}$ situado en la membrana plasmática por metabolitos de la glucosa, y la otra del metabolismo intracelular de acil CoA de cadena larga en el ciclo de Krebs y la generación de productos metabólicos.

En la secreción de insulina tienen lugar los siguientes acontecimientos de forma secuencial:

1. Un transportador específico de la glucosa (GLUT2), concentrado en las microvellosidades, que se orientan hacia los canalículos, facilita la difusión de la glucosa hacia las células $\beta$, manteniéndola en una concentración intracelular similar a la del espacio intersticial (Berne et al, 2005).

2. La enzima glucoquinasa es el sensor celular que controla la respuesta subsiguiente de la célula $\beta$, fosforilando a la glucosa para dar glucosa-6-fosfato (Matschinsky et el., 1998). Posteriormente, a través de la glucolisis, se origina piruvato, el cual condiciona 
la generación de una señal liberadora de insulina y la secreción paralela. Aunque el piruvato y el lactato originados intracelularmente son estimuladores de la secreción de insulina, el piruvato y el lactato del plasma sanguíneo no lo son, ya que la célula $\beta$ tiene muy pocos transportadores para estos ácidos orgánicos.

3. La oxidación de la glucosa conduce al aumento rápido de la concentración intracelular de adenosín trifosfato (ATP), de la proporción ATP/adenosín difosfato (ADP) y de la formación de adenina dinucleótido (NADH), nicotinamida adenina dinucleótido fosfato (NADPH) e iones de hidrógeno $\left(\mathrm{H}^{+}\right)$. La importancia crítica de la generación de ATP se ilustra con el descubrimiento de que la proteína desacoplante de la fosforilación oxidativa 2 (UCP-2), que disipa la energía procedente de la cadena transportadora de electrones en forma de calor en lugar de generar ATP, está presente en las células $\beta$. Cuando la UCP-2 se sobreexpresa o se regula positivamente, y por consiguiente se forma menos ATP, la secreción de insulina disminuye, lo que sugiere que la sobreproducción de la UCP-2 contribuye al desarrollo de la diabetes inducida por obesidad (Langin, 2001).

4. Al aumentar la proporción de ATP/ADP, el canal de $\mathrm{K}^{+}$ATP dependiente se cierra y la membrana se despolariza. Esto conduce a la apertura de un canal de $\mathrm{Ca}^{2+}$ dependiente de voltaje, con lo que aumenta la concentración intracelular de $\mathrm{Ca}^{2+}$ y se activa el mecanismo de movimiento de los gránulos de secreción a través de los microtúbulos (Matschinsky et al, 1998). Una proteína G (GTPasa), unida a la vesícula secretora, interacciona con unas proteínas de la membrana plasmática denominadas fusinas, produciéndose la fusión de ambas y la exocitosis de insulina en forma de hexámeros. En la vena porta, los hexámeros de insulina se disocian en dímeros y luego, más lentamente en monómeros (Webb et al., 2001). Los canales de $\mathrm{K}^{+}$son unidades heterooctaméricas compuestas de dos subunidades, una formadora del poro (kir6.x) y otra subunidad reguladora de tipo ATP-binding casette denominada SUR (receptor de sulfonilurea). A esta última es a la que se unen los antidiabéticos orales del tipo de la sulfonilurea cerrando los canales de $\mathrm{K}^{+3}$.

Todos los procesos anteriores ocurren dentro del primer minuto después de la exposición a la glucosa por las células $\beta$. Una secuencia de eventos similar ocurre en la estimulación de la secreción de insulina por otros nutrientes, como aminoácidos y cetoácidos, aunque los transportadores y los pasos enzimáticos son diferentes (Webb et al, 2001). 
Existe un mecanismo adicional de liberación de insulina mediado por AMP cíclico (cAMP) en la célula $\beta$. El cAMP estimula la liberación de insulina a través de una proteína cinasa dependiente de cAMP que fosforila varias proteínas implicadas en la exocitosis y facilita el intercambio de GTP-GDP de proteínas G. Las proteínas G estimuladoras son las responsables de los efectos liberadores de varios péptidos, como el glucagón, mediados por la insulina, mientras que las proteínas $\mathrm{G}$ inhibidoras median los efectos supresores mediados por insulina de la secreción de péptidos como la somatostatina. Por otra parte, una proteína $G$ estimuladora unida a la fosfolipasa C media la capacidad de la acetilcolina para estimular la secreción de insulina a través de la formación del segundo mensajero fosfatidilinositol y de la activación de la proteína cinasa C. El péptido insulinotrópico dependiente de glucosa (GIP) y el péptido análogo al glucagón 1 (GLP-1), que son segregados a la circulación sanguínea por las células $\mathrm{L}$ y $\mathrm{K}$ del intestino delgado, también estimulan la secreción de insulina a través de la activación de la proteína cinasa A (PKA) por el mecanismo independiente de los canales de $\mathrm{K}^{+}$, mediado por la produción de cAMP (Cluck et al., 2005).

\subsection{REGULACIÓN DE LA SECRECIÓN DE INSULINA.}

La secreción de insulina en un sentido amplio está gobernada por un sistema de retroalimentación (feedback) que incluye el suministro de nutrientes. Cuando el suministro es abundante se segrega insulina y ésta estimula la utilización metabólica de los nutrientes, inhibiendo simultáneamente la movilización de sustratos endógenos de naturaleza similar. Cuando el suministro de nutrientes es bajo o ausente, se impide la secreción se insulina y aumenta la movilización de los combustibles endógenos.

Sabemos que la glucosa es el principal estimulador de la secreción de insulina, a su vez, la insulina estimula el uso de la glucosa por los tejidos. Por debajo de un nivel umbral de glucosa $(2,8 \mathrm{mmol} / \mathrm{L} \circ 50 \mathrm{mg} / \mathrm{dL})$ virtualmente no se segrega insulina. La respuesta que representa la mitad de la máxima ocurre a concentraciones de glucosa de $8 \mathrm{mmol} / \mathrm{L}(144 \mathrm{mg} / \mathrm{dL})$ y la respuesta máxima a concentraciones superiores a los 17 $\mathrm{mmol} / \mathrm{L}$ (306 mg/dL) (Berne et al., 2005).

Cuando la glucosa se administra por vía oral se desencadena una respuesta mayor que cuando la administración es por vía intravenosa. La razón es que, además de la glucosa, el GIP y el GLP-1 producidos en el intestino son importantes agentes 
estimuladores de la secreción de insulina. La rápida insulinogénesis que sigue a la administración oral de glucosa modera el aumento inicial de la glucosa en la sangre. Por el contrario, la somatostatina liberada desde los islotes de forma paracrina 0 neurocrina y desde el intestino (paracrina) limita la secreción de insulina (Kahn, 1996).

La glucosa y los aminoácidos son estimuladores sinérgicos de la secreción de insulina, de forma que la respuesta es mayor que la correspondiente a la suma de los efectos individuales de la glucosa y de los aminoácidos. Los triacilglicéridos (TG) ejercen sólo un pequeño efecto estimulador de la secreción de insulina; este efecto es indirecto y se debe a la producción de GIP. Por otra parte, los cetoácidos a concentraciones elevadas, correspondientes a un ayuno prolongado, estimulan modestamente la secreción de insulina; este efecto contribuye a mantener un nivel bajo de insulina en ausencia de ingesta de nutrientes. Los ácidos grasos libres, especialmente los saturados de cadena larga como el estearato, aumentan la secreción de insulina en respuesta a la glucosa durante el ayuno al aumentar la concentración de acil CoA en las células $\beta$; éstos aumentan la formación de fosfolípidos de membrana y como consecuencia el diacilglicerol y la actividad de la PKC (Dobbins et al., 1998). Sin embargo, la exposición a largo plazo de las células $\beta$ a los acil CoA causa la apoptosis de las mismas, considerándose uno de los mecanismos implicados en el desarrollo de la diabetes tipo 2 secundaria a la obesidad (McGarry et al., 1999).

Tanto el $\mathrm{K}^{+}$como el $\mathrm{Ca}^{2+}$ son esenciales para la secreción de insulina mediada por glucosa. Así, la deficiencia relativa de insulina es común en sujetos con depleción de $\mathrm{K}^{+}, \mathrm{Ca}^{2+}$, o vitamina $\mathrm{D}$; el $\mathrm{Mg}^{2+}$ también ejerce un efecto regulador. Por otra parte, la actividad simpática y las catecolaminas estimulan la secreción de insulina vía receptores beta-adrenérgicos, pero inhiben la secreción a través de los alfaadrenérgicos. Además, la actividad parasimpática vía nervio vago y la actividad cefálica que precede a la ingesta de alimentos también aumentan la secreción de insulina.

La hiperplasia de las células beta puede también conducir a un aumento en la secreción de insulina (Bonner-Weir et al., 2000). Las células $\beta$ crecen facultativamente en relación a las demandas corporales de insulina asociadas a determinados cambios fisiológicos como el embarazo y la vejez, o patológicos como la obesidad (Edlund, 2001). La glucosa estimula tanto la proliferación como la muerte de las células $\beta$ y, probablemente, mantiene una proporción adecuada de masa celular para la regulación del metabolismo (Maedler et al., 2001). La glucosa aumenta los niveles de $\mathrm{Ca}^{2+}$ intracelular, lo que conduce a la activación de una fosfatasa denominada calcineurina, 
la cual provoca a su vez la localización nuclear de unos complejos de transcripción denominados NFAT (factor nuclear de células T activadas), que son esenciales para aumentar la expresión de los genes que regulan la proliferación y la función de células, Ins 1, Hnf4a, Gck, Glut2 y Cdk4. Por tanto, los NFAT constituyen una diana terapeútica prometedora, no sólo para el tratamiento de la diabetes sino de otras patologías que cursan con alteraciones del crecimiento de las células $\beta$, tales como los insulinomas (Heit et al, 2006).

Por otra parte, ciertas hormonas como el cortisol, la hormona del crecimiento, el lactógeno placentario y las hormonas tiroideas, pueden directa o indirectamente causar hiperplasia, usualmente por antagonizar la acción insulínica e incrementar las necesidades de insulina por los tejidos periféricos. Las células $\beta$ tienen receptores de insulina y ésta ejerce un efecto de feedback negativo sobre su propia secreción, siendo este efecto independiente de la concentración de la glucosa plasmática. La unión de insulina a su receptor en la célula $\beta$ también origina acciones mitóticas en lo que constituye un feedback de tipo positivo (Bevan, 2001). Se ha demostrado que la leptina es capaz de modular la secreción de insulina (De Luis et al., 2008). La leptina inhibe la síntesis y la secreción de insulina, al inhibir la apertura de los canales de $\mathrm{K}^{+}$. Esta acción cierra el círculo de feedback negativo entre ambas hormonas, ya que la insulina estimula la secreción se leptina, de forma independiente a la capacidad de aumento de la masa adiposa.

El péptido ghrelina también parece ejercer un efecto inhibidor sobre la secreción de insulina y se ha establecido una asociación negativa entre los niveles de ghrelina y de insulina tanto en humanos como en varios modelos animales (Gil-Campos et al., 2006). No obstante, parece que ghrelina acilada estimula la secreción de insulina mientras que la desacilada inhibe la respuesta (Gauna et al., 2004).

El resultado neto de los numerosos factores que influyen en la síntesis y secreción de la insulina es mantener unos niveles plasmáticos basales de $10 \mathrm{mU} / \mathrm{L}$. Después de un ayuno prolongado de varios días la concentración se reduce hasta un 50\%; un descenso similar ocurre con el ejercicio prolongado. Los niveles plasmáticos aumentan 3-10 veces después de una comida y el pico ocurre entre 30-60 minutos después del inicio de la alimentación. Además, existen pulsos de secreción con ciclos de 15 minutos y pulsos de ciclo más largo (alrededor de 2 horas), ocasionados por el control de la glucosa. En condiciones basales, el hígado está expuesto de forma regular a una concentración de insulina 2-3 veces superior a la de otros órganos y este aumento 
alcanza 5-10 veces superior después de la estimulación de las células $\beta$ (Del Prato et al., 2002).

\subsection{ACCIONES DE LA INSULINA.}

Los efectos de la insulina implican numerosos órganos y vías de señalización intracelular que son críticas desde el punto de vista metabólico. Muchos de sus efectos requieren habitualmente la presencia de glucosa y algunos de ellos están aumentados porque la insulina inhibe la secreción del glucagón, una hormona con efectos antagónicos a los de la insulina. Los principales tejidos sobre los que actúa la insulina son músculo, tejido adiposo e hígado.

En relación al metabolismo de los glúcidos la insulina estimula la oxidación de la glucosa e inhibe su producción, bajando los niveles circulantes. En el hígado la insulina induce la glucoquinasa que cataliza la fosforilación de la glucosa-6-fosfato y promueve el almacenamiento en forma de glucógeno por activación del complejo enzimático de la glucógeno sintasa (GS)( Klover et al., 2004). Al mismo tiempo estimula la glucolisis, que origina piruvato y lactato, al aumentar la actividad de las enzimas fosfofructoquinasa y piruvato quinasa. Asimismo, la oxidación del piruvato y del lactato aumenta por la actividad incrementada de la piruvato deshidrogenada (PDH). Además, la insulina inhibe la glucogenólisis hepática al disminuir la actividad de la glucógeno fosforilasa y la expresión de la glucosa-6-fosfatasa. Por otra parte, la insulina inhibe la gluconeogénesis al disminuir la captación hepática de aminoácidos procedentes del músculo, así como la expresión o las actividades de las enzimas glucogenogénicas piruvato carboxilasa, fosfoenolpiruvato, carboxiquinasa y fructosa1,6-bisfosfatasa. De esta manera, el piruvato es desviado a la síntesis de acetil CoA, que puede retornar al citoplasma vía citrato y regenerar acetil CoA en el citoplasma por activación de la citrato liasa, dirigiendo la síntesis de ácidos grasos a través de la formación de malonil CoA, una reacción catalizada por la acetil CoA carboxilasa que también es activada por la insulina. Así, se activa la vía de las pentosas fosfato por la glucosa-6-P deshidrogenada lo que origina NADPH necesario para la síntesis de ácidos grasos (Webb et al., 2001).

En el músculo y en tejido adiposo, la insulina estimula el trasporte de glucosa además del flujo sanguíneo. Dependiendo de la concentración de insulina, entre el 20 y el 50\% de la glucosa se oxida en el músculo por activación de la PDH y la restante se dirige a 
la síntesis de glucógeno por activación de la GS. Las fibras de tipo I son más sensibles que las de tipo II (Bonadonna et al., 1993). En el tejido adiposo la mayor parte de la glucosa es convertida en glicerofosfato, que se utiliza para la esterificación de los ácidos grasos por la activación de la gliceraldehído fosfato deshidrogenada, lo que permite su almacenamiento en forma de TG; en una menor proporción también la glucosa puede servir para sintetizar ácidos grasos (Kahn et al., 2006).

En relación al metabolismo de los lípidos la insulina promueve el depósito de grasa en el tejido adiposo al inhibir la lipolisis, un proceso mediado por la lipasa sensible a las hormonas por un mecanismo que implica la disminución del cAMP y la inhibición de la proteína cinasa A. Hay que resaltar que la grasa abdominal visceral es menos sensible a la insulina que el tejido adiposo subcutáneo. La consecuencia principal de la disminución del flujo de ácidos grasos libres ( $A G L)$ desde el tejido adiposo al hígado es la reducción marcada en la síntesis de cetoácidos cuya utilización por los tejidos periféricos es también estimulada por la insulina. Así, la insulina es la hormona anticetogénica por excelencia. Además, la insulina induce la lipoproteinlipasa (LPL) en el tejido adiposo favoreciendo la captación de AGL. En el músculo la insulina suprime la acción de la LPL en proporción inversa a la estimulación de la captación de glucosa e inhibe la lipólisis de los depósitos de TG, así como la captación y la oxidación de los ácidos grasos. En el hígado los AGL procedentes de la circulación son reesterificados con glicerofosfato para formar TG. Asimismo se sintetizan ácidos grasos a partir de glucosa, como se ha indicado anteriormente. La acción anticetogénica de la insulina en el hígado se debe probablemente a la inhibición de la AMP cinasa, una enzima que a su vez inhibe la aminociclopropano-1-carboxílico (ACC). Ello conlleva el aumento de la formación de malonil CoA, el cual inhibe la carnitina acil transferasa, enzima responsable de la transferencia de $A G L$ desde el citoplasma a la mitocondria para su oxidación y conversión a cetoácidos. La insulina también favorece la síntesis de colesterol hepático a partir de acetil CoA al activar a la enzima limitante del proceso, hidroximetil-glutaril-CoA reductasa. En paralelo con el aumento del depósito de los TG, la insulina disminuye la síntesis de la apo $\mathrm{B}$, dando como resultado neto una supresión aguda de la liberación de lipoproteínas de muy baja densidad (VLDL). Sin embargo, bajo condiciones de hiperinsulinemia, la elevada proporción de síntesis de TG eleva finalmente los de las VLDL circulantes.

El tejido adiposo también secreta varias proteínas bioactivas o adipocinas, que regulan el metabolismo de la glucosa. Entre estas adipocinas están incluidas leptina, resistina, adiponectina y factor de necrosis tumoral- $\alpha$ (TNF $\alpha$ ). La interleucina 6 y el TNF- $\alpha$ 
aumentan en la mayoría de animales y en humanos con obesidad y resistencia a insulina, aunque el papel de la resistina en cuanto a la relación entre obesidad y resistencia a insulina es cuestionable (Aller et al., 2007).

Por lo que se refiere al metabolismo proteico, la insulina aumenta la síntesis proteica y la captación y secuestro de aminoácidos desde el plasma sanguíneo en todos los órganos diana. Por tanto la insulina es una hormona anabólica. Durante la fase de asimilación de la proteína de la dieta, el aumento de insulina limita el incremento de los aminoácidos plasmáticos, especialmente los de cadena ramificada (BCA). Además estimula el transporte de pendiente de $\mathrm{Na}^{+}$de los aminoácidos neutros en el músculo. El aumento de la síntesis proteica ocurre por un incremento de la transcripción de numerosos genes, aumento de la proporción de traducción de los ARN mensajeros (mARN) y aumento de la síntesis de ribosomas (Kimball et al., 2002). Por otra parte y de forma más evidente, la insulina inhibe la proteólisis. Esta acción se manifiesta por la supresión de la liberación de BCA y de aminoácidos aromáticos desde el músculo y la inhibición de su oxidación. Por el contrario, la insulina tiene muy poco efecto sobre el flujo de alanina.

La insulina no sólo es una hormona anabólica general, sino que induce la expresión de genes y estimula la síntesis de macromoléculas en tejidos tales como el cartílago y el hueso que contribuyen directamente al crecimiento corporal. Se han estudiado individuos con diabetes tipo 2 que presentan alteraciones en la masa ósea y podrían presentar mayor riesgo de fracturas (Pérez-Castrillón et al., 2004)

También influye indirectamente sobre el crecimiento al estimular la transcripción de otros factores de crecimiento relacionados con ella, como el factor análogo a la insulina 1 (IGF-1) (Bevan et al., 2001).

\subsection{EL GLUCAGÓN.}

El glucagón, al igual que otras hormonas polipeptídicas, está codificada por un gen preproglucagón, que tiene seis exones, los cuales codifican un precursor de glucagón y los precursores del péptido similar al glucagón (GLP - 1 y GLP - 2). La estructura primaria de las tres hormonas está altamente conservada en los mamíferos, lo que sugiere la preservación de la una actividad biológica crítica (Mojsov S, et al, 1986). 
El producto del gen proglucagón depende del tejido que lo sintetiza. En las células alfa de los islotes pancreáticos, la forma biológicamente activa liberada es el glucagón. Un fragmento de proglucagón es también liberado por las células alfa de los islotes. Su secuencia incluye tanto el GLP-1 y GLP-2, pero estas secuencias están flanqueadas por aminoácidos que hacen a ambos productos biológicamente inactivos. En las células $L$ del intestino delgado y grueso, sucede lo contrario. Aquí, el GLP-1 y GLP-2 se escinde de la secuencia proglucagón en sus formas biológicamente activas. La diferencia de los productos secretados del gen proglucagón se debe al diferente procesamiento postraduccional mediado presumiblemente por diferentes enzimas en cada uno de los tejidos (Taborsky GJ, et al, 2010).

\section{Efectos de glucagón}

Acción hepática.

El sitio principal de acción fisiológica del glucagón es el hígado. Este está expuesto a concentraciones de glucagón que son de dos a tres veces mayores que los niveles a los en otros órganos. El glucagón es secretado en la vena porta y parcialmente extraído por el hígado. Además, los niveles sistémicos de glucagón endógeno son generalmente inferiores a los necesarios para afectar a los receptores de glucagón en el tejido adiposo para provocar la lipolisis y el glucagón no tiene ningún efecto apreciable sobre la glucogenólisis muscular. En tercer lugar, los niveles de glucagón portal activan los abundantes receptores hepáticos de glucagón. Estos receptores están acoplados a proteínas G S (GS), que activan la adenilato ciclasa a través de su subunidad alfa. El aumento resultante de los niveles hepáticos de adenosinmonofosfato cíclico (AMPc) activa la proteína quinasa $A$, que a su vez, fosforila las enzimas necesarias para activar la glucogenólisis hepática (Exton JH, 2001)

\section{Glucogenólisis y gluconeogénesis}

Incluso niveles basales de glucagón en la vena porta son suficientes para estimular cerca de las tres cuartas partes de la producción de glucosa en ayunas, tanto en animales experimentales como en humanos. Sin embargo, este grado de estimulación depende de los bajos niveles de insulina, como se observan en el ayuno. A pesar que el glucagón aumenta las enzimas hepáticas que median los procesos de la gluconeogénesis, la contribución de la gluconeogénesis a la producción de glucosa basal es generalmente menor en animales grandes y humanos. Sólo cuando el ayuno 
es muy prolongado hay un volumen considerable de los precursores necesarios para una producción de glucosa significativa a partir de la gluconeogénesis. Los niveles fisiológicos de glucagón no tienen participación directa en la movilización de glicerol a partir del tejido adiposo y de la movilización de aminoácidos a musculares (Taborsky GJ, 2010)

Los aumentos de glucagón endógeno por encima del nivel de ayuno también estimulan de forma importante la producción hepática de glucosa, en gran parte por la glucogenólisis. Por ejemplo, los incrementos de glucagón tan pequeños como $10 \mathrm{pg} /$ $\mathrm{ml}$ aumentan la producción hepática de glucosa en un $25 \%$. Así, los cambios de la secreción de glucagón en toda su producción fisiológica de control de valores de glucosa hepática a través de su rango fisiológico.

El efecto del glucagón en la producción de glucosa hepática tiene un efecto transitorio. De hecho, la respuesta de producción de glucosa hepática a un incremento escalonado de glucagón es un pico rápido seguido por un una respuesta menor pero más sostenida. Curiosamente, este es el patrón de producción de glucosa hepática necesaria para lograr un aumento rápido pero sostenido de la glucosa plasmática. De hecho, parte de las características de ese efecto en la secreción del glucagón se deben al aumento de la glucosa en plasma y su estimulación de la secreción de insulina, los cuales inhiben la producción de glucosa hepática. Sin embargo, esta retroalimentación negativa explica sólo una parte de este efecto; la mayoría parece ser una inhibición de la vía de señalización intrahepática del glucagón (Wada $\mathrm{M}$, et al, 1995; Taborsky GJ, 2010). 


\section{REVISIÓN DE LA OBESIDAD.}

\subsection{EPIDEMIOLOGÍA DE LA OBESIDAD.}

Aunque hay evidencia que la prevalencia de la obesidad está disminuyendo en algunas poblaciones, la prevalencia de exceso de peso continua alta en muchos países del mundo. La obesidad se define como un Índice de Masa Corporal mayor a $30 \mathrm{~kg} / \mathrm{m} 2$ y representa un grado de acumulación de grasa que puede afectar a la salud en general.

La prevalencia de obesidad en sociedades como la estadounidense ha alcanzado proporciones epidémicas (Mokdad et al., 2003). En 2008 se reportó que mas del 34\% de la población adulta estadounidense era obesa y un $64,5 \%$ presentaba sobrepeso. Estos porcentajes son el resultado de una tendencia al aumento de pacientes con exceso de peso en los últimos años. La proporción de pacientes obesos aumentó en un $8,3 \%$ entre los períodos $1976-1980$ y $1988-1994$, en un $7,6 \%$ adicional entre 1988 1994 y entre 1999-2000 también se produjo un aumento del 8,6\% en el porcentaje de adultos con sobrepeso. (Flegal FK, et al, 2010).

La Organización Mundial de la salud indicó que en 2008 se registraron 1500 millones de adultos mayores de 20 años con sobrepeso y de ellos, 200 millones de hombres y 300 millones de mujeres fueron obesos (Media Centre OMS, 2011) En la actualidad, se estima que al menos el $25 \%$ de los niños en los Estados Unidos presentan sobrepeso o son obesos. En las sociedades industrializadas, el sobrepeso y la obesidad son cada vez más frecuentes, especialmente en los niños. Esto es especialmente cierto en las culturas urbanizadas en la que ha disminuido la actividad física y la alimentación se basa en dietas altas en grasa y calorías y los alimentos preparados se han vuelto más comunes y accesibles. Se prevé que en 2015 este número será casi el doble (Centers for Disease Control and Prevention, 2011)

Los datos publicados por la Organización Mundial de la Salud (OMS) y la Asociación Internacional para el Estudio de la Obesidad (IASO) muestran que más del $50 \%$ de la población adulta en la Unión Europea sufre actualmente sobrepeso u obesidad, lo que indica que el número de personas obesas se ha triplicado en las últimas dos décadas. Se ha demostrado que la obesidad es más frecuente en personas con un bajo nivel educativo y entre las clases sociales más bajas. Aunque el análisis comparativo de la prevalencia de la obesidad por clase social presenta dificultades (diferencias en la 
definición operativa de sus variables) entre los distintos estudios, estos coinciden en que la prevalencia de obesidad se incrementa al reducirse la clase social (OrtizMoncada, et al, 2006).

A pesar que la proporción de pacientes obesos es en general algo menor en Europa, las prevalencias son elevadas y siguen la misma tendencia que en Estados Unidos. La prevalencia de obesidad en Europa presenta una gran variabilidad entre países y oscila entre el $30 \%$ de la población adulta en Yugoslavia y el 5\% aproximadamente en Suiza (Molarius et al., 2000). Apoyando que la proporción de pacientes obesos también está aumentando en Europa, en Suecia y Bélgica la proporción de pacientes obesos aumentó un 3 y un 5,3\%, respectivamente, entre los años 1980 y 1997.

\subsubsection{Prevalencia de la obesidad en España}

Los datos del Estudio de Nutrición y Riesgo Cardiovascular en España (ENRICA), un estudio transversal llevado a cabo entre junio de 2008 y octubre 2010 en 12.883 personas representativas de la población de España mayor de 18 años, no institucionalizada, muestra un índice de masa corporal medio en los adultos españoles de 26,9 kg m-2 (27,4 en los hombres y 26,3 en mujeres), el cual aumentó con la edad. La prevalencia de sobrepeso fue del $39,4 \%$ (46,4\% en los hombres y el $32,5 \%$ en mujeres), y la prevalencia de obesidad fue $22,9 \%$ (24,4\% en hombres y $21,4 \%$ en mujeres). La frecuencia de sobrepeso y obesidad aumenta con la edad fue mayor en hombres que en mujeres, excepto para los mayores de 65 años, donde la obesidad es más frecuente en las mujeres (Tabla 3).

En cuanto a la obesidad mórbida, la prevalencia fue de 1,2\% en la muestra total del estudio, el $0,6 \%$ en los hombres y el 1,8\% (IC 95\% 1,4-2,2\%) en las mujeres.

La prevalencia de obesidad abdominal (OA) fue del 35,5\% (31,7\% en hombres y $39,2 \%$ en mujeres). En cada edad, la prevalencia de OA fue mayor en mujeres que en hombres, y alcanzó el 50,9\% de los hombres y el 69,7\% de las mujeres mayores de 65 años. La frecuencia de la obesidad y OA disminuyó con el aumento del nivel educativo en cada sexo. Este gradiente social es especialmente notable para la obesidad en las mujeres, por lo que el $29 \%$ de las mujeres con educación primaria o menos tenía obesidad frente a sólo el $11 \%$ de las personas con estudios universitarios.

Así mismo, la prevalencia ajustada por edad de la obesidad y OA fue muy elevada en las Islas Canarias y en el sur de España. La diferencia absoluta entre las regiones con 
mayor y menor prevalencia de obesidad es del $16 \%$ en hombres y $12 \%$ en mujeres (Gutierrez Fisac JL, et al, 2011).

En la población infantil y juvenil española (2-24 años), de acuerdo a los resultados del estudio enKid (Serra-Majem et al., 2003), la prevalencia de obesidad se estima en un $13,9 \%$ y el sobrepeso en un $12,4 \%$. En conjunto, sobrepeso y obesidad suponen el $26,3 \%$. La obesidad es significativamente más prevalente en varones (15,6\%) que en mujeres (12,0\%). En el grupo de varones, las tasas más elevadas se observaron entre los 6 y los 13 años. En las mujeres, las tasas de prevalencia más elevadas se observaron entre los 6 y los 9 años.

Los resultados del estudio enKid han puesto de manifiesto que la obesidad en la población española en edad infantil y juvenil está adquiriendo dimensiones que merecen una atención especial. La prevalencia de obesidad según este estudio es más importante en la población en edad escolar, especialmente en los años que preceden a la pubertad.

El consumo elevado de productos de bollería industrial y otros alimentos ricos en grasas, el bajo consumo de frutas y verduras y un estilo de vida sedentario se han identificado como factores determinantes de la obesidad en este grupo de edad (Gutiérrez-Fisac JL et al., 2005).

En la mayoría de estudios realizados en adultos en España la prevalencia de obesidad es más elevada en las mujeres y aumenta a medida que avanza la edad. Entre los factores que influyen en una mayor prevalencia de obesidad destacan, por un lado, los ligados al estilo de vida: mayor sedentarismo, menor consumo de frutas y verduras, así como el incremento del aporte calórico a expensas de grasas o de alcohol. Por otra parte, la multiparidad, un bajo nivel socioeconómico y cultural, y el hecho de residir en las comunidades autónomas del sureste del país, Canarias y del noroeste están asociados a una prevalencia superior de obesidad en comparación al resto.

El análisis de los datos de la Encuesta Nacional de Salud refleja un aumento en la prevalencia de obesidad más acusado en las personas con menor nivel educativo. El incremento absoluto fue mayor en los individuos con nivel de estudios bajo, en los que la obesidad pasó del 8,9 y el $10,7 \%$ en 1987 al 18,1 y el $20,5 \%$ en 2001 en hombres y mujeres, respectivamente.

La prevalencia de obesidad en España es menor que en los Estados Unidos (EE.UU.), donde el 34\% de la población mayor de 20 años o más eran obesos en 2008 
(Flegal KL, et al, 2010). En Europa, hay cierta variabilidad en la prevalencia de la obesidad; los resultados del estudio ENRICA son similares a los de Gran Bretaña, con $23 \%$ de la personas con obesidad en mayores de 16 años en 2009 o de Finlandia, donde el $21 \%$ de los hombres y el $24 \%$ de las mujeres de más de 30 años y eran obesos en 2000. Sin embargo, la prevalencia de obesidad en España es mucho mayor que la de Portugal en 2003-2005, donde el 14\% de la población tenía obesidad (Gutierrez-Fisac, et al, 2011).

Tradicionalmente, la prevalencia de sobrepeso en España fue mayor en los hombres, mientras que la obesidad fue mayor en mujeres. Sin embargo, tanto en España y en otros países la frecuencia de obesidad en los últimos diez años ha aumentado más en hombres que en mujeres. Por lo tanto, la prevalencia actual de obesidad en España es algo mayor en los hombres. Por el contrario, en España y varios países como los EE.UU. o Inglaterra la obesidad abdominal es más frecuente en mujeres que en hombres. Al igual que en los EE.UU. y otros países europeos (por ejemplo, Portugal, Inglaterra y Finlandia), la obesidad en España presenta un gradiente socioeconómico inverso. Esto es consistente con el menor nivel de actividad física de tiempo libre y menor adhesión a la dieta mediterránea en personas con bajo nivel educativo en España .

Finalmente, la gran variación geográfica en la prevalencia de la obesidad y OA en España es también una característica de la epidemiología de la obesidad en muchos países. Los factores que podrían explicar las diferencias regionales en la obesidad y, específicamente, el gradiente norte-sur en España no están claros. Además, recientes estudios regionales y locales muestran que este patrón también afecta a otros factores de riesgo cardiovasculares como la hipertensión y la hipercolesterolemia. Este patrón se ha ligado tradicionalmente al bajo nivel socioeconómico de las Islas Canarias y el sur de España. Además, la reducción de la actividad física y el empeoramiento de los hábitos alimenticios, que han conducido a la epidemia de la obesidad en las últimas décadas, pueden haber sido más pronunciados en el sur de España que en otras regiones debido a circunstancias económicas y sociales. (Gutierrez-Fisac, et al, 2005) 


\begin{tabular}{|l|l|l|l|l|}
\hline Grupo & $\mathbf{n}$ & IMC (medio) & Sobrepeso & Obesidad \\
\hline Total & 12036 & $26.9 \%$ & $39.4 \%$ & $22.9 \%$ \\
\hline $18-44$ años & 6018 & $25.5 \%$ & $33.4 \%$ & $15 \%$ \\
\hline $45-64$ años & 3580 & $27.9 \%$ & $44.9 \%$ & $27.8 \%$ \\
\hline$>65$ años & 2438 & $28.8 \%$ & $46 \%$ & $35 \%$ \\
\hline Hombres & 5957 & $27.4 \%$ & $46.4 \%$ & $24.4 \%$ \\
\hline $18-44$ años & 3127 & $26.5 \%$ & $41.5 \%$ & $18.6 \%$ \\
\hline $45-64$ años & 1782 & $28.4 \%$ & $51.9 \%$ & $30.9 \%$ \\
\hline$>65$ años & 1048 & $28.4 \%$ & $51.7 \%$ & $30.6 \%$ \\
\hline Mujeres & 6080 & $26.3 \%$ & $32.5 \%$ & $21.4 \%$ \\
\hline $18-44$ años & 2891 & $24.4 \%$ & $24.6 \%$ & $11.1 \%$ \\
\hline $45-64$ años & 1798 & $27.3 \%$ & $38.0 \%$ & $24.7 \%$ \\
\hline$>65$ años & 1390 & $29.1 \%$ & $41.7 \%$ & $38.3 \%$ \\
\hline
\end{tabular}

Tabla 3: Indice de masa corporal (IMC) y prevalencia de sobrepeso y obesidad en España. Estudio ENRICA. (Gutierrez - Fisac JL, et al, 2011).

\subsection{ETIOLOGÍA DE LA OBESIDAD.}

Hay varios factores que pueden conducir al desarrollo de la obesidad. Estos factores incluyen la genética, el sedentarismo y el exceso de calorías consumidas. Algunos medicamentos como los corticoides y fármacos antipsicóticos también pueden causar aumentos significativos de peso como efecto secundario. Algunos factores psicosociales también pueden contribuir al desarrollo de la obesidad. En última instancia, estos factores se combinan para producir un desequilibrio entre la ingesta calórica y el gasto energético.

Muchas teorías han sido expuestas tratando de explicar los orígenes de la epidemia de obesidad que vivimos en nuestros días. Neil en 1962 propuso la teoría de genes ahorradores, esta teoría mantiene que en los individuos que los expresan se optimiza la extracción de nutrientes ingeridos a partir los alimentos, haciendo a estos individuos más eficientes en la acumulación de grasa durante las épocas de abundancia, traduciéndose en una ventaja evolutiva en épocas de escasez de alimentos. Con el tiempo, la supervivencia de los individuos con "genes ahorradores" se vio favorecida en comparación con aquellos que no los expresaban. A la luz de la abundancia de alimentos disponibles hoy y los cambios hacia estilos de vida más sedentarios, esta teoría ofrece una explicación plausible de la epidemia de obesidad (Parks, et al, 2011). 
Quienes se oponen a esta teoría, refutan la idea debido a que las hambrunas siempre tuvieron un efecto devastador generalizado en la raza humana. Otros señalan, que siguiendo los principios básicos de la genética, si los genes ahorrativos fueran una ventaja evolutiva, la mayoría de la población sería obesa en este momento.

Una teoría más reciente propuesta por John Speakman incorpora la observación que no todos los seres humanos modernos son obesos, y propone que el fenotipo obeso es el resultado de la deriva genética, y con la eliminación de la necesidad de tener características depredadoras para la búsqueda de alimentos que limitan el peso corporal, los seres humanos se encuentran ahora en un proceso evolutivo que fomenta la perpetuación de los fenotipos obesos (Parks, et al, 2011).

Es posible que los orígenes de la obesidad puedan ser explicados por estas teorías, pero es más probable que una combinación de eventos evolutivos, socio-económicos y biológicos hayan dado lugar a la actual epidemia de obesidad, aunque algunas variantes genéticas pueden ahora manifestarse debido a la alta disponibilidad de energía (mayor tamaño de las raciones, alimentos con alta densidad energética) y por el alto sedentarismo que existe en las sociedades desarrolladas. Aunque existen diferencias interindividuales en la respuesta a diversas intervenciones dietéticas o de ejercicio físico, se han llevado a cabo algunos intentos para establecer diferencias en función del genotipo (De Luis et al., 2008).

La obesidad, la diabetes, el síndrome metabólico se asocian con mayor riesgo cardiovascular. Algunos de estos riesgos pueden surgir a través de un mecanismo protrombótico y proinflamatorio, según lo evidenciado por los niveles elevados de proteína C reactiva y la interleucina 6 . No se sabe exactamente si el síndrome metabólico produce un riesgo mayor que la suma de sus componentes individuales, pero sigue siendo un marcador útil para los pacientes que se encuentran en riesgo cardiovascular (Mc Kenney RL, et al, 2011)

El aumento de peso y la adiposidad se determinan por el equilibrio entre el gasto energético y la ingesta calórica. La ingesta calórica está determinada tanto por la cantidad de alimentos ingerida, como por la composición nutricional de la misma. Mas del $30 \%$ de las calorías de la dieta occidental provienen de la grasa. La grasa es más rica en calorías que los carbohidratos o proteínas y tiene un menor impacto sobre la saciedad que los hidratos de carbono o las proteínas 
La ingesta de alimentos está controlada en gran parte por el apetito, el cual está regulado por el hipotálamo en una forma compleja a través de múltiples mecanismos diferentes. Una de estas hormonas es la leptina, que se produce en el tejido adiposo y es un poderoso supresor del apetito.

El Péptido Similar al Glucagon 1 (GLP1) es una hormona del grupo de las incretinas que se produce en el intestino. Se ha demostrado que inhibe la ingesta de alimentos cuando se administra de forma exógena. También hay otras hormonas producidas en el intestino que parecen tener un efecto supresor sobre el hambre y la saciedad. Estas hormonas son la colecistoquinina, enterostatina, polipéptido $\mathrm{Y}$, la hormona estimulante de melanocitos, hormona liberadora de corticotropina, el TNF-1, y la obestatina.

Además de los supresores del apetito, hay varias hormonas que son fuertes estimulantes del hambre. La ghrelina es producida por el intestino y parece tener 2 efectos principales: estimulación de la secreción de hormona del crecimiento y el aumento de la ingesta de alimentos. Cuando una persona se anticipa a la ingestión de alimentos, aumentan de las concentraciones séricas de la ghrelina. A la inversa, después de una comida, la secreción de ghrelina es suprimida. Además las pérdidas de peso inducidas por dieta y ejercicio aumentan los niveles de ghrelina estimulando el apetito, lo que podría complicar los esfuerzos realizados con las dietas hipocalóricas. Un descenso en la concentración sérica de ghrelina se demostró después del bypass gástrico (BPG) en un estudio y ha sido propuesto como un mecanismo por el cual la cirugía bariátrica puede inducir pérdida de peso y la corrección de la hiperglucemia (Cummings D, et al, 2002)

Otros estimulantes del apetito incluyen el neuropéptido $\mathrm{Y}$, dinorfina, la hormona concentradora de la melanina, la noradrenalina, el factor liberador de la hormona del crecimiento, la orexina-A y orexina-B.

Hay varias áreas en el cerebro que son importantes en la modulación del apetito. Estas áreas incluyen el núcleo arcuato, donde actúa la leptina, el núcleo del tracto solitario, donde se reciben las señales vagales, el núcleo paraventricular y las regiones lateral y ventromedial del hipotálamo, así como áreas de la amígdala (Bethoud HR, et al 2002).

El sistema nervioso simpático también tiene un papel en la modulación de la ingesta de energía. Los glucocorticoides estimulan la ingesta, mientras que la activación del 
sistema nervioso simpático periférico disminuye la ingesta de alimentos a través de los receptores b3-adrenérgicos.

El ejercicio y mecanismos de gasto energético contrarrestan el efecto de los efectos de la ingesta calórica. El gasto energético total (GET) se compone tanto de gasto energético en reposo (GER) y las calorías quemadas a través del ejercicio. El GER es la cantidad de energía que necesita el cuerpo durante todo el día para llevar a cabo reacciones químicas básicas y las funciones fisiológicas cuando está en reposo. El GER representa el $70 \%$ de la GET. El GER aumenta a medida que la masa grasa aumenta por lo que las personas obesas no tienen una menor GER o tasa metabólica basal. La termogénesis inducida por alimentos constituye otro $15 \%$ a $20 \%$ del GET. La actividad física constituye sólo un $10 \%$ a $15 \%$ del GET, que es el único componente fácilmente modificable de la GET (Ravussin E, et al 1988).

Los mecanismos implicados en la pérdida de energía, en forma de calor proceden de la termogénesis, que en humanos se activa al aumentar la tasa metabólica basal, inducida por la acción de nutrientes y hormonas. Los roedores y otros mamíferos disponen de un tejido especializado, el tejido adiposo marrón, que tienen una gran cantidad de mitocondrias que presentan una proteína UCP1 (uncoupled protein 1) que permite desacoplar el metabolismo oxidativo de la generación de ATP. La activación (el frío o el exceso de ingesta) o inhibición (por ayuno o gestación) de la actividad UCP1 permite a estos animales ajustar la liberación de calor. En los humanos, salvo en el período de adaptación del neonato, el tejido adiposo marrón está circunscrito a unas escasas localizaciones residuales y se considera que su funcionalidad es muy limitada. Tampoco la presencia de posibles actividades desacoplantes (UCP2 y UCP3) en otros tejidos parece que juegue un papel significativo en la termogénesis, a pesar de que su sobreexpresión en animales puede determinar un fenotipo no obeso (Clapham et al, 2000). Ensayos anteriores realizados en nuestro grupo de investigación estudian la asociación entre el polimorfismo -55CT del gen ucp3 con la distribución de grasa en pacientes obesos y tampoco se observaron diferencias en los parámetros antropométricos entre los grupos que poseían la mutación y los que no (De Luis et al, 2007).

El control del peso corporal también está condicionado por la actividad metabólica y en concreto, por la dinámica de las reservas grasas del organismo. Así, el adipocito desempeña un papel paracrino y endocrino que autorregula su capacidad de almacenamiento y que interviene en el control hipotalámico de la ingesta y en los mecanismos de utilización y almacenamiento de las reservas. El adipocito segrega, 
por ejemplo, leptina, proteína estructuralmente similar a la familia de las citocinas y que es capaz de modular la secreción de neuropéptidos que controlan la ingesta. La actividad biológica de la leptina se lleva a cabo al unirse a un receptor específico en el que en ocasiones ocurren mutaciones. Se ha comprobado, por tanto, que la leptina está implicada en obesidad y desórdenes metabólicos, aunque se sabe que también intreviene en otras vías de señalización implicadas en cáncer, formación de hueso, asma, etc. (De Luis et al., 2009).

Un defecto genético conocido que causa obesidad afecta a la leptina. Los ratones que son deficientes en leptina debido a un defecto en la hormona o en su receptor demuestran infertilidad, hiperinsulinemia, hiperfagia, y resistencia a la insulina. Se ha demostrado que la suplencia exógena de leptina en estos ratones pude revertir las manifestaciones de la deficiencia (Chen $\mathrm{H}$ et al, 1996).

La deficiencia de leptina también se ha encontrado en los seres humanos, inicialmente descubierta en individuos consanguíneos. Cuando estos pacientes recibieron leptina, exógena se observó una importante pérdida de peso y una disminución en el consumo de alimentos. Aunque este descubrimiento fue muy prometedor, muchos pacientes obesos no tienen un defecto en el gen de la leptina. De hecho, en la mayoría de los pacientes con obesidad se ha encontrado que se han elevado los niveles de leptina en suero. Así, el papel de la leptina en la terapia de la obesidad no está claro. (Ravussin $E$, et al, 2009).

Hay cierto consenso en considerar de forma independiente aquellos tipos de obesidad que tienen un origen genético y que se asocian a problemas de desarrollo físico e intelectual. Sin embargo, en la mayor parte de pacientes que desarrollan obesidad es difícil establecer una única causa, ya que la obesidad se debe a la interacción entre genes y ambiente. Los genes candidatos, hacen referencia a su efecto sobre el peso corporal, la adiposidad, la distribución de la grasa, la ingestión de nutrientes, las señales orexígenas y saciantes, el gasto energético, la termogénesis inducida por la dieta, la actividad física y las comorbilidades, entre otros.

La obesidad tiene un fuerte componente familiar como lo demuestran múltiples estudios. Los gemelos idénticos tienden a tener pesos similares, con mayor frecuencia que los gemelos no idénticos, y la distribución de la grasa de los niños adoptados parece seguir las características de los padres biológicos. Algunos factores específicos que influyen en el desarrollo de la obesidad también parecen tener una base hereditaria. Estos factores incluyen la tasa metabólica, la actividad física espontánea, y 
la termogénesis inducida por los alimentos. La obesidad también está asociada a trastornos genéticos como el síndrome de Prader-Willi y Bardet-Biedl, pero hay por lo menos otros 22 desórdenes conocidos.

Hay varios genes que han sido implicados en el desarrollo de la obesidad. Un ejemplo es el gen TINA, que produce retinitis, daños hipotalámicos, así como sobreestimulación del apetito. Otros genes que se han implicado en el desarrollo de obesidad, codifican enzimas tales como prohormona convertasa 1 que está involucrada en el procesamiento de pre-hormonas a hormonas. La pérdida del factor estimulante de los melanocitos, que es un factor de saciedad, también puede conducir a obesidad severa, al igual que la pérdida de su receptor (el receptor de la melanocortina 4) Estos defectos genéticos son de particular interés, sin embargo, se necesitan más investigaciones antes de poder valorar sus aplicaciones terapéuticas.

Los factores y deficiencias genéticas son sólo una parte de la explicación del por qué del desarrollo de obesidad y DM2. Los factores ambientales y de comportamiento también contribuyen significativamente al desarrollo de estas condiciones. Los dos principales factores que causan aumento de peso son la ingesta excesiva de calorías y la escasa actividad física. Cualquiera de estas condiciones crea un desequilibrio del consumo de energía, favoreciendo la acumulación de reservas de grasa y la ganancia de peso.

El exceso de ingesta calórica se perpetúa por el fácil acceso a los alimentos llamados "de conveniencia" con bajo coste y alto contenido en grasas. Así mismo los avances en el transporte, así como una disminución en el trabajo manual laboral conduce a una dramática disminución en el nivel general de actividad física de la población. Los factores de comportamiento también influyen en el desarrollo de la obesidad. Por ejemplo, en el estudio Framingham se ha demostrado que la obesidad tiene un fuerte componente social. Se ha visto que las personas que están rodeadas de personas obesas se ven influidas por los comportamientos de estos individuos. Esta influencia a su vez puede conducir a una mayor ingesta calórica y a un nivel menor de actividad física (Christakis NA, et al, 2007).

Se cree que el entorno intrauterino puede jugar un papel importante en la programación metabólica durante la vida el individuo. Por ejemplo, los estudios con roedores han mostrado que la diabetes gestacional puede provocar un síndrome de exceso de insulina. Asimismo, en estudios similares, la deficiencia de insulina se puede desarrollar después de un período de desnutrición. Este hallazgo sugiere que el 
ambiente temprano pueden influir en los patrones de apetito, actividad física, e incluso en preferencias alimentarias durante la vida de un individuo. (Mc Kenney $R L$, et al, 2011).

No debemos olvidar la presencia de diferentes variantes de determinados genes y las interacciones entre ellos que influyen sobre la respuesta a la dieta.

\subsection{DIAGNÓSTICO Y CLASIFICACIÓN.}

La obesidad es una enfermedad crónica multifactorial que se define por la existencia de un exceso de grasa corporal que pone al individuo en una situación de riesgo para su salud.

En varones se considera un porcentaje normal de grasa corporal entre el 12 y el $20 \%$ del peso corporal, mientras que en mujeres es normal un porcentaje entre el 20 y el $30 \%$. En general, se definen como obesos aquellos sujetos varones con un porcentaje de grasa corporal superior al $25 \%$. Las mujeres se consideran obesas si presentan un porcentaje de grasa corporal superior al 33\%. Se considera limítrofe un porcentaje entre el 21 y el $25 \%$ en varones y entre el 31 y el 33\% en mujeres (AACE/ACE, 1998). Aun cuando se dispone de tecnología precisa para la medición de la cantidad de grasa corporal, esta metodología no está al alcance de la práctica clínica habitual. Por ello, se recurre a estimaciones de ésta a partir de datos antropométricos de fácil obtención en la práctica clínica diaria.

El método más aceptado para definir y clasificar la obesidad es el índice de masa corporal (IMC), que se define como el cociente entre el peso (en kilogramos) y el cuadrado de la talla (en metros). Múltiples estudios han demostrado una correlación aceptable entre el IMC y el porcentaje de grasa corporal. Además, el cálculo del IMC es más exacto que la medida aislada del peso en la estimación de la grasa corporal total (Van Hubbard S., 2000). Es cierto que el IMC presenta limitaciones como la sobrestimación del porcentaje de grasa en individuos musculosos (deportistas) o la infravaloración en sujetos con baja masa magra (ancianos) y que la relación entre IMC y grasa corporal no es la misma en distintas poblaciones.

Aun cuando el punto de corte del IMC para definir obesidad ha ido variando ligeramente, tiende a aceptarse como obesidad un valor de IMC superior a $30 \mathrm{~kg} / \mathrm{m}^{2}$, que es precisamente el punto de corte para definir obesidad propuesto por la OMS en 
su clasificación del peso corporal recogida en la Tabla 4. La clasificación de la Sociedad Española para el Estudio de la Obesidad (SEEDO) introduce ligeras matizaciones a la clasificación de la OMS (Tabla 5).

Fundamentalmente, subdivide la categoría de sobrepeso en dos subcategorías (sobrepeso grado I, IMC: 25-26,9 kg/m², y sobrepeso grado 2, IMC: $27-29,9 \mathrm{~kg} / \mathrm{m}^{2}$ ) y distingue un grado de obesidad 4 para los pacientes con IMC superior a $50 \mathrm{~kg} / \mathrm{m}^{2}$.

Si bien la estimación del exceso de grasa corporal que define la obesidad se basa en el cálculo del IMC, múltiples estudios muestran que los riesgos para la salud asociados con la obesidad no sólo dependen de la adiposidad total sino también de su distribución. Ya en la década de los cincuenta, Vague describió que el exceso de grasa abdominal o central representaba un mayor riesgo para la salud que ha sido corroborada en diversos estudios (Vague J., 1956).

Por ello, aunque no forma parte de la definición de obesidad, en la evaluación del paciente obeso se recomienda la valoración de la distribución de la grasa corporal. Se ha sugerido que se puede obtener una estimación clínica a partir de medidas antropométricas (Tabla 6), como el perímetro de la cintura, la relación entre los perímetros de cintura y cadera o el diámetro sagital (SEEDO, 2000).

\begin{tabular}{|l|l|}
\hline \multicolumn{2}{|c|}{ Valores límites del IMC $\left(\mathrm{kg} / \mathbf{m}^{2}\right)$} \\
\hline Normopeso & $18,5-24,9$ \\
\hline Sobrepeso & $25-29,9$ \\
\hline Obesidad grado 1 & $30-34,9$ \\
\hline Obesidad grado 2 & $35-39,9$ \\
\hline Obesidad grado 3 & $\geq 40$ \\
\hline
\end{tabular}

Tabla 4. Criterios de la OMS para definir la obesidad en grados según el índice de masa corporal (IMC) 


\begin{tabular}{|l|l|}
\hline \multicolumn{2}{|c|}{ Valores límites del IMC $\left(\mathbf{k g} / \mathbf{m}^{2}\right)$} \\
\hline Peso insuficiente & $<18,5$ \\
\hline Normopeso & $18,5-24,9$ \\
\hline Sobrepeso grado 1 & $25-26,9$ \\
\hline $\begin{array}{l}\text { Sobrepeso grado } 2 \\
\text { (preobesidad) }\end{array}$ & $27-29,9$ \\
\hline Obesidad grado 1 & $30-34,9$ \\
\hline Obesidad grado 2 & $35-39,9$ \\
\hline $\begin{array}{l}\text { Obesidad grado 3 } \\
\text { (mórbida) }\end{array}$ & $40-49,9$ \\
\hline $\begin{array}{l}\text { Obesidad grado 4 } \\
\text { (extrema) }\end{array}$ & $\geq 50$ \\
\hline
\end{tabular}

Tabla 5 Criterios de la SEEDO para definir la obesidad en grados según el índice de masa corporal (IMC)

\begin{tabular}{|l|l|l|}
\hline $\begin{array}{c}\text { Medida límite superior } \\
\text { de la normalidad }\end{array}$ & Varones & Mujeres \\
\hline Índice cintura-cadera & 1 & 0.90 \\
\hline $\begin{array}{l}\text { Circunferencia de la } \\
\text { cintura }(\mathrm{cm})\end{array}$ & 102 & 88 \\
\hline Diámetro sagital (cm) & 25 & 25 \\
\hline
\end{tabular}

Tabla 6. Datos antropométricos para la evaluación de la distribución de la grasa corporal

\subsection{COMPLICACIONES DE LA OBESIDAD.}

El sobrepeso y la obesidad se asocian con un aumento de la morbilidad y la mortalidad. Este incremento depende claramente del grado de sobrepeso u obesidad, y es más elevado para los individuos con mayor IMC. Algunos estudios epidemiológicos observan un aumento progresivo del riesgo relativo de muerte por cualquier causa en relación con el IMC. Así, en individuos con IMC superior a 40 $\mathrm{kg} / \mathrm{m} 2$, el riesgo relativo puede llegar a 2,5 en comparación con el de individuos con 
peso normal (Calle et al., 1999). De la misma manera, en los sujetos con sobrepeso u obesidad se detecta un aumento del riesgo de sufrir diversas enfermedades (Tabla 7).

\begin{tabular}{|l|l|}
\hline Endocrinometabólicas & $\begin{array}{l}\text { Diabetes mellitus, tolerancia defectuosa a la glucosa, } \\
\text { resistencia a la insulina, dislipemia, síndrome } \\
\text { metabólico, gota, ovario poliquístico }\end{array}$ \\
\hline Cardiovasculares & $\begin{array}{l}\text { Hipertensión arterial, enfermedad coronaria, } \\
\text { insuficiencia cardíaca, enfermedad vascular cerebral } \\
\text { isquémica, estasis venosa, trombosis venosa } \\
\text { profunda, embolia pulmonar }\end{array}$ \\
\hline Digestivas & $\begin{array}{l}\text { Litiasis biliar, hernia hiatal, esteatohepatitis no } \\
\text { alcohólica }\end{array}$ \\
\hline Respiratorias & Apnea del sueño, síndrome de hipoventilación \\
\hline Reumatismos & Artrosis, dolor lumbar \\
\hline Cáncer & $\begin{array}{l}\text { Esófago, colon, recto, vesícula biliar, riñón, próstata, } \\
\text { útero, mama acantosis }\end{array}$ \\
\hline Genitourinarias & $\begin{array}{l}\text { Incontinencia urinaria, alteraciones menstruales, } \\
\text { infertilidad }\end{array}$ \\
\hline Neurológicas & Hipertensión endocraneal benigna \\
\hline Celulitis, intertrigo, foliculitis, estrías
\end{tabular}

Tabla 7. Principales complicaciones asociadas a la obesidad

\subsection{TRATAMIENTO DE LA OBESIDAD.}

El tratamiento ideal de la obesidad es la prevención. Los objetivos terapéuticos de la pérdida de peso están dirigidos a mejorar o eliminar las comorbilidades asociadas a la obesidad y disminuir el impacto de las futuras complicaciones médicas relacionadas con el exceso de peso. Bajo estas premisas, los objetivos de pérdida de peso no deben centrarse en alcanzar el peso ideal, sino en conseguir pequeñas pérdidas de peso (entre un 5-10\% del peso inicial) pero mantenidas a largo plazo. Las herramientas disponibles incluyen cambios en el estilo de vida (plan de alimentación, 
actividad física, modificación conductual) y la farmacoterapia. En casos de especial gravedad, y en individuos previamente seleccionados, tiene sus indicaciones la cirugía de la obesidad.

El consenso SEEDO 2007 para la evaluación del sobrepeso y la obesidad recomienda los siguientes criterios para la intervención terapéutica en función del índice de masa corporal (Tabla 8):

\begin{tabular}{|c|c|c|}
\hline $\begin{array}{c}\text { IMC } \\
\left(\mathrm{kg} / \mathrm{m}^{2}\right)\end{array}$ & \multicolumn{2}{|c|}{ Intervención } \\
\hline $18,5-22$ & No justificada & $\begin{array}{l}\text { Consejos sobre alimentación } \\
\text { saludable y actividad física }\end{array}$ \\
\hline $22-24,9$ & $\begin{array}{l}\text { No justificada, salvo en caso de } \\
\text { aumento superior a } 5 \mathrm{~kg} / \text { año y } \\
\text { factores de riesgo cardiovascular } \\
\text { asociados }\end{array}$ & $\begin{array}{l}\text { Reforzar consejos sobre } \\
\text { alimentación saludable } \\
\text { Fomentar la actividad física }\end{array}$ \\
\hline $25-26,9$ & $\begin{array}{l}\text { No justificada si el peso es estable, la } \\
\text { distribución de la grasa es periférica } \\
\text { y no hay enfermedades asociadas } \\
\text { Justificada si hay factores de riesgo } \\
\text { cardiovascular y/o distribución central } \\
\text { de la grasa }\end{array}$ & $\begin{array}{l}\text { Consejos dietéticos } \\
\text { Fomentar la actividad física } \\
\text { Controles periódicos }\end{array}$ \\
\hline $27-29,9$ & Pérdida del $5-10 \%$ del peso corporal & $\begin{array}{l}\text { Alimentación hipocalórica. } \\
\text { Fomentar la actividad física } \\
\text { y cambios en el estilo de } \\
\text { vida. Controles periódicos. } \\
\text { Evaluar la asociación de } \\
\text { fármacos si no hay } \\
\text { resultados tras } 6 \text { meses }\end{array}$ \\
\hline $30-34,9$ & $\begin{array}{l}\text { Pérdida del } 10 \% \text { del peso corporal } \\
\text { Control y seguimiento en unidad de } \\
\text { obesidad si coexisten comorbilidades } \\
\text { graves }\end{array}$ & $\begin{array}{l}\text { Alimentación hipocalórica } \\
\text { Fomentar la actividad física } \\
\text { y cambios en el estilo de } \\
\text { vida } \\
\text { Controles periódicos }\end{array}$ \\
\hline
\end{tabular}




\begin{tabular}{|c|c|c|}
\hline & & $\begin{array}{l}\text { Evaluar la asociación de } \\
\text { fármacos si no hay } \\
\text { resultados tras } 6 \text { meses }\end{array}$ \\
\hline $35-39,9$ & $\begin{array}{l}\text { Pérdida }>10 \% \text { del peso corporal } \\
\text { Control y seguimiento en unidad de } \\
\text { obesidad }\end{array}$ & $\begin{array}{l}\text { Actuación terapéutica inicial } \\
\text { similar al grupo anterior } \\
\text { Si no hay resultados tras } 6 \\
\text { meses: evaluar dietas de } \\
\text { muy bajo contenido calórico } \\
\text { y/o cirugía bariátrica si hay } \\
\text { comorbilidades graves }\end{array}$ \\
\hline$>40$ & $\begin{array}{l}\text { Pérdida }>20 \% \text { del peso corporal } \\
\text { Control y seguimiento en unidad de } \\
\text { obesidad. }\end{array}$ & $\begin{array}{l}\text { Actuación terapéutica inicial } \\
\text { similar al grupo anterior Si } \\
\text { no hay resultados tras } 6 \\
\text { meses: evaluar dietas de } \\
\text { muy bajo contenido calórico } \\
\text { y/o cirugía bariátrica }\end{array}$ \\
\hline
\end{tabular}

Tabla 8. Criterios para la intervención terapéutica según el IMC.

\subsubsection{Tratamiento farmacológico.}

Desde la introducción de la hormona tiroidea para el tratamiento de la obesidad en 1893, casi todos los fármacos que se han probado como tratamiento en pacientes obesos han causado consecuencias no deseadas que requirieron su retirada del mercado.

Otro problema que rodea el tratamiento farmacológico de la obesidad es la percepción de la temporalidad en los tratamientos, que hace que las recidivas sean frecuentes cuando se suspende el tratamiento (Bray, 2011).

La base en cualquier tratamiento dirigido a la obesidad es la consecución de un equilibrio energético negativo. 
En general, el grupo de fármacos que se han utilizado en el tratamiento de la obesidad se pueden dividir en dos amplias categorías:

- Actúan principalmente fuera del cerebro. Sin importar el lugar principal de acción, el efecto neto debe ser una reducción en la absorción de alimentos, un aumento en el gasto de energía, o ambos.

- Actúan principalmente sobre el sistema nervioso central para reducir la ingesta de alimentos.

El tratamiento farmacológico debe utilizarse como apoyo del dietético y del ejercicio, pero no debe utilizarse nunca como único tratamiento. La posibilidad de su prescripción puede considerarse en obesos con un IMC de $30 \mathrm{~kg} / \mathrm{m} 2$ ó más, en los que haya fallado la dieta, el ejercicio y los cambios conductuales, o en aquéllos con un IMC de 27 ó más si se asocian factores importantes de morbilidad como diabetes, hipertensión, dislipemia, etc.

El orlistat que actúa localmente en el intestino delgado sobre la lipasa pancreática e inhibe de forma selectiva la absorción de grasa alimentaria, induciendo así una pérdida de peso por disminución de la grasa corporal, reduciendo y movilizando los depósitos de grasa (especialmente la grasa visceral).

El bloqueo de la absorción de un $30 \%$ de la grasa alimentaria conlleva una reducción del $30 \%$ de la energía procedente de la grasa y por tanto, una reducción del aporte energético total que hay que sumar a la reducción energética propia de la dieta hipocalórica. El resultado, desde el punto de vista clínico, es una mayor pérdida de peso en comparación con la que se consigue con la dieta hipocalórica. Como se anticipa por su mecanismo de acción, los pacientes que siguen una dieta hipograsa tienen un efecto menor con el tratamiento. (Bray, 2011)

Datos de diferentes ensayos clínicos y entre ellos el estudio XPERT, han demostrado que una pérdida de peso $>5 \%$ en 3 meses es un predictor preciso de una pérdida de peso sostenida a largo plazo. La efectividad de orlistat es algo menor en las personas con diabetes mellitus tipo 2 (Toplak et al, 2005). Los efectos beneficiosos sobre el control glucémico son mucho mayores de lo esperado para la pérdida de peso observada. Dos teorías intentan explicar este fenómeno probablemente relacionado con una mejoría de la sensibilidad a la insulina inducida por orlistat, ya sea 
disminuyendo el contenido lipídico en tejidos sensibles a la insulina (como hígado y músculo) o incrementando las concentraciones del GLP-1, con una clara acción incretina..

La seguridad y eficacia de este fármaco a largo plazo están refrendadas por el estudio XENDOS, estudio clínico de tratamiento farmacológico de la obesidad de una duración de 4 años. Los resultados de este estudio permiten concluir que a largo plazo orlistat es un fármaco efectivo para alcanzar y mantener una pérdida de peso entre el $5 \%$ y el $10 \%$ del peso inicial. Además, el uso de orlistat permite reducir en un $45 \%$ el desarrollo de diabetes mellitus tipo 2 en pacientes obesos con tolerancia alterada a la glucosa. En la pérdida de peso obtenida con orlistat hay una importante reducción de los depósitos de grasa corporales cuando se compara con la realización de dieta sola, especialmente de la grasa visceral, lo que se traduce en una reducción significativa del perímetro de la cintura y, por otra en la mejoría subsiguiente de las comorbilidades asociadas (Torgerson et al, 2004).

En 2005, se publica en JAMA un estudio sobre el efecto del orlistat en el peso y la composición corporal de niños obesos mayores de 12 años (Chanoine et al, 2005). Los niños tratados con orlistat perdieron seis veces más grasa, sin pérdida de masa magra y con pérdidas significativas de IMC y perímetro de cintura, frente a placebo (dieta + ejercicio).

El orlistat también ha demostrado su eficacia y seguridad en el tratamiento de la obesidad en adolescentes. Por este motivo, ha sido aprobada su utilización en este colectivo de jóvenes, siendo por tanto, el único fármaco permitido para el tratamiento coadyuvante de la obesidad durante la adolescencia.

El orlistat no se absorbe en un grado significativo, y sus efectos secundarios están relacionados con el bloqueo de la digestión de triglicéridos y las pérdidas fecales de grasa. Los síntomas son frecuentes al principio, pero disminuyen a medida que los pacientes aprenden a usar el medicamento. La calidad de vida en los pacientes tratados con orlistat puede mejorar a pesar de las preocupaciones sobre síntomas gastrointestinales. Orlistat puede causar disminuciones pequeñas pero significativas en los niveles de vitaminas liposolubles. Los niveles por lo general permanecen dentro del rango normal, pero algunos pacientes pueden necesitar suplementos vitamínicos. Debido a que es imposible determinar qué pacientes necesitan vitaminas, es conveniente proporcionar un complejo multivitamínico. Orlistat no parece afectar la absorción de otros fármacos con excepción del Aciclovir (Bray, 2011) 
Otro bloqueador de la Lipasa pancreatica, el Cetilistat A (ATL-962) está en desarrollo. Los estudios en voluntarios sugieren que presenta menos efectos secundarios que el Orlistat con efectos similares en la pérdida de peso. (Kopelman P, 2007).

La sibutramina se introdujo como fármaco para el tratamiento de la obesidad en 1997, y hasta hace poco estuvo aprobado por la FDA para su uso a largo plazo. Se trata de una molécula que inhibe selectivamente la recaptación de noradrenalina y serotonina.

Sus efectos han sido evaluados en varios estudios multicéntricos controlados doble ciego, con resultados positivos. En humanos produce una pérdida significativa de peso, dosis-dependiente por aumento de la sensación de saciedad y disminución del apetito. También se ha descrito un potencial efecto termogénico que se ha estimado en un 3-5\% del gasto energético (Hansen et al, 2010).

La sibutramina, junto al empleo de dieta, ejercicio y modificación del estilo de vida produce una pérdida de peso superior a la de placebo de $4,5 \mathrm{~kg}$ en ensayos a largo plazo, incluyendo pacientes con DM2, donde la pérdida de peso con medidas convencionales es muy escasa ( $\mathrm{Li} Z$ et al, 2005). Sin embargo, en Octubre de 2010 la Agencia Europea de Medicamentos recomendó la suspensión del uso del medicamento por un aumento en eventos cardiovasculares no fatales en uno de los subgrupos del estudio SCOUT (James WP, et al, 2010)

La pérdida de peso asociada a sibutramina se acompañaba de incrementos significativos en las concentraciones de HDL y disminución de las de triglicéridos, pero sin modificar las concentraciones de colesterol total (estudio STORM, 2000).

Otros medicamentos de acción simpaticomimética como benzfetamina, dietilpropión, fendimetracina, y fentermina se comercializan en los Estados Unidos como anorexígenos. Los perfiles de efectos secundarios de los medicamentos simpaticomiméticos son similares. Estos agentes pueden producir insomnio, sequedad de boca, astenia, y estreñimiento. La seguridad de los medicamentos simpatomiméticos supresores del apetito ha sido objeto de considerable controversia debido a que la dextroanfetamina es adictiva, sin embargo simpaticomiméticos como fentermina, dietilpropon y benzfetamina, han demostrado poco potencial de abuso en modelos animales. Estos fármacos simpaticomiméticos también pueden aumentar los niveles de tensión arterial. (Bray, 2011) 
El Rimonabant fue autorizado en la Unión Europea en junio de 2006 como tratamiento de la obesidad junto con la dieta y el ejercicio para el tratamiento de pacientes obesos (IMC $\geq 30 \mathrm{~kg} / \mathrm{m} 2$ ), o pacientes con sobrepeso (IMC > $27 \mathrm{~kg} / \mathrm{m} 2$ ) con factores de riesgo asociados, como la diabetes tipo 2 o dislipemia. En el momento de su autorización, las alteraciones psiquiátricas de tipo depresivo se identificaron como el problema de seguridad más relevante asociado a este medicamento. En estudios de fase III en los Estados Unidos se han reportado 3 casos de suicidio consumado en pacientes que estaban recibiendo esta medicación.

En cuanto a su situación en España se comercializó en marzo de 2008 siendo su uso muy reducido al encontrarse excluido de la financiación pública. En febrero de 2009, la Agencia Española de Medicamentos y Productos Sanitarios retira al Rimonabant del mercado.

Otros medicamentos no aprobados específicamente para el tratamiento de la obesidad se han ensayado por sus efectos sobre el peso, como los antidepresivos Fluoxetina, Sertralina y Bupropion, los anticonvulsivantes Topiramato, Zonisamida y Lamotrigina. También hipoglucemiantes como la Metformina, el análogo sintético de la amilina Pramlintide, y el análogo del GLP1 Exenatide. (Bray, 2011)

En los últimos años se ha empezado a describir el papel del péptido YY (PYY) en la fisiopatología de la obesidad y se lo considera de gran potencial para el desarrollo de futuros fármacos antiobesidad. El péptido $Y Y$ tiene una acción saciante actuando en los núcleos que controlan el apetito en el sistema nervioso central. Los sujetos obesos presentan concentraciones en ayunas menores que los individuos con peso normal, y estas concentraciones aumentan con la pérdida de peso. El incremento postprandial de las concentraciones de PYY es menor en sujetos obesos que en sujetos con peso normal y parece que aumentan cuando se someten a un by-pass gástrico. Están en investigación potenciales tratamientos antiobesidad como la administración de PYY y agonistas del PYY, con resultados dispares pero prometedores (Gimenez et al., 2009).

\subsubsection{Tratamiento quirúrgico: Cirugía Bariátrica}

Hoy en día junto con el aumento global de la prevalencia de la obesidad en los países desarrollados, también hemos asistido a un aumento en el número de enfermos con obesidad mórbida o extrema. Estos pacientes presentan un riesgo de morbimortalidad muy elevado y suelen presentar una historia de repetidos fracasos tras tratamientos dietéticos por lo que es improbable que logren disminuir su peso significativamente sólo con dieta y ejercicio. Todas estas consideraciones, junto con el desarrollo de 
técnicas quirúrgicas menos agresivas y con menores complicaciones hacen que la cirugía bariátrica sea una de las principales opciones terapéuticas en estos pacientes.

La cirugía bariátrica empezó a desarrollarse como técnica para perder peso en 1954 (Greenway, 1996). Este tipo de intervenciones tienen unas especiales características anestésicas y operatorias, por tanto la valoración de los candidatos debe ser realizada minuciosamente.

La pérdida importante de peso es posible con las distintas técnicas que hoy se realizan y los mejores resultados depende de que el paciente esté bien informado de la técnica y de los riesgos que implica y que el seguimiento, de por vida, se lleve a cabo por un equipo especializado.

Se realizará una dieta especial que en el postoperatorio puede ser determinante para el éxito de la cirugía, sobre todo de las técnicas restrictivas. Se harán controles analíticos rutinarios para detectar posibles déficits nutricionales sobre todo en las técnicas mixtas y en las malabsortivas. En la mayoría de los casos se deberán dar suplementos de hierro, vitamina B12, B1, ácido fólico calcio y vitamina A y D y otros oligoelementos como Zinc y magnesio.

Actualmente la cirugía bariátrica es el tratamiento más eficaz para la obesidad mórbida y sus comorbilidades. Como ejemplo citamos una publicación de 2007 del estudio de obesos suecos (SOS) en el que se incluían más de 4000 obesos, divididos en dos grupos (uno de los cuales intervenidos de cirugía bariátrica y el otro que reciben tratamiento convencional). En dicho estudio se concluye que además de que la cirugía bariátrica se asocia a una reducción del $13 \%$ al $27 \%$ de peso durante más de 15 años, disminuye el porcentaje de casos de mortalidad asociados infarto cardiovascular y a cáncer (Sjostrom, 2007).

Sus principales aspectos técnicos y fisiopatológicos se discutirán más adelante. 


\section{SINDROME METABÓLICO.}

La creciente prevalencia de la obesidad va de la mano del incremento en la prevalencia de DM2 enfermedad coronaria y cerebrovascular con las consiguientes implicaciones sanitarias y financieras en todo el mundo.

El síndrome metabólico comprende un conjunto de factores de riesgo para desarrollar diabetes y enfermedades cardiovasculares. Las opiniones varían respecto a la definición y etiología del síndrome metabólico y si debe ser definida como un síndrome de resistencia a la insulina, como el conjunto de consecuencias metabólicas de la obesidad o como el riesgo del paciente diabético de padecer enfermedades cardiovasculares. Algunos consideran que no es un síndrome propiamente dicho sino más bien una compilación de correlaciones estadísticas (Grundy SM, 2004).

El síndrome metabólico ha sido objeto de amplias discusiones en la literatura médica desde la agrupación de los factores de riesgo metabólicos, enfermedad arterial coronaria, diabetes y HTA, descritos como "Síndrome X" por Reaven en 1988. Los factores iniciales descritos entonces, incluyen tolerancia alterada a la glucosa, hiperinsulinemia, niveles elevados de triglicéridos (TG), y niveles reducidos de lipoproteínas de alta densidad. (HDL). (Gallagher EJ, et al, 2011).

\subsection{CRITERIOS PARA EL DIAGNÓSTICO DEL SINDROME METABÓLICO.}

Existen diferentes criterios para el diagnostico de síndrome metabólico, pero en nuestro medio los más utilizados son los del ATPIII

\section{Definición ATP III (NCEP - ATPIII, 2001)}

El diagnóstico del síndrome metabólico es realizado cuando 3 o más de los siguientes factores de riesgo están presentes:

- Circunferencia abdominal $>102 \mathrm{~cm}$ ( $>40$ in) en hombres y $>88 \mathrm{~cm}$ (>35 in) en mujeres

- Triglicéridos séricos $>/=150 \mathrm{mg} / \mathrm{dL}(>/=1.7 \mathrm{mmol} / \mathrm{L})$

- Presión arterial $>/=130 / 85 \mathrm{~mm} \mathrm{Hg}$

- HDL Colesterol $<40 \mathrm{mg} / \mathrm{dL} \quad(<1.0 \mathrm{mmol} / \mathrm{L})$ en hombres y $<50 \mathrm{mg} / \mathrm{dL} \quad(<1.3$ $\mathrm{mmol} / \mathrm{L}$ ) en mujeres 
- Glucosa de ayunas 110 a $126 \mathrm{mg} / \mathrm{dL}$ (6.1 a $7.0 \mathrm{mmol} / \mathrm{L})(100 \mathrm{mg} / \mathrm{dL}[>/=5.6$ $\mathrm{mmol} / \mathrm{L}]$ también puede ser apropiado)

En 2005, estos criterios fueron modificados, disminuyendo el punto de corte para la glucemia en ayunas $(100 \mathrm{mg} / \mathrm{dL})$ y teniendo en cuenta los criterios antropométricos en determinados grupos étnicos para definir la obesidad abdominal introducidos en los Criterios de la IDF (Grundy S, et al, 2005).

\section{Definición de la OMS (World Health Organization, 1999)}

Diabetes, glucosa basal alterada, tolerancia a la glucosa alterada o resistencia a la insulina y al menos 2 de los siguientes criterios:

- Relación cintura-cadera >0,90 en hombres o >0,85 en mujeres.

- Triglicéridos séricos $>/=150 \mathrm{mg} / \mathrm{dL}$ o HDL colesterol $<35 \mathrm{mg} / \mathrm{dL}$ en hombres y $<40 \mathrm{mg} / \mathrm{dL}$ en mujeres.

- Presión arterial $>/=140 / 90 \mathrm{mmHg}$

- Excreción de albúmina urinaria $>20 \mathrm{ug} / \mathrm{min}$ o relación albúmina - creatinina $>/=$ $30 \mathrm{mg} / \mathrm{g}$

\section{Definición de la International Diabetes Federation (IDF) (Alberti KG, et al, 2005)}

De acuerdo a la definición de la IDF, para que una persona tenga síndrome metabólico debe tener:

- Obesidad central (definido como circunferencia de cintura $>/=94 \mathrm{~cm}$ para hombres caucásicos y $>/=80 \mathrm{~cm}$ para mujeres caucásicas, con valores étnicos específicos para otros grupos)

Más dos de los siguientes 4 factores:

- Nivel de triglicéridos (TG) elevados: >/= $150 \mathrm{mg} / \mathrm{dL}$ (1,7 mmol/L), o tratamiento específico para esta anormalidad lipídica

- Colesterol HDL reducido: $<40 \mathrm{mg} / \mathrm{dL}(1,03 \mathrm{mmol} / \mathrm{L})$ en hombres y $<50 \mathrm{mg} / \mathrm{dL}$ $(1,29 \mathrm{mmol} / \mathrm{L})$ en mujeres, o tratamiento específico para esta anormalidad lipídica

- Tensión arterial (TA) elevada: TA sistólica $>/=130$ o TA diastólica $>/=85 \mathrm{~mm}$ $\mathrm{Hg}$, o tratamiento de hipertensión previamente diagnosticada 
- Glucosa plasmática en ayunas elevada $>/=100 \mathrm{mg} / \mathrm{dL}(5,6 \mathrm{mmol} / \mathrm{L}), 0$ diabetes tipo 2 previamente diagnosticada. Si la glucosa en ayunas es $>5,6$ $\mathrm{mmol} / \mathrm{L} \circ 100 \mathrm{mg} / \mathrm{dL}$, el test de tolerancia oral a la glucosa (TTOG) es fuertemente recomendada pero no es necesaria para definir la presencia del síndrome.

Parece lógico que las definiciones y los criterios para identificar o diagnosticar el síndrome metabólico continuarán en desarrollo, cuando se definan mejor las variables para detectar los factores de riesgo cardiovascular en poblaciones de riesgo.

Los informes de tasas de prevalencia varían ampliamente según los criterios utilizados, la edad de la población, género, grupo étnico, prevalencia de la obesidad en la población estudiada y el medio ambiente. Basado en el estudio NHANES 1999 2002, se estima que el $34,6 \%$ de la población estadounidense cumplen los criterios de ATP III para el síndrome metabólico. Hay diferencias de género mínimas: 34,4\% de los varones y el $34,5 \%$ de las mujeres. Se ha demostrado un aumento de la prevalencia según avanza la edad. (Ford et al, 2002).

El estudio DARIOS incluyó a 67024 participantes de 10 comunidades autónomas que representan aproximadamente el $70 \%$ de la población de España de 35 años a 74 años. En general, 7832 de los participantes tuvo criterios para el diagnostico de síndrome metabólico, con una prevalencia del $32 \%$ en varones y $29 \%$ en mujeres. En promedio, los hombres con síndrome metabólico fueron 4 años mayores que aquellos que no cumplían los criterios. En las mujeres la diferencia fue de 9 años. (Fernández Borges et al, 2012)

La importancia práctica en las definiciones del Síndrome Metabólico es definir los criterios pertinentes para predecir el desarrollo de la DM2 y la enfermedad cardiovascular. En los Estados Unidos en 2003, la prevalencia de enfermedad cardiovascular fue del $34,2 \%$ y fue uno de los factores contribuyentes en el $37,3 \%$ de los fallecimientos. (Reaven GM, 2011).

Los datos de la NHANES II muestran que la combinación de enfermedades cardiovasculares y diabetes preexistentes aumenta significativamente el riesgo de mortalidad por enfermedad coronaria y enfermedades cardiovasculares en general (Malik S, et al, 2004). Con independencia de los clásicos factores de riesgo de Framingham (edad, tabaquismo, colesterol total, niveles de HDLc y TA sistólica), algunos investigadores han encontrado que el síndrome metabólico se asocia con una 
probabilidad mayor de padecer enfermedades cardiovasculares y transmite un mayor riesgo que los Criterios de Framingham para desarrollar DM2. (Rutter MK, et al, 2005). Por otra parte, los Investigadores de Framingham informan que no existe ningún aumento en el poder predictivo para enfermedad coronaria con la adición de la obesidad abdominal, triglicéridos o glucosa en ayunas a su algoritmo de riesgo a 10 años. (Wilson PW, et al, 2004)

Tres recientes meta-análisis de estudios prospectivos que investigaron el síndrome metabólico como factor de riesgo de enfermedad cardiovascular y mortalidad muestran un aumento del riesgo relativo de ambos eventos. También se ha demostrado la existencia de una probabilidad mayor de eventos cardiovasculares y mortalidad con el síndrome metabólico tanto en presencia como en ausencia de diabetes, sin embargo, la presencia de diabetes, junto con síndrome metabólico, aumenta significativamente el riesgo (Gallagher EJ, et al, 2011).

El aumento del riesgo de enfermedad cardiovascular con el síndrome metabólico no parece ser explicada en su totalidad por la resistencia a la insulina. En los estudios que calculan la resistencia a la insulina por el modelo de homeostasis de la resistencia a la insulina (HOMA-IR), el poder predictivo del síndrome metabólico para el desarrollo de diabetes y enfermedad cardiovascular ha demostrado ser independiente de la HOMA-IR. También hay conflicto en cuanto a si el síndrome metabólico en su conjunto le confiere un mayor riesgo de enfermedades cardiovasculares y diabetes que sus componentes individuales (Zalesin KC, et al, 2011).

\subsection{PATOGENESIS.}

Aunque los factores de riesgo para el síndrome metabólico han sido identificados, su etiología sigue sin estar del todo entendida. Como había propuesto inicialmente Reaven, parece probable que la resistencia a la insulina sea el vínculo de unión entre los componentes del síndrome metabólico

Muchos, factores moleculares, genéticos y en el estilo de vida se han descrito como predisponentes del síndrome metabólico. Estos incluyen la obesidad y los trastornos del tejido adiposo, la inactividad física; la dieta, las anormalidades del receptor de insulina y su señalización; cascadas inflamatorias; disfunción mitocondrial; moléculas de origen inmunológico, hepático, vascular (incluyendo adiponectina, leptina, PAI-1, la 
resistina, angiotensinógeno), receptores endocannabinoides; receptores nucleares, hormonas y la variabilidad poligénica en individuos y grupos étnicos.

En respuesta a la estimulación de glucosa, las células pancreáticas Beta liberan insulina, que conduce a la supresión de la gluconeogénesis hepática y a la captación de glucosa y el aumento de su metabolismo por el músculo y el tejido adiposo. El transporte de glucosa en las células está mediado por los transportadores de glucosa (GLUT). Uno de los transportadores de glucosa más importantes, el GLUT4, está regulado por la insulina. En respuesta a la insulina el GLUT4 es liberado de las vesículas de almacenaje en el retículo endoplásmico para internalizar la glucosa. Este es el gran paso que controla la velocidad de la captación de glucosa mediada por insulina y la sintesis de glucógeno muscular. La concentración celular de GLUT4 en los adipocitos disminuye con muchos factores entre los cuales está la edad avanzada y la obesidad. En el músculo esquelético de los obesos y diabéticos, el GLUT4 es disfuncional. El ejercicio y la adiponectina parecen aumentar la expresión del GLUT4 coincidiendo con la sensibilidad a la insulina.

Con la resistencia a la insulina, inicialmente se produce una pérdida postprandial de la respuesta a la insulina, que conduce a hiperglucemia postprandial. Posteriormente, hay una exagerada respuesta de insulina, que a lo largo del tiempo produce una hiperinsulinemia crónica, conduciendo a la resistencia. (Gallagher EJ, et al, 2011).

La obesidad tiene un papel importante en la resistencia a la insulina. Se sabe que el tejido adiposo funciona como un órgano endocrino produciendo factores como interleukina 6, TNF alfa, resistina, lipoproteína lipasa, proteinas estimuladoras de la acilación, proteinas colesteril-éster, proteína transportadora de retinol 4 (RBP4), estrógenos, angiotensinógeno, leptina, adiponectina, factor de crecimiento similar a la insulina (IGF-1), y monobutirina (Gallagher EJ, et al, 2011).

La adiposidad visceral se asoció independientemente con resistencia a la insulina, niveles inferiores de HDL, niveles más altos de apolipoproteína B, RBP4 y triglicéridos, partículas más pequeñas de LDL; rigidez aórtica, calcificación coronaria, obesidad y HTA (Poirier P, et al, 2006)

Se ha demostrado que la obesidad contribuye al síndrome metabólico mediante el aumento de ácidos grasos no esterificados (AGNE) y la producción de citoquinas inflamatorias, que se traducen en resistencia a la insulina, dislipemia, hipertensión, y la 
producción de factores protrombóticos. Los AGNE son ácidos grasos derivados de la lipólisis de los triglicéridos y son por lo general una fuente de energía en el ayuno. En los sujetos obesos, los niveles de AGNE están aumentados a pesar de los niveles altos de insulina. En el músculo esquelético, el exceso de AGNE contribuye a la resistencia a la insulina, aumentando los niveles de diacilglicerol (DAG), inhibiendo la señalización normal de la Insulina (Reaven, GM, 2011)

En el hígado, los AGNE causan resistencia a la insulina de una manera similar, llevando a un estado de gluconeogénesis aumentada y la acentuación de la hiperglucemia por el aumento de la producción hepática de glucosa que resulta en la enfermedad del hígado graso no alcohólico (NAFLD). También contribuyen al aumento de las VLDL, triglicéridos, apolipoproteína $B$ y pequeñas partículas de LDL, además de un aumento de la lipasa hepática que degrada el HDL. Otras anormalidades asociadas con niveles elevados de AGNE son la disfunción endotelial, la apoptosis de las células beta, y el aumento del PAI-1.

Las citocinas inflamatorias, como TNF alfa e IL-1b son producidas por los macrófagos en el tejido adiposo. Además, producen otras citocinas proinflamatorias que conducen a deterioros en la señalización de la insulina. Estas citocinas también activan, directa o indirectamente los genes proinflamatorios que conducen a un ciclo de autoperpetuación de la disregulación de las citoquinas inflamatorias y a la utilización inadecuada de la energía. (Gallagher et al, 2011)

El TNF alfa también se ha demostrado que disminuye la óxido nítrico sintetasa endotelial, que produce una disminución de expresión de los genes mitocondriales que regulan la fosforilación oxidativa, produciendo un aumento del estrés oxidativo celular, con la acumulación de moléculas reactivas del oxígeno y un mayor estrés a nivel del retículo endoplásmico así como la disminución de la vida media del óxido nítrico (NO). (Nisoli E, et al, 2007)

Una disminución de la expresión de PPARg co-activador 1a (PGC1a), un co-regulador inducible en el control de la función mitocondrial ha sido encontrado en individuos obesos y diabéticos que pueden llevar a una estimulación del apetito por disminución del ATP hepático debido a la disfunción mitocondrial, asociando también una disminución en la tolerancia al ejercicio y una fatigabilidad aumentada. (Liang CP, et al, 2007). 
La proteína transportadora de retinol 4 (RBP4) es el transportador de la vitamina $A$ en la sangre. Se han encontrado unos niveles séricos elevados así como una expresión aumentada de RBP4 en el tejido adiposo en ratones con mutaciones específicas para el GLUT4. Como se mencionó anteriormente, la disminución de la expresión del GLUT4 es una característica común de la obesidad, la resistencia a la insulina y la DM2. Estos hallazgos llevaron a un interés en el posible papel de la RBP4 en la resistencia a la insulina. En los seres humanos, los mayores niveles de RBP4 se encuentran con la obesidad, la DM2, la tolerancia alterada a la glucosa, y en individuos con importante historial familiar de DM2. En algunos estudios la RBP4 se correlaciona con la resistencia a la insulina más concretamente que la adiponectina, la leptina, el IL-6, o la Proteina C-reactiva (PCR). Como RBP4 es la proteína principal de transporte para la vitamina $A$, se ha postulado que el retinoide sintético fenretinida, podría reducir los niveles de RBP4 y mejorar la sensibilidad a la insulina, aunque esto aún no se ha determinado (Yang Q, et al, 2005).

La hipertensión arterial es aproximadamente 6 veces más frecuente en obesos que en sujetos delgados. Según el estudio NHANES III, la hipertensión está presente en el $15 \%$ de hombres y mujeres con un IMC de $25 \mathrm{~kg} / \mathrm{m} 2$ o menos, y el $42 \%$ de los varones y el $38 \%$ de las mujeres con un IMC mayor de $30 \mathrm{~kg} / \mathrm{m} 2$. El mecanismo que genera la hipertensión parece ser una combinación de los efectos hemodinámicos de la obesidad en el gasto cardiaco, y la resistencia vascular periférica (RVP). El aumento de RVP se piensa que es un resultado de la hiperactividad simpática, la expansión de volumen, los efectos antinatriureticos de la insulina, y el aumento del angiotensinógeno II y el aumento de IL-6 con el correspondiente aumento del estrés oxidativo, que conduce a una disminución de óxido nítrico y a disfunción endotelial. (Poirier $\mathrm{P}$, et al, 2006)

Otros factores implicados en las alteraciones metabólicas asociadas con la obesidad y el riesgo cardiovascular son la adiponectina, leptina, resistina y la proteina de unión de los ácidos grasos al adipocito (A-FABP). La ausencia de leptina conduce a obesidad extrema, como se ha demostrado en ratones y los humanos (Hutley L, et al, 2011).

Sin embargo la mayoría de los individuos obesos, tendrán niveles elevados de leptina presentando resistencia a su efecto supresor del apetito. También, la leptina está vinculada a la resistencia a la insulina, pero tiene consecuencias mixtas en otras anomalías cardiovasculares. La leptina parece actuar en los adipocitos y aumenta la 
expresión de genes PGC1a, que aumentan la biogénesis mitocondrial y potencialmente, aumentan la oxidación mitocondrial. (Nisoli E, et al, 2007). La adiponectina es una adipocina anti-inflamatoria producida por adipocitos. Su expresión se ve afectada por la insulina, glucocorticoides, agonistas beta-adrenérgicos y TNF alfa. Está disminuida en la obesidad y aumentada en personas delgadas. Parece ser que que tienen un efecto anti-aterogénico por sus propiedades anti-inflamatorias. Sus niveles y su relación con el índice índice HOMA IR se han descrito como marcador discriminatorio de síndrome metabólico en algunas subpoblaciones de pacientes obesos. (De Luis DA, et al, 2011,1)

La resistina, una hormona producida por los adipocitos, parece oponerse a la acción de insulina, sin embargo, su significado funcional en los seres humanos no es todavía conocido (De Luis DA, et al 2011, 2).

La proteína transportadora de ácidos grasos del adipocito(A-FABP) es una proteína citosólica presente en los adipocitos maduros, macrófagos y en el torrente sanguíneo. Sus niveles elevados se corresponden con las características del síndrome metabólico. Recientemente, se han encontrado individuos con una variante genética funcional del gen A-FABP, resultando en una disminución de su expresión y en una disminución de los triglicéridos y de la incidencia de DM2 y enfermedad coronaria. (Tuncman G, et al, 2006).

Recientemente, el sistema cannabinoide ha despertado un gran interés debido a sus efectos de los parámetros cardiovasculares y metabólicos y sus posibilidades de manipulación farmacológica. Dos receptores de cannabinoides (CB1 y CB2) se han identificado hasta la fecha. El CB1 se encuentra en el sistema nervioso central (SNC), en particular en la corteza cerebral, el hipotálamo, los circuitos de recompensa (núcleo accumbens y la amígdala), y la hipófisis anterior. También se encuentra en el tejido adiposo blanco, el sistema nervioso entérico, los hepatocitos y los miocitos del músculo esquelético. La expresión de los receptores CB1 y CB2 está inhibida por los glucocorticoides, la leptina, y la dopamina y estimulada por el glutamato. La activación de los receptores CB1 tiene efectos centrales en la estimulación del apetito, así como en el aumento de la lipogénesis hepática y la disminución en la absorción de glucosa muscular. La activación aumentada también se asocia con la disminución de los niveles de adiponectina. El CB2 parece estar más asociado al sistema inmune. Los inhibidores de los receptores cannabinoides se han mostrado útiles como supresores del apetito induciendo pérdida de peso y mejorando la dislipidemia y la utilización de la 
glucosa. Uno de estos fármacos (Rimonabant) hasta hace poco había sido aprobado en Europa como tratamiento médico para la obesidad. (Matias I, et al, 2008), pero ha sido retirado del mercado por efectos adversos.

Parece existir un papel de los glucocorticoides, las hormonas sexuales, y la hormona del crecimiento $(\mathrm{GH})$ en el desarrollo del síndrome metabólico. Los adipocitos expresan la enzima 11b-hidroxiesteroide deshidrogenasa (11b-HSD), que convierte cortisona inactiva a cortisol activo, dando lugar a una mejora local de los niveles de glucocorticoides. La enzima es particularmente elevada en el tejido adiposo visceral de los individuos obesos (Walker BR, et al, 2006)

Los esteroides sexuales han sido implicados en la regulación de la expresión y secreción de adiponectina. La testosterona se ha demostrado que inhibe selectivamente la adiponectina de alto peso molecular. Los niveles bajos de adiponectina se han asociado con el desarrollo del síndrome metabólico en mujeres posmenopáusicas. (Hutley L, et al, 2005) La hormona del crecimiento también ha sido relacionada con un mayor riesgo de desarrollar síndrome metabólico.

Es evidente que la comprensión de los complejos mecanismos que regulan la fisiopatogénesis del síndrome metabólico, la obesidad, diabetes mellitus y enfermedades cardiovasculares puede ayudar a superar las actuales controversias y lo que es más importante a entender como prevenir y tratar de la mejor forma estas complejas condiciones. 


\section{CIRUGÍA BARIATRICA Y METABÓLICA.}

La relación entre obesidad y cirugía se empieza a materializar cuando dos circunstancias se suceden. Primero la obesidad se reconoce como una entidad nosológica per se con comorbilidad importante y cuando la obesidad se hace epidémica. (Baker, 2011)

Por otra parte, y antes de que existiera el concepto de cirugía de la obesidad o de enfermedades metabólicas, Friedman y colabs. en 1955 publicaron un estudio de tres casos de pacientes con diabetes de tipo 1 que fueron intervenidos de gastrectomía debido a úlcera gástrica, que presentaron mejoría progresiva y completa de la DM. (Friedman et al, 1955). Otros autores como Angervall en 1961 y Forgács and Halmos en 1973 publicaron experiencias similares en pacientes diabéticos intervenidos de gastrectomía por una patología gástrica benigna presentando un mejor control metabólico después de la cirugía (Angervall et al, 1961 y Forgács et al, 1973).

En el año 1995, Pories estudió más de 600 pacientes obesos operados por by-pass gástrico, de los cuales el 54\% tenían diabetes mellitus, y en los que la cirugía restauró y mantuvo los niveles de glucosa, insulina y hemoglobina glicosilada normales en el $91 \%$ de los pacientes en un periodo de 14 años. Además, se observaron estos cambios inmediatamente después de la cirugía, en la primera semana postoperatoria (Pories et al., 1995).

Esta novedad introduce un nuevo concepto sobre el tratamiento de la DM2, que se denomina cirugía metabólica.

En 2004 Buchwald y colabs. señalaron que el efecto más sorprendente de la cirugía bariátrica, no es la pérdida de peso, sino la impactante remisión de diabetes tipo 2 , una enfermedad anteriormente considerada progresiva e incurable (Buchwald et al., 2004). Este estudio fue el resultado de 2.738 referencias, 22.094 pacientes de $1990 \mathrm{a}$ 2002 en los cuales encontraron que a tras la cirugía bariátrica existe una completa resolución de diabetes mellitus tipo 2 en el 47,8\% de los pacientes sometidos a banda gástrica ajustable, $83,6 \%$ a by-pass gástrico y $97,9 \%$ a derivación biliopancreática 0 switch duodenal. En la segunda etapa se incluyeron 621 estudios con 888 tratamientos en 135.246 pacientes. En esta revisión se ponen de manifiesto mejorías 
de la diabetes mellitus tipo 2 después de la cirugía bariátrica, con niveles normales de insulina, hemoglobina glicosilada y glucemia en ayunas (Buchwald, et al, 2004).

Con el objetivo de buscar cual es el mejor procedimiento, se han realizados diversos estudios con resultados dispares. En general, los procedimientos bariátricos se han clasificado como restrictivos, malabsortivos o mixtos. En los restrictivos se busca la disminución de la ingesta calórica disminuyendo el volumen de comida que el paciente es capaz de consumir. Los procedimientos malabsortivos buscan producir un "bypass" en porciones variables del circuito absortivo para disminuir la absorción total de calorías.

En este capitulo se hará mención de los procedimientos mas importantes, dados su frecuencia de aplicación en el pasado y presente y su aplicación en nuestro medio.

\subsection{ESTUDIOS EXPERIMENTALES.}

Rubino y colabs. demostraron que el by-pass gastroyeyunal controlaba la diabetes a largo plazo en un estudio experimental con ratas Goto Kakizaki (animales espontáneamente diabéticos de tipo 2 y no obesos) (Rubino el al., 2004).

Nuestro grupo encontró los mismos resultados en el control glucémico con una derivación gastroyeyunal en el mismo modelo de rata diabética, pero sorprendentemente además de una disminución en los niveles de glucagón se encontró una disminución en los niveles de leptina que podría explicar a nivel de la célula Beta, una mejoría en la secreción de insulina (Pacheco et al, 2007).

Rubino y colabs. realizaron un estudio comparativo en ratas con DM2, en donde a un grupo se les realizó un by-pass duodenoyeyunal preservando el estómago y excluyendo el intestino proximal; a otro grupo se les realizó una gastroyeyunoanastomosis. El primer grupo fue reoperado restaurando el paso a través del duodeno. El segundo grupo fue reoperado para excluir el intestino proximal. No hubo diferencias en la ingesta ni el peso entre ambos grupos. Las ratas tratadas con by-pass duodenoyeyunal mostraron una mejoría en la tolerancia a la glucosa; al restaurar el paso al duodeno se regresó al estado previo a la primera cirugía. El grupo operado de gastroyeyunoanastomosis no tuvo cambios inicialmente, sin embargo al reoperarlas y excluir el duodeno, mejoraron significativamente el control metabólico. La exclusión del intestino proximal mejora claramente el estado metabólico, 
independientemente del control de peso; lo que da a entender que probablemente existan factores del intestino proximal que contribuyan a la fisiopatología de la DM2 (Rubino et al., 2006).

Por otra parte, existe un modelo quirúrgico que apoya la hipótesis de que el aumento de las hormonas intestinales puede por sí solo actuar como mediador de la disminución de peso y de la ingesta de alimentos, es la transposición ileal. Fue diseñado por primera vez en 1981 para aislar los efectos de la estimulación intestinal distal en ausencia de malabsorción y restricción y se llevo a cabo en ratas wistar, no diabéticas. Este procedimiento consiste en la transposición de un segmento aislado (10-20 cm) de íleon-yeyuno distal que contiene toda la vasculatura e innervación, a la región duodeno-yeyunal. Los resultados de la cirugía de transposición ileal son que las ratas ingieren menos alimento y pierden peso después del procedimiento y tienen aumentos significativos en la secreción y síntesis de las hormonas del intestino distal, como PYY y GLP-1. Estos hallazgos son consistentes con la hipótesis de que los mayores niveles de las hormonas intestinales regulan el peso corporal y la ingesta de alimentos en forma independiente (Koopmans et al., 1984).

Otros estudios realizados por Patriti y colabs. con ratas no obesas (Goto-kakizaki), pero con comportamiento de diabetes tipo 2 y a las que se practica una transposición ileal, no demuestran ningún efecto en la ingesta ni en el peso, y como en otros estudios se presenta un aumento significativo en el GLP-1 (Patriti et al., 2005). Tian Wang y colabs. compararon dos procedimientos, la transposición ileal y una derivación duodenoyeyunal modificada en el mismo modelo de rata diabética para control de glucosa. Ambos procedimientos mostraron disminución de los niveles de glucosa, e incremento en la secreción de GLP-1 al compararlos con ratas control. El grupo de transposición ileal presentó una secreción mayor y más rápida de GLP-1 en comparación con la derivación duodenoyeyunal. Asimismo, el tiempo quirúrgico y la recuperación fueron mayores en este último (Wang et al., 2008).

En un estudio reciente, Strader y colaboradores demostraron que la transposición ileal mejora los niveles de glucosa y la tolerancia a la glucosa en ratas con diabetes causada por estreptozotocina e incluso en ratas no diabéticas, con un incremento importante en la secreción de GLP1 y PYY con niveles normales de GIP (Strader et al., 2009).

Sabench y colaboradores iniciaron un estudio que pretendía valorar la transposición ileal como tratamiento quirúrgico de la obesidad mórbida relacionada con la diabetes 
mellitus tipo 2 gracias a la acción del GLP-1, relacionando el by-pass gástrico con la gastroplastia vertical. Para ello se intervinieron ratas de tipo Zucker, obesas y modelo de diabetes tipo 2 (Sabench et al., 2008). La intervención que produjo una mayor pérdida de peso fue el by-pass gastroyeyunal. Se produjo una disminución de la ingesta calórica significativa en todos los grupos de intervención. No se consiguió corregir el estado de hiperglucemia intensa en ninguno de los grupos, aunque en el grupo de la transposición se logró frenar el estado de cetosis. El aumento de GLP-1 fue sólo significativo en la transposición ileal.

La gastrectomía tubular o en manga también ha demostrado su utilidad en la mejoría del control metabólico en animales, por mecanismos que no están del todo claros pero que son independientes de la pérdida de peso. Un estudio reciente en ratas Goto Kakizaki comparó los efectos en el control metabólico del bypass gastroyeyunal y de la gastrectomía en manga, observando un mejor control glucémico en el grupo de la gastrectomía con una disminución significativa de los niveles de grelina ( $L i F$, et al, 2009). En otro estudio Chambers y su grupo demostraron que en ratas obesas, la gastrectomía en manga fue tan efectiva como el BPG en el incremento de secreción de GLP1 e insulina, así como en la mejora de la sensibilidad hepática a la insulina con independencia de la pérdida de peso (Chambers AP, et al, 2011, 1).

Estos resultados descritos han dado pie a una verdadera revolución en la investigación sobre la fisiopatología de la DM2 y en forma más importante sobre el abordaje terapéutico y la posibilidad de ofrecer un manejo quirúrgico.

\subsection{PROCEDIMIENTOS MALABSORTIVOS:}

\subsubsection{Bypass yeyuno-ileal y derivación yeyuno-cólica.}

Los primeros procedimientos quirúrgicos para el control de peso fueron de tipo malabsortivo puro. En 1952 el sueco Viktor Henrikson publica un caso de resección de un segmento de $105 \mathrm{cms}$ de intestino delgado en una mujer obesa de 32 años. A pesar de ganar $2 \mathrm{~kg}$ en 14 meses de observación la paciente manifiesta sentirse mejor, mas saludable y enérgica. (Henrikson V, 1994)

Los primeros intentos de pérdida de peso quirúrgica en los Estados Unidos fueron similares en concepto, pero diferentes en diseño. En 1954, Kremen y colegas, de la 
Universidad de Minnesota, publicaron los resultados de sus experimentos elaborados en perros, seguidos de un by-pass yejuno-ileal en un humano, sin resección intestinal. En la década de 1960, Payne y su grupo publicaron una serie de casos con 10 pacientes en quienes un segmento de yeyuno proximal de 38 a $51 \mathrm{~cm}$ de largo fue anastomosado al colon transverso. El procedimiento de derivación yeyuno-cólica como se denominó produjo importante pérdida de peso, con resolución de comorbilidades pero asoció importante diarrea, deshidratación y desequilibrios electrolíticos graves que requirieron reversión completa del procedimiento o conversión a bypass yeyunoileal. (Kremen et al, 1954; Payne et al, 1963)

A pesar de la popularidad y el éxito en la pérdida de peso del procedimiento en los 60 y 70 se asoció con graves complicaciones. El síndrome de asa ciega o las deficiencias de vitaminas, nefrolitiasis y colelitiasis hicieron que el auge del procedimiento fuera decayendo a favor de otros con menos morbilidad.

\subsection{PROCEDIMIENTOS COMBINADOS.}

\subsubsection{Derivación bilio-pancreática.}

A mediados de los 70 el grupo de Scopinaro en Italia desarrollo la Derivación Biliopancreática. El procedimiento consiste en gastrectomía distal parcial con cierre del muñón duodenal asociada a sección yeyunal a $250 \mathrm{~cm}$ de la válvula ileo-cecal con reconstrucción en $Y$ de Roux con pie de asa a $50 \mathrm{~cm}$ de la válvula. Aunque la extremidad biliopancreática no forma parte del canal alimentario, el transporte de jugos biliares y pancreáticos impide excesivo crecimiento bacteriano y así elimina el síndrome de asa ciega. La gastrectomía parcial introdujo un componente restrictivo al procedimiento para mejorar la pérdida de peso global inicial lograda. El mantenimiento a largo plazo de la pérdida de peso se atribuyó al bypass yeyuno-ileal.

Los resultados a largo plazo fueron satisfactorios reportando un promedio de exceso de peso perdido al primer año del 75\% siendo la mayoría de pacientes capaces de mantenerlo a largo plazo. El efecto sobre el control glucémico en pacientes con diabetes fue igualmente impresionante, con una cura del 98\% en 10 años. (Scopinaro $\mathrm{N}$, et al, 1996). El efecto de la DBP en hipertensión e hiperlipidemia también fue favorable. Sin embargo, los efectos secundarios a largo plazo fueron significativos. Las principales complicaciones fueron diarrea, heces malolientes, flatulencia, anemia, 
ulceración perianal, malabsorción de proteínas, síndrome de dumping, neuropatía periférica, encefalopatía de Wernicke y desmineralización ósea secundaria a la mala absorción de calcio y vitamina D. La incidencia de la mayoría de estos efectos secundarios fueron controlados con un seguimiento estrecho y permanente. La desnutrición proteica es un problema particularmente importante, caracterizado por hipoalbuminemia, anemia, edema, astenia y alopecia (Montes M., et al, 2009, 1). La causa es multifactorial, incluyendo la ingesta insuficiente de restricción gástrica y absorción insuficiente por un asa común demasiado corta. Los intentos de aumentar la pérdida de peso llevaron a drásticas reducciones en el tamaño de la bolsa gástrica. Para maximizar la pérdida de peso y minimizar el la desnutrición proteica, la longitud del asa alimentaria aumentó de entre 200 y $250 \mathrm{~cm}$ a entre 300 y $350 \mathrm{~cm}$. Este aumento llevó a una reducción adicional de la desnutrición protéica sin comprometer significativamente la pérdida de peso (Scopinaro N, et al, 2006)

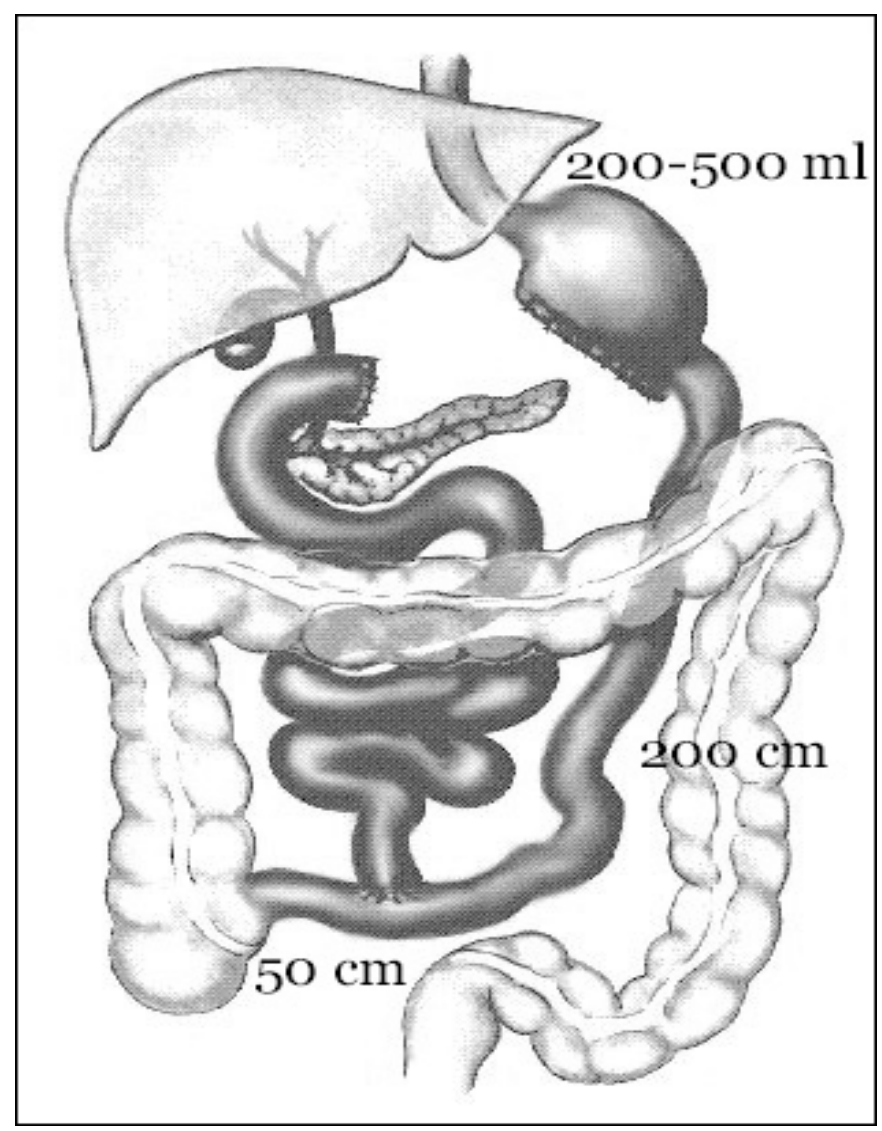

Figura 1: Derivación bilio-pancreática de Scopinaro.

\subsubsection{Derivación Bilio-pancreática con switch duodenal.}

Buscando evitar los efectos adversos detectados con el procedimiento de Scopinaro. Hess y Marceau desarrollaron una variación en los 80. Preservando el píloro se 
controla el dumping y se minimiza el riesgo de úlceras anastomóticas por los ácidos gástricos. El componente restrictivo se mantuvo mediante una gastrectomía en manga. El intestino completo se mide desde el ligamento de Treitz a la válvula ileocecal. Se calcula el $40 \%$ de esa distancia desde la válvula ileocecal, cortando el yeyuno y hace una reconstrucción en $Y$ de Roux con el duodeno proximal. La extremidad biliopancreática se anastomosa al íleon, 75 a $100 \mathrm{~cm}$ proximal a la válvula ileocecal (Lagace et al, 1995; Hess et al, 1998).

Las principales diferencias entre los 2 procedimientos fueron la ausencia de úlceras marginales y del síndrome de dumping en los pacientes con switch duodenal. Al tener el asa común ligeramente más larga también se encontró menos insuficiencia hepática, insuficiencia renal y alteraciones graves de electrolitos. Sin embargo, en algunos pacientes, fueron requeridos procedimientos de revisión para alargar el canal común por desnutrición protéica, pérdida excesiva de peso y diarrea mal tolerada. (Hess, et al, 1998).

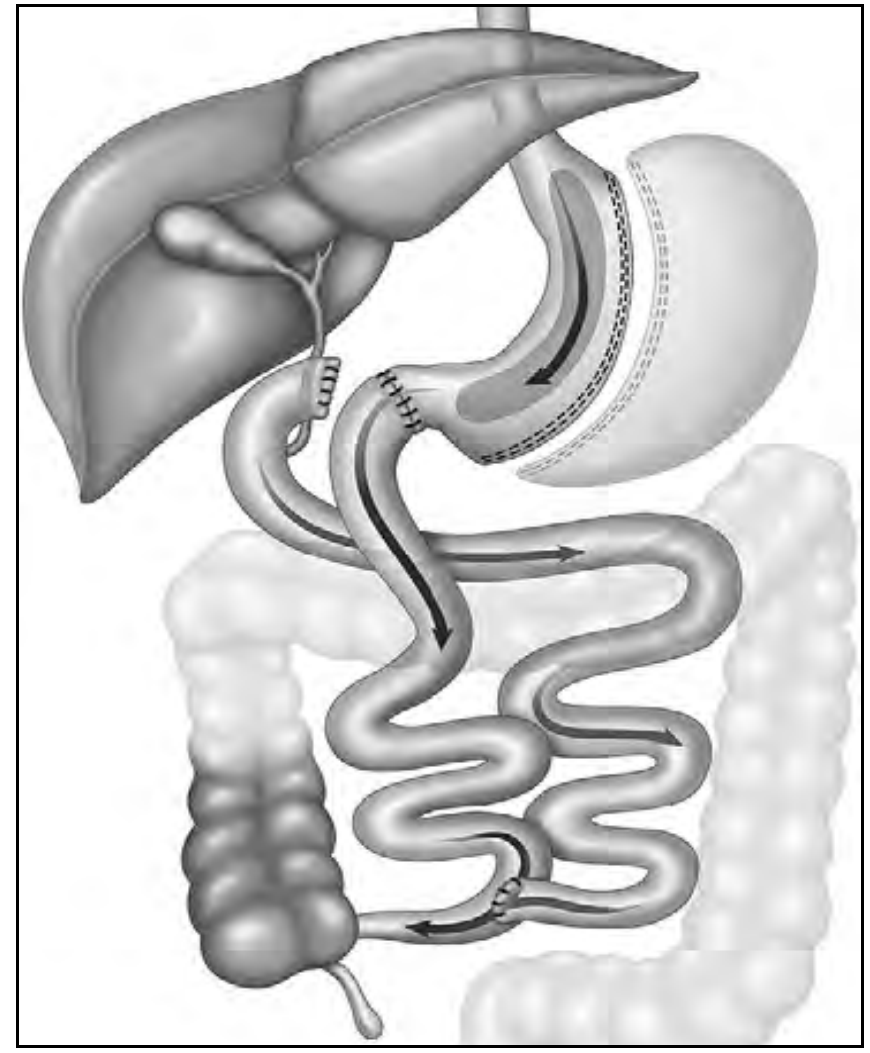

Figura 2: Derivación Bilio-pancreática con switch duodenal 


\subsubsection{Bypass Gástrico}

En busca de una operación de pérdida de peso sin los efectos secundarios perjudiciales de la Derivación Bilio-pancreática, el Dr. Edward E. Mason, de la Universidad de lowa, desarrolló el bypass gástrico. En oposición de las operaciones mencionadas anteriormente, este procedimiento introdujo la restricción gástrica como la causa principal de la pérdida de peso. El concepto se basa en observaciones en los pacientes que habían sido sometidos a una gastrectomía parcial con gastroyeyunostomía Billroth II para enfermedad péptica. En estos pacientes se observó que perdían peso y tenían dificultades para recuperarlo a largo plazo. El bypass gástrico se realizó por primera vez por Mason y lto el 10 de mayo de 1966, en una mujer de 50 años de edad con un índice de masa corporal (IMC) de 43 kg/m2. Esta paciente había sido objeto de múltiples reparaciones fallidas de hernias ventrales y el bypass gástrico se realizó con la esperanza de ayudar a que lograr un peso más manejable. Nueve meses más tarde, había perdido $27 \mathrm{~kg}$ y su hernia ventral fue reparada con éxito. El procedimiento consistió en dividir el estómago horizontalmente y la posterior realización de una gastro-yeyunostomía en asa a la bolsa gástrica proximal. Se diseñó un remanente gástrico pequeño con una anastomosis también pequeña para producir un retraso en el vaciado gástrico (Masson et al, 1967)

En 1977, Griffen y su grupo introdujeron una configuración de la reconstrucción en Y de Roux para reemplazar la gastro-enteroanastomosis en asa. Esta modificación mejoró la técnica en 3 formas: elimina el reflujo biliar en el reservorio, añade un componente malabsortivo a la operación y disminuye la tensión en la anastomosis gastro-yeyunal.

En 1983, Torres y colaboradores introdujeron otra modificación, realizando el reservorio sobre la curvadura menor gástrica donde técnicamente era más fácil, el suministro de sangre es mejor y hay menos propensión a la distensión (Torres JC, et al, 1983). En los años 80 Salmon sugirió añadir una gastroplastia en banda al reservorio para evitar la dilatación del mismo y Fobi utilizó un anillo de (Salmon PA, 1988; Fobi M, 1991)

Aunque el bypass gástrico ofrece ventajas en comparación con el Bypass yeyuno-ileal y la Derivación Biliopancreática con menos diarrea, menor desnutrición proteica y 
hepatopatía, pero a expensas de mayores porcentajes de recuperación de peso perdido. Así mismo estos pacientes requieren suplementación de calcio, hierro y vitamina B12 por la exclusión del estómago distal y el intestino proximal durante toda la vida. (Baker, 2011).
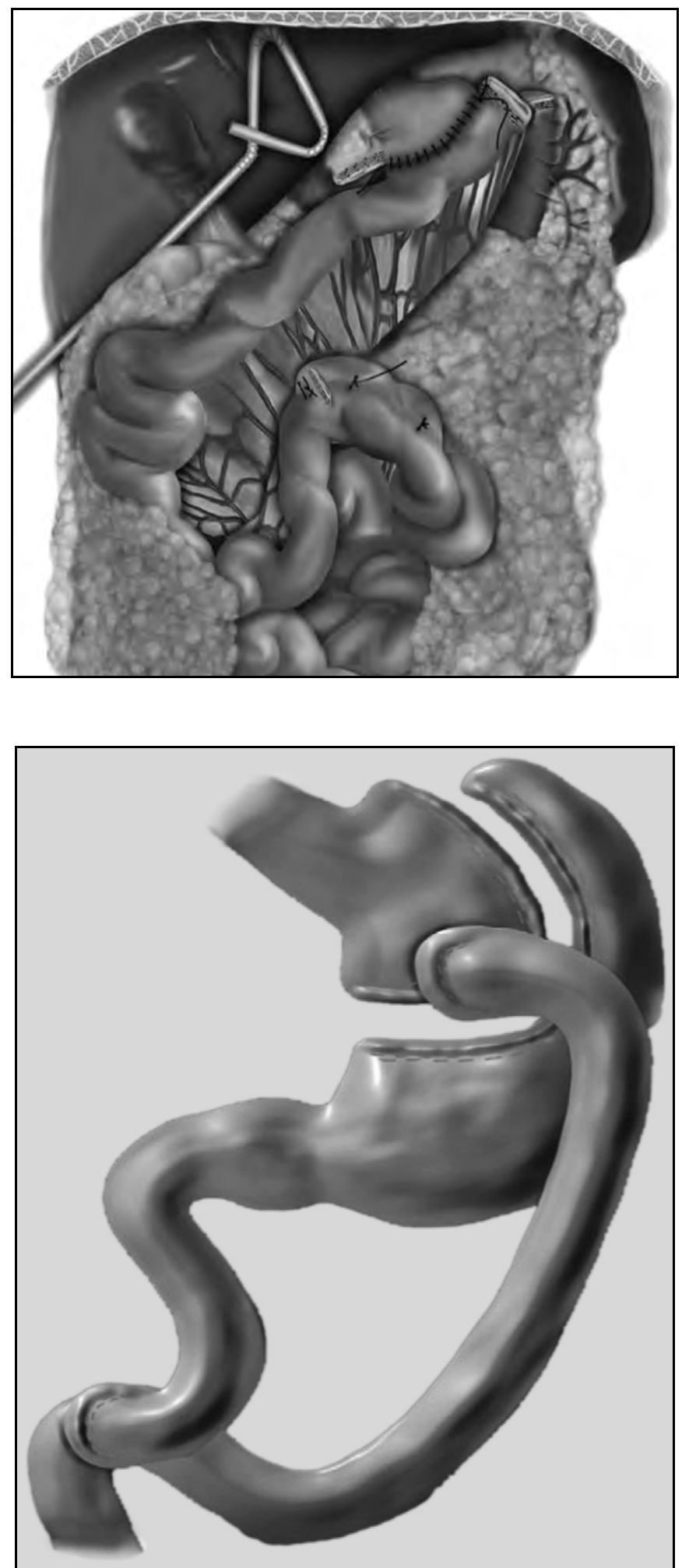

Figura 3: Representación "in vivo" y esquemática del Bypass gástrico con reconstrucción en Y de Youx 


\subsection{PROCEDIMIENTOS RESTRICTIVOS}

\subsubsection{Gastroplastias.}

Se desarrolla buscando una alteración de la anatomía gástrica para restringir la ingesta calórica e inducir saciedad precoz, evitando un bypass intestinal y su morbilidad asociada a largo plazo.

Los primeros intentos se llevaron a cabo por en 1971. La gastroplastia horizontal consistía en la división horizontal de la parte superior del estómago, creando una pequeña bolsa superior con una conexión a la bolsa más grande inferior a través de un pequeño canal a lo largo de la curvatura mayor del estómago. La pérdida de peso fue insatisfactoria con recuperación posterior de peso por la dehiscencia de la línea de grapas, la dilatación de la bolsa o el canal de conexión (Printen KJ, et al, 1973).

A finales de 1970, Gómez modifica el procedimiento añadiendo una segunda aplicación la línea de grapas para evitar la dehiscencia y reforzado el canal con un collarín externo de Mersilene para evitar su dilatación. Esta última modificación se asoció con fibrosis excesiva y obstrucción secundaria por lo cual abandonó la malla realizando una sutura de refuerzo en el anillo. Sin embargo, el anillo fallaba por la erosión de la sutura y la posterior dilatación del estoma. Casi al mismo tiempo Pace y sus colegas y Carey y Martin realizaron modificaciones en ese mismo sentido pero las fallas continuaron. Por otra parte, ninguna de estas modificaciones estuvo dirigida a solucionar la dilatación de la bolsa. Para solucionar esta deficiencia, Long y Collins en 1978 comenzaron a utilizar una línea de grapas oblicua desde el fundus, justo lateral al ángulo de His, hasta el estoma que se apoya en la curvatura menor del estómago. Esta técnica se basa en la idea de que la curvatura menor tiene más grosor en el músculo y por lo tanto sería menos propensa a la dilatación. El estoma se reforzó con una sutura de polipropileno para evitar la dilatación. Posteriormente introdujo un anillo de silastic para evitar la erosión y dilatación del estoma. (Baker, 2011)

Mason desarrolla la gastroplastia vertical con banda o anillada en 1980. Sus criterios para realizar este procedimiento eran eficacia, seguridad, ausencia de efectos secundarios indeseables y reversibilidad (Mason EE, 1982). 
El procedimiento consistió en la creación de una bolsa vertical orientada a lo largo de la parte proximal de la curvadura menor. El tamaño de la bolsa se calibra con una sonda. Se determina que el tamaño de la bolsa ideal debe ser menor de $50 \mathrm{ml}$. La salida de la bolsa es reforzada por una banda de malla de polipropileno que pasa a través de una ventana creada por una grapadora circular. El estoma también fue calibrado usando una sonda para asegurar un diámetro de entre 10 y 12 mm.

La gastroplastia vertical ha demostrado ser técnicamente menos exigente que el bypass gástrico y elimina los problemas de dumping, las úlceras y la anemia. Su popularidad aumentó durante la década posterior y los resultados a corto plazo fueron favorables, con pérdidas de peso superiores a $60 \%$ en un año. A los 5 años, sin embargo, sólo el $50 \%$ de los pacientes mantenía la pérdida en el exceso de peso y esta se redujo a $40 \%$ de los pacientes en 10 años. (Balsiguer BM, et al, 2000) Los fallos fueron, en parte, causados por la dehiscencia de la línea de grapas hasta en un $48 \%$ de los pacientes, dependiendo de la técnica usada. Aunque es menos común, la estenosis del estoma por la cicatrización excesiva de la malla también se ha reportado. Las comparaciones directas con el BPG demostraron que la gastroplastia vertical con banda esta asociada con menores pérdidas de peso, pérdidas menos sostenidas a largo plazo y menos éxito en el control de la DM2. Además se han publicado, informes de altas tasas de reintervención y conversiones a bypass, por lo cual hoy por hoy se utiliza cada vez menos (Baker, 2011).

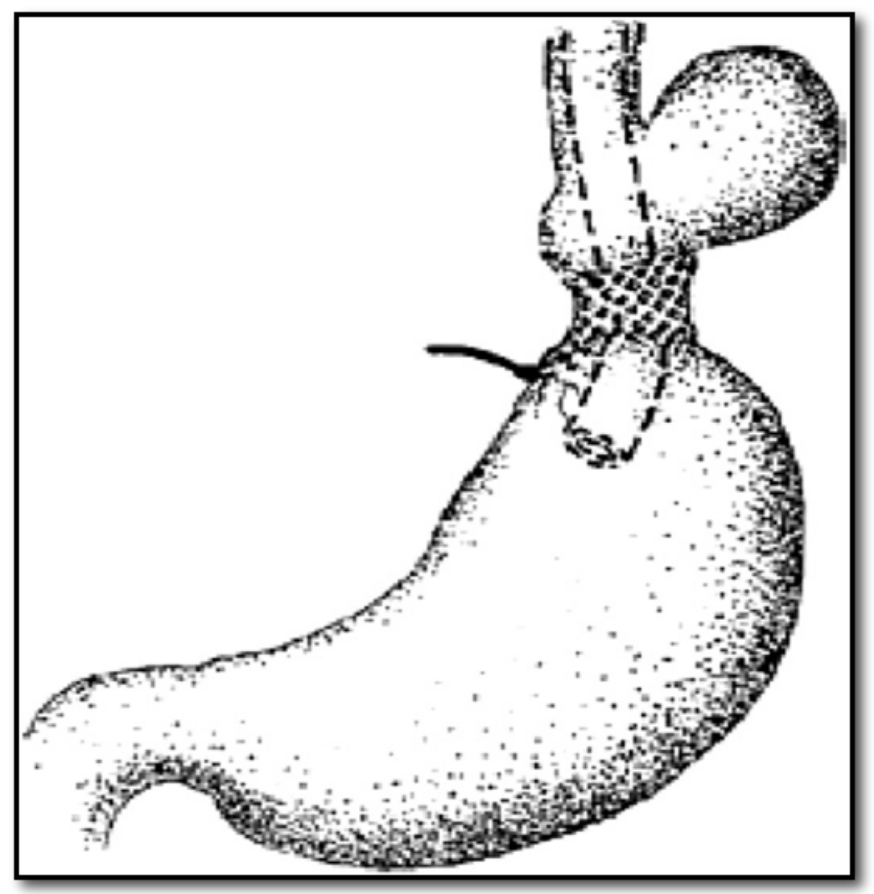

Figura 4: Gastroplastia vertical anillada o con banda. 


\subsubsection{Banda gástrica ajustable.}

La banda gástrica, no implica ningún corte transversal o grapado del estómago y no produce alteraciones en la continuidad del tracto gastrointestinal. En 1978, Wilkinson y Peloso fueron los primeros en colocar una banda no ajustable en un ser humano. La banda constaba de una amplia franja de $2 \mathrm{~cm}$ de grosor de malla Marlex alrededor de la parte superior del estómago del paciente (Wilkinson LH, et al, 1981).

Sobre este mismo tiempo, Molina y Oria (Molina M, et al, 1983) en Houston realizaron intervenciones similares con un injerto de Dacron no ajustable para rodear la parte superior del estómago. Otros cirujanos, como Kolle en Noruega o Naslund y colaboradores en Suecia, también utilizaron mallas para realizar sus versiones de los estos procedimientos (Naslund I, et al, 1994).

En los primeros años de la década de los 80 , se utilizó la silicona como alternativa mas segura a las mallas no ajustables, pero era difícil el ajuste del estoma y fueron comunes los deslizamientos y los prolapsos. También se presentaron estenosis intratables con vómitos severos y dilatación esofágica secundaria.

Posteriormente se desarrollaron dispositivos ajustables. Kuzmak reporta una mejoría en la pérdida de peso con una reducción de las complicaciones cuando se comparan la banda inflable con la versión no ajustable. Pronto se hizo evidente que las bandas ajustables fueron superiores a las iniciales dado que el estoma podía modificarse de forma individualizada según las necesidades de los pacientes (Kuzmak LI, 1986). Las bandas desarrolladas por Forsell y Kuzmak han sufrido numerosas modificaciones cuando fueron comercializadas. Con el advenimiento de la laparoscopia, la implantación de la banda gástrica tuvo un importante auge, primero en Europa y Australia, y más tarde en los Estados Unidos. Forsell diseñó un dispositivo conocido la Banda Gástrica Ajustable Sueca y fue aprobado para su uso en Europa en 1996, a pesar de haber estado disponible en Suecia desde 1987. Fue aprobado en definitiva, para su uso en los Estados Unidos a finales de 2007. La banda de Kuzmak se conoce como sistema LAP-BAND (Allergan, Inc., Irvine, CA, EE.UU.) y fue aceptado para su uso en Europa y Australia a mediados de la década de 1990, pero no recibió la aprobación de la FDA hasta 2001 (Stiffen R, 2008).

Los primeros estudios mostraron resultados favorables. Una de las principales complicaciones era el deslizamiento de la banda hacia arriba, el prolapso gástrico a 
través de la banda causando obstrucción gástrica o la dilatación gástrica proximal. La incidencia de esta complicación se ha reducido en gran medida por la alteración de la técnica de colocación. Otras complicaciones observadas incluyen la erosión de la banda, dilatación esofágica, y problemas relacionados con el reservorio y el estoma.

Hay muchos estudios que documentan los resultados en miles de pacientes que tienen bandas gástricas ajustables con seguimiento a largo plazo. Aunque técnicamente es más segura y el procedimiento es menos difícil, no presenta pérdidas de peso tan favorables y la reducción de la comorbilidad alcanzada por otros procedimientos bariátricos. El porcentaje de pérdida de exceso de peso, aunque variable entre los estudios, es en promedio alrededor del $50 \%$ pero en general, toma 2 a 3 años para alcanzarlo, en comparación con 12 a 18 meses con otros procedimientos. Un seguimiento estrecho de los ajustes también se requiere para obtener resultados óptimos. Las tasas de reintervención también varían y han mejorado con el tiempo, pero se acercan al 5\% por año. Muchas de las reoperaciones incluyen la eliminación de banda, su reemplazo o la conversión a un procedimiento bariátrico diferente (Shen $\mathrm{R}$, et al, 2004)

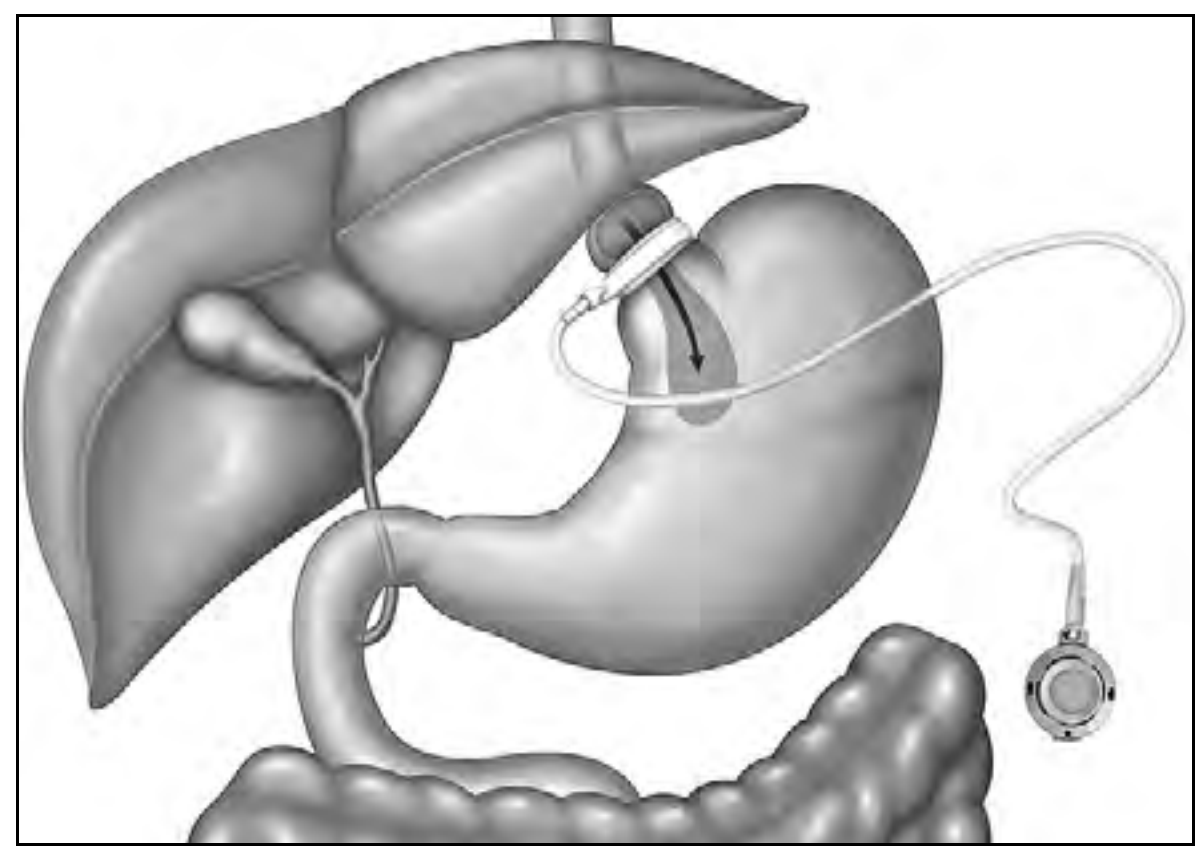

Figura 5: Banda gástrica ajustable. 


\subsubsection{Gastrectomía en manga o vertical.}

También conocida como gastrectomía tipo sleeve por su nombre en inglés, consiste en una gastrectomía vertical que reseca la mayor parte del fundus y cuerpo, dejando un tubo delgado dependiente de la curvadura menor gástrica conservando el antro y el píloro. El procedimiento fue descrito originalmente por Marceau y colabs. en la década de 1990 como el componente restrictivo del Switch duodenal (Marceau P, et al 1993). Sin embargo, sus verdaderos orígenes como procedimiento independiente se inició en la década de 1980 por Johnston y colegas en el Reino Unido, buscando un procedimiento mas sencillo y que no requiriera material protésico para su realización. El nuevo tipo de gastroplastia consiste en la creación de un tubo estrecho a lo largo de la curvatura menor del estómago, La salida en el antro no estaba envuelta en malla para evitar la erosión o la estenosis. El vaciamiento gástrico normal se regula posteriormente por un píloro intacto (Johnston, et al, 2003).

Se hicieron modificaciones al procedimiento original en los años siguientes para simplificar la técnica, mejorar el mantenimiento de la pérdida de peso, y para facilitar la adaptación al abordaje laparoscópico (Mc Mahon MJ, 2007).

Con el cambio de la cirugía abierta a la laparoscopia en la cirugía bariátrica, la manga gástrica también se ha utilizado como parte de un procedimiento en dos tiempos en pacientes superobesos, ya sea anterior a un switch duodenal o un bypass gástrico, disminuyendo las dificultades técnicas que plantea la intervención en estos pacientes. Debido a que la gastrectomía en manga es técnicamente menos complicada de llevar a cabo se comenzó a realizar este procedimiento, a la espera de un año o dos para posteriormente realizar la parte malabsortiva del procedimiento de una forma más fácil y segura, pero se ha visto que muchos de los pacientes pierden peso de una forma adecuada, haciendo innecesaria la segunda intervención. (Silecchia G, et al, 2004)

La gastrectomía en manga como procedimiento independiente se ha vuelto más popular en la última década. Es técnicamente menos exigente que el bypass gástrico o el switch duodenal, se asocia con un mínimo de morbilidad, evita el uso de materiales extraños. Así mismo presenta una menor tasa de complicaciones a largo plazo como úlceras anastomóticas, dumping, hernias internas y déficit asociados a malabsorción 
Las complicaciones asociadas con el procedimiento incluyen las fugas de la línea de sutura y estenosis. Esta última complicación ocurre generalmente en la incisura angularis. Las fugas en la línea de grapas pueden ser preocupantes pues el reservorio es un tubo de alta presión siendo complicada su curación espontánea.

Los datos de seguimientos hasta 5 años muestran una pérdida global del $55 \%$ del exceso de peso, con un rango de $33 \%$ a $85 \%$. La pérdida insuficiente o la recuperación del mismo ha conducido a la conversión del procedimiento a un Bypass o un Switch duodenal (Baker, 2011).

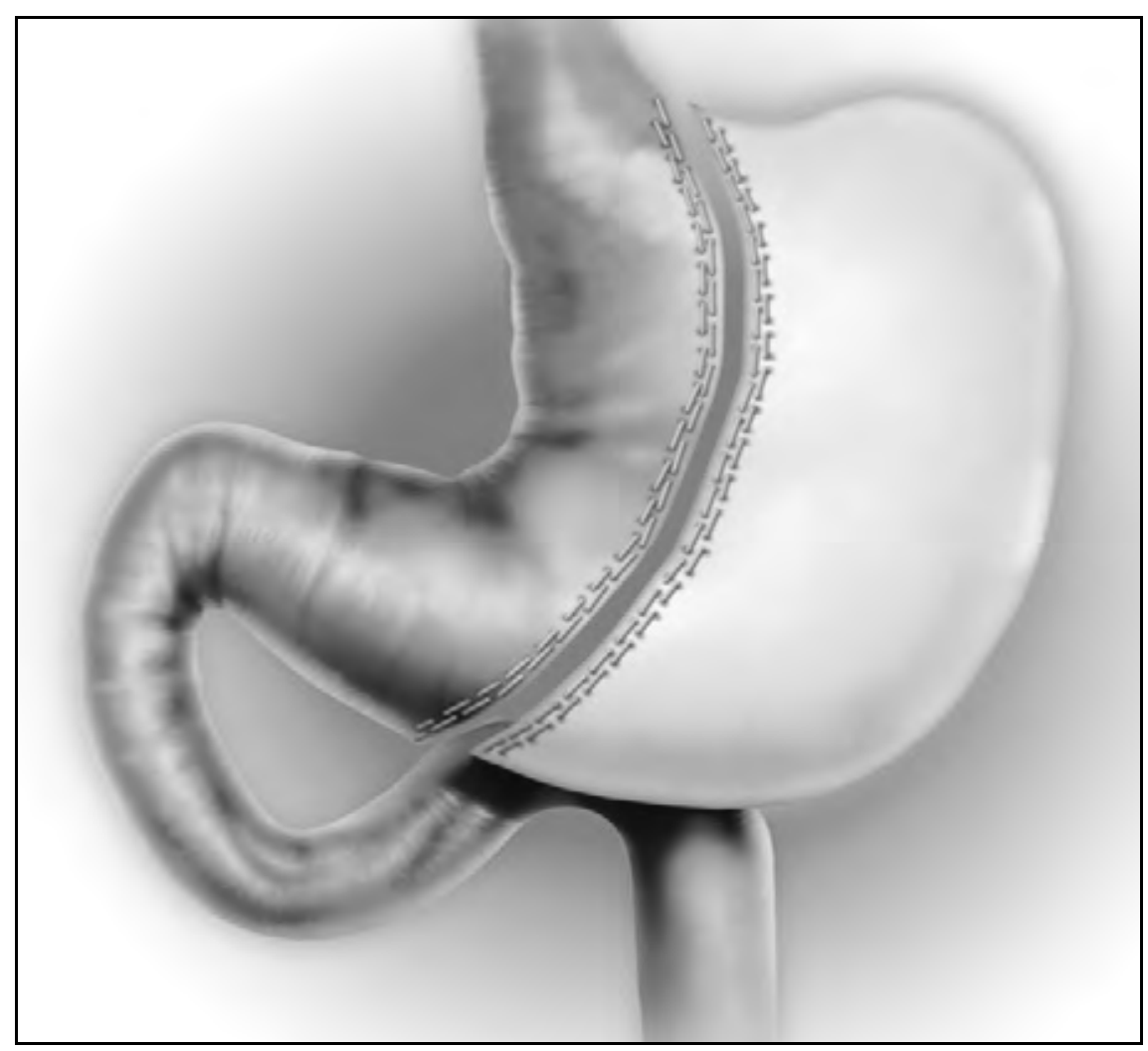

Figura 6: Gastrectomía vertical o en manga

\subsection{LAPAROSCOPIA EN CIRUGÍA BARIÁTRICA.}

La introducción, desarrollo y perfeccionamiento de las técnicas laparoscópicas han sido el mayor contribuyente al aumento en el número de procedimientos bariátricos realizados en la última década. Las estancias mas cortas asociadas a una recuperación más rápida, con menos dolor y la reducción de problemas como infecciones de herida o hernias ha llevado a los pacientes a demandar cada vez más los procedimientos laparoscópicos para la obesidad 
Los primeros procedimientos se realizaron en la década de 1990. Broadbent colocó una banda gástrica no adjustable con éxito en 1992. Belachew y su grupo colocaron en Bélgica la primera banda adjustable en 1993. También en 1993, Wittgrove y Clark realizaron con éxito el primer bypass gástrico laparoscópico y publicaron sus resultados en 500 pacientes en el año 2000. Gagner realizó el primer Switch duodenal laparoscópico en 1999.

Las comparaciones de resultados entre los primeros procedimientos laparoscópicos y abiertos demostraron que existía una curva de aprendizaje para lograr resultados similares.

Con el tiempo, la mortalidad, las fugas anastomóticas, los tiempos operatorios, y otros resultados han mejorado para igualar o superar, los relacionados con la cirugía abierta. En la actualidad, los procedimientos bariátricos laparoscópicos son mucho mas comunes que los realizados por abordaje convencional (Baker, 2011)

\subsection{FISIOLOGIA DE LA PERDIDA DE PESO TRAS CIRUGÍA BARIATRICA.}

Independientemente de las teorías evolutivas, la obesidad no se puede superar sin cambios significativos que afectan tanto la ingesta calórica y el gasto energético. En algún momento en la vida de una persona obesa, el equilibrio entre la ingesta de calorías y el gasto de energético se pierde y sólo se puede restablecer con un saldo negativo entre consumo y gasto energético. La cirugía bariátrica ofrece este contrapeso y permite que el paciente alcance los objetivos de forma realista y reducir al mínimo los efectos perjudiciales de las comorbilidades.

Uno de los primeros estudios que informan sobre la eficacia de la cirugía en el tratamiento de la comorbilidad asociada a la obesidad fue publicado por Friedman en 1955, informando la mejoría de la diabetes mellitus después de la realización de una gastrectomía subtotal (Friedman ML, et al, 1955). Varias décadas más tarde, Pories y su grupo revisando su experiencia con la cirugía de bypass gástrico en pacientes obesos que mostraron pérdidas de peso efectivas y duraderas (en un período de 14 años), junto con una resolución de $83 \%$ de la DM 2 (definida como normoglucemia sin necesidad de medicamentos) (Pories, et al, 2011).

Teniendo en cuenta la gran cantidad de estudios que demuestran la mejoría en la 
comorbilidad asociada a la obesidad en pacientes sometidos a procedimientos de cirugía bariátrica incluso antes de presentar pérdidas de peso significativas, en 2007, casi 25 años después de su fundación la Sociedad Americana de Cirugía Bariátrica cambió su nombre al de Sociedad Americana de Cirugía Metabólica y Bariátrica.

\subsubsection{El eje Endocrino Entero-Encefálico, Obesidad y Cirugía Bariátrica.}

Desde Pavlov se conoce que la secuencia de eventos fisiológicos digestivos empieza incluso antes de la ingestión de alimentos, tales como la liberación de varias hormonas entericas. Durante la comida, se activan redes neuronales complejas que estimulan los centros de recompensa del cerebro. Un estudio reciente sugiere que la cirugía bariátrica puede alterar los patrones de activación neural en los centros de recompensa mesolímbicos en respuesta a la alimentación. Estos cambios se asocian a una reducción subjetiva del apetito y pone de relieve la importancia de descifrar cómo la cirugía bariátrica altera la comunicación de las vías del eje endocrino enteroencefálico. Este eje se cree que es el núcleo de la regulación fisiológica del apetito humano, del proceso de la ingesta de nutrientes, y de la homeostasis de la energía y el metabolismo humano y se regula por varias hormonas (Power ML, et al, 2008).

\subsubsection{La ghrelina}

Conocida como la hormona del hambre, la ghrelina es producida principalmente por células $P / D 1$ en el fundus gástrico. Sus niveles aumentan antes de una comida 0 cuando la persona cree que tiene hambre y sus niveles disminuyen rápidamente después de la ingestión de alimentos. A pesar de que tiene muchos efectos fisiológicos, el papel clave de la ghrelina en la cirugía de la obesidad está en los efectos neurotrópicos del péptido a través del eje endocrino entero-encefálico. Vía receptores en los núcleos arqueado y lateral del hipotálamo, la ghrelina estimula la liberación hipotalámica de varios neuropeptidos tales como el neuropéptido Y (NPY) y la hormona del crecimiento. El resultado es que facilita un estado orexígeno, o un estado de mayor apetito a través de la activación de las neuronas NPY. Por el contrario, una reducción significativa en los niveles de ghrelina, tales como los observados inmediatamente después de una comida, se traducen en una sensación de saciedad (Diniz MF, et al, 2010).

Numerosos estudios han establecido el papel de la ghrelina como estimulante del 
apetito, pero sus efectos sobre el metabolismo pueden ser más complejos

Se ha demostrado que los niveles basales de ghrelina pueden tener una relación inversa con el peso corporal y el balance energético. Los niveles de ghrelina basales en las personas con peso normal o bajo son significativamente más altos en comparación con los obesos, pero según un estudio de English, los sujetos obesos tenían niveles significativamente más bajos de ghrelina basal, pero comer no causó una disminución significativa en sus niveles circulantes haciendo más difícil que los individuos obesos alcancen una sensación de saciedad después de comer. Actualmente no se tiene claro el por qué de este fenómeno (English PJ, et al, 2002; Parks, et al, 2011).

Los niveles basales de ghrelina aumentan con la pérdida de peso en pacientes sometidos a tratamientos de control de peso no quirúrgicos, haciendo más difícil su éxito, incluso en pacientes sometidos a dieta en fases iniciales sin presentar aún cambios reales en el peso corporal.

En este sentido, la cirugía bariátrica puede ofrecer lo que ningún otro tratamiento puede. Los estudios realizados en pacientes después de BPG han informado de que la ghrelina plasmática es baja a pesar de una disminución de peso significativa. Sin embargo, este hallazgo ha sido inconsistente en la literatura. (Kelishade $R$, et al, 2008).

Los resultados contradictorios de cómo la cirugía bariátrica afecta la ghrelina pueden ser causados por varios factores, incluyendo diferencias en la técnica quirúrgica, el uso de diferentes sistemas de medición, así como las funciones fisiológicas complejas y múltiples de la ghrelina. (Soares JB, et al, 2008)

La gastrectomía vertical y el BPG implican la exclusión del fundus del flujo de nutrientes y favorecen una disminución de la ghrelina posquirúrgica. Sin embargo, el grado de exclusión del fundus puede variar dependiendo del cirujano y esto puede contribuir a la disparidad en los resultados.

Descubrimientos recientes de los múltiples productos de los genes que producen la ghrelina (por ejemplo obestatina y la ghrelina desacil) pueden aumentar o antagonizar los efectos de la ghrelina. (Soares JB,et al, 2008) 
Además de esto, en un estudio realizado por Le Roux y colaboradores se informó que la ghrelina no afectó el apetito o la ingesta de alimentos en pacientes con una vagotomía quirúrgica. Por lo tanto, las operaciones bariátricas que implican la resección gástrica y una vagotomía, pueden inhibir el papel de la grhelina en la estimulación del apetito y el consumo de alimentos. (Le Roux CW, et al, 2005)

\subsubsection{Neuropéptido $Y$}

A nivel del hipotálamo y de los centros reguladores centrales del cerebro, el Neuropéptido $Y$ (NPY) es la señal dominante hormonal que regula la ingesta de nutrientes y el metabolismo. La actividad de NPY es ubicua en todo el cuerpo, y es uno de los neuropéptidos más abundantes en el cerebro humano. EI NPY afecta a numerosos procesos fisiológicos tales como la regulación del ritmo circadiano, la respuesta al estrés y el metabolismo.

La liberación de NPY es estimulada por señales orexigénas como la ghrelina y se inhibe por señales de anorexígenos, como la leptina y el péptido YY (PYY). Entre sus muchas actividades el NPY es un potente estimulante del apetito y los estudios con animales han confirmado la relación entre NPY y un aumento de ingesta de alimentos, así como el desarrollo de obesidad y en humanos también parece intervenir en el desarrollo del síndrome metabólico, sin embargo los efectos para bloquear su acción en este sentido no han sido satisfactorios usando nuevos antagonistas del receptor de NPY (Hanson ES, et al, 1995)

En un amplio estudio multicéntrico, aleatorizado y controlado, el uso de antagonistas del NPY produjo pérdidas de peso estadísticamente significativas pero clínicamente irrelevantes tras un periodo de 52 semanas. Del mismo modo, estudios de los niveles de NPY tras BPG en pacientes diabéticos y no diabéticos no mostraron cambios significativos a pesar de la pérdida de peso efectiva y los cambios en el índice de masa corporal. Por lo tanto, a pesar de sus efectos orexigénos conocidos, el papel del NPY como diana terapéutica en el tratamiento de la obesidad no está bien establecido (Erondu N, et al, 2006).

\subsubsection{Péptido YY}

Se produce en respuesta a la presencia de nutrientes en el lumen del intestino por las células $L$ con mayor presencia a nivel del íleon terminal y colon. Ejerce un estímulo 
anorexígeno en las neuronas NPY Además, el PYY tiene muchos efectos viscerales tales como la inhibición de la motilidad gastrointestinal y reducción de secreciones intestinales y pancreáticas produciendo una disminución del flujo de nutrientes a través del tracto gastrointestinal, un efecto conocido como el freno ileal, siendo el PYY uno de los componentes clave de esta retroalimentación negativa.

En un estudio experimental, la infusión de PYY ha demostrado reducir la ingesta de nutrientes en sujetos obesos y delgados (Sloth B, et al, 2007). Otro estudio cuantifica los efectos de la administración de PYY y mostró una disminución del 30\% en la cantidad de alimentos que se consumen en una comida tipo buffet tanto por sujetos obesos como delgados. Además, también se demostró que la infusión de PYY provocó una disminución en los niveles de ghrelina, lo que sugiere una interacción entre la supresión del apetito y la estimulación del eje enteroendocrino. (Batherham $R L$, et al, 2003)

Se ha demostrado que las personas obesas producen bajos niveles de referencia de PYY en comparación con aquellas personas de peso normal, pero no todos los informes han confirmado este hallazgo. (Batherham RL, et al, 2003)

La cirugía bariátrica y el BPG en particular, han demostrado que aumentan los niveles de PYY, incluso precozmente. Este procedimiento aumenta la velocidad de tránsito de nutrientes a las zonas secretoras de PYY del intestino (íleon y colon), y esto puede provocar que el aumento observado en la respuesta del PYY postprandial después del BPG. De acuerdo con este mecanismo, la banda gástrica no aumentó los niveles de PYY en pacientes obesos, mientras que el BPG y la gastrectomía en manga produjeron un aumento sostenido de los niveles de PYY durante un periodo de 12 meses. (Karamanos SK, et al, 2008)

Además, el aumento de los niveles postprandiales de PYY no se observó en pacientes sometidos a tratamientos médicos para pérdida de peso.

\subsubsection{La leptina.}

Producida por el tejido adiposo, la leptina actúa a nivel del hipotálamo para contrarrestar las señales inducidas por orexigénos como la grelina y el NPY. La leptina activa la propiomelanocortina, que a su vez induce la liberación de otros anorexígenos. La leptina no es una hormona intestinal pero promueve la conducta anoréxica y se 
cree que está involucrada en la producción de la sensación de plenitud o saciedad después de una comida.

En contraste con la ghrelina, los niveles séricos de leptina no son dependientes a corto plazo de la ingesta; los niveles de leptina son más un reflejo de perfil metabólico de una persona a través del tiempo y dependen de la cantidad de tejido adiposo existente. Por lo tanto, las personas obesas tienen mayores niveles de leptina circulante. Sin embargo, se cree que los individuos obesos se vuelven resistentes a los efectos anorexígenos de la leptina, lo que reduce la potencia de sus efectos inhibidores sobre los centros reguladores del apetito (Beckman LM, et al, 2010).

La administración de leptina exógena ha sido probada como tratamiento de la obesidad. En 1999, un estudio multicéntrico, aleatorizado y controlado mostró resultados prometedores en personas delgadas y obesas en respuesta a la leptina exógena pero estudios posteriores no han reproducido este hallazgo. Parece que la leptina puede ser un marcador de la pérdida de peso en lugar de un efector y estudios recientes han confirmado que los niveles de leptina disminuyen a medida que se pierde peso, independientemente de la forma de lograrlo. (Ram E, et al, 2005)

Varios estudios han demostrado la resolución de la resistencia a la leptina después de procedimientos quirúrgicos bariátricos. Los niveles de leptina disminuyen de manera significativa en los individuos que se han sometido a un BPG y se correlacionan con el porcentaje de pérdida de peso. (Park et al, 2011).

\subsection{IMPACTO DE LA CIRUGÍA BARIATRICA EN LA COMORBILIDAD ASOCIADA AL SOBREPESO Y LA OBESIDAD.}

Los desafíos de la epidemia de obesidad no se limitan a la preocupación por el peso, sino también a las discapacidades fisiológicas, psicosociales y económicas asociadas.

La probabilidad de curación de las enfermedades asociadas a la obesidad depende de muchos factores, incluyendo la duración y severidad de la enfermedad, la cantidad de pérdida de peso alcanzado y la contribución de la obesidad a la gravedad de la enfermedad. La cirugía bariátrica (CB) puede reducir significativamente el peso corporal, resolver las comorbilidades relacionadas con la obesidad y mejorar a largo plazo la supervivencia. (Maggard MA, et al, 2005) 
La mortalidad global de la CB en un meta-análisis fue de $0,28 \%$; se coloca en la categoría más baja de mortalidad para las operaciones electivas que se realizan en los Estados Unidos (Buchwald H, et al, 2009).

Un estudio observacional de cohortes mostró que, después de una media de 5,3 años, la CB se asoció con una pérdida media del exceso de peso de $67,1 \%$, produciendo importantes reducciones en el riesgo cardiovascular, endocrinológico, respiratorio, y en las enfermedades infecciosas y psiquiátricas así como en algunos tipos de cáncer. (Cremieux PY, et a, 2010)

El impacto en las enfermedades concomitantes depende del tipo de procedimiento realizado, la cantidad de peso perdida, las alteraciones hormonales y las particularmente en las incretinas, el grado de malabsorción, los cambios en la motilidad, y el efecto sobre los hábitos alimenticios. (Kaul A, et al, 2011)

\subsubsection{Diabetes Mellitus Tipo 2.}

La cirugía bariátrica ha demostrado ser algo más que un tratamiento eficaz de la diabetes; es capaz de lograr inigualables resultados terapéuticos. La Asociación Americana de Diabetes indica la cirugía bariátrica para el tratamiento de la diabetes tipo 2 en pacientes con IMC mayor o igual a $35 \mathrm{~kg} / \mathrm{m} 2$. Así, la comprensión de los mecanismos responsables de la alta tasa de resolución de la diabetes después de la cirugía bariátrica es clínicamente relevante y puede conducir a nuevas dianas terapéuticas. (ADA, 2011)

Asimismo y basándonos en un punto de vista epidemiológico el 90\% de los casos de diabetes podrían prevenirse evitando la obesidad. La mayoría (67\%) de personas con diabetes tipo DM 2 tienen un índice de masa corporal (IMC) mayor o igual a 30.

En el estudio de sujetos obesos suecos (SOS), la cirugía comparada con tratamientos no quirúrgicos, disminuyó el riesgo de desarrollar diabetes más de 3 veces, mientras que la resolución de la diabetes fue 3 veces más frecuente en 10 años. (Sjostrom L, et al, 2004). Otros estudios han demostrado similares ventajas significativas y sostenidas de la CB en comparación con otros tratamientos médicos 
Como se ha comentado en otros apartados, Pories y su grupo encontraron importantes mejoras en los parámetros de la DM2 tras BPG. El 82.9\% de los pacientes diabéticos mantuvieron un control metabólico adecuado a largo plazo tras la intervención. También un $98.7 \%$ de pacientes con glucemia basal alterada mantuvieron niveles normales de glucosa en plasma, hemoglobina glicosilada e insulina. (Pories W, et al, 1995)

Un meta-análisis de todos los estudios de CB desde 1990 hasta 2006 (Buchwald H, et al, 2009) encontró que $78,1 \%$ de los pacientes diabéticos tuvieron una resolución completa, y la diabetes mejoró o desapareció en el 86,6\% de los pacientes. La mejoría fue mayor para los pacientes sometidos a derivación biliopancreática (DBP) o switch duodenal $(95,1 \%)$, seguido por BPG $(80,3 \%)$, gastroplastia $(79,7 \%)$ y banda gástrica ajustable $(56,7 \%)$. La proporción de pacientes con una resolución de la diabetes en puntos de tiempo menor, igual y mayor a dos años fue constante. Los niveles de insulina se redujeron significativamente después de la cirugía, al igual que la hemoglobina A1c y la glucosa en ayunas. En algunas series se ha observado hasta un $100 \%$ de resolución completa de la DM con la DBP (Montes M et al, 2009, 2).

La cirugía metabólica es igual de eficaz en pacientes con un IMC bajo (<35 kg/m2) en el control de la DM2, sin presentar cambios indeseables en el peso. Así mismo subpoblaciones de riesgo de obesos también presentan importantes tasas de resolución de la DM 2 tras CB (Fried M, et al, 2010).

En comparación con BPG, la DBP y el switch duodenal mostraron una mejor resolución DM a los 3 años en los pacientes superobesos, con un IMC superior a 50 $\mathrm{kg} / \mathrm{m} 2$ (60\% vs $100 \%$, respectivamente). También se ha demostrado que los pacientes con DM2 que se sometieron a CB tienen menos complicaciones derivadas de la enfermedad. (Mc Donald KJ, et al, 1997)

Estudios caso-control han observado la presencia de hiperinsulinemia severa e hipoglucemia de inicio tardío después de la $C B$ lo que sugiere que estos procedimientos pueden tener un efecto estimulante de las células Beta (Kaul A, et al, 2011).

La resolución de la enfermedad se ha relacionado clásicamente con la pérdida de peso pero no hay una relación directa de causa y efecto, ya que la resolución puede 
ocurrir en cuestión de días después de la cirugía, incluso antes de observar pérdida de peso objetiva. (Poiries WJ et al, 2001)

El estudio de Hickey y Pories se planteó como objetivo analizar si la pérdida de peso era la causante de que la cirugía bariátrica controlara la DM 2 en pacientes con obesidad mórbida. Para ello se estudiaron 12 mujeres con obesidad mórbida y DM 2 de las cuales 6 habían sido sometidas a by-pass gástrico pero éste había fracasado en la pérdida de peso y otras 6 no habían sido intervenidas. Ambos grupos eran comparables en peso e IMC que se mantuvo estable durante al menos 6 meses. Los resultados se resumen en que la leptina disminuyó un $40 \%$ en las pacientes intervenidas, la concentración de insulina en plasma disminuyó, al igual que la glucemia; la sensibilidad a la insulina mejoró, sin embargo la primera fase, la secreción de la insulina no varió. La conclusión fue que el by-pass gástrico disminuye la leptina y mejora los niveles de insulina y glucosa plasmática en ayunas y la sensibilidad a la insulina a pesar de que estas pacientes sigan siendo obesas (Hickey et al., 1998).

Los mecanismos que influyen en la resolución de la DM establecida, incluyen la reducción en la ingesta de calorías, la supresión del apetito, la pérdida de peso después de la cirugía, la disminución de la producción de glucosa hepática, el aumento en la captación de glucosa, cambios en el vaciamiento gástrico, la disminución en los niveles de leptina o el aumento en su sensibilidad, la disminución de la resistencia a la insulina o el aumento de sus niveles y la mejora en la capacidad de respuesta de células Beta a la glucosa; también la reducción de los niveles de ghrelina, cambios en los niveles del péptido inhibidor gástrico (GIP) y el aumento de los niveles de los derivados de las células $L$ (GLP-1, PYY). Se ha demostrado que la BPG disminuye la actividad de la enzima dipeptidil peptidasa-4 (DPP-4), pudiendo dar lugar a niveles de incretinas más altos y niveles mas bajos de glucosa en sangre (Kaul A, et al, 2011).

\section{A. El eje enteroinsular.}

La mejoría precoz de la diabetes en pacientes intervenidos de cirugía bariátrica antes de que cualquier pérdida de peso significativa sea alcanzada, cambia la idea de la pérdida de peso como único mecanismo para la normalización del metabolismo de la glucosa. 
Los estudios han dilucidado los efectos de la cirugía bariátrica en el eje enteroinsular, específicamente en una familia de péptidos implicados en la síntesis, secreción y regulación de la insulina: las incretinas.

\section{B. Péptido insulinotrópico dependiente de glucosa. (GIP).}

También conocido como péptido inhibidor gástrico, es una incretina producida por las células $\mathrm{K}$ en el duodeno y yeyuno interviene en la regulación de las células beta pancreáticas, el control de la glucosa dependiente de insulina y los niveles postprandiales de glucagón, y el metabolismo de ácidos grasos. Se cree que el GIP es liberado por el intestino delgado proximal en respuesta a la presencia de glucosa dentro su luz. Los procedimientos bariátricos en los cuales se realiza un bypass del duodeno y yeyuno proximal (como la BPG o la DBP) resultan en la exclusión total del paso de nutrientes y glucosa en el intestino proximal dando lugar a una estimulación casi nula de las células $\mathrm{K}$, una reducción en los niveles de GIP y una disminución en el estímulo a la célula beta y a la producción de insulina. Se ha postulado que este mecanismo es responsable para la resolución temprana de la diabetes. Sin embargo, los estudios del GIP, su papel en la cirugía bariátrica, y en la resolución de la diabetes no han sido concluyentes. (Parks, 2011).

\section{Péptido similar al glucagón-1 (GLP1).}

El péptido similar al glucagón-1 (GLP-1) es otra de las incretinas importantes en la fisiología de la obesidad. EI GLP-1 tiene muchas funciones fisiológicas, incluyendo la estimulación de la secreción de insulina por el páncreas, un incremento en la sensibilidad a la insulina de las células pancreáticas, (alfa y beta) la inhibición de la secreción de glucagón, y la reducción del hambre

Es producida por las células $L$ en el tracto gastrointestinal distal (íleon terminal y colon), y sus niveles aumentan en respuesta a la presencia de nutrientes en estas zonas del tubo digestivo. El aumento del nivel del GLP-1 se ha demostrado que induce la supresión del apetito en obesos e individuos de peso normal y se considera un componente del mecanismo de freno ileal.

Además, se ha propuesto que el GLP-1 es un factor clave que conduce a la rápida resolución de la diabetes mellitus después de la cirugía bariátrica produciendo un rápido incremento en los niveles de GLP-1 con la llegada rápida de nutrientes tras 
procedimientos derivativos que a su vez conduce a una alteración de la fisiología metabólica, limitando el consumo adicional de nutrientes, aumentando la producción de insulina y mejorando la sensibilidad a la misma. (Thomas S, et al, 2010)

\section{El efecto incretina.}

Se ha demostrado que la administración intravenosa de glucosa no tiene el mismo efecto sobre el metabolismo del eje enteroinsular que la administración oral de dosis equivalentes. Este fenómeno se ha llamado el efecto incretina y le da relevancia adicional a la producción intestinal de las incretinas como un importante mecanismo por el cual el control glucémico y la remisión de la diabetes se puede esperar tras una cirugía bariátrica.

En un estudio aleatorizado, prospectivo comparando la gastrectomía en manga y BPG, se encontró una mejoría en la resistencia a la Insulina (medida por el modelo de evaluación homeostático [HOMA]), disminución de los niveles de insulina en ayunas y un aumento posprandial de los niveles de GLP-1 en ambos grupos, antes de cualquier pérdida significativa de peso (Peterli $R$, et al, 2009)

Aunque los efectos sobre el eje enteroinsular tras el BPG son consistentes con el conocimiento actual, los efectos de la gastrectomía vertical o en manga no se conocen bien y requieren mayor estudio. Además, la resolución de la diabetes después de la manga gástrica es más probable que sea el resultado de la restricción calórica y la pérdida de peso sostenida en el tiempo.

A pesar de la existencia de nuevos tratamientos médicos prometedores, hasta la fecha no existe una sustancia conocida o medicamento capaz de reproducir los mecanismos y los resultados de pérdida de peso y la resolución de la diabetes con la velocidad y la magnitud vistos con la cirugía bariátrica.

Las directrices actuales en el tratamiento de la DM 2 se basan en aumentar progresivamente el número y el tipo de medicamentos por el empeoramiento en el control glucémico, produciendo un efecto negativo sobre la reserva de células beta y disminuyendo la posibilidad de la remisión de la diabetes. Se cree que uno de los factores asociados con una remisión incompleta de la diabetes después de la cirugía bariátrica es una larga historia de enfermedad. (Deitel $M, 2011$ ). La Asociación Americana de la Diabetes reconoció recientemente las ventajas de la cirugía bariátrica 
y la asumió como una opción viable de tratamiento en pacientes obesos aptos para intervención (Park, et al, 2011)

Hasta hace poco se tenía claro que los procedimientos quirúrgicos que excluyen el intestino proximal incrementan GLP-1 y esta hormona ha demostrado mejorar la DM 2, siendo el GLP-1 el candidato principal para mediar la mejoría de la diabetes con las técnicas quirúrgicas derivativas en comparación con los procesos restrictivos puros.

Hay gran cantidad de evidencia en la literatura respecto a los resultados a largo plazo de diferentes procedimientos bariátricos y sus resultados en pacientes diabéticos. En un estudio reciente publicado por De Paula y colabs. evaluaron los resultados preliminares de interponer un segmento de íleon al yeyuno proximal, asociado a una gastrectomía en manga para controlar la diabetes mellitus tipo 2 en pacientes con IMC menor a $35 \mathrm{~kg} / \mathrm{m} 2$. Una característica importante de esta operación es la exposición temprana de nutrientes digeridos al íleon interpuesto, permitiendo una elevación temprana de GLP- 1, corrigiendo la fase temprana de la secreción defectuosa de insulina. La segunda característica es la restricción calórica, y la tercera es la disminución en la estimulación excesiva del duodeno. Durante 7 meses de seguimiento, se logró un control adecuado de glucosa en $86,9 \%$ de los pacientes; ninguno requirió insulina en el postoperatorio. Concluyeron que la interposición ileal con gastrectomía en manga es un procedimiento prometedor para el control de la diabetes mellitus y síndrome metabólico, sin embargo se necesita un mayor seguimiento postoperatorio (De Paula et al, 2008).

Cohen y colabs. describieron sus resultados iniciales de by-pass duodenoyeyunal en pacientes con $\mathrm{IMC}<35 \mathrm{~kg} / \mathrm{m} 2$, donde preservaron el estómago. Reportaron una resolución rápida de la diabetes, con normalización de los niveles de glucosa en ayuno, insulina y hemoglobina glicosilada, sin asociarse a cambios significativos de IMC. Con estos resultados iniciales concluyen que el by-pass duodenoyeyunal es una cirugía segura que puede representar una opción terapéutica de gran valor para la diabetes (Cohen et al, 2007).

La serie más grande de pacientes publicada por Ramos y colabs. describe los resultados a 6 meses de 20 pacientes sometidos a derivación duodenoyeyunal laparoscópica; los pacientes tenían DM2 de 2 a 8 años de diagnóstico y se encontraban en control con distintos esquemas de hipoglucemiantes orales. EI IMC promedio preoperatorio fue de $27 \mathrm{~kg} / \mathrm{m} 2$, a los 3 meses de $25 \mathrm{~kg} / \mathrm{m} 2$ y a los 6 meses de $24 \mathrm{~kg} / \mathrm{m} 2$. Las cifras de glucosa en ayunas preoperatoria fue de 171,3 mg/dL 
mientras que a 3 y 6 meses fue de 107 y $96 \mathrm{mg} / \mathrm{dL}$ respectivamente. Al final del estudio solamente 2 pacientes (10\%) continuaron con requerimientos de hipoglucemiantes a dosis menores a las preoperatorios (Ramos et al., 2009).

Un metanálisis de más de 130 estudios demuestra la resolución o la mejora de la diabetes en una mayoría significativa de pacientes (Buchwald $\mathrm{H}$ et al, 2004). En particular, la diabetes tipo 2 se resolvió o mejoró en alrededor del $80 \%$ de los casos. Además, las dislipidemias pueden resolverse o mejorar considerablemente en el $70 \%$ $95 \%$ de los pacientes tratados quirúrgicamente, y la hipertensión puede hacerlo en el 87\%-95\%. (Frachetti et al, 2009) Los pacientes con enfermedad más precoz parecen mostrar una resolución más completa. En un estudio observacional (Adams et al, 2007), las tasas globales de mortalidad fueron $40 \%$ menores durante un periodo de seguimiento medio de 7 años en pacientes que se habían sometido a cirugía bariátrica, frente a aquellos que no, y los fallecimientos relacionados con la diabetes se redujeron en un $92 \%$.

La remisión de la diabetes se ha observado en diferentes grados, después de la gastrectomía vertical. Una revisión sistemática reciente (Gill RS, et al, 2010) evaluó las tasas de mejora de la diabetes después de la gastrectomía vertical y encontró 28 estudios que cumplieron con sus criterios de inclusión. La población de pacientes incluyó 673 pacientes con un promedio preoperatorio de IMC de 47,4 kg/m2. En este análisis se observó una remisión de la diabetes en el 66,2\% de los pacientes. Se observó una mejoría o remisión de la DM2 en el 97\% de los pacientes de los estudios que analizaron estos 2 parámetros. La HbA1c media disminuyó de 7,9 a 6,2 en los 11 estudios que incluyeron a esta medida de control de la glucosa.

Un ensayo aleatorio, controlado en Taiwan comparando BPG y GV como tratamiento de la diabetes tipo 2 (definiendo remisión como glucosa en ayunas <126 mg/dl y $\mathrm{HbA1c}<6,5 \%$ sin terapia hipoglucemiante). Se observó que la GV dio lugar a la remisión de la diabetes en el $47 \%$ de los pacientes tras 1 año de seguimiento y se asoció con una reducción media del $3 \%$ en los niveles de $\mathrm{HbA1c}$. El bypass gástrico tenía mayores efectos sobre la pérdida de peso, circunferencia de la cintura, y la tasa de remisión de la DM2 (93\%) (Lee WJ, et al, 2011).

En un estudio de pacientes sometidos a GV y BPG que fueron emparejados por la gravedad y la duración de la diabetes, (Vidal J, et al, 2008) se encontró que ambos grupos tenían una tasa de remisión de la DM2 de 84\% y tasas comparables de 
resolución del síndrome metabólico en un año (62\% GV vs 67\% de BPG).

\subsubsection{Hipertensión arterial.}

La hipertensión arterial (HTA) es una de las comorbilidades más comunes asociadas con la obesidad. Alrededor del $40 \%$ al $70 \%$ de los pacientes sometidos a CB son hipertensos. Los mecanismos que se han propuesto para explicar la contribución de la obesidad al desarrollo de HTA incluyen una alteración del sistema reninaangiotensina-aldosterona, el aumento de la presión intra-abdominal, el aumento de la actividad del sistema nervioso simpático, el desarrollo de resistencia a la insulina, hiperleptinemia, resistencia a la leptina, alteración en factores de coagulación así como inflamación y disfunción endotelial.

El estudio SOS sueco, mostró una reducción de la presión arterial sistólica a los 2 años en el grupo quirúrgico. La CB mejora sustancialmente o resuelve la HTA en la mayoría de los pacientes $(37 \%$ - 53\%) o reduce la necesidad de antihipertensivos $(18 \%-36 \%)$ (Sjostrom L, et al, 2004). Esta tendencia persiste en las personas de más de 60 años de edad.

Los pacientes con deficiencia de vitamina $D$ tienen tasas significativamente más bajas de resolución de la hipertensión en comparación con aquellos con niveles adecuados de vitamina $D$, sin embargo la corrección de la deficiencia con suplementos de vitamina D (50.000 UI por semana) permite la resolución de la hipertensión en estos pacientes. (Carlin A, et al, 2008).

La resolución de la HTA inducida por la pérdida de peso reduce notablemente el riesgo de enfermedad arterial coronaria (EC). La CB disminuye el riesgo de EC a tasas inferiores a las estimadas por edad y sexo en la población general.

Las tasas de resolución de la HTA difieren en función del procedimiento. Después de la implantación de la banda gástrica ajustable la resolución de la HTA se situó entre el $48 \%$ y el $95 \%$, después de gastrectomia en manga, entre el $78 \%$ y $93,8 \%$, después del BPG, entre el 54\% y el 90,7\% y después del switch duodenal en pacientes superobesos, las tasas de resolución fueron más de 68\% (Kaul A, et al, 2011)

Reducciones significativas de la tensión arterial se puede ver dentro del primer mes después de la cirugía, con hasta el $25 \%$ de pacientes que presentan resolución 
completa y $36 \%$ mejorías importantes. (Magee CJ, et al, 2011)

En pacientes superobesos (IMC> $50 \mathrm{~kg} / \mathrm{m} 2$ ), al igual que los pacientes con DM, la DBP y el switch duodenal muestran una mejor resolución de la hipertensión a los 3 años en comparación con BPG (68\% vs 38,6\%). (Prachand V, et al, 2010)

Los pacientes normotensos no mostraron reducción significativa de la presión arterial sistólica después de la cirugía y sólo una mínima y gradual disminución en la presión diastólica. Los mejores resultados se observaron en los pacientes hipertensos sin tratamiento activo. Las tasas de resolución de la hipertensión dependen de la duración de la HTA preexistente, con mejores resultados en los que la hipertensión tenía menos de 4 años de diagnosticada (Hinojosa M, et al, 2009).

\subsubsection{Hiperlipidemia.}

La hiperlipidemia está presente en hasta un 50\% de los pacientes con obesidad mórbida y es uno de los principales factores de riesgo modificable en el desarrollo de la aterosclerosis y enfermedad coronaria.

Tras diez años de seguimiento en el estudio SOS se detectó que la reducción de TG fue de $18 \%$ después de la banda gástrica ajustable, un $15 \%$ y $28 \%$ después del BPG. La reducción del colesterol total fue del $5 \%$ después de la BGA, y el 12,6\% después del BPG. El aumento en el colesterol HDL fue del 20,4\% después de la BGA, y el $47,5 \%$ después del BPG. (Sjostrom L, et al, 2004)

La gastrectomía en manga produce una mejora notable en la hiperlipidemia, con mejoría o resolución en más del $70 \%$ de los pacientes. La BPG y la DBP, al provocar una mala absorción de grasas producen una marcada mejoría en el perfil lipídico.

Un estudio retrospectivo de pacientes intervenidos de BPG e hiperlipidemia mostró una optimización de los niveles séricos de colesterol total, triglicéridos y LDL en todos los pacientes dentro de los 6 meses posteriores a la cirugía. Los niveles de colesterol HDL mejoraron más lentamente, hasta alcanzar los niveles deseados en un plazo de 12 meses y alcanzaron el mejor nivel en 4 años. Ninguno de los pacientes que tomaban hipolipemiantes requirió tratamiento al final del estudio. (Jamal M, et al, 2010) 
Al comparar la gastrectomía en manga con BPG, algunos de los estudios mostraron resultados comparables (75\% y $78 \%$, respectivamente), mientras que en otros la tasa de mejoría o resolución fue significativamente mayor en el grupo del BPG (100\%) que en el grupo de la gastrectomía (75\%). (Lakdawala M, et al, 2010)

La DBP con switch duodenal mejora o resuelve completamente la hiperlipidemia en la mayoría de los casos. En los pacientes superobesos (IMC> $50 \mathrm{~kg} / \mathrm{m} 2$ ), el switch duodenal muestra una mejor resolución de la dislipidemia a 3 años en comparación con BPG (72\% frente a $26,3 \%)$. Incluso en pacientes no obesos o ligeramente obesos el switch duodenal sin resección gástrica, ha mostrado mejores resultados. (Cossu ML, et al, 2004)

\subsubsection{Trastornos cardiovasculares.}

\section{A. Insuficiencia Cardiaca Congestiva}

La combinación del aumento de la masa de células adiposas y el aumento de masa muscular en pacientes obesos da como resultado un volumen circulante mayor. La pérdida de peso por restricción calórica o por cirugía bariátrica promueve cambios hemodinámicos favorables.

La CB en pacientes con obesidad mórbida reduce el espesor de la pared del ventrículo izquierdo y en general la masa ventricular, promueve cambios en el miocardio, tanto estructurales como funcionales que mejoran el rendimiento cardíaco, con mejorías asociadas en el volumen telediastólico del ventrículo derecho lo que podría prevenir la progresión a disfunción ventricular derecha. Los beneficios de la CB en la regresión ventricular continúan aún cuando la pérdida de peso se ha detenido (Kaul $A$, et al, 2011) .

\section{B. Enfermedad Coronaria.}

La obesidad mórbida es un factor de riesgo independiente para el EC y después de una $C B$ estos riesgos disminuyen. La función microvascular coronaria se evaluó encontrando que los efectos vasculares de la $C B$ fueron independientes de la presencia y los cambios en otros factores conocidos de riesgo cardiovascular. 
Las Alteraciones de la repolarización ventricular están significativamente aumentados en los sujetos con obesidad mórbida. Estas anomalías en el intervalo QT mejoran sustancialmente después de DBP. Este cambio es independiente de la pérdida de peso y pueden estar relacionados con la modificación quirúrgica del eje enteroinsular. (Bezante GP, et al, 2007)

Donadelli reportó una reducción de riesgo cardiovascular global a 10 años a partir del primer año después de BPG, con una reducción del 1,1\% del riesgo absoluto y una reducción del 2,3\% del porcentaje de riesgo. (Donadelli SP, et al, 2011).

El estudio SOS, comparando un grupo control con un grupo quirúrgico, encontró que la CB parecía ser un tratamiento seguro y viable en la mejora de los factores de riesgo cardiovascular y puede ser utilizado como una estrategia para la prevención secundaria. (Delling L, et al, 2010)

\section{La aterosclerosis}

La CB tiene resultados positivos en los marcadores inflamatorios, estructurales y funcionales de aterosclerosis coronaria. Parece que al revertir algunos de los factores de riesgo para el desarrollo de la aterosclerosis, incluyendo la resistencia a la insulina, los niveles de lípidos, diabetes y HTA, la CB puede revertir o reducir la progresión de la placa aterosclerótica.

La evidencia disponible sugiere que la actuación en términos generales en las adipocinas neurotróficas derivadas del factor pigmentario del epitelio (PEDF) se asocian en mejoras en la adiposidad visceral, el síndrome metabólico, la diabetes y la aterosclerosis. La CB reduce los niveles de PEDF (Tschoner A, et al, 2011).

Asimismo, el aumento en los niveles séricos de óxido nítrico y la disminución de los niveles elevados de L-arginina así como la disminución de la proteína $\mathrm{C}$ reactiva, pueden contribuir a diversos efectos beneficiosos de la pérdida de peso después de $\mathrm{CB}$, especialmente en el contexto de la aterosclerosis (Kaul A, et al, 2011).

\subsubsection{Apnea obstructiva del sueño y asma.}

El síndrome de apnea obstructiva del sueño (SAOS) es un problema común entre los pacientes obesos, con una tasa de prevalencia de más del $70 \%$. 
La Enfermedad pulmonar obstructiva crónica (EPOC) y otras enfermedades pulmonares (Incluyendo SAOS) disminuyen significativamente después de la CB (de $57,7 \%$ a 16,2\%, 3 años después de la cirugía). Se han reportado efectos en variables clínicas y marcadores inflamatorios asociados con el SAOS causando una disminución significativa en el índice de apneas-hipopneas, las citoquinas y los niveles de leptina después de CB (Pallayova M, et al, 2011).

Las altas tasas de resolución de SAOS después de BS se ha demostrado en muchos estudios. El uso de dispositivos de presión positiva continua (CPAP) cesó en el 52,9\% de los pacientes con SAOS que se habían sometido a gastrectomía en manga en un año. Dos estudios retrospectivos observaron la resolución completa de la SAOS después de la $\mathrm{CB}$ en una población con obesidad mórbida entre 1 y 3 años después de la cirugía. (Sammour T, et al, 2010).

El aumento en el índice de masa corporal aumenta el riesgo y severidad del asma. En un cuestionario de seguimiento tras $\mathrm{CB}$ se encontró la disminución en el número de medicamentos necesarios para controlar los síntomas del asma. (Reddy RC, et al, 2011).

\subsubsection{Trastornos renales.}

La fisiopatología subyacente asociada con la obesidad y los trastornos renales incluye la resistencia a la insulina, la deficiencia de ta adiponectina, el hiperaldosteronismo, entre otros factores.

Las anormalidades de la estructura renal en individuos obesos y obesos mórbidos incluyen aumento de peso del riñón, glomerulomegalia, anomalías de los podocitos, expansión mesangial, y alteraciones del intersticio renal. Estas anomalías están acompañadas por anormalidades funcionales como hiperperfusión renal, el aumento del flujo plasmático renal, aumento de la tasa de filtración glomerular y albuminuria. Tanto la obesidad y el síndrome metabólico han sido identificados como potentes predictores de insuficiencia renal crónica.

La obesidad es un factor de riesgo independiente para el desarrollo de enfermedad renal crónica terminal con un $23 \%$ más de probabilidades en los pacientes con IMC alto (> $30 \mathrm{~kg} / \mathrm{m} 2)$. El mecanismo de los efectos de la obesidad sobre la función renal no se conoce bien. Un posible mecanismo puede ser que la obesidad conduce a un 
entorno proinflamatorio y una alteración de la hemodinámica renal, produciendo glomeruloesclerosis e hiperfiltración La obesidad parece aumentar el efecto de la hipertensión en la albuminuria. Esta disfunción renal en general mejora después de la CB (Kaul A, et al, 2011).

Saliba y colabs., encontraron que el aclaramiento de creatinina disminuyó en un 15\% en los diabéticos y el $21 \%$ en los no diabéticos 12 meses después del BPG. La función tubular se mantuvo sin cambios en los sujetos no diabéticos, pero un empeoramiento se produjo en los sujetos diabéticos. Estos resultados ponen de relieve la importancia del tratamiento de la obesidad antes de la aparición de diabetes establecida y sus complicaciones. (Saliba J, et al, 2010)

En los pacientes con enfermedad renal se observó una resolución, mejoría o estabilización de la enfermedad renal en el $20 \%$ de los pacientes 1 año después de la BPG, con resolución completa en un paciente seguido durante 9 años. Varios reportes de caso que describen pacientes con los criterios establecidos de disfunción renal también han mostrado una mejoría o estabilización en la proteinuria y creatinina sérica tras varios meses de seguimiento después del BPG. (Kaul A, et al, 2011)

LA CB puede conducir a una insuficiencia renal aguda postoperatoria (IRA) en hasta el $8,5 \%$ de los casos. Los factores de riesgo que predisponen a la lesión renal aguda incluyen un mayor IMC, la hiperlipidemia, y el uso preoperatorio de la Inhibidores de la enzima conversora de la angiotensina (IECA) y antagonistas del receptor de la angiotensina 2 (ARA2) Sin embargo, en pacientes con obesidad mórbida sometidos a diálisis la CB puede mejorar sus comorbilidades y prepararlos para recibir un trasplante. (Mondanlou K, et al, 2009)

Por lo tanto, la $\mathrm{CB}$ ha surgido recientemente como una intervención útil para la enfermedad renal asociada a la obesidad, tanto para la prevención del daño renal futuro como para la mejoría de la lesión renal establecida.

\subsubsection{Trastornos digestivos.}

Los pacientes obesos tienen hasta 2,4 veces mas síntomas gastro-intestinales que los individuos con un peso adecuado. También presentan mayor exposición ácida en el esófago distal y un mayor número de episodios de reflujo gastro-esofágico, mejorando de forma importante tras la CB. 
Es de esperar que los distintos procedimientos de CB tengan diferentes efectos sobre la enfermedad por reflujo gastroesofágico. Un reciente meta-análisis mostró una disminución en la sintomatología del reflujo (del 32,9\% al 7,7\%), disminución de la medicación antirreflujo (del $27,5 \%$ al 9,5\%), así como disminución en la prevalencia de la esofagitis erosiva (del $33,3 \%$ al $27 \%$ ) después de la Banda gástrica ajustable. Sin embargo, se informó de nuevos síntomas de reflujo en 15\% y esofagitis de novo en el $22,9 \%$ de los pacientes (De Jong JR, et al, 2010).

La gastrectomía vertical parece aumentar el reflujo en comparación con la banda gástrica y el BPG. La forma del estómago remanente tiene importancia en este aspecto porque la preservación del antro puede disminuir el reflujo en contraste con un patrón tubular o un reservorio superior. EI BPG mejora significativamente la pirosis, la regurgitación ácida, eructos, flatulencia y dolor abdominal. El BPG ha demostrado excelentes resultados en el RGE de difícil manejo en pacientes con obesidad mórbida y se ha utilizado para salvar los síntomas del reflujo después de la cirugía restrictiva (Foster A, et al, 2003).

La obesidad es un factor de riesgo significativo para el desarrollo de la esteatosis hepatica, esteatohepatitis no alcohólica y enfermedad del hígado graso no alcohólico. La esteatosis hepática se ve agravada por la hiperlipidemia. La cirugía bariátrica mejora la esteatosis, la actividad necroinflamatoria y la fibrosis hepática en pacientes con obesidad mórbida y esteatohepatitis no alcohólica. La enfermedad del hígado graso no alcohólico, relacionada con el aumento de la peroxidación lipídica del hígado y la expresión de las enzimas del citocromo P450 2E1, también mejora de forma significativa con la pérdida de peso inducida por la CB (Weiner RA, 2010).

\subsubsection{Trastornos musculo-esqueléticos.}

La obesidad se asocia con una serie de problemas de movilidad, dolores músculoesqueléticos, artrosis y gota los cuales afectan de manera significativa la calidad de vida. Por cada 5 kilogramos de aumento en el índice de masa corporal, se ha calculado un aumento del $36 \%$ en el riesgo de desarrollar dolor articular y osteoartritis.

Una revisión de todos los estudios de CB y dolor articular desde 1965 hasta 2009 reportó una subjetiva mejoría o resolución de artralgias u osteoartritis que van desde $32 \%$ al $100 \%$ tras 1 año de la intervención. Articulaciones importantes como el tobillo, 
la cadera y la rodilla mostraron una mejoría significativa. Por otra parte, la mejoría del dolor articular por lo general se produjo en los primeros 6 meses (Vincent HK, et al, 2010).

Los individuos con obesidad mórbida y enfermedades degenerativas de las articulaciones, que son considerados inadecuados para la artroplastia por el exceso de peso, podrían ser considerados para una $\mathrm{CB}$, antes del recambio articular. La artroplastia total de la articulación después del tratamiento quirúrgico de la obesidad tiene resultados excelentes con una tasa de complicaciones aceptable.

\subsubsection{Trastornos psicológicos, neurológicos y sexuales.}

Los factores psicológicos están íntimamente relacionados con la obesidad mórbida y la comida puede ser utilizada para suplir ciertas carencias psicológicas. La pérdida de peso mejora enormemente la depresión causada por la obesidad. Un estudio griego analizó a 59 mujeres obesas antes y después de procedimientos de cirugía bariátrica encontrando reducciones significativas en la depresión, así como mejoras significativas en el deseo sexual, excitación, lubricación, satisfacción y la función sexual total un año después de la cirugía (Assimakopoulos K, et al, 2011).

Las irregularidades menstruales son comunes en mujeres con obesidad mórbida y pueden conducir a la anemia. El síndrome de ovario poliquístico esta asociado a la obesidad con frecuencia (30\% - 70\%) la cual modifica la expresión clínica y analítica del síndrome, siendo la $\mathrm{CB}$ un tratamiento interesante en este aspecto. Se ha observado una disminución en el hirsutismo y la testosterona total y libre, androstenediona y el sulfato de dehidroepiandrosterona y una restauración de los ciclos menstruales regulares y la ovulación paralelas a la pérdida de peso después de CB. (Escobar-Morreale HF, et al, 2005). Los niveles de testosterona en hombres también mejoraron después de la cirugía.

\section{Hipertensión intracraneal}

La obesidad mórbida se asocia con hipertensión intracraneal, que responde bien a la CB. El 97\% por ciento de los pacientes intervenidos presentaron una resolución del edema de papila después de la cirugía, el 92\% resolución completa o casi completa de los déficits del campo visual, y el resto de los pacientes logró la estabilización de la pérdida progresiva de visión previa. Además, la migraña puede ser exacerbada por la 
obesidad y hay una marcada reducción de los síntomas y menor incidencia y severidad de los ataques migrañosos después de la CB. (Bond DS, et al, 2011)

\subsubsection{Cáncer.}

En los Estados Unidos, aproximadamente 85.000 nuevos casos de cáncer al año están relacionados con obesidad. Investigaciones recientes han encontrado que, cuando el índice de masa corporal aumenta en $5 \mathrm{~kg} / \mathrm{m} 2$, la mortalidad por cáncer aumenta en un $10 \%$. Los mecanismos subyacentes pueden ser factores dependientes o independientes del peso corporal. (Ashrafian $\mathrm{H}$, et al, 2011). Estos efectos incluyen la mejora de la resistencia a la insulina, una atenuación del síndrome metabólico, así como la disminución del estrés oxidativo, la inflamación y la modulación de los esteroides sexuales, las hormonas intestinales, la energética celular, el sistema inmunológico y las adipocinas. Después de 13 años de seguimiento en el estudio SOS, la CB ha demostrado la disminución significativa de la incidencia de cáncer en mujeres. Un mecanismo propuesto para la reducción en esta incidencia es que la pérdida de peso inducida por la CB modifica la producción de citoquinas relacionadas con la función de las células asesinas naturales mejorando su actividad. (Sjostrom L, et al, 2009)

\subsection{EL FUTURO CERCANO}

El campo de la Cirugía Metabólica está en permanente evolución, y esta se ha visto acelerada por el desarrollo en nuevas técnicas quirúrgicas que mejoran de forma contundente la seguridad y tolerabilidad de los procedimientos y por la investigación y el conocimiento de las bases moleculares que rigen la obesidad y las comorbilidades asociadas a la misma. La evolución de la cirugía bariátrica ha sido claramente impulsada por muchas influencias diferentes. Entre ellas se encuentran una mejor comprensión de la biología del tracto gastrointestinal, las mejoras en la técnica y las nuevas tecnologías quirúrgicas.

Otro aspecto a tener en cuenta es el impacto financiero de los procedimientos bariátricos en los pacientes y el sistema de salud, incluyendo las aseguradoras privadas. Medicare es un programa de cobertura socio-sanitaria administrado por el gobierno de los Estados Unidos, el cual provee atención funcionando como un Seguro Médico a determinados grupos de personas, como por ejemplo, los mayores de 65 
años. El programa también financia los programas de formación de médicos residentes en los Estados Unidos. En 2004 Medicare reconoció oficialmente la obesidad como una enfermedad por derecho propio y la cobertura de los procedimientos bariátricos se convirtió en algo más fácil de obtener. En nuestro medio el sistema de salud reconoce la cobertura de algunos procedimientos de Cirugía Bariátrica, pero su universalidad está comprometida por limitaciones económicas que repercuten en amplias listas de espera y la exclusión de ciertos procedimientos potencialmente útiles en determinados pacientes.

En los últimos años Medicare ha autorizado a la Sociedad Americana de Cirugía Metabólica y Bariátrica y a los Centros de Excelencia del Colegio Americano de Cirujanos, la realización de ciertos procedimientos en determinados pacientes. En los últimos años también más compañías de seguros privados empiezan a tener cobertura de cirugía bariátrica.

Los estudios han demostrado un ahorro de costes o por lo menos la rentabilidad de la cirugía bariátrica. Estudios recientes en los Estados Unidos han demostrado que la cirugía bariátrica es coste-efectiva en determinadas poblaciones y el coste de la cirugía se recupera en unos 25 meses, (Ikramuddin S, et al, 2009) debido al ahorro en costes derivados del tratamiento de las comorbilidades. A pesar de esto los costes directos de la intervención continúan siendo altos y difíciles de sostener por las aseguradoras y el sistema de salud.

Sin embargo, si el desarrollo de los procedimientos continua es probable que los costes disminuyan. Los estudios que comparan los procedimientos abiertos con los laparoscópicos reportan tasas de complicaciones similares, pero significativamente menor estancia hospitalaria en la laparoscopia y una disminución en los costes derivados de los cuidados postoperatorios, complicaciones respiratorias y de pared abdominal derivadas de la cirugía abierta.

Las técnicas quirúrgicas están en permanente evolución. Así mismo cada vez se hacen mas reproducibles y seguras con la utilización de sistemas quirúrgicos de reciente desarrollo y la especialización y formación específica de los equipos quirúrgicos (Lee SM, et al, 2011). 


\subsubsection{Algunas Intervenciones quirúrgicas en evolución.}

\section{A. La interposición lleal y la Adaptación Digestiva.}

Descrita por primera vez por Mason en 1999, la interposición ileal se dirige regular la actividad neurohormonal provocando la inducción de pérdida de peso mediante la reubicación de una parte del íleon en el yeyuno proximal. Una porción de 170 a 200 $\mathrm{cm}$ del íleon terminal se extirpa dejando $30 \mathrm{~cm}$ de íleon distal, y se implanta a $50 \mathrm{~cm}$ del ligamento de Treitz por dos anastomosis yeyuno-ileales. La continuidad del intestino se restaura con una anastomosis yeyuno-ileal distal (Mason EE, 1999).

En la adaptación digestiva, descrita por primera vez por Santoro y su grupo en 2006, en lugar de la reubicación del íleon en un yeyuno intacto, se mueve el íleon proximalmente resecando la mayor parte del yeyuno. El intestino se reseca desde 50 a $100 \mathrm{~cm}$ del ligamento de Treitz hasta $250 \mathrm{~cm}$ de la válvula íleo-cecal y los extremos libres se anastomosan. Se cree que al mover un segmento de íleon más cerca del estómago se expone a más nutrientes después de una comida dando como resultado una realimentación hormonal más rápida y pronunciada, produciendo un rápido, y sin embargo duradero efecto de saciedad, basados en el concepto del freno ileal. Para aumentar este efecto, ambos procedimientos son a menudo completados por una manga gástrica para proporcionar un componente restrictivo a la operación. La manga gástrica está diseñada para limitar la cantidad de calorías que se pueden tomar con las comidas. (Santoro $\mathrm{E}$, et al, 2006). Se produce por un efecto mecánico y otro hormonal basado en la disminución de los niveles de ghrelina. La malabsorción observada en estos procedimientos es leve, debido a que casi todo el íleon es funcional y la longitud total del intestino permite la adecuada absorción de nutrientes. Los efectos hormonales descritos incluyen el aumento postprandial en los niveles séricos del péptido similar al glucagón 1 (GLP1) y el polipéptido YY.

Santoro y colabs. reportaron una pérdida del exceso de peso corporal del $80 \%$ después de 12 meses en un estudio, y en otro una reducción a un índice de masa corporal (IMC) medio de 20,1 kg/m2, con una resolución de la hipertensión en el $87,5 \%$, DM2 en el $92,3 \%$ y la dislipidemia en el $75,8 \%$ de los pacientes. (Santoro E, et al, 2006)

Resultados similares se han publicado para la interposición ileal. El grupo de De Paula 48 reportó una pérdida de exceso de peso promedio de $84,5 \%$, con resolución de la 
hipertensión en el 88,4\%, DM tipo 2 en el 84,2\% y la dislipemia en el 82,3\% con una media seguimiento de 38 meses. Cuando se aplica a una población de menor peso (IMC medio de $33,8 \mathrm{~kg} / \mathrm{m} 2$ ), se encontró un efecto metabólico aún más pronunciado con $100 \%$ de resolución de la hipertensión y de la DM2 (Kumar KV, et al, 2009). Estas intervenciones están ganando popularidad como procedimientos puramente metabólicos en este grupo de pacientes.

\section{B. La plicatura gástrica}

En los últimos años, la creciente popularidad de la gastrectomía en manga ha llevado a algunos cirujanos a desarrollar técnicas encaminadas a reducir la luz del estómago, sin gastrectomía. Estos procedimientos se denominan "plicatura gástrica". Múltiples formas de plicatura han sido publicadas, solas o en combinación con otros procedimientos bariátricos. Fue descrita inicialmente en 2007 por Talebpour y Amoli. El procedimiento consiste en plegar la curvatura mayor medialmente donde se sutura a la curvatura menor en dos capas. Esto cierra parcialmente el estómago creando de un gran pliegue intraluminal. (Talebpour M, et al, 2007)

En una población de pacientes con un IMC promedio preoperatorio de $47 \mathrm{~kg} / \mathrm{m} 2$, se observó una pérdida del exceso de peso de $61 \%$ después de 12 meses en 56 pacientes, 60\% a los 24 meses en 50 pacientes, y el 57\% a los 36 meses en 11 pacientes. (Talebpour M, et al, 2007). Similares resultados se encontraron en otro estudio que reportó un promedio de exceso de peso perdido de 53,4\% en una serie de seis pacientes con una media de índice de masa corporal a partir de 43,3 kg/m2 y 12 meses de seguimiento. (Brethauer $\mathrm{S}$, et al, 2011). En el mismo estudio, una técnica diferente llamada "la plicatura anterior" mostró una reducción de peso más modesta. Ramos publicó una serie de 15 pacientes con una media de IMC de $41 \mathrm{~kg} / \mathrm{m} 2$, con pérdidas del exceso de peso del $60 \%$ de media en 12 meses. En los nueve pacientes seguidos durante 18 meses, la pérdida de peso se mantuvo estable en 62\% (Ramos A, et al, 2010).

En todos los estudios, las tasas de complicaciones eran bajas, e incluían obstrucción gástrica, vómitos, fugas, perforación gástrica y esofagitis. Pocas complicaciones a largo plazo se han visto, pero el seguimiento sigue siendo limitado, dada la relativa novedad de este procedimiento.

Un enfoque combinado de la banda gástrica, con la plicatura esta siendo evaluado debido a que la banda puede proteger la plicatura gástrica de altas presiones, lo que 
podría reducir los fallos que se producen con el tiempo.

A pesar de la plicatura gástrica aún no se ha analizado en grandes estudios a largo plazo, los resultados actuales son prometedores (Lee SM, et al, 2011).

\subsubsection{Nuevas Indicaciones en Cirugía Bariátrica: La Cirugía Metabólica.}

Los hallazgos de los estudios recientes han hecho que los criterios ya clásicos de intervención estén siendo revisados. Actualmente, los pacientes con un IMC superior a $40 \mathrm{~kg} / \mathrm{m} 2$ eran candidatos a tratamiento quirúrgico, al igual que aquellos con un IMC entre 35 y $40 \mathrm{~kg} / \mathrm{m} 2$ con comorbilidades importantes que interfieren con su estilo de vida. Todos los pacientes deben haber recibido tratamiento y seguimiento para perder peso sin cirugía.

Recientemente, estas directrices han sido reevaluadas en varios frentes debido a nuevos datos que sugieren los beneficios de la cirugía bariátrica en pacientes que no cumplen estos criterios. Un estudio reciente (De Maria, et al, 2010) mostró que el BPG consiguió una pérdida de peso significativa y la resolución de la DM tipo II en el 76\% de los pacientes con un IMC entre 30 y $35 \mathrm{~kg} / \mathrm{m} 2$. Otro grupo comparó los resultados en los pacientes con un IMC 30 a $40 \mathrm{~kg} / \mathrm{m} 2$ intervenidos con la banda gástrica ajustable comparándolos con tratamientos médicos. (Dixon JB, et al, 2008). El grupo intervenido presenta una perdida en el exceso de peso del $62,5 \%$ frente al $4,3 \%$ en el grupo de terapia convencional, con una disminución significativamente mayor de la hemoglobina A1c, la insulina plasmática y los niveles de glucosa en el primer grupo.

Basados en esta evidencia, la Conferencia de Consenso de la Sociedad Americana de Cirugía Bariátrica y Metabólica en el año 2004 amplió indicaciones para la cirugía bariátrica para incluir a pacientes con un IMC de 30 a $34,9 \mathrm{~kg} / \mathrm{m} 2$ con una comorbilidad que pueda ser "curada o mejorada notablemente por una pérdida de peso sustancial y mantenida". (Buchwald $\mathrm{H}, 2005)$. En una declaración reciente en las Guías Alemanas de Cirugía de la Obesidad también se incluyen aquellos pacientes con IMC 30 a 35 kg/m2 con DM tipo 2 y se eliminan las anteriores limitaciones de edad Runkel $\mathrm{N}$, et al, 2011). Si la evolución de la cirugía bariátrica permite que los procedimientos sigan siendo cada vez más seguros, menos invasivos, y más eficaces, las indicaciones para estos procedimientos seguirá evolucionando en el futuro. 


\subsubsection{Nuevas técnicas quirúrgicas}

\section{Cirugía Mínimamente Invasiva de Puerto único .}

La cirugía laparoscópica con Puerto único (Single Incision Laparoscopic Surgery SILS) ha evolucionado rápidamente en los últimos 5 años. Inicialmente concebida como una forma de minimizar el trauma de la pared abdominal durante la cirugía laparoscópica y reducir con ello el dolor y mejorar la estética, se ha enfrentado a numerosas dificultades técnicas relacionadas principalmente con la yuxtaposición de los instrumentos en un solo punto en la pared abdominal. Esto causó considerables problemas con el acceso abdominal, el mantenimiento del neumoperitoneo y la triangulación de los instrumentos en el sitio de la operación para permitir la retracción adecuada; pero el desarrollo de instrumental específico ha permitido la realización de procedimientos cada vez mas complejos, acercando sus posibilidades a las de la laparoscopia convencional. (Lee SM, et al, 2011)

\section{Cirugía Endoscópica Trans-luminal por orificios naturales (Natural Orifices Trasluminal Endoscopic Surgery: NOTES)}

La gran mayoría de cirujanos consideran que el término NOTES sólo se aplica a los procedimientos realizados por vía transoral, transvaginal y transanal, excluyendo a las intervenciones por vía trasumbilical.

Aunque la aplicación de estos procedimientos se origina en 1979 con la introducción de la primera inserción endoscópica percutánea de un tubo de gastrostomía, la primera descripción detallada de la cirugía por orificios naturales fue presentada por Kalloo en 2004, quien describió su experiencia en la realización peritoneoscopia transgástrica en cerdos de $50 \mathrm{~kg}$ (Kaloo AN, et al, 2004).

La aplicación de NOTES a procedimientos bariátricos ha sido limitada principalmente por la falta de una plataforma operatoria fiable. Sin embargo, se ha publicado algún caso de procedimientos híbridos. Lacy y su grupo del Hospital Clínico de Barcelona informaron de la realización de una gastrectomía en manga minilaparoscópica en una mujer de 67 años de edad, con un índice de masa corporal de $37 \mathrm{~kg} / \mathrm{m} 2$, hipertensión y diabetes. Se utilizó un acceso transvaginal para la visualización con un gastroscopio flexible, un puerto transumbilical de $12 \mathrm{~mm}$ se utiliza para la disección con instrumentos y grapadoras endoscópicas, y dos puertos $2 \mathrm{~mm}$ se utilizan para la 
retracción. El tiempo operatorio fue de 150 minutos, no hubo complicaciones y el paciente evolucionó favorablemente después de la operación abandonando el hospital 3 días después de la cirugía. (Lacy AM, et al, 2009)

Si se continua en el progreso del NOTES y con el desarrollo de nuevos instrumentos y técnicas, probablemente juegue un papel cada vez más importante en el tratamiento de los pacientes bariátricos. Esto puede ser mediante procedimientos NOTES puros, pero lo más probable es que estos procedimientos proporcionen un conjunto de nuevas herramientas que pueden ser utilizadas como adyuvantes de las técnicas actuales, como la Cirugía por orificios naturales asistida por minilaparoscopia. (Minilaparoscopy Assisted Natural Orifices Surgery MANOS).

\section{Robótica}

Aprobado por la FDA en 2001, el robot quirúrgico Da Vinci (Intuitive Surgical) se ha convertido en el sistema robótico estándar para los cirujanos en una variedad de especialidades. Aunque algunos cirujanos han adoptado este robot para procedimientos específicos, el uso del robot por los cirujanos generales ha sido menos común que entre los cirujanos urológicos y ginecológicos. Sin embargo, la cirugía asistida robóticamente puede ofrecer algunas ventajas en la cirugía bariátrica.

La implantación de banda gástrica ajustable, la gastrectomía en manga, y el Switch duodenal han sido reportados. Los resultados en los tiempos de operación han sido mixtos, con algunos informes de mayores tiempos de operación con el robot. La prolongación del tiempo quirúrgico puede haber reflejado la curva de aprendizaje del equipo quirúrgico. Las tasas de pérdida de peso fueron similares para la banda gástrica ajustable implantada con asistencia robótica que con laparoscopia convencional, con tasas de complicaciones dispares según el estudio consultado. (Horgan S, et al, 2011)

\subsubsection{Endoscopia en procedimientos bariátricos}

\section{Balón Intragástrico}

El primer balón intragástrico ampliamente utilizado fue introducido en 1982. Conceptualmente simple, el balón Intragástrico se implementa mediante un endoscopio en el estómago, y a través de un catéter de insuflación, el globo se 
hinchaba hasta un volumen de $220 \mathrm{ml}$. y se dejaba libremente en el estómago. Este dispositivo demuestra en varios estudios que no proporcionan ninguna ventaja en la pérdida de peso en comparación con la modificación del estilo de vida y fue inferior a la cirugía bariátrica. También el índice de efectos secundarios importantes fue inaceptable y se retira del Mercado en 1988.

En 1999, un nuevo dispositivo se presenta como alternativa, el BioEnterics intragastric balloon (BIB) introducido por Allergan, hecho en silicona, de forma cilíndrica y rellenable con 400 a $700 \mathrm{ml}$ de solución salina.

La experiencia internacional con el BIB ha sido bien documentada. Por ejemplo Genco comunicó su experiencia en Italia la participación de 2515 pacientes con un IMC promedio de $44,4 \mathrm{~kg} / \mathrm{m} 2$. Después de 6 meses de tratamiento, la pérdida del exceso de peso media fue del $33,9 \%$, y la mejoría en las comorbilidades en los pacientes que las presentaban fue del $89 \%$ (1.242 pacientes). Las complicaciones más frecuentes fueron: esofagitis $(1,27 \%)$; obstrucción gástrica $(0,76 \%)$, rotura del balón $(0,36 \%)$, úlcera gástrica $(0,19 \%)$ y perforación gástrica $(0,19 \%)$. (Genco A, et al, 2005).

Nuevos dispositivos están en desarrollo, destinados a causar distensión gástrica, con píldoras ingeribles que se hinchan una vez están en el estómago. BaroNova está trabajando en el desarrollo de una píldora que se hincha una vez en el estómago y luego se degrada en una semana para ser eliminada. Gelesis está desarrollando una tecnología similar. Están probando una píldora que contiene cientos de partículas de hidrogel de componentes alimentarios; cuando se exponen al agua, estas partículas se hinchan y forman un material gelatinoso. Aunque ninguna de estas tecnologías se ha probado en ensayos a gran escala, su desarrollo puede ser prometedor para grupos seleccionados de pacientes (Lee SM, et al, 2011).

\section{Manga gástrica endoluminal}

El revestimiento gastrointestinal EndoBarrier es un tubo de $60 \mathrm{~cm}$ de largo de fluoropolímeros impermeables con un anclaje de nitinol que se coloca endoscópicamente en el bulbo duodenal. El EndoBarrier fue desarrollado para imitar el bypass duodenoyeyunal evitando el contacto entre el bolo alimenticio y la mucosa duodenal y su mezcla con las secreciones biliares y pancreáticas hasta el yeyuno medio. Las pruebas en animales fueron prometedoras para seguridad y la eficacia. El primer estudio prospectivo en humanos reportó una pérdida del exceso de peso de 
23,6\% después de la recuperación del dispositivo 12 semanas después de la colocación. (Rodriguez-Grunert L, et al, 2008)

Otro estudio reporta eventos adversos en 26 de 30 pacientes incluyendo náuseas, dolor abdominal, la formación de pseudopólipos e inflamación local, pero sin complicaciones graves. El estudio también analizó los efectos metabólicos del EndoBarrier. De los 30 pacientes estudiados, 8 eran diabéticos y la necesidad de medicamentos, glucosa sérica, y $\mathrm{Hb}$ A1c mejoraron en siete de los ocho. (Schouten R, et al, 2010).

El EndoBarrier ahora cuenta con aprobación y está siendo utilizado en el Reino Unido, Países Bajos, y Chile, y ensayos clínicos se están realizando en los Estados Unidos. Sin embargo, el uso del dispositivo está actualmente aprobado sólo para un tiempo limitado de uso (Schouten R, et al, 2010).

El manguito ValenTx de colocación endoscópica es un dispositivo similar, pero está anclado en el esófago y se extiende a través del estómago y el duodeno hasta el yeyuno proximal. Proporciona una derivación endoscópica, que podría afectar tanto a la restricción como a la absorción. Los ensayos iniciales con este dispositivo han demostrado una pérdida media del exceso de peso de 39,7\% en los 17 pacientes que completaron el ensayo, con una mejora de la $\mathrm{Hb} \mathrm{A} 1 \mathrm{C}$ en los cuatro pacientes que tenían niveles elevados antes del procedimiento (Sandler BJ, et al, 2011).

Estos dispositivos pueden llegar a ser un medio seguro, eficaz y mínimamente invasivo en el tratamiento de la obesidad, la diabetes, y patologías asociadas, pero el tiempo dirá si son efectivos y seguros a largo plazo.

\subsubsection{La electro-estimulación gástrica}

El primer marcapaso gástrico fue descrito por primera vez en 1995 pero los resultados de los estudios iniciales para pérdida de peso fueron inconsistentes. En la actualidad hay múltiples sistemas de estimulación gástrica que se pueden implantar por vía laparoscópica o endoscópica, con resultados dispares en efectividad.

No todos los pacientes responden a las señales generadas por el marcapasos. Actualmente se están estudiando los criterios para identificar los pacientes que responden, que pueden perder hasta un $40 \%$ del exceso de peso, y los que no 
responden, que incluso llegan a ganar peso. Según el análisis de diferentes parámetros como la edad, el IMC, y la percepción de los pacientes de su salud física y emocional evaluados, estos fueron los criterios que más influyeron en los resultados. (Martin Duce, et al, 2007)

Dada la relativa agresividad y la modesta eficacia de estas tecnologías, la utilidad de la neuromodulación sigue siendo polémica y probablemente requerirá un refinamiento significativo en su funcionamiento antes de su aplicación sistemática. 

OBJETIVOS. 

1. Valorar el efecto de la gastrectomía vertical en la tolerancia a la glucosa y en los niveles circulantes de insulina, glucagón, GLP-1, GIP y leptina en un modelo de rata diabéticas no obesa.

2. Valorar la relación de los péptidos intestinales y la leptina con la producción y secreción de insulina por el islote pancreático.

3. Valorar el efecto de la gastrectomía vertical sobre la expresión de insulina en los islotes de ratas diabéticas no obesas.

4. Valorar el efecto de la gastrectomía vertical sobre la producción y secreción de insulina en los islotes de ratas diabéticas no obesas. 

MATERIALES Y MÉTODOS. 





\section{A. DISEÑO DEL ESTUDIO}

\section{Tipo de estudio}

Ensayo experimental en animales.

\section{Población de estudio}

Se partió de un total de 30 ratas adultas diabéticas no obesas de tipo Goto-Kakizaki, que fueron intervenidas quirúrgicamente. Para el análisis fueron excluidas las ratas que no sobrevivieron a la cirugía (mortalidad del 33.3\%, 10 ratas).

\section{B. PROTOCOLO EXPERIMENTAL Y VARIABLES RECOGIDAS}

Tras un periodo de aclimatación de los animales en el Animalario de la Facultad de Medicina de Valladolid, se comienza con el protocolo.

A continuación se definen los tiempos marcados en el protocolo para realizar las distintas técnicas:

I. Semana 0 (o tiempo basal): Tras dos semanas de aclimatación de las ratas en el animalario, previo a la intervención quirúrgica.

II. Semana 1: A la semana del acto quirúrgico.

III. Semana 8: A las 8 semanas del acto quirúrgico.

En el tiempo basal (antes de la intervención quirúrgica) y después de la operación (a la semana y a las 8 semanas) se midió el peso y se realizó un test de tolerancia a glucosa en todos los tiempos del protocolo. Este test consiste en la medición de la glucemia en ayunas y después de dos horas de la sobrecarga oral de glucosa.

Además, a los 20 minutos de la sobrecarga de glucosa se extrajo sangre venosa para la determinación posterior de los niveles de hormonas (insulina, GLP-1, GIP, glucagón y leptina) en suero y también se midió la glucemia.

Finalmente, en la semana 8 después del acto quirúrgico se sacrificaron los animales respetando las normas éticas que rigen el empleo de animales de experimentación 
(RD 1201/2005). A continuación, se procedió al aislamiento de islotes y a los ensayos de experimentación animal correspondientes para el estudio de estos parámetros:

a) Producción de insulina en diferentes medios de incubación (un medio que simula las condiciones fisiológicas basales con glucosa $5 \mathrm{mM}$ y otro medio con 16,7 mM de glucosa o en condiciones de estímulo).

b) Cuantificación de la insulina contenida en el islote a partir del homogeneizado obtenido por sonicado.

Todas las determinaciones hormonales se realizaron en la misma sesión, al final del protocolo, mediante ELISA para reducir la variabilidad intra e interensayo.

c) Expresión genética de insulina cuantificada mediante reacción en cadena de polimerasa $(\mathrm{RCP})$ a tiempo real.

Además, se analizó la morfología de los islotes. Se fotografiaron los islotes más representativos en un microscopio de contraste de fases y se midieron sus diámetros y áreas mediante un software especial para microscopía (Axiovision® de Zeiss).

También se calcularon las siguientes variables metabólicas referidas a resistencia y a sensibilidad a insulina:

d) Indice de resistencia a insulina o índice HOMA (Homeostasis model assessment) que fue calculado según la fórmula siguiente:

HOMA $=($ insulina $\times$ glucosa $) / 405$

expresada la insulina en $\mathrm{uU} / \mathrm{mL}$ y la glucosa en $\mathrm{mg} / \mathrm{dL}$.

e) Índice QUICKI (Quantitative Insulin-sensitivity Check Index), o de sensibilidad a la insulina, que se calculó mediante la fórmula que figura a continuación:

$$
\text { QUICKI = 1/[loginsulina }+ \text { logglucosa }]
$$

donde la insulina es expresada en $\mu \mathrm{g} / \mathrm{L}$ y la glucosa en $\mathrm{mg} / \mathrm{dL}$. 
En la Tabla 9 figuran las mediciones realizadas, sus unidades y cuál fue el método de determinación utilizado:

\begin{tabular}{|c|c|c|c|}
\hline VARIABLES & Muestra & UNIDADES & Técnicas analíticas \\
\hline Peso & & $\mathrm{g}$ & Microbalanza (Salter ${ }^{(B)}$ ) \\
\hline Glucosa & sangre total & $\mathrm{mg} / \mathrm{dL}$ & $\begin{array}{l}\text { Glucómetro (One Touch }{ }^{\circledast} \text {, } \\
\text { LifeScan) }\end{array}$ \\
\hline Insulina & suero, sonicado, medio & $\mu g / L$ & ELISA (DRG Diagnostics ${ }^{(\oplus)}$ ) \\
\hline GLP-1 & suero & $\mathrm{ng} / \mathrm{mL}$ & EIA $\left(\right.$ Phoenix $\left.{ }^{(\Theta)}\right)$ \\
\hline GIP & suero & $\mathrm{ng} / \mathrm{mL}$ & EIA $\left(\right.$ Phoenix $\left.{ }^{(B)}\right)$ \\
\hline Leptina & suero & $\mathrm{pg} / \mathrm{mL}$ & ELISA (DRG Diagnostics $\left.{ }^{(}\right)$ \\
\hline Glucagón & suero & $\mathrm{pg} / \mathrm{mL}$ & EIA $\left(\right.$ YK Yanaihara $\left.{ }^{(}\right)$ \\
\hline Indice HOMA & & Adimensional & \\
\hline Índice QUICKI & & Adimensional & \\
\hline $\begin{array}{l}\text { Expresión del gen } \\
\text { de la insulina } \\
\text { Morfología islotes }\end{array}$ & ARNm & $\begin{array}{c}\text { Adimensional } \\
\mu \mathrm{m} \text { y } \mu \mathrm{m}^{2}\end{array}$ & $\begin{array}{l}\text { RCP a tiempo real } \\
\text { (iCycler, BioRad) } \\
\text { Microscopía Axiovert } \\
\text { 200/Axiovisión }\end{array}$ \\
\hline
\end{tabular}

Tabla 9. Mediciones realizadas

\section{INSTALACIONES.}

Para la realización de este protocolo ha sido necesaria la coordinación y uso de las instalaciones de:

- Unidad de Apoyo a la Investigación del Hospital Universitario Río Hortega de Valladolid.

- Centro de Investigación de Endocrinología y Nutrición Clínica (CIENC) de la Facultad de Medicina de Valladolid.

- Animalario de la Universidad de Valladolid.

- Departamento de Cirugía Experimental de la Facultad de Medicina (Universidad de Valladolid). 


\section{MATERIALES, TÉCNICAS Y EXPERIMENTOS REALIZADOS}

\section{ANIMALES UTILIZADOS}

Para los experimentos se utilizaron ratas diabéticas no obesas de tipo Goto-Kakizaki, procedentes de Taconic M\&B® (Copenhague, Dinamarca) de 16 a 18 semanas de edad (Figura 7).

Este modelo espontáneo de ratas Goto-Kakizaki fue desarrollado por la Universidad de Tohoku en 1975 mediante cruces endogámicos de ratas Wistar (Rattus norvegicus). Éstas presentaban niveles de glucosa mayores durante el test oral de tolerancia a glucosa a lo largo de varias generaciones. En la actualidad es comercializado por Taconic Farm Inc. (Lille Skensved, Dinamarca).

Este modelo animal exhibe como consecuencia de varios mecanismos que incluyen el empeoramiento ontogenético del desarrollo de los islotes, desorden metabólico, trastornos hormonales y vasculares similares a los de la diabetes humana Las ratas desarrollan diabetes tipo 2 en aproximadamente 14-16 semanas de edad. Entre sus características incluyen hiperglucemia en ayunas, deficiencia en la secreción de insulina en respuesta tanto a la glucosa in vivo como en islotes pancreáticos aislados, resistencia a la insulina y poliuria. Las complicaciones tardías como la retinopatía, microangiopatía, neuropatía y nefropatía han sido descritas en la literatura. Su variedad genética: Aco1b, Alpa, Amy2a, Anpepa, Es1a, Es2a, Es3a, Es4a, Es4b, Es6a, Es7b, Es9a, Esda, Es14b, Es15a, Es18a, Fh1b, Hao1a, Hbba, Pepcb, Pgd1b, Svp1a. Color albino (a, Tyrc).

La evaluación de una técnica de una cirugía bariátrica como la gastrectomía vertical en un animal con diabetes mellitus sin obesidad permite evaluar la modificación postquirúrgica de la acción de los péptidos intestinales sobre los niveles de insulina circulante y de leptina, glucagon, GLP-1 y GIP, la glucemia y la funcionalidad de la célula beta. Con este modelo animal se puede obviar el efecto beneficioso de la pérdida de peso secundario a la cirugía bariátrica y analizar el impacto de los péptidos intestinales y adipocitarios en los islotes pancreáticos con este tipo de cirugía.

Antes de comenzar los experimentos in vivo se dejaron a los animales un periodo de adaptación de dos semanas desde que se recibieron en el animalario de la Facultad de Medicina. 
La temperatura del animalario fue de $20-22^{\circ} \mathrm{C}$ y los animales fueron sometidos a un ciclo de luz/oscuridad de 12 horas de luz y 12 horas de oscuridad, manteniéndose estabulados en jaulas de dos en dos y perfectamente etiquetados.

Todos fueron alimentados con dietas comerciales estándar para roedores (Global Diet 2014, HarlanTM Interfauna Ibérica S.A.) y agua ad libitum.

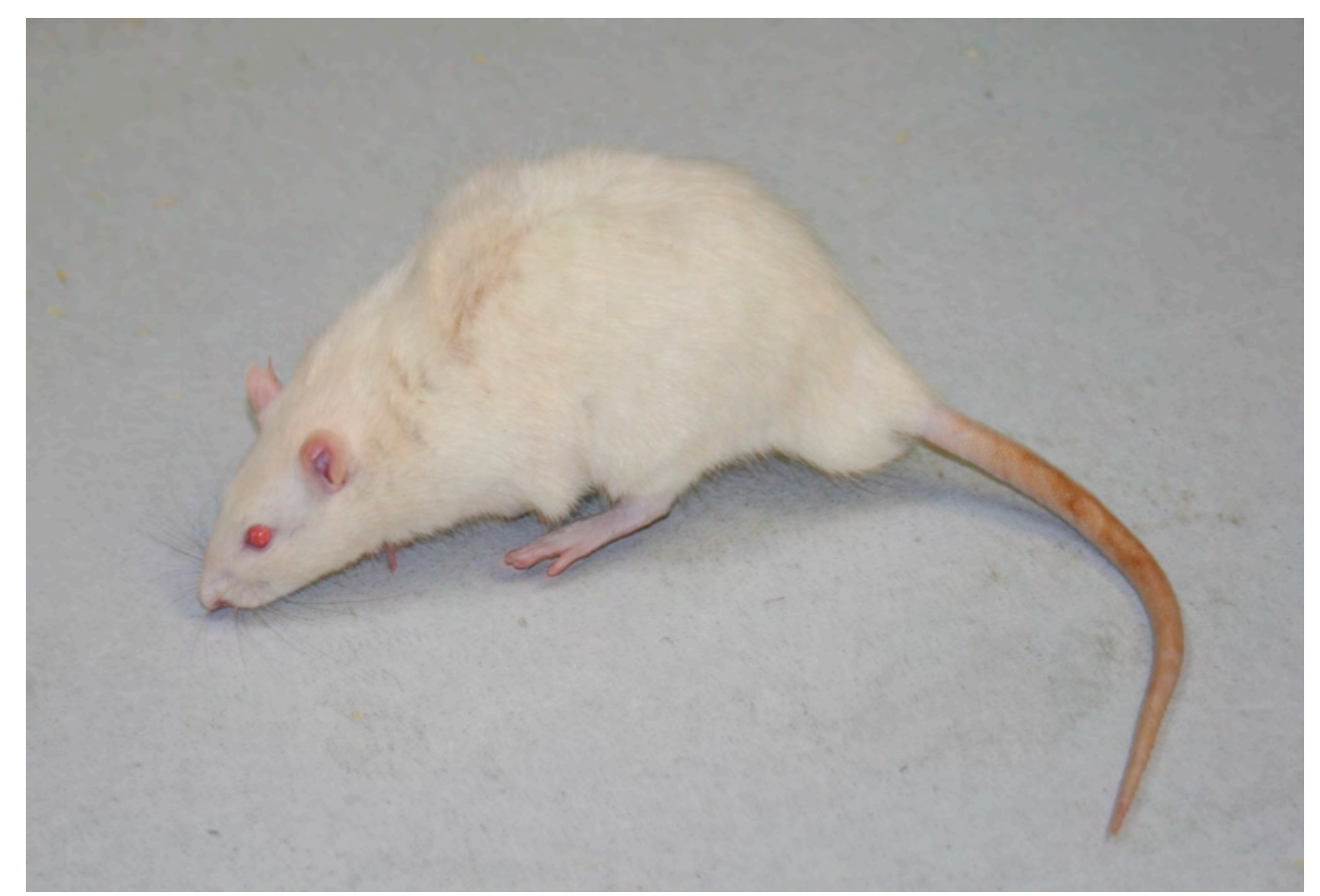

Figura 7. Rata Goto-Kakizaki

\section{E. EXPERIMENTOS IN VIVO.}

\section{Medidas antropométricas}

Se pesaron los animales en una balanza especializada (Salter ${ }^{\circledR}$ 323) siempre a la misma hora del día, para reducir así los errores debidos al ritmo circadiano de ingesta de comida (Figura 8).

Se realizaron las pesadas en todos los tiempos marcados en el protocolo, de este modo además de registrarse los pesos se calcularon las dosis adecuadas de glucosa para hacer los sobrecargas orales y de los fármacos utilizados en el protocolo. 


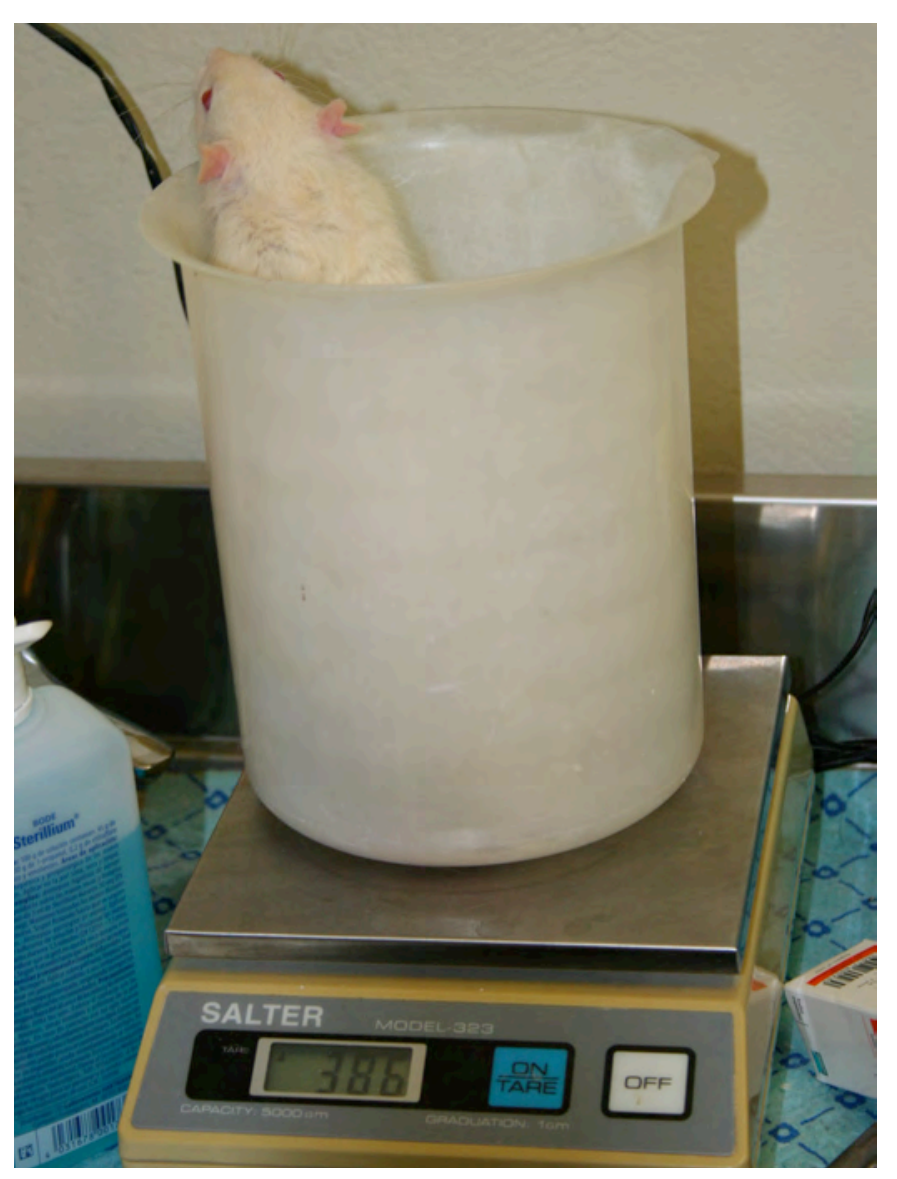

Figura 8: Pesaje del animal.

\section{Test de tolerancia a glucosa}

Para realizar el test de tolerancia a la glucosa se administró una sobrecarga oral de glucosa a la dosis correspondiente dependiendo del peso del animal (1 $\mathrm{g}$ de glucosa/kg peso).

Dicha sobrecarga se realizó tras intubación oro-faríngea del animal con una cánula metálica de $3 \mathrm{~mm}$. Esta canulación se realizó sin anestesia para no anular el efecto se succión. La cánula estaba conectada a una jeringa que contenía la glucosa disuelta $\left(\right.$ (GlycoSull $^{\circledR}$ )(Figura 9).

Se determinó la glucemia en ayunas antes de la sobrecarga de glucosa, a los 20 y a los 120 minutos tras la sobrecarga.

La glucemia se midió, tomando una gota de sangre extraida de la cola del animal (Figura 10), con el mismo glucómetro (One Touch, Ultra ${ }^{\mathrm{TM}}$, LifeScan, Johnson and Johnson company ${ }^{\circledR}$ ) para todas las muestras. La glucosa de la muestra de sangre se 
mezcla con la glucosa oxidasa y una serie de reactivos químicos especiales que contiene la tira reactiva y se produce una pequeña corriente eléctrica. Esta corriente se mide en el glucómetro, la fuerza de la corriente cambia con la cantidad de glucosa en la muestra de sangre y el resultado se muestra en la pantalla en $\mathrm{mg} / \mathrm{dL}$. El rango de detección de este glucómetro está entre 20 y $600 \mathrm{mg} / \mathrm{dl}$ y el C.V. es $\leq 3,2$.

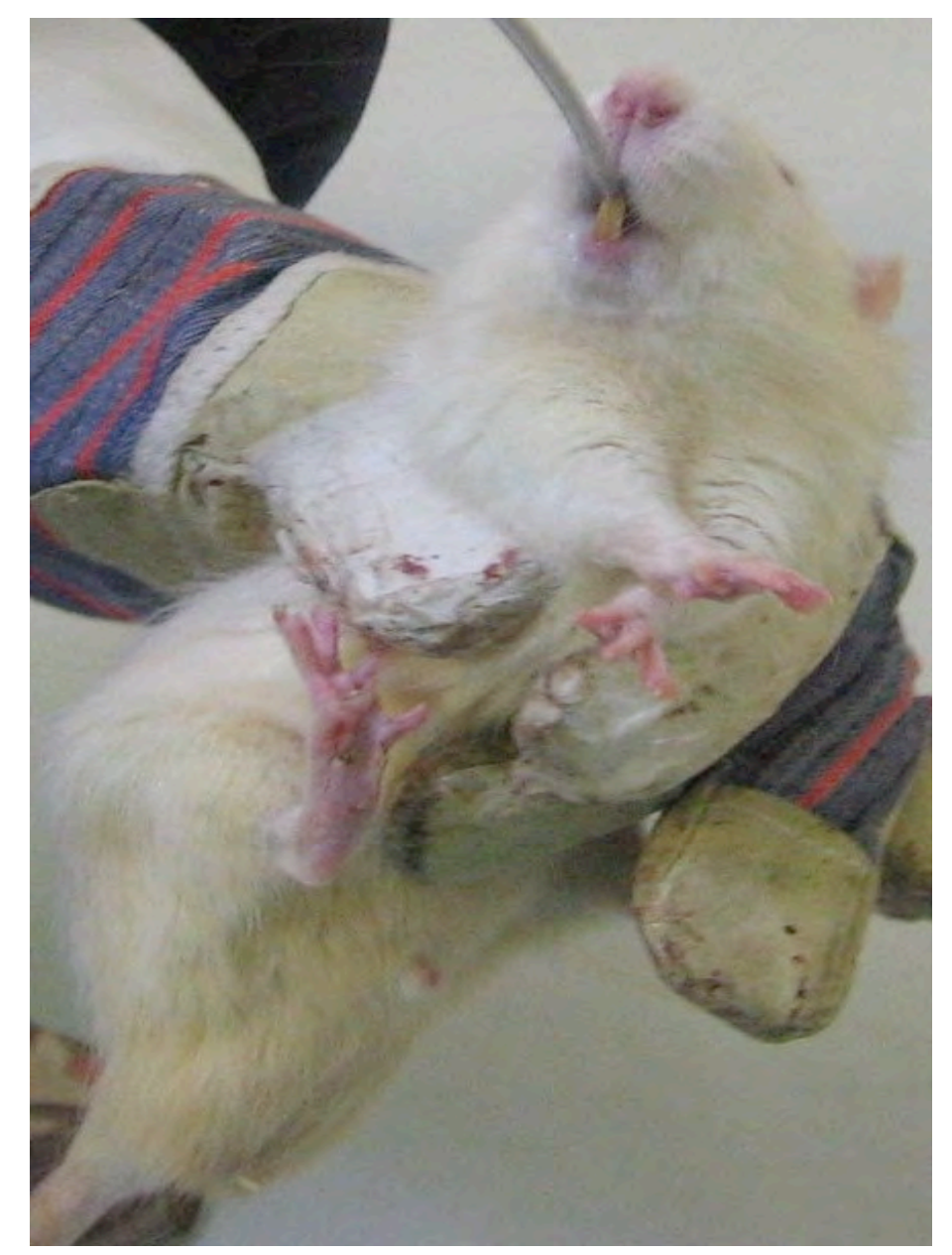

Figura 9: Canulación orofaringea para la sobrecarga oral de glucosa 


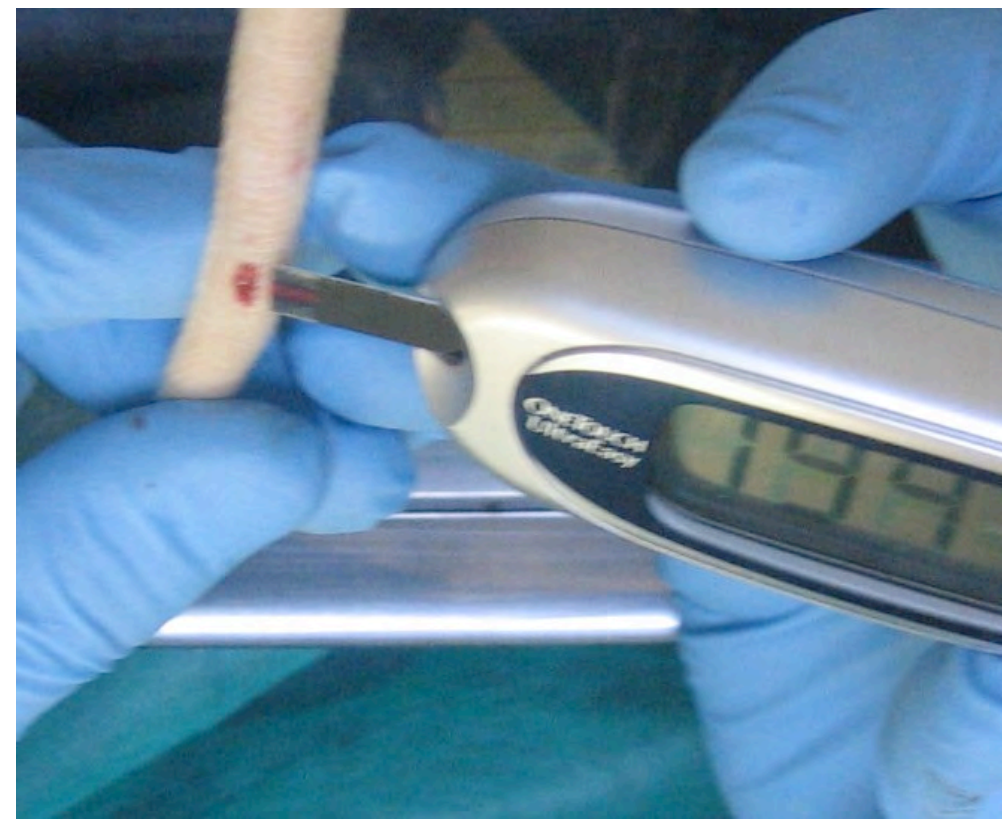

Figura 10: Determinación de la glucemia en sangre venosa de la cola

\section{Obtención y tratamiento de muestras para determinaciones hormonales}

Para las determinaciones hormonales en el suero, se obtuvo sangre de la vena yugular a los 20 minutos de la sobrecarga de glucosa. Esta extracción se llevó a cabo con el animal anestesiado con 100-150 mg/kg de ketamina (Merial Laboratorios S.A.).

Tras la inmovilización del animal de sus extremidades y extension cervical, la piel a nivel de la punción fue rasurada y desinfectada con clorhexidina al 0,5\%. Se realizó una incisión de $1,5 \mathrm{~cm}$ a nivel cervical, por encima de la primera costilla y a 0,5 cm de la linea media esternal y con una pequeña disección identificamos la vena yugular externa.

La extracción se realizó con un aguja de 23G y jeringa de 2,5 ml, hasta una cantidad máxima del $10-15 \%$ del volumen total de sangre $(1-1,5 \mathrm{ml})$ del animal.

Después de la extracción realizamos una leve presión de 10 segundos para control de la hemorragia y se cerró la incisión cutánea con sutura monofilamento irreabsorbible (polipropileno de 4/0).

Tras la extracción de sangre, las muestras se centrifugaron a 3000 rpm durante 10 minutos e inmediatamente se separaron los sueros y fueron alicuotados, etiquetados y almacenados $\mathrm{a}-80^{\circ} \mathrm{C}$ para su posterior análisis. 


\section{Técnica quirúrgica: Gastrectomía Vertical.}

Se realizó en todas las ratas intervenidas, una gastrectomía vertical (Sleeve gastrectomy) no calibrada, con sutura mecánica reforzada con sutura manual. (Figura 11), según técnica descrita por Patrikakos y su grupo, basados en los modelos previos descritos por de Bona Castelan y otros autores en trabajos previos. (Patrikakos, et al, 2009; de Bona Castelan, et al, 2007; Li F, et al, 2009).

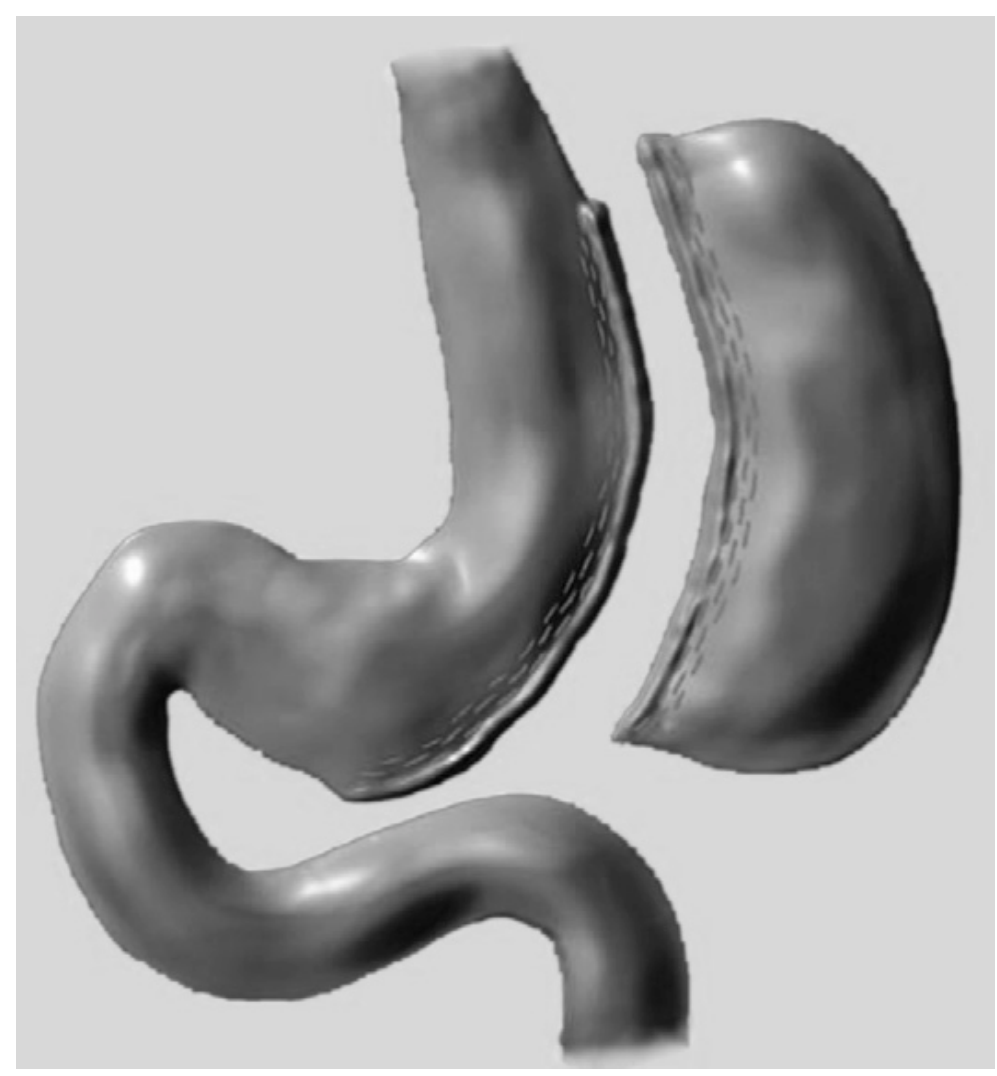

Figura 11: Representación esquemática de la gastrectomía vertical.

Después de ayuno durante la noche antes de la intervención, fueron anestesiadas mediante punción intraperitoneal con una mezcla de $150 \mathrm{mg} / \mathrm{kg}$ de ketamina, 0,3 mg/kg de atropina y $1 \mathrm{mg} / \mathrm{kg}$ de diazepam.

Se preparó el campo quirúrgico con una manta térmica para evitar la pérdida de calor, se usó material estéril, y se inmovilizó al animal. La cirugía se realizó con técnica quirúrgica estéril utilizando una lámpara de iluminación y con instrumental de microcirugía.

Previo a la incisión se le inyectaron $2 \mathrm{ml}$ de suero fisiológico a nivel subcutáneo, se rasuró el abdomen, y la zona se desinfectó con clorhexidina al 0,5\%. Para la profilaxis antibiótica preoperatoria, se utilizó Shotapen® L.A (100.000 UI Penicililina G procaina, 100.000 UI Penicilina G benzatina y $200 \mathrm{mg}$ de Dihidroestreptomicina por $\mathrm{mL}$ ). Éste es 
un antibiótico con función bactericida de larga acción, que nos permitió un buen control infeccioso. Se administró a una dosis de $0,1 \mathrm{ml} /$ rata vía intramuscular que se repitió a las 72 horas.

Se realizó una incisión de unos 2 - $3 \mathrm{~cm}$ a nivel abdominal (Figura 12), se identificó el estomago y se coaguló o ligó el ligamento gastroesplénico con sutura reabsorbible monofilamento (poli-p-dioxanona) de 5/0 (Figura 13). El control de la hemorragia durante la cirugía se realizó mediante digito presión y cauterización.

El epiplón mayor fue dividido y ligado con suturas de poli-p-dioxanona 5/0 según necesidad para liberar el antro distal y el píloro. Se marca el punto de corte distal gástrico a unos 2-3 mm del píloro teniendo cuidado de no estenosar la luz gástrica a ese nivel, dado que no se utilizó bujía de calibración ni sonda naso gástrica para la sección gástrica. Posteriormente se marcó con sutura simple el nivel de corte proximal en el fundus gástrico.

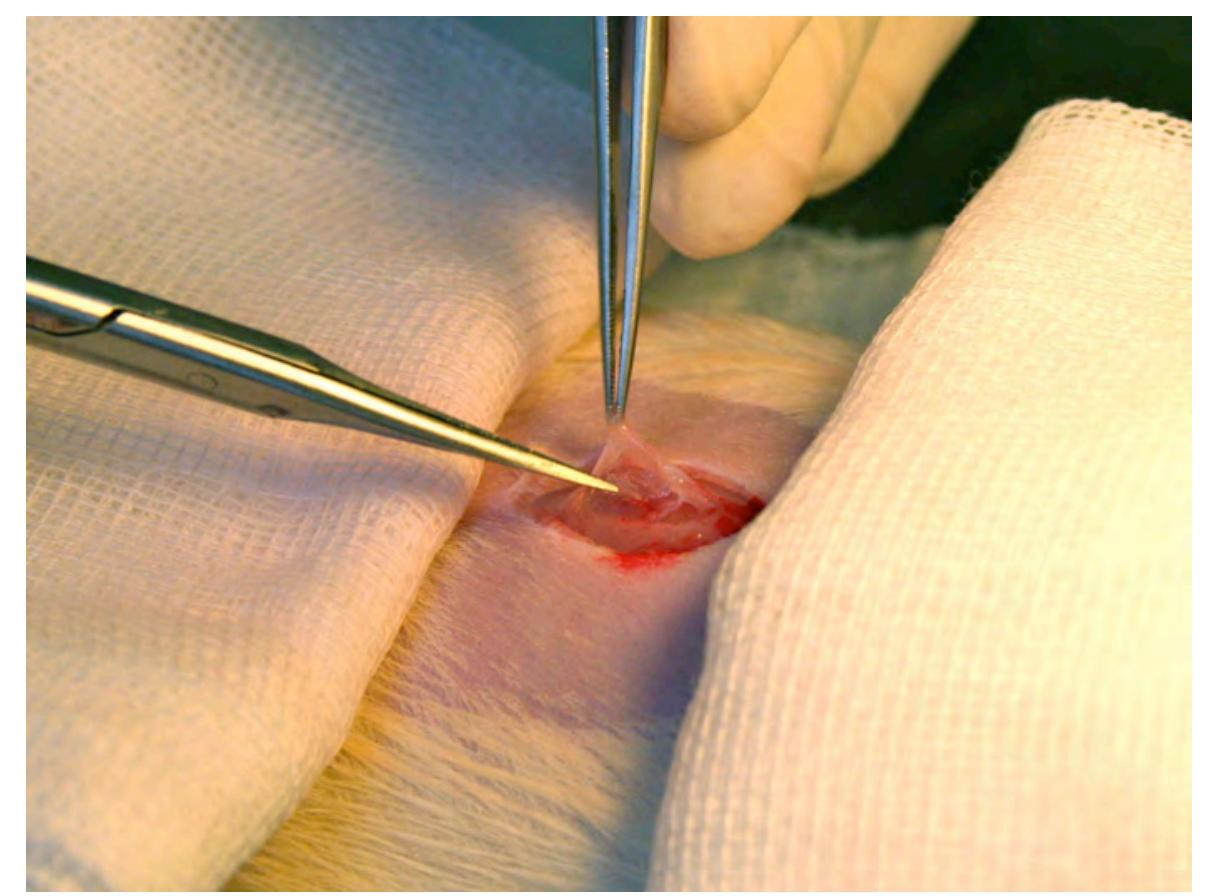

Figura 12: Incisión. 


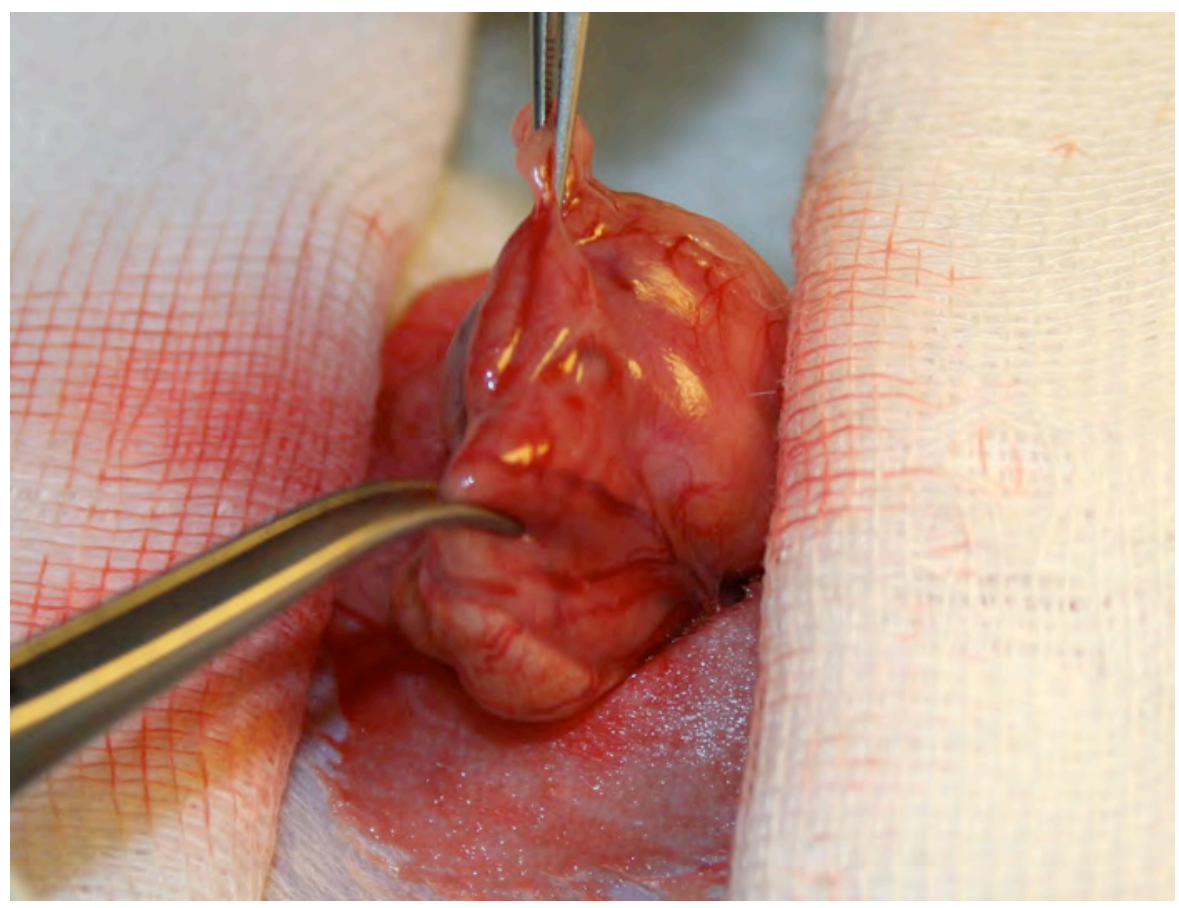

Figura 13: Identificación y disección del estómago.

Se utilizó una grapadora mecánica DST TA 45 con 2 líneas de grapas de 3.5mm (Tyco Healthcare Group LP, Norwalk, Connecticut, USA) (Figuras 14 y 15), que fue posicionada entre las dos suturas de marca previamente colocadas comprobando siempre el volumen de estómago remanente a nivel del cuerpo y antro gástrico (Figura 16). Se realizó la sección gástrica a lo largo de la curvatura mayor incluyendo el fundus (Figura 17). Posteriormente se comprobó la integridad de la sutura mecánica y se limpió cuidadosamente el borde libre de la sutura para evitar la contaminación peritoneal. La sutura mecánica fue reforzada con una sutura manual transfixiante continua de poli-ddioxanona 5/0 (Figuras 18 y 19), obteniendo con la misma la hemostasia del borde de sección gástrico. Con este tipo de gastrectomía se obtiene una reducción del volumen gástrico aproximada de $70-80 \%$, siendo mayor a nivel proximal (80\%) que distal (70\%). 


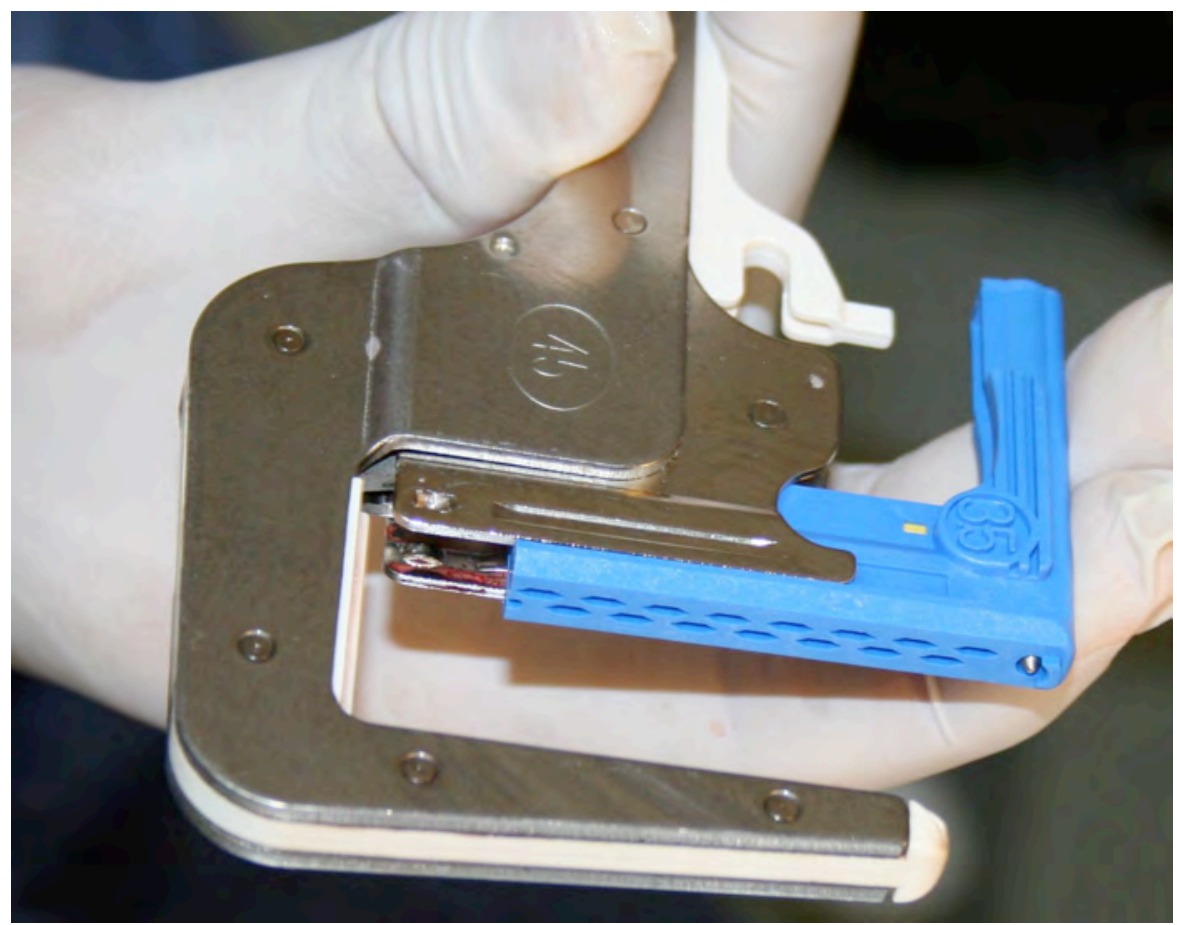

Figura 14: Grapadora mecánica

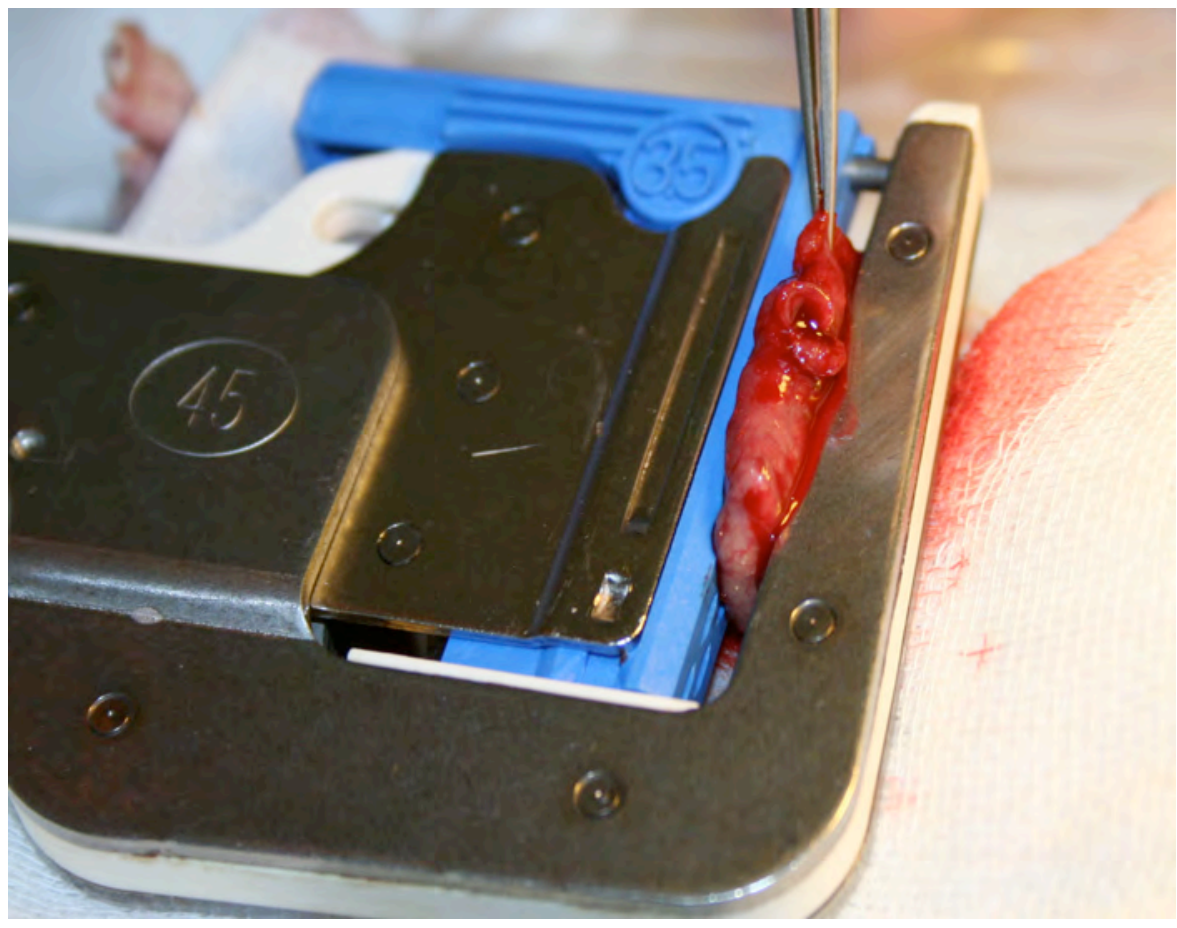

Figura 15: Grapado del estómago. 


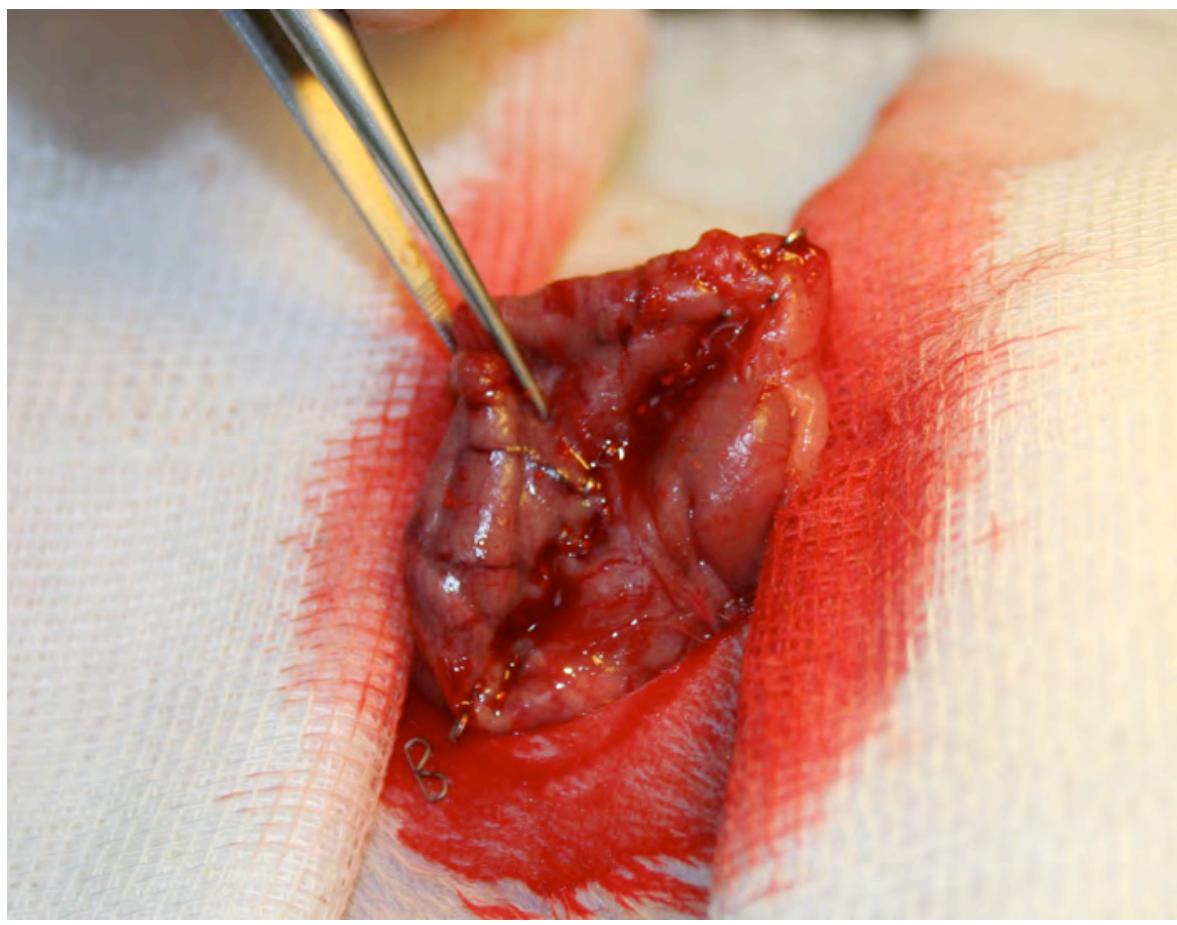

Figura 16: Posición de las grapas en el estómago.

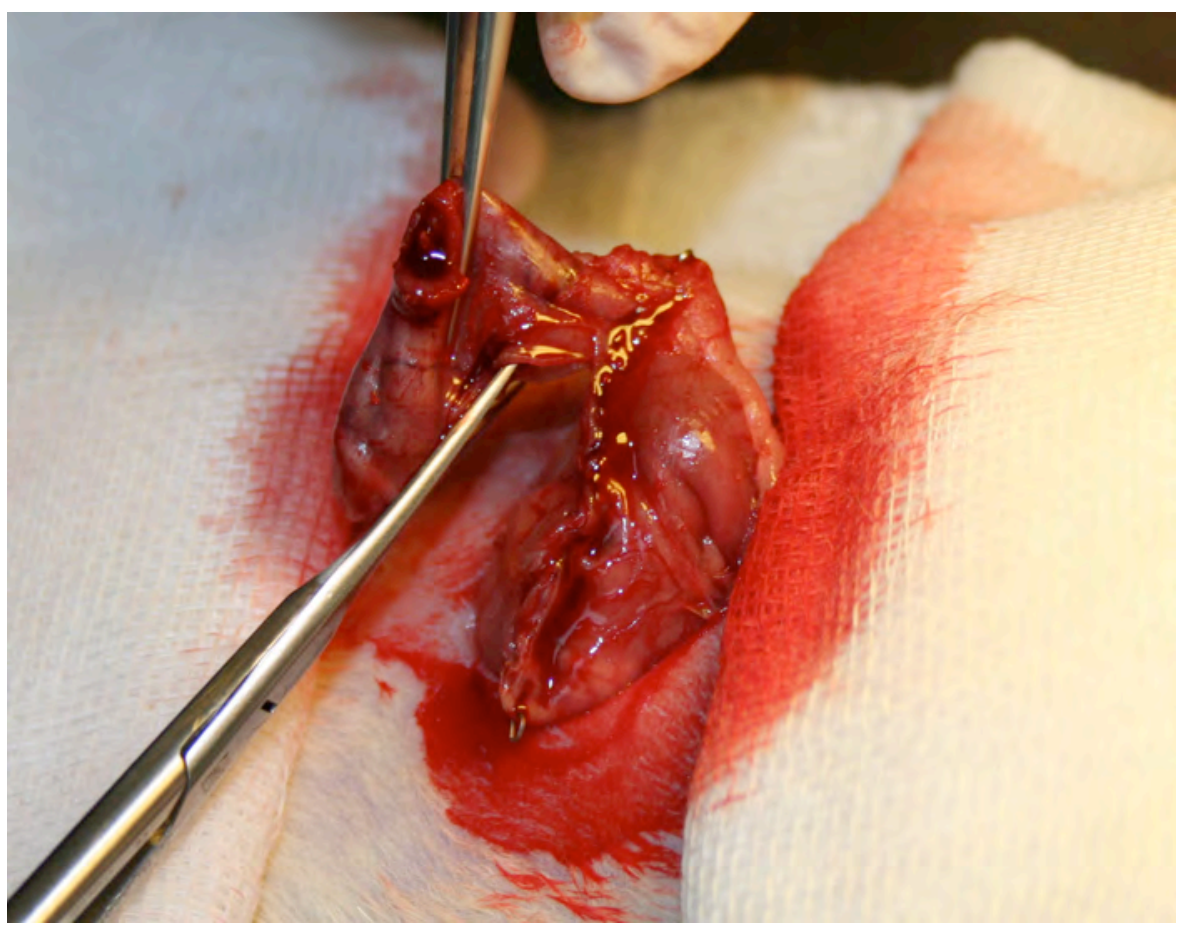

Figura 17: Sección gástrica. 


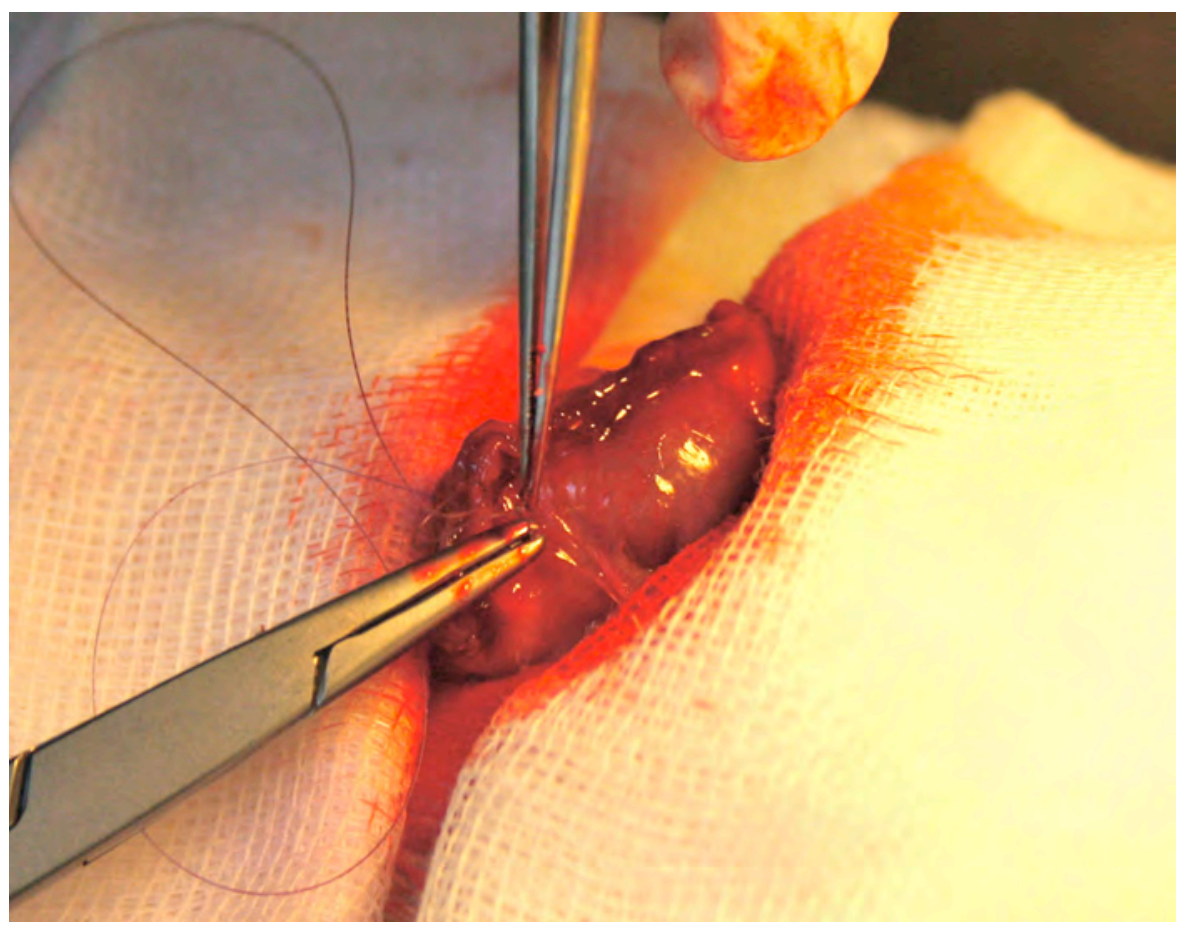

Figura 18: Refuerzo manual del grapado.

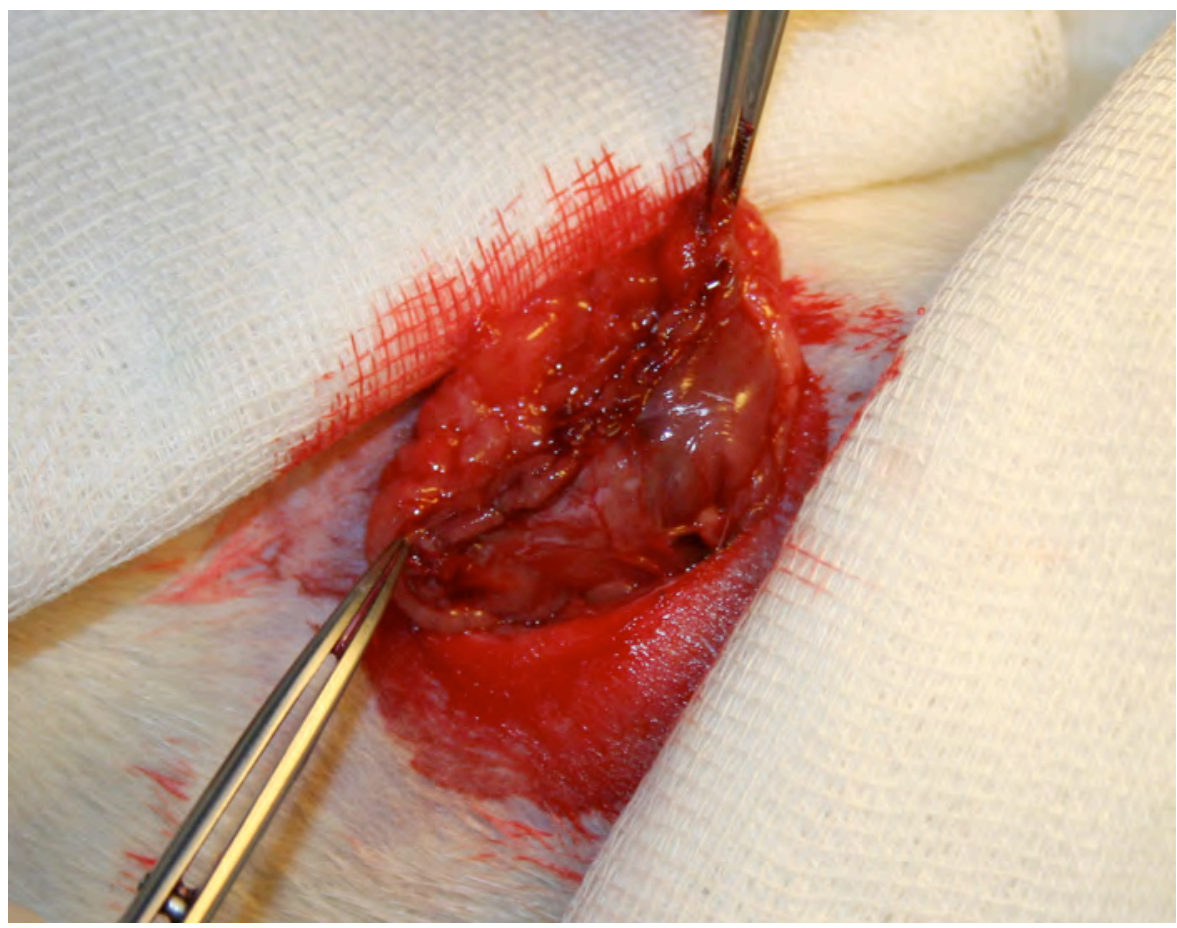

Figura 19: Vista final de la gastrectomía. 
Para finalizar, se comprueba la hemostasia y se infunden 3-4 cc de Suero Fisiológico templado intraperitoneal. La pared abdominal se cierra con una doble sutura continua de poli-p-dioxanona 4/0, y la piel se cierra con sutura de puntos sueltos de monofilamento irreabsorbible (polipropileno 3/0).

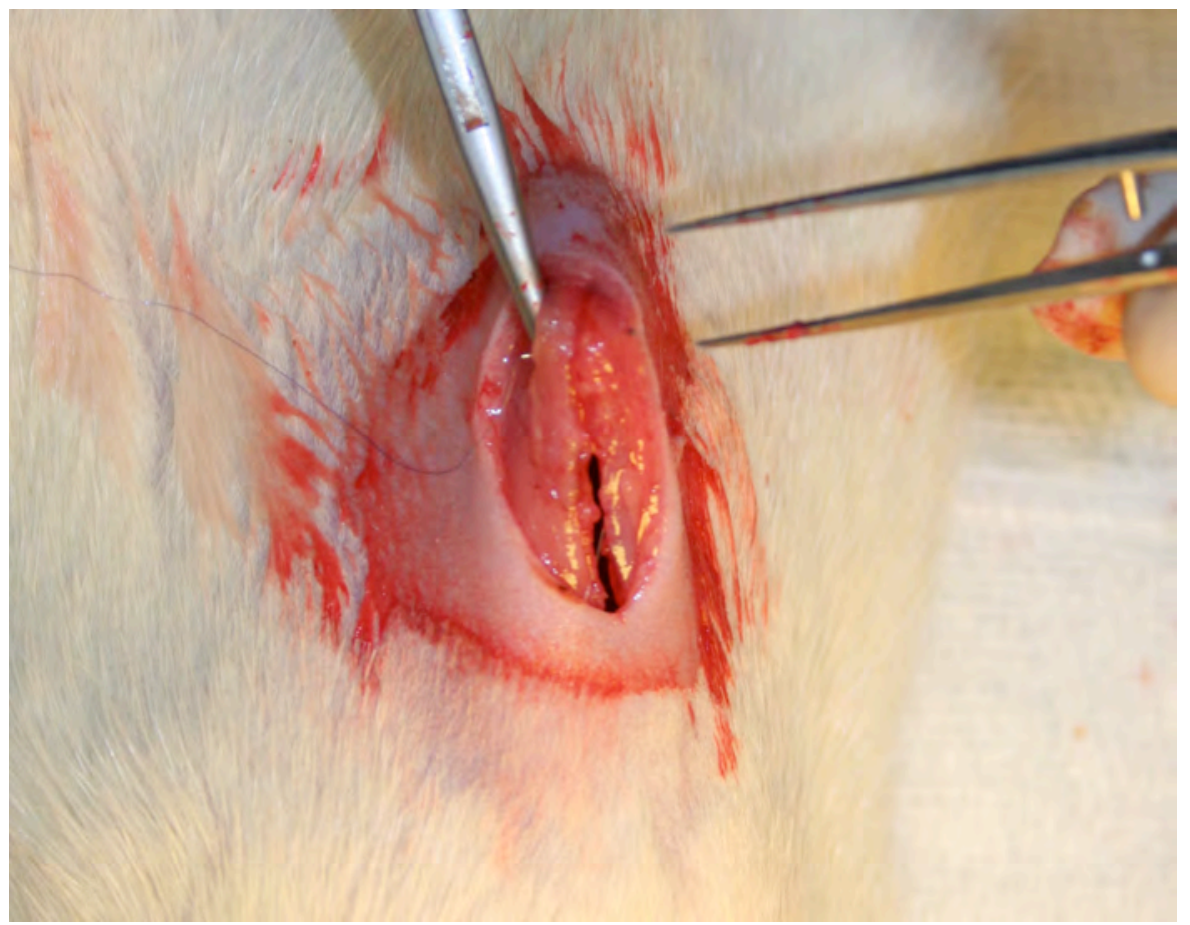

Figura 20: Cierre muscular.

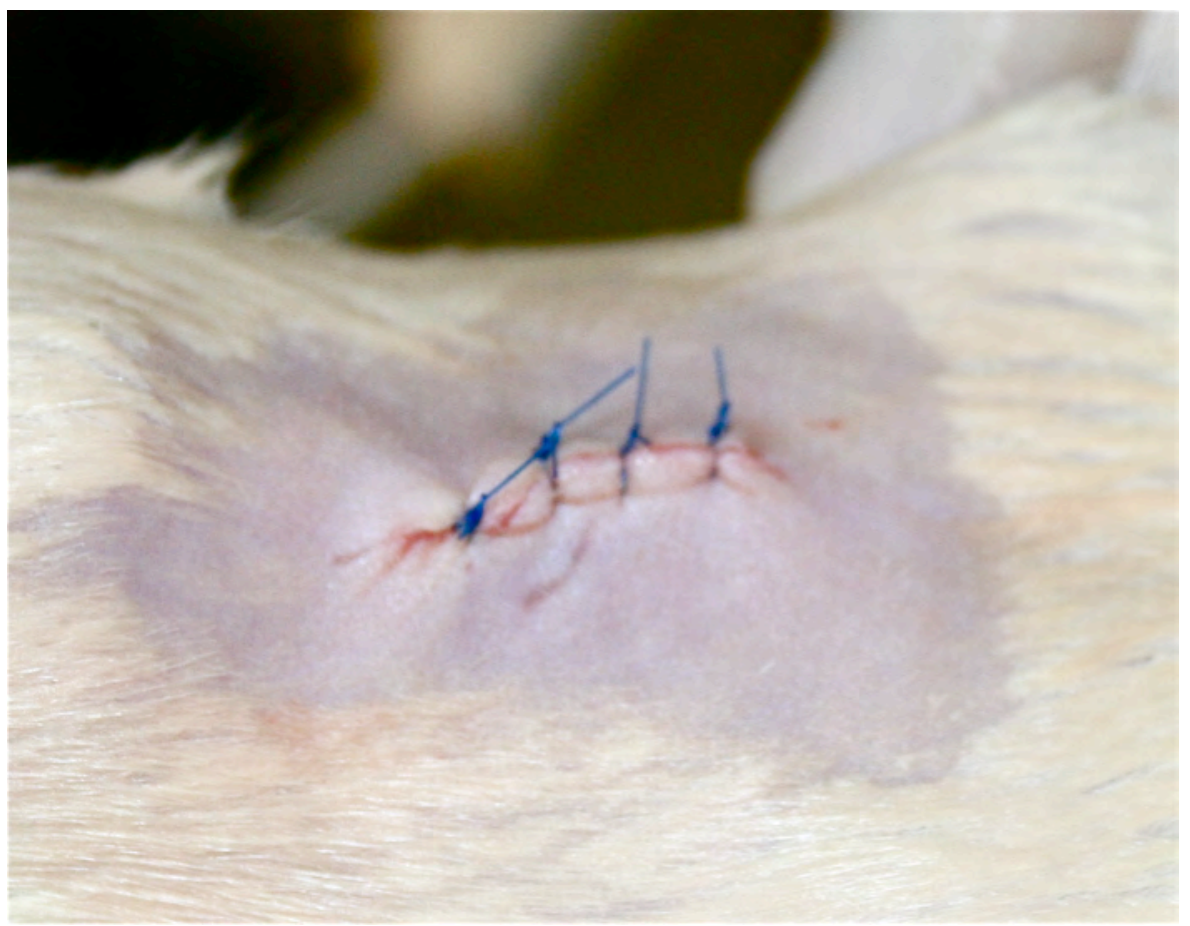

Figura 21: Cierre de piel. 
Una vez terminada la cirugía, la recuperación post-anestésica se realizaba en jaulas individuales con mantas térmicas y con papel de celulosa para evitar el trauma ocular producido por el serrín. Tras la cirugía se inyectaba suero fisiológico en la proporción de $15 \mathrm{~mL} / \mathrm{kg}$ cada 12 horas a nivel subcutáneo y durante los 3 días posteriores se les administró Flunixin a $5 \mathrm{mg} / \mathrm{kg} /$ día dividido en 2 dosis como analgesia. En el preoperatorio y a las 72 horas de la cirugía se les suministra $0,1 \mathrm{~mL}$ de antibiótico de amplio espectro (Shotapen L.A.®) por vía intramuscular (aproximadamente 0,3 mL/Kg). Se le suministró agua ad-libitum, y a las 24 horas gelatinas azucaradas, reintroduciendo a las 48-72 horas la alimentación con pienso estándar. 


\section{F. EXPERIMENTOS IN VITRO}

\section{Estudios en islotes pancreáticos aislados}

1. Preparación de disoluciones para el aislamiento e incubación de islotes pancreáticos

Los reactivos utilizados para prepararar las siguientes disoluciones se adquirieron de las casas comerciales Sigma-Aldrich $\AA$ : albúmina de suero bovino (o BSA), $\mathrm{Na} \mathrm{H}_{2} \mathrm{PO}_{4}$, HEPES, colagenasa y ditizona; y de Merck $\AA$ : $\mathrm{NaCl}, \mathrm{KCl}, \mathrm{NaHCO}_{3}, \mathrm{MgCl}_{2}$, y glucosa.

1.) Solución Krebs-Ringer-Bicarbonato (KRB) suplementada con BSA ( $5 \mathrm{mg} / \mathrm{mL})$ a un $\mathrm{pH}$ de 7,4 y $\mathbf{5} \mathbf{~ m M}$ de glucosa, que se utilizó para incubar el grupo de islotes en las condiciones basales del experimento.

La disolución KRB está formada por los siguientes reactivos: $\mathrm{NaCl} 115 \mathrm{mM}, \mathrm{KCl} 5 \mathrm{mM}$, $\mathrm{NaHCO}_{3} 10 \mathrm{mM}, \mathrm{MgCl}_{2}$ 1,1 mM, NaH $\mathrm{PO}_{4} 1,2 \mathrm{mM}$, HEPES $25 \mathrm{mM}$.

2.) Solución KRB con BSA de idéntica composición que la disolución anterior pero con glucosa $\mathbf{1 6 , 7} \mathrm{mM}$, que se utilizó para incubar el grupo de islotes de las condiciones de estímulo.

Ambas disoluciones se ajustaron a un $\mathrm{pH}$ de 7,4 con un pHmetro $\left(\right.$ Oakton $\left.^{\circledR}\right)$.

3.) Solución de colagenasa. Se pesaron $16 \mathrm{mg}$ de Colagenasa Tipo $\mathrm{V}$ y se disuelvió en $2 \mathrm{~mL}$ de solución KRB sin Albúmina con el fin de obtener una concentración de colagenasa de $8 \mathrm{mg} / \mathrm{mL}$.

4.) Solución de tinción. Se preparó una solución stock con 50 mg de ditizona (DTZ) en $5 \mathrm{~mL}$ de dimetil sulfóxido, se alicuotó y almacenó a $-20^{\circ} \mathrm{C}$. El día del experimento de islotes y tras descongelación de una alícuota la DTZ fue añadida a una concentración de $100 \mu \mathrm{g} / \mathrm{mL}$ a la solución KRB-BSA (solución de aislamiento). La ditizona se utiliza para teñir selectivamente las células beta ya que ésta se une al $\mathrm{Zn}^{2+}$ de la insulina.

En la preparación de las disoluciones se utilizó agua estéril, una balanza de precisión (Sartorius), un agitador (Raypa) y material de vidrio (Pyrex). 


\section{Preparación del páncreas y microdisección del tejido pancreático}

Los islotes pancreáticos fueron aislados mediante digestión con Colagenasa tipo $\mathrm{V}$ mediante un método basado en el de Lacy \& Kostianovsky (Lacy, 1967) y se separaron del tejido exocrino manualmente bajo un estereomicroscopio (Zeiss 200 ${ }^{\circledR}$ ) con la ayuda de agujas finas.

\subsection{Extracción del páncreas}

A las 8 semanas del acto quirúrgico se sacrificaron los animales en la cámara de $\mathrm{CO}_{2}$. Se colocaron sobre el costado derecho y se rociaron con etanol al $70 \%$ para evitar contaminaciones. Se utilizó material quirúrgico estéril $\left(\right.$ Martin $\left.^{\circledR}\right)$ para abrir el abdomen haciendo una incisión en el costado izquierdo.

Sujetando el bazo con las pinzas se extrajo la mayor parte del páncreas. Una vez extraído, se depositó en una placa petri estéril de 10 centímetros de diámetro (Nunc $\left.{ }^{\circledR}\right)$ con solución KRB sin albúmina.

A continuación, se localizó la desembocadura del colédoco (zona rica en islotes pancreáticos) accediendo desde la parte inferior del estómago y se extrajo el resto del páncreas, depositando esta parte también en la placa de $10 \mathrm{~cm}$ para retirar el tejido adiposo visible y limpiar el tejido pancreático (Figura 22).

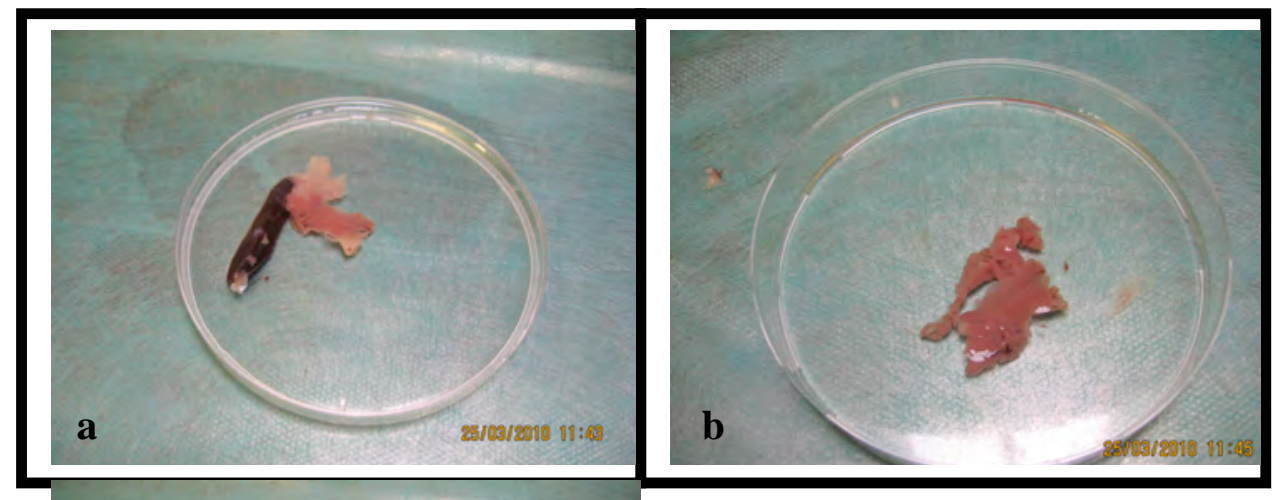

Figura 22. a) Tejido pancreático y tejidos adyacentes. b) Páncreas limpio

\subsection{Digestión del tejido}

Una vez limpio, el páncreas se pasó a una placa petri pequeña, de $2 \mathrm{~cm}$ de diámetro, inyectándose en el tejido $2 \mathrm{~mL}$ de una solución enzimática filtrada de colagenasa comercial aislada a partir de Clostridium histolyticum, que se había disuelto minutos antes en disolución KRB sin albúmina (Figura 23). 


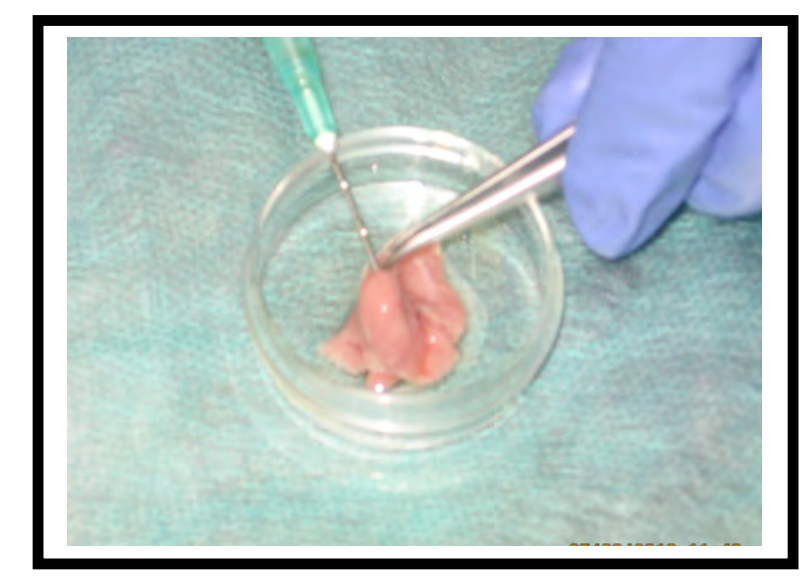

Figura 23. Inyectando colágenasa en el páncreas una vez extraído y limpio.

A continuación, se pasó a un pequeño vaso de precipitados, se disgregó con las tijeras y finalmente se hizo pasar a través de una pipeta Pasteur de plástico para que la disgregación del tejido fuera más homogénea.

El tejido pancreático disgregado se pasó a un tubo de $15 \mathrm{~mL}$ (Falcon®), añadiéndose hasta $10 \mathrm{~mL}$ de solución de aislamiento. Dicho tubo, tapado con parafilm ${ }^{\circledR}$ para evitar la entrada de agua, fue incubado en un baño termostatizado (Raypa ${ }^{\circledR}$ ) a $37^{\circ} \mathrm{C}$ con agitación manual vigorosa y constante durante 10 minutos aproximadamente.

Transcurrido este tiempo, y dado que el tejido tiende a depositarse en el fondo del tubo, se retiró la solución de enzima mediante decantación cuidadosa. Se realizaron 3 lavados con solución KRB sin albúmina, centrifugándose (Nahita ${ }^{\circledR}$ ) después de cada lavado durante 30 segundos a 3000 rpm y decantando el sobrenandante. Además, el tubo se agitó en cada lavado para que el tejido se desprendiera del fondo y el lavado fuera efectivo. Por último, se mantuvo el tejido en dicha solución de aislamiento y en hielo para preservarlo en las mejores condiciones posibles durante el tiempo de aislamiento de los islotes.

\section{Aislamiento de islotes}

\subsection{Tinción de islotes con ditizona}

Se añadieron $100 \mu \mathrm{L}$ de la solución de stock de DTZ, previamente preparada, en 10 $\mathrm{mL}$ de la solución de aislamiento.

El tejido pancreático en la solución de tinción se mantuvo a $37^{\circ} \mathrm{C}$ en el incubador durante $10 \mathrm{~min}$. Se retiró la solución de tinción y se añadió nuevo medio de aislamiento. 


\subsection{Aislamiento de islotes}

Se separó una pequeña cantidad de tejido pancreático, añadiéndose en una placa de petri grande.

El aislamiento se hizo con la ayuda de un estereomicroscopio (Zeiss $200 \AA$ ), utilizando agujas subcutáneas de insulina para realizar cuidadosamente el aislamiento de los islotes del tejido pancreático exocrino, de uno en uno (Figura 24).

Una vez limpios, los islotes se recogieron con la pipeta automática, depositándolos en placas de Petri pequeñas refrigeradas que contenían $1 \mathrm{~mL}$ de solución KRB suplementada con $5 \mathrm{mg} / \mathrm{mL}$ de BSA.

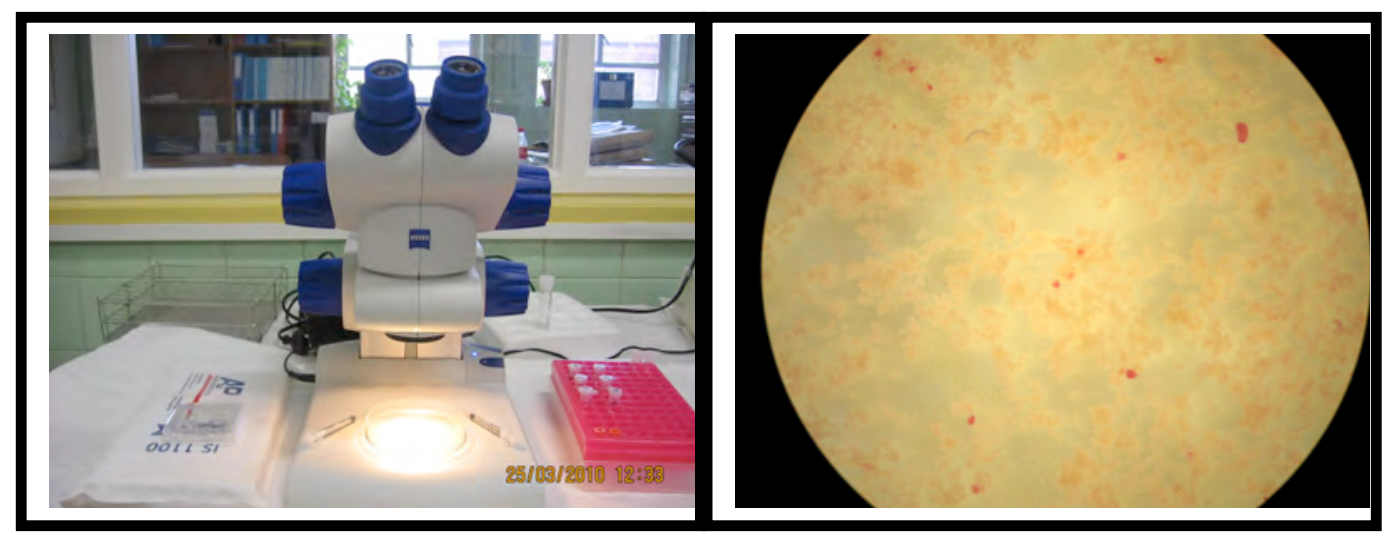

Figura 24. Estereomicroscopio (a la izquierda) en el que se aíslan los islotes que se observan en la imagen (a la derecha).

\section{Morfología de los islotes: Imágenes y medida de los islotes}

Las imágenes de los islotes en placa fueron obtenidas con una cámara digital conectada a un microscopio invertido de contraste de fases (Zeiss, Axiovert 200®) y procesadas con un software de análisis de imagen para microscopía (Axiovision®), con el que se midieron su diámetro y su área (en $\mu \mathrm{m}$ y $\mu \mathrm{m}^{2}$, respectivamente). La viabilidad de los islotes fue valorada indirectamente a través de la intensidad de la tinción con DTZ (Figura 25). 


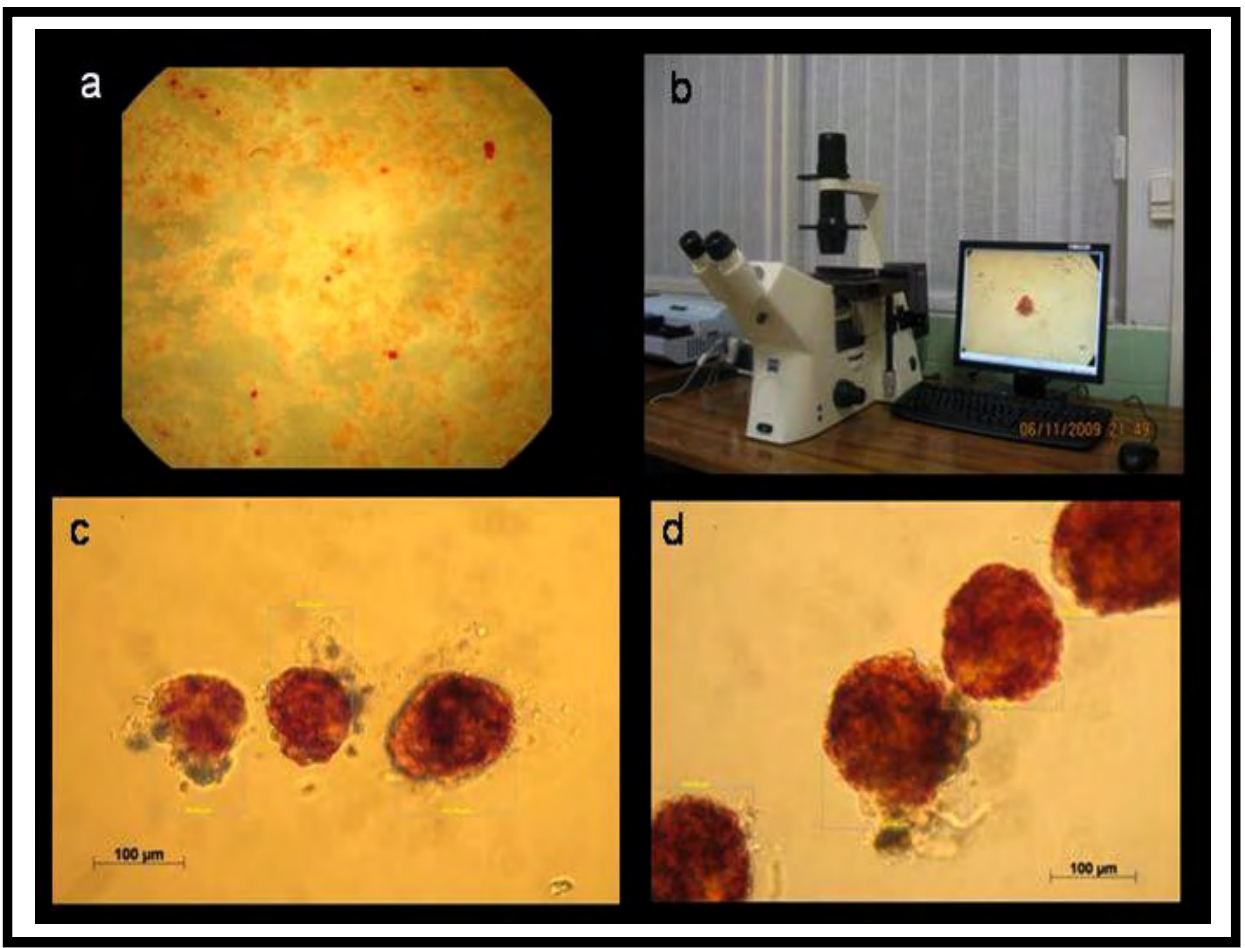

Figura 25. Imágenes de los islotes pancreáticos. Arriba: (a) Islotes en el tejido pancreático una vez digerido y sin aislar del tejido exocrino. b) Microscopio de luz invertida en el que se obtuvieron las imágenes de los islotes. Abajo: Micrografías (20X) de los islotes aislados. (c y d).

\section{Incubación de islotes y medida de la secreción en islotes aislados}

Para el estudio de la función secretora de las células $\beta$ se incubaron durante 60 minutos dos grupos de 7 islotes cada uno (grupo de secrección basal y grupo de estímulo) teñidos con DTZ en un incubador de $\mathrm{CO}_{2}\left(95 \% \mathrm{O}_{2}+5 \% \mathrm{CO}_{2}\right.$, Hucoa Erloss $\left.{ }^{\circledR}\right)$ a $37^{\circ} \mathrm{C}$. Se emplearon como medios de incubación: para el grupo control, 1 $\mathrm{mL}$ de KRB suplementado con BSA a un $\mathrm{pH}$ de 7,4 en presencia de $5 \mathrm{mM}$ de glucosa; y para el grupo de estímulo, $1 \mathrm{~mL}$ de KRB suplementado con BSA a un $\mathrm{pH}$ de 7,4 en presencia de $16,7 \mathrm{mM}$ de glucosa.

El proceso comenzó con una preincubación de ambos grupos durante 10 minutos en presencia de $5 \mathrm{mM}$ de glucosa con el objetivo de estabilizar la secreción. A continuación, se realizó la incubación propiamente dicha, según el grupo. A diferentes tiempos $(0,30,60 \mathrm{~min})$ se pipeteó $1 \mathrm{~mL}$ de medio de incubación, reponiéndose la misma cantidad en cada ocasión (Figura 26). Las muestras obtenidas fueron 
almacenadas a $-40^{\circ} \mathrm{C}$ para analizar la secreción de insulina al medio mediante inmunoensayo (ELISA) posteriormente.

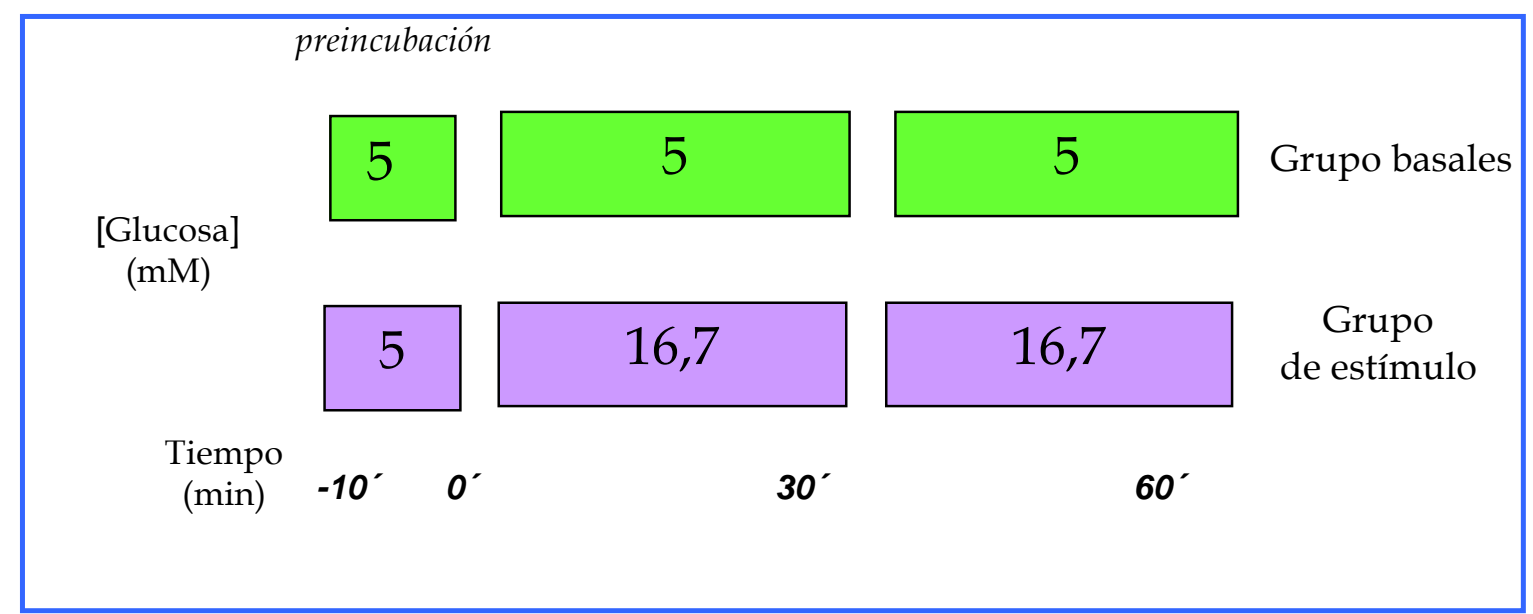

Figura 26. Esquema de los tiempos en los experimentos de secreción de insulina al medio de los islotes ante distintas concentraciones de glucosa.

\section{Sonicado de los islotes. Medida de la insulina contenida por islote}

Se obtuvieron dos grupos de 3 islotes, depositándose en un tubo con $1 \mathrm{~mL}$ de agua destilada. Para romper las membranas celulares se utilizó un sonicador (Sonics, VibraCell囚), administrando 3 pulsos de 30 segundos cada uno (Figura 27). Con el fin de diluir la concentración de insulina, se añadió de nuevo $1 \mathrm{~mL}$ de agua, almacenándose ambos tubos a $-40^{\circ} \mathrm{C}$. La insulina presente en el homogeneizado obtenido por sonicado se determinó mediante ELISA con posterioridad. 


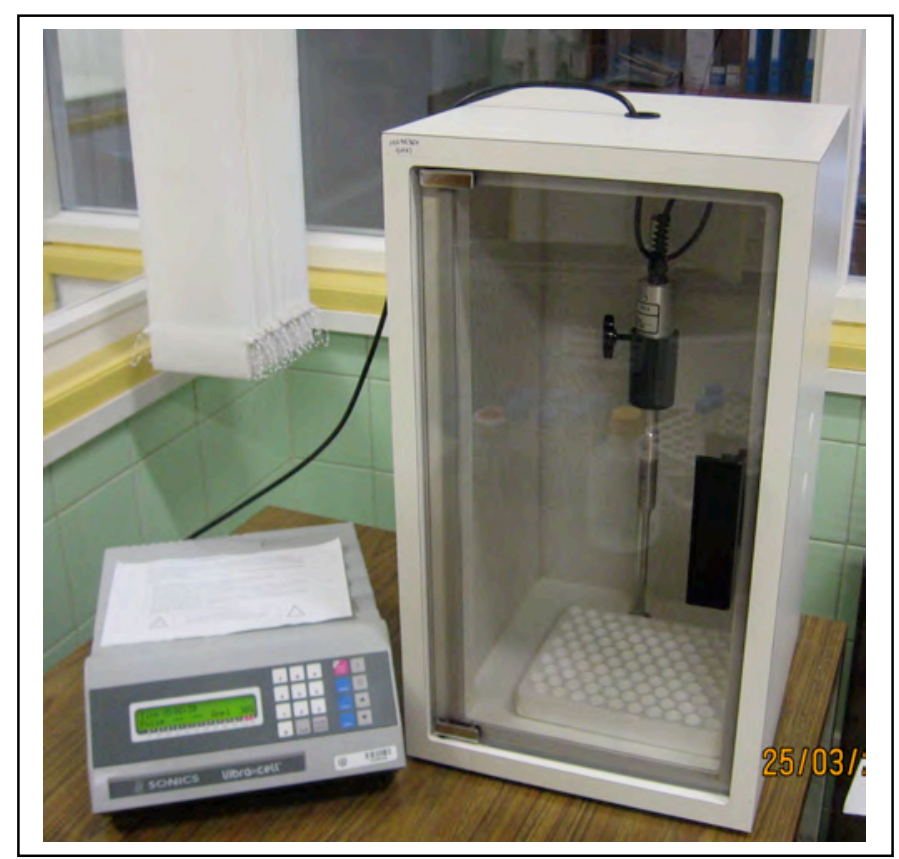

Figura 27. Sonicador (Sonics, VibraCell®), y campana de insonorización.

\section{Determinaciones hormonales}

\section{Insulina}

La determinación cuantitativa de insulina en suero o medio de incubación se realizó mediante inmunoensayo ligado a enzimas (Rat insulin ELISA de DRG Internacional ${ }^{\circledR}$, USA, EIA-2048).

Este ensayo está basado en la técnica del sandwich directo, en la cual dos anticuerpos monoclonales se dirigen contra determinantes antigénicos separados en la molécula de insulina. Durante la incubación la insulina de la muestra reacciona con el anticuerpo anti-insulina conjugado con la enzima peroxidasa y con los anticuerpos anti-insulina unidos a la fase sólida (o a la placa provista por el kit). Mediante un lavado se retira el anticuerpo marcado con la enzima que no se ha unido. El conjugado que se ha unido se detecta por reacción con la tetrametilbencidina (TMB). La reacción se detiene añadiendo ácido sulfúrico para dar un punto final colorimétrico que es leído a $450 \mathrm{~nm}$ en el espectrofotómetro (Multiskan Ascent ${ }^{\circledR}$, Thermo Electron Corporation) (Figura 28). Los resultados han sido procesados en todos los inmunoensayos mediante un sofware asociado Ascent SW v.2.6. 


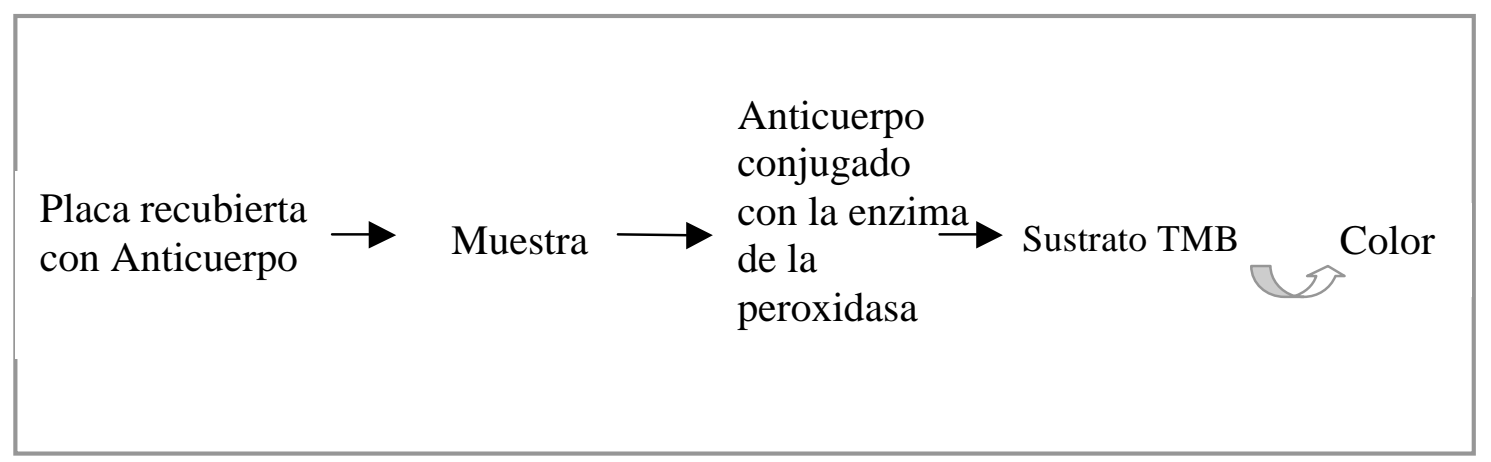

Figura 28. ELISA tipo sandwich directo para la determinación de Insulina (TMB = tetrametilbencidina)

La concentración de insulina se obtuvo enfrentando las absorbancias de los calibradores frente al logaritmo de la concentración y usando una curva de regresión tipo cubic spline (Figura 29).

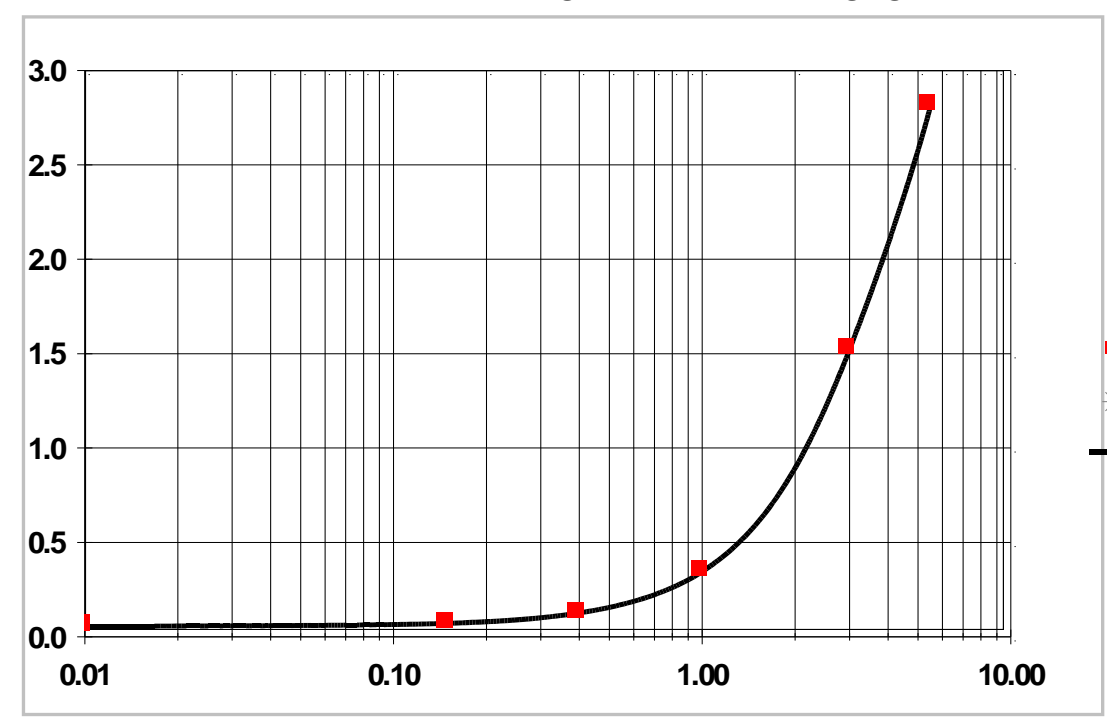

Figura 29. Curva de calibración de la insulina $(\mu \mathrm{g} / \mathrm{L})$

En cada ensayo se incluyeron controles internos de calidad, cuyo resultado dentro de \pm 2 desviaciones estándar (DE) fue criterio imprescindible para la aceptación de la serie. El límite de detección de este ensayo es de 0,07 $\mu \mathrm{g} / \mathrm{L}$, el rango analítico va de 0,07 a $5,5 \mu \mathrm{g} / \mathrm{L}$ y el coeficiente de variación (CV) total es menor del $4 \%$ para cualquier concentración en ese rango. 


\section{Leptina}

La determinación cuantitativa de la leptina en suero se llevó a cabo utilizando el kit Leptin (Rat) ELISA de DRG Diagnostics (EIA-3115).

Este kit utiliza un anticuerpo policlonal inmovilizado en la placa que se une a la leptina de las muestras o del estándar. Después de un periodo de incubación, el exceso de estándar o de muestra se lava y se añade el anticuerpo de leptina marcado con la enzima de la peroxidasa del rabano picante (HRP). Después de una segunda incubación el exceso de anticuerpo marcado se lava y se añade el sustrato, el cual reacciona con dicho anticuerpo unido previamente a la leptina capturada en la placa. El color generado por la reacción enzima-sustrato se lee a $450 \mathrm{~nm}$ y es directamente proporcional a la concentración de leptina en la muestra (Figura 30).

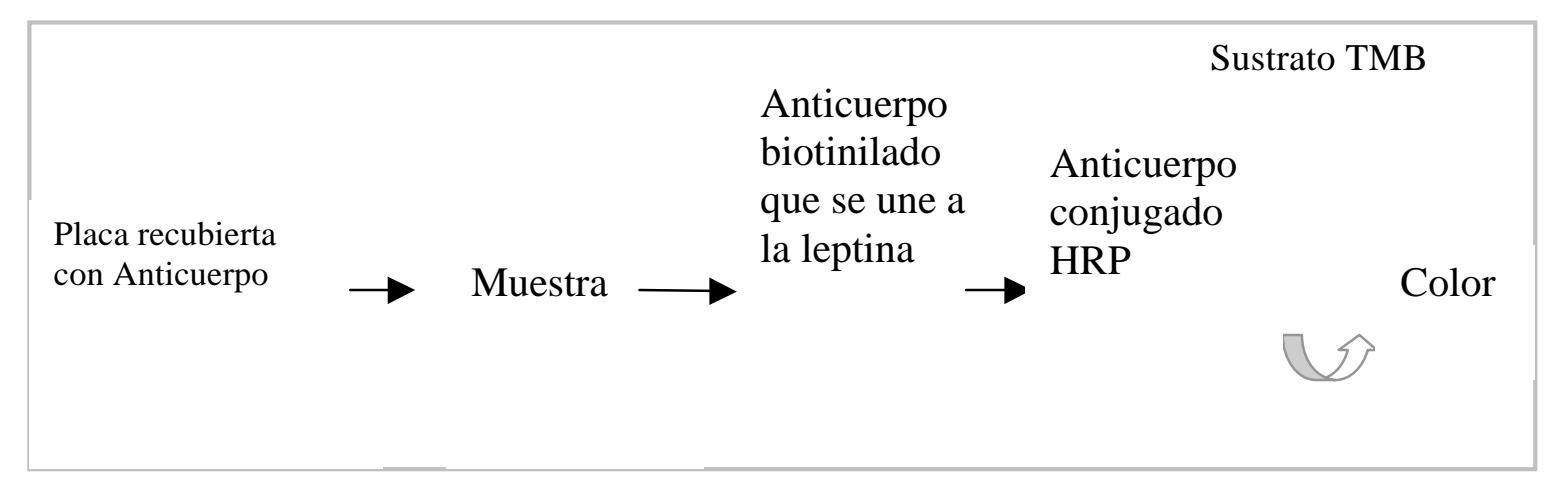

Figura 30. ELISA tipo sándwich indirecto para la determinación de leptina ( $\mathrm{TMB}=$ tetrametilbencidinA, $\mathrm{HRP}=$ enzyme horseradish peroxidase)

La concentración de leptina se obtuvo enfrentando las absorbancias de los calibradores frente al logaritmo de la concentración y usando una curva de regresión tipo cubic spline (Figura 31). 


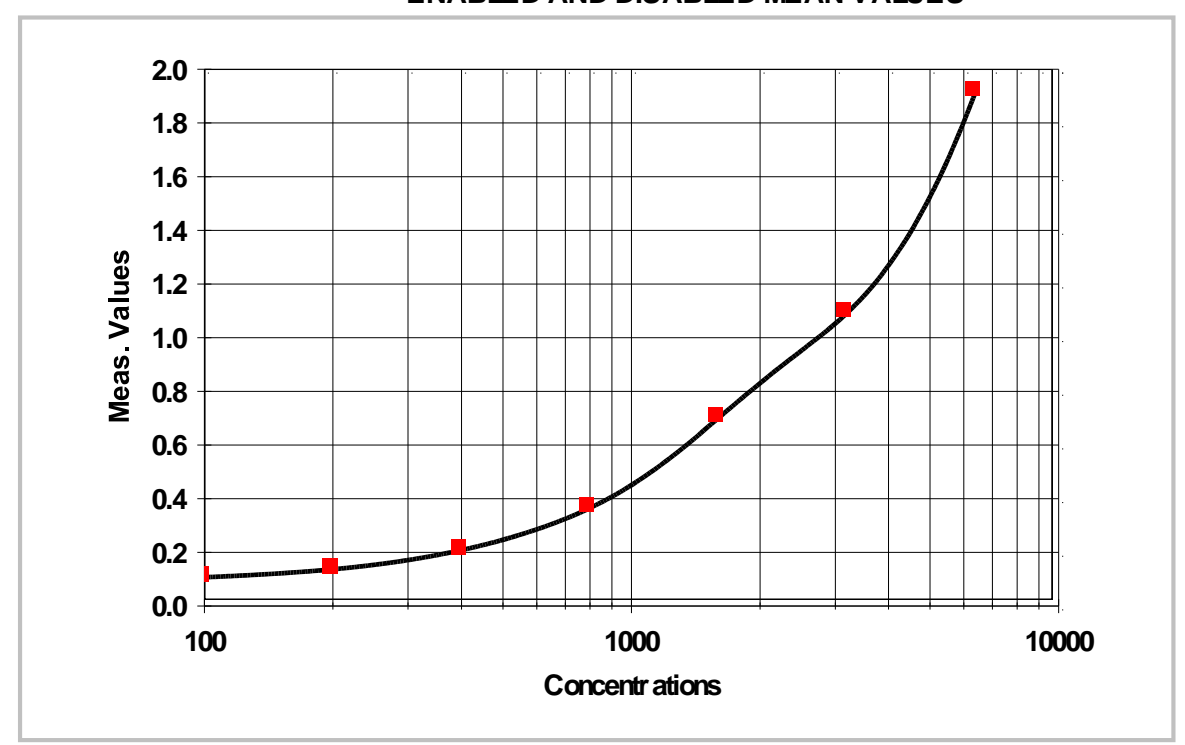

Figura 31. Curva de calibración de la leptina en suero $(\mathrm{pg} / \mathrm{mL})$

En cada ensayo se incluyeron controles internos de calidad, cuyo resultado dentro de \pm 2 DE fue criterio imprescindible para la aceptación de la serie. El límite de detección del ensayo es de $67,2 \mathrm{pg} / \mathrm{mL}$ y el rango analítico es de $67,2-6400 \mathrm{pg} / \mathrm{mL}$. El CV interensayo es $\leq 2,5 \%$ para concentraciones $\geq 2000 \mathrm{pg} / \mathrm{mL}$ y $\leq 8,0 \%$ para concentraciones $\leq 300 \mathrm{pg} / \mathrm{mL}$. El CV intraensayo es $\leq 4,1 \%$ para concentraciones $\geq 2000 \mathrm{pg} / \mathrm{mL}$ y $\leq 11,0 \%$ para concentraciones $\leq 300 \mathrm{pg} / \mathrm{mL}$.

\section{GIP}

La concentración de GIP en suero se midió con el Gastric Inhibitory Peptide (GIP) Rat EIA Kit (EK-027-12, Phoenix Pharmaceuticals, Inc.).

La immunoplaca en este kit está pre-cubierta con el anticuerpo secundario y los sitios de unión inespecífica se bloquean. El anticuerpo secundario se puede unir al fragmento Fc del anticuerpo primario (anticuerpo anti-péptido) a cuyo fragmento Fab se unen de forma competitiva el péptido biotinilado y al estándar o la muestra. El péptido biotinilado interactúa con la estreptavidina-peroxidasa del rábano picante (SAHRP) que cataliza la solución de sustrato. La intensidad del color es directamente proporcional a la cantidad del complejo péptido-biotina-SA-HRP, pero inversamente proporcional a la cuantía del péptido en las soluciones estándar o en las muestras. Esto es debido a la competencia en la unión del péptido con biotina, con el péptido estándar o con las muestras al anticuerpo primario (Figura 32). 


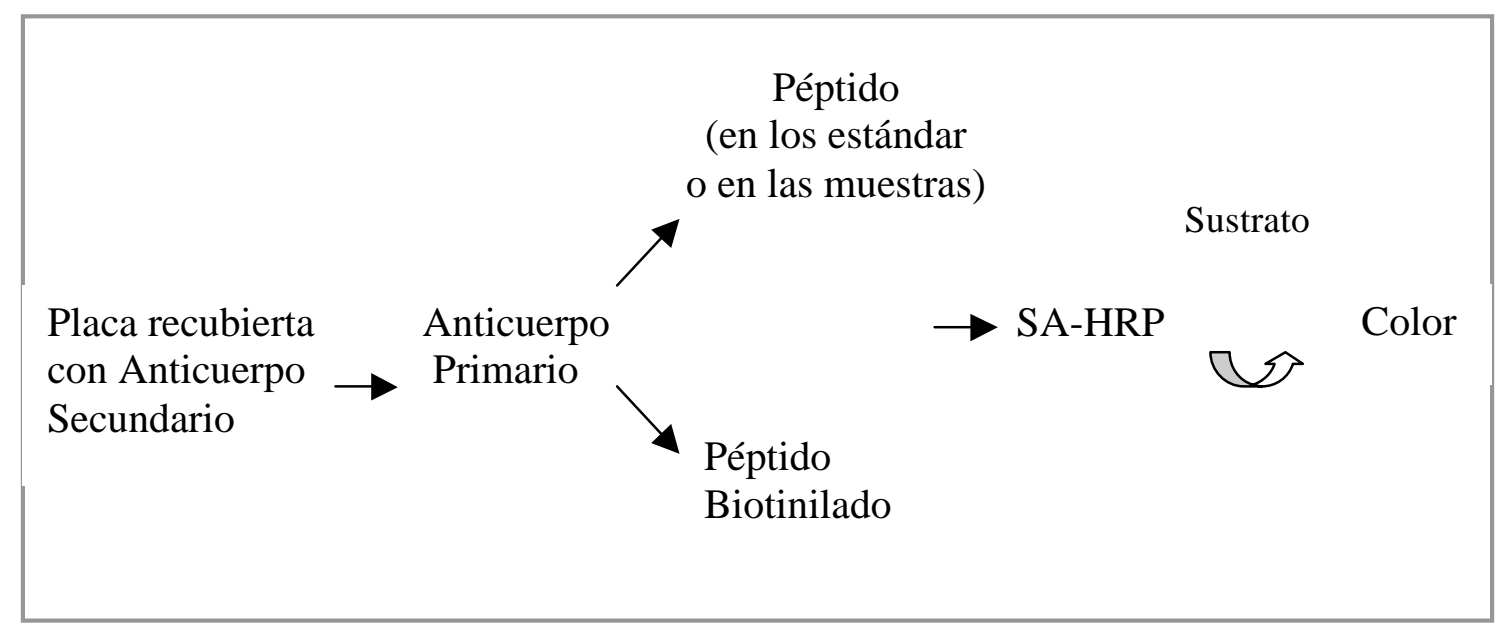

Figura 32. Enzimoinmunoanálisis (EIA) para la determinación de GIP o GLP-1 ( $\mathrm{HRP}=$ enzyme horseradish peroxidase, SA-HRP = streptavidin-horseradish peroxidase)

La concentración de GIP se obtuvo enfrentando las absorbancias de los calibradores frente al logaritmo de la concentración y usando una curva de regresión logística de 4 parámetros (Figura 33).

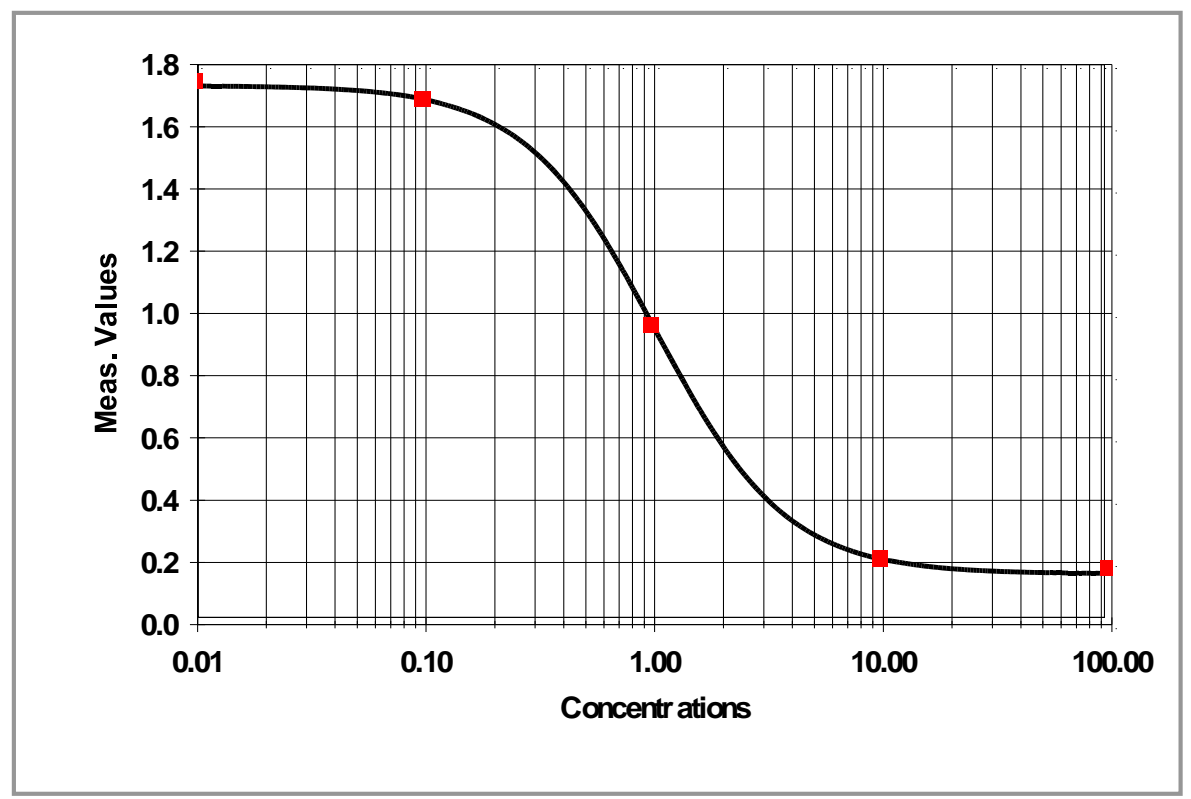

Figura 33. Curva de calibración del GIP en suero $(\mathrm{ng} / \mathrm{mL})$ $r^{2}=1,000 ; y=b+(a-b) /(1+x c)^{\wedge} d$

(donde $a=1,732 ; b=0,163 ; c=0,996 ; d=1,525$ )

En cada ensayo se incluyeron controles internos de calidad, cuyo resultado dentro de $\pm 2 \mathrm{DE}$ fue criterio imprescindible para la aceptación de la serie. El límite de detección del ensayo es de $0,35 \mathrm{ng} / \mathrm{mL}$ y el rango analítico es de 0,35-100 $\mathrm{ng} / \mathrm{mL}$. El CV total del 
ensayo es $\leq 11,0 \%$ en todas las concentraciones. El ensayo no muestra reactividad cruzada con el glucagón ni el GLP-1.

\section{GLP-1}

Para la determinación de GLP-1 en suero utilizamos el kit GLP-1 (7-36) Amide (Human, Rat, Mouse) EIA Kit (EK-028-11, Phoenix Pharmaceuticals, Inc.)

La inmunoplaca en este kit está pre-cubierta con el anticuerpo secundario y los sitios de unión inespecífica se bloquean. El anticuerpo secundario se puede unir al fragmento Fc del anticuerpo primario (anticuerpo anti-péptido) a cuyo fragmento Fab se unen de forma competitiva el péptido biotinilado y al estándar o la muestra. El péptido biotinilado interactúa con la estreptavidina-peroxidasa del rábano picante (SAHRP) que cataliza la solución de sustrato. La intensidad del color es directamente proporcional a la cantidad del complejo péptido-biotina-SA-HRP, pero inversamente proporcional a la cuantía del péptido en las soluciones estándar o en las muestras. Esto es debido a la competencia en la unión del péptido con biotina, con el péptido estándar o con las muestras al anticuerpo primario (Figura 34).

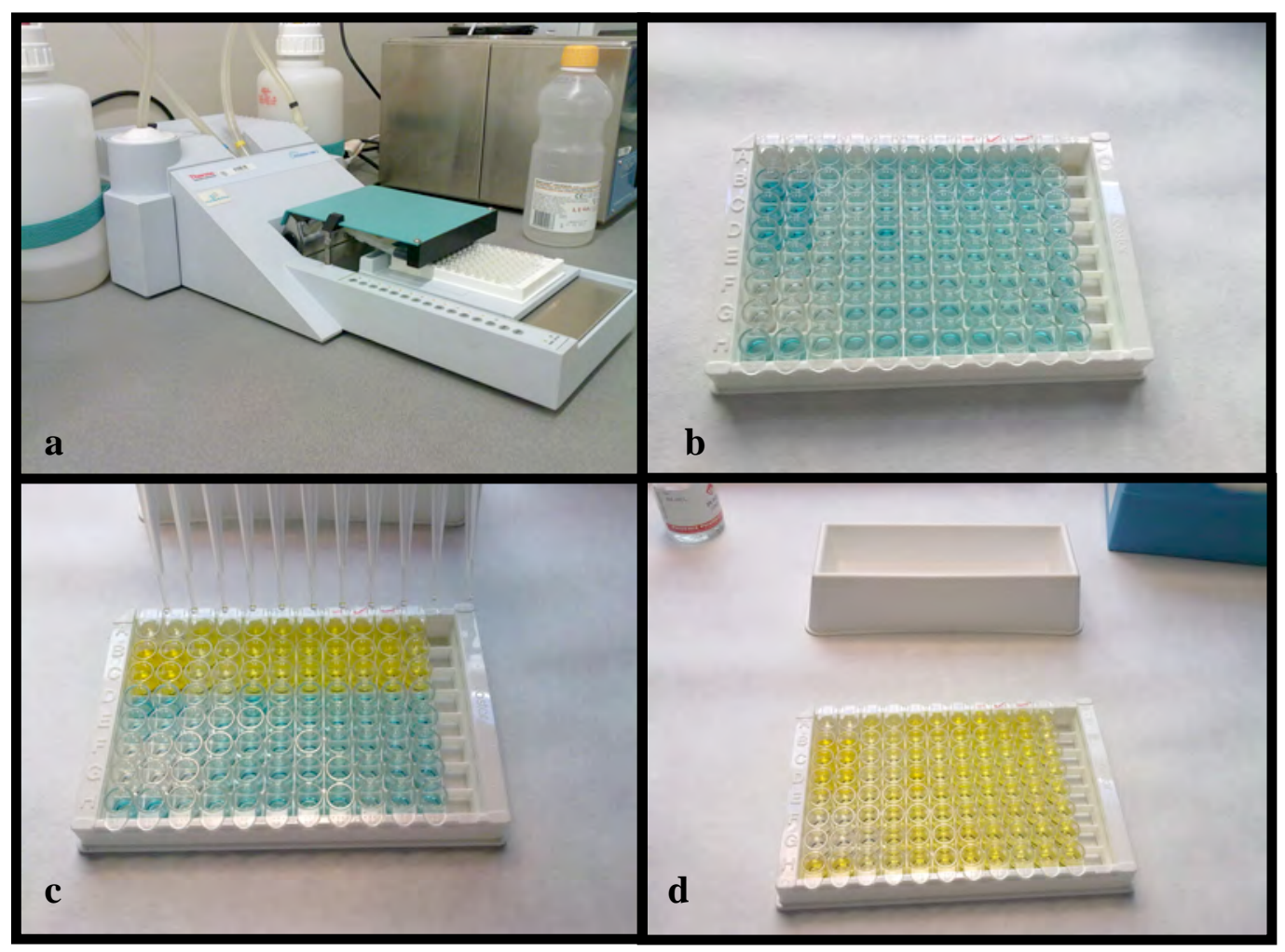

Figura 34. Algunas fases del protocolo del ensayo de GLP-1.

a) Lavador automático de placas, b) placa después de la incubación con el sustrato, c) parada de la reacción con $\mathrm{HCl}$, d) placa preparada para medir absorbancias a $450 \mathrm{~nm}$. 
La concentración de GLP-1 se obtuvo enfrentando las absorbancias de los calibradores frente al logaritmo de la concentración y usando una curva de regresión logística de 4 parámetros (Figura 35).

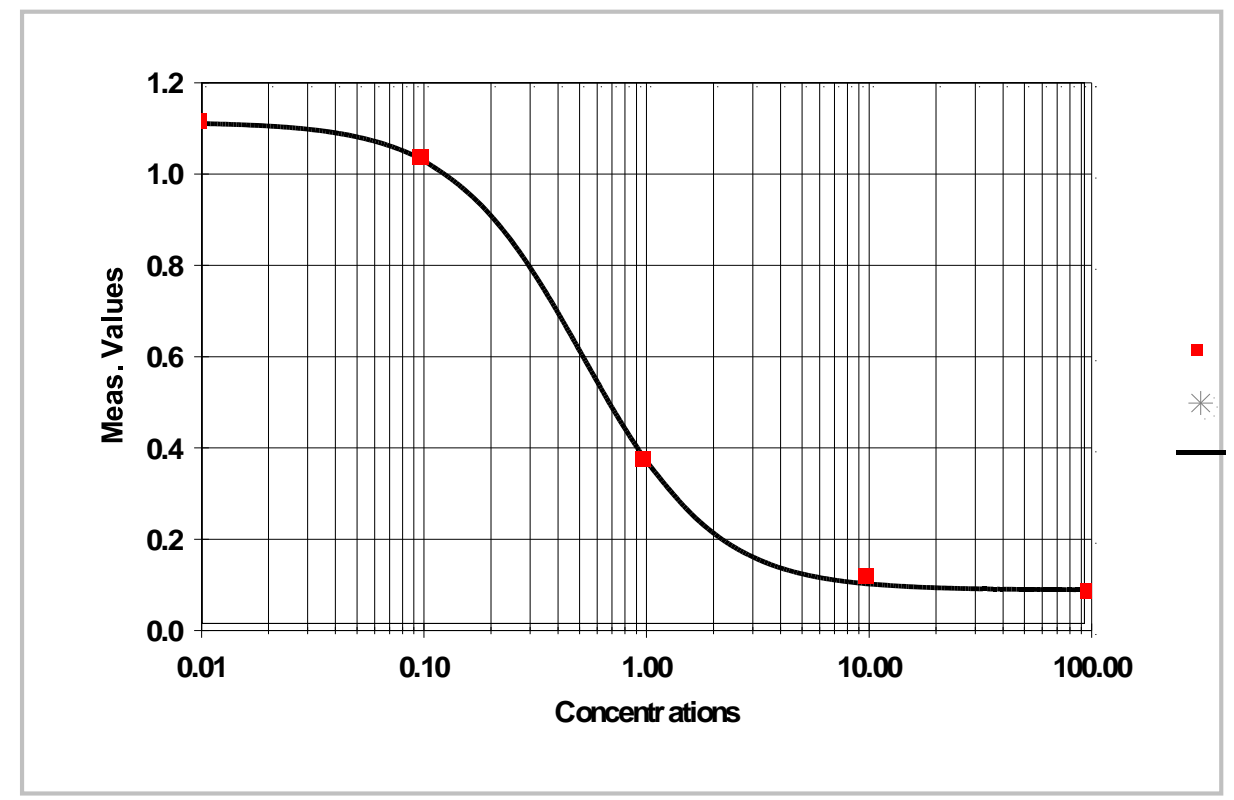

Figura 35. Curva de calibración del GLP-1 en suero $(\mathrm{ng} / \mathrm{mL})$

$r^{2}=1,000 ; y=b+(a-b) /(1+x c)^{\wedge} d$

(donde $a=1,114 ; b=0,089 ; c=1,936 ; d=1,469$ )

En cada ensayo se incluyeron controles internos de calidad, cuyo resultado dentro de $\pm 2 \mathrm{DE}$ fue criterio imprescindible para la aceptación de la serie. El límite de detección del ensayo es de $0,11 \mathrm{ng} / \mathrm{mL}$ y el rango analítico es de 0,11-100 $\mathrm{ng} / \mathrm{mL}$. El CV total del ensayo es $\leq 11,0 \%$ en todas las concentraciones. El ensayo no muestra reactividad cruzada con el glucagón, el GIP o la insulina.

\section{Glucagón}

Para la determinación cuantitativa de glucagón en suero de rata se utilizó el kit Glucagon EIA For determination of Rat, Mouse or Human GIñucagon (YK090 Yanaihara Institute Inc, Japón).

Este kit se basa en un inmunoensayo enzimático competitivo con una combinación de anticuerpos altamente específicos para el glucagón y el sistema biotina-avidina. La placa del ensayo está recubierta con anticuerpos de conejo anti glucagón. El glucagón estándar o las muestras, y el antígeno marcado se añaden a los pocillos en una reacción inmune de tipo competitivo. Después de la incubación y el lavado de la placa, la estreptavidina marcada con HRP (SA-HRP) se agrega para formar el complejo SA- 
HRP-glucagón biotinilado-anticuerpo en la superficie de los pocillos. Por último, la actividad de la enzima HRP está determinada por diclorhidrato de o-fenilendiamina y la concentración de glucagón pancreático se determina midiendo la absorbancia a 490 $\mathrm{nm}$.

La concentración de glucagón se obtuvo enfrentando las absorbancias de los calibradores frente al logaritmo de la concentración y usando una curva de regresión logística de 4 parámetros (Figura 36).

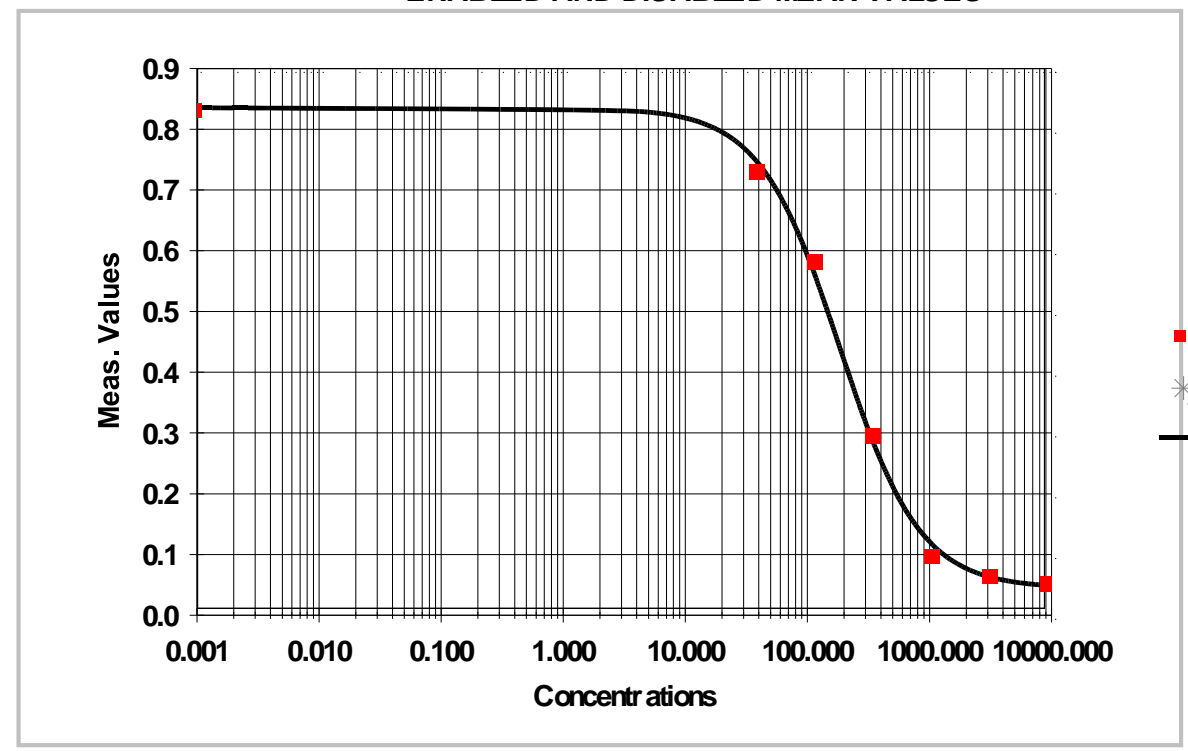

Figura 36. Curva de calibración del Glucagón en suero $(\mathrm{pg} / \mathrm{mL})$

$$
r^{2}=0,993 ; y=b+(a-b) /(1+x c)^{\wedge} d
$$

(donde $a=0,835 ; b=0,045 ; c=0,005 ; d=1,323$ )

En cada ensayo se incluyeron controles internos de calidad, cuyo resultado dentro de $\pm 2 \mathrm{DE}$ fue criterio imprescindible para la aceptación de la serie. El rango de este ensayo está entre $50-10.000 \mathrm{pg} / \mathrm{ml}$ y el CV intraensayo fue $\leq 5,1$ y el CV interensayo fue $\leq 18,9$. El kit tiene una alta especificidad con el glucagón pancreático y no muestra reactividad cruzada con el glucagón intestinal, GLP-1 y GLP-2. 


\section{Reacción en Cadena de la Polimerasa (RCP) a tiempo real}

\section{Introducción y fundamento}

La RCP cuantitativa ( $\mathrm{qRCP}$ ) es una variante de la reacción en cadena de la polimerasa utilizada para amplificar ADN y cuantificar simultáneamente el producto de la amplificación. Para ello emplea, del mismo modo que la RCP convencional, un molde de ADN, cebadores específicos o primers, desoxirribonucleótidos trifosfato (dNTPs), un tampón de reacción adecuado y una ADN polimerasa termoestable; a dicha mezcla se le añade un fluoróforo que se une al ADN, emitiendo fluorescencia detectable en un termociclador con un módulo óptico añadido cuando se produce su excitación. La cantidad de fluorescencia emitida es proporcional a la tasa de generación de los productos específicos amplificados. Esta medición se realiza después de cada ciclo de amplificación detectando en tiempo real la generación de los productos. En nuestros ensayos utilizamos el SYBR-Green I, un fluoróforo intercalativo inespecífico que se une al surco menor del ADN bicatenario con gran afinidad, aumentando su fluorescencia unas 1000 veces. El SYBR Green es excitado mediante luz azul $\left(\lambda_{\max }=488 \mathrm{~nm}\right)$ y emite luz verde $\left(\lambda_{\max }=522 \mathrm{~nm}\right)$.

En la PCR cuantitativa el molde que se utiliza es ADN complementario, obtenido por retrotranscripción a partir de ARN, molécula que refleja la expresión de un gen concreto en una célula y en un momento determinado.

\section{Recogida y conservación de muestras}

La PCR permite analizar los niveles de ARN mensajero de la insulina partiendo de pequeñas cantidades de muestra. Para llevar a cabo este protocolo se parte de 15 islotes pancreáticos aislados de cada rata, que se añaden a un tubo con $100 \mu \mathrm{L}$ de RNA later (Cat\#7021\# Ambion®). El RNA later es una solución acuosa que penetra en los tejidos y que permite el almacenamiento de muestras durante largos periodos de tiempo, estabilizando y protegiendo el ARN.

Tras la extracción, los islotes se mantienen a 4ํㅡ durante 24 horas para que la solución penetre en ellos; posteriormente son almacenados a $-80 \stackrel{\circ}{C}$. 


\section{Extracción de ARN total}

Con el fin de obtener los mejores rendimientos, al trabajar con ARN, se tomaron las máximas precauciones para evitar contaminaciones con ARNasas y la degradación del ARN. Para ello la extracción se realizó bajo una campana de flujo laminar (AV-100, Telstar®).

El ARN se extrae según el manual de instrucciones del Aurum total RNA fatty and fibrous tissue Kit de Bio-Rad ${ }^{\circledR}$ de los islotes de ambos grupos.

Este procedimiento permite purificar el ARN total a partir de las muestras usando un reactivo de aislamiento de ARN (PureZol \#732-6880\#). Posteriormente, se añade cloroformo al lisado, se mezcla y centrifuga para conseguir la separación de las fases orgánica y acuosa. La fase acuosa que contiene el ARN, se recupera y se mezcla cuidadosamente con etanol. La muestra se pasa a través de una columna provista de una membrana de sílica a la que se unen los ácidos nucleicos. Se realizan varios lavados para eliminar las proteínas y restos celulares, además damos un tratamiento con ADN-asa I para eliminar cualquier resto de ADN genómico. Finalmente, se diluye la columna con una solución provista por el kit y se obtiene el ARN.

Se mide la concentración de ARN en el espectrofotómetro (Smart Spec ${ }^{\mathrm{TM}}$ Plus de Bio$\operatorname{Rad}^{\circledR}$ ) a $260 \mathrm{~nm}$ para poner 1 microgramo en la siguiente reacción.

\section{RT- RCP (Transcripción reversa)}

Se obtiene ADN copia (cDNA) a partir de los ARN totales con el kit iScript cDNA synthesis de Bio-Rad ${ }^{\circledR}$, que incluye una transcriptasa reversa (RT) derivada del MMLV (Virus de la leucemia murina de Moloney), optimizada para una síntesis de copia de ADN fiable.

A continuación se muestran las cantidades de los componentes que se usaron durante la reacción para un volumen final de $20 \mu \mathrm{L}$ y el protocolo térmico: 


\section{Componentes de la reacción}

- $4 \mu \mathrm{L}$ de mezcla de reacción iScript 5X

- $1 \mu \mathrm{L}$ de enzima transcriptasa reversa iScript

- $1 \mu \mathrm{g}$ de molde de ARN

- $3 \mu \mathrm{L}$ de agua libre de nucleasa

\section{$>$ Protocolo térmico}

- 5 min a $25^{\circ} \mathrm{C}$

- 30 min a $42{ }^{\circ} \mathrm{C}$

- 5 min a $85^{\circ} \mathrm{C}($ mantener a $4 \stackrel{\circ}{\circ})$

\section{RCP Cuantitativa}

Después de aislar ARN total y de hacer la transcripción reversa de ARN a ADN copia, se midieron los niveles de ARN mensajero (expresión) de insulina mediante amplificación por PCR cuantitativa a tiempo real en el sistema iCycler (Bio-Rad $\left.{ }^{\odot}\right)$, utilizando como reactivo el $I Q^{T M} S Y B R \Theta$ Green Supermix de Bio-Rad®, que contiene buffer $2 X$ con los dNTPs, la iTaq ADN polimerasa, $6 \mathrm{mM}$ de $\mathrm{MgCl}$ 2, SYBRGreen I y fluoresceína.

Cuando se utiliza la qRCP para determinar niveles de expresión es necesario normalizar los resultados de la amplificación para corregir las variaciones producidas en los procesos de pipeteo, extracción de ARN y reacción RT. Para ello se analiza la expresión de un gen de referencia como control interno, un gen cuya expresión permanezca prácticamente constante en las diferentes condiciones experimentales. Para nuestro tejido de partida hemos elegido el gen de la enzima gliceroaldehído 3fosfato deshidrogenasa (GAPDH) como gen de referencia frente a nuestro gen experimental, el gen de la insulina-1.

El ensayo para la cuantificación del gen de insulina fue diseñado, optimizado y validado en nuestro laboratorio antes de ser aplicado en las muestras del estudio. 


\title{
4.1. Diseño, optimización y validación del ensayo
}

El diseño de un ensayo de RCP cuantitativa a tiempo real incluye el diseño de los primers o cebadores, la optimización de las condiciones de reacción (básicamente, la determinación de la temperatura de anillamiento específica para detectar el gen en estudio) y el cálculo de la eficiencia de la reacción mediante la construcción de una recta patrón (estándar).

\subsubsection{Diseño de cebadores o primers}

Las secuencias de los pares de primers fueron diseñadas por metabion international AG (Alemania), utilizando el programa Beacon Designer 4.0 (Premier Biosoft Internationa ${ }^{\circledR}$ ) (Tabla 10):

\author{
Primers \\ Secuencia de $5^{\prime}$ a $3^{\prime}$ \\ Insulina Forward: TTC TAC ACA CCC AAG TCC CGT C \\ Reverse: ATC CAC AAT GCC ACG CTT CTG C \\ GAPDH Forward: TGC CAT CAC TGC CAC TCA GAA GAC \\ Reverse: GGA TGA CCT TGC CCA CAG CCT TG
}

Tabla 10. Secuencias primers de los genes de Insulina y GAPDH.

Estas secuencias fueron comprobadas mediante búsqueda en la base de datos BLAST (Basic Local Alignment Search Tool) del National Center for Biotechnology Information (NCBI), que forma parte de la National Library of Medicine (NLM) de Estados Unidos.

\subsubsection{Condiciones de reacción: temperatura de fusión}

La RCP cuantitativa permite con el SYBR Green, identificar fragmentos amplificados de ADN concretos a partir de la temperatura de fusión (también denominado valor Tm, del inglés melting temperature), que es específica para el fragmento amplificado que se está buscando; y cuyos resultados son obtenidos a partir de la observación de la curva de fusión de las muestras de ADN analizadas. 
Para determinar la especificidad del ensayo se realizó, por tanto, un experimento de PCR seguido de una curva de melting en gradiente de temperatura, según el protocolo referido a continuación. En el paso 2 del ciclo 3, se aplicó el gradiente de temperatura (desde 50 a $60^{\circ} \mathrm{C}$ ) para determinar la temperatura óptima de annealing o de unión de los primers mediante el posterior análisis de las curvas de fusión o melting curves.

\section{Protocolo térmico}

\section{- Amplificación de ADN}

Ciclo 1

30 segundos a $95^{\circ} \mathrm{C}$

Ciclo 2

3 minutos a $95^{\circ} \mathrm{C}$ (activación de la ADN polimerasa)

Ciclo 4 (40 veces)

10 segundos a $95{ }^{\circ} \mathrm{C}$ (desnaturalización del ADN bicatenario)

30 segundos de $\mathbf{5 0}$ a $\mathbf{6 0} \stackrel{\circ}{ } \mathbf{C}$ (hibridación los cebadores con el ADN)

30 segundos a $72 \stackrel{\circ}{ } \mathrm{C}$ (polimerización de nuevas cadenas de ADN)

- Disociación o fusión (melting) de las cadenas de ADN

Ciclo 4

1 minuto a $95^{\circ} \mathrm{C}$

1 minuto a $60 \stackrel{\circ}{C}$

Ciclo 5 (70 veces)

10 segundos a $60{ }^{\circ} \mathrm{C}$

$>\quad$ Componentes de las reacciones para Insulina y GAPDH $(\mathrm{Vr}=25 \mu \mathrm{L})$

- $12,5 \mu \mathrm{L}$ iQ SYBR SuperMix

- $1 \mu \mathrm{L}$ de primer forward Insulina (o de GAPDH)

- $1 \mu \mathrm{L}$ de primer reverse Insulina (o de GAPDH)

- $1 \mu \mathrm{L}$ de cDNA

- $9,5 \mu \mathrm{L}$ de $\mathrm{H} 2 \mathrm{O}$

El resultado del experimento se refleja en el gráfico de amplificación o RCP (Figura 37) y en la curva de melting (Figuras 38 y 39 ). 
El Ct o ciclo umbral (Threshold cycle) es el ciclo en el que la señal de fluorescencia de la reacción cruza el umbral. Se trata de un indicador fiable del número de copias iniciales, porque está inversamente relacionado con la cantidad de material inicial. Para determinarlo, se fija una línea umbral suficientemente amplia para eliminar el "ruido" de los primeros ciclos de amplificación sin interferir con el área en el que la señal de amplificación comienza a aumentar exponencialmente por encima del ruido.

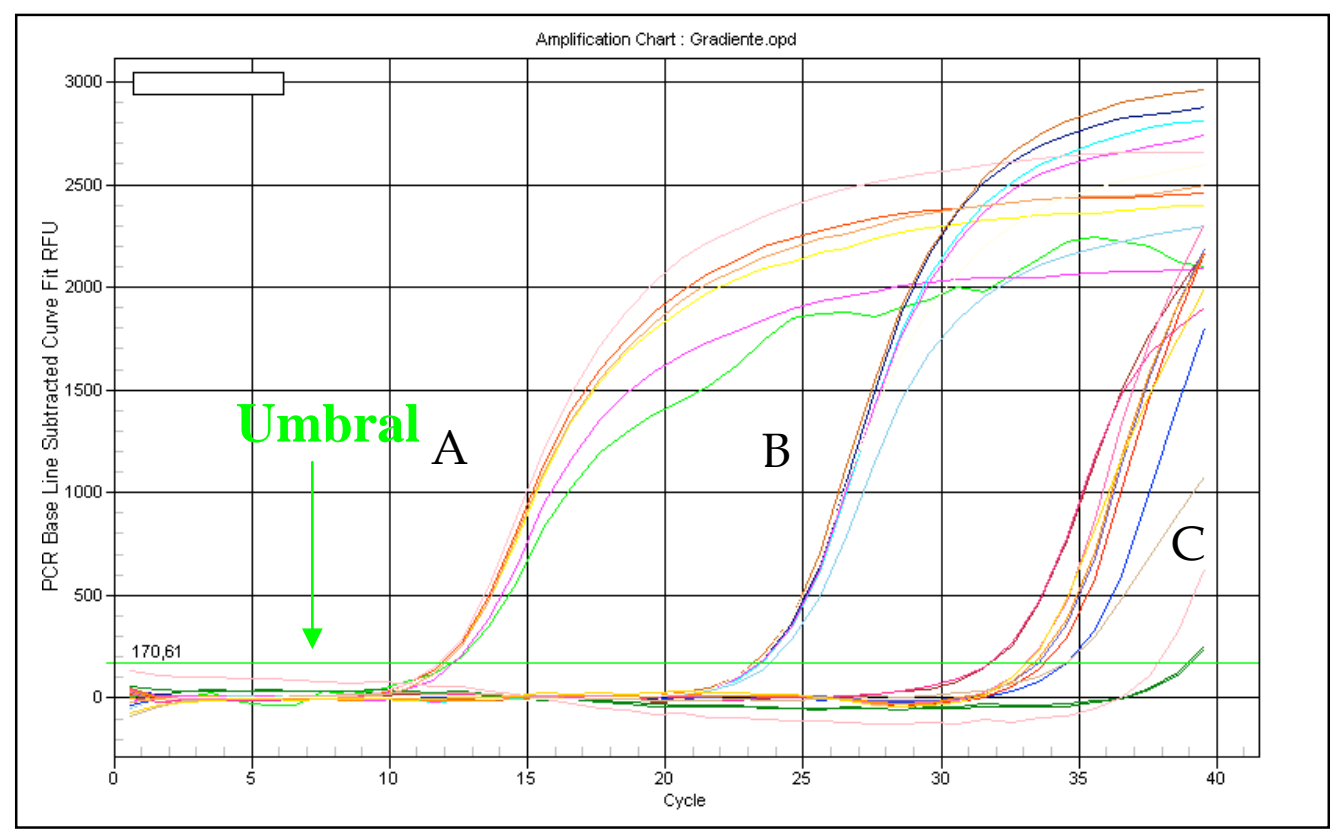

Figura 37. Gráfico de amplificación (SYBR-490) por ciclo. A: Insulina; B: GAPDH; C: Control negativo

Una vez finalizada la RCP, se realizó la curva de fusión o de melting, para lo cual se aumenta progresivamente la temperatura de las muestras desde una temperatura baja, en la que todas las secuencias están hibridadas. Al mismo tiempo, se monitoriza la fluorescencia. Cuando se alcanza la temperatura de fusión (Tm) de un fragmento, se observa un descenso repentino de fluorescencia, debido a que la doble cadena de ADN se desnaturaliza a cadena simple. Cada descenso de fluorescencia se convierte en un pico, y se detectan tanto picos como descensos de temperatura o, lo que es lo mismo, fragmentos de ADN.

La monitorización de las curvas de fusión tras la amplificación es un método que nos permitió analizar fácilmente la posible existencia de artefactos debidos a la formación de dímeros de primers y otros productos inespecíficos de la reacción. 


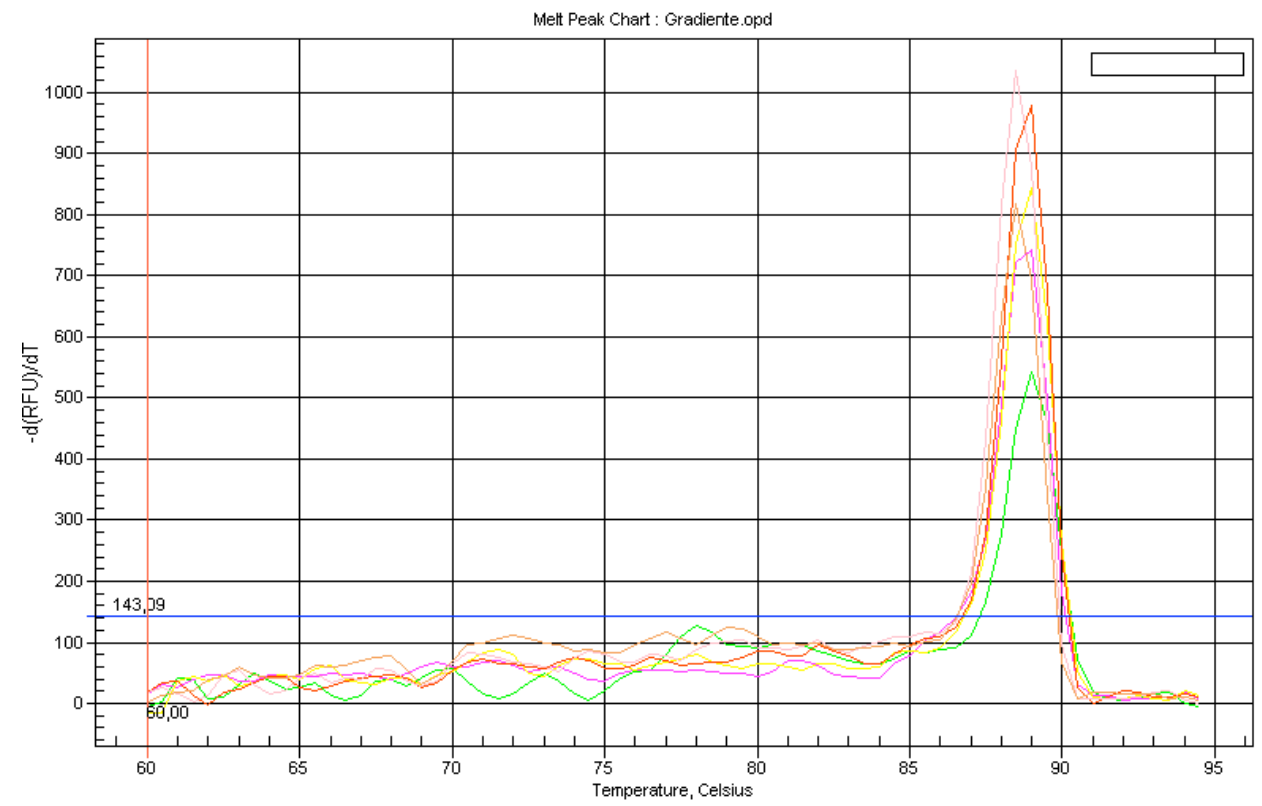

Figura 38. Curva de melting de Insulina con gradiente de temperatura (50-60ำ

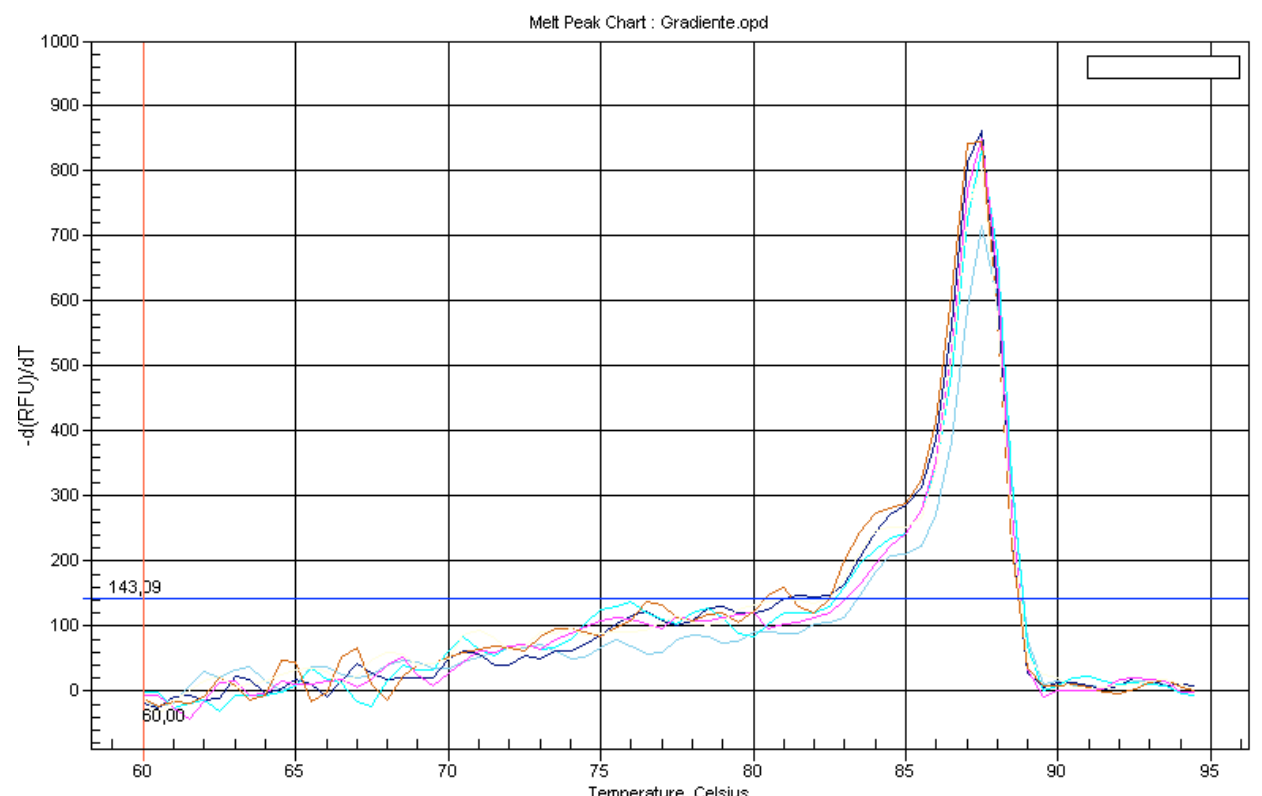

Figura 39. Curva de melting de GAPDH con gradiente de temperatura (50-60ำ)

Finalmente, se eligimos la temperatura a la cual, con el Ct más bajo, no existían dímeros de primers $u$ otros artefactos. Para nuestros ensayos elegimos como óptima la temperatura de $52^{\circ} \mathrm{C}$ (Figura 40 ). 


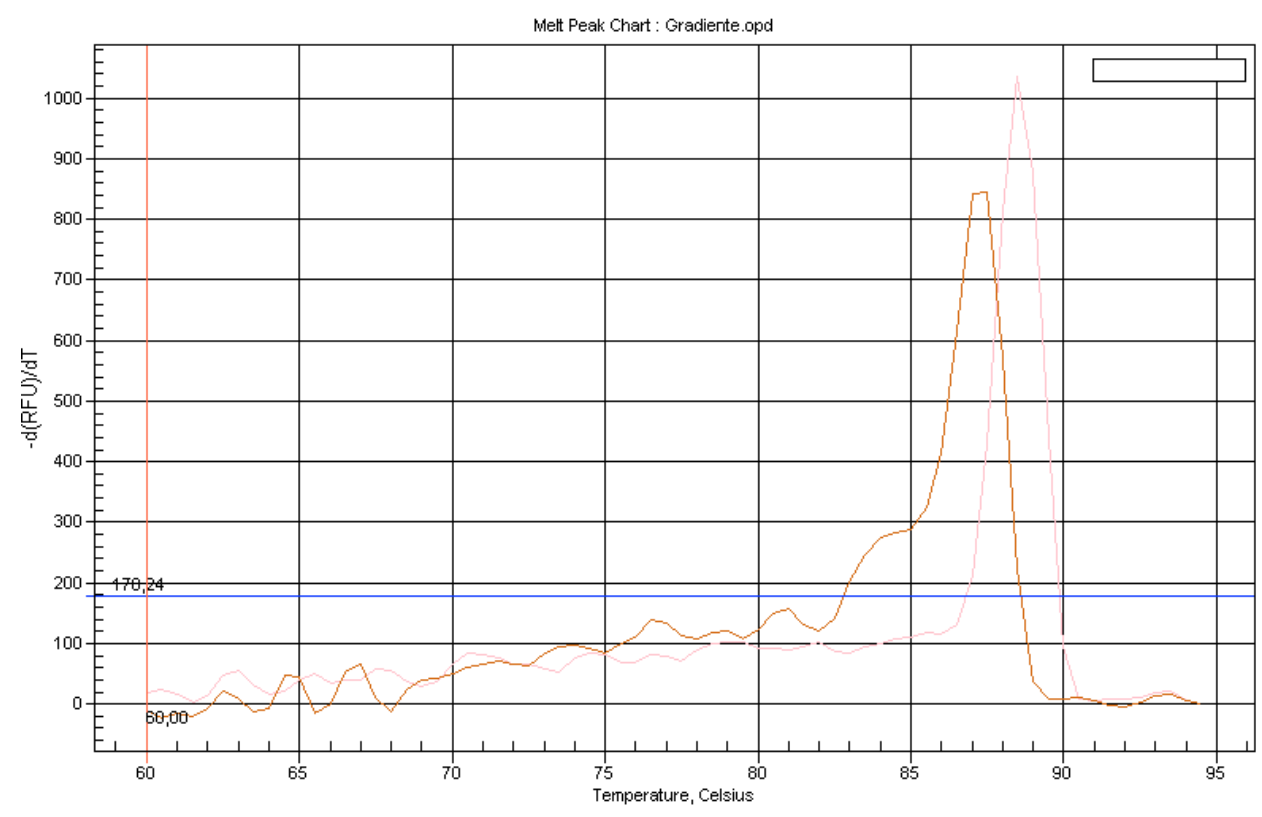

Figura 40. Curva de melting a $52^{\circ} \mathrm{C}$

\subsection{Curva estándar. Cálculo de la eficiencia}

Aunque la cuantificación de ADN se realizó en términos relativos (comparación con el resultado del gen de referencia), fue necesario conocer la eficiencia de amplificación de las parejas de cebadores para ambos genes (el gen de estudio: gen de la Insulina y el gen de referencia o housekeeping: gapdh).

Para calcular la eficiencia usamos la curva estándar o diluciones de una muestra de referencia.

La pendiente de la regresión se relaciona con la eficiencia de las reacciones:

$$
\text { Eficiencia }(\eta)=[10(-1 / \text { pendiente })]-1
$$

La pendiente de la recta de regresión obtenida al representar los valores de Ct frente al logaritmo de la concentración inicial de ADN depende de la eficiencia de la reacción.

En este ensayo utilizamos los mismos componentes de la reacción que en el ensayo del gradiente de temperatura, excepto la cantidad de cDNA, que varía en los distintos pocillos de la placa de RCP según las diluciones (1, 0,5; 0,25 y 0,125). Se ensayaron siempre por triplicado cada uno de los dos genes. 
El esquema del protocolo térmico fue el mismo, variando en el paso 2 del ciclo 3 , en vez de hacer un gradiente de temperatura, le aplicamos la temperatura óptima de 52 $\stackrel{\circ}{ } \mathrm{C}$.

Mediante la ayuda del software asociado al termociclador iCycler, el iQ-5 Estándar Optical System Sofware de Bio-Rad, y con los datos de los Ct calculamos las eficiencias de nuestros genes, siendo para el gen de la Insulina 108,8 \% (Figura 41) y para el gen gapdh 126,6\% (Figura 42).

\section{Protocolo térmico}

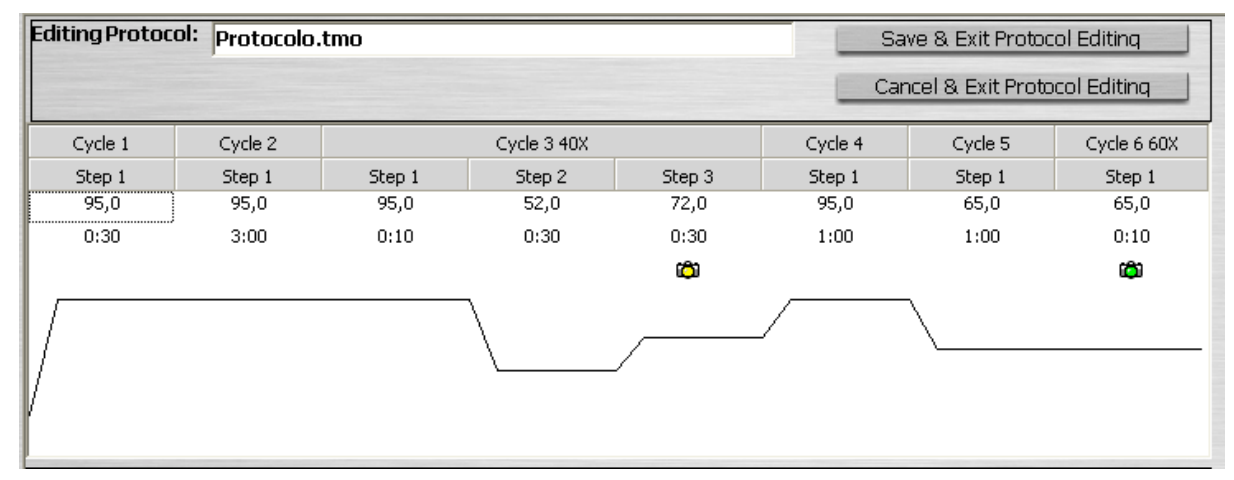

\section{Componentes de la reacción}

- $12,5 \mu \mathrm{L}$ de iQ SYBR SuperMix

- $1 \mu \mathrm{L}$ de primer forward

- $1 \mu \mathrm{L}$ de primer reverse

- $\operatorname{cDNA}(1 \mu \mathrm{L}, 0,5 \mu \mathrm{L}, 0,25 \mu \mathrm{L}, 00,125 \mu \mathrm{L})$

- $\mathrm{H} 2 \mathrm{O}(9,5 \mu \mathrm{L}, 10 \mu \mathrm{L}, 10,25 \mu \mathrm{L}$ o 10,375 $\mu \mathrm{L})$.

- Volumen final de reacción $25 \mu \mathrm{L}$

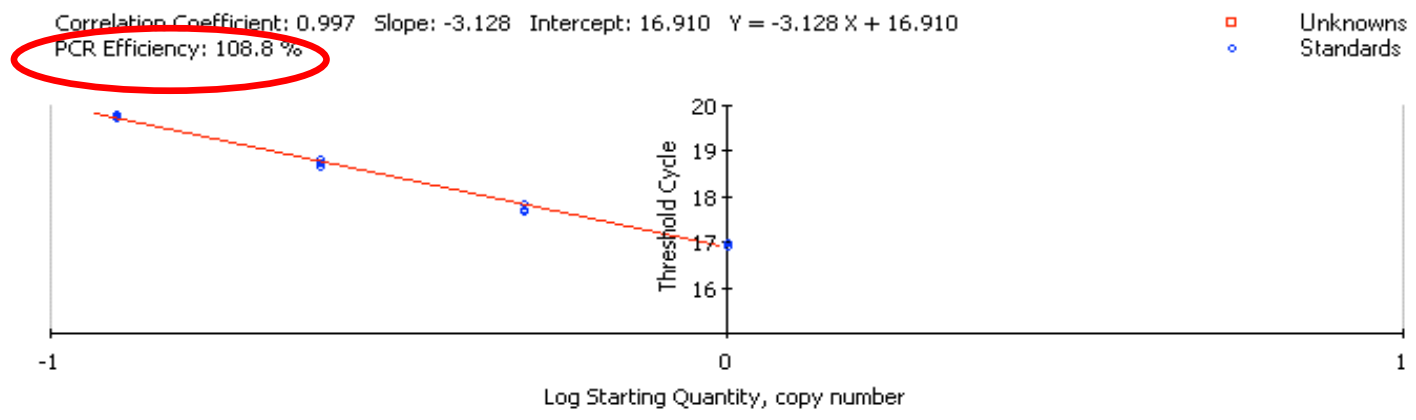

Figura 41. Curva estándar Insulina 


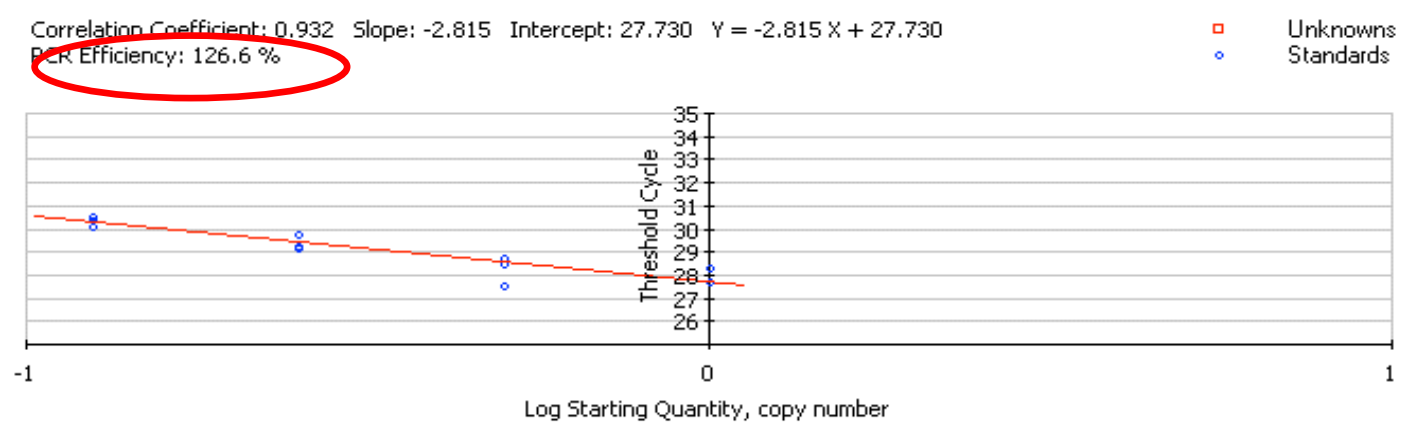

Figura 42. Curva estándar GAPDH

\subsection{Análisis de expresión de genes}

El protocolo térmico y los componentes de las distintas reacciones para cada muestra procedente de cada animal fueron los mismos que en los pasos anteriores.

\section{$>\quad$ Protocolo térmico}

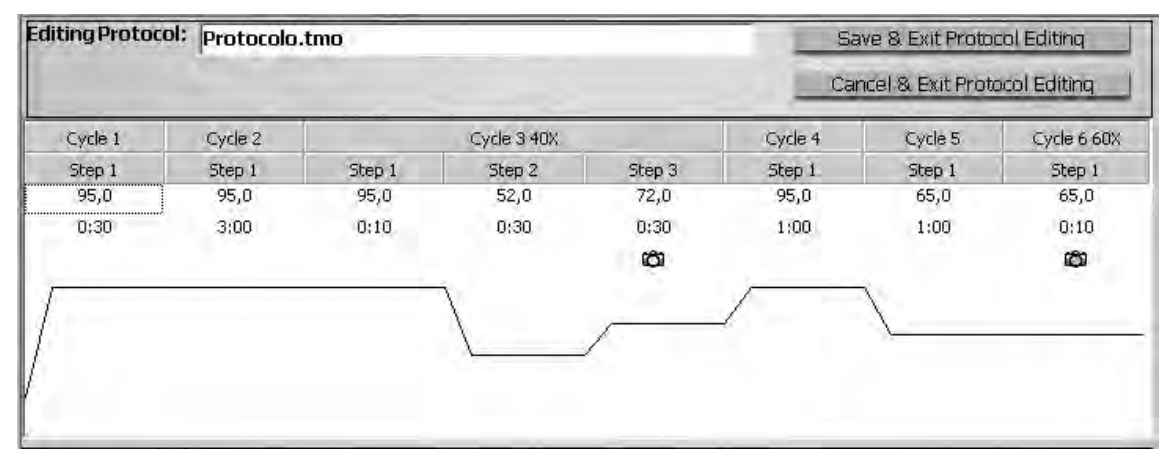

\section{Componentes de las reacciones para Insulina y GAPDH $(\mathrm{Vr}=25 \mu \mathrm{L})$}

- $12,5 \mu \mathrm{L}$ iQ SYBR SuperMix

- $1 \mu \mathrm{L}$ de primer forward Insulina (o de GAPDH)

- $1 \mu \mathrm{L}$ de primer reverse Insulina (o de GAPDH)

- $1 \mu \mathrm{L}$ de cDNA de cada muestra

- $9,5 \mu \mathrm{L}$ de $\mathrm{H} 2 \mathrm{O}$ 
Se calculan las medias de los Ct de cada muestra que se había medido por triplicado y teniendo en cuenta estas eficiencias de los genes calculadas en los experimentos anteriores, calculamos los niveles de expresión de cada muestra con respecto a la expresión de una muestra control.

Los datos de los Ct correspondientes a estas muestras fueron copiados en unas hojas de cálculo basadas en el programa de Microsoft Excel (Gene Expresión Analysis for iCycler $i Q^{\circledR}$ ) creada para hallar la expresión de los genes.

Una vez halladas las medias de los Ct de cada muestra, que se había medido por triplicado y teniendo en cuenta estas eficiencias de los genes calculadas en los experimentos anteriores, calculamos los niveles de expresión de cada muestra con respecto a la expresión de una muestra control.

Para hacer la cuantificación relativa de la expresión del gen de la insulina, usamos el método ddCt, ya que tenemos un sólo gen de referencia (Pfaffl Nuc Acids Res 29, 2003-2007). Este método se basa en la siguiente fórmula:

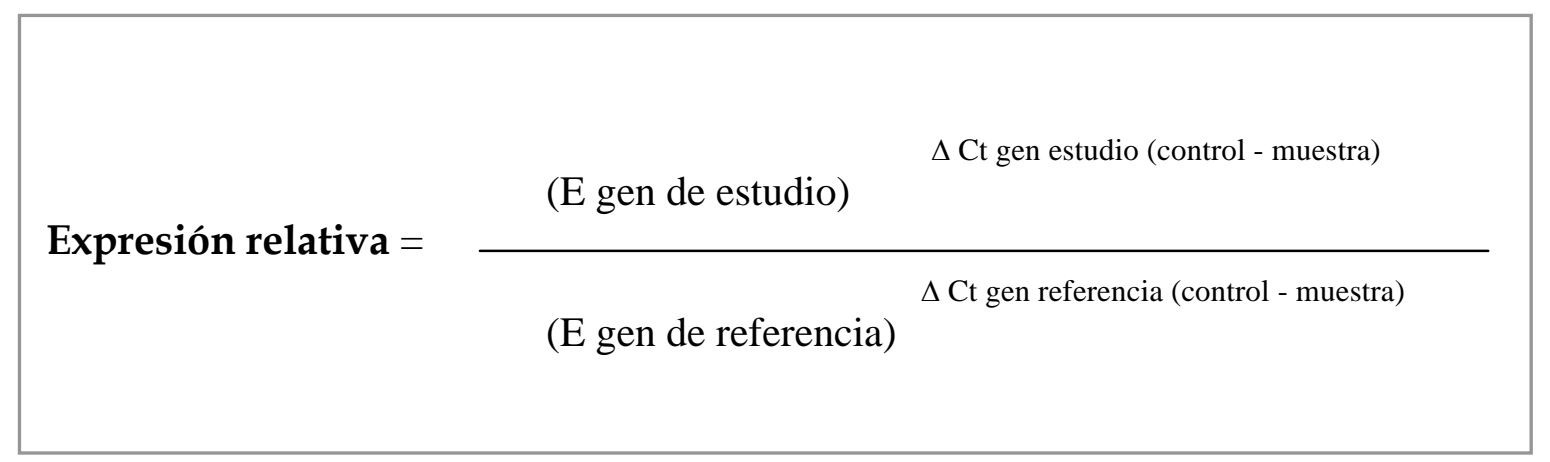

Siendo:

$\Delta$ Ct gen estudio (control - muestra); diferencia entre el valor del Ct del control (control negativo en nuestro caso) y el Ct de la muestra en el gen de estudio (insulina).

$\Delta$ Ct gen referencia (control - muestra); diferencia entre el valor del Ct del control (control negativo en nuestro caso) y el Ct de la muestra en el gen de referencia (gapdh). 


\section{G. ANÁLISIS ESTADISTICO}

Las variables cuantitativas serán descritas como media \pm desviación estándar (DE) y su normalidad será establecida con la prueba de Kolmogorov-Smirnov. Por su parte, las variables cualitativas serán descritas mediante frecuencias absolutas y relativas (porcentajes). Los gráficos utilizados en la descripción de las variables cuantitativas (medias) por grupos serán los gráficos de barras o las barras de error (en ambos casos con intervalo de confianza del 95\%).

La estadística analítica fue realizada según las condiciones de aplicación, utilizando las siguientes pruebas:

- Para estudiar las diferencias entre medias la t de Student o la de la U de MannWhitney.

- Para determinar las diferencias de las medias con relación al valor basal la t de Student para muestras relacionadas o la prueba de Wilcoxon.

- Para establecer la relación entre variables cuantitativas la correlación de Pearson o la de Spearman.

El nivel de significación se consideró para una $p \leq 0,05$.

El análisis estadístico se realizó con el programa SPSS v. 15.0 con licencia de la Universidad de Valladolid.

\section{H. REVISIÓN BIBLIOGRÁFICA}

La revisión bibliográfica se ha realizada a través de la página de PubMed (http://www.ncbi.nlm.nih.gov/PubMed), un servicio de acceso libre online a la Base de datos Medline proporcionado por la National Library of Medicine (NLM).. Para la búsqueda inicial se han empleado términos libres con las palabras clave "cirugía metabólica", "cirugía bariátrica", "gastrectomía vertical en ratas y Goto-Kakizaki", "diabetes tipo 2", "insulina", "incretinas", "leptina”, "islotes pancreáticos”, "tolerancia a la glucosa". 
La búsqueda libre ha sido completada con la utilización de vocabulario controlado $(\mathrm{MeSH})$ restringiéndola a un término o ampliándola a varios si ha sido necesario. En ocasiones, los términos de búsqueda se han limitado a los años 1995-2012, a la búsqueda de revisiones y de artículos completos, en inglés y español. De los artículos recuperados se seleccionaron los que aportaban la información más relevante a criterio personal.Además, se han utilizado los manuales adjuntos a algunos de los materiales requeridos y libros de texto y las monografías actualizadas de mayor relevancia. Una parte de la bibliografía se obtuvo a través de los estudios o revisiones procedentes de las fuentes anteriores.

\section{ASPECTOS LEGALES Y FINANCIACIÓN}

La realización de este trabajo se ha atenido a lo dispuesto en la normativa legal vigente sobre experimentación animal y, en particular, en el Real Decreto 1201/2005, de 10 de octubre, sobre protección de los animales utilizados para experimentación y otros fines científicos, y la Ley 32/2007, de 7 de noviembre, para el cuidado de los animales en su explotación, transporte, experimentación y sacrificio. Se contó, asimismo, con la aprobación de la Comisión de Investigación del Hospital Universitario Río Hortega y del Comité Ético de Investigación Clínica del Área Oeste de Valladolid.

El trabajo ha sido financiado por la Red temática de Envejecimiento y Fragilidad (RETICEF) (RD06/0013/1019) del Instituto de Salud Carlos III, por la Gerencia Regional de Salud de la Consejería de Sanidad de la Junta de Castilla y León a través del proyecto de investigación con referencia GRS 193/A/08 y por el Hospital Universitario Río Hortega (SACYL). 

RESULTADOS. 



\section{SECCIÓN 1}

\section{RESULTADOS DE LOS ENSAYOS IN VIVO Y EN LOS ISLOTES PANCREÁTICOS}

\section{PESOS DE LOS ANIMALES}

El peso presentó una distribución normal (Figuras 43 - 45) en el grupo experimental y en los diferentes tiempos.

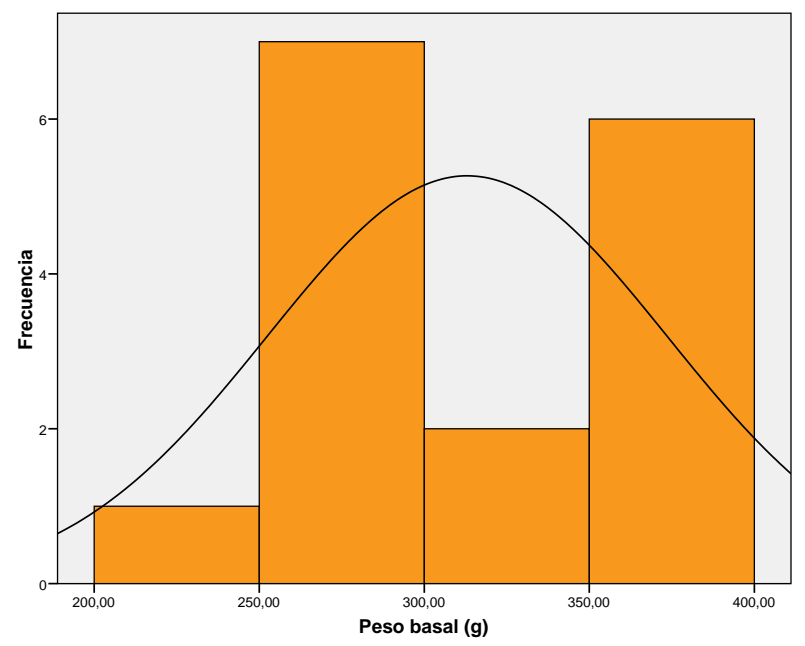

Figura 43: Peso de los animales (gramos) en la semana 0 del ensayo.

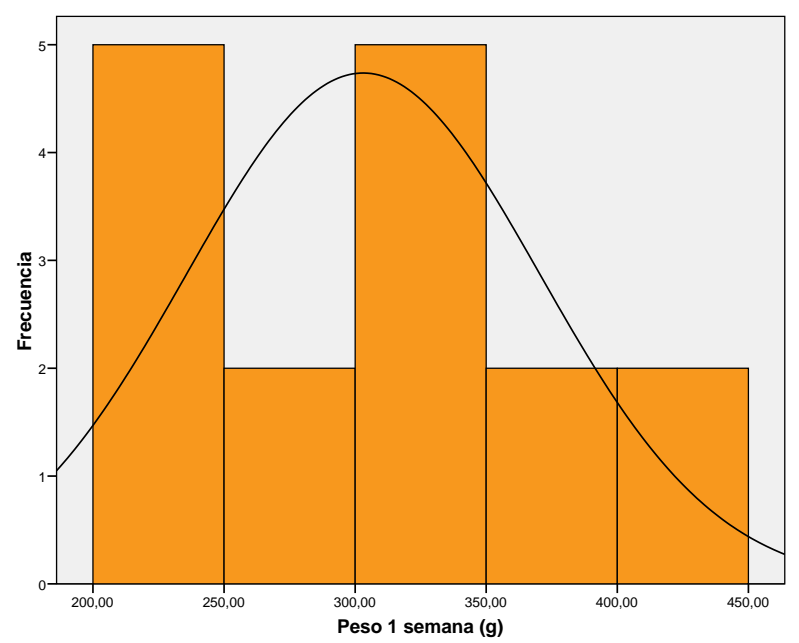

Figura 44: Peso de los animales (gramos) en la semana 1 


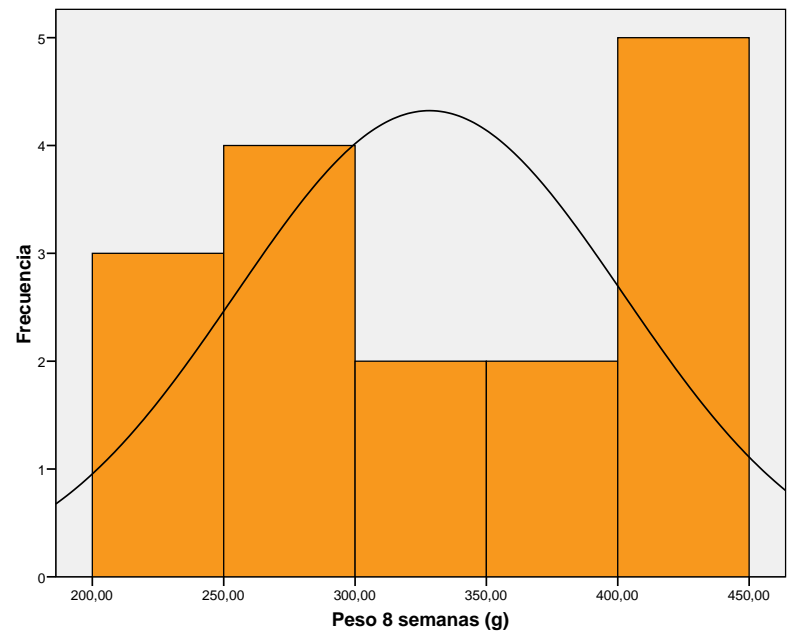

Figura 45: Peso de los animales (gramos) la semana 8 del ensayo.

Se observó una mínima tendencia al aumento de peso en el grupo experimental, a las 8 semanas de la intervención, que no fue estadísticamente significativa (Tabla 11, Figura 46).

\begin{tabular}{|l|c|c|c|}
\hline & Semana 0 & Semana 1 & Semana 8 \\
\hline PESO & $313,0 \pm 60,6$ & $303,1 \pm 67,4$ & $328,3 \pm 73,8$ \\
\hline
\end{tabular}

Tabla 11: Diferencias de peso (gr) en los diferentes tiempos.

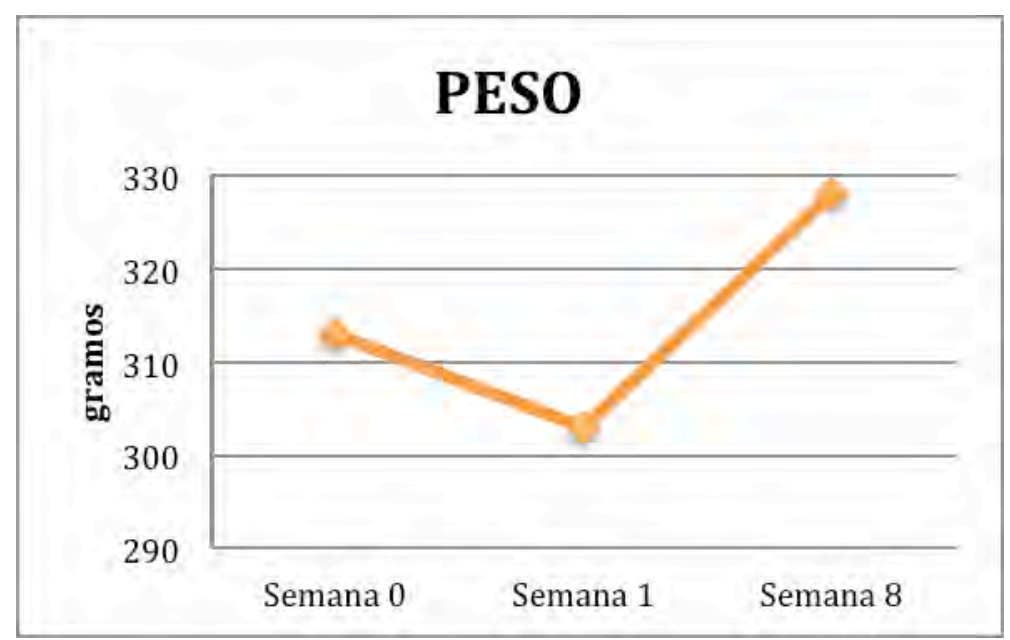

Figura 46: Pesos de los animales (gramos). 


\section{TEST DE TOLERANCIA ORAL A LA GLUCOSA.}

Todas las diferentes variables estudiadas presentaron una distribución normal (Figuras 47-61).

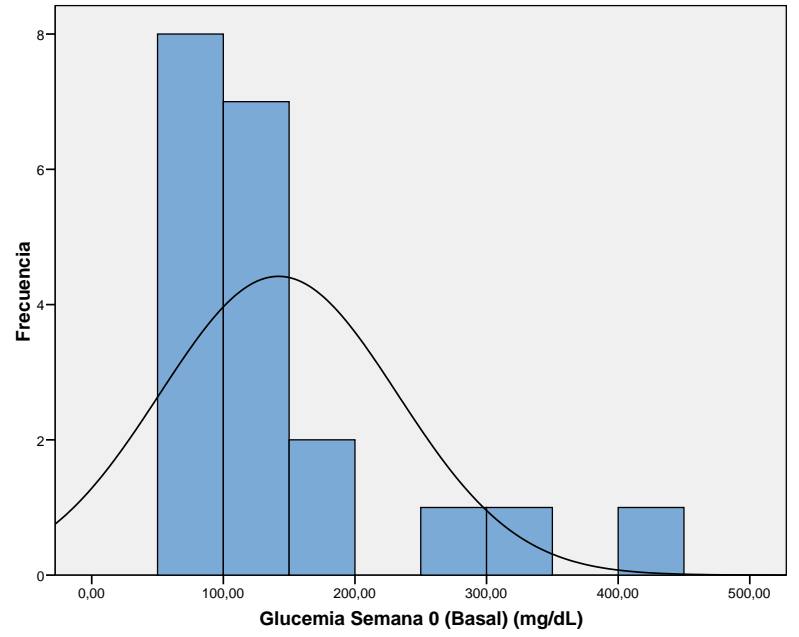

Figura 47: Glucemia basal a la semana 0 del experimento

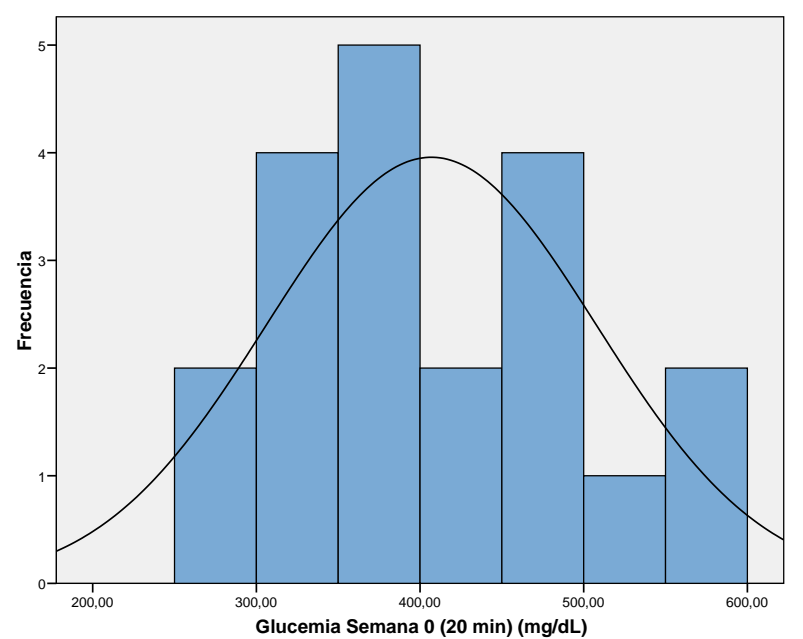

Figura 48: Glucemia a los 20 minutos del test de tolerancia oral a la glucosa (TTOG) en la semana 0.

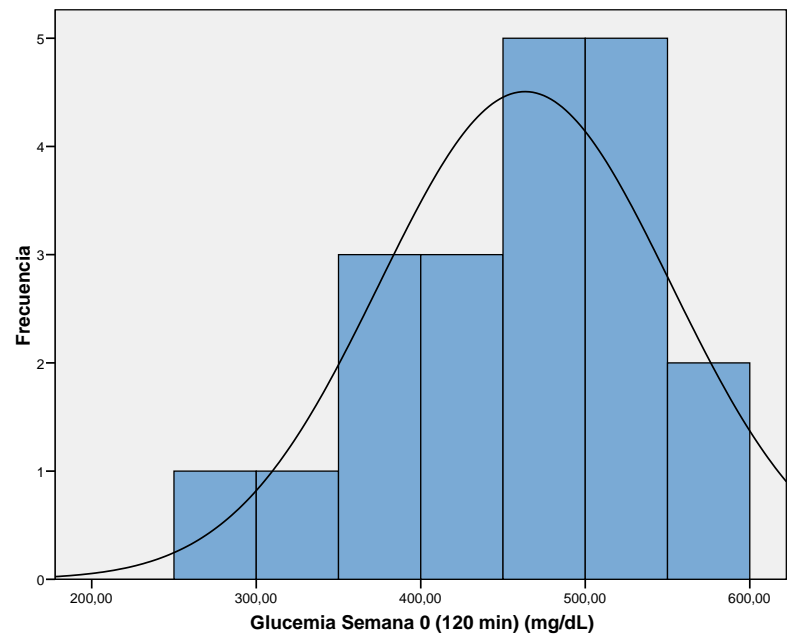

Figura 49: Glucemia a los 120 minutos del test de tolerancia oral a la glucosa (TTOG) en la semana 0. 


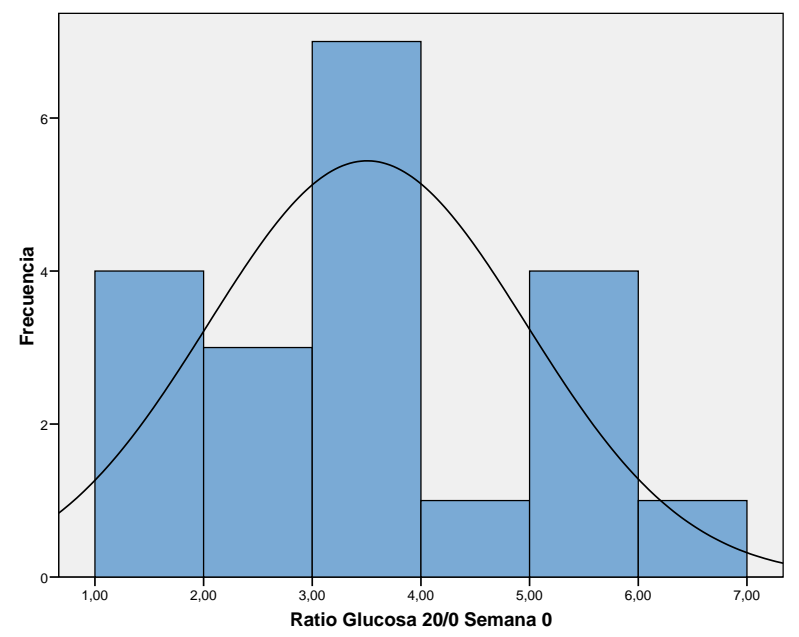

Figura 50: Ratio de glucemias a los 20 minutos del test de tolerancia oral a la glucosa (TTOG) y basal en la semana 0 .

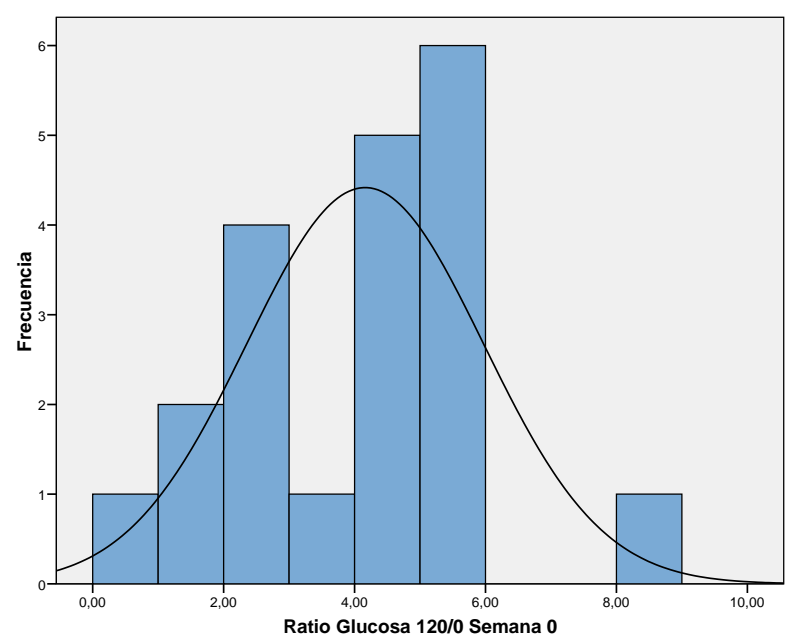

Figura 51: Ratio de glucemias a los 120 minutos del test de tolerancia oral a la glucosa (TTOG) y basal en la semana 0 .

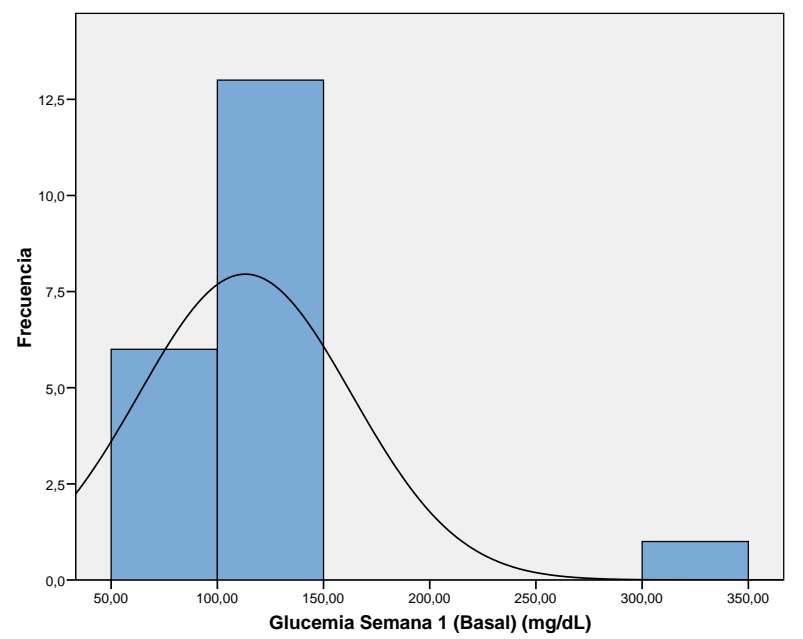

Figura 52: Glucemia basal en la semana 1 del experimento. 


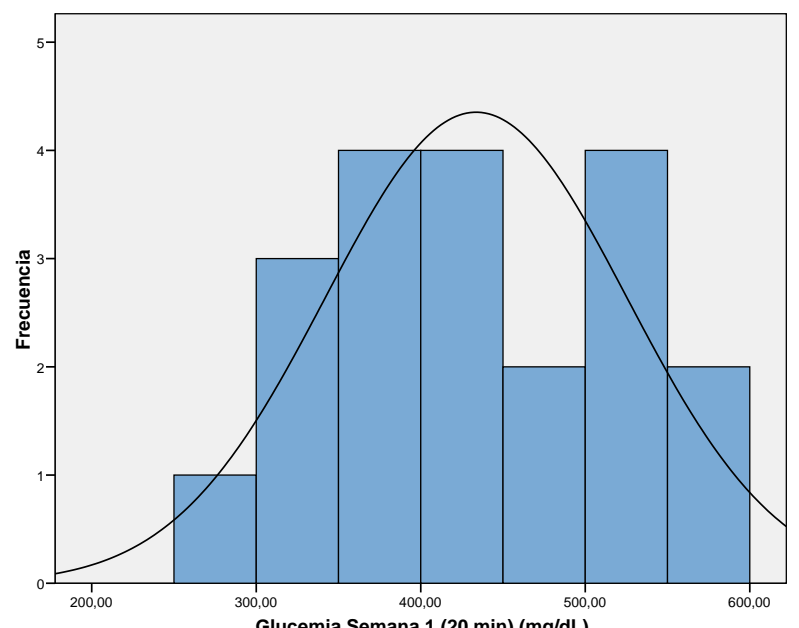

Figura 53: Glucemia a los 20 minutos del test de tolerancia oral a la glucosa (TTOG) en la semana 1.

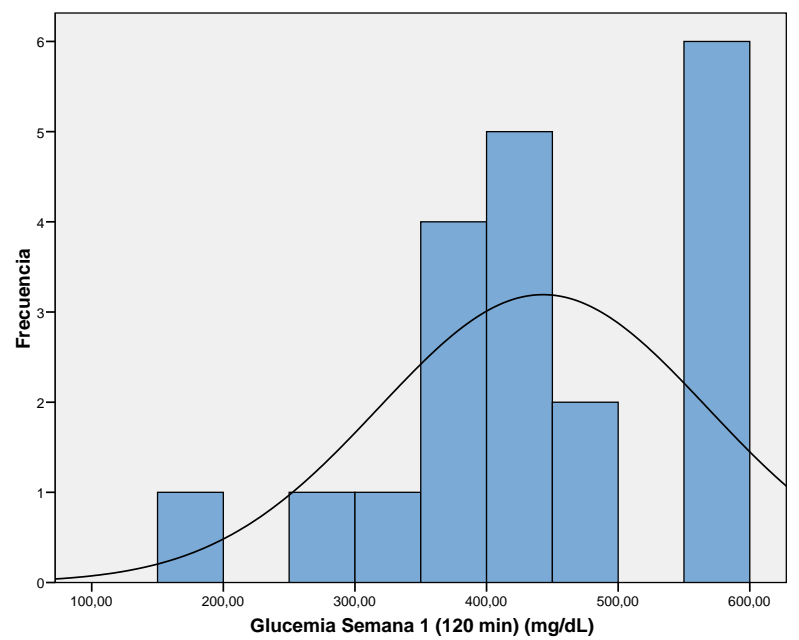

Figura 54: Glucemia a los 120 minutos del test de tolerancia oral a la glucosa (TTOG) en la semana 1.

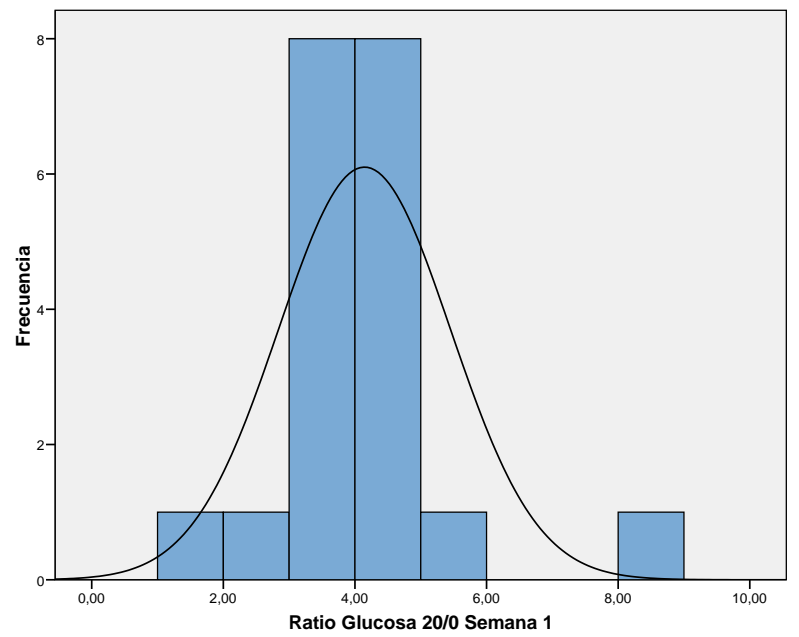

Figura 55: Ratio de glucemias a los 20 minutos del test de tolerancia oral a la glucosa (TTOG) y basal en la semana 1. 


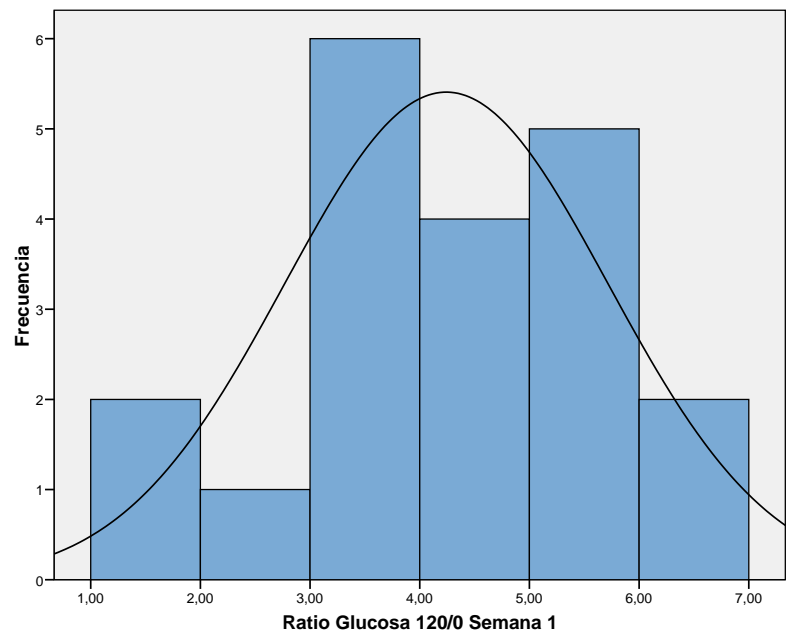

Figura 56: Ratio de glucemias a los 120 minutos del test de tolerancia oral a la glucosa (TTOG) y basal en la semana 1.

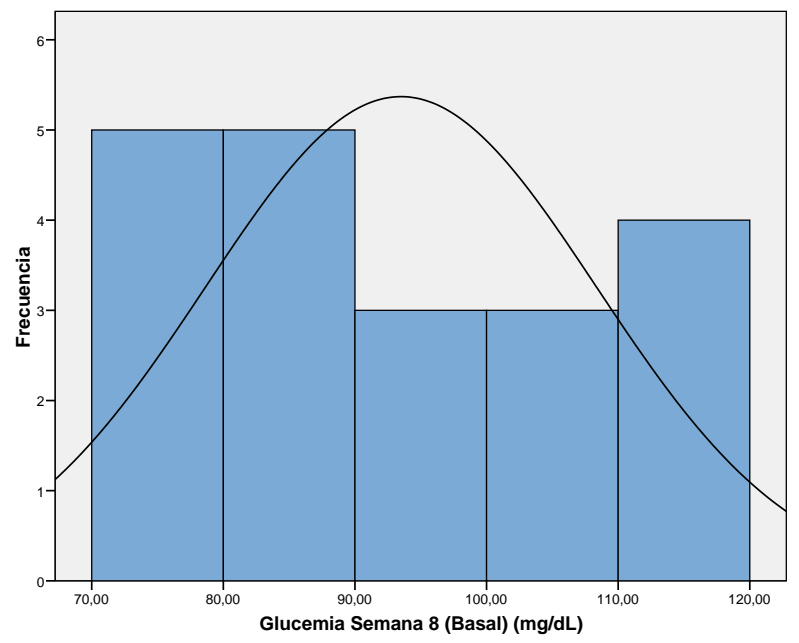

Figura 57: Glucemia basal en la semana 8.

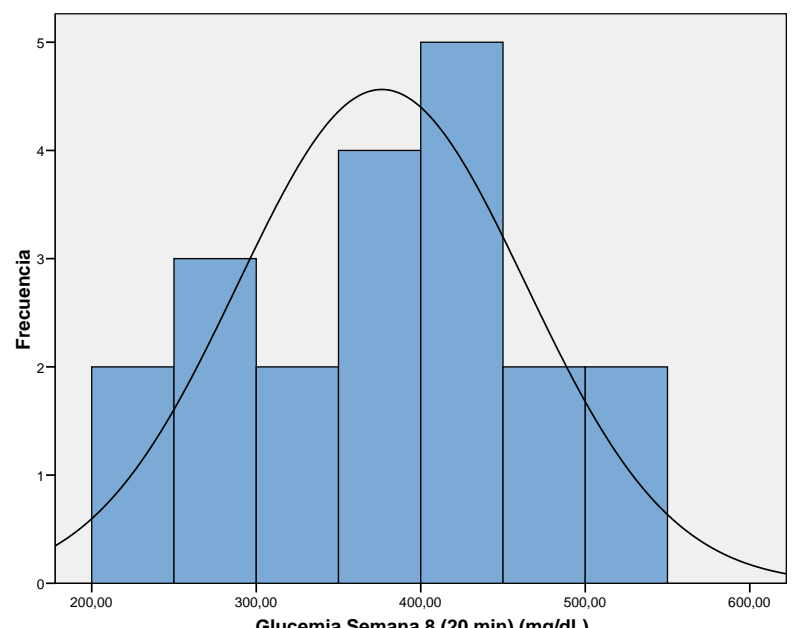

Figura 58: Glucemia a los 20 minutos del test de tolerancia oral a la glucosa (TTOG) en la semana 8. 


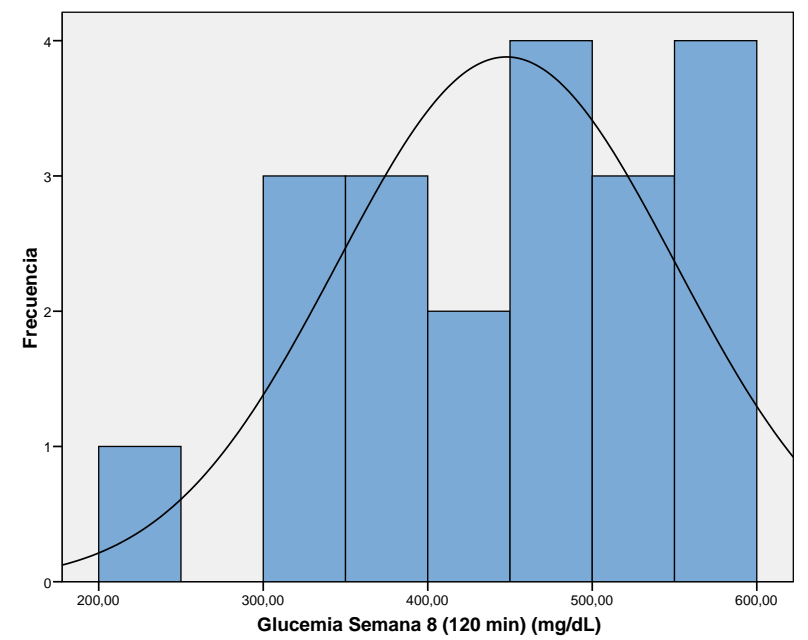

Figura 59: Glucemia a los 120 minutos del test de tolerancia oral a la glucosa (TTOG) en la semana 8.

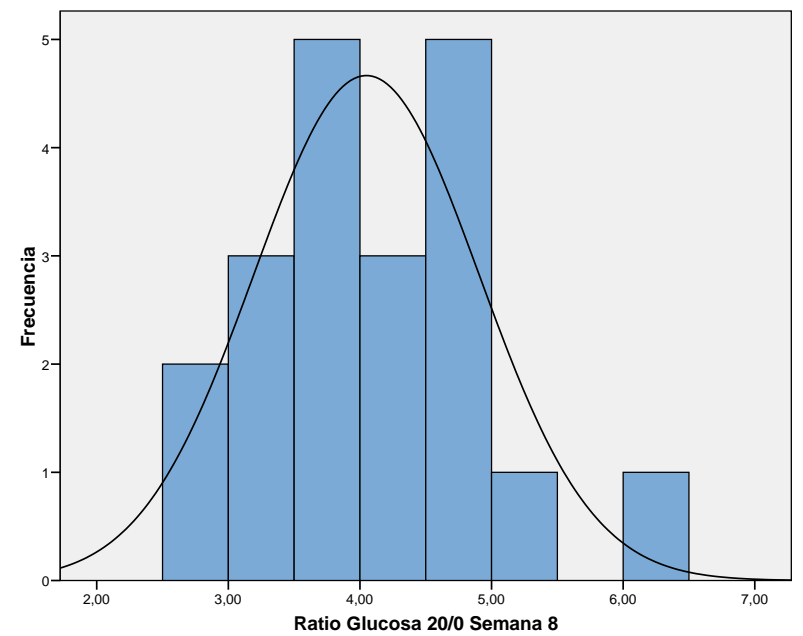

Figura 60: Ratio de glucemias a los 20 minutos del test de tolerancia oral a la glucosa (TTOG) y basal en la semana 8.

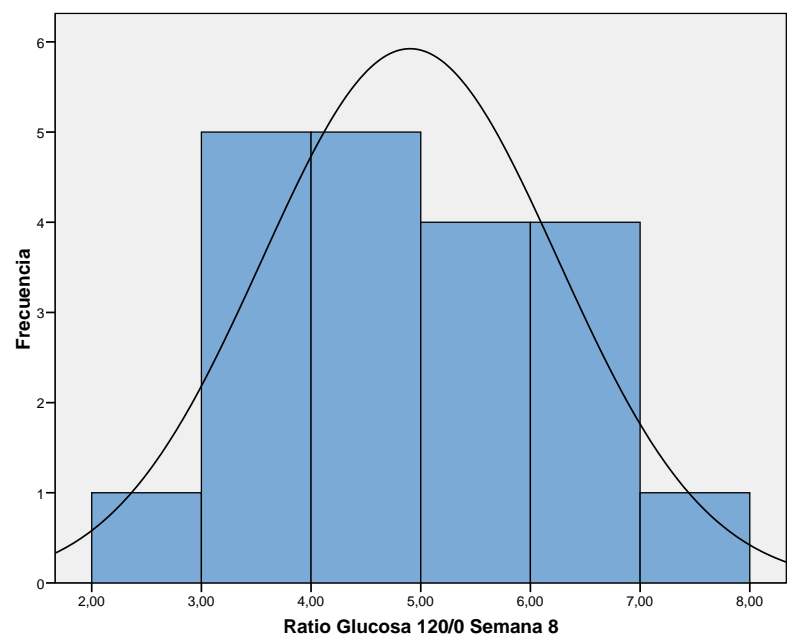

Figura 61: Ratio de glucemias a los 120 minutos del test de tolerancia oral a la glucosa (TTOG) y basal en la semana 8 . 
Se observó una disminución significativa de los niveles de glucemia basal a la semana 8 de la intervención, llegando a cifras de normoglucemia. (Tabla 12 y Figura 62) Las glucemias tras la sobrecarga oral de glucosa mejoraron ligeramente en la semana 8 en la medición realizada a los 20 minutos y en las semanas 1 y 8 a los 120 minutos respecto a las cifras preoperatorias, sin alcanzar significación estadística. (Tabla 12 y Figuras 63 y 64) En los ratios 20/0 y 120/0 no se observaron diferencias significativas (Tabla 12 y Figura 65).

\begin{tabular}{|c|c|c|c|}
\hline & Semana 0 & Semana 1 & Semana 8 \\
\hline $0 \mathrm{~m}$ & $141,9 \pm 90,3$ & $113,1+/-50,1$ & $93,5+/-14,8^{*}$ \\
\hline $20 \mathrm{~m}$ & $406,9+/-100,8$ & $433,6+/-91,6$ & $376,3+/-87,4$ \\
\hline $120 \mathrm{~m}$ & $463,4+/-88,5$ & $442,9+/-124,9$ & $447,8+/-102,8$ \\
\hline Ratio 20/0 & $3,5+/-1,4$ & $4,1+/-1,3$ & $4,0+/-0,8$ \\
\hline Ratio 120/0 & $4,1+/-1,8$ & $4,2+/-1,4$ & $4,9+/-1.3$ \\
\hline
\end{tabular}

Tabla 12: Evolución temporal en los niveles de glucemia $(\mathrm{mg} / \mathrm{dl})$ basales y tras TTOG en los diferentes tiempos.

${ }^{*} \mathrm{p}=0,023$ comparado con semana 0 .

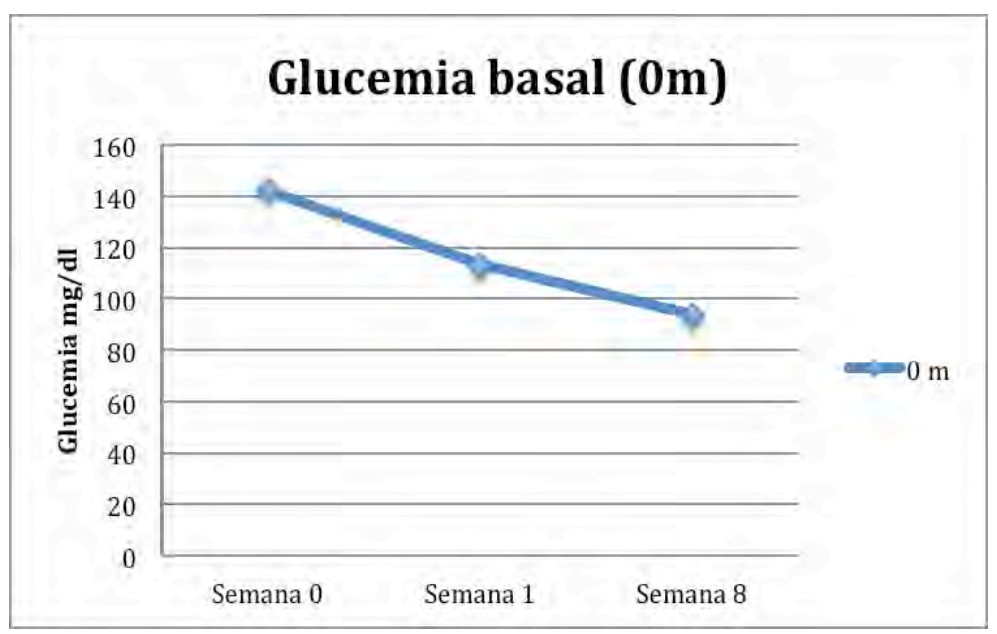

Figura 62: Glucemia basal.

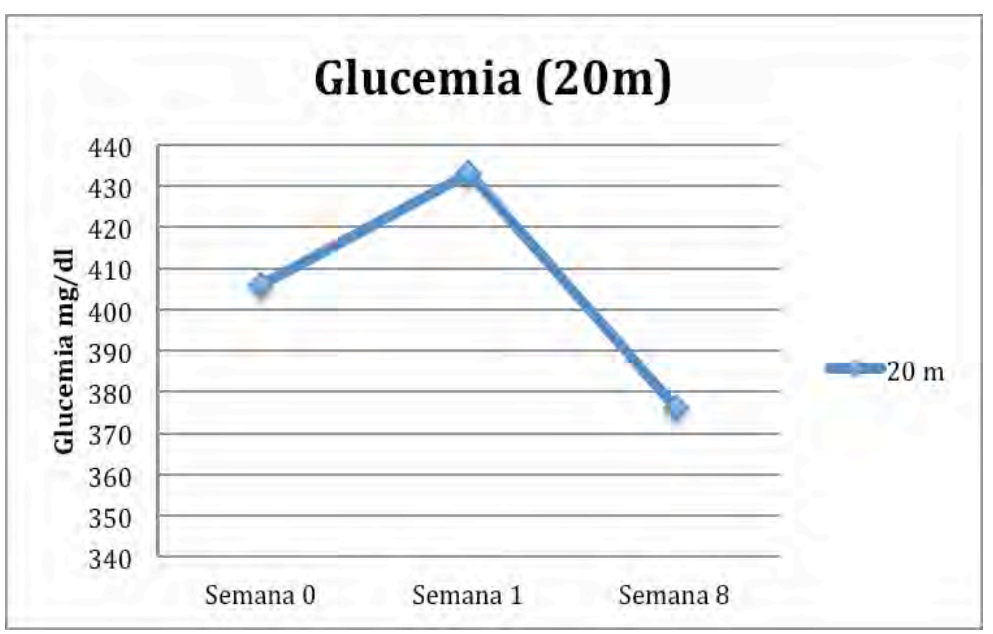

Figura 63: Glucemia tras 20 minutos del TTOG. 


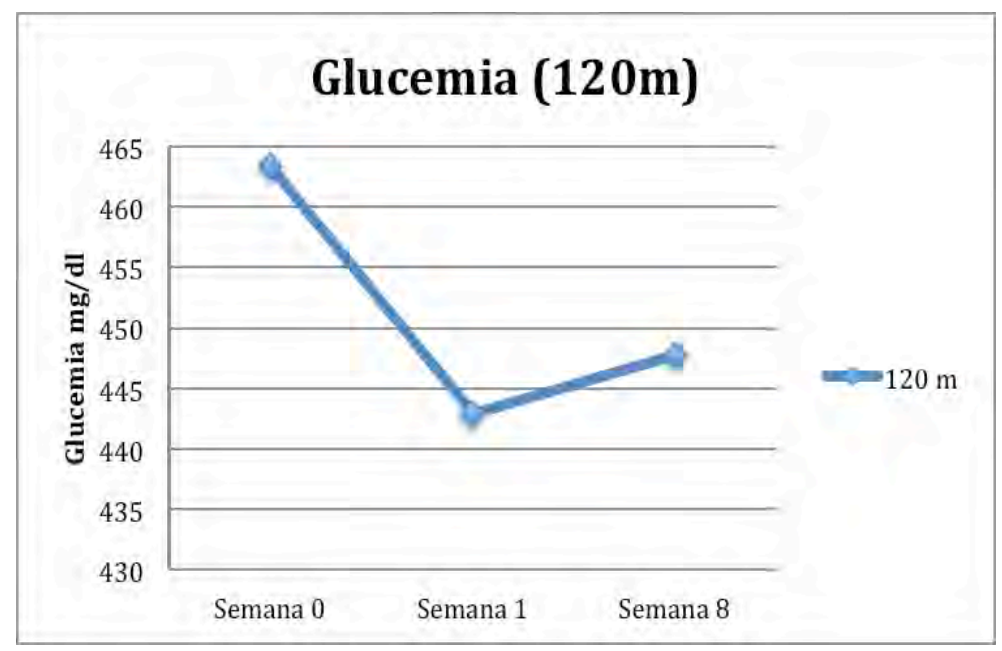

Figura 64: Glucemia tras 120 m del TTOG.

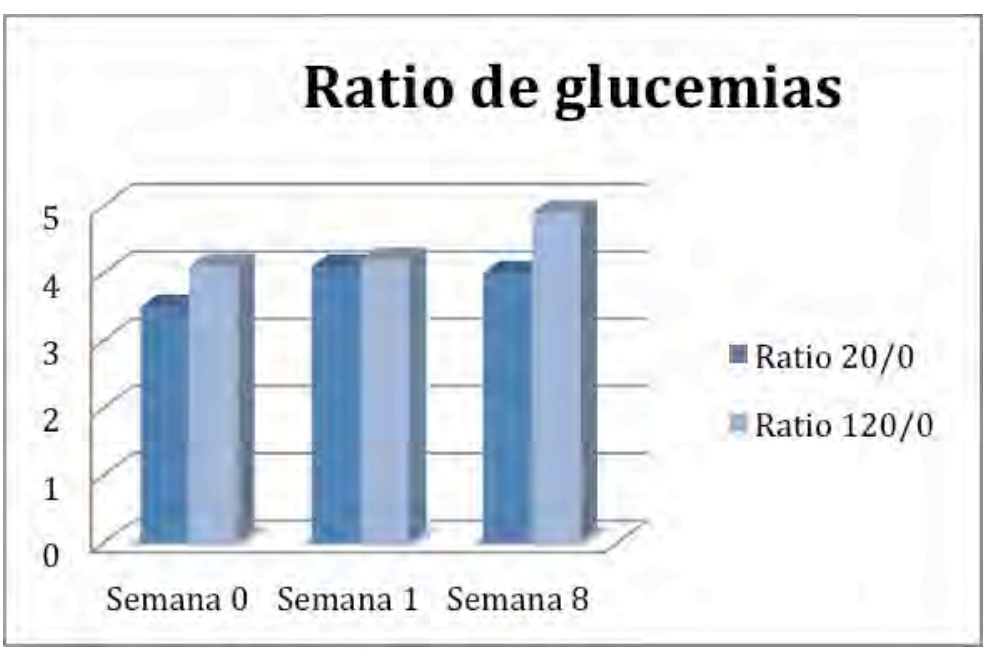

Figura 65: Ratio de glucemia tras 20 y 120 minutos del TTOG y glucemia basal.

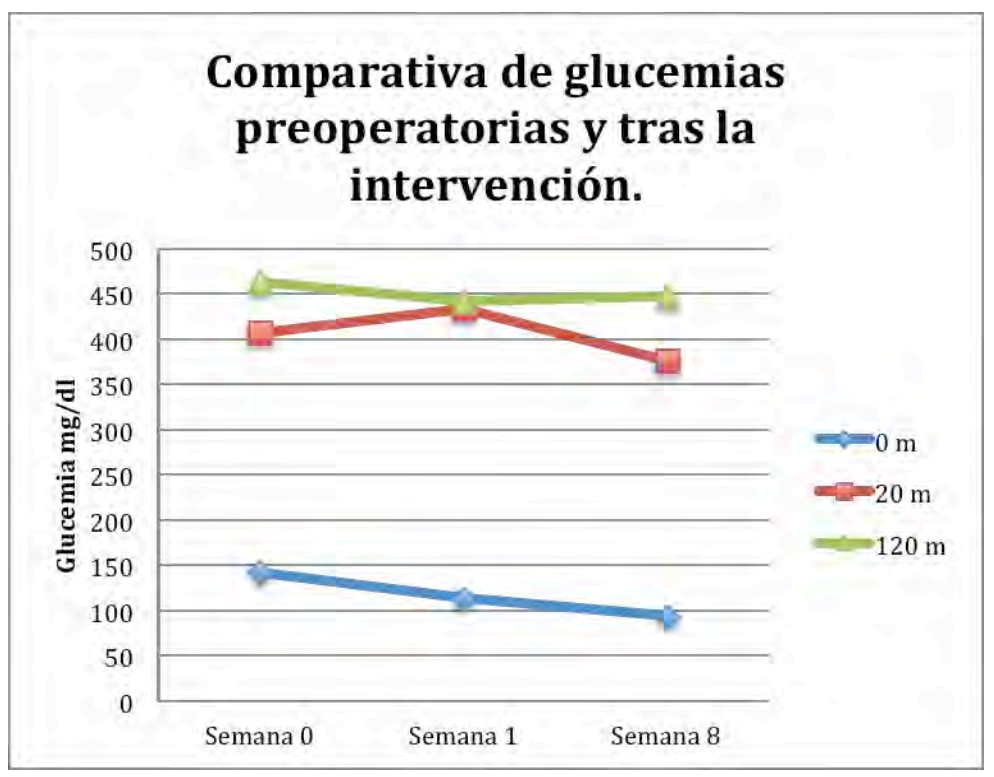

Figura 66: Comparativa de glucemias en los diferentes tiempos del experimento. 


\section{RESULTADOS DE LOS PÉPTIDOS ENTEROINSULARES}

\subsection{INSULINA}

Los valores de insulina (determinados tras sobrecarga oral de glucosa) presentaron una distribución normal en el grupo experimental (Figuras 67 - 69).

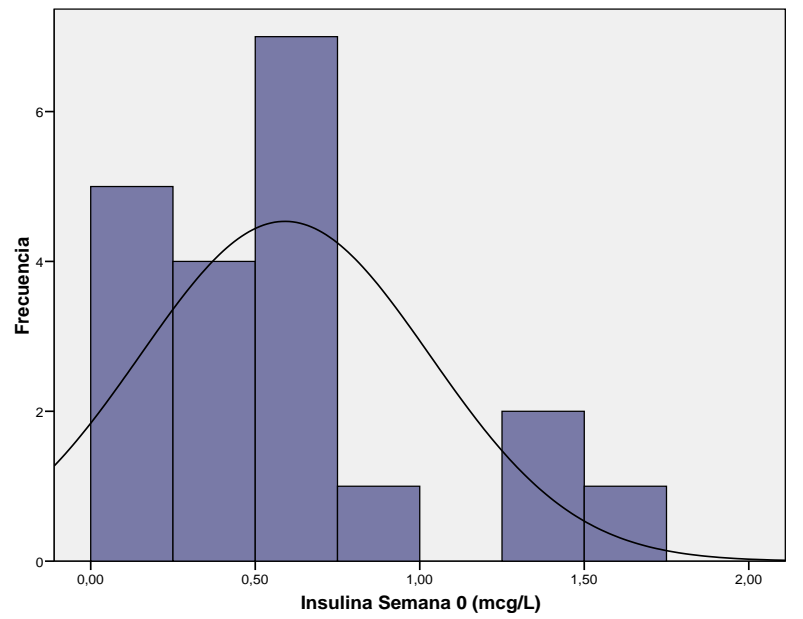

Figura 67: Niveles de insulina sérica en la semana 0 del experimento.

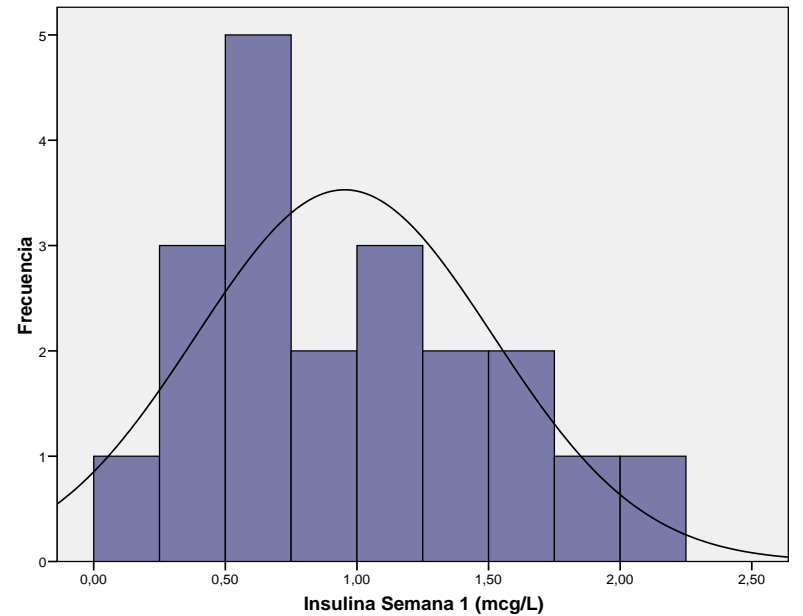

Figura 68: Niveles de insulina sérica en la semana 1 del experimento.

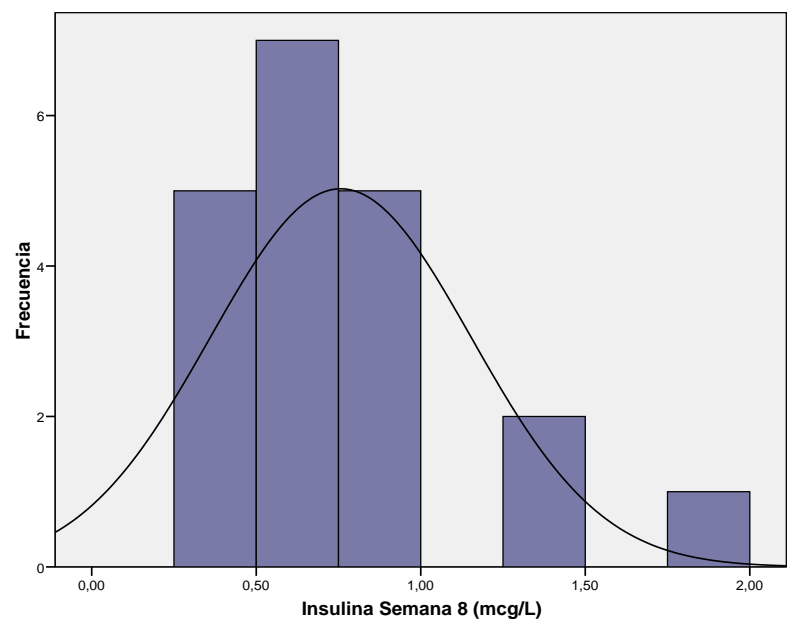

Figura 69: Niveles de insulina sérica en la semana 8 del experimento. 
Se observó un aumento en la concentración de insulina en las semanas 1 y 8 siendo mayor y estadísticamente significativo en la semana 1 del protocolo (Tabla 13 y Figura 70).

\begin{tabular}{|c|c|c|c|c|c|}
\hline & Semana 0 & Semana 1 & Semana 8 & $\begin{array}{c}\text { Diferencias } \\
\mathbf{0 - 1}(\%)\end{array}$ & $\begin{array}{c}\text { Diferencias } \\
\mathbf{0 - 8}(\%)\end{array}$ \\
\hline Insulina & $0,59 \pm 0,43$ & $0,95 \pm 0,56^{*}$ & $0,75 \pm 0,39$ & $+65 \%$ & $+27 \%$ \\
\hline
\end{tabular}

Tabla 13: Evolución temporal en los niveles de insulina $(\mathrm{mcg} / \mathrm{l})$ y diferencias respecto al basal. ${ }^{*} \mathrm{p}=0,02$ comparado con semana 0 .

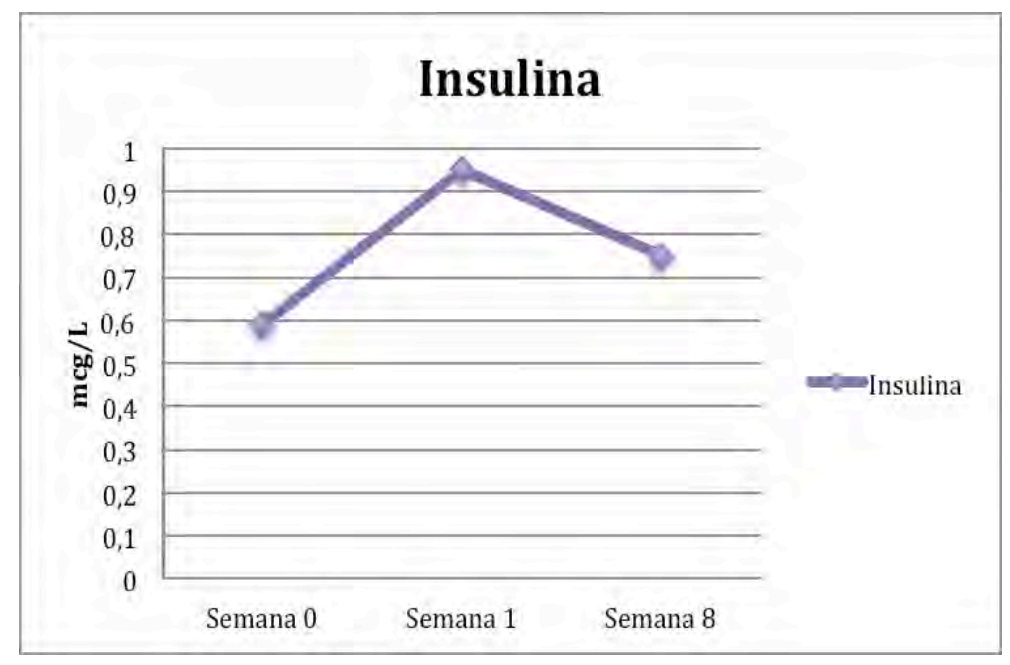

Figura 70: Niveles de insulina. 


\subsection{INDICE DE RESISTENCIA A LA INSULINA (HOMA)}

Los resultados en los diferentes tiempos del experimento al calcular el índice de resistencia a la insulina HOMA, mostraron una distribución normal (Figuras 71 - 73).

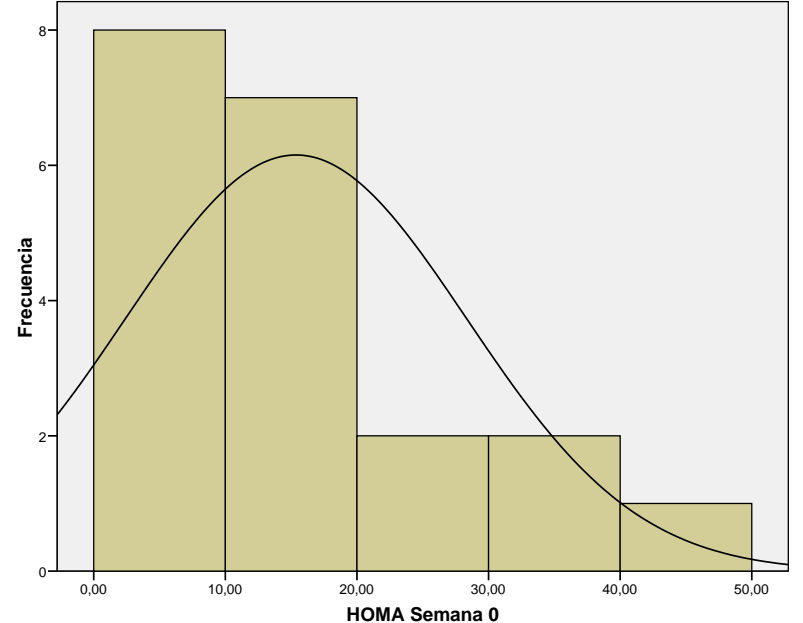

Figura 71: Indice de Resistencia a la Insulina (HOMA) en la semana 0.

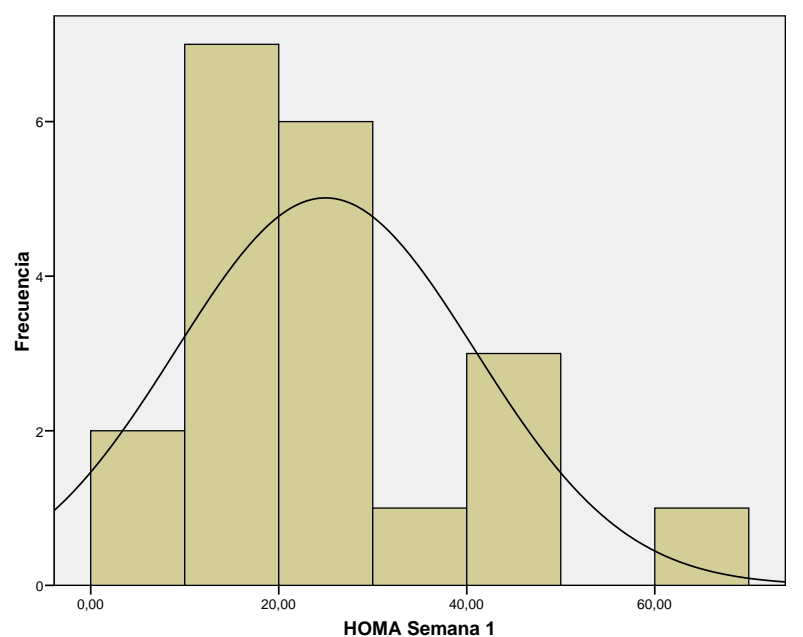

Figura 72: Indice de Resistencia a la Insulina (HOMA) en la semana 1.

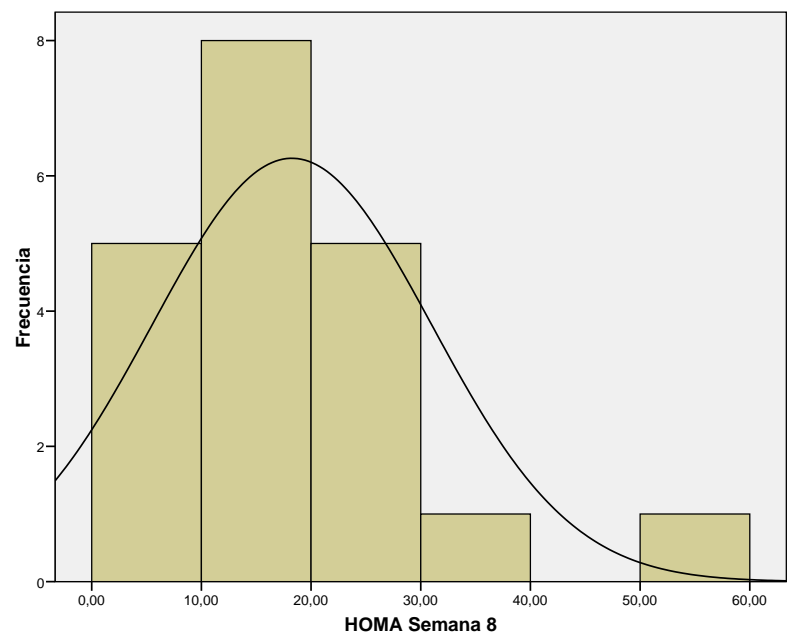

Figura 73: Indice de Resistencia a la Insulina (HOMA) en la semana 8. 
Se observó un aumento en la resistencia a la insulina medida por el índice HOMA en los diferentes tiempos del experimento siendo este aumento, estadísticamente significativo en la semana 1 ( Tabla 14 y Figura 74)

\begin{tabular}{|l|c|c|c|}
\hline & Semana 0 & Semana 1 & Semana 8 \\
\hline HOMA & $15,3 \pm 12,9$ & $24,9 \pm 15,9^{*}$ & $18,2 \pm 12,7$ \\
\hline
\end{tabular}

Tabla 14: Evolución en el Indice de resistencia a la Insulina HOMA. ${ }^{*} p=0,046$ comparado con semana 0 .

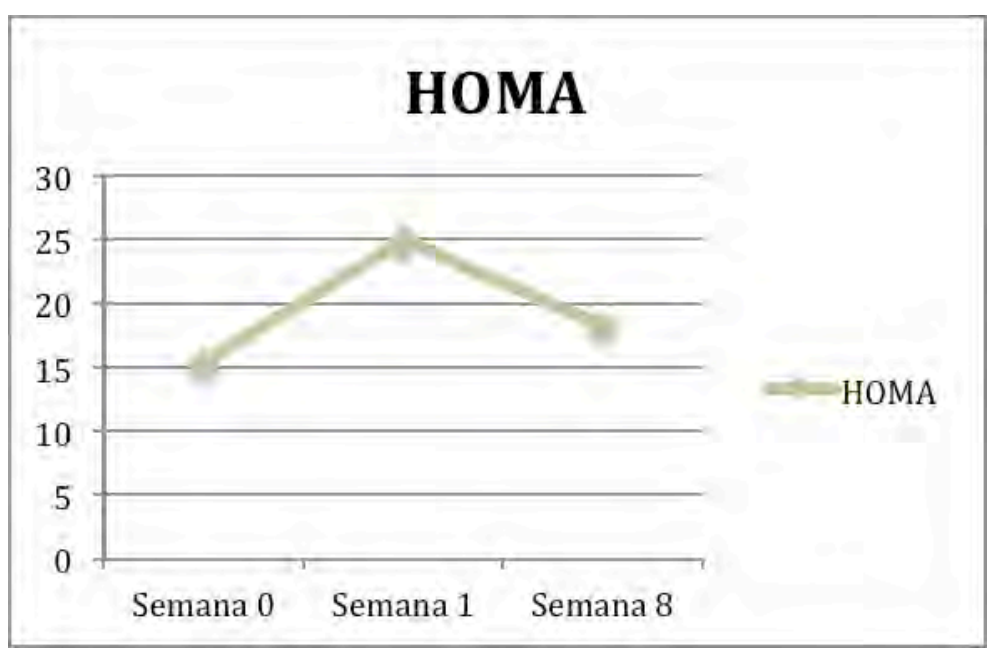

Figura 74: Evolución temporal del índice de resistencia a la insulina (HOMA) 


\subsection{INDICE DE SENSIBILIDAD A LA INSULINA QUICKi.}

Los datos del índice de sensibilidad a la insulina mostraron una distribución normal excepto en la semana 1 que presentaron una distribución no normal.

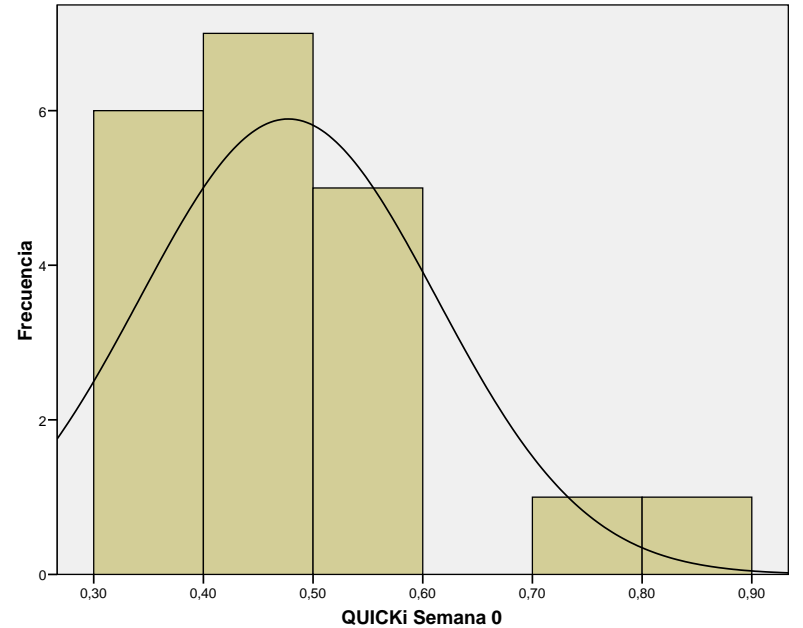

Figura 75: Indice de sensibilidad a la insulina (QUICKi) en la semana 0.

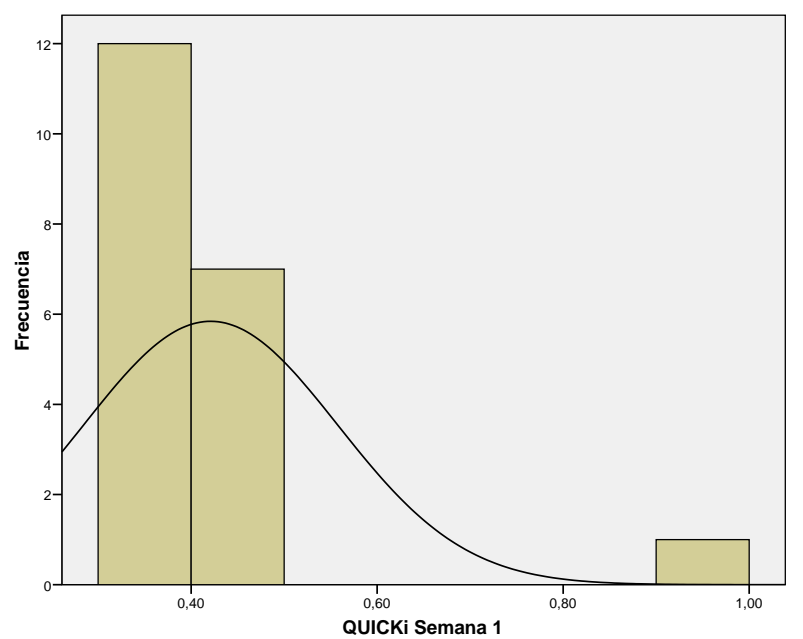

Figura 76: Indice de sensibilidad a la insulina (QUICKi) en la semana 1.

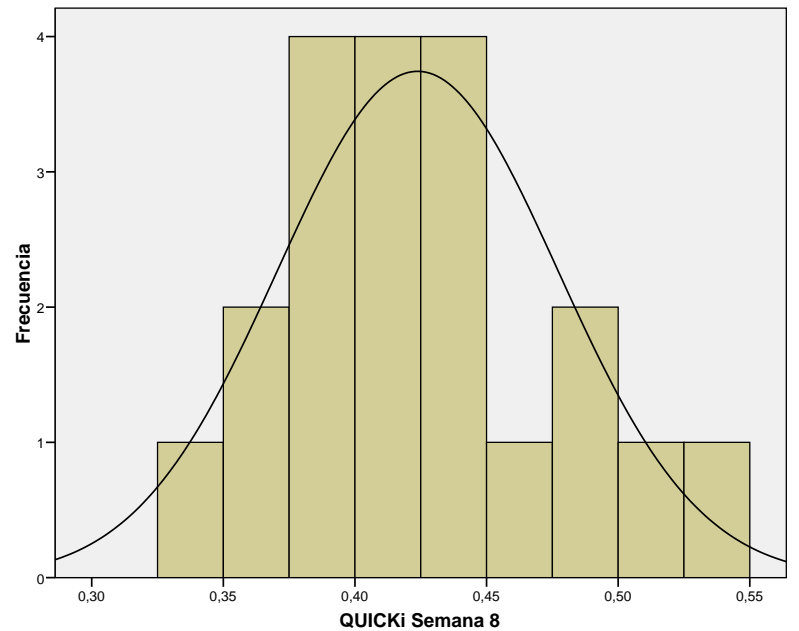

Figura 77: Indice de sensibilidad a la insulina (QUICKi) en la semana 8. 
En lo que se refiere a la sensibilidad a la insulina medida por el índice QUICKi, se observó una disminución no significativa en los animales intervenidos quirúrgicamente respecto a la medida en la semana 0 (Tabla 15, Figura 78 ).

\begin{tabular}{|l|c|c|c|}
\hline & Semana 0 & Semana 1 & Semana 8 \\
\hline QUICKi & $0,47 \pm 0,13$ & $0,42 \pm 0,13$ & $0,42 \pm 0,05$ \\
\hline
\end{tabular}

Tabla 15: Evolución en el Indice de sensibilidad a la insulina QUICKi.

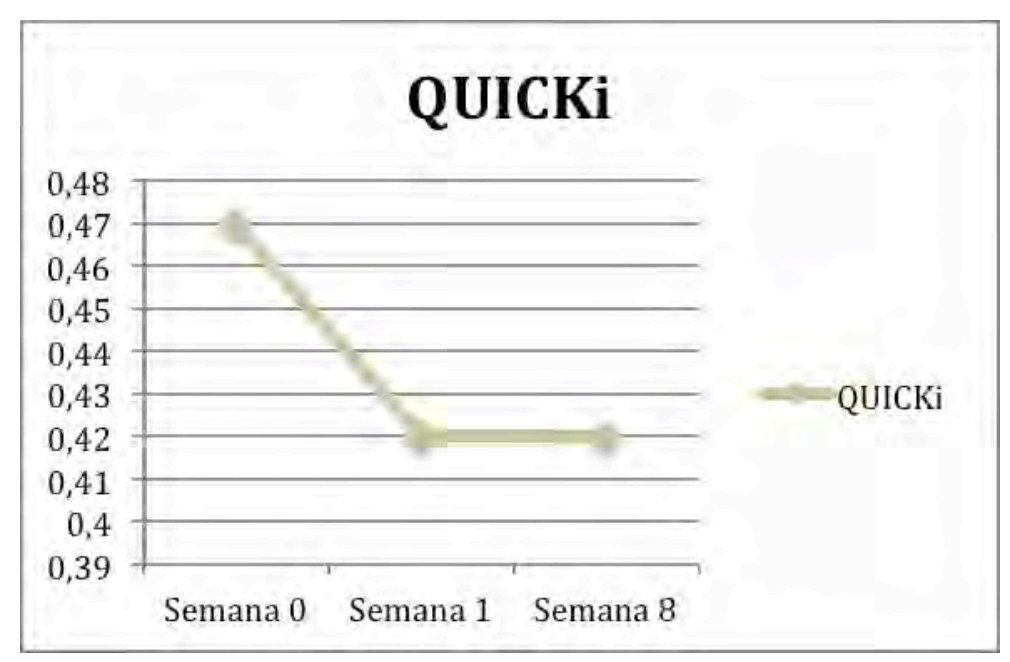

Figura 78: Evolución temporal del índice de sensibilidad a la insulina (QUICKi). 


\subsection{PEPTIDO SIMILAR AL GLUCAGON 1 (GLP 1).}

Los valores del GLP1 presentaron una distribución normal en el grupo experimental (Figuras 79 - 81).

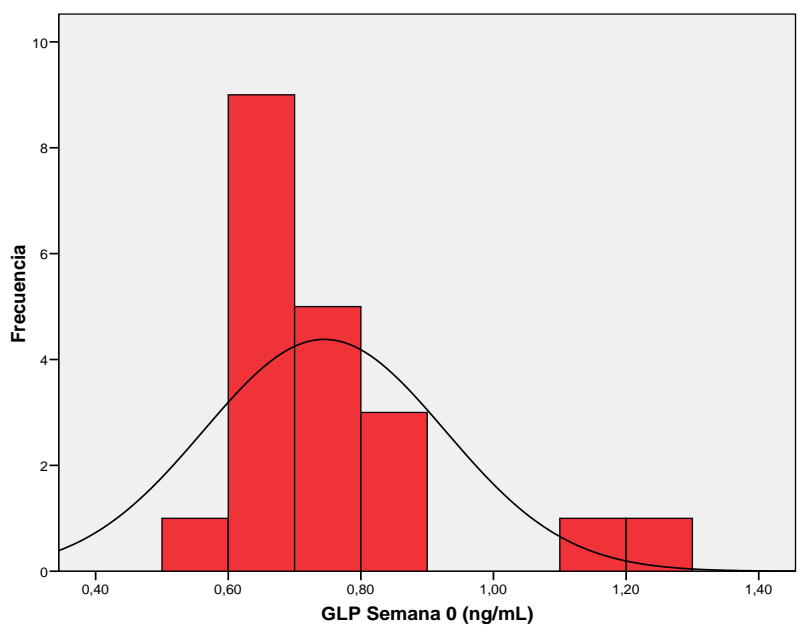

Figura 79: Niveles de GLP-1 en la semana 0.

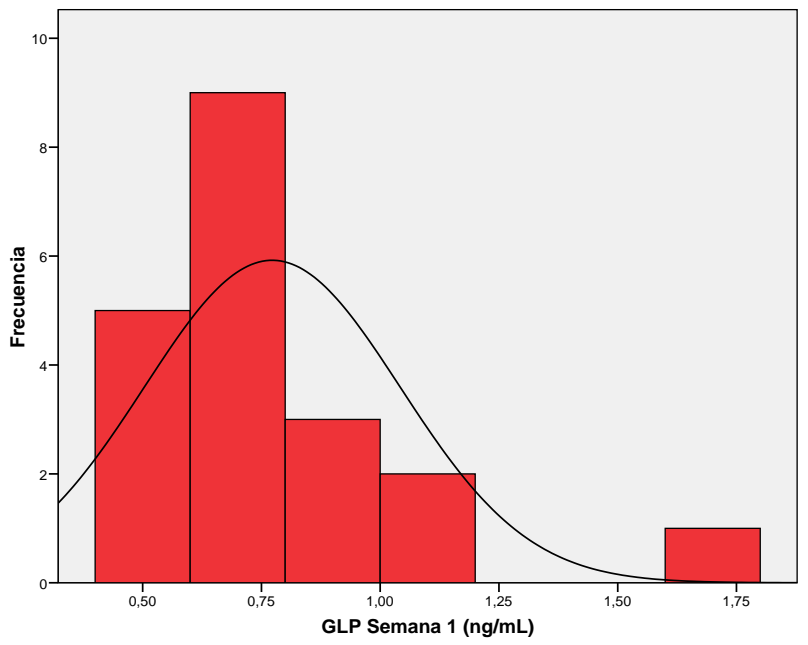

Figura 80: Niveles de GLP-1 en la semana 1.

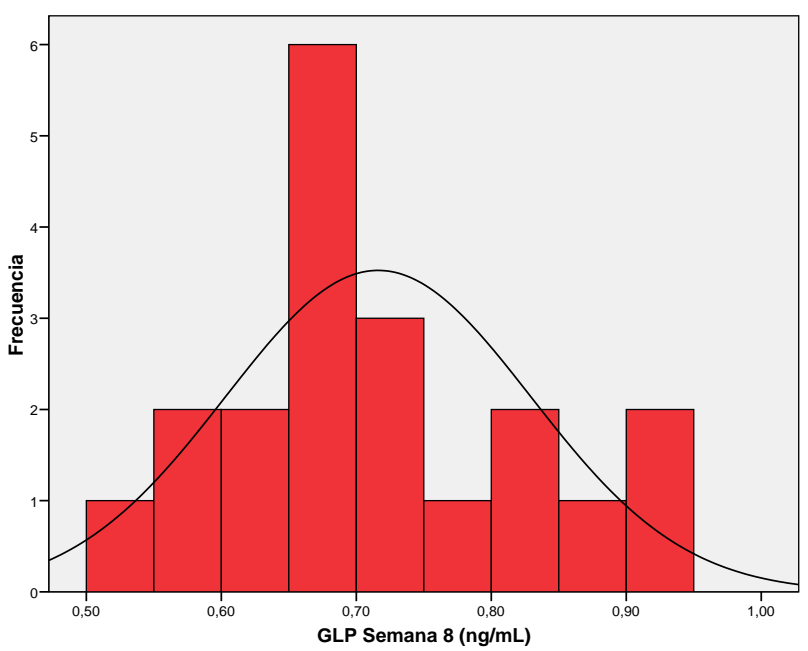

Figura 81: Niveles de GLP-1 en la semana 8. 
Respecto a los niveles basales las diferencias en las semanas 1 y 8 fueron mínimas y no alcanzaron significación estadística. (Tabla 16 y Figura 82).

\begin{tabular}{|l|c|c|c|}
\hline & Semana 0 & Semana 1 & Semana 8 \\
\hline GLP 1 & $0,74 \pm 0,18$ & $0,77 \pm 0,26$ & $0,71 \pm 0,11$ \\
\hline
\end{tabular}

Tabla 16: Evolución en los niveles de GLP1 ( $\mathrm{ng} / \mathrm{mL})$.

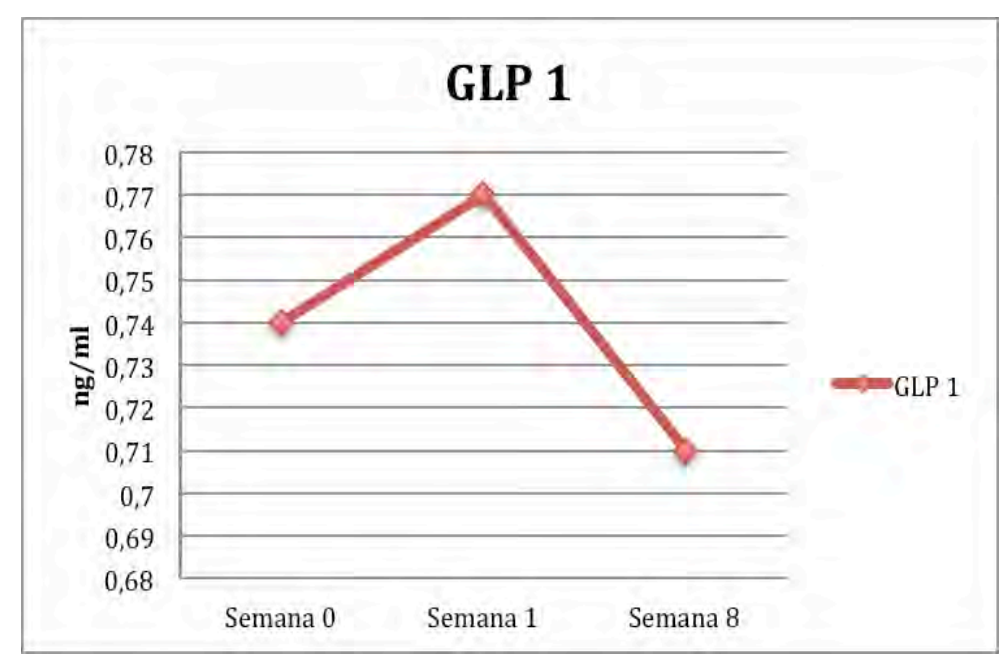

Figura 82: Evolución en los niveles de GLP1 


\subsection{PÉPTIDO INHIBIDOR GÁSTRICO (GIP).}

Las concentraciones de GIP presentaron una distribución normal en el grupo analizado (Figuras 83 - 85)

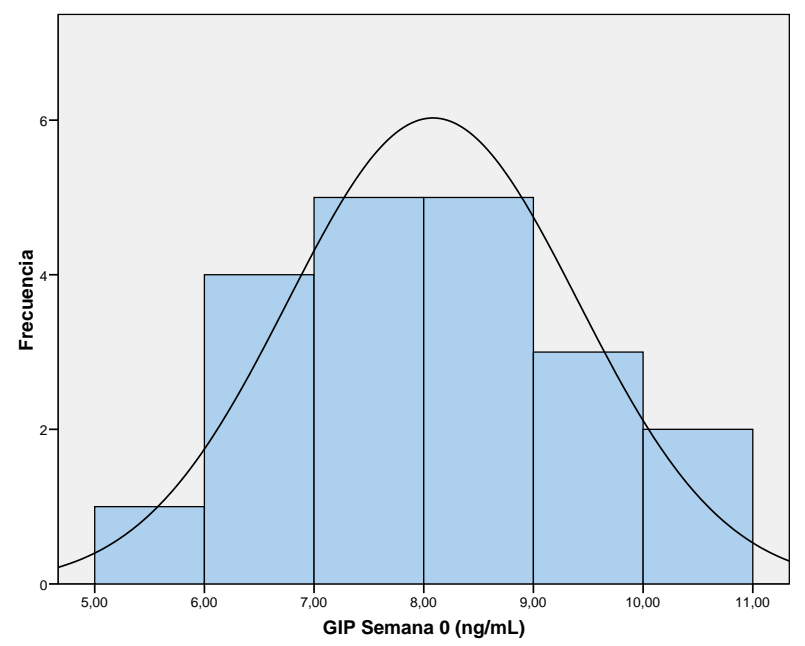

Figura 83: Niveles de GIP en la semana 0.

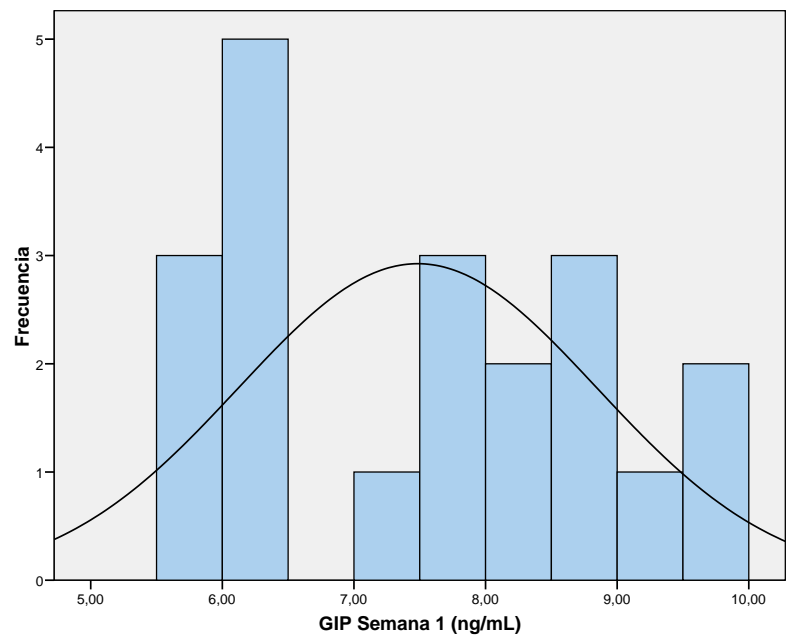

Figura 84: Niveles de GIP en la semana 1.

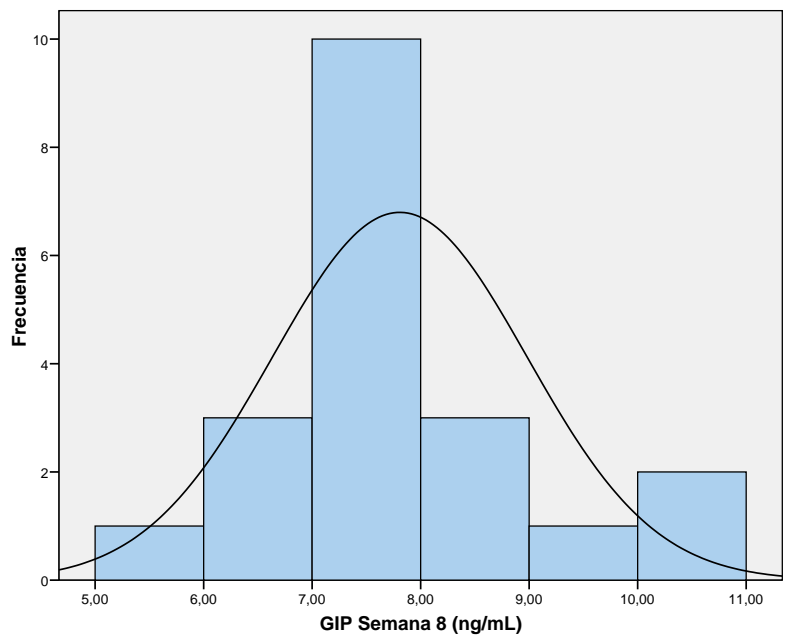

Figura 85: Niveles de GIP en la semana 8. 
No se encontraron diferencias significativas en los niveles de GIP en suero obtenidos, en los diferentes tiempos del experimento. (Tabla 17, Figura 52)

\begin{tabular}{|l|c|c|c|}
\hline & Semana 0 & Semana 1 & Semana 8 \\
\hline GIP & $8,08 \pm 1,32$ & $7,48 \pm 1,36$ & $7,80 \pm 1,17$ \\
\hline
\end{tabular}

Tabla 17: Evolución temporal en los niveles de GIP (ng/mL).

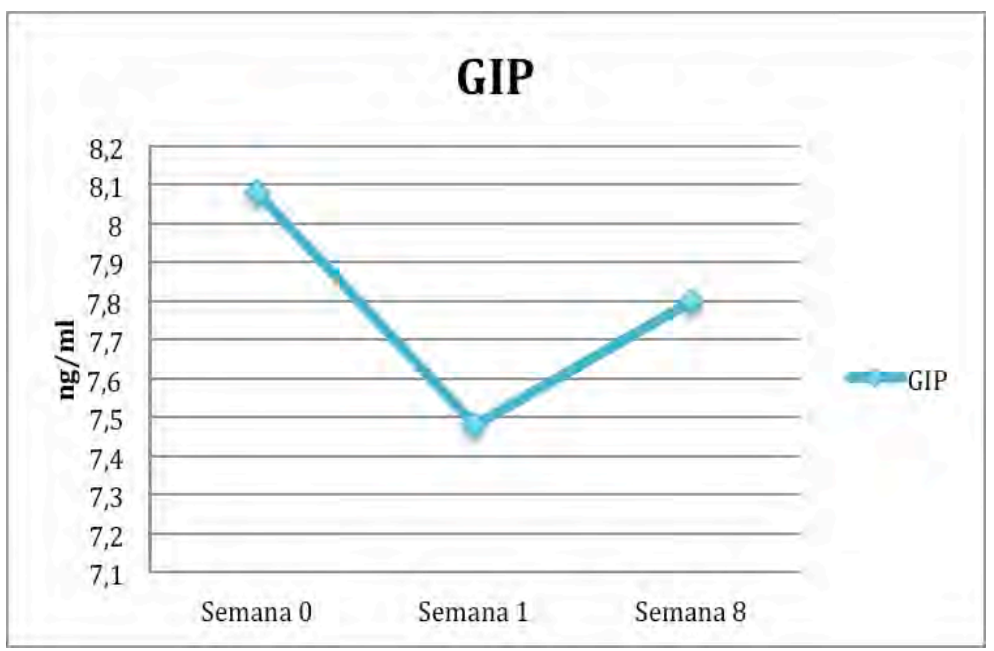

Figura 86: Niveles de GIP 


\subsection{GLUCAGON}

Los niveles de glucagón medidos durante el experimento presentaron una distribución normal en todos los casos (Figuras 87 - 89).

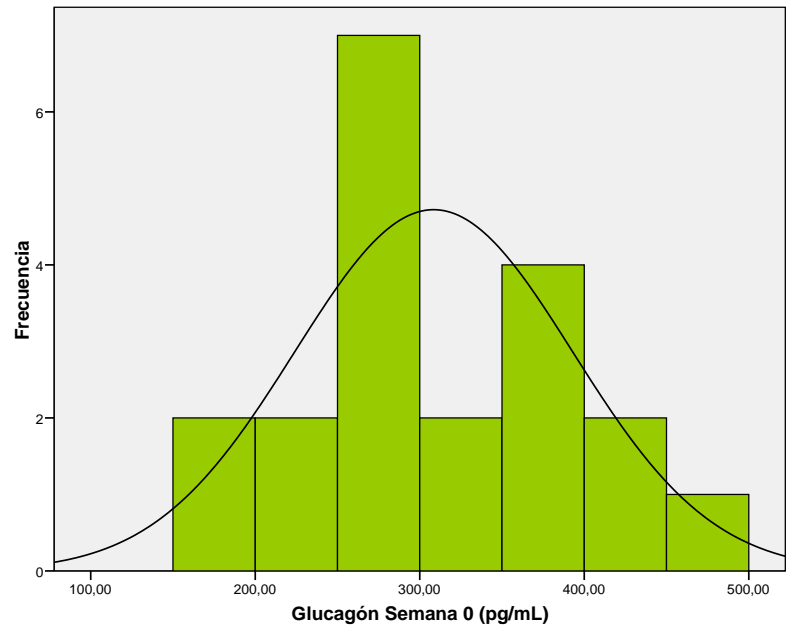

Figura 87: Niveles de glucagón en la semana 0

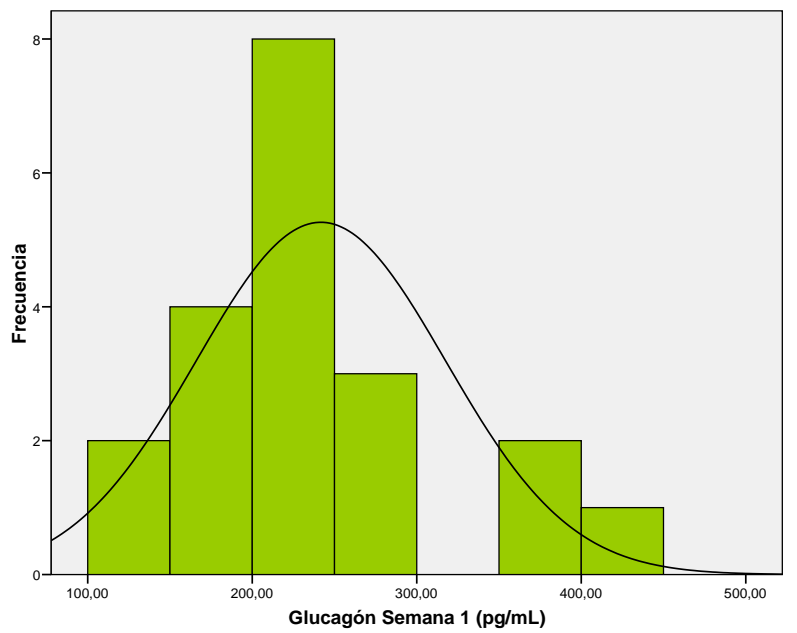

Figura 88: Niveles de glucagón en la semana 1

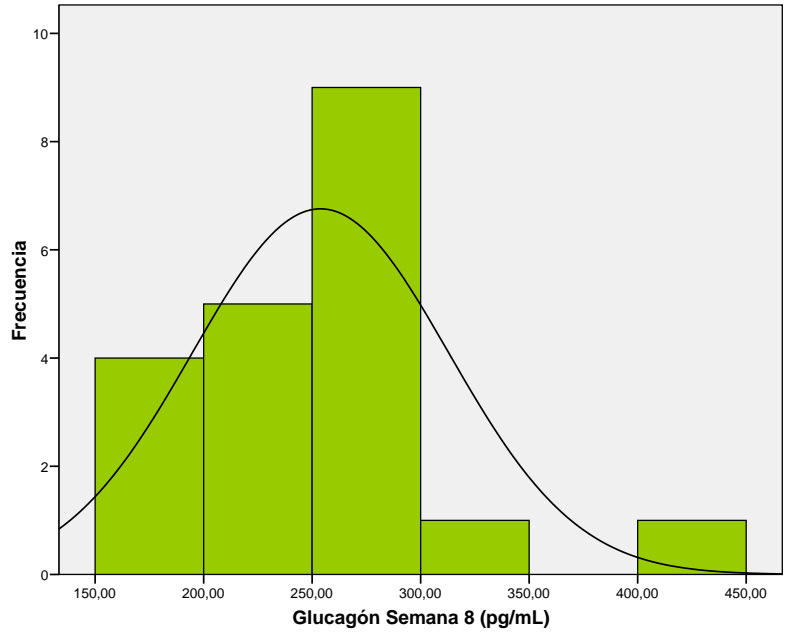

Figura 89: Niveles de glucagón en la semana 8 
Al comparar los niveles preoperatorios con los observados en los diferentes tiempos tras la intervención, se observó una disminución estadísticamente significativa en las semanas 1 y 8 del postoperatorio (Tabla 18 y Figura 90).

\begin{tabular}{|l|c|c|c|}
\hline & Semana 0 & Semana 1 & Semana 8 \\
\hline GLUCAGON & $308,4 \pm 84,4$ & $241,7 \pm 75,8^{*}$ & $253,8 \pm 59,0^{\star *}$ \\
\hline
\end{tabular}

Tabla 18: Evolución temporal en los niveles de glucagón $(\mathrm{pg} / \mathrm{mL})$ ${ }^{*} p=0,016$ comparado con semana 0 ${ }^{* *} p=0,04$ comparado con semana 0

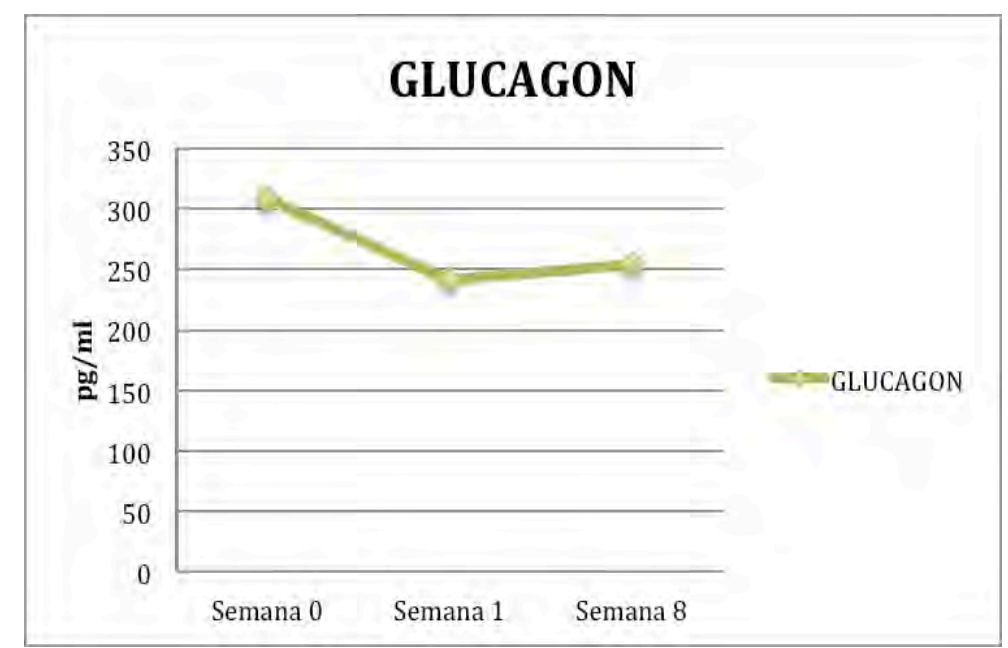

Figura 90: Niveles de glucagón. 


\subsection{LEPTINA}

Los niveles de leptina en suero en las muestras analizadas, presentaron una distribución normal (Figura 91 - 93).

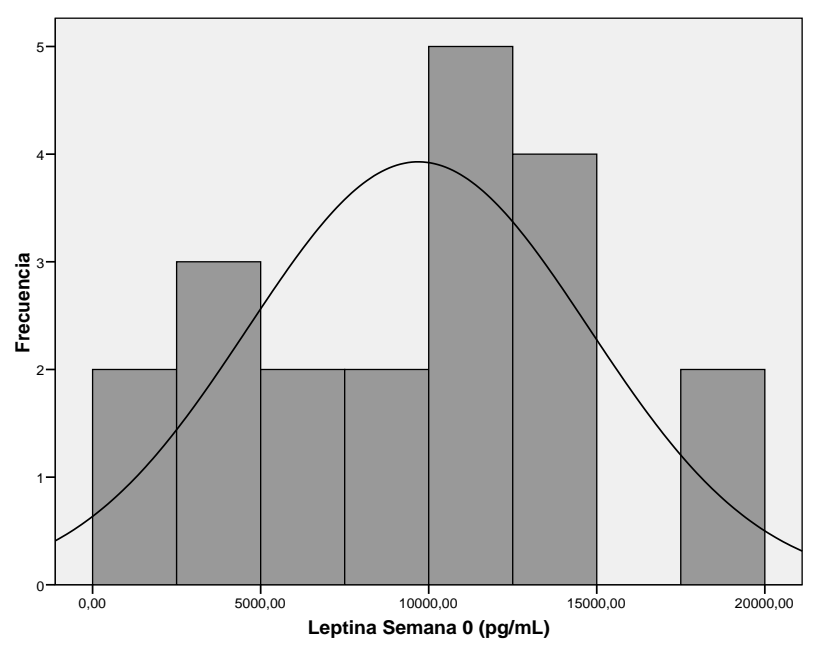

Figura 91: Niveles de leptina en la semana 0

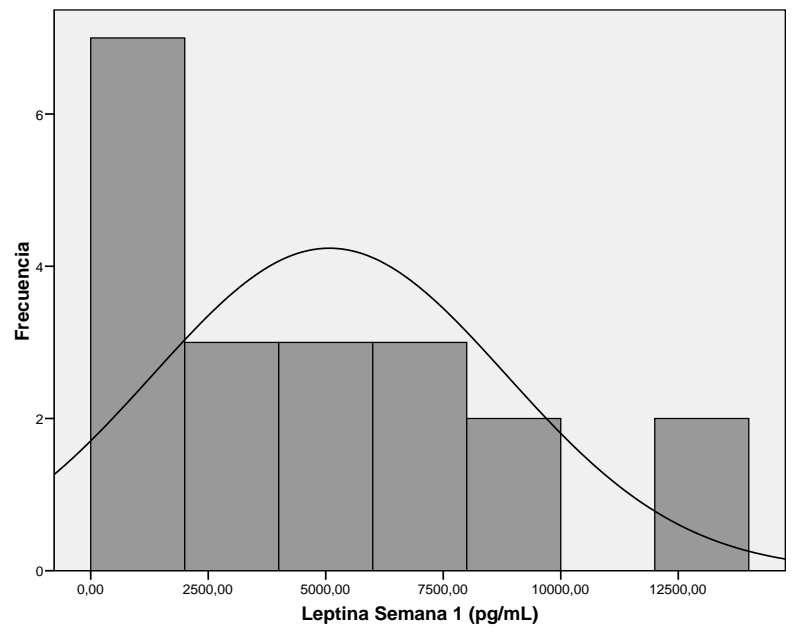

Figura 92: Niveles de leptina en la semana 1

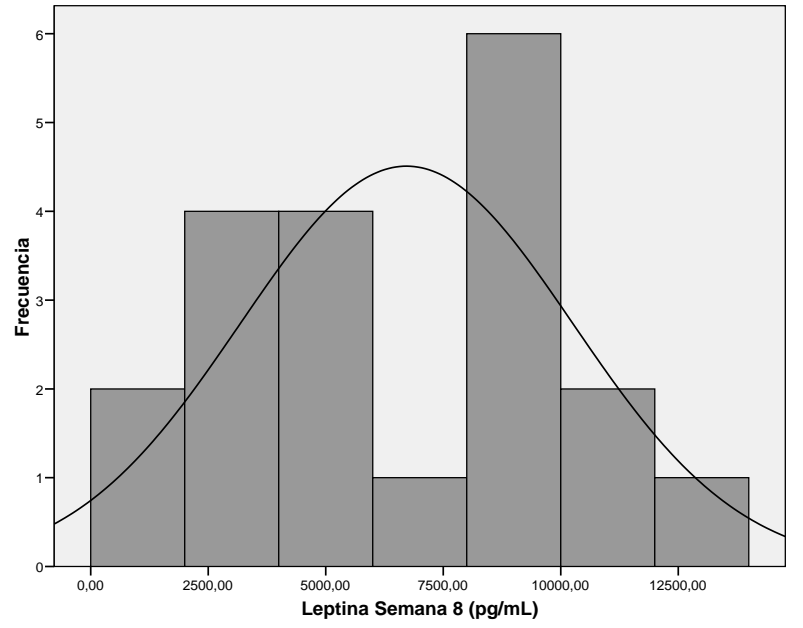

Figura 93: Niveles de leptina en la semana 8 
Se observó una disminución mantenida en las cifras de leptina sérica en las semanas 1 y 8 que en ambos casos alcanzó la significación estadística. (Tabla 19 y Figura 94)

\begin{tabular}{|l|c|c|c|}
\hline & Semana 0 & Semana 1 & Semana 8 \\
\hline LEPTINA & $9692,6 \pm 5077,4$ & $5079,4 \pm 3765,7^{*}$ & $6719,8 \pm 3539,5^{\star *}$ \\
\hline
\end{tabular}

Tabla 19: Evolución temporal en las cifras de leptina ( $\mathrm{pg} / \mathrm{ml})$. ${ }^{*} p=0,001$ comparado con semana 0
${ }^{* *} p=0,04$ comparado con semana 0

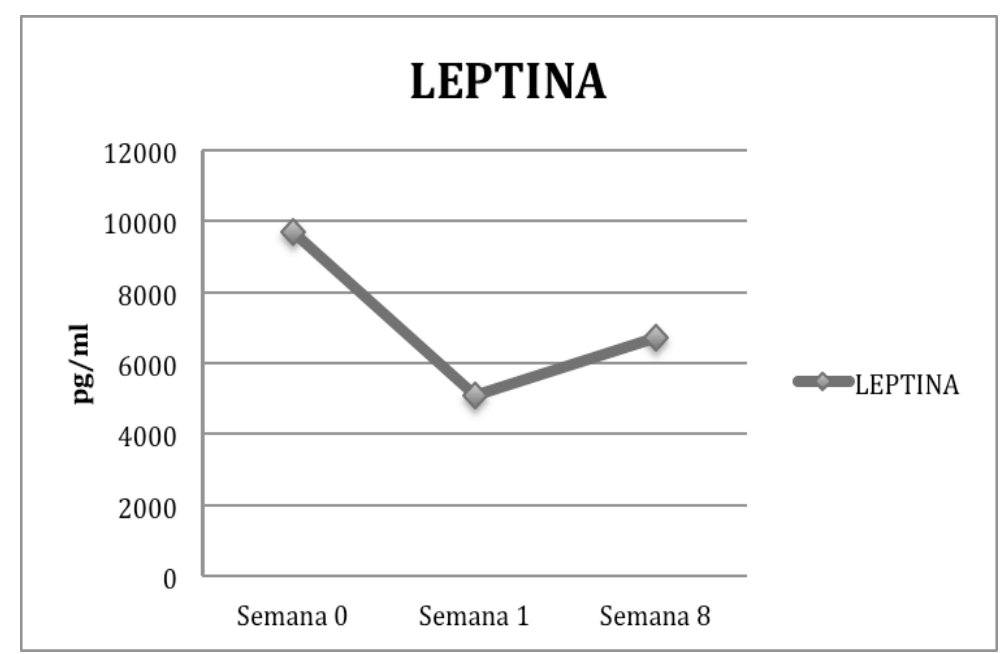

Figura 94: Niveles de leptina. 


\section{SECRECIÓN DE INSULINA AL MEDIO DE INCUBACIÓN}

Respecto a la secreción de insulina en condiciones basales, las variables recogidas presentaron una distribución normal, excepto el ratio 30' / 0' (Figuras 95 - 100).

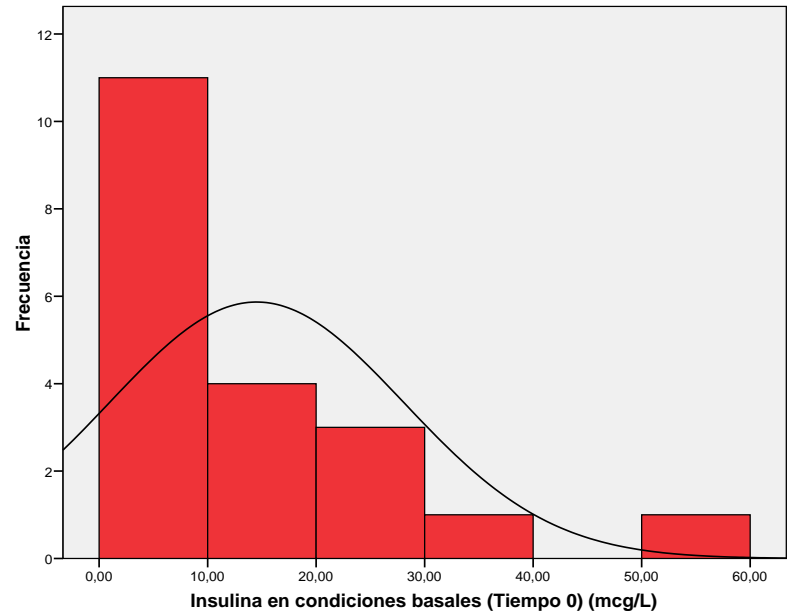

Figura 95: Secreción de Insulina en condiciones basales (Tiempo 0) (medio KRB + BSA y glucosa 5 Mm)

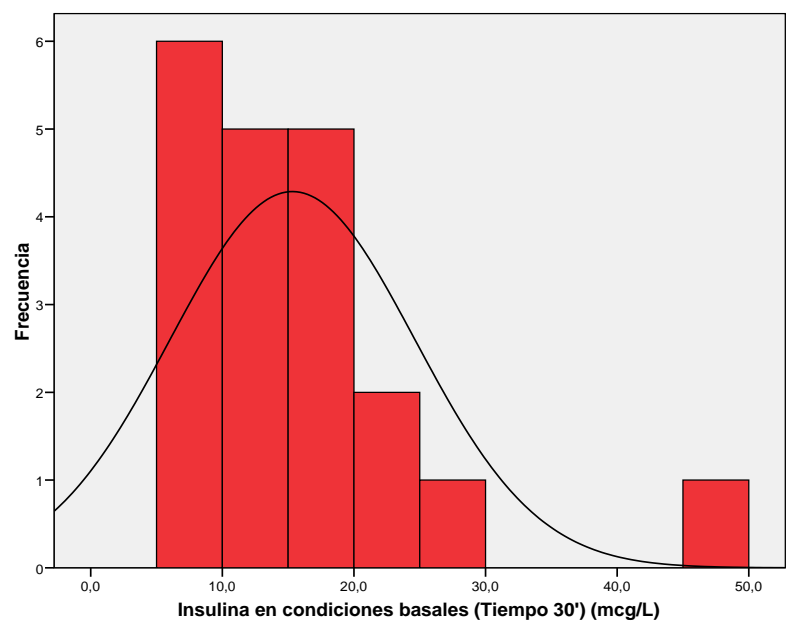

Figura 96: Secreción de Insulina en condiciones basales (30 min) (medio KRB + BSA y glucosa 5 Mm)

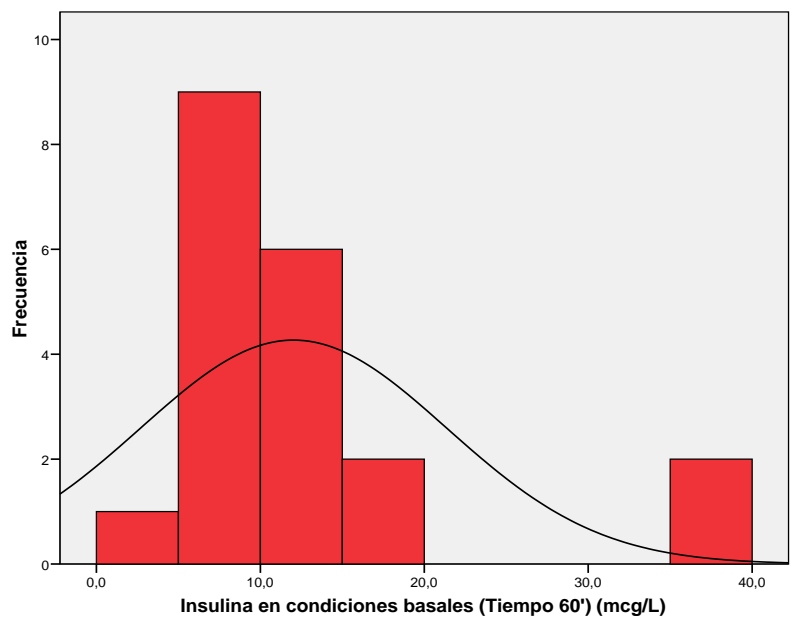

Figura 97: Secreción de Insulina en condiciones basales (60 min.) (medio KRB + BSA y glucosa 5 Mm) 


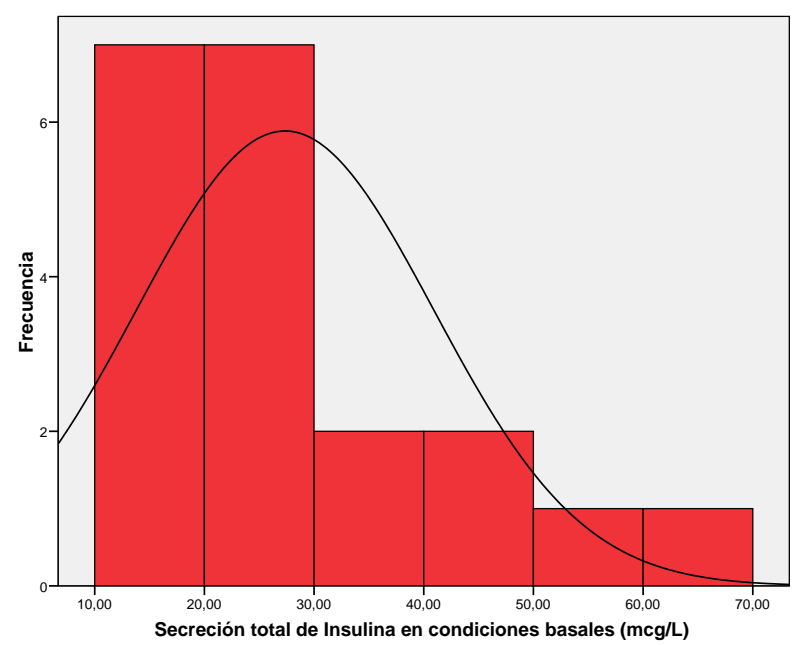

Figura 98: Secreción Total de Insulina en condiciones basales (medio KRB + BSA con glucosa 5 Mm)

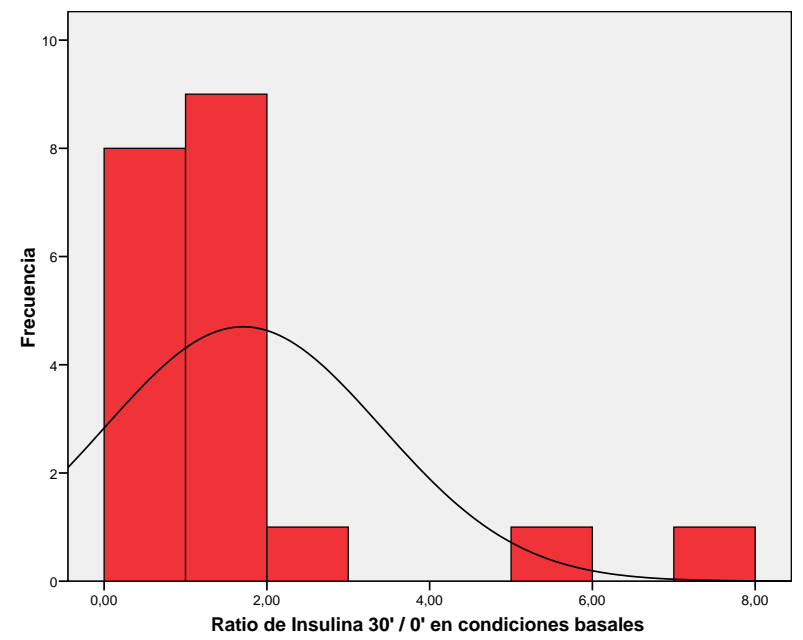

Figura 99: Ratio de secreción de insulina de los tiempos 30 y 0 en condiciones basales.

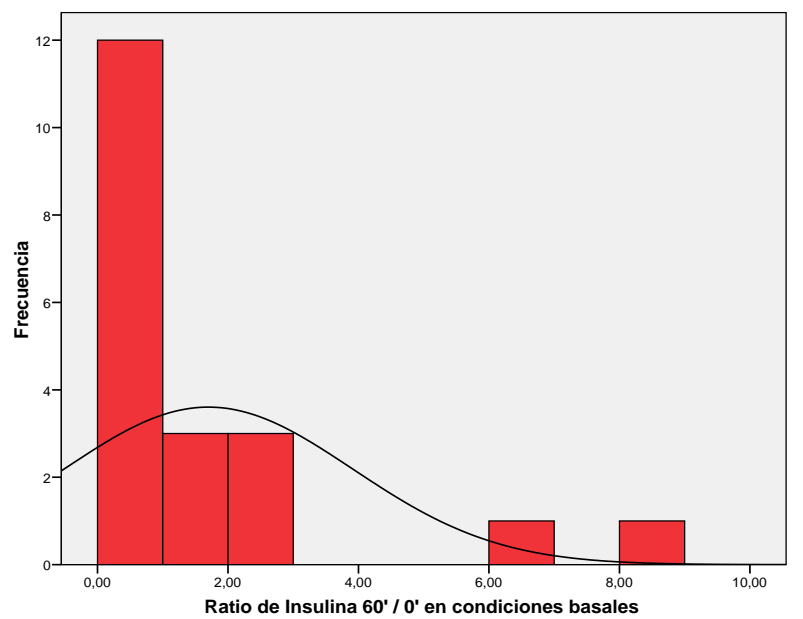

Figura 100: Ratio de secreción de insulina de los tiempos 60 y 0 en condiciones basales.

Las variables de insulina secretada en condiciones de estímulo presentaron una distribución no normal excepto la insulina en el tiempo 0' (Figuras 101 - 106). 


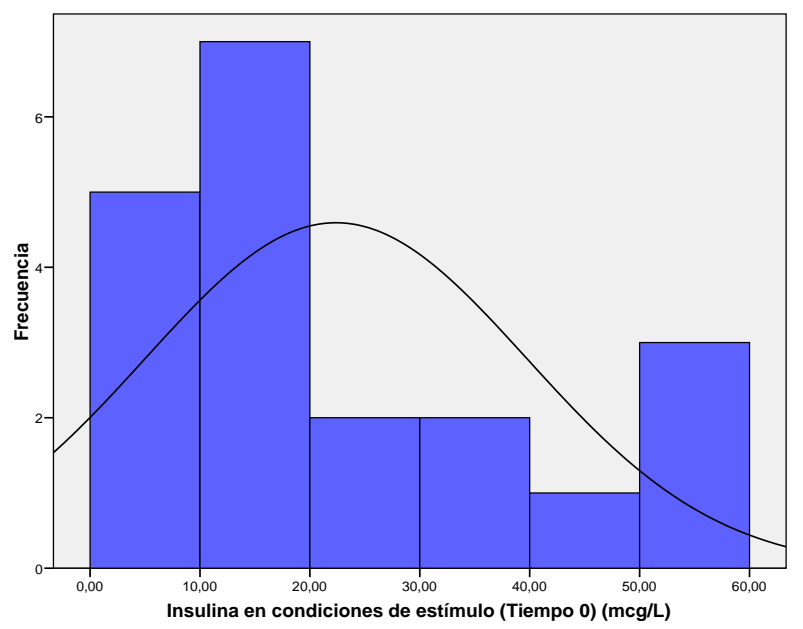

Figura 101: Secreción de Insulina en condiciones de estímulo (Tiempo 0) (medio KRB + BSA con glucosa $16,7 \mathrm{Mm}$ )

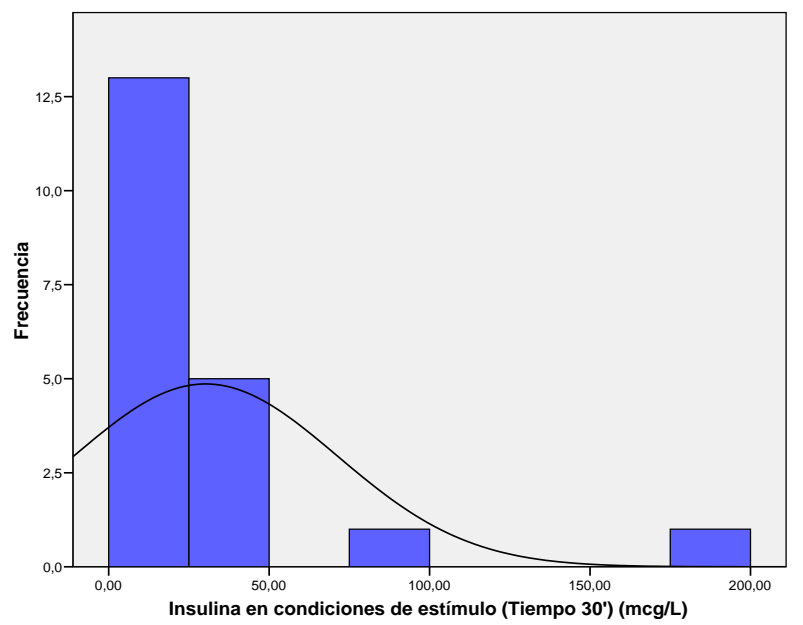

Figura 102: Secreción de Insulina en condiciones de estímulo (30 min) (medio KRB + BSA con glucosa $16,7 \mathrm{Mm})$

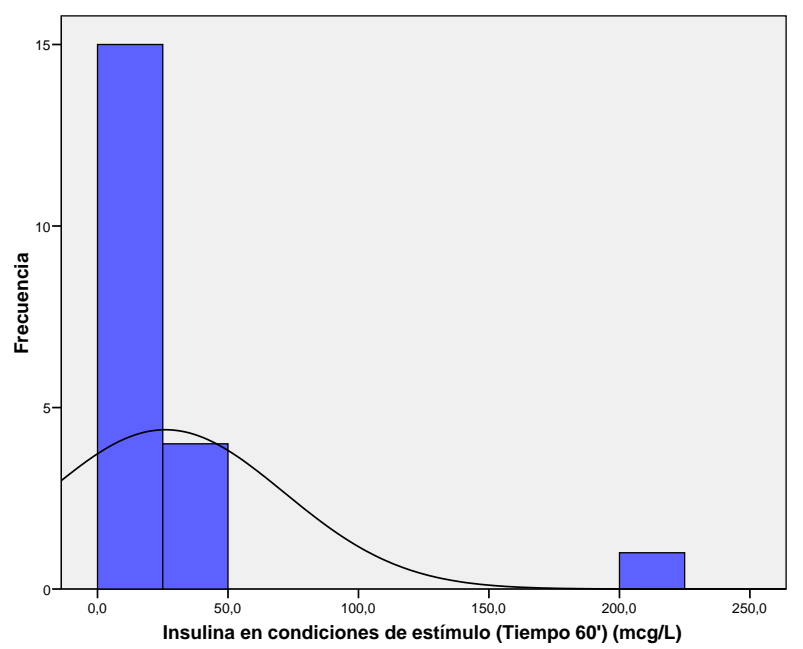

Figura 103: Secreción de Insulina en condiciones de estímulo (60 min) (medio KRB + BSA con glucosa $16,7 \mathrm{Mm})$ 


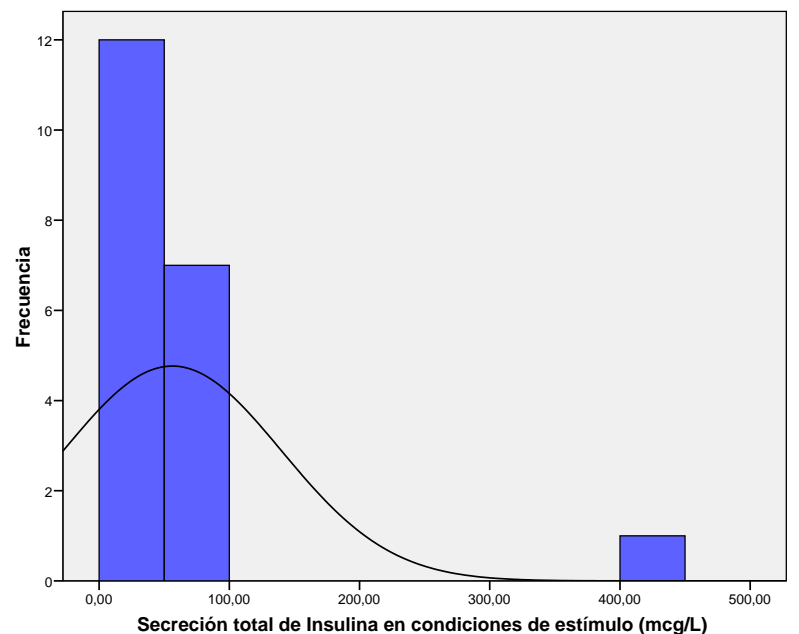

Figura 104: Secreción Total de Insulina en condiciones de estímulo (medio KRB + BSA con glucosa 16,7 $\mathrm{Mm})$

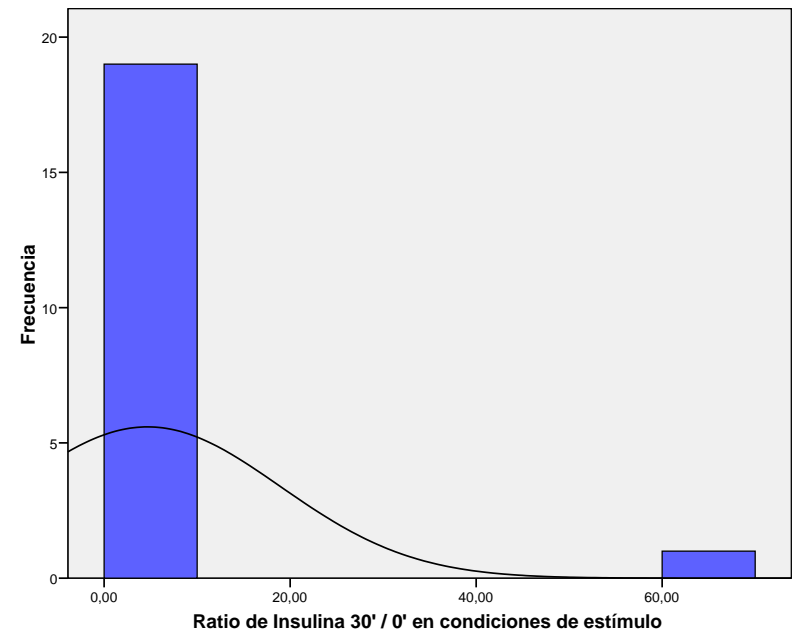

Figura 105: Ratio de secreción de insulina de los tiempos 30 y 0 en condiciones de estímulo.

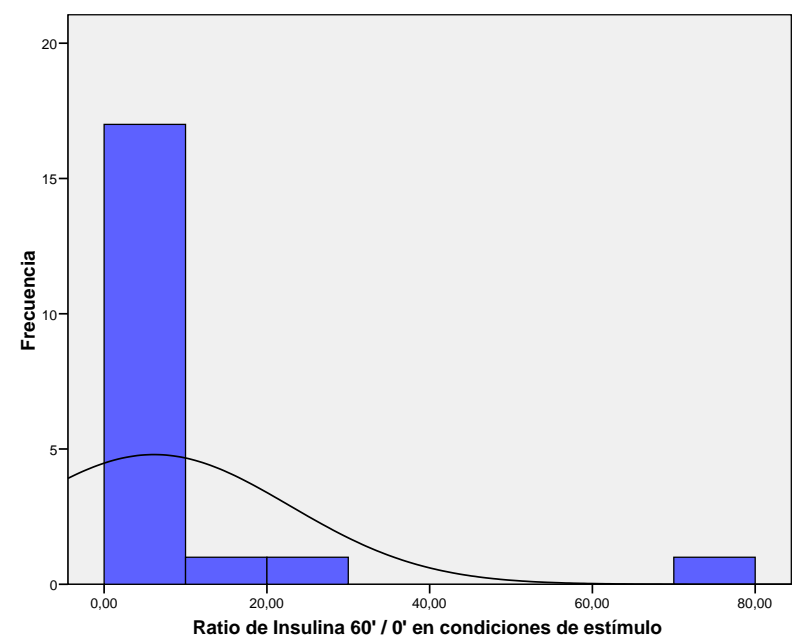

Figura 106: Ratio de secreción de insulina de los tiempos 60 y 0 en condiciones de estímulo. 
Como se puede observar en la Tabla 20 y en las figuras 107 a 109, se observó una diferencia estadísticamente significativa al comparar los resultados de la insulina secretada por los islotes en condiciones basales y de estímulo, en cada tiempo del experimento. Incluso en el tiempo 0 existe una diferencia significativa debido a que las mediciones no se realizan en los mismos islotes en cada condición. Así mismo se observó un aumento cuantitativo importante al comparar los ratios de los diferentes tiempos, en condiciones basales y tras estímulo, pero que no alcanzó significación estadística en ninguno de los casos.

\begin{tabular}{|l|c|c|c|}
\hline & $\begin{array}{c}\text { Condiciones } \\
\text { Basales }\end{array}$ & $\begin{array}{c}\text { Condiciones } \\
\text { de Estímulo }\end{array}$ & $\boldsymbol{P}$ \\
\hline $\mathbf{0}^{\prime}$ & $14,5 \pm 13,6$ & $22,4 \pm 17,4$ & 0,006 \\
\hline $\mathbf{3 0}$ & $15,3 \pm 9,3$ & $30,2 \pm 41,0$ & $<0,05$ \\
\hline $\mathbf{6 0}$ & $12,0 \pm 9,3$ & $26,0 \pm 45,5$ & 0,003 \\
\hline Secreción total & $27,3 \pm 13,6$ & $56,2 \pm 83,7$ & 0,028 \\
\hline Ratio 30' / 0' & $1,7 \pm 1,7$ & $4,7 \pm 14,3$ & $N S$ \\
\hline Ratio 60' / $\mathbf{0}^{\prime}$ & $1,7 \pm 2,2$ & $6,1 \pm 16,7$ & $N S$ \\
\hline
\end{tabular}

Tabla 20. Secreción de insulina ( $\mu \mathrm{g} / \mathrm{L}$ ) en CONDICIONES BASALES y TRAS ESTÍMULO (medio $K R B+B S A$ con glucosa $5 \mathrm{Mm}$ o $16,7 \mathrm{mM}$, respectivamente).

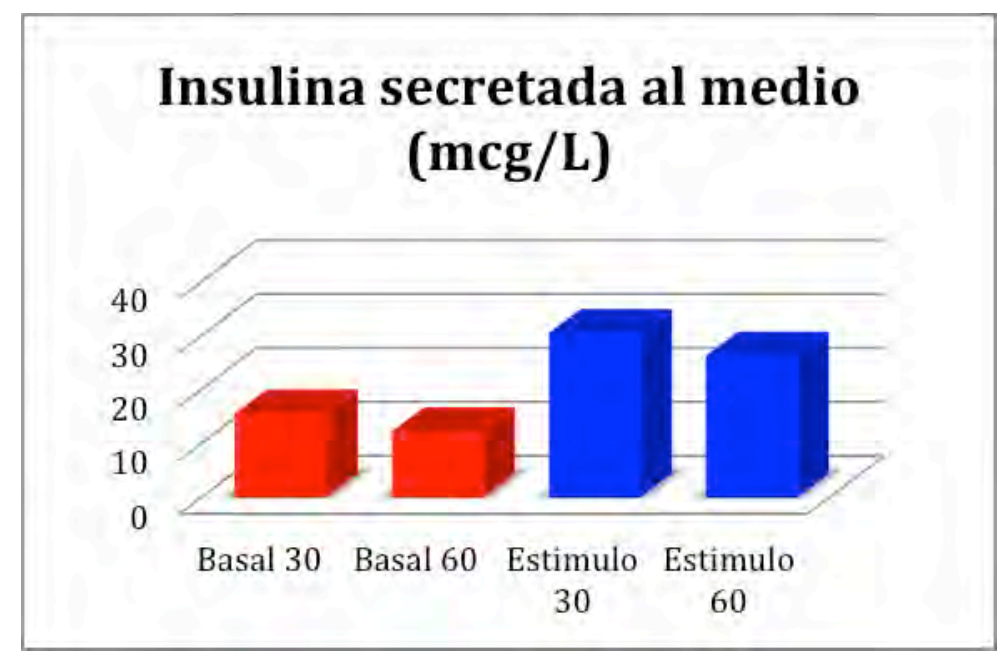

Figura 107: Secreción de insulina ( $\mu \mathrm{g} / \mathrm{L})$ en CONDICIONES BASALES y TRAS ESTíMULO (medio KRB + BSA con glucosa $5 \mathrm{Mm}$ o $16,7 \mathrm{mM}$, respectivamente). 


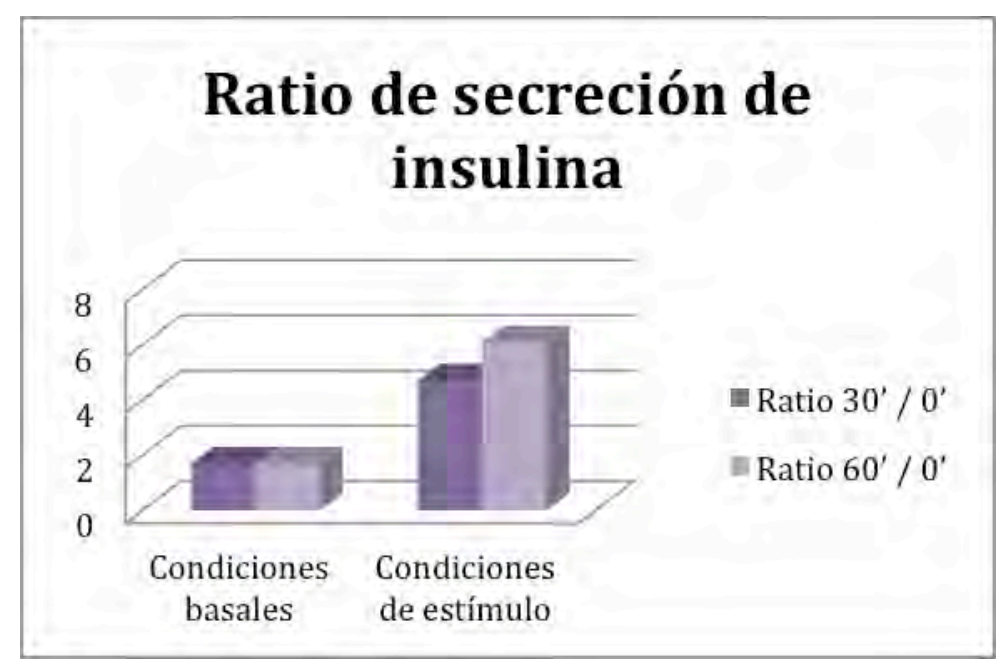

Figura 108: Comparativa entre los Ratios de secreción de Insulina en los tiempos 30/0 y 60/0 en condiciones basales y de estímulo

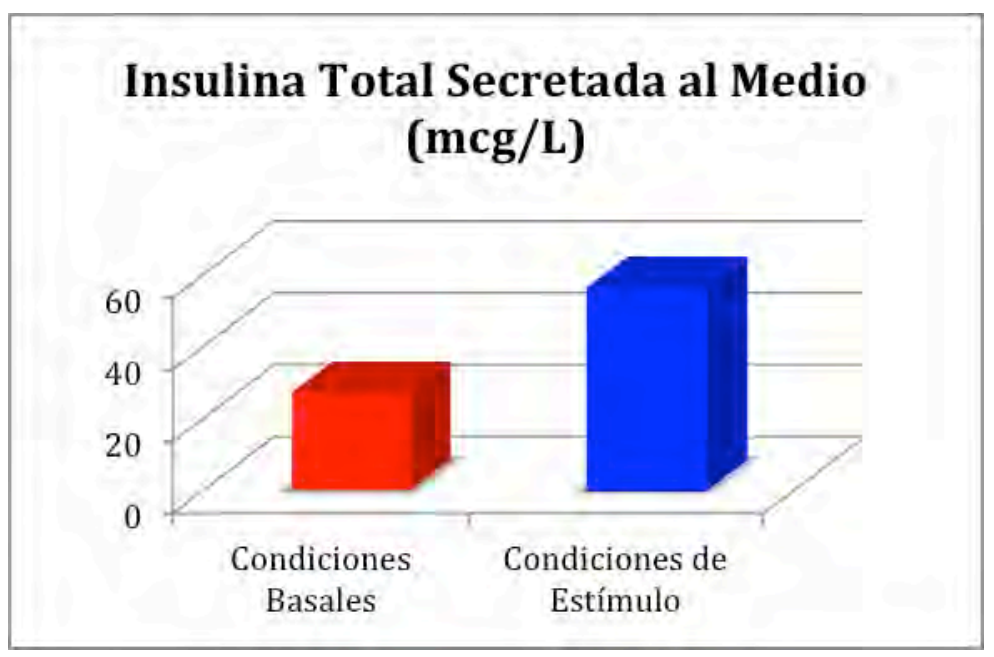

Figura 109: comparativa entre los valores de secreción total de insulina en condiciones basales y de estímulo 


\section{INSULINA CONTENIDA EN LOS ISLOTES}

Los resultados del contenido de insulina en el islote tuvieron una distribución no normal en el grupo experimental (Figura 110).

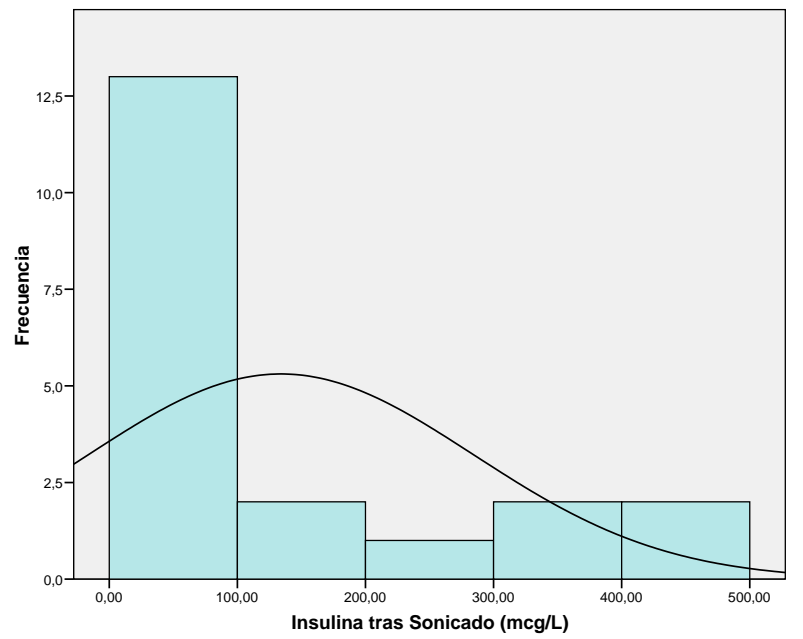

Figura 110: Valores de Insulina en el islote tras homogenización por sonicado.

La media del contenido de insulina en el islote fue de 134,0 $\pm 150,3 \mathrm{mcg} / \mathrm{L}$.

\section{EXPRESIÓN GÉNICA DE INSULINA}

La expresión relativa de ARN mensajero del gen de la insulina-1 en relación a una rata control, tuvo una distribución no normal (Figura 111), con un valor medio de 3,9 $\pm 7,3$.

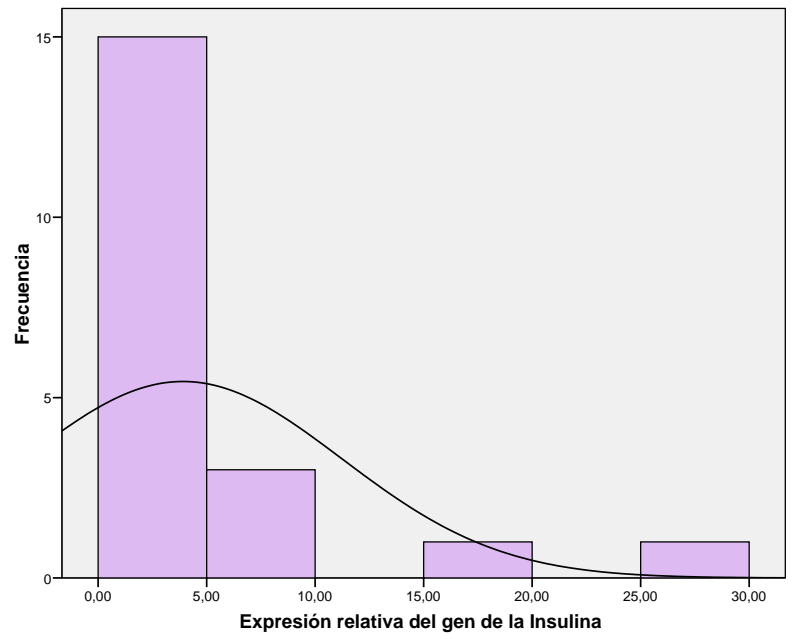

Figura 111: Distribución de los valores de expresión relativa del gen de la insulina. 


\section{SECCIÓN 2}

\section{RELACIÓN ENTRE LAS VARIABLES}

\section{Insulina}

\section{Semana 0.}

La insulina en sangre correlacionó con la glucosa a los 20 minutos de la sobrecarga oral de glucosa sin alcanzar significación estadística y con el HOMA, pero no lo hizo con ninguna molécula. $(r=0,423, p=0,063 ; r=0,937, p=0,000$ respectivamente)

\section{Semana 1.}

Se mantuvo la correlación positiva con el HOMA $(r=0,937, p=0,018)$

\section{Semana 8.}

Se observa una correlación positiva con la glucosa a los 20 minutos de la sobrecarga oral de glucosa $(r=0,684, p=0,001)$ Además se mantuvo la correlación positiva con el HOMA $(r=0,961, p=0,000)$.

\section{Glucosa 20 minutos.}

\section{Semana 0.}

La glucemia a los 20 minutos de la sobrecarga oral de glucosa se correlaciona positivamente con el HOMA ( $r=0,650, p=0,002)$.

\section{Semana 1.}

No se encontraron correlaciones.

\section{Semana 8.}

Los niveles de glucosa en sangre a los 20 minutos de la sobrecarga oral, tuvieron una correlación positiva con los niveles de insulina en sangre $(r=0,684,0,001)$

\section{GLP-1}

Semana 0.

En esta semana se encontró una correlación negativa con el glucagón $(r=-0,522, p=$ $0,018)$ 
Semana 1.

No se encontraron correlaciones.

Semana 8.

No se encontraron correlaciones.

GIP

Semana 0.

No se encontraron correlaciones.

Semana 1.

Observamos una correlación positiva con el glucagón estadísticamente no significativa $(r=0,412 p=0,071)$. También se encontró una correlación positiva con la leptina en este momento del experimento $(r=0,780, p=0,000)$.

Semana 8.

No se encontraron correlaciones.

\section{Glucagón}

Semana 0.

Los niveles de glucagón en sangre se correlacionaron negativamente con los niveles de GLP 1 ( $r=-0.522, p=0,018)$.

Semana 1.

Observamos una correlación positiva con los niveles séricos de GIP, pero no tuvo significación estadística $(r=0,412, p=0071)$.

Semana 8.

No se encontraron correlaciones.

\section{Leptina}

Semana 0.

No se detectan correlaciones. 


\section{Semana 1.}

Observamos una correlación positiva con el GIP en este momento del experimento $(r=0,780 ; p=0,000)$.

\section{Semana 8.}

No se detectan correlaciones.

\section{Secreción de Insulina}

El ratio de secreción de Insulina entre los 60 y los 0 minutos en condiciones basales (ratio 60/0) (medio KRB + BSA con glucosa $5 \mathrm{Mm}$ ) mostró una correlación positiva con los valores obtenidos del ratio de secreción de insulina $60 / 0$ en condiciones de estímulo (medio KRB + BSA con glucosa 16,7 mM) $(r=0,776, p=0,000)$.

Así mismo el ratio de secreción de insulina 60 / 0 en condiciones basales mostró una correlación positiva con los valores de la expresión del gen de la insulina $(r=0,635, p=$ $0,003)$.

Los valores de la secreción total de insulina tras la estimulación de los islotes mostraron una correlación positiva con los niveles de insulina obtenidos tras homogenización de los islotes por sonicado $(r=0,510, p=0,022)$.

El ratio de secreción de insulina entre los 60 y 0 minutos en condiciones de estimulación mostró una correlación positiva con los valores calculados de la expresión genética de la insulina $(r=0,519, p=0,019)$.

\section{Correlación entre las moléculas y los valores obtenidos en los experimentos in vitro.}

Al correlacionar los valores de las moléculas obtenidas en los experimentos in vivo con los experimentos in vitro, se observa una correlación positiva entre los niveles de insulina a las 8 semanas de la intervención con el ratio de secreción de insulina por el islote entre los tiempos 60 y 0 en condiciones basales. $(r=0,445, p=0,049)$.

Así mismo se encuentra una correlación lógica entre los niveles de glucosa y los valores de los índices HOMA y QUICKi, con los valores de secreción de insulina por el islote. 
232 RESULTADOS

Al analizar los demás valores de las moléculas, no se detectaron correlaciones significativas con los valores obtenidos en los experimentos in vitro.

Los datos correspondientes a las correlaciones analizadas se muestran en las Tablas 21 a 24. 
RESULTADOS 233

\begin{tabular}{|c|c|c|c|c|c|c|c|c|}
\hline \multirow{2}{*}{ 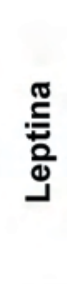 } & e & $\begin{array}{l}\text { ֻ } \\
\text { ণ } \\
\text { - }\end{array}$ & $\begin{array}{l}\text { N } \\
0 \\
0 \\
0\end{array}$ & $\begin{array}{l}\mathbb{O} \\
\bigotimes \\
0\end{array}$ & $\begin{array}{l}\text { \& } \\
6 \\
0 \\
0\end{array}$ & $\begin{array}{l}\infty \\
\infty \\
0 \\
0 \\
0\end{array}$ & $\begin{array}{l}\text { o } \\
\infty \\
0 \\
0\end{array}$ & \\
\hline & - & $\underset{\text { N }}{\text { Ò }}$ & $\begin{array}{l}\infty \\
\stackrel{8}{8} \\
\text { i }\end{array}$ & $\frac{\text { Oo }}{0}$ & $\frac{\stackrel{n}{\sigma}}{\sigma}$ & 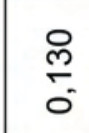 & \begin{tabular}{l}
$\infty$ \\
\multirow{O}{0}{} \\
0 \\
\end{tabular} & \\
\hline \multirow{2}{*}{ 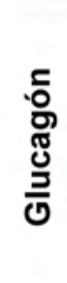 } & Q & $\begin{array}{l}\mathscr{Q} \\
\text { T. } \\
0\end{array}$ & $\frac{\infty}{\circ}$ & $\begin{array}{l}\mathscr{0} \\
\mathbb{0} \\
0\end{array}$ & 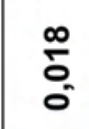 & $\begin{array}{l}\mathscr{N} \\
\text { N } \\
\text { o }\end{array}$ & & \\
\hline & - & 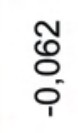 & $\begin{array}{l}\bar{o} \\
\text { po } \\
\text { o- }\end{array}$ & $\frac{\hat{m}}{i}$ & 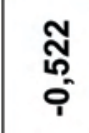 & 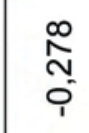 & & \\
\hline \multirow{2}{*}{$\frac{0}{0}$} & Q & $\begin{array}{l}\frac{\mathscr{R}}{0} \\
0^{\prime}\end{array}$ & $\begin{array}{l}\text { N } \\
\text { مْ } \\
0\end{array}$ & $\begin{array}{l}\text { ¿े } \\
0 \\
0 \\
0\end{array}$ & $\begin{array}{l}\text { ণ্ডে } \\
\text { O }\end{array}$ & & & \\
\hline & - & 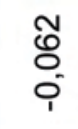 & $\frac{10}{\frac{6}{0}}$ & $\begin{array}{l}\hat{\circ} \\
\text { O } \\
\text { i }\end{array}$ & 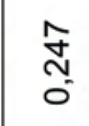 & & & \\
\hline \multirow{2}{*}{$\bar{a}$} & a & $\begin{array}{l}\text { O } \\
\infty \\
0 \\
0\end{array}$ & $\begin{array}{l}\text { ᄋ } \\
\text { ᄋ } \\
\circ\end{array}$ & $\begin{array}{l}\infty \\
\infty \\
0 \\
0\end{array}$ & & & & \\
\hline & - & $\begin{array}{l}\mathscr{O} \\
\text { O } \\
\text { O }\end{array}$ & $\begin{array}{l}\text { ஜ } \\
\text { ه } \\
\text { í }\end{array}$ & $\begin{array}{l}\text { ஜ) } \\
8 \\
\text { i }\end{array}$ & & & & \\
\hline \multirow{2}{*}{ 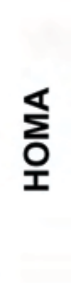 } & 2 & $\begin{array}{l}\text { ठ̊ } \\
\text { ర }\end{array}$ & ণั & & & & & \\
\hline & - & ๙ু & $\begin{array}{l}\text { 유 } \\
\text { ○ }\end{array}$ & & & & & \\
\hline \multirow{2}{*}{ 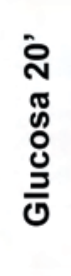 } & Q & 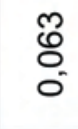 & & & & & & \\
\hline & 1 & $\begin{array}{l}\stackrel{\mathscr{N}}{+} \\
\text { ó }\end{array}$ & & & & & & \\
\hline \multirow{2}{*}{ 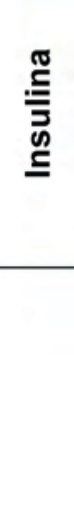 } & e & & & & & & & \\
\hline & & 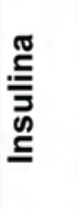 & 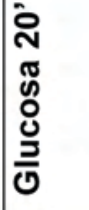 & 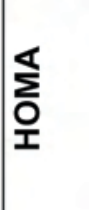 & ড্ & $\frac{0}{\mathrm{~N}}$ & 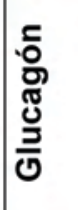 & כِّ \\
\hline
\end{tabular}

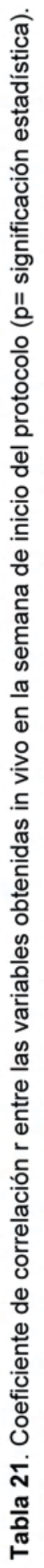




\begin{tabular}{|c|c|c|c|c|c|c|c|c|}
\hline \multirow{2}{*}{ 冚 } & 2 & 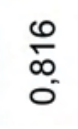 & 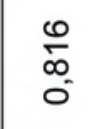 & $\begin{array}{l}\text { L } \\
\infty \\
0 \\
0\end{array}$ & $\begin{array}{l}n \\
\infty \\
\infty \\
0 \\
0\end{array}$ & ঃ & $\begin{array}{l}\underset{\sim}{+} \\
\underset{0}{*}\end{array}$ & \\
\hline & - & $\begin{array}{l}0 \\
\text { గn } \\
0\end{array}$ & $\stackrel{\stackrel{N}{0}}{\overleftarrow{\sigma}}$ & $\begin{array}{l}\text { fo } \\
\text { ó }\end{array}$ & $\begin{array}{l}\mathscr{O} \\
\text { O̊. } \\
\text { o. }\end{array}$ & $\frac{\stackrel{8}{\infty}}{\stackrel{\infty}{0}}$ & $\frac{\infty}{\infty}$ & \\
\hline \multirow{2}{*}{ 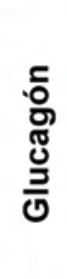 } & e & $\begin{array}{l}\stackrel{\Sigma}{N} \\
\text { D. }\end{array}$ & $\stackrel{0}{\infty}$ & $\begin{array}{l}\text { ల్ } \\
\text { ల్ } \\
0\end{array}$ & $\begin{array}{l}\text { के } \\
\text { m } \\
\text { ó }\end{array}$ & $\begin{array}{l}\bar{\Lambda} \\
0 \\
0\end{array}$ & & \\
\hline & - & 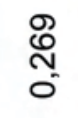 & $\begin{array}{l}\text { ON } \\
\text { } \\
\text { i }\end{array}$ & $\underset{0}{\stackrel{10}{N}}$ & 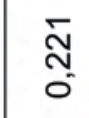 & 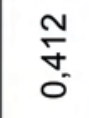 & & \\
\hline \multirow{2}{*}{$\frac{0}{\mathrm{~J}}$} & 2 & $\begin{array}{l}\mathscr{2} \\
\infty \\
0 \\
0\end{array}$ & $\begin{array}{l}\text { ల్ } \\
\text { O. } \\
0\end{array}$ & $\begin{array}{l}\mathscr{8} \\
\& \\
0\end{array}$ & $\begin{array}{l}\text { D. } \\
0 \\
0 \\
0\end{array}$ & & & \\
\hline & - & ్ָరి & $\begin{array}{l}\text { ণ } \\
\text { ర్ } \\
\text { - }\end{array}$ & $\underset{\delta}{\sigma}$ & $\begin{array}{l}\infty \\
\stackrel{0}{\circ} \\
0\end{array}$ & & & \\
\hline \multirow{2}{*}{ ¿্ } & a & $\begin{array}{l}\text { I } \\
\text { J }\end{array}$ & 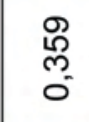 & $\begin{array}{l}\text { Oे } \\
0 \\
0 \\
0\end{array}$ & & & & \\
\hline & - & $\frac{\widetilde{\infty}}{\sigma}$ & $\underset{ }{\stackrel{N}{i}}$ & $\begin{array}{l}\infty \\
\stackrel{0}{\circ} \\
\circ\end{array}$ & & & & \\
\hline \multirow{2}{*}{ 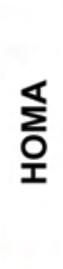 } & 2 & ঃे & $\frac{20}{0}$ & & & & & \\
\hline & - & $\begin{array}{c}\text { ळু } \\
\text { o }\end{array}$ & 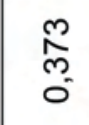 & & & & & \\
\hline \multirow{2}{*}{ 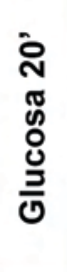 } & 2 & $\begin{array}{l}\stackrel{+}{N} \\
\sigma^{-}\end{array}$ & & & & & & \\
\hline & - & $\begin{array}{l}\bar{\infty} \\
0 \\
0\end{array}$ & & & & & & \\
\hline \multirow{2}{*}{ 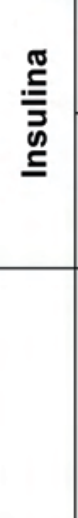 } & 2 & & & & & & & \\
\hline & & 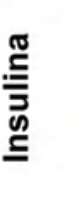 & 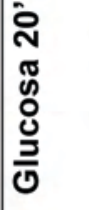 & ํㅗㄴ & لِ & $\frac{2}{0}$ & 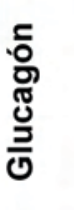 & 옳 \\
\hline
\end{tabular}

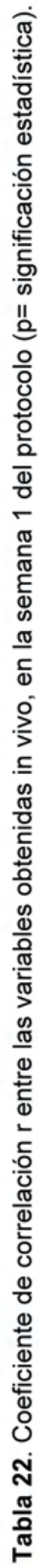


RESULTADOS 235

\begin{tabular}{|c|c|c|c|c|c|c|c|c|}
\hline \multirow{2}{*}{ } & Q & \begin{tabular}{l}
$\infty$ \\
\multirow{2}{n}{} \\
0 \\
0
\end{tabular} & $\frac{N}{\sigma_{0}^{\circ}}$ & $\begin{array}{l}\text { న్ } \\
0 \\
0 \\
0\end{array}$ & \begin{tabular}{c}
+ \\
\multirow{2}{*}{} \\
0
\end{tabular} & 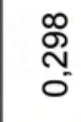 & $\begin{array}{l}\text { \&్ల } \\
\text { Oొ }\end{array}$ & \\
\hline & - & $\frac{\widetilde{m}}{\sigma}$ & $\begin{array}{l}0 \\
00 \\
0 \\
0 \\
0\end{array}$ & $\frac{\bar{m}}{\sigma}$ & $\frac{0}{\frac{1}{2}}$ & 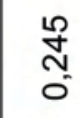 & 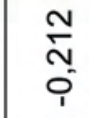 & \\
\hline \multirow{2}{*}{ 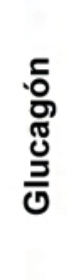 } & e & $\begin{array}{c}\text { P } \\
\infty \\
0 \\
0\end{array}$ & 厄̊ & $\begin{array}{l}\text { ஜ } \\
\infty \\
0 \\
0\end{array}$ & $\begin{array}{l}\text { o } \\
\text { +o } \\
0\end{array}$ & $\begin{array}{l}\text { ○ी } \\
\infty \\
0 \\
0\end{array}$ & & \\
\hline & - & $\begin{array}{l}\text { శ్ } \\
\text { ర్ } \\
\text { - }\end{array}$ & $\begin{array}{l}0 \\
\frac{0}{0} \\
0\end{array}$ & $\begin{array}{l}\bar{J} \\
\end{array}$ & 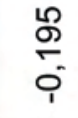 & $\begin{array}{l}\text { \& } \\
\text { ठ } \\
0\end{array}$ & & \\
\hline \multirow{2}{*}{$\frac{0}{\sigma}$} & 2 & $\frac{O}{\frac{0}{0}}$ & $\begin{array}{c}\check{\infty} \\
\sigma^{\circ}\end{array}$ & 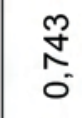 & $\begin{array}{l}\infty \\
\infty \\
\infty \\
0 \\
0\end{array}$ & & & \\
\hline & - & $\begin{array}{l}\text { : } \\
0 \\
0 \\
0 \\
0 \\
1\end{array}$ & $\begin{array}{l}10 \\
0 \\
0 \\
0\end{array}$ & \begin{tabular}{l}
$\infty$ \\
\multirow{1}{0}{} \\
$i$
\end{tabular} & 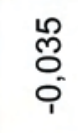 & & & \\
\hline \multirow{2}{*}{ 逭 } & Q & 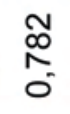 & $\frac{N}{\hat{N}}$ & $\begin{array}{l}\text { \& } \\
\stackrel{\circ}{\circ}\end{array}$ & & & & \\
\hline & - & $\begin{array}{l}\mathscr{8} \\
\square \\
0\end{array}$ & $\begin{array}{l}\infty \\
0 \\
0 \\
0 \\
\end{array}$ & 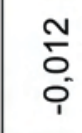 & & & & \\
\hline \multirow{2}{*}{ 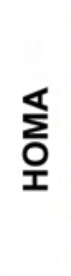 } & e & 응 & $\begin{array}{l}\text { 음 } \\
\text { ه }\end{array}$ & & & & & \\
\hline & - & $\begin{array}{c}\delta \\
\delta \\
\delta\end{array}$ & $\begin{array}{l}\frac{10}{\infty} \\
\sigma^{-}\end{array}$ & & & & & \\
\hline \multirow{2}{*}{ 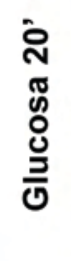 } & Q & ${ }_{0}^{\overline{0}}$ & & & & & & \\
\hline & - & $\begin{array}{l}\mathbb{8} \\
\mathbb{0} \\
0 \\
0\end{array}$ & & & & & & \\
\hline \multirow{2}{*}{ 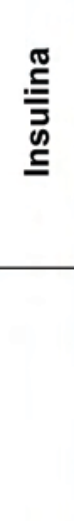 } & Q & & & & & & & \\
\hline & & 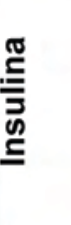 & 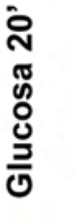 & 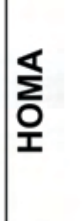 & 밈 & $\frac{9}{v}$ & 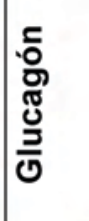 & لَّ \\
\hline
\end{tabular}

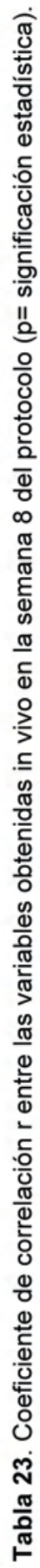




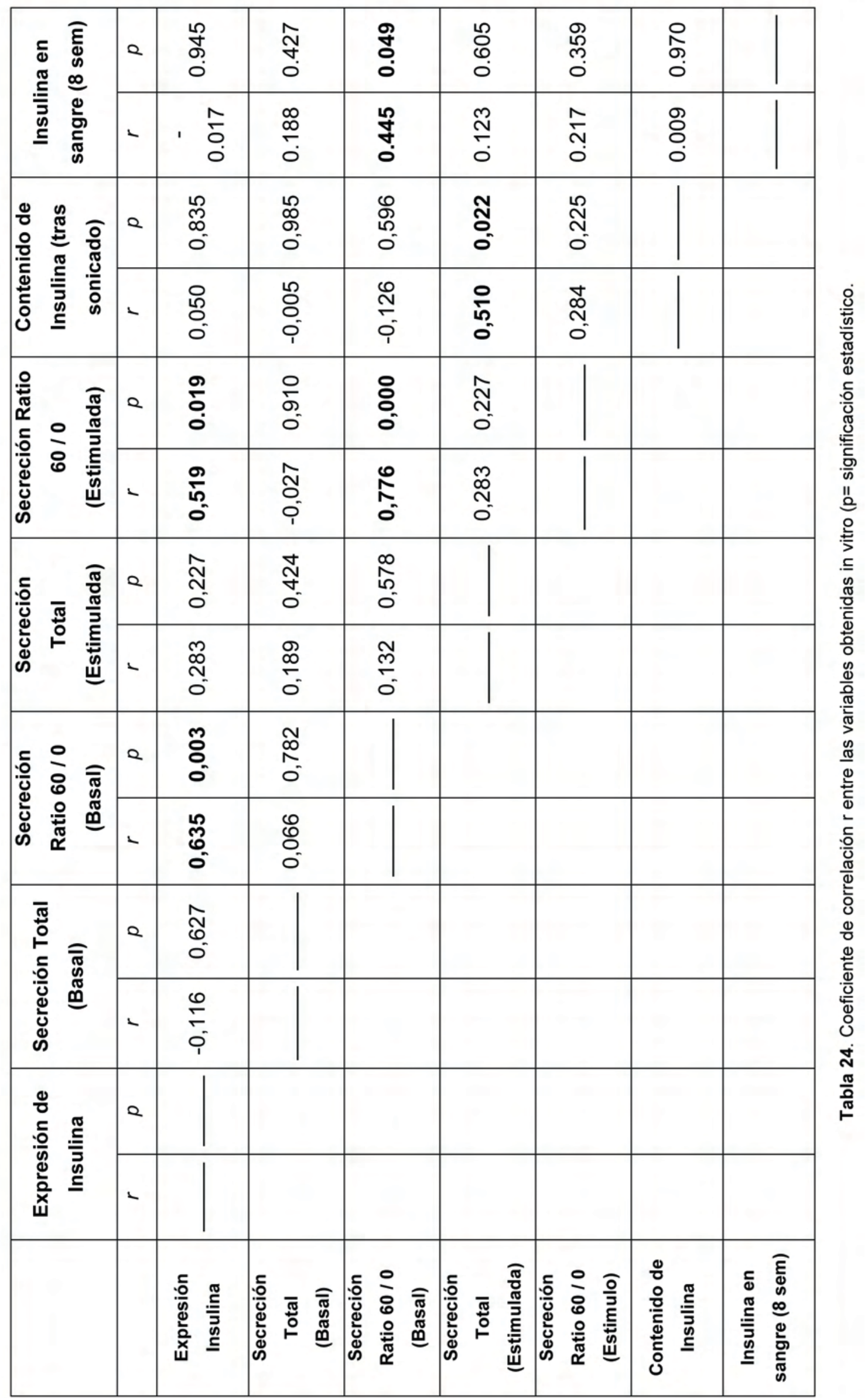




DISCUSIÓN. 



\section{Elección del modelo animal y de la técnica quirúrgica}

A pesar del pequeño tamaño de los órganos, la anatomía del intestino de la rata es muy parecida a la de los humanos. También existen similitudes en la fisiología y sabiendo que aproximadamente de 10 a 13 días de la vida de una rata equivalen a un año de la vida de una persona, es posible estudiar los cambios fisiológicos a largo plazo de la cirugía bariátrica (Rao RS et al, 2010).

Teniendo en cuenta que el objetivo de este trabajo ha sido estudiar los cambios fisiológicos y moleculares que se producen después de la cirugía que excluye el fundus gástrico, antes del inicio del estudio se analizaron en nuestro grupo de investigación los modelos animales disponibles para la realización del mismo. Las ratas más comúnmente usadas son varios tipos de ratas obesas aunque hay varios modelos de ratas, diabéticas o no, disponibles para experimentación. La variedad Sprague-Dawley (SD) producida por Robert W. Dawley en 1925, son ratas no diabéticas no obesas que pueden desarrollar obesidad con dietas especiales hipercalóricas y tienen como principal ventaja una alta resistencia a la agresión quirúrgica. Otro tipo de rata obesa son las Zucker, producidas por el Dr. Luis Zucker en 1961 a partir de una mutación espontánea. Esta mutación da lugar a un defecto en la síntesis de una proteína del receptor de la leptina. Su expresión del fenotipo incluye la obesidad y altos niveles de leptina en sangre. Hay controles no obesos del mismo tipo útiles en estudios comparativos (Zucker magra); son resistentes a la insulina, presentan hipertrigliceridemia e hipercolesterolemia y han sido ampliamente utilizados para estudiar la respuesta a la cirugía bariátrica y sus efectos sobre el síndrome metabólico. Una variación es la rata Zucker diabética grasa (Zucker Diabetic Fatty, ZDF). Representan un modelo animal de diabetes mellitus tipo 2 que no es dependiente de la insulina. Las principales desventajas son su alto precio, una intensa polidipsia, un olor desagradable y una alta mortalidad post-quirúrgica (Clark $\mathrm{J}$ et al, 1983). Esta fragilidad puede en cierta medida restringir su uso.

En un intento de crear colonias que son más adecuadas y adaptadas a la herencia poligénica de la obesidad, dos líneas se desarrollaron a partir de ratas SpragueDawley que puede proporcionar una buena inferencia de síndrome metabólico en las situaciones de obesidad y en ausencia de ella. Sus características son: obesidad, síndrome metabólico, hipertensión, hiperinsulinemia y resistencia a la insulina. La otra subpoblación es la rata resistente a la obesidad. Las características de estas ratas son 
las mismas, pero en un modelo sin obesidad. Otro modelo de obesidad se ha creado recientemente por el cruce de ratas obesas Sprague-Dawley, con resistencia a la insulina como resultado de obesidad poligénica de inicio en la edad adulta y ratas diabéticas Zucker magras con función beta alterada pero leptina normal. Este modelo se conoce como la Davis-DM2 (Universidad de California) y tiene un comportamiento muy similar a la DM2 clínica. (Cummings BP et al, 2008).

Algunos nuevos modelos también presentan síndrome metabólico. Todos ellos tienen hiperinsulinemia, resistencia a la insulina y obesidad, pero se utilizan selectivamente para estudiar los componentes cardiovasculares y renales del síndrome metabólico (Sabench F et al, 2011). El modelo OLETF (Otsuka Long-Evans Tokushima) fue creado a partir de una colonia de ratas Long-Evans, presenta diabetes espontánea, poliuria, polidipsia y obesidad discreta, así como desarrollo tardío de hiperglucemia (a partir de las 18 semanas de edad) (Kawano K, et al 1992).

Algunas ratas son obesas debido a la inducción hormonal: la administración de corticoides, somatostatina, glucagón y catecolaminas, entre otros métodos. La diabetes mellitus también pueden ser desarrollada por inducción farmacológica mediante la administración de estreptozotocina que induce un estado diabético debido a la destrucción de las células beta pancreáticas (Sabench F et al, 2011).

El efecto de la cirugía bariátrica sobre la diabetes es, obviamente mejor estudiado con ratas diabéticas. Una vez analizados los factores enumerados antes, así como la disponibilidad en nuestro medio y la experiencia de trabajos previos de nuestro grupo de investigación, elegimos las ratas Goto-kakizaki (GK) que son diabéticas pero no son obesas y resultan idóneas ya que con este modelo podemos obviar el efecto beneficioso de la pérdida de peso secundario a la cirugía bariátrica y analizar la modificación postquirúrgica de la acción de los péptidos intestinales sobre los niveles de insulina circulante, glucemia y funcionalidad de los islotes pancreáticos.

La rata Goto-Kakizaki (Goto Y et al, 1976), fue creada en Japón a partir de un cruce endogámico de ratas Wistar pero con glucemias en el umbral superior de la normalidad. El modelo de control es la rata Wistar. Estos animales presentan un aumento de la resistencia periférica a la insulina y alteraciones en el metabolismo de los lípidos. Típicamente, la glucemia en ayunas está sólo ligeramente elevada, pero aumenta considerablemente tras la ingesta de glucosa (Arias et al, 2007). Al nacer, la rata GK presenta un número reducido de islotes de Langerhans. No son ratas obesas, 
pero metabólicamente reproducen los modelos de la diabetes mellitus tipo 2. Los defectos en la secreción de insulina estimulada por glucosa, la resistencia periférica a la insulina, hiperinsulinemia y la hiperglucemia pueden ser detectados precozmente aproximadamente a las 4 semanas del nacimiento, empeorando de forma progresiva para alcanzar su nivel máximo hacia las 12 semanas. Numerosos artículos han estudiado el mecanismo por el cual se produce este trastorno en las células beta (Sabench F. et al, 2011). En respuesta a la hiperglucemia, se ha demostrado que aumenta la apoptosis en estas células así como el estrés oxidativo (Koyama $\mathrm{M}$ et al, 1998). Se ha deducido que el desarrollo de diabetes tipo 2 en este modelo animal es multifactorial. Se incluye una susceptibilidad genética para expresar una disfunción de las células pancreáticas, una disminución en la neogénesis de células $B$ programada que es transmitida a través de varias generaciones. Además existe una disminución en la diferenciación de células $B$ asociada con un estado inflamatorio que conduce a estrés oxidativo, fibrosis del islote y un trastorno en su vascularización (Portha B et al 2010). Las ratas Goto Kakizaki son muy útiles en los estudios metabólicos, pero son costosas, posiblemente porque muy pocos laboratorios producen estas cepas (Mistri S et al, 2009).

Al igual que otros modelos animales con diabetes mellitus, la rata GK desarrolla algunas características que pueden ser comparadas con las complicaciones de la diabetes humana, incluyendo lesiones renales (Janssen et al, 1999), cambios estructurales en los nervios periféricos (Murakawa et al., 2002) y anomalías en la retina (Sone et al, 1997).

Sin embargo existen diferencias entre las complicaciones observadas en animales y en humanos y está en discusión si actualmente se dispone de algún modelo animal que refleje de modo fiable las complicaciones de la diabetes humana (Gavin et al, 2010).

Como se comenta en otros apartados, se realizó en todas las ratas intervenidas una gastrectomía vertical (Sleeve gastrectomy) no calibrada con sutura mecánica reforzada según la técnica descrita por Patrikakos y su grupo, modificando los modelos descritos por de Bona Castelan y otros autores en trabajos previos. (Patrikakos, et al, 2009; de Bona Castelan, et al, 2007; Li F, et al, 2009). Tal vez la principal diferencia de la técnica que utilizamos con las realizadas por otros autores es la realización de la gastrectomía con una grapadora mecánica, que disminuye de una forma importante el tiempo operatorio al evitar la realización de una de las dos suturas manuales en la línea de 


\section{DISCUSIÓN}

corte del estómago. Por otra parte, la sutura mecánica puede dar problemas en la calibración ya que es fácil dejar áreas de fundus o de antro sin resecar y que pueden empeorar en mayor o menor medida la función restrictiva de la intervención, o producir el efecto contrario, esto es debido a las características rígidas de la grapadora y al no realizar una calibración intraluminal de la gastrectomía es fácil dejar sin una luz suficiente la zona del cuerpo y producir una oclusión de la salida gástrica que en estos animales casi siempre es mortal.

Referente a las complicaciones posquirúrgicas, las muertes ocurridas (10 casos) fueron en la mayoría de los casos dentro de las primeras 72 horas (8 casos) y en solo 1 se encontraron signos de fallo de sutura con peritonitis secundaria en la necropsia. Posiblemente, este hecho sea debido a un fallo metabólico grave por hiperglucemia intensa ante una intervención que dura unos 45 minutos de media, siendo ésta duración similar a la reportada en otras series. (Sabench et al., 2009). Los otros 2 fallecimientos de la serie se dieron tardíamente (mas de 2 semanas de la intervención) y en un caso no se encontraron hallazgos relevantes en la necropsia; en el otro el fallecimiento se debió posiblemente a una infección cutánea que no respondió al tratamiento instaurado. 


\section{Antecedentes de la cirugía metabólica}

A mediados del siglo $X X$ se comienza a publicar la relación entre la mejoría de la diabetes y la cirugía gástrica resectiva (Forgacs et al, 1973), pero no es hasta la década de los 90, momento en el que la cirugía bariátrica experimenta gran desarrollo, cuando ese hecho adquiere relevancia. El trabajo de Pories y colabs. de 1995, titulado: “¿Quién lo hubiera sospechado?: una cirugía demuestra ser el tratamiento más efectivo para la diabetes del adulto" se podría considerar el punto de partida de la actualmente denominada cirugía metabólica (Poires et al, 1995).

Recientemente, Shin y colabs. han publicado un estudio en el que utilizaban ratas Sprague Dawley en el cual se había inducido obesidad con una dieta rica en grasas y se había sometido a un grupo a una técnica de bypass gástrico en $Y$ de Roux. Se extrajeron muestras de sangre de 3 a 4 meses después de la cirugía y cuando las ratas operadas redujeron significativamente su peso las compararon con uno de los grupos control (ratas en las que se había inducido la obesidad y en las que se había simulado una cirugía). En estas ratas control la hiperleptinemia, la hiperinsulinemia basal, la hiperglucemia así como la intolerancia a la glucosa se mantuvo, mientras que en las ratas obesas operadas se revertía completamente y no mostraban diferencias en estos parámetros con respecto al grupo de control alimentado con dieta normal (Shin et al, 2009).

El modelo de experimentación animal de Shin reproduce los cambios hormonales y glucémicos observados en los pacientes obesos sometidos a este tipo de cirugía y en la misma línea existe una publicación de 2010 en la que estudian ratas del mismo tipo en las cuales se ha inducido obesidad mediante dieta que fueron sometidas a bypass gastroyeyunal en $Y$ de Roux. Después de 14 días de la intervención quirúrgica se compararon con otro grupo de ratas control obesas. La ingesta de comida, el peso y la masa grasa descendieron, alcanzaron una glucemia normal y los niveles de insulina descendieron mientras que el ratio glucosa/insulina se elevó. Estos valores persistieron también en el día 28 después de la cirugía (Bonhomme et al, 2011).

La cirugía bariátrica en animales de experimentación no sólo se ha realizado en animales en los que se ha inducido la obesidad mediante dieta sino que también se han utilizado ratas de tipo Zucker, que son genéticamente obesas y un modelo espontáneo de diabetes tipo 2. Como ejemplo nos referimos a los ensayos publicados en 2009 por Sabench y colabs. en los cuales se comparaban grupos de ratas Zucker 
(obesas y diabéticas). A uno de los grupos se le practicaba una transposición ileal; a un segundo grupo un bypass gastroyeyunal, y al tercer grupo una gastrectomía vertical. Se detectó una mayor pérdida de peso con el by-pass gastroyeyunal (Sabench et al., 2009).

En otro trabajo de nuestro grupo de investigación, los resultados difieren de los obtenidos en ratas diabéticas no obesas en las que la mejoría en la diabetes inducidas por la exclusión duodeno-yeyunal es independiente de la pérdida de peso ya que el peso de nuestras ratas permanece sin disminuir en el grupo intervenido quirúrgicamente y no existen diferencias significativas entre este grupo y el grupo control en los distintos tiempos del protocolo (Domingo M, 2011; De Luis et al, 2012). Estos resultados confirman los resultados obtenidos anteriormente por nuestro grupo (Pacheco et al, 2007).

El concepto de cirugía metabólica se consolida con la revisión de Buchwald en la que de 22.000 pacientes operados detectaron un $76 \%$ de resolución global de la diabetes y un $85 \%$ si se considera la mejoría clínica (Buchwald et al, 2004). Las derivaciones biliopancreáticas, tanto la original de Scopinaro como la modificación de Hess y Marceau y el cruce duodenal, consiguen la resolución de la enfermedad en el 98,9\% de los casos, el bypass gástrico obtiene cifras mayores del $83 \%$, la gastroplastia vertical anillada un $71 \%$ y la banda ajustable un $50 \%$ (Dixon et al, 2008).

La cirugía bariátrica se ha convertido en un tratamiento común para la obesidad asociada a diabetes tipo 2 y actualmente está reconocido como un tratamiento eficaz para la prevención, control o reversión de la enfermedad (Rubino et al, 2002).

Sin embargo, el efecto antidiabético de la cirugía ha sido, hasta hace poco tiempo, interpretado como un resultado exclusivo de un incremento en la sensibilidad de insulina debido a la pérdida de peso (Geloneze et al, 2001). Sabemos que el control glucémico se produce a menudo antes de que los pacientes pierdan peso significativamente, lo que sugiere la existencia de un efecto directo con la cirugía en lugar de un fenómeno secundario relacionado con el peso corporal (Cummings et al, 2008).

La mejoría en diabetes tipo 2 después de la cirugía gastrointestinal también se ha demostrado en pacientes con obesidad leve y en individuos no obesos y en algunos 
protocolos ya se acepta la intervención quirúrgica como tratamiento de la DM2 con índice de masa corporal (IMC) de 30 a $35 \mathrm{~kg} / \mathrm{m} 2$ (Runkel N, et al, 2011).

En un ensayo de 80 pacientes con IMC de $30-35 \mathrm{~kg} / \mathrm{m}^{2}$ se trataron con una dieta baja en calorías, modificación en el estilo de vida y farmacoterapia o con banda gástrica ajustable laparoscópica. Como punto de partida, el 38\% de los pacientes en cada grupo había sido diagnosticado de síndrome metabólico. Dos años después de la cirugía, el $24 \%$ de los pacientes que no se habían sometido a la cirugía tenían síndrome metabólico, frente al 3\% de los pacientes operados (O’Brien et al, 2006).

Cohen y colabs. publicaron un estudio que mostraba una marcada reducción en los niveles en plasma de glucosa en ayunas, en una serie de 37 pacientes con IMC $<35$ $\mathrm{kg} / \mathrm{m}^{2}$ que se habían sometido a un by-pass gástrico en $\mathrm{Y}$ de Roux (Cohen et al, 2006).

Un año después, este mismo grupo de investigadores publicó los resultados de los primeros dos pacientes con diabetes mellitus tipo 2 operados mediante bypass duodenoyeyunal; estos pacientes tenían un IMC de 29 y de $30 \mathrm{~kg} / \mathrm{m}^{2}$ respectivamente. Una vez realizada la cirugía, los niveles de $\mathrm{HbA} 1 \mathrm{c}$ de los pacientes se normalizaron a los 3 meses y se estabilizaron después de 9 meses a $5-6 \%$ (desde $8-9 \%$ del preoperatorio). Es muy importante señalar que ninguno de los pacientes perdió peso lo que reafirma la teoría de que los mecanismos antidiabéticos son independientes de la pérdida de peso (Cohen et al, 2007).

Geloneze y su grupo han publicado los resultados sobre los efectos en el control glucémico de 12 pacientes no obesos (con IMC: $25-29.9 \mathrm{~kg} / \mathrm{m}^{2}$ ) diagnosticados de diabetes mellitus tipo 2 y los compararon frente a un grupo de pacientes control, seleccionados entre los pacientes preseleccionados para el estudio que se negaron a ser operados y recibieron tratamiento médico estándar. A los 6 meses de la cirugía, los pacientes operados mostraron una gran reducción en la glucosa en ayunas, un $14 \%$ frente a un $7 \%$ en grupo control (Geloneze et al, 2009), reducción significativa en los valores de hemoglobina glicosilada desde $8,78 \%$ a 7,84\% en $B G Y(p<0,01)$ y de $8,93 \%$ a $8,71 \%$ en el grupo control $(p<0.05)$ y reducciones en los requerimientos diarios de insulina (93\% frente a un 29\%, $p<0,01)$. De los 12 pacientes, 10 dejaron el tratamiento con insulina y mantuvieron la medicación oral. Tampoco se detectaron diferencias en ambos grupos en el IMC. 
La gastrectomía vertical se llevó a cabo originalmente como el componente restrictivo del cruce duodenal. Esta gastrectomía parcial sirve para reducir la capacidad gástrica y producir a corto plazo pérdida de peso, mientras que el componente de malabsorción de la operación (derivación biliopancreática) se realizaba en un segundo tiempo quirúrgico. Sin embargo en algunos pacientes no se pudo realizar el bypass intestinal y las primeras investigaciones encontraron una pérdida de peso sustancial y clínicamente significativa con la primera intervención (Brethauer SA, 2011). Posteriormente la gastrectomía vertical se desarrolló como una estrategia de gestión de riesgos para los pacientes muy obesos o de alto riesgo quirúrgico, quienes difícilmente tolerarían un procedimiento de mayor envergadura. (Regan JP et al, 2003) En este enfoque por etapas, las condiciones médicas de los pacientes mejoraron tras 1 o 2 años después de la gastrectomía, y a muchos se le practicó un procedimiento de bypass intestinal en una segunda etapa (bypass gástrico o switch duodenal). En un estudio realizado por Cottam y su grupo (Cottam D et al, 2006) 126 pacientes superobesos de alto riesgo con IMC medio preoperatorio de 65,3 kg/m2 fueron sometidos a una gastrectomía vertical como procedimiento de primera etapa. La media de la pérdida de exceso de peso en 1 año fue del $43 \%$ y se observaron reducciones significativas en el número de comorbilidades y el grado del ASA (Sociedad Americana de Anestesiología). En los últimos 10 años, la gastrectomía vertical cada vez se utiliza más como procedimiento único y ha adquirido popularidad entre los pacientes y los cirujanos bariátricos, representando actualmente el $5 \%$ de todas las operaciones bariátricas realizadas mundo. (Buchwald $\mathrm{H}, 2009$ )

La remisión de la diabetes mellitus después de la realización de la gastrectomía vertical (GV) se ha reportado en diferentes grados. Una revisión sistemática reciente de Gill y colabs. ha evaluado las tasas de mejoría de la diabetes mellitus después de la GV encontrando una remisión de la diabetes en el 66,2\% de los pacientes. En este mismo trabajo, en los estudios que reportaron mejoría y remisión de la diabetes mellitus, un total de $97 \%$ de los pacientes mejoraron. La hemoglobina A1c media ( $\mathrm{HbA1c}$ ) disminuyó de 7,9\% a 6,2\% en los 11 estudios que incluyeron a esta medida de control de la glucosa. En un ensayo controlado de Taiwan en el cual se compararon el BPG con la GV como tratamiento de la diabetes mellitus tipo 2, la GV dio lugar a la remisión de la diabetes en el $47 \%$ de los pacientes a 1 año y se asoció con una reducción media del $3 \%$ en los niveles de $\mathrm{HbA1c}$. El bypass gástrico sin embargo, tenía más efectos sobre la pérdida de peso, la disminución en la circunferencia de cintura, y la tasa de remisión de la diabetes mellitus tipo 2 (93\%), así como la mejoría en los parámetros del síndrome metabólico. (Lee WJ et al, 2011). En otro estudio de 
pacientes sometidos a GV y BPG que fueron emparejados por la gravedad y la duración de la diabetes mellitus, Vidal y cols. encontraron que ambos grupos tenían tasas de un $84 \%$ de remisión de la diabetes mellitus y tasas comparables de resolución del síndrome metabólico en un año (62\% GV vs el 67\% de BPG). (Vidal J. et al, 2008).

Se ha observado también una mejoría en otras importantes comorbilidades relacionadas con la obesidad y el síndrome metabólico tras la realización de la GV, además de la mejoría significativa o la resolución de la apnea del sueño, dolor en las articulaciones, depresión y el edema de miembros inferiores. (Brethauer SA et al, 2011).

Los mecanismos de acción a través de los cuales la GV produce saciedad precoz, control del hambre y la mejoría en los parámetros metabólicos son objeto de controversia. Inicialmente se creía que era una intervención de carácter puramente restrictivo, pero posteriormente algunos estudios reportaron cambios en las hormonas intestinales y los efectos metabólicos de este procedimiento han desafiado este concepto. La ghrelina, producida principalmente en el fundus gástrico, disminuye después de una GV. (Langer $F$ et al, 2005) y se ha demostrado que esa disminución que persiste 5 años después del procedimiento. (Bohdjalian A et al, 2010). Aunque la ghrelina puede influir en los cambios en el hambre, la saciedad y el metabolismo de la glucosa después de la GV, es poco probable que sea el único mecanismo que contribuye a los efectos a largo plazo del procedimiento.

Numerosos estudios han reportado el papel de la ghrelina como regulador de la ingesta y sus cambios tras la realización de diferentes técnicas quirúrgicas de cirugía bariátrica (Cummings $\mathrm{D}$ et al, 2002; Rubino $\mathrm{F}$ et al, 2002). La cirugía bariátrica gástrica no solo afecta la capacidad gástrica y el área de absorción de nutrientes y grasas sino también el patrón de secreción de los péptidos que regulan la ingesta y la digestión. El hecho que la ghrelina sea principalmente sintetizada en el fundus gástrico y que es un potente factor orexígeno ha dado lugar a numerosos estudios para identificar un nexo con la cirugía (Sabench $\mathrm{F}$ et al, 2008)

Con la gastrectomía vertical casi todo el fundus gástrico es resecado, lo cual sugiere que tras la intervención los niveles de ghrelina, en teoría deberían bajar. Los resultados en la pérdida de peso encontrados en la gastrectomia vertical pueden ser debidos en parte a la disminución en los niveles de ghrelina, que reducen 
considerablemente la ingesta (Langer $F$ et al 2005).

El tránsito rápido de nutrientes al intestino distal es uno de los mecanismos responsables de la saciedad precoz y la mejoría en el metabolismo de la glucosa después de un BPG. Estos efectos están mediados por hormonas intestinales (PYY y GLP-1) producidos en las células L localizadas en el intestino distal. (Uglioni $B$ et al, 2009).

Los trabajos existentes muestran que el transporte de nutrientes también se incrementa después de una GV. Melissas y cols. (Melissas J et al, 2007 y 2008) demostraron que hay un mayor vaciamiento gástrico después de la GV y este tránsito rápido de alimentos sólidos en el intestino distal podría tener efectos similares sobre la masa de células $L$ que el BPG. En otro ensayo aleatorizado comparando BPG y GV laparoscópica, se demostraron aumentos del PYY en ayunas y postprandiales similares después de estos dos procedimientos. En este mismo estudio la pérdida de peso fue significativamente mayor a los 12 meses de la GV (69,7\% frente al 60,5\%), que se atribuyó a los bajos niveles de ghrelina y disminución del apetito visto después de GV en comparación con BPG (Karamanakos SN et al, 2008).

Hasta la fecha de nuestra revisión bibliográfica, no existen estudios que diluciden con claridad los mecanismos hormonales diferentes a la disminución de la ghrelina que median la pérdida de peso y la remisión de la diabetes mellitus después de una GV, pero parece claro que la intervención tiene múltiples efectos metabólicos más allá de la pérdida de peso. 


\section{Resultados sobre el peso y el control glucémico tras la Gastrectomía Vertical.}

De forma similar a lo observado en nuestro grupo experimental, varios estudios reportan que cuando se realiza una GV en ratas no obesas se observa una pérdida de peso inicial que se recupera posteriormente. Se han hecho pocos estudios sobre el efecto de la gastrectomía vertical en pacientes con bajo grado de obesidad y su eficacia a lo largo del tiempo, por lo tanto deben hacerse más ensayos que analicen los beneficios a largo plazo de este tipo de cirugía para pacientes no obesos o con sobrepeso leve. (Baltasar, et al, 2005) Cuando la gastrectomía vertical se realizó en ratas obesas de forma exógena (especialmente debido a una dieta elevada en grasas), la pérdida de peso inicial fue recuperada sólo en parte, y la curva fue mucho más gradual. El peso inicial no fue totalmente recuperado y la pérdida de peso neta fue bastante considerable. Como se observa en diversas series en humanos, la pérdida de exceso de peso fue superior al 50\%, lo cual demuestra que esta intervención es altamente efectiva para este tipo de pacientes. (Baltasar et al, 2005). Cuando se analiza un modelo animal con ratas con un tipo genético de obesidad los efectos de la intervención fueron particularmente positivos. Esto último sugiere que la contribución genética a la obesidad de los pacientes debería ser evaluado antes de la intervención así como si esto puede influenciar en la efectividad de la cirugía. (Sabench F et al, 2008).

En otro estudio se observó que al comparar un grupo de ratas no diabéticas, no obesas, intervenidas de GV comparadas con un grupo control al que se le realizó una laparotomía sin gastrectomía, el patrón de pérdida de peso fue similar en ambos grupos. Esto sugiere que la deprivación post-quirúrgica de alimentos y el estrés tenían casi el mismo efecto en ambos grupos. Los dos grupos recibieron comida ad libitum después del séptimo día postoperatorio, pero en el grupo experimental se observó que la pérdida de peso continuó hasta el día 15 postoperatorio recuperando el peso perdido a partir de este punto. Al final del experimento, el grupo control aumentó su peso promedio, lo cual es normal para los roedores durante su vida, mientras que en el grupo experimental se documentó, al igual que en nuestro experimento, un mantenimiento del peso al compararlo con los valores preoperatorios. (Patrikakos P, et al 2009)

La diabetes mellitus de tipo 2 puede ser un desequilibrio entre incretinas y factores antiincretinas que conduce a una respuesta retardada de la insulina y a una alteración de su acción a nivel de los tejidos diana. Los factores antiincretinas son 
sobreproducidos probablemente en el intestino proximal de los diabéticos, como consecuencia la exclusión del duodeno evita este fenómeno.

Rubino y cols. en un estudio experimental en ratas Goto Kakizaki (espontáneamente diabéticas tipo 2 no obesas) demostraron que la derivación gastroyeyunal controlaba la diabetes mellitus a largo plazo en estos animales (Rubino et al, 2004). La media en los niveles de glucosa en ayunas en el plasma tres semanas después de la cirugía fue $96,3 \pm 10,1 \mathrm{mg} / \mathrm{dL}$ (siendo los valores en el preoperatorio $159 \pm 47 \mathrm{mg} / \mathrm{dL} ; \mathrm{p}<0,01$ ).

En 2007, nuestro grupo encontró resultados similares en el control glucémico con una derivación gastroyeyunal en el mismo modelo de rata diabética (Pacheco et al, 2007). Los niveles de glucosa mejoraron a las semana, y al mes de la cirugía en todos los tiempos de un test de tolerancia a la glucosa (en ayunas, a los 20 minutos y a los 120 minutos).

Sin embargo al realizar la GV en el experimento que se presenta ahora se encontró una disminución de los valores de glucemia basal en todos los tiempos del experimento, siendo significativa en la semana 8 del experimento, pero no hubo cambios significativos tras el test de tolerancia oral a la glucosa.

Esta misma situación la refieren Gatmaitan y cols. en su estudio en ratas obesas Sprague Dawley sometidas a un bypass gástrico en $Y$ de Roux en el que después de cuatro semanas de la cirugía no detectaron diferencias estadísticamente significativas en las glucemias con respecto al grupo control. Cabe señalar que en este grupo de ratas encontraron un aumento drástico en la secreción de insulina por parte de los islotes pancreáticos aislados y expuestos a un medio con una concentración elevada de glucosa (Gatmaitan et al, 2010).

En uno de los trabajos de Sabench Pereferrer, en el cual se analizan varios modelos en animales diabéticos a los que se les realizó una GV, los resultados en la mejoría en los niveles de glucemia son irregulares. En los primeros modelos con ratas no diabéticas se observa en general mejoría en los niveles de hiperglucemia cuando estaba presente en el preoperatorio. En el modelo en que se utilizaron las ratas Zucker Diabetic Fatty, (ZDF) hubo una mejoría considerable y altamente significativa ( $p$ $<0.001$ ) una semana después de la intervención, aunque los valores no alcanzaron los niveles de normoglucemia. En la semana 14, los niveles de glucemia no fueron significativamente diferentes a los valores pre-intervención (Sabench et al, 2008). 
En otro trabajo reciente, se realizó una GV en ratas ZDF. A los 45 días de la intervención los niveles de glucosa aumentaron significativamente en las ratas control, aumentando de forma no significativa en el grupo de ratas operadas. (Lifante $\mathrm{J}$ et al 2012)

Nuestros resultados reproducen parcialmente los reportados por Li y su grupo (Li F, et al 2009) en el cual comparan 4 grupos de ratas Goto-Kakizaki, en los cuales se realizó una GV, un bypass duodeno-yeyunal y una intervención control de cada una de las intervenciones anteriores. En los 4 grupos se observó una disminución de los niveles de glucemia basal en un primer momento con un rebote progresivo en los grupos control. Así mismo se observó una mejoría estadísticamente significativa entre los valores preoperatorios y a las 10 semanas de la intervención en las ratas intervenidas, siendo mayor la mejoría en el grupo gastrectomizado. Cabe destacar que el test de tolerancia se realizó sin anestesiar a las ratas, y comparando la metodología con la de nuestro estudio, conviene tener precaución en la interpretación de los datos obtenidos de glucosa ya que las muestras de sangre fueron tomadas cuando la rata se encontraba todavía bajo los efectos de la anestesia. Se sabe que en estas condiciones se induce hiperglucemia y menores niveles de insulina.

Adicionalmente, las ratas intervenidas en el estudio de Li, tenían entre 8 y 10 semanas de edad, mientras que en nuestro grupo utilizamos ratas con edades comprendidas entre 16 y 18 semanas y se sabe que las ratas Goto Kakizaki desarrollan completamente las características fenotípicas de la diabetes como hiperglucemia en ayunas, deficiencia en la secreción de insulina in vivo e in vitro, resistencia a la insulina y poliuria, aproximadamente hacia las 12 a 14 semanas.

Recientemente se ha publicado un trabajo por Sun y su grupo en el cual se realizó una GV en un grupo y un bypass duodeno-yeyunal asociado a GV en otro, con sus respectivos grupos control, en ratas GK de 11 semanas de edad. Se observó una mejora en la glucosa basal y tras sobrecarga oral de glucosa en los grupos intervenidos, así como en los índices de resistencia a la insulina (HOMA R), sin diferencias significativas entre los grupos intervenidos (Sun D et al, 2012).

Otros trabajos experimentales han fallado en demostrar la mejoría precoz en los niveles de glucemia y cambios en las incretinas en ratas diabéticas tras una gastrectomía vertical (Wang $Y$, et al, 2011). Ante estos hallazgos se plantea la 


\section{DISCUSIÓN}

posibilidad de que la GV tenga una mayor utilidad en pacientes diabéticos de corta evolución y que cada intervención pueda tener sus indicaciones teniendo en cuenta el tipo de paciente, la etiología, la patogénesis y la duración de las alteraciones en el metabolismo de los hidratos de carbono.

Incluso hay autores de prestigio, como Goldfine y su grupo de la Universidad de Harvard que prefieren ser cautos a dar opiniones respecto a los efectos hormonales y metabólicos a corto plazo de la cirugía bariátrica en pacientes diabéticos ante los niveles de evidencia de los estudios actuales, sobretodo respecto a técnicas quirúrgicas de más reciente popularización como la gastrectomía vertical (Goldfine $A B$, et al, 2009; Lautz D, et al 2011).. 


\section{Resultados de insulina y glucagón}

Se sabe que en individuos sanos la insulina y el glucagón actúan de forma antagónica para mantener las concentraciones plasmáticas de glucosa dentro del intervalo de la normalidad. Ambas hormonas están presentes en la sangre la mayor parte del tiempo. En estado postprandrial o después de una sobrecarga oral de glucosa (estado en el que han sido cuantificadas dichas moléculas) domina la insulina y el organismo se encuentra en estado anabólico.

Sin embargo, en un modelo animal de diabetes mellitus tipo 2 se da un fenómeno de insulinresistencia, los niveles de insulina al principio suelen ser normales o incluso elevados y a lo largo del proceso patológico, se transforma en una deficiencia en insulina.

En nuestro trabajo se observó un aumento estadísticamente significativo en los niveles de insulina sérica a la semana de la intervención manteniéndose en la semana 8 pero sin alcanzar significación estadística.

Al comparar la GV y la derivación duodeno-yeyunal con GV y sus respectivos controles, Sun encontró aumentos en los niveles de insulina estadísticamente significativos en los grupos intervenidos respecto a los controles sin encontrar diferencias entre los grupos operados de ratas GK jóvenes (Sun D et al, 2012).

El aumento en los niveles de insulina se puede explicar por el aumento del efecto incretina que se hallaba disminuido en este modelo animal previo a la cirugía bariátrica, con un aumento en los niveles de incretinas que se han observado en trabajos previos de nuestro grupo de investigación. (Domingo M, 2011).

En estos ensayos observamos cómo este efecto incretina se encuentra fundamentalmente ejercido por el GLP-1. Los niveles de GLP-1 aumentaron desde la primera semana después de una derivación gastro-yeyunal, siendo estadísticamente significativa ocho semanas después de la cirugía.

En este orden de ideas, se ha propuesto en otros trabajos, que los cambios que se observan tanto en la DM2 manifiesta como en su mejoría en los niveles de insulina y glucagón están relacionados con los niveles de incretinas y en particular con el GLP 1, 
debido a la estimulación del intestino distal por la entrega más rápida de nutrientes al mismo. El aumento de los niveles de GLP-1 en plasma estimulan la secreción de insulina y suprimen la secreción de glucagón, mejorando así el metabolismo de la glucosa (Briatore L et al, 2010; Rubino F et al, 2010). La otra teoría mas propugnada sostiene que la exclusión del intestino proximal reduce o suprime la secreción de hormonas anti-incretinas, que conduce a la mejora en el control fisiológico de la glucosa en sangre. Contrarios a estas teorías, procedimientos restrictivos, tales como GV y la gastroplastia con banda han demostrado que también son capaces de mejorar o resolver la diabetes mellitus tipo 2 (Mingrone $\mathrm{G}$ et al, 2009)

Sin embargo y como se analizará mas adelante, los niveles de GLP 1 y GIP permanecieron invariables durante los diferentes tiempos de nuestro experimento. Los mecanismos por los cuales se obtuvo la mejoría en los niveles de insulina independientemente de la pérdida de peso y del efecto incretina pueden estar relacionados con otras vías hormonales que no han sido estudiadas en este trabajo.

Un reciente ensayo clínico prospectivo y aleatorizado comparó la respuesta glucémica y hormonal después del BPG laparoscópico y la GV encontrando que 3 meses después de la cirugía, no se detectaron diferencias significativas en la secreción de insulina, GLP-1 y PYY entre los dos procedimientos. Por el contrario la reducción de la secreción de ghrelina en el grupo de la GV fue más importante que en el grupo del BPG. Estos resultados apoyan la importancia de la ghrelina en la mejora de la homeostasis de la glucosa tras GV (Peterli R et al, 2009).

Varios autores han encontrado un aumento de PYY en ayunas y postprandial después de procedimientos restrictivos. Karamanakos y su grupo, compararon prospectivamente pacientes intervenidos de GV y BPG encontrando un aumento similar del PYY en ayunas y postprandial después de estos dos procedimientos, mientras que la ghrelina solo disminuyó después de la GV (Karamanakos SN et al, 2008).

El PYY es una hormona secretada en el íleon distal junto con el GLP-1. La obesidad se asocia con menores niveles de PYY basales. El aumento de los niveles pre y postprandiales de PYY tras una GV sin bypass intestinal sugiere un mecanismo neuronal o humoral en la modulación del PYY. La GV está asociada con una disminución de la secreción de ácido gástrico que puede dar lugar a la salida al duodeno de quimo sin digerir. Este aumento en el $\mathrm{pH}$ duodenal es una de las hipótesis 
para explicar la elevada secreción de PYY después de la GV. Algunos estudios recientes refuerzan el papel del PYY en la mejoría en la sensibilidad a la insulina tras cirugía bariátrica (Rizzelo M et al, 2010).

En otro estudio la GV produjo, según los autores, un reequilibrio del metabolismo lo que mejoró el estado de hiperinsulinismo en los animales que no habían desarrollado DM2 y al aumento de los niveles de insulina en ratas diabéticas (ZDF) cuyas reservas de insulina reducidas eran responsables de su descompensación metabólica (Sabench F et al, 2008).

En el estudio de Li y colabs. en ratas GK no se encontraron diferencias significativas en los niveles de insulina basal y tras estímulo con glucosa entre los grupos intervenidos de GV y bypass duodeno-yeyunal y sus grupos control, a pesar de las mejoras significativas encontradas en los niveles de glucemia comentadas antes. (Li F et al, 2009).

En lo que respecta a los niveles de glucagón tras la gastrectomía vertical, las técnicas de ELISA revelaron una disminución estadísticamente significativa en sus niveles plasmáticos a lo largo del protocolo. Trabajos en humanos han mostrado un aumento no significativo en los niveles de glucagón a pesar de obtener mejorías precoces en los niveles de glucemia tras una GV (Romero F, et al, 2011),

A pesar que la regulación de la glucemia en unos determinados límites depende tanto de la insulina como del glucagón en base a perfiles de funcionamiento antagónicos, se sabe muy poco de la regulación de la célula alfa, pero es aceptado que el control en la secreción de glucagón es multifactorial siendo la hiperglucagonemia un importante componente de las anormalidades metabólicas asociadas con la DM2. (Gromada J et al 2007, Shah P, et al, 2000)

Debido a que el efecto paracrino es importante dentro del islote, todavía no se sabe con exactitud si la inhibición en la secreción de glucagón a concentraciones elevadas de glucosa es debida estrictamente a la glucosa o a un efecto paracrino de las células vecinas.

Se ha propuesto un modelo de regulación de la secreción de glucagón que explica como el incremento de la concentración extracelular de glucosa, llevaría a un aumento intracelular de la relación ATP/ADP que daría lugar al bloqueo de los canales $\mathrm{k}^{+} \mathrm{ATP}$, 
despolarizando así la membrana hasta valores de potencial para los cuales se inactivan las corrientes dependientes de voltaje que sustentan los potenciales de acción. Esto, por tanto, llevaría a la disminución de la actividad eléctrica. Por el contrario, la apertura de canales de $\mathrm{Ca}^{2+}$ en fase eléctrica activa a baja concentración de glucosa facilita la entrada de $\mathrm{Ca}^{2+}$ extracelular dando lugar a una señal oscilatoria. Este aumento de $\mathrm{Ca}^{2+}$ en el citosol favorece la exocitosis de los gránulos de glucagón (Gopel et al, 2000).

La elevación de la glucemia puede ejercer un efecto directo sobre la célula alfa y la secreción de glucagón, o puede participar indirectamente al estimular la secreción de células beta y activando respuestas paracrinas (Quesada et al, 2006). Entre varios mecanismos, uno de los más importantes en la inhibición de la secreción de glucagón que es el llevado a cabo por la insulina.

La diabetes mellitus está asociada a una excesiva biosíntesis y secreción de glucagón. La hiperglucagonemia asociada a la diabetes mellitus se manifiesta en situación basal (Unger et al, 1981) y la administración intravenosa de glucosa no produce la disminución esperada de los niveles plasmáticos, sino incluso un aumento.

La importante reducción en los niveles de glucagón de la semana 1 de nuestro trabajo sugiere que la cirugía mejora parte de los mecanismos fisiopatológicos asociados a la diabetes mellitus tipo 2.

Se ha demostrado que el glucagón es inhibido por el GLP-1 (Nauck et al., 2002). Sin embargo, los mecanismos por los cuales se produce la supresión de glucagón no están claros hasta el momento. Se considera que pudiera ser ejercido indirectamente a través de la estimulación de la secreción de insulina y de somatostatina, sin embargo, se ha postulado un efecto directo dado la presencia de receptores de GLP-1 en las células alfa pancreáticas (Somols et al, 1986).

En los niveles plasmáticos de insulina también habría que considerar el efecto del glucagón extrapancreático que parece provenir del tracto intestinal (Blázquez et al, 1976), aunque se desconoce la posible contribución del glucagón extrapancreático al total del glucagón circulante tanto en individuos sanos como en diabéticos.

En próximas investigaciones se podría medir el glucagón secretado por las células alfa directamente a través de la concentración en el medio de incubación en los islotes 
pancreáticos aislados con el objetivo de esclarecer los mecanismos relacionados con el desarrollo de la diabetes y el origen de la modulación en los mecanismos moleculares asociados a la exclusión de parte del tracto gastrointestinal.

\subsection{Resultados de sensibilidad a insulina}

La mayoría de los estudios en humanos después de una cirugía bariátrica recogen cambios favorables en la sensibilidad a la insulina.

Como se muestra en la publicación de Cummigs y colabs, el índice de sensibilidad a insulina medido a través del test de tolerancia a glucosa intravenosa incrementó de 4 a 5 veces (Cummings et al, 2005).

La sensibilidad a la insulina estimada por el HOMA y el área debajo de la curva después de un test de tolerancia a glucosa intravenosa incrementó significativamente 6 días después del by-pass gastroyeyunal en $Y$ de Roux antes de que se produjera la pérdida de peso (Wickremesekera et al, 2005). Estos datos son similares a los que obtuvimos en trabajos previos, en ratas GK en los que la mejoría en cuanto a la sensibilidad de insulina medida por el índice QUICKi y de disminución de la resistencia a insulina (HOMA R) se dan una semana después de la cirugía (Domingo $M, 2011$ ). Sin embargo en este trabajo de investigación y teniendo en cuenta que el índice HOMA R se calcula con las cifras de glucemia a los 20 minutos tras la sobrecarga de glucosa y que los niveles de insulina aumentaron de forma significativa a la semana de la intervención, se encontró que el índice HOMA R aumentó de forma significativa a la semana de la intervención. El índice de sensibilidad a la insulina (QUICKi) no presentó variaciones significativas a lo largo del experimento.

Bitar y colabs. estudiaron las alteraciones en la dinámica de la glucosa en el mismo modelo animal de diabetes mellitus tipo 2 y concluyeron que en ratas GK la resistencia a insulina ocurre a nivel hepático y del músculo, que el transporte de glucosa en el músculo está asociado a defectos en el transportador GLUT-4 y en las vías de señalización de la insulina, y que la resistencia a insulina en el músculo podría ser de origen genético (Bitar et al, 2005). 


\section{Discusión sobre los resultados de hormonas gastrointestinales:}

\section{Resultados de las incretinas: GLP-1 y GIP}

Es en general aceptado el efecto endocrino que se produce al realizar un bypass del intestino proximal. En humanos, este procedimiento ha mostrado cambios en la producción de hormonas; disminución de leptina, incremento de GLP-1 y de GIP (Hickey et al, 1998), incluso antes de modificaciones en el peso (Rubino et al, 2004).

Sin embargo no está clara la forma en que los procedimientos en los que no se realiza una exclusión del intestino proximal tienen un efecto beneficioso precoz en la homeostasis de la glucosa por medio de mecanismos hormonales.

Los mecanismos hormonales mejor estudiados que intervienen en la mejoría del peso y el metabolismo de la glucosa tras GV, son la disminución en los niveles de ghrelina, así como el aumento en el PYY y la disminución de la leptina. Los efectos de la ghrelina están relacionados con un complicado sistema hormonal de regulación del apetito que incluye el AgRP, el neuropéptido $\mathrm{Y}$ y la leptina. El AgRP es un neuropéptido producido en el hipotálamo que ha demostrado ser un agonista inverso de los receptores de melacortina MC3-R y MC4-R y está directamente relacionado con el metabolismo y el control de peso. (Jackson PL et al, 2006). Este es coexpresado con el NPY, incrementando el apetito y disminuyendo el metabolismo y el gasto de energía y es considerado uno de los estimulantes del apetito más potentes y durables. Su acción orexígena es inhibida por la leptina y estimulada por la ghrelina (Papailiou J et al 2010).

Los estudios de seguimiento de la GV en humanos han mostrado altas tasas de resolución de la DM2 independientemente del porcentaje de exceso de peso perdido y de la normalización de la masa grasa (Rizzelo M et al, 2010). Estos datos sugieren que existen mecanismos adicionales que contribuyen a mejorar los diferentes parámetros metabólicos alterados en el paciente diabético tras una GV y confirman que es algo más que un procedimiento puramente restrictivo. Al parecer la ghrelina suprime la adiponectina, una hormona que aumenta la sensibilidad a la insulina y bloquea la señalización hepática de la insulina. Se ha postulado que la disminución en los niveles de ghrelina aumenta la capacidad de secreción de insulina en los islotes 
habilitados para hacerlo con el fin de suplir con la demandas aumentadas de insulina en el paciente obeso (Yada T et al, 2008).

Así, parte de la mejoría en los niveles de glucosa observada en pacientes diabéticos intervenidos con una GV puede deberse a la disminución en los niveles de ghrelina, sin embargo y como se expone más adelante, existen datos de cambios precoces en los niveles de diferentes hormonas, incluso a un nivel similar a los observados en procedimientos derivativos.

Trabajos previos de nuestro grupo de investigación han mostrado un aumento en los niveles de GLP-1 desde la primera semana tras un bypass gastro-yeyunal siendo significativamente mayor en la semana 8 , además de una disminución desde la semana 1 de glucagón pancreático, una mejoría en la tolerancia a la glucosa y una mejoría en la función de las células beta pancreáticas. (Domingo M, 2011; De Luis DA, et al 2012)

Estos resultados concuerdan con los ensayos de Kindel y cols. en los que al realizar una derivación duodeno-yeyunal en ratas Goto-kakizaki concluyeron que la mejoría en la tolerancia a la glucosa es mediada a través de la acción de GLP-1 (Kindel et al, 2009).

Actualmente se sabe que el tránsito acelerado de nutrientes al intestino distal es uno de los mecanismos responsables de la saciedad precoz y la mejoría en el metabolismo de la glucosa después de un bypass gástrico. Estos efectos están mediados por hormonas intestinales (PYY y GLP-1) producidos en las células $L$ del intestino distal. La evidencia muestra que el transporte de nutrientes también se incrementa después de una GV. Melissas y cols (Melissas J, et al, 2007 y 2008), demostraron que el vaciamiento gástrico se encuentra aumentado después de una GV y este tránsito rápido de alimentos sólidos en el intestino distal puede tener efectos similares en la masa de células $L$ como en el BPG.

Incrementos en la respuesta de algunas hormonas gastrointestinales como GLP 1 han sido reportados después de un BPG. No hay consenso sobre los valores normales de GLP 1 en las diferentes situaciones fisiológicas relacionadas con la composición corporal. Muchos autores han reportado que en pacientes obesos los valores de GLP 1 permanecen bajos, pero valores bajos también se han encontrado en casos de anorexia nerviosa (Tomazik PJ et al, 2004). Como ya se ha dicho, la regulación del 
GLP 1 depende principalmente de la enzima dipeptidil dipeptidasa IV (DPP IV) la cual degrada al GLP 1 reduciendo su vida media a unos pocos minutos; se ha visto que esta enzima se encuentra anormalmente alta en algunos sujetos obesos (Lugari $R$, et al, 2004), por lo cual este factor debe ser tenido en cuenta al analizar muestras sanguíneas de GLP 1, ya que si no se utiliza un inhibidor de la DPP IV, se pueden obtener niveles bajos falsos de GLP 1. (Sabench F, et al, 2008)

El BPG y la GV producen cambios en la sensibilidad sistémica a la insulina, dependientes del peso y cambios en la sensibilidad hepática a esta hormona, el GLP 1 postprandial y la liberación de insulina, independientes del peso. En un estudio experimental en ratas presentado por Chambers y cols, sugieren que estos dos procedimientos incrementan los niveles de GLP 1, siendo este incremento crítico para la mejoría metabólica que se espera con estas intervenciones. (Chambers, et al, 2011, $1)$.

Aunque no hay muchos estudios que analicen los cambios en los niveles de GLP 1 en pacientes diabéticos sometidos a una GV, Peterli y su grupo encontraron un incremento marcado y similar en los niveles de GLP 1 al comparar el BPG con la GV, sin embargo solo 3 de los 14 sujetos analizados eran diabéticos (Peterli et al, 2009). Por otra parte otro estudio reporta un incremento en los valores postprandiales de GLP 1 tras BPG pero no tras cirugías restrictivas gástricas incluida la GV en una cohorte de 16 pacientes diabéticos, sin embargo se debe tener en cuenta un sesgo se selección, ya que se incluyeron pacientes con banda gástrica ajustable en el mismo grupo de estudio. (Kashyap SR et al, 2010). Otro activador potencial de los cambios en los niveles de incretinas podría ser un reflejo vagal producido por el aumento de nutrientes en el intestino proximal. (Rocca AS et al, 1999).

En otra publicación posterior de Peterli y su grupo (Peterli et al, 2012), que presenta un estudio prospectivo aleatorizado en pacientes no diabéticos, se encontró que los niveles de GLP 1 aumentaron de forma marcada tras BPG y GV siendo mayor el aumento en el BPG. Según los autores, una posible explicación a estos cambios es que el aumento en los niveles de GLP 1 puede ser influenciado por otras señales hormonales proximales como el aumento en la colecistocinina (CCK) encontrado en los pacientes intervenidos de GV (Gaylinn B et al, 2010). Como ya se ha dicho, otra posible explicación es el vaciamiento gástrico acelerado y el contacto del quimo con las células $L$ en el intestino distal. Sin embargo los resultados de estos estudios no pueden ser explicados por las teorías del intestino proximal o distal. Así mismo 
Romero y colabs. reportan cambios similares en los valores de GLP-1, GIP, y GLP-2 tempranamente en pacientes diabéticos intervenidos de BPG y GV (Romero $F$ et al, 2012).

Estos resultados sugieren que el balance entre las hormonas proximales (ghrelina, CCK) y las distales (GLP 1, PYY) son claves en la comprensión de los mecanismos por los que mejora la homeostasis de la glucosa tras procedimientos restrictivos como la GV. (Peterli R, et al 2012).

Por otra parte, se han publicado algunos modelos experimentales en los cuales se analizan las repercusiones en el metabolismo de la glucosa de la GV. En un trabajo de Sabench y su equipo se intervinieron 4 grupos de ratas diabéticas y no diabéticas y sus respectivos controles, obteniendo resultados dispares. En lo que se refiere a los niveles de GLP 1, se observaron niveles menores a los valores preoperatorios, siendo aun menores en los controles intervenidos, datos a su vez similares a los obtenidos en dietas hipocalóricas. Los autores atribuyen este hecho al efecto anorexígeno del trauma operatorio y a la ausencia de la hiperestimulación del intestino distal como el observado en las intervenciones malabsortivas (Sabench F, et al, 2008).

Al igual que los resultados obtenidos en nuestro experimento en el que no se encontraron variaciones significativas en los valores de GLP 1, otros experimentos no han obtenido cambios en los niveles de GLP 1 al realizar otro tipo de cirugía restrictiva como la gastroplastia vertical anillada. (Kellum JM, et al, 1990). Masuda compara grupos de ratas diabéticas obesas intervenidas de gastroplastia vertical anillada y GV con un grupo control obteniendo diferencias mínimas pero significativas en los niveles de GLP 1 del grupo tratado con GV frente a los controles pero no con la gastroplastia y a su vez el grupo de gastroplastia no tuvo diferencias con el control (Masuda T, et al, 2011)

Por otro lado trabajos como el de Chambers (Chambers AP, et al, 2011, 2) y Li (Li F, et al, 2009), muestran incrementos significativos en los niveles de GLP 1 al compararlos con los grupos controles en el postoperatorio de una GV. En el primer caso las ratas intervenidas fueron del tipo Long Evans obesas e hiperinsulinémicas tras una dieta hipercalórica y en el segundo y como ya se comentó antes, se utilizaron, ratas Goto Kakizaki, pero con edades y pesos menores a los utilizadas por nosotros. Se podría hipotetizar que estas diferencias hayan influido en la disparidad de resultados obtenidos. Así mismo, Sun publica recientemente mejorías estadísticamente 
significativas en los niveles de GLP-1 en ratas GK de 11 semanas de edad, intervenidas de una GV y un bypass dudeno-yeyunal asociado a una GV, siendo mayor el aumento en las ratas sometidas al procedimiento derivativo. (Sun D et al, 2012).

Otro factor a tener en cuenta es el de la técnica quirúrgica utilizada. En el caso de los experimentos de Li o los de Sun, no se utilizó una sutura mecánica, que por sus características físicas podría dejar en la region cardial y prepilórica fragmentos de parénquima gástrico que una técnica manual podría resecar más fácilmente. Desconocemos si esas mínimas diferencias técnicas puedan tener alguna influencia en los resultados obtenidos pero es una idea que dejamos planteada para experimentos posteriores

La diabetes mellitus asociada a la resistencia a insulina en humanos y animales de experimentación se ha relacionado con niveles elevados de GIP como consecuencia de una respuesta exagerada de las células K. (Cho YM et al, 2010; Fauci et al, 2009). Estas observaciones sugieren que la exclusión del lugar de síntesis y secreción de GIP aporta efectos beneficiosos no sólo en la reducción del peso sino que también mejora la tolerancia a glucosa.

En cualquier caso, parece que las variaciones en los niveles de GIP después de la cirugía son interesantes, ya que los defectos en las vías de señalización de GIP se encuentran entre las alteraciones más destacadas en diabetes mellitus tipo 2 (Nauck et al, 1993).

Los estudios sobre los efectos de un BPG sobre los niveles de GIP tras la estimulación con alimentos han mostrado resultados no concluyentes. Bose y su grupo han reportado un aumento en los niveles mitigados de GIP en un grupo de mujeres diabéticas sometidas a un BPG. (Bose M et al, 2010).

Numerosos estudios reportan que las concentraciones plasmáticas de GIP se redujeron en los pacientes después de una cirugía gástrica con una reconstrucción en $Y$ de Roux (Mingrone G. 2009). Sin embargo, en otros trabajos los niveles séricos de GIP después de una DGY o de una DBP no han mostrado cambios, (Lefébvre P. 2008 y Pacheco et al, 2007).

Hay muy pocos estudios que hayan analizado los niveles de GIP tras una GV. El 
grupo de Romero comparó a un grupo de GV con otro intervenido mediante BPG y un grupo control. Los niveles basales tras la intervención no variaron. Tras la estimulación con alimento los niveles de GIP aumentaron significativamente tras la GV sin hacerlo en el grupo del BPG (Romero F, et al, 2012). De Paula reporta incrementos similares en los niveles de GIP en dos grupos de pacientes con GV y 2 tipos de interposición ileal, una de las cuales conlleva una exclusión duodenal. Sorprendentemente los niveles de GIP fueron los mismos en ambos grupos a pesar del bypass duodenal en uno de ellos (De Paula Al et al, 2008). Resultados similares han sido publicados recientemente, al comparar grupos de ratas GK jóvenes intervenidas de GV y un bypass duodeno-yeyunal asociado a una GV y sus controles, en los que no se observó ninguna diferencia en los niveles de GIP entre los grupos. (Sun D et al 2012).

En el estudio de Wang, no se observaron cambios en los niveles de GLP 1 ni de GIP a las 4 y 8 semanas tras una $G V$ en ratas SD con diabetes mellitus inducida por estreptozocina. Como ya se mencionó, en este estudio tampoco se obtuvieron cambios en los niveles de glucosa. (Wang $Y$ et al, 2011).

Al observar estos resultados y compararlos con los de nuestro trabajo en el cual no se obtuvieron diferencias estadísticamente significativas entre los valores pre y postoperatorios de GIP, consideramos que es difícil compararlos por las marcadas diferencias entre los estudios. 


\section{Resultados de leptina}

En los últimos años se ha revolucionado el conocimiento de la regulación hormonal de la homeostasis de la energía y se ha cambiado sustancialmente nuestra visión del tejido adiposo entendiéndolo no sólo como un órgano de almacenamiento sino como un órgano endocrino activo que produce citocinas, como la leptina que afecta al metabolismo de la glucosa y de las grasas.

Los niveles de leptina disminuyen de manera significativa en los individuos que se han sometido a un BPG y se correlacionan con el porcentaje de pérdida de peso. (Park et al, 2011). La disminución rápida de los niveles plasmáticos de leptina después de un BPG o una DBP también se ha comprobado en humanos dónde el IMC permanece sin cambios (de Marins et al, 1999) al igual que ocurrió en nuestro grupo de animales de experimentación, donde se observó un descenso significativo en los niveles séricos de leptina en todos los tiempos del experimento. Cabe reiterar en este punto que nuestra población de ratas Goto-kakizaki no era obesa ni existió un descenso en el peso estadísticamente significativo a lo largo del protocolo. Esta observación sugiere que la composición de la grasa corporal no es el único factor que regula los niveles de leptina.

Estos datos concuerdan con los obtenidos por nuestro grupo en trabajos anteriores realizados en ratas Goto Kakizaki que tras 1 semana y 1 mes de ser sometidas a una exclusión del duodeno y yeyuno proximal se observó un drástico descenso en los niveles plasmáticos de leptina (De Luis D, et al, 2012; Domingo M, 2011; Pacheco D et al, 2007).

Se ha propuesto la existencia de un factor desconocido producido en el duodeno o en el yeyuno en respuesta a la estimulación del alimento, que sería responsable de un tipo de resistencia a leptina y un incremento compensatorio de los niveles de leptina en plasma, común en los pacientes obesos (Mantzoros et al, 1999). De acuerdo con esta teoría, al excluir parte del duodeno o del yeyuno, la causa de la resistencia a leptina desaparece o se reduce de manera que la concentración de leptina en plasma desciende. Por otro lado, una deficiencia congénita de leptina se ha asociado con obesidad severa, intolerancia a glucosa y resistencia a insulina en humanos (Brennan et al, 2006) 
Recientemente, se ha estudiado la influencia de un polimorfismo (lys 656 asn) en el gen receptor de la leptina en pacientes sometidos a una derivación biliopancreática (De Luis, 2010).

Existen evidencias que la leptina puede ser un marcador de la pérdida de peso en lugar de un efector y estudios recientes han confirmado que los niveles de leptina disminuyen a medida que se pierde peso, independientemente de la forma de lograrlo. (Ram E et al, 2005)

En un estudio de 2006 en el que se compararon grupos de pacientes sometidos a una banda gástrica laparoscópica y un BPG, los niveles de leptina fueron mucho menores en este último grupo (Korner J et al, 2006) Así mismo, en otro estudio se compararon los niveles de leptina pre y postoperatorios en diferentes tiempos tras un BPG, obteniendo menores niveles de leptina, los cuales fueron directamente proporcionales a la pérdida de peso. (Swarbrick M. et al, 2008) Otros estudios han tenido resultados similares en gastroplastia vertical y banda gástrica ajustable (Riedl M. et al, 2008)

Numerosos estudios han observado el comportamiento de los niveles de leptina tras una intervención de cirugía bariátrica obteniendo resultados irregulares (Beckman LM et al, 2010). Los valores de leptina no son consistentes entre los estudios revisados, al contrario que en otras hormonas gastrointestinales. Algunos estudios han demostrado niveles mas bajos de leptina basal en el postoperatorio del BPG comparándolos con los valores preoperatorios y con sujetos de peso normal, con sobrepeso y obesos, mientras otros no encontraron diferencias estadísticamente significativas entre las poblaciones estudiadas (Korner, et al, 2005).

Sin embargo al analizar los datos de manera conjunta, estos sugieren que la leptina disminuye tras una intervención de cirugía bariátrica como al BPG y su descenso se asocia a los cambios en las medidas antropométricas. Estos hallazgos son congruentes con la noción que la leptina es secretada en proporción con la masa grasa corporal. (Beckman LM, et al, 2010).

La Interacción entre la leptina y el eje enteroinsular se ha comprobado que existe. Al igual que en nuestro trabajo, De Paula y colabs. demostraron que la concentración plasmática de leptina en el postoperatorio de la GV disminuyó significativamente. La leptina suprime la secreción de insulina y la desensibilización de la leptina tanto en el hipotálamo como en las células beta pancreáticas y puede ser una importante factor 
en la patogénesis de la diabetes mellitus asociada a la obesidad. Por lo tanto, niveles más bajos de leptina puede ser otro factor que contribuye a un aumento de la secreción de insulina. (De Paula L et al, 2009).

En otro trabajo con ratas Davis de la Universidad de California, diabéticas, intervenidas con GV las concentraciones de leptina basal permanecieron más bajas que en los grupos control más allá de los 5 meses del postoperatorio (Cummings BP et al, 2012). En otro trabajo de este grupo se reportó que las concentraciones de leptina en plasma aumentan en estas ratas antes de la aparición de la DM 2 debido al aumento en la adiposidad y al incremento de las concentraciones de insulina en sangre. A la inversa, las concentraciones de leptina disminuyen con la aparición de la DM 2 en este tipo de ratas debido a la disminución de la masa adiposa y las concentraciones de insulina circulante. (Cummings BP, et al, 2008)

Stefater y colabs. en un trabajo con ratas obesas hiperalimentadas sometidas a una gastrectomía vertical, hipotetizaron que los cambios en el patrón de alimentación que conduce a la perdida de peso tras una GV se podría deber a los cambios en la sensibilidad a la leptina, concluyendo que este cambio en la motivación que tiene el animal de experimentación para comer no es el resultado de importantes alteraciones en la producción de la leptina ni en el eje leptina-mineralocortina. (Stefeater $\mathrm{M}$, et al, 2010).

Exceptuando los trabajos desarrollados en nuestro grupo de investigación publicados previamente (De Luis DA, et al, 2012; Domingo M, 2011; Pacheco D, et al, 2007) no se han encontrado trabajos que controlen los niveles de leptina en un modelo experimental de DM 2 sin obesidad, y por tanto nuestros hallazgos son interesantes en la medida que la disminución de los niveles de leptina en nuestro trabajo no se pueden explicar por la disminución en el peso de los animales de experimentación

Los resultados de nuestros trabajos muestran que la significativa reducción en los niveles de leptina ocurre sin una alteración significativa en el peso de los sujetos intervenidos, lo cual sugiere que los niveles de leptina son regulados por mecanismos influenciados por la intervención quirúrgica. Teniendo en cuenta esto último, la disminución en los niveles de leptina refleja posiblemente una mejoría en la sensibilidad a la misma que puede jugar un rol importante en la inducción del control de la hiperglucemia. 
Por todo ello, la explicación fisiopatológica de este descenso llamativo de los niveles de leptina tras la cirugía, así como su papel en el control metabólico de la diabetes mellitus y sus posibles aplicaciones terapéuticas es un área con múltiples implicaciones, incluso desde el punto de vista genético y que por tanto será necesario evaluar en un futuro. 


\section{Resultados del contenido de insulina en el islote}

A pesar del hecho que las diferentes colonias de ratas Goto Kakizaki vienen de una única colonia criada en Japón hace más de 20 años han mantenido unas características estables en cuanto a la intolerancia la glucosa, sin embargo se han encontrado diferencias en otras características como el número de células beta, el contenido de insulina en el islote y la secreción de insulina por parte del mismo entre las diferentes colonias establecidas alrededor del mundo. Esto sugiere la influencia del ambiente en que han sido criadas y la expresión de nuevos cambios genéticos manifestados como los contrastes reportados entre algunas de sus características fenotípicas (Portha B et al, 2009).

Existe gran controversia en cuanto al contenido de insulina en los islotes de las ratas Goto Kakizaki. En la colonia de ratas GK de París las concentraciones de insulina en los islotes descendieron entre un 40 y un $60 \%$ respecto a ratas Wistar, con una disminución en el número de células beta de $15 \%$ respecto al control (Giroix et al, 1999). En otras colonias de GK se encontraron similares o moderadamente reducidos al compararse con los controles (Metz et al, 1999; Abdel-Halim, 1993; Salehi et al, 1999). Sin embargo en colonias como las de Estocolmo, Japón, Seattle o Tampa, los valores de contenido de insulina en el islote fueron similares o moderadamente disminuidos con respecto a las ratas control (Portha B et al, 2009).

En la síntesis de insulina, una vez que el precursor de insulina, la preproinsulina ha sido modificada a proinsulina es necesario que intervengan dos endopetidasas, la prohormona convertasa-1 (PC1) y la proconvertasa-2 (PC2), de manera que la escisión dará lugar a insulina y péptido C. En las ratas GK se observa un marcado descenso en la PC 2 que no tiene un gran impacto sobre la velocidad de procesamiento de la proinsulina tanto in vitro y como in vivo, mostrando que la biosíntesis de insulina estimulada por glucosa permanece normal en islotes frescos de GK (Guest et al, 2002).

El hallazgo de que la biosíntesis de la proinsulina y su procesamiento son normales en ratas GK sugiere que la liberación defectuosa de insulina en las células beta no proviene de un fallo en el reconocimiento de la glucosa como activador de la biosíntesis de la prohormona y la biogénesis de los gránulos de secreción. 
Esto último se corrobora en varios estudios. En un estudio reciente el uso del Liraglutide, un análogo del GLP 1 en ratas GK, disminuyó los niveles de glucemia y mejoró la tolerancia a la glucosa en el grupo tratado, sin cambios significativos en el flujo sanguíneo en el islote ni en la concentración de insulina en el islote respecto al grupo control (Wu L, et al, 2012).

En ensayos previos de nuestro grupo de investigación, la insulina contenida en los islotes resultó ser similar en grupos experimentales y controles no intervenidos, lo que refuerza el hecho de que la biosíntesis de insulina está preservada en ratas GK. Además, estos resultados ponen de manifiesto que la mejoría en la secreción de insulina al medio inducida por glucosa en ratas intervenidas quirúrgicamente no es modulado a través de un mecanismo relacionado con la biosíntesis de insulina.

No obstante, los resultados de Ghanaat-Pour y colabs. mostraron un contenido de insulina significativamente más alto en islotes procedentes de ratas GK diabéticas cuando se compararon con ratas Wistar sanas (Ghanaat-Pour et al, 2007), proponiendo que la biosíntesis de proinsulina podría estar controlada a nivel translacional y también a través de la estabilización del ARNm de proinsulina en vez de a nivel transcripcional (Webb et al, 2000).

Esta discordancia en los resultados, nos sugiere para próximos ensayos añadir una variante en el método de análisis de la muestra. En este sentido, aunque la muestra se recogiera del mismo modo, el resultado de la concentración de insulina medido mediante ELISA, se podría comparar con el contenido total de proteína mediante un ensayo estándar de determinación de proteínas o comparar con la cantidad de ADN de la muestra de partida. 


\section{Resultados de secreción de insulina al medio por los islotes.}

Uno de los aspectos más interesantes tras analizar los resultados de las intervenciones bariátricas más populares es la rápida mejoría en el metabolismo de la glucosa tras la intervención, y entre los posibles factores causales de esta mejoría, los mecanismos que regulan la secreción de insulina parecen tener una particular importancia. Sin embargo estos mecanismos posiblemente no son los mismos al comparar diferentes procedimientos. La comprensión de este efecto adicional a la pérdida de peso puede darnos nuevas ideas respecto a la patogénesis de la DM2 y ayudar al desarrollo de nuevos procedimientos terapéuticos o farmacológicos (Dixon $\mathrm{J}$ et al, 2012).

Las reducciones sustanciales que se dan precozmente tras la intervención quirúrgica en la lipotoxicidad y la glucotoxicidad y la disminución de la inflamación local en el islote pueden ser los mecanismos iniciales que median la mejoría precoz en la función de la célula beta (Weir JC et al, 2009)

Uno de los parámetros fenotípicos mejor conservados entre las cepas de ratas GK alrededor del mundo son las deficiencias en la secreción de insulina tras el estímulo con glucosa; asimismo numerosas alteraciones en el binomio estímulo-secreción en las células beta de ratas GK han sido descritas en diferentes cepas analizadas. (Portha, et al, 2001; Gauigier et al, 1994; Galli et al, 1996; Salehi et al, 1999).

No obstante, a pesar de no haber diferencias significativas en el peso corporal, niveles de glucosa basal o tras tolerancia oral o intravenosa de glucosa in vivo (en ratas de 8 semanas de edad), una leve disminución en la secreción de insulina en respuesta a la glucosa con un aumento en la secreción de glucagón en respuesta a la arginina, se observó en las ratas de la cepa Taconic, como las utilizadas en nuestro experimento, respecto a las ratas GK de la cepa de Paris (Portha B et al, 2009).

Existen gran cantidad de argumentos que indican que el fallo en la secreción de insulina, en las células beta de las ratas GK es debido, al menos parcialmente, a un entorno metabólico anormal (gluco-lipotoxicidad). Cuando se estudiaron islotes aislados de ratas GK recién nacidas prediabéticas en condiciones estáticas in vitro, estos muestran una respuesta secretoria en respuesta a glucosa a altas concentraciones, leucina o leucina mas glutamina similar a la de ratas Wistar de la misma edad. Esto sugiere que no existe un defecto mayor intrínseco en las células 
beta de ratas GK prediabéticas las cuales pueden ser consideradas como competentes en la respuesta a la glucosa, al menos en condiciones in vitro (Portha B, et al 2009).

Estudios in vivo han demostrado que en ratas adultas la secreción de insulina está disminuida en respuesta a la infusión de glucosa intravenosa. Así mismo, estudios in vitro con páncreas aislados y perfundidos o con islotes aislados han mostrado que tanto las fases tempranas como las tardías de la secreción de insulina están marcadamente afectadas en las ratas GK adultas. (Tourrel C et al, 2002).

En nuestro trabajo, la secreción de insulina aumentó de forma estadísticamente significativa al comparar la secreción de insulina obtenida por sonicado de los islotes incubados en una concentración de glucosa de $5 \mathrm{mM}$, con los incubados en concentraciones de glucosa de $16,7 \mathrm{mM}$, en los diferentes tiempos del experimento. Desafortunadamente en este experimento no fue posible contar con un grupo control para dar más validez a nuestros resultados.

En otro trabajo publicado por nuestro grupo de investigación no se observaron diferencias estadísticamente significativas entre el grupo de islotes procedentes de ratas GK controles y los de ratas GK intervenidas mediante derivación gastro yeyunal (DGY) al incubarlos en condiciones basales (5 mM de glucosa). Sin embargo, cuando incubamos los islotes de ambos grupos en un medio que contiene una concentración fisiológica de glucosa elevada $(16,7 \mathrm{mM})$ y los comparamos, vemos que la secreción total de insulina al medio de incubación es significativamente mayor en el rama DGY que en la rama Control, especialmente en el periodo que va desde 30 hasta 60 minutos. Esto pone de manifiesto que la intervención ha mejorado la liberación de insulina inducida por glucosa en los islotes de ratas GK (De Luis DA et al, 2012; Domingo M, 2011).

Esto concuerda con los estudios de Giroix y colabs. en los que se concluía que la biosíntesis de insulina está preservada en islotes de ratas GK y que probablemente el defecto en la liberación de insulina estaría asociado, al menos en parte, a una deficiencia en el metabolismo oxidativo de la glucosa en las mitocondrias de los islotes pancreáticos de ratas GK (Giroix et al, 1992).

Resulta interesante comparar los resultados de nuestros trabajos con los de GhanaatPour y colabs, en los ensayos en los que expusieron a un grupo de islotes de ratas 
Goto-Kakizaki a glucosa $3 \mathrm{mM}$ y $20 \mathrm{mM}$ frente a un grupo control de ratas Wistar durante 60 minutos (Ghanaat-Pour, 2007). En éstos experimentos en las ratas GK no se observaban cambios estadísticamente significativos en la secreción de insulina inducida por glucosa ante las diferentes situaciones experimentales, sin embargo en las ratas control si se apreció un aumento significativo de la secreción inducida por glucosa.

Estos resultados ponen de manifiesto que la gastrectomía vertical realizada en este modelo experimental parece restaurar parcialmente la secreción de insulina inducida por glucosa por los islotes pancreáticos al medio.

Siguiendo con este tipo de ensayos, ponemos como ejemplo los llevados a cabo por Gatmaitan y cols. Este grupo había realizado un bypass gástrico en $Y$ de Roux a un grupo de ratas obesas. Después de cuatro semanas de la intervención quirúrgica fueron incubados dos grupos de islotes aislados en medios que contenían $2 \mathrm{mM}$ de glucosa y $20 \mathrm{mM}$ de glucosa. En dichos experimentos observaron que la secreción de insulina al medio fue 7,6 veces mayor en el grupo de ratas operadas que en el grupo control cuando se estimularon con glucosa $20 \mathrm{mM}$ (Gatmaitan et al, 2010).

Nuestros resultados son semejantes a los observados en humanos en los que se muestra un incremento en el pico de respuesta a insulina y un aumento en la función de la célula beta después de un test de tolerancia basado en la toma de un suplemento oral estándar tras BPG. En este estudio también se analizaron los resultados tras cirugía gástrica restrictiva en la que se incluyó la GV. No se observaron cambios relevantes en los parámetros mencionados anteriormente, aunque hay que destacar que en el grupo de cirugía gástrica restrictiva 3 de los 7 sujetos fueron intervenidos con la técnica de la banda gástrica laparoscópica y esto puede ser un factor de confusión (Kashyap et al, 2010).

Estos cambios en la capacidad secretora de la célula beta podrían ser algunos de los mecanismos metabólicos primarios implicados en la reversión de la diabetes mellitus tipo 2 después de una cirugía bariátrica.

Por otro lado, se ha mostrado que el GLP-1 incrementa la secreción de insulina dependiente de glucosa, que estimula la transcripción del gen de la insulina, y que inhibe la apoptosis de las células beta en los distintos modelos animales. En el mismo sentido, Farilla demostró que también en islotes humanos existe una mejor respuesta 
a la glucosa en presencia de GLP-1 y que esta incretina inhibe la apoptosis de las células beta (Farilla et al, 2003). Cabe mencionar el posible efecto que puede tener el descenso de los niveles de leptina observado en este y otros experimentos sobre la funcionalidad de los islotes pancreáticos. (Buettner et al, 2006). 


\section{Resultados de expresión génica de insulina}

La glucosa es el factor regulador fisiológico de la función de las células beta más importante $y$, por lo tanto, tiene un papel central en la regulación de la expresión del gen de insulina. La glucosa regula la expresión del gen de la insulina a todos los niveles, incluyendo la transcripción, splicing y estabilización y traducción del ARN mensajero (Welsh et al, 1985).

El papel desempeñado por la glucosa en la regulación de la actividad de unión de Pdx1 a la región A3 del promotor del gen de la insulina se ha demostrado directa 0 indirectamente en varias situaciones experimentales (Macfarlane et al, 1999).

Existen pocos trabajos que hayan analizado la expresión génica de la célula beta tras cirugía bariátrica. Trabajos previos de nuestro grupo han podido demostrar un aumento significativo en la expresión relativa de insulina en un grupo de ratas intervenidas comparadas con un grupo control. (Domingo M, 2011; De Luis DA et al, 2012).

Los cambios enterohormonales que se observan tras cirugía bariátrica, no se observan tras procedimientos no resectivos como la banda gástrica laparoscópica o tras dieta. Algunos de estos cambios incluidos la elevación en los niveles de GLP 1 pueden promover la regeneración de los islotes pancreáticos así como el mantenimiento de la masa celular y la función del páncreas endocrino. La expresión de la $\mathrm{Pdx} 1$ y el consumo de bromodexouridina (un análogo de la timidina que es incorporado dentro del DNA celular cuando la célula se divide) por parte de las células beta están incrementados tras el BPG (Zen Li et al, 2010).

En el estudio de Zen y su grupo, se sometió a un grupo de ratas de este modelo experimental a un bypass gástrico y las compararon frente a dos grupos control. Las ratas fueron sacrificadas en el postoperatorio en las semanas 1, 2, 4, y 12. Se analizaron células del páncreas, entre otras técnicas, mediante PCR cuantitativa a tiempo real para detectar el ARNm de Pdx-1. En comparación con el grupo control se observó un aumento significativo en la expresión de $A R N m$ en el grupo que se intervino quirúrgicamente en todos los tiempos del protocolo. (Zen Li et al, 2010). 
Sin embargo el hecho de la mejoría en el número y la función celular tras el BPG sigue siendo controvertido (Meier JJ et al, 2006). Trabajos recientes sugieren que la ruta de administración de nutrientes parece ser un evento primario y potencialmente reversible para el establecimiento de las respuestas endocrinas y de la célula beta (Dirksen $C$ et al, 2010; Mc Laughlin T et al, 2010).

Algunos cambios que la cirugía bariátrica produce en la expresión génica en otros tejidos que intervienen en el metabolismo de la glucosa también han sido estudiados. Estudios anteriores muestran que la glucosa puede incrementar los niveles del ARNm de GLUT2 a nivel hepático (Eriksson J et al, 1992; lqbal C et al, 2008). La glucosa debe pasar a través de la membrana de la célula beta hasta el citoplasma para que la glucokinasa (GCK) pueda empezar su ciclo metabólico y este proceso es regulado por GLUT2. Este transportador transmembrana trabaja sin limitaciones en circunstancias fisiológicas pero la secreción de insulina está comprometida en la diabetes mellitus tipo 2 y el nivel de expresión de GLUT2 está disminuido. La GCK hace que el hígado absorba glucosa mas fácilmente en los momentos de hiperglucemia y la deficiencia de GCK puede afectar la función de la célula beta y empeorar la secreción de insulina. La disminución en la síntesis o en la función de la GCK reduce la utilización de la glucosa, bloquea la síntesis de glucógeno y produce hiperglucemia (Grimsby J et al, 2008)

La expresión de GLUT2 y la GCK es afectada por muchos factores. Dongley intervino un grupo de ratas GK buscando los cambios en la expresión de GLUT 1 y GCK, para lo cual realizó una derivación duodenoyeyunal y una GV en cada grupo. El ARNm y la expresión proteica del GLUT2 y la GCK hepática en la derivación fueron mayores que en el grupo de GV. En ambos casos se reportó una mejoría en los parámetros de la glucosa. (Dongley $Z$ et al, 2012).

Teniendo en cuenta que el incremento en la transcripción del ARNm de insulina ocurre a los pocos minutos de la estimulación de glucosa, pero sin embargo la vida media de los $A R N m$ es de 1 a 4 días, es difícil entender como este cambio rápido podría afectar significativamente a la producción o a la secreción en respuesta al alimento. Además los cambios en la transcripción del gen de la insulina también pueden modular su producción en respuesta a los cambios en la dieta a largo plazo.

Los mecanismos por los cuales el GLP 1 modula las células beta han sido objeto de numerosas investigaciones focalizadas principalmente en 3 vías: Mejoras en la proliferación celular; inhibición de la apoptosis de las células beta y diferenciación de 
células madre en el epitelio ductal vía neogénesis (Brubaker et al, 2004). Estudios similares han mostrado que el GIP también puede estimular la proliferación de células beta (INS-1) (Trumper A et al, 2001; Trumper A, et al, 2002).

También se ha demostrado que GLP-1 estimula la expresión del gen de insulina a través de diversos mecanismos: activando directamente el elemento de respuesta a AMP cíclico situado en la región reguladora $5^{\prime}$ del gen de la insulina, potenciando la actividad de unión de $\mathrm{Pdx}-1$ en respuesta a glucosa, estimulando la transcripción de $\mathrm{Pdx}-1$ y activando el factor nuclear de las células $\mathrm{T}$ activadas a través de la activación de calcineurina en respuesta al aumento de calcio intracelular (Cluck et al., 2005).

Algunos trabajos recientes pueden mostrar de forma indirecta como cambios en los niveles de incretinas, particularmente en el GLP-1, como los que se observan tras intervenciones de cirugía bariátrica pueden intervenir en la expresión génica de la célula beta.

Como ya se ha dicho, los perfiles de expresión génica revelan cambios significativos en el ARNm de los islotes envueltos en el control de muchos aspectos de la función de la célula beta, como por ejemplo la regulación epigenética de la expresión génica, la diferenciación celular, la morfogénesis, el metabolismo, la respuesta a estímulos, el transporte y la transducción de señales. Los análogos de incretinas como el Exenatide parecen tener un impacto importante en algunos procesos epigenéticos como alteraciones estables en genes potencialmente expresables durante el desarrollo y la proliferación celular. Bcl2-like 1 que es una proteína antiapoptótica y el factor modificador de Bcl2 (Bcl2 modifyng factor Bmf) una proteína proapoptótica fueron regulados a la baja por pioglitazona y exenatide en islotes de ratas GK (Ghanaat-Pour et al, 2009).

La Vidagliptina, un antagonista de la dipeptidil dipeptidasa 4 (DPP4) puede mejorar la proliferación de células alfa y beta pancreáticas e incrementar el número de nuevos pequeños islotes. También inhibe la infiltración de macrófagos en el islote y estimula la expresión del Pdx 1 en ratas GK jóvenes (Inaba W et al, 2012).

También la leptina reduce la secreción de insulina mediante la activación de la fosfodiesterasa $B$ y la expresión del gen a través de la activación de STAT3 (Buettner et al, 2006). 
Se ha demostrado que la leptina inhibe la secreción de insulina y la expresión del gen de la preproinsulina en las células beta. En un trabajo alemán se analizaron la transducción de la señal mediada por leptina y la regulación del gen de la preproinsulina a nivel molecular en las células beta (Laubner et al, 2005). Además se ha demostrado que la leptina interfiere con la actividad de los canales de potasio dependientes de ATP y la señalización del GLP-1 en las células pancreáticas. Como parte de un mecanismo de retroalimentación negativa, la insulina estimula la secreción de leptina en el tejido adiposo creando el que se ha denominado eje adipo-insular (Keuhnen $\mathrm{P}$ et al, 2011).

La estimulación con leptina permite la fosforilación dependiente de Janus cinasa (JAK)-2 y la translocación nuclear de STAT3 y STAT5b en células $\beta$ INS-1. La leptina también induce la expresión de ARNm de SOCS3 (JAK-STAT inhibitor supresor of cytokine signaling) en células INS-1, en islotes pancreáticos humanos y en islotes de ratón ob/ob in vivo. A la vista de sus resultados propusieron que SOCS3 representa un inhibidor transcripcional del gen de la preproinsulina que es inducido por leptina a través de la señalización JAK-STAT en células beta (Laubner et al, 2005).

Otras vías moleculares por las cuales la leptina inhibe la secreción de insulina han sido descritas. EI PP1 alfa es un gen que codifica la subunidad catalítica de la protein fosfatasa 1 (PP1) y se ha sugerido que juega un papel en la secreción de insulina en las células beta. La inhibición in vitro de la PP1 con ácido okadáico disminuye la secreción de insulina estimulada por glucosa en las células beta. EI PP1 alfa ha sido identificado como un gen inhibido por la leptina. El compromiso de la inhibición de la PP1 mediada por leptina puede provocar la disfunción del eje entero-insular durante el desarrollo de la hiperinsulinemia y la DM2 (Keuhnen P et al, 2011).

Teniendo en cuenta lo expuesto y el hecho de la disminución significativa en los niveles en sangre de leptina en las ratas intervenidas en nuestro experimento, podemos deducir que la disminución de la leptina puede regular la expresión del gen de la insulina favoreciendo un aumento en su transcripción probablemente al no activarse SOCS3, así como estimular la secreción de insulina al disminuir la inhibición de la leptina sobre la PP1. 

CONCLUSIONES. 



\section{Conclusiones de la tesis}

PRIMERA. La gastrectomía vertical ha mejorado las cifras de glucemia basal en ratas Goto-kakizaki (no obesas y diabéticas tipo 2) de forma precoz y mantenida en el tiempo, hasta niveles de normoglucemia (desde la primera semana, siendo estadísticamente significativa a la octava semana después de la cirugía) sin que se produjeran cambios en el peso significativos a lo largo del protocolo.

SEGUNDA. Se ha observado una recuperación de los niveles plasmáticos de insulina en el grupo intervenido quirúrgicamente frente a los niveles preoperatorios en las semanas 1 y 8 , siendo significativo en la primera semana. $(0,95 \pm 0,56 \mu \mathrm{g} / \mathrm{L}$ en la semana 1 respecto a $0,59 \pm 0,43 \mu \mathrm{g} / \mathrm{L}$ al inicio del protocolo).

TERCERA. La gastrectomía vertical da lugar a modificaciones en los niveles de glucagón después de una SOG desde la primera semana de la intervención quirúrgica que se mantienen en la octava semana.

Se ha observado un descenso en los niveles de glucagón desde la primera semana $(241,7 \pm 75,8 \mathrm{pg} / \mathrm{mL}) \quad$ manteniéndose 8 semanas después de la gastrectomía vertical $(253,8 \pm 59,0 \mathrm{pg} / \mathrm{mL})$ cuando los comparamos con los niveles anteriores a la cirugía $(308,4 \pm 84,4 \mathrm{pg} / \mathrm{mL})$, siendo esta disminución estadísticamente significativa en ambos casos.

CUARTA. La gastrectomía vertical realizada en este modelo experimental, no ha producido cambios significativos en los niveles de hormonas incretinas (GLP 1 y GIP), al ser comparados con los niveles preoperatorios de dichas hormonas. 
QUINTA. La gastrectomía vertical dio lugar a una disminución estadísticamente significativa en los niveles de leptina desde 9692,6 $\pm 5077,4 \mathrm{pg} / \mathrm{mL}$ al inicio del protocolo hasta $5079,4 \pm 3765,7 \mathrm{pg} / \mathrm{mL}$ una semana después de la cirugía manteniéndose a las ocho semanas, con un valor de $6719,8 \pm 3539,5 \mathrm{pg} / \mathrm{mL}$.

SEXTA. La gastrectomía vertical parece mejorar la capacidad secretora de la célula beta que se manifiesta con el aumento estadísticamente significativo del contenido de insulina obtenida por sonicado en condiciones de estímulo, (glucosa 16, $7 \mathrm{mM}$ ) de los islotes pancreáticos aislados medido en los tiempos 0,30 y 60 minutos al comparar con los valores obtenidos en condiciones basales (glucosa $5 \mathrm{mM}$ ). La imposibilidad de contar con un grupo control en este experimento no permite emitir una conclusión más firme en este apartado.

SEPTIMA. El aislamiento de islotes pancreáticos de ratas Goto-kakizaki sometidas a una gastrectomia vertical puede ser una herramienta útil para el entendimiento de la modulación de la célula beta, en cuanto a su expresión génica y secreción de insulina en la cirugía bariátrica realizada como tratamiento para la diabetes mellitus tipo 2. 
ABREVIATURAS. 



\section{Abreviaturas}

ADA: American Diabetes Association

ADP: Adenosín difosfato

AGL: Ácidos grasos libres

Agrp: Agouti Related Protein

AMPc: AMP cíclico

ARA II: Antagonistas del receptor angiotensinógeno

ARNm: ARN mensajero

ATP: Adenosín trifosfato

BGYR: Bypass gástrico en "Y" de Roux

BSA: albúmina de suero bovino

CART: cocaine and anphetamine-regulated transcript

CCK: Colecistoquinina

cDNA: ADN copia

Ct: Threshold cycle o ciclo umbral

DBP: Derivación biliopancreática

DE: Desviación estándar

DGY: Derivación gastroyeyunal

DM: Diabetes mellitus

DMG: Diabetes mellitus gestacional

DTZ: Ditizona

ECV: Enfermedad cardiovascular

EIA: Enzimoimmunoanálisis

ELISA: Enzyme-linked immuoSorbent Assay

GAPDH: enzima gliceroaldehído 3-fosfato deshidrogenasa

Ex-4: Exendina 4

FAD: Flavín adenín dinucleótido

GBA: Glucemia basal alterada

GIP: Péptido inhibidor gástrico

GLP-1: glucagon like peptide 1

GRB2: Proteína 2 de unión al receptor de crecimiento

GS: Glucógeno Sintasa 
GV: Gastrectomía vertical

HbA1c: Hemoglobina glicosilada

HLA: Antígeno leucocitario humano

HMC: Complejo mayor de histocompatibilidad

HMG-coA: Hidroximetil glutaril coenzima A

HOMA: Homeostasis model assassment

HRP: Enzima de la peroxidasa del rábano picante

HTA: Hipertensión

IC: Índice de confianza

IECA: Enzima convertidora de la angiotensina

IMC: Índice de masa corporal

IPG: Inositolfosfoglicano

IQ: Intervención quirúrgica

IRS: Receptor de la insulina

ITG: Intolerancia a la glucosa

JAK: Janus cinasa

KRB: Krebs-Ringer-Bicarbonato

LDL: Lipoproteínas de baja densidad

LPL: Lipoproteinlipasa

LSH: Lipasa sensible a hormonas

MAPK: Proteína cinasa dependiente de mitógenos

NADPH: Nicotinamida adenine dinucleótido fosfato

NFAT: Factor nuclear de las células $T$ activadas

NPH: Neutral protamine Hagedorn insulin

NPY: Neuropéptido $Y$

NS: No significativo

PC: Enzima proconvertasa

PDH: Piruvato deshidrogenasa

PI3K: Fosfoinosítido 3-cinasa

PK: Proteína cinasa

PP: Polipéptido pancreático

PTP: Proteína tirosina fosfatasa

PYY: Péptido YY

qPCR: PCR cuantitativa

QUICKI: Quantitative Insuli-sensitivity Check Index 
RCP: Reacción en cadena de la polimerasa

$\mathbf{R T}$ : Enzima retrotranscriptasa

SA-HRP: Estreptavidina-peroxidasa del rábano picante

SEEDO: Sociedad Española para el Estudio de la Diabetes

SOC: inhibitor supresor of cytokine signaling

SOG: Sobrecarga oral de glucosa

TG: Triglicéridos

TMB: Tetrametilbencidina

TNF-a: Factor de necrosis tumoral

TTOG: Test de tolerancia oral a la glucosa

UCP: Uncoupled protein

UKPDS: UK Prospective Diabetes Study Group.

VLDL: Lipoproteínas de muy baja densidad 



\section{BIBLIOGRAFÍA.}



- Abdel-Halim SM, Guenifi A, Efendić S, Ostenson CG. Both somatostatin and insulin responses to glucose are impaired in the perfused pancreas of the spontaneously noninsulin-dependent diabetic GK (Goto-Kakizaki) rats. Acta Physiol Scand. 1993 Jun;148(2):219-26.

- Ackermann RW, Hansen JB, Nauck M. Basal-bolus therapy with insulin detemir/ inulin aspart improves glycaemic control and reduces hypoglycaemia: data from the German cohort of the Predictivetm. Actas del European Association of the Study of Diabetes congress, 2006. Póster número 978.

- Agius L. New hepatic targets for glycaemic control in diabetes. Best Pract Res Clin Endocrinol Metab 2007; 21: 587-605.

- Aguilera E, Morínigo R, Recasens M, Casamitjana R, Conget I. Autoantibody levels during the early course of type 1 diabetes. Diabetes Care 2000;23:1864-5.

- Alberti KG, Zimmet P, Shaw J; IDF Epidemiology Task Force Consensus Group. The metabolic syndrome--a new worldwide definition. Lancet. 2005 Sep 24-30;366(9491):1059-62.

- Aller R, de Luis DA, Fernandez L, Calle F, Velayos B, Olcoz JL, et al. Influence of insulin resistance and adipokines in the grade of steatosis of nonalcoholic fatty liver disease. Dig Dis Sci. 2008 Apr;53(4):1088-92.

- American Diabetes Association. Diagnosis and classification of diabetes mellitus. Diabetes Care. 2011;34 Suppl 1:S62.

- American Diabetes Association. Diagnosis and Classification of Diabetes Mellitus. Diabetes Care. 2010 January; 33(Supplement_1): S62-S69

- American Diabetes Association. Report of the Expert Committee on the Diagnosis and Classification of Diabetes Mellitus. Diabetes Care. 1997;20:1183-97.

- American Diabetes Association. Standards of medical care in diabetes 2011. Diabetes Care 2011;34(Suppl 1):S11-61.

- Ampudia-Blasco FJ, Rosenstock J. Insulin strategies in type 2 diabetes. Avances en Diabetología. 2008;24 (1): 7-20.

- Angervall L, Dotevall G, Tillander H. Amelioration of diabetes mellitus following gastric resection. Acta Med Scand. 1961 Jun;169:743-8. 
- Apelqvist J, Larsson J, Agardh CD. Long-term prognosis for diabetic patients with foot ulcers. J Intern Med. 1993 Jun;233(6):485-91 .

- Arias-Díaz J, Balibrea J. Modelos animales de intolerancia a la glucosa y diabetes tipo 2. Nutr Hosp. 2007;22(2):160-68.

- Ashrafian H, Ahmed K, Rowland SP, et al. Metabolic surgery and cancer: protective effects of bariatric procedures. Cancer 2011;117(9):1788-99.

- Asmar M, Holst JJ. Glucagon-like peptide 1 and glucose-dependent insulinotropic polypeptide: new advances. Curr Opin Endocrinol Diabetes Obes. 2010 Feb;17(1):57-62.

- Assimakopoulos K, Karaivazoglou K, Panayiotopoulos S, et al. Bariatric surgery is associated with reduced depressive symptoms and better sexual function in obese female patients: a one-year follow-up study. Obes Surg $2011 ; 21(3): 362-6$.

- Bailey CJ, Turner RC. Metformin. N Engl J Med 1996; 334: 574-79.

- Bailey CJ. New therapies for diabesity. Curr Diab Rep 2009;9:360-67.

- Baker M. The History and Evolution of Bariatric Surgical Procedures Surg Clin N Am 2011;91:1181-1201.

- Balsiger BM, Poggio JL, Mai J, et al. Ten and more years after vertical banded gastroplasty as primary operation for morbid obesity. J Gastrointest Surg 2000; 4:598-605.

- Baltasar A, Serra C, Pérez N, Bou R, Bengochea M, Ferri L. Laparoscopic sleeve gastrectomy: a multipurpose bariatric operation. Obes Surg 2005;15:1124-8.

- Barnett AH, Harper R, Toorawa R, Patel S, Woerle HJ. Linagliptin monotherapy improves glycaemic control in type 2 diabetes patients for whom metformin therapy is inappropriate. European Association for the Study of Diabetes; Stockholm, Sweden; Sept 20-24, 2010. 823.

- Batterham RL, Cohen MA, Ellis SM, et al. Inhibition of food intake in obese subjects by peptide YY3-36. N Engl J Med 2003;349(10):941-8.

- Bayo J, Latorre PM, García F, Vázquez JA. Factores de riesgo asociados a la prevalencia de diabetes mellitus no insulinodependiente en Lejona (Vizcaya). Med Clin 1996;107:572-7. 
- Beckman LM, Beckman TR, Earthman CP. Changes in gastrointestinal hormones and leptin after Roux-en-Y gastric bypass procedure: a review. J Am Diet Assoc 2010;110(4):571-84.

- Berne RN, Levy MN, Koeppen BM, Staton BA. Berne-Levy Physiology.5. ${ }^{a}$ ed. St. Louis, MO: Mosby; 2005, Cap:34;461-465.

- Bethoud HR. Multiple neural systems controlling food intake and body weight. Neurosci Biobehav Rev 2002;26:393.

- Bevan P. Insulin signalling. J Cell Sci. 2001 Apr;114(Pt 8):1429-30. Review

- Bezante GP, Scopinaro A, Papadia F, et al. Biliopancreatic diversion reduces QT interval and dispersion in severely obese patients. Obesity (Silver Spring) 2007; 15(6):1448-54.

- Bitar MS, Al-Saleh E, Al-Mulla F. Oxidative stress--mediated alterations in glucose dynamics in a genetic animal model of type II diabetes. Life Sci. 2005 Sep 30;77(20):2552-73.

- Black C, Donnelly P, Mclntyre L, Royle PL, Shepherd JP, Thomas S. Meglitinide analogues for type 2 diabetes mellitus. Cochrane Database Syst Rev 2007; 2:

- Blazquez E, Muñoz-Barragan L, Patton GS, Orci L, Dobbs RE, Unger RH. Gastric A-cell function in insulin-deprived depancreatized dogs. Endocrinology. 1976 Nov;99(5):1182-8.

- Blazquez E, Muñoz-Barragan L, Patton GS, Orci L, Dobbs RE, Unger RH. Gastric A-cell function in insulin-deprived depancreatized dogs. Endocrinology. 1976 Nov;99(5):1182-8.

- Bohdjalian A, Langer FB, Shakeri-Leidenmuhler S, et al. Sleeve gastrectomy as sole and definitive bariatric procedure: 5 -year results for weight loss and ghrelin. Obes Surg 2010;20:535-40.

- Bond DS, Vithiananthan S, Nash JM, et al. Improvement of migraine headaches in severely obese patients after bariatric surgery. Neurology 2011;76(13): 1135-8.

- Bonhomme S, Guijarro A, Keslacy S, Goncalves CG, Suzuki S, Chen C, Meguid MM. Gastric bypass up-regulates insulin signaling pathway. Nutrition. 2011 Jan;2

- Bonner-Weir S. Postnatal pancreatic beta cell growth. Endocrinology. 2000 Jun;141(6):1926-9. 
- Bose M, Teixeira J, Olivan B, Bawa B, Arias S, Machineni S, Pi-Sunyer FX, Scherer PE, Laferrere B. Weight loss and incretin responsiveness improve glucose control independently after gastric bypass surgery. $J$ Diabetes 2010;2:47-55

- Botas P, Delgado E, Castaño G, Díaz de Greñu C, Prieto J, Díaz-Cadórniga FJ. Prevalencia de diabetes mellitus e intolerancia a la glucosa en población entre 30 y 75 años en Asturias. Rev Clin Esp.

- Bray G. Medications for Weight Reduction. Med Clin N Am 2011;95: 9891008

- Brennan AM, Mantzoros CS. Drug insight: the role of leptin in human physiology and pathophysiology: emerging clinical applications in leptin deficient states. Nat Clin Pract Endocrinol Metab 2006;2:318-27.

- Brethauer SA, Harris JL, Kroh M, et al. Laparoscopic gastric plication for treatment of severe obesity. Surg Obes Relat Dis 2011;7(1):15-22.

- Brethauer SA, Sleeve Gastrectomy. Surg Clin N Am 2011;91: 1265-1279

- Briatore L, Salani B, Andraghetti G, et al. Beta-cell function improvement after biliopancreatic diversion in subjects with type 2 diabetes and morbid obesity. Obesity (Silver Spring). 2010;18:932-6.

- Buchwald H, Estok R, Fahrbach $\mathrm{K}$, et al. Weight and type 2 diabetes after bariatric surgery: systematic review and meta-analysis. Am $\mathrm{J}$ Med 2009;122(3): 248-56, e5.

- Buchwald H. Consensus conference statement bariatric surgery for morbid obesity: health implications for patients, health professionals, and third-party payers. Surg Obes Relat Dis $2005 ; 1(3): 371-81$.

- Buchwald H, Avidor Y, Braunwald E, Jensen MD, Pories W, Fahrbach K, Schoelles K. Bariatric surgery: a systematic review and meta-analysis. JAMA. 2004 Oct 13;292(14):1724-37. Review.

- Buettner C, Pocai A, Muse ED, Etgen AM, Myers MG Jr, Rossetti L. Critical role of STAT3 in leptin's metabolic actions. Cell Metab. 2006 Jul;4(1):49-60.

- Carlin A, Yager K, Rao D. Vitamin D depletion impairs hypertension resolution after Roux-en-Y gastric bypass. Am J Surg 2008;195(3):349-52

- Centers for Disease Control and Prevention. National diabetes fact sheet: national estimates and general information on diabetes and prediabetes in the 
United States, 2011. Atlanta (GA): U.S. Department of Health and Human Services, Centers for Disease Control and Prevention; 2011.

- Chambers AP, Jessen L, Ryan KK, Sisley S, Wilson-Pérez HE, Stefater MA, Gaitonde SG, Sorrell JE, Toure M, Berger J, D'Alessio DA, Woods SC, Seeley RJ, Sandoval DA. Weight-independent changes in blood glucose homeostasis after gastric bypass or vertical sleeve gastrectomy in rats. Gastroenterology. 2011 (1) Sep;141(3):950-8. Epub 2011 Jul 12.

- Chambers AP, Stefater MA, Wilson-Perez HE, Jessen L, Sisley S, Ryan K, Gaitonde S, Sorrell JS, Toure M, et al. Similar effects of roux-en-Y gastric bypass and vertical sleeve gastrectomy on glucose regulation in rats. Physiology \& Behavior 2011 (2);105: 120-123

- Chanoine JP, Hampl S, Jensen C, Boldrin M, Hauptman J. Effect of orlistat on weight and body composition in obese adolescents: a randomized controlled trial. JAMA 2005; 293: 2873-83.

- Chen DC, Stern JS, Atkinson RL. Effects of ileal transposition on food intake, dietary preference, and weight gain in zucker obese rats. Am $\mathrm{J}$ Physiol 1990;258:R269-73.

- Cho YM, Kieffer TJ. K-cells and glucose-dependent insulinotropic polypeptide in health and disease. Vitam Horm. 2010;84:111-50.

- Christakis NA, Fowler JH. The spread of obesity in a large social network over 32 years. N Engl J Med 2007;357:379.

- Clark J, Palmer CJ, Shaw WN. The diabetic Zucker fatty rat. Proc Soc Exp Biol Med. 1983;173:68-75.

- Claus TH, Pan CQ, Buxton JM, et al. Dual-acting peptide with prolonged glucagon like peptide-1 receptor agonist and glucagon receptor antagonist activity for the treatment of type 2 diabetes. J Endocrinol 2007;192:371-80.

- Cluck MW, Chan CY, Adrian TE. The regulation of amylin and insulin gene expression and secretion. Pancreas. 2005 Jan; 30(1):1-14.

- Cluck MW, Chan CY, Adrian TE. The regulation of amylin and insulin gene expression and secretion. Pancreas. 2005 Jan; 30(1):1-14.

- Cluck MW, Chan CY, Adrian TE. The regulation of amylin and insulin gene expression and secretion. Pancreas. 2005 Jan; 30(1):1-14.

- Cohen R, Pinheiro JS, Correa JL, Schiavon CA. Laparoscopic Roux-en-Y gastric bypass for BMI $<35 \mathrm{~kg} / \mathrm{m}^{2}$ : a tailored approach. Surg Obes Relat Dis 2006;2:401-4. 
- Cohen R, Pinheiro JS, Correa JL, Schiavon CA. Laparoscopic Roux-en-Y gastric bypass for BMI $<35 \mathrm{~kg} / \mathrm{m}^{2}$ : a tailored approach. Surg Obes Relat Dis 2006;2:401-4.

- Cohen R, Schiavon C, Pinheiro J, Correa J, Rubino F. Duodenal-jejunal bypass for the treatment of ype 2 diabetes in patients with body mass index of 22-34 kg/m2. Surg Obes Relat Dis 2007:3:195-7.

- Conget I. Diagnóstico, clasificación y patogenia de la diabetes mellitus. Rev Esp Cardiol 2002;55(5):528-35.

- Cory S, Ussery-Hall A, Griffin-Blake S, Easton A, Vigeant J, Balluz L, Garvin W, Greenlund K; Centers for Disease Control and Prevention (CDC). Prevalence of selected risk behaviors and chronic diseases and conditionssteps communities, United States, 2006-2007. MMWR Surveill Summ. 2010 Sep 24;59(8):1-37

- Cory, S, Ussery-Hall, A, Griffin-Blake, S, et al Prevalence of selected risk behaviors and chronic diseases and conditions-steps communities, United States, 2006-2007 MMWR CDC Surveill Summ. 2010;59:S1.

- Cossu ML, Noya G, Tonolo GC, et al. Duodenal switch without gastric resection: results and observations after 6 years. Obes Surg 2004;14(10):1354-9.

- Cremieux PY, Ledoux S, Clerici C, et al. The impact of bariatric surgery on comorbidities and medication use among obese patients. Obes Surg 2010;20(7): 861-70.

- Cummings BP, Bettaieb A, Graham JL, Stanhope KL, Kowala M, Haj FG, Chouinard ML, Havel PJ. Vertical Sleeve Gastrectomy Improves Glucose and Lipid Metabolism and Delays Diabetes Onset in UCD-T2DM Rats. Endocrinology. 2012 Aug;153(8):3620-32.

- Cummings BP, Digitale EK, Stanhope KL, et al. Development and characterization of a novel rat model of type 2 diabetes mellitus: the UC Davis type 2 diabetes mellitus UCD-T2DM rat. Am J Physiol Regul Integr Comp Physiol. 2008 Dec;295(6):R1782

- Cummings DE, Overduin J, Shannon MH, Foster-Schubert KE. Hormonal mechanisms of weight loss and diabetes resolution after bariatric surgery. Surg Obes Relat Dis, 2005, 1:358-368.

- Cummings D, Weigle D, Frayo R, Breen P, Ma M, Dellinger E, et al. Plasma ghrelin levels after diet induced weight loss or gastric bypass surgery. $\mathrm{N}$ Engl J Med 2002;346:1623-30. 
- De Bona Castelan J, Bettiol J, d'Acampora AJ, Castelan JV, de Souza JC, Bressiani V, Giroldi SB. Sleeve gastrectomy model in Wistar rats. Obes Surg. 2007 Jul;17(7):957-61.

- De Fronzo RA. Pathogenesis of type 2 Diabetes: metabolic and molecular implications for identifying diabetes genes. Diabetes Reviews 1997;5:177269.

- De Jong JR, Besselink MG, van Ramshorst B, et al. Effects of adjustable gastric banding on gastroesophageal reflux and esophageal motility: a systematic review. Obes Rev 2010;11(4):297-305.

- De Luis D, Domingo M, Romero A, Gonzalez Sagrado M, Pacheco D, Primo $D$, Conde R. Effects of duodenal-jejunal exclusion on beta cell function and hormonal regulation in Goto-Kakizaki rats. Am J Surg. 2012 Aug;204(2):2427.

- De Luis DA, Aller R, Izaola O, Conde R, Sagrado MG. The ratio of adiponectin to HOMA as an index of metabolic syndrome in obese women. Ann Nutr Metab. 2011 (1) Oct;58(4):301-6.

- De Luis DA, Gonzalez Sagrado M, Conde R, Aller R, Izaola O, Primo D. Lack of association of serum resistin levels with metabolic syndrome criteria in obese female patients. Clin Biochem. 2011 (2).

- De Luis DA, Aller R, Izaola O, Gonzalez Sagrado M, Conde R, Perez Castrillon JL. Effects of lifestyle modification on adipocytokine levels in obese patients. Eur Rev Med Pharmacol Sci. 2008 Jan-Feb;12(1):33-9.

- De Luis DA, Perez Castrillon JL, Dueñas A. Leptin and obesity. Minerva Med. 2009 Jan 30.

- De Maria EJ, Winegar DA, Pate VW, et al. Early postoperative outcomes of metabolic surgery to treat diabetes from sites participating in the ASMBS bariatric surgery center of excellence program as reported in the bariatric outcomes longitudinal database. Ann Surg 2010;252(3):559-66

- De Pablos Velasco PL, Martínez Martín FJ, Rodríguez-Pérez F, Anía BJ, Losada A, Betancor P. Prevalence and determinants o diabetes mellitus and glucose intolerance in Canarian Caucasian population -comparison of the ADA and the 1985 WHO criteria. The Guia Study. Diabetic Medicine 2001;18:235-41.

- DECODE-Study-Group. Age- and sex-specific prevalences of diabetes and impaired glucose regulation in 13 European cohorts. Diabetes Care (2003) 26:61-69 
- Deitel M. Update: why diabetes does not resolve in some patients. Obes Surg $2011 ; 21(6): 794-6$

- Del Prato S, Marchetti P, Bonadonna RC. Phasic insulin release and metabolic regulation in type 2 diabetes. Diabetes. 2002 Feb;51 Suppl 1:S10916.

- Delling L, Karason K, Olbers T, et al. Feasibility of bariatric surgery as a strategy for secondary prevention in cardiovascular disease: a report from the Swedish obese subjects trial. J Obes 2010;2010.

- DePaula AL, Macedo A, Schraibman V, Mota R, Vencio S. Hormonal evaluation following laparoscopic treatment of type 2 diabetes mellitus patients with BMI 20-34. Surg Endosc 2009; 23:1724-1732

- DePaula AL, Macedo A, Schraibman V, Mota R, Vencio S. The great debate: medicine or surgery: what is best for the patient with type 2 diabetes? Diabetes Care. 2011 Mar;34(3):763-70.

- DIAMOND Project Group. Incidence and trends of childhood type 1 diabetes worldwide 1990-1999. Diabet Med 2006;23:857-66

- Diniz M de F, Azeredo Passos VM, Diniz MT. Bariatric surgery and the gutbrain communication-the state of the art three years later. Nutrition 2010;10:925-31.

- Dirksen C, Hansen DL, Madsbad S, et al. Postprandial diabetic glucose tolerance is normalized by gastric bypass feeding as opposed to gastric feeding and is associated with exaggerated GLP-1 secretion: a case report. Diabetes Care 2010;33: 375-377

- Dixon JB, Le Roux CW, Rubino F, Zimmet P.Bariatric surgery for type 2 diabetes. Lancet 2012; 379: 2300-11.

- Dixon JB, O'Brien PE, Playfair J, Chapman L, Schachter LM, Skinner S, et al. Adjustable gastric banding and conventional therapy for type 2 diabetes. JAMA. 2008;299:316-23.

- Domingo M. Efectos de la Derivación Gastroyeyunal en la funcionalidad y la expresión génica de los islotes pancreáticos y hormonas enteroinsulares en un modelo de rata diabética no obesa. Tesis Doctoral, Universidad de Valladolid 2011.

- Donadelli SP, Salgado W Jr, Marchini JS, et al. Change in predicted 10-year cardiovascular risk following Roux-en-Y Gastric bypass surgery: who benefits? Obes Surg 2011;21(5):569-73. 
- Donglei Z, Liesheng L, Xun J, Chenzhu Z, Weixing D. Effects and mechanism of duodenal-jejunal bypass and sleeve gastrectomy on GLUT2 and glucokinase in diabetic Goto-Kakizaki rats. Eur J Med Res. 2012 Jun 11;17(1):15.

- Edlund H. Developmental biology of the pancreas. Diabetes. 2001 Feb;50 Suppl 1:S5-9.

- Encuesta Nacional de Salud, 2003. Ministerio de Sanidad y Consumo. Disponible en www.msc.es/estadEstudios/estadisticas/docs/ENSE2003_SN.pdf. Consultado el 18 de mayo de 2012.

- English PJ, Ghatei MA, Malik IA, et al. Food fails to suppress ghrelin levels in obese humans. J Clin Endocrinol Metab 2002;87(6):2984.

- Eriksson J, Koranyi L, Bourey R, Schalin-Jantti C, Widen E, Mueckler M, Permutt AM, Groop LC: Insulin resistance in type 2 (non-insulin- dependent) diabetic patients and their relatives is not associated with a defect in the expression of the insulin responsive glucose transporter (GLUT-4) gene in human skeletal muscle. Diabetologia 1992, 35:143-147.

- Erondu N, Gantz I, Musser B, et al. Neuropeptide Y5 receptor antagonism does not induce clinically meaningful weight loss in overweight and obese adults. Cell Metab 2006;4(4):275-82.

- Escobar-Morreale HF, Botella-Carretero Jl, Alvarez-Blasco F, et al. The polycystic ovary syndrome associated with morbid obesity may resolve after weight loss induced by bariatric surgery. J Clin Endocrinol Metab 2005;90(12):6364-9.

- Esmatjes E, Goicolea I, Cacho L, De Pablos P, Rodríguez R, Roche M, et al. Nefropatía en la diabetes mellitus tipo II: prevalencia en España. Av Diabetol. 1997;13:29-35.

- Expert Panel on Detection, Evaluation, and Treatment of High Blood Cholesterol in Adults. Executive Summary of The Third Report of The National Cholesterol Education Program (NCEP) Expert Panel on Detection, Evaluation, And Treatment of High Blood Cholesterol In Adults (Adult Treatment Panel III). JAMA. 2001 May 16;285(19):2486-97.

- Exton JH. Glucagon signal-transduction mechanisms. In: Jefferson LS, Cherrington, AD, Goodman, HM, eds. Handbook of physiology. New York: Oxford University Press; 2001, 435-50.

- Farilla L, Bulotta A, Hirshberg B, Li Calzi S, Khoury N, Noushmehr H, Bertolotto C, Di Mario U, Harlan DM, Perfetti R. Glucagon-like peptide 1 
inhibits cell apoptosis and improves glucose responsiveness of freshly isolated human islets. Endocrinology. 2003 Dec;144(12):5145-8.

- Fernandez-Berges D, et al. Sindrome metabólico en España: prevalencia y riesgo coronario asociado a la definición armonizada y a la propuesta por la OMS. Estudio DARIOS. Rev Esp Cardiol. 2012

- Flegal KM, Williamson DF. Incident CHD and excess body weight in the US population. Obesity (Silver Spring). 2010 Jun;18(6):1069; author reply 106970.

- Fobi M. Why the operation I prefer is silastic ring vertical gastric bypass. Obes Surg 1991;1(4):423-6.

- Fonseca VA, Handelsman Y, Staels B. Colesevelam lowers glucose and lipid levels in type 2 diabetes: the clinical evidence. Diabetes Obes Metab 2010; 12: 384-92.

- Ford ES, Giles WH, Dietz WH. Prevalence of the metabolic syndrome among US adults: findings from the third National Health and Nutrition Examination Survey. J Am Med Assoc 2002;287(3):356-9.

- Forgacs S, Halmos T. Improvement of glucosa tolerance in diabetics following gastrectomy. Z Gastroenterol; 1973.11:293-6.

- Foster A, Laws H, Gonzalez Q, et al. Gastrointestinal symptomatic outcome after laparoscopic Roux-en-Y gastric bypass. J Gastrointest Surg 2003;7(6): 750-3.

- Franks PW, Mesa JL, Harding AH, Wareham NJ. Gene-lifestyle interaction on risk of type 2 diabetes. Nutr Metab Cardiovasc Dis. 2007;17:104-24.

- Fried M, Ribaric G, Buchwald JN, et al. Metabolic surgery for the treatment of type 2 diabetes in patients with $\mathrm{BMl}<35 \mathrm{~kg} / \mathrm{m} 2$ : an integrative review of early studies. Obes Surg 2010;20(6):776-90.

- Friedman MN, Sancetta AJ, Magovern GJ. The amelioration of diabetes mellitus following subtotal gastrectomy. Surg Gynecol Obstet. 1955 Feb;100(2):201-4.

- Gallagher, EJ, LeRoith D, Karnieli E. The Metabolic Syndrome-from Insulin Resistance to Obesity and Diabetes. Med Clin N Am 95 (2011) 855-873.

- Galli J, Li LS, Glaser A, Ostenson CG, Jiao H, Fakhrai-Rad H, Jacob HJ, Lander ES, Luthman H. Genetic analysis of non-insulin-dependent diabetes mellitus in the GK rat. Nat Genet 1996;12: 31-37. 
- Gatmaitan P, Huang H, Talarico J, Moustarah F, Kashyap S, Kirwan JP, Schauer PR, Brethauer SA. Pancreatic islet isolation after gastric bypass in a rat model: technique and initial results for a promising research tool. Surg Obes Relat Dis. 2010 Sep-Oct;6(5):532-7

- Gauguier D, Nelson I, Bernard C, Parent V, Marsac C, Cohen D, Froguel P. Higher maternal than paternal inheritance of diabetes in GK rats. Diabetes. 1994 Feb;43(2):220-4.

- Gauna C, Meyler FM, Janssen JA, Delhanty PJ, Abribat T, Van Koetsveld P. Administration of acylated ghrelin reduces insulin sensitivity, whereas the combination of acylated plus unacylated ghrelin strongly improves insulin sensitivity. J Clin Endocrinol Metab. 2004 Oct;89(10):5035-42.

- Gaylinn BD, Thorner MO. Luminal influences to orchestrate gastroenterological hormone secretion: the fat, long-chain fatty acid, cholecystokinin, glucagon-like peptide 1 axis. J Clin Endocrinol Metab. 2010;95:503-4

- Gaziano JM, Cincotta AH, O'Connor CM, et al. Randomized clinical trial of quick-release bromocriptine among patients with type 2 diabetes on overall safety and cardiovascular outcomes. Diabetes Care 2010; 33: 1503-08.

- Geloneze B, Geloneze SR, Fiori C, Stabe C, Tambascia MA, Chaim EA, Astiarraga BD, Pareja JC. Surgery for nonobese type 2 diabetic patients: an interventional study with duodenal-jejunal exclusion. Obes Surg. 2009 Aug;19(8):1077-83

- Geloneze B, Tambascia MA, Pareja JC, Repetto EM, Magna LA. The insulin tolerance test in morbidly obese patients undergoing bariatric surgery. Obes Res. 2001 Dec;9(12):763-9.

- Genco A, Bruni T, Doldi SB, et al. BioEnterics intragastric balloon: the Italian experience with 2,515 patients. Obes Surg 2005;15(8):1161-4.

- Ghanaat-Pour H, Huang Z, Lehtihet M, Sjöholm A. Global expression profiling of glucose-regulated genes in pancreatic islets of spontaneously diabetic Goto-Kakizaki rats. J Mol Endocrinol. 2007 Aug;39(2):135-50.

- Ghanaat-Pour H, Sjöholm A. Gene expression regulated by pioglitazone and exenatide in normal and diabetic rat islets exposed to lipotoxicity. Diabetes Metab Res Rev. 2009 Feb;25(2):163-84.

- Gil-Campos M, Aguilera CM, Cañete R, Gil A. Ghrelin: a hormone regulating food intake and energy homeostasis. Br J Nutr. 2006 Aug;96(2):201-26. 
- Gill RS, Birch DW, Shi X, et al. Sleeve gastrectomy and type 2 diabetes mellitus: a systematic review. Surg Obes Relat Dis 2010;6:707-13.

- Giroix MH, Baetens D, Rasschaert J, Leclercq-Meyer V, Sener A, Portha B, Malaisse WJ. Enzymic and metabolic anomalies in islets of diabetic rats: relationship to B cell mass. Endocrinology. 1992 May;130(5):2634-40.

- Giroix MH, Saulnier C, Portha B. Decreased pancreatic islet response to Lleucine in the spontaneously diabetic GK rat: enzymatic, metabolic and secretory data. Diabetologia 1999;42: 965-977.

- Goday A. Epidemiology of diabetes and its non-coronary complications. Rev Esp Cardiol. 2002 Jun;55(6):657-70.

- Goldfine AB, Shoelson SE, Aguirre V. Expansion and contraction: treating diabetes with bariatric surgery. Nat Med 2009;15: 616-7.

- González Sagrado M, Conde R, Aller R, Izaola O, Primo D, De Luis DA. Lack of association of serum resistin levels with metabolic syndrome criteria in obese female patients. Clin Biochem. 2011 Nov;44(16):1280-3. Epub 2011 Sep 16.

- Gopel SO, Kanno T, Barg S, Weng XG, Gromada J, Rorsman P. Regulation of glucagons release in mouse alpha-cells by KATP channels and inactivation of TTX-sensitive Na+ channels. J Physiol. 2000; 528: 509-520.

- Gopel SO, Kanno T, Barg S, Weng XG, Gromada J, Rorsman P. Regulation of glucagons release in mouse alpha-cells by KATP channels and inactivation of TTX-sensitive Na+ channels. J Physiol. 2000; 528: 509-520.

- Goto Y, Kakizaki M. Production of spontaneous diabetic rats by repetition of selective breeding. Tohoku J Exp Med. 1976;119:85-90.

- Gough SC. A review of human and analogue insulin trials. Diabetes Res Clin Pract. 2007 Jul;77(1):1-15.

- Green BD, Flatt PR. Incretin hormone mimetics and analogues in diabetes therapeutics. Best Pract Res Clin Endocrinol Metab 2007;21: 497-516

- Greenway FL. Surgery for obesity. Endocrinol Metab Clin North Am 1996;25:1005-27.

- Grimsby J, Sarabu R, Corbett WL, Haynes NE, Bizzarro FT, Coffey JW, Guertin KR, Hilliard DW, Kester RF, Mahaney PE, et al: Allosteric activators of glucokinase: potential role in diabetes therapy. Science 2003, 301:370373. 
- Gromada J, Franklin I, Wollheim CB (2007) alfa Cells of the endocrine pancreas: 35 years of research but the enigma remains. Endocr Rev 28:84116

- Gruessner AC, Sutherland DE, Gruessner RW. Long-term outcome after pancreas transplantation. Curr Opin Organ Transplant. 2012 Feb;17(1):100-5.

- Grundy S, Cleeman J, Daniels S, et al. Diagnosis and management of the metabolic syndrome: an American Heart Association/National Heart, Lung, and Blood Institute scientific statement. Circulation 2005;112(17):2735--52.

- Grundy SM, Brewer HB Jr, Cleeman JI, Smith SC Jr, Lenfant C; American Heart Association; National Heart, Lung, and Blood Institute. Definition of metabolic syndrome: Report of the National Heart, Lung, and Blood Institute/American Heart Association conference on scientific issues related to definition. Circulation. 2004 (1) Jan 27;109(3):433-8.

- Guest, P.C., Abdel-Halim, S.M., Gross, D.J., Clark, A., Poitout, V., Amaria, et al. Proinsulin processing in the diabetic Goto-Kakizaki rat. J. Endocrinol. 2002. 175, 637-647.

- Gutiérrez-Fisac JL, Guallar-Castillón P, León-Muñoz LM, Graciani A, Banegas JR, Rodríguez-Artalejo F. Prevalence of general and abdominal obesity in the adult population of Spain, 2008-2010: the ENRICA study. Obesity Reviews. Article first published online : 12 DEC 2011. Consultado el 3 de marzo de 2012.

- Gutiérrez-Fisac JL, Regidor E, Banegas JR, Rodríguez-Artalejo F. Prevalencia de obesidad en la población adulta española: 14 años de crecimiento continuado. MedClin (Barc) 2005; 124:196-7.

- Hansen D, Toubro S, Stock M, MacDonald I, Astrup A. Thermogenic effects of sibutramine in humans. Am J Clin Nutr 1998; 68: 1180-6.

- Hansen HH, Hansen G, Tang-Christensen M, Larsen PJ, Axel AM, Raben A, Mikkelsen JD. The novel triple monoamine reuptake inhibitor tesofensine induces sustained weight loss and improves glycemic control in the dietinduced obese rat: comparison to sibutramine and rimonabant. Eur $\mathrm{J}$ Pharmacol. 2010 Jun 25;636(1-3):88-95.

- Hanson ES, Dallman MF. Neuropeptide Y (NPY) may integrate responses of hypothalamic feeding systems and the hypothalamo-pituitary-adrenal axis. $J$ Neuroendocrinol 1995;7(4):273-9.

- Hansson L, Zanchetti A, Carruthers SG, Dahlöf B, Elmfeldt D, Julius S, et al. Effects of intensive blood-pressure lowering and low-dose aspirin in patients 
with hypertension: principal results of the Hypertension Optimal Treatment (HOT) randomised trial. Lancet. 1998;351:1755-62.

- Heise T, Nosek L, Rønn BB, Endahl L, Heinemann L, Kapitza C, Draeger E. Lower within-subject variability of insulin detemir in comparison to NPH insulin and insulin glargine in people with type 1 diabetes. Diabetes. 2004 Jun;53(6):1614-20.

- Heit JJ, Apelqvist AA, Gu X, Winslow MM, Neilson JR, Crabtree GR, Kim SK. Calcineurin/NFAT signalling regulates pancreatic beta-cell growth and function. Nature. 2006 Sep 21;443(7109):345-9.

- Henrikson V. [Kan tunnfarmsresektion forsvaras som terapi mot fettsot? Nordisk Medicin 1952;47:744]. Can small bowel resection be defended for therapy for obesity? Obes Surg 1994;4:54-5.

- Hernández G, Macarro J, Fernández J, Fernández J. Prevalencia de retinopatía diabética en Extremadura. Av Diabetol. 1996;12:165-71.

- Hernandez Pascual C., Giralt Josa J., Simo Canonge R. Tratamiento de la retinopatía diabética. Endocrinol Nutr. 2008;55:92-98.

- Hess DS, Hess DW. Biliopancreatic diversion with a duodenal switch. Obes Surg 1998;8:267-82.

- Hickey MS, Pories WJ, MacDonald KG Jr et al. A new paradigm for type 2 diabetes mellitus, could it be a disease of the foregut? Ann Surg 1998;227:637-644.

- Hinojosa M, Varela J, Smith B, et al. Resolution of systemic hypertension after laparoscopic gastric bypass. J Gastrointest Surg 2009;13(4):793-7.

- Horgan S, Vanuno D. Robots in laparoscopic surgery. J Laparoendosc Adv Surg Tech A 2001;11(6):415-9.

- Horner KM, Byrne NM, Cleghorn GJ, Näslund E, King NA. The effects of weight loss strategies on gastric emptying and appetite control. Obes Rev 2011;12:935-951.

- Hutley L, Prins JB. Fat as an endocrine organ: relationship to the metabolic syndrome. Am J Med Sci 2005;330(6):280-9.

- Ikramuddin S, Klingman D, Swan T, et al. Cost-effectiveness of Roux-en-Y gastric bypass in type 2 diabetes patients. Am J Manag Care 2009;15(9): 607-15. 
- Inaba W, Mizukami H, Kamata K, Takahashi K, Tsuboi K, Yagihashi S. Effects of long-term treatment with the dipeptidyl peptidase-4 inhibitor vildagliptin on islet endocrine cells in non-obese type 2 diabetic Goto-Kakizaki rats. Eur J Pharmacol. 2012 Sep 15;691(1-3):297-306.

- Iqbal CW, Qandeel HG, Zheng Y, Duenes JA, Sarr MG: Mechanisms of ileal adaptation for glucose absorption after proximal-based small bowel resection. J Gastrointest Surg 2008, 12:1854-1864. discussion 1864-1855.

- Jackson PJ, Douglas NR, Chai B, et al. Structural and molecular evolutionary analysis of agouti and agouti-related proteins. Chem Biol. 2006;13:1297-305.

- Jamal M, Wegner R, Heitshusen D, et al. Resolution of hyperlipidemia follows surgical weight loss in patients undergoing Roux-en-Y gastric bypass surgery: a 6-year analysis of data. Surg Obes Relat Dis 2010;7(4):473-9.

- James WP, Astrup A, Finer N, Hilsted J, Kopelman P, Rossner S, et al. Effect of sibutramine on weight maintenance after weight loss: a randomised trial. STORM Study Group (Sibutramine Trial of Obesity Reduction and Maintenance). Lancet 2000; 356: 2119-25

- James WP, Caterson ID, Coutinho W, Finer N, Van Gaal LF, Maggioni AP, et al. SCOUT Investigators. Effect of sibutramine on cardiovascular outcomes in overweight and obese subjects. N Engl J Med. 2010 Sep 2;363(10):905-17.

- Janssen U, Phillips AO, Floege J. Rodent models of nephropathy associated with type II diabetes. J Nephrol 1999; 12 (3):159-72.

- Kahn SE. Regulation of beta-cell function in vivo. Diabetes metab Rev. 1996;4:372-84.

- Karamanakos SN, Vagenas K, Kalfarentzos F, et al. Weight loss, appetite suppression, and changes in fasting and postprandial ghrelin and peptide-YY levels after Roux-en-Y gastric bypass and sleeve gastrectomy: a prospective, double blind study. Ann Surg 2008;247:401-7.

- Karvonen M, Viik-Kajander M, Moltchanova E, et al. Incidence of childhood type 1 diabetes worldwide. Diabetes Mondiale (DiaMond) Project Group. Diabetes Care 2000;23:1516-26.

- Kashyap SR, Daud S, Kelly KR, Gastaldelli A, Win H, Brethauer S, Kirwan JP, Schauer PR. Acute effects of gastric bypass versus gastric restrictive surgery on beta-cell function and insulinotropic hormones in severely obese patients with type 2 diabetes. Int J Obes Lond 2010;34:462-471.

- Kaul A, Sharma J. Impact of Bariatric Surgery on Comorbidities Surg Clin N Am 2011;91: 1295-131. 
- Kelishadi R, Hashemipour M, Mohammadifard N, et al. Short- and long-term relationships of serum ghrelin with changes in body composition and the metabolic syndrome in prepubescent obese children following two different weight loss programmes. Clin Endocrinol 2008;69(5):721-9.

- Klover PJ, Mooney RA. Hepatocytes: critical for glucose homeostasis. Int J Biochem Cell Biol. 2004 May;36(5):753-8.

- Koopmans H, Ferri GL, Sarson DL, Polack JM, Bloom SR. The effects of ileal transposition and jejunoileal bypass on food intake and GI hormone levels in rats. Physiol Behav 1984;33:601-9.

- Kopelman P, Bryson A, Hickling R, et al. Cetilistat (ATL-962), a novel lipase inhibitor: a 12-week randomized, placebo-controlled study of weight reduction in obese patients. Int J Obes (Lond) 2007;31(3):494-9.

- Korner J, Bessler M, Cirilo LJ, Conwell IM, Daud A, Restuccia NL, Wardlaw SL. Effects of Roux-en-Y gastric bypass surgery on fasting and postprandial concentrations of plasma ghrelin, peptide $\mathrm{YY}$, and insulin. J Clin Endocrinol Metab. 2005;90:359-365.

- Korner J, Bessler M, Inabnet W, Taveras C, Holst JJ. Exaggerated glucagonlike peptide-1 and blunted glucose-dependent insulinotropic peptide secretion are associated with Roux-en-Y gastric bypass but not adjustable gastric banding. Surg Obes Relat Dis 2007; 3: 597-601.

- Korner J, Inabnet W, Conwell IM, Taveras C, Daud A, Olivero-Rivera L, Restuccia NL, Bessler M. Differential effects of gastric bypass and banding on circulating gut hormone and leptin levels. Obesity (Silver Spring). 2006 Sep;14(9):1553-61.

- Koyama M, Wada R, Sakuraba H, et al. Accelerated loss of islet beta cells in sucrose-fed Goto-Kakizaki rats, a genetic model of non-insulin-dependent diabetes mellitus. Am J Pathol. 1998;153(2):537-45.

- Kozian DH, Barthel A, Cousin E, et al. Glucokinase-activating GCKR polymorphisms increase plasma levels of triglycerides and free fatty acids, but do not elevate cardiovascular risk in the Ludwigshafen Risk and Cardiovascular Health Study. Horm Metab Res 2010;42:502-06.

- Kremen A, Linner J, Nelson C. An experimental evaluation of the nutritional importance of proximal and distal small intestine. Ann Surg 1954;140:439-44.

- Kumar KV, Ugale S, Gupta N, et al. lleal interposition with sleeve gastrectomy for control of type 2 diabetes. Diabetes Technol Ther 2009;11(12):785-9. 
- Kuzmak LI. Silicone gastric banding: a simple and effective operation for morbid obesity. Contemp Surg 1986;28:13-8

- Lacy AM, Delgado S, Rojas OA, et al. Hybrid vaginal MANOS sleeve gastrectomy: technical note on the procedure in a patient. Surg Endos 2009;23(5): 1130-7.

- Laferrère $B$, et al. Effect of weight loss by gastric bypass surgery versus hypocaloric diet on glucose and incretin levels in patients with type 2 diabetes. J Clin Endocrinol Metab 2008; 93:2479-85.

- Lagace M, Marceau P, Marceau S, et al. Biliopancreatic diversion with a new type of gastrectomy: some previous conclusions revisited. Obes Surg 1995;5:411-8.

- Lakdawala M, Bhasker A, Mulchandani D, et al. Comparison between the results of laparoscopic sleeve gastrectomy and laparoscopic Roux-en-Y gastric bypass in the Indian population: a retrospective 1 year study. Obes Surg 2010;20(1): 1-6.

- Langer F, Reza M, Bohdjalian A, Felberbauer F, Zacherl J, Wenzl E, et al. Sleeve gastrectomy and gastric banding: effects on plasma ghrelin levels. Obes Surg 2005;15:1024-9.

- Langin D. Diabetes, insulin secretion, and the pancreatic beta-cell mitochondrion. N Engl J Med. 2001 Dec 13;345(24):1772-4.

- Laubner K, Timothy J, Kieffer , Ni T, Lam A, Niu X, et al. Inhibition of Preproinsulin Gene Expression by Leptin Induction of Suppressor of Cytokine Signaling 3 in Pancreatic. Cells Diabetes, 2005 Dec, Vol. 54 (12), 3410-3417.

- Lautz D, Halperin F, Goebel-Fabbri A, Goldfine AB. The great debate: medicine or surgery: what is best for the patient with type 2 diabetes? Diabetes Care. 2011 Mar;34(3):763-70.

- Le Roux CW, Neary NM, Halsey TJ, et al. Ghrelin does not stimulate food intake in patients with surgical procedures involving vagotomy. J Clin Endocrinol Metab 2005;90(8):4521-4.

- Lee SM, Pryor AD. Future Directions in Bariatric Surgery. Surg Clin N Am $2011 ; 91: 1373-1395$

- Lee WJ, Chong K, Ser KH, et al. Gastric bypass vs sleeve gastrectomy for type 2 diabetes mellitus: a randomized controlled trial. Arch Surg 2011;146:143-8. 
- Lee WJ, Ser KH, Chong K, et al. Laparoscopic sleeve gastrectomy for diabetes treatment in nonmorbidly obese patients: efficacy and change of insulin secretion. Surgery. 2010;147:664-9.

- Lefèbvre P. Type 2 diabetes mellitus: integration in view, at last! Diabetes Metab. 2008 Feb;34 Suppl 2:S41-2.

- Leslie RD, Williams R, Pozzilli P. Clinical review: Type 1 diabetes and latent autoimmune diabetes in adults: one end of the rainbow. J Clin Endocrinol Metab. 2006;91(5):1654.

- Li F, Zhang G, Liang J, Ding X, Cheng Z, Hu S. Sleeve gastrectomy provides a better control of diabetes by decreasing ghrelin in the diabetic GotoKakizaki rats. J Gastrointest Surg. 2009 Dec;13(12):2302-8.

- $\quad$ Li Y, Xu W, Liao Z, Yao B, Chen X, Huang Z, Hu G, Weng J. Induction of long-term glycemic control in newly diagnosed type 2 diabetic patients is associated with improvement of beta-cell function. Diabetes Care. 2004;27(11):2597.

- Li Z, Zhang HY, Lv LX, Li DF, Dai JX, Sha O, Li WQ, Bai Y, Yuan L. Roux-en$Y$ gastric bypass promotes expression of PDX-1 and regeneration of betacells in Goto-Kakizaki rats. World J Gastroenterol. 2010 May 14;16(18):224451.

- Li Z, Maglione M, Tu W, Mojica W, Arterburn D, Shugarman LR, et al. Metaanalysis: pharmacologic treatment of obesity. Ann Intern Med 2005; 142: 53246.

- Liang CP, Han S, Senokuchi T, et al. The macrophage at the crossroads of insulin resistance and atherosclerosis. Circ Res 2007;100(11):1546-55.

- Lifante JL, Milone L, Korner J, Kopsombut G, Sebastian M, Inabnet WB. Sleeve Gastrectomy Improves Glucose Homeostasis in Zucker Diabetic Fatty Rats Obes Surg 2012;22:1110-1116

- Ludwig B, Ludwig S, Steffen A, Saeger HD, Bornstein SR. Islet versus pancreas transplantation in type 1 diabetes: competitive or complementary? Curr Diab Rep. 2010 Dec;10(6):506-11. Review.

- Lugari R, Dei Cas A, Ugolotti D, Barilli AL, Camellini C, Ganzerla GC. Glucagon-like peptide 1 (GLP-1) secretion and plasma dipeptidyl peptidase IV (DPP-IV) activity in morbidly obese patients undergoing biliopancreeatic diversion. Horm Metab Res 2004;36:111-5. 
- Lupi R, Del Guerra S, Mancarella R, et al. Insulin secretion defects of human type 2 diabetic islets are corrected in vitro by a new reactive oxygen species scavenger. Diabetes Metab 2007;33:340-45.

- Maahs DM, West, NA, Lawrence JM, ScD, Mayer-Davis EJ. Epidemiology of Type1 Diabetes. Endocrinol Metab Clin N Am 39 (2010) 481-497

- MacFarlane WM, Chapman JC, Shepherd RM, Hashmi MN, Kamimura N, Cosgrove KE, O'Brien RE, Barnes PD, Hart AW, Docherty HM, Lindley KJ, Aynsley-Green A, James RF, Docherty K, Dunne MJ. Engineering a glucoseresponsive human insulin-secreting cell line from islets of Langerhans isolated from a patient with persistent hyperinsulinemic hypoglycemia of infancy. J Biol Chem. 1999 Nov 26;274(48):34059-66.

- Maedler K, Spinas GA, Lehmann R, Sergeev P, Weber M, Fontana A, et al. Glucose induces beta-cell apoptosis via upregulation of the Fas receptor in human islets. Diabetes. 2001 Aug;50(8):1683-90.

- Magee CJ, Barry J, Arumugasamy M, et al. Laparoscopic sleeve gastrectomy for high-risk patients: weight loss and comorbidity improvement-short-term results. Obes Surg 2011;21(5):547-50.

- Maggard MA, Shugarman LR, Suttorp M, et al. Meta-analysis: surgical treatment of obesity. Ann Intern Med 2005;142(7):547-59.

- Malik S, Wong ND, Franklin SS, et al. Impact of the metabolic syndrome on mortality from coronary heart disease, cardiovascular disease, and all causes in United States adults. Circulation 2004;110(10):1245-50.

- Mantzoros CS. The role of leptin in human obesity and disease: a review of current evidence. Ann Intern Med 1999; 20:130:671-680.

- Martin Duce A; Diez del Val I. Cirugía de la Obesidad Mórbida. Guías Clínicas de la Asociación Española de Cirujanos 2007. 298-299.

- Martín P, Díaz JA, Durán A, García de la Torre N, Benedí A, Calvo I, et al. Pie diabético. Endocrinol Nutr. 2006;53:60-7.

- Mason EE, Ito C. Gastric bypass in obesity. Surg Clin North Am 1967;47(6): $1345-51$.

- Mason EE. Vertical banded gastroplasty for obesity. Arch Surg 1982;117:701-6.

- Masuda T, Ohta M, Hirashita T, Kawano Y, Eguchi H, Yada K, Iwashita Y, Kitano S. A Comparative Study of Gastric Banding and Sleeve Gastrectomy in an Obese Diabetic Rat Model. Obes Surg 2011 21:1774-1780 
- Matschinsky FM, Glaser B, Magnuson MA. Pancreatic beta-cell glucokinase: closing the gap between theoretical concepts and experimental realities. Diabetes. 1998 Mar;47(3):307-15.

- Mayfield J. Diagnosis and classification of diabetes mellitus: new criteria. Am Fam Physician. 1998 Oct 15;58(6):1355-62, 1369-70.

- McDonald KJ, Long S, Swanson M, et al. The gastric bypass operation reduces the progression and mortality of non-insulin-dependent diabetes mellitus. J Gastrointest Surg 1997;1(3):213-20

- McGarry JD, Dobbins RL. Fatty acids, lipotoxicity and insulin secretion. Diabetologia. 1999 Feb;42(2):128-38.

- McKenney RL, Short DK. Tipping the Balance: the Pathophysiology of Obesity and Type 2 Diabetes Mellitus. Surg Clin N Am 2011;91:1139-1148.

- McLaughlin T, PeckM, Holst J, Deacon C. Reversible hyperinsulinemic hypoglycemia after gastric bypass: a consequence of altered nutrient delivery. J Clin Endocrinol Metab 2010;95:1851-1855

- McMahon MJ. Laparoscopic sleeve gastrectomy: from magenstrasse and mill to sleeve. [supplement A]. In: Proceedings supplement from the international consensussummit on sleeve gastrectomy. NewYork (NY): Bariatric Times; 2007. p.3-4.

- Meier JJ, Butler AE, Galasso R, Butler PC. Hyperinsulinemic hypoglycemia after gastric bypass surgery is not accompanied by islet hyperplasia or increased beta-cell turnover. Diabetes Care 2006;29:1554 - 1559

- Melissas J, Daskalakis M, Koukouraki S, et al. Sleeve gastrectomy-a "food limiting" operation. Obes Surg 2008;18:1251-6.

- Melissas J, Koukouraki S, Askoxylakis J, et al. Sleeve gastrectomy: a restrictive procedure? Obes Surg 2007;17:57-62.

- Mendell JR, Sahenk Z. Painful sensory neuropathy. N Engl J Med. 2003 Jul 17;349(3):306-7.

- Metz SA, Meredith M, Vadakekalam J, Rabaglia ME, Kowluru A. A defect late in stimulus-secretion coupling impairs insulin secretion in Goto-Kakizaki diabetic rats. Diabetes. 1999 Sep;48(9):1754-62.

- Metzger BE, Gabbe SG, Persson B, Buchanan TA, Catalano PA, Damm P, Dyer AR, Leiva A, Hod M, Kitzmiler JL, Lowe LP, Mclntyre HD, Oats JJ, 
Omori Y, Schmidt MI. International association of diabetes and pregnancy study groups recommendations on the diagnosis and classification of hyperglycemia in pregnancy. Diabetes Care. 2010;33(3):676.

- Mingrone G, Castagneto-Gissey L. Mechanisms of early improvement/resolution of type 2 diabetes after bariatric surgery. Diabetes Metab. 2009;35:518-23.

- Ministerio de Sanidad: Estrategia en Diabetes del SNS. www.sediabetes.org/gestor/upload/estrategia_diabetes_sistema_nacional_sal ud. pdf Consultado 19 de febrero de 2012.

- Mistry SB, Omana JJ, Kini S. Rat models for bariatric surgery and surgery for type 2 diabetes mellitus. Obes Surg. 2009 May;19(5):655-60.

- Modanlou KA, Muthyala U, Xiao H, et al. Bariatric surgery among kidney transplant candidates and recipients: analysis of the United States Renal Data System and literature review. Transplantation 2009;87(8):1167-73.

- Mojsov S, Heinrich G, Wilson IB, Ravazzola M, Orci L, Habener JF. Preproglucagon gene expression in pancreas and intestine diversifies at the level of post-translational processing. J Biol Chem. 1986;261(25):11880-9.

- Mokdad AH, Ford ES, Bowman BA, Dietz WH, Vinicor F, Bales VS, Marks JS. Prevalence of obesity, diabetes, and obesity-related health risk factors, 2001. JAMA. 2003;289(1):76.

- Molarius A, Seidell JC, Sans S, Tuomilehto J, Kuulasmaa K. Educational level, relative body weight, and changes in their association over 10 years: an international perspective from the WHO MONICA Project. Am J Public Health. 2000 Aug;90(8):1260-8.

- Molina M, Oria HE. Gastric segmentation: a new, safe, effective, simple, readily revised and fully reversible surgical procedure for the correction of morbid obesity. In: 6th Bariatric Surgery Colloquium. lowa City (IA), June 2-3, 1983

- Montes M, Pacheco D, De Luis DA, et al. Resultados Clínicos y Consecuencias Nutricionales de la Derivación Bilio-pancreática. Comunicación oral. XI Congreso de la Asociación Castellano-leonesa de Cirujanos. Valladolid 2009 (1).

- Montes M, Pacheco D, De Luis DA, et al. Sindrome Metabólico y Derivación Bilio-pancreática. Comunicación oral. XI Congreso de la Asociación Castellano-leonesa de Cirujanos. Valladolid 2009 (2). 
- Murakawa Y, Zhang W, Pierson CR, Brismar T, Ostenson CG, Efendic S y cols. Impaired glucose tolerance and insulinopenia in the GK-rat causes peripheral neuropathy. Diabetes Metab Res Rev 2002; 18 (6): 473-83.

- Naslund I, Granstrom L, Stockeld D, et al. Marlex mesh gastric banding: a 712 year follow-up. Obes Surg 1994;4:269-73.

- National Diabetes Data Group. Diabetes in America. 2d ed. Bethesda, Md.: National Institutes of Health, National Institute of Diabetes and Digestive and Kidney Diseases, 1995; NIH publication no. 95-1468.

- Nauck MA, Heimesaat MM, Behle $\mathrm{K}$ et al. Effects of glucagon- like peptide 1 on counter regulatory hormone responses, cognitive functions and insulin secretion during hyperinsulinemic stepped hypoglycaemic clamp experiments in healthy volunteers. J Clin Endocrinol Metab, 2002; 87: 1239-1246.

- Nauck MA, Heimesaat MM, Behle $\mathrm{K}$ et al. Effects of glucagon- like peptide 1 on counter regulatory hormone responses, cognitive functions and insulin secretion during hyperinsulinemic stepped hypoglycaemic clamp experiments in healthy volunteers. J Clin Endocrinol Metab, 2002; 87: 1239-1246.

- Nauck MA, Heimesaat MM, Orskov C, Holst JJ, Ebert R, Creutzfeldt W, et al. Preserved incretin activity of glucagon-like peptide 1 [7-36 amide] but not of synthetic human gastric inhibitory polypeptide in patients with type-2 diabetes mellitus. J Clin Invest. 1993 Jan;91(1):301-7.

- Nisoli E, Clementi E, Carruba MO, et al. Defective mitochondrial biogenesis: a hallmark of the high cardiovascular risk in the metabolic syndrome? Circ Res 2007;100(6):795-806.

- Noguchi H, Matsumoto S. Islet transplantation at the Diabetes Research Institute Japan. J Hepatobiliary Pancreat Surg. 2008 ;15(3):278-83. Epub 2008 Jun 6 .

- O'Brien PE, et al. Treatment of mild to moderate obesity with laparoscopic adjustable gastric banding or an intensive medical program: a randomized trial. Ann Intern Med 2006;144:625-33.

- Olson DE, Rhee MK, Herrick K, Ziemer DC, Twombly JG, Phillips LS. Screening for diabetes and pre-diabetes with proposed A1C-based diagnostic criteria. Diabetes Care 2010; 33: 2184-89.

- Ortiz-Moncada R, Alvarez-Dardet C, Miralles-Bueno JJ, Ruiz-Cantero MM, Dal Re Saavedra MA, Villar-Villalba C, Pérez-Farinos N, Serra-Majem L. Determinantes sociales de sobrepeso y obesidad en España 2006. Med Clin(Barc) 2011;137(15):678-684 
- Pacheco D, de Luis DA, Romero A, González Sagrado M, Conde R, Izaola O, Aller R, Delgado A. The effects of duodenal-jejunal exclusion on hormonal regulation of glucose metabolism in Goto-Kakizaki rats. Am J Surg. 2007 Aug;194(2):221-4.

- Pallardo Sánchez LF. Drugs with incretin effects. A therapeutic alternative in type 2 diabetes mellitus. Avances en Diabetología. 2008;24 (1): 4-6.

- Pallayova M, Steele KE, Magnuson TH, et al. Sleep apnea determines soluble TNF-alpha receptor 2 response to massive weight loss. Obes Surg $2011 ; 21(9): 1413-23$.

- Papailiou J, Albanopoulos K, Toutouzas KG, Tsigris C, Nikiteas N, Zografos G. Morbid obesity and sleeve gastrectomy: how does it work? Obes Surg. 2010 Oct;20(10):1448-55. Review.

- Park C, Torquati A. Physiology of Weight Loss Surgery. Surg Clin N Am 2011;91: 1149-1161

- Patout CA Jr, Birke JA, Horswell R, Williams D, Cerise FP. Effectiveness of a comprehensive diabetes lower-extremity amputation prevention program in a predominantly low-income African-American population. Diabetes Care. 2000 Sep;23(9):1339-42.

- Patrikakos P, Toutouzas KG, Perrea D, Menenakos E, Pantopoulou A, Thomopoulos T, Papadopoulos S, Bramis JI. A surgical rat model of sleeve gastrectomy with staple technique: long-term weight loss results. Obes Surg. 2009 Nov;19(11):1586-90. Epub 2009 Sep 15.

- Patriti A, Facchiano E. Early improvement of glucose tolerance after ileal transposition in a non-obese type 2 diabetes rat model. Obesity Surgery 2005;15:1258-1264.

- Payne J, DeWind L, Commons R. Metabolic observations in patients with jejunocolic shunts. Am J Surg 1963;106:273-89.

- Pérez Freirre N. y Calle Pascual A. Tratamiento de las complicaciones neuropáticas de la diabetes mellitus. Endocrinol Nutr. 2008;55:99-104.

- Pérez-Castrillón JL, De Luis D, Martín-Escudero JC, Asensio T, del Amo R, Izaola O. Non-insulin-dependent diabetes, mineral density, and cardiovascular risk factors. J Diabetes Complications. 2004 NovDec;18(6):317-21.

- Peterli R, Steinert R, Woelnerhanssen B, Peters T, Christoffel-Courtin C, Gass M, Kern B, von Fluee M, Beglinger C.. Metabolic and Hormonal 
Changes After Laparoscopic Roux-en-Y Gastric Bypass and Sleeve Gastrectomy: a Randomized, Prospective Trial. Obes Surg 2012;22:740-748.

- Peterli R, Wolnerhanssen B, Peters T, et al. Improvement in glucose metabolism after bariatric surgery: comparison of laparoscopic Roux-en-Y gastric bypass and laparoscopic sleeve gastrectomy: a prospective randomized trial. Ann Surg 2009;250(2):234-41

- Philippe J, Raccah D. Treating type 2 diabetes: how safe are current therapeutic agents? Int J Clin Pract 2009; 63: 321-32.

- Pinhas-Hamiel O, Dolan LM, Daniels SR, Standiford D, Khoury PR, Zeitler P. Increased incidence of non-insulin-dependent diabetes mellitus among adolescents. J Pediatr. 1996;128(5 Pt 1):608.

- Pinhas-Hamiel O, Zeitler P. The global spread of type 2 diabetes mellitus in children and adolescents. J Pediatr. 2005;146(5):693.

- Poirier P, Giles TD, Bray GA, et al. Obesity and cardiovascular disease: pathophysiology, evaluation, and effect of weight loss: an update of the 1997 American Heart Association scientific statement on obesity and heart disease from the Obesity Committee of the Council on Nutrition, Physical Activity, and Metabolism. Circulation 2006;113(6):898-918.

- Pories WJ, Mehaffey J, Staton KM. The Surgical Treatment of Type Two Diabetes Mellitus. Surg Clin N Am 2011;91: 821-836

- Pories WJ, Swanson MS, MacDonald KG, Long SB, Morris PG, Brown BM, et al. Who would have thought it?: an operation proves to be the most effective therapy for adult onset diabetes. Ann Surg. 1995;222:339-52.

- Portha B, Giroix MH, Serradas P, Morin L, Tormo MA, Bailbe D. Cellular basis of pancreatic beta-cells in non-insulin dependent diabetes. In Insulin Secretion and Pancreatic beta-cell Research. Flatt PR, Lenzen S, Eds. London, Smith-Gordon, 1994, p. 461-472

- Portha B, Lacraz G, Chavey A, et al. Islet structure and function in the GK rat. Adv Exp Med Biol. 2010;654:479-500.

- Portha B, Lacraz G, Kergoat M, et al. The GK rat beta-cell: a prototype for the diseased human beta-cell in type 2 diabetes? Mol Cell Endocrinol 2009;297:73-85

- Portha B, Serradas P, Bailbé D, Suzuki K, Goto Y, Giroix M-H. Beta Cell insensitivity to glucose in the GK rat, a spontaneous nonobese model for type II diabetes. Diabetes 1991;40: 486-491. 
- Portha B., Giroix M.-H., Serradas P.P., Gangnerau M.N., Movassat J., Rajas F., et al. Beta-cell function and viability in the spontaneously diabetic GK rat. Information fromthe GK/Par colony. Diabetes 2001, 50, 89-93.

- Power ML, Schulkin J. Anticipatory physiological regulation in feeding biology: cephalic phase responses. Appetite 2008;50(2):194-206.

- Prachand V, Ward M, Alverdy J. Duodenal switch provides superior resolution of metabolic comorbidities independent of weight loss in the super-obese $(\mathrm{BMI}>$ or $=50 \mathrm{~kg} / \mathrm{m} 2)$ compared with gastric bypass. J Gastrointest Surg. 2010 Feb;14(2):211-20.

- Quesada I., Todorova M.G., Soria B. Different metabolic responses of a, b and d-cells monitored by redox confocal microscopy within the intact islet of Langerhans. Biophys. J. 2006; 90: 2641-2650.

- Quesada I., Todorova M.G., Soria B. Different metabolic responses of a, b and d-cells monitored by redox confocal microscopy within the intact islet of Langerhans. Biophys. J. 2006; 90: 2641-2650.

- Ram E, Vishne T, Maayan R, et al. The relationship between BMI, plasma leptin, insulin and proinsulin before and after laparoscopic adjustable gastric banding. Obes Surg 2005;15(10):1456-62.

- Ramos A, Galvao Neto M, Galvao M, et al. Laparoscopic greater curvature plication: initial results of an alternative restrictive bariatric procedure. Obes Surg 2010;20(7):913-8.

- Ramos C.,Galvão M., de Souza YM, Galvão M, Murakami A, Silva A, et al. Laparoscopic Duodenal-Jejunal Exclusion in the Treatment of Type 2 Diabetes Mellitus in Patients with BMI $<30 \mathrm{~kg} / \mathrm{m} 2$ (LBMI). Obes surg 2009; 19:307-312.

- Rao RS, Rao V, Kini S. Animal models in bariatric surgery--a review of the surgical techniques and postsurgical physiology. Obes Surg. 2010 Sep;20(9):1293-305. Review.

- Ravussin E, Lillioja S, Knowler WC, et al. Reduced rate of energy expenditure as a risk factor for body weight gain. N Engl J Med 1988;31

- Ravussin E, Smith SR, Mitchell JA, et al. Enhanced weight loss with pramlintide/ metreleptin: an integrated neurohormonal approach to obesity pharmacotherapy. Obesity (Silver Spring) 2009;17(9):1736-43.

- Reaven GM, Insulin Resistance: the Link Between Obesity and Cardiovascular Disease. Med Clin N Am 2011;95:875-892 
- Reddy RC, Baptist AP, Fan Z, et al. The effects of bariatric surgery on asthma severity. Obes Surg 2011;21(2):200-6.

- Redondo MJ, Eisenbarth GS. Genetic control of autoimmunity in Type I diabetes and associated disorders. Diabetología. 2002, 45:605.

- Regan JP, Inabnet WB, Gagner M, et al. Early experience with two-stage laparoscopic Roux-en-Y gastric bypass as an alternative in the super-super obese patient. Obes Surg 2003;13:861-4.

- Riedl M, Vila G, Maier C, Handisurya A, Shakeri-Manesch S, Prager G, Wagner O, Kautzky-Willer A, Ludvik B, Clodi M, Luger A. Plasma osteopontin increases after bariatric surgery and correlates with markers of bone turnover but not with insulin resistance. J Clin Endocrinol Metab. 2008;93:2307-2312.

- Rizzello M, Abbatini F, Casella G, et al. Early postoperative insulin-resistance changes after sleeve gastrectomy. Obes Surg 2010;20:50-5.

- Rocca AS, Brubaker PL. Role of the vagus nerve in mediating proximal nutrient-induced glucagon-like peptide-1 secretion. Endocrinology 1999;140:1687-1694.

- Rodriguez-Grunert L, Galvao Neto MP, Alamo M, et al. First human experience with endoscopically delivered and retrieved duodenal-jejunal bypass sleeve. Surg Obes Relat Dis 2008;4(1):55-9.

- Roglic G, Unwin N, Bennett PH, Mathers C, Tuomilehto J, Nag S, et al. The burden of mortality attributable to diabetes: realistic estimates for the year 2000. Diabetes Care. 2005 Sep;28(9):2320-1.

- Romero F, Nicolau J, Flores L, Casamitjana R, Ibarzabal A, Lacy A, Vidal J. Comparable early changes in gastrointestinal hormones after sleeve gastrectomy and Roux-En-Y gastric bypass surgery for morbidly obese type 2 diabetic subjects. Surg Endosc. 2012 Feb 1.

- Rosenstock J, Banarer S, Fonseca VA, et al. The 11- $\beta$-hydroxysteroid dehydrogenase type 1 inhibitor incb13739 improves hyperglycemia in patients with type 2 diabetes inadequately controlled by metformin monotherapy. Diabetes Care 2010; 33: 1516-22.

- Rosenstock J, Park G, Zimmerman J; U.S. Insulin Glargine. Type 1 Diabetes Investigator Group. Basal insulin glargine versus NPH insulin in patients with type 1 diabetes on multiple daily insulin regimens. U.S. Insulin Glargine Type 1 Diabetes Investigator Group. Diabetes Care. 2000 Aug;23(8):1137-42.

- Rubino F, Forgione A, Cummings DE et al. The mechanism of diabetes control after gastrointestinal bypass surgery reveals a role of the proximal 
small intestine in the pathophysiology of type 2 diabetes. Ann Surg 2006; 244 : 741-749.

- Rubino F, Gagner M. Weight loss and plasma ghrelin levels. N Engl J Med 2002;347:1379-81.

- Rubino F, Marescaux J. Effect of duodenal-jejunal exclusion in a non-obese animal model of type 2 diabetes: a new perspective for an old disease. Ann Surg. 2004 Jan; 239(1):1-11.

- Rubino F, Schauer PR, Kaplan LM, et al. Metabolic surgery to treat type 2 diabetes: clinical outcomes and mechanisms of action. Annu Rev Med. 2010;61:393-411.

- Runkel N, Colombo-Benkmann M, Huttl TP, et al. Evidence-based German guidelines for surgery for obesity. Int J Colorectal Dis 2011;26(4):397-404.

- Rutter MK, Meigs JB, Sullivan LM, et al. Insulin resistance, the metabolic syndrome, and incident cardiovascular events in the Framingham offspring study. Diabetes 2005;54(11):3252-7.

- Sabench Pereferrer F, Hernàndez Gonzàlez M, Del Castillo Déjardin D. Experimental metabolic surgery: justification and technical aspects.. Obes Surg. 2011 Oct;21(10):1617-28.

- Sabench Pereferrer F, Hernández M, Blanco S, Sánchez A, Morandeira A, del Castillo D. Efectos de la transposición ileal, el bypass gastroyeyunal y la gastroplastia vertical en la regulación de la ingesta en un modelo experimental de obesidad relacionada con diabetes mellitus tipo 2. Cir Esp $2009 ; 85(4): 222-228$.

- Sabench Pereferrer F, Gonzàlez MH, Rovira AF, Blasco SB, Rivas AM, del Castillo Déjardin D. Influence of sleeve gastrectomy on several experimental models of obesity: metabolic and hormonal implications. Obes Surg. 2008 Jan;18(1):97-108. Epub 2007 Dec 8.

- Salehi A, Henningsson R, Mosén H, Ostenson CG, Efendic S, Lundquist I. Dysfunction of the islet lysosomal system conveys impairment of glucoseinduced insulin release in the diabetic GK rat. Endocrinology 1999;140: 30453053.

- Saliba J, Kasim NR, Tamboli RA, et al. Roux-en-Y gastric bypass reverses renal glomerular but not tubular abnormalities in excessively obese diabetics. Surgery 2010;147(2):282-7. 
- Salmon PA. Gastroplasty with distal gastric bypass: a new and more successful weight loss operation for the morbidly obese. Can J Surg 1988;31(2):111-3.

- Sammour T, Hill A, Singh P, et al. Laparoscopic sleeve gastrectomy as a singlestage bariatric procedure. Obes Surg 2010;20(3):271-5.

- Santer R, Calado J. Familial renal glucosuria and SGLT2: from a mendelian trait to a therapeutic target. Clin J Am Soc Nephrol 2010;5:133-41.

- Santoro S, Malzoni CE, Velhote MC, et al. Digestive adaptation with intestinal reserve: a neuroendocrine-based operation for morbid obesity. Obes Surg 2006;16(10):1371-9.

- Santos E, Fernández-Vigo J, Fernández C, Macarro A, Fernández J. Prevalencia de retinopatía diabética en la Comunidad Autónoma de Extremadura. Arch Soc Esp Oftalmol. 2005;80:187-94.

- Schouten R, Rijs CS, Bouvy ND, et al. A multicenter, randomized efficacy study of the EndoBarrier Gastrointestinal Liner for presurgical weight loss prior to bariatric surgery. Ann Surg 2010;251(2):236-43.

- Scopinaro N, Gianetti E, Adami G, et al. Biliopancreatic diversion for obesity at eighteen years. Surgery 1996;119:261-8.

- Scopinaro N. Biliopancreatic diversion: mechanisms of action and long-term results. Obes Surg 2006;16(6):683-9.

- Serra-Majem LI, Ribas Barba L, Aranceta Bartrina J, Pérez Rodrigo C, Saavedra Santana P, Peña Quintana L. Obesidad infantil y juvenil en España. Resultados del Estudio Enkid (1998-2000). Med Clin (Barc) 2003; 121: 725-32

- Shah P, Vella A, Basu A, Basu R, Schwenk WF, Rizza RA. Lack of suppression of glucagon contributes to postprandial hyperglycemia in subjects with type 2 diabetes mellitus. J Clin Endocrinol Metab 2000;85:4053-4059.

- Shen R, Dugay G, Rajaram K, et al. Impact of patient follow-up on weight loss after bariatric surgery. Obes Surg 2004;14:514-9.

- Shin D. The effect of seamustard on blood lipid profiles and glucose level of rats fed diet with different energy composition. Nutr Res Pract. 2009 Spring;3(1):31-7. doi: 10.4162/nrp.2009.3.1.31. Epub 2009 Mar 31.

- Siebenhofer A, Plank J, Berghold A, Jeitler K, Horvath K, Narath M, Gfrerer R, Pieber TR. Cochrane Database Syst Rev. 2006 Apr 19;(2):CD00328 
- Silecchia G, Boru C. Effectiveness of laparoscopic sleeve gastrectomy (first stage of biliopancreatic diversion with duodenal switch) on comorbidities in super-obese high risk patients. Obes Surg 2006;16(9):1138-44.

- Sjostrom L, Gummesson A, Sjostrom CD, et al. Effects of bariatric surgery on cancer incidence in obese patients in Sweden (Swedish Obese Subjects Study): a prospective, controlled intervention trial. Lancet Oncol 2009;10(7): 653-62.

- Sjostrom L, Lindroos AK, Peltonen M, et al. Lifestyle, diabetes, and cardiovascular risk factors 10 years after bariatric surgery. $\mathrm{N}$ Engl $\mathrm{J}$ Med 2004;351(26): 2683-93.

- Sjöström L, Narbro K, Sjöström CD, Karason K, Larsson B, Wedel H, et al. Effects of bariatric surgery on mortality in Swedish obese subjects. N Engl J Med. 2007 Aug 23;357(8):741-52.

- Sloth B, Holst JJ, Flint A, et al. Effects of PYY1-36 and PYY3-36 on appetite, energy intake, energy expenditure, glucose and fat metabolism in obese and lean subjects. Am J Physiol Endocrinol Metab 2007;292(4):E1062-8

- Soares JB, Leite-Moreira AF. Ghrelin, des-acyl ghrelin and obestatin: three pieces of the same puzzle. Peptides 2008;29(7):1255-70

- Sociedad Española para el Estudio de la Obesidad (SEEDO). Consenso SEEDO 2000 para la evaluación del sobrepeso y la obesidad y el establecimiento de criterios de intervención terapéutica. Med Clin (Barc) 2000;115:587-97.

- Sone H, Kawakami Y, Okuda Y, Sekine Y, Honmura S, Matsuo K y cols. Ocular vascular endothelial growth factor levels in diabetic rats are elevated before observable retinal proliferative changes. Diabetología 1997; 40 (6): 726-30.

- Soriguer F. Goday A. Bosch-Comas A. Bordiú E. Calle-Pascual A. Carmena R. Casamitjana R. Castaño L. Castell C. Catalá E. Delgado E. Franch J. Gaztambide S. Girbés J y otros. Prevalence of diabetes mellitus and impaired glucose regulation in Spain: the Di@bet.es Study. Diabetologia (2012) 55:88-93

- Stefater MA, Pérez-Tilve D, Chambers AP, Wilson-Pérez HE, Sandoval DA, Berger J, Toure M, Tschöep M, Woods SC, Seeley C. Sleeve Gastrectomy Induces Loss of Weight and Fat Mass in Obese Rats, but Does Not Affect Leptin Sensitivity. Gastroenterology. 2010 June ; 138(7): 2426-2436.e3. 
- Steffen R. The history and role of gastric banding. Surg Obes Relat Dis 2008;4: S7-13.

- Strader AD, Clausen TR, Goodin SZ, Wendt D. lleal interposition improves glucose tolerance in low dose streptozotocin-treated diabetic and euglycemic rats. Obes Surg. 2009 Jan;19(1):96-104

- Sullivan PW, Morrato EH, Ghushchyan V, Wyatt HR, Hill JO. Obesity, inactivity, and the prevalence of diabetes and diabetes-related cardiovascular comorbidities in the U.S., 2000-2002. Diabetes Care. 2005;28(7):1599.

- Sun D, Liu S, Zhang G, Chen W, Yan Z, Hu S. Type 2 Diabetes Control in a Nonobese Rat Model Using Sleeve Gastrectomy with Duodenal-Jejunal Bypass (SGDJB). Obes Surg. 2012 Aug 22. [Epub ahead of print]

- Swarbrick MM, Stanhope KL, Austrheim-Smith IT, Van Loan MD, Ali MR, Wolfe BM, Havel PJ. Longitudinal changes in pancreatic and adipocyte hormones following Roux-en-Y gastric bypass surgery. Diabetologia. 2008;51:1901-1911.

- Taborsky GJ. The Physiology of Glucagon. J Diabetes Sci Technol 2010;4(6):1338 1344

- Tahrani AA, Bailey CJ, Del Prato S, Barnett AH. Management of type 2 diabetes: new and future developments in treatment. Lancet 2011; 378: 18297

- Talebpour M, Amoli BS. Laparoscopic total gastric vertical plication in morbid obesity. J Laparoendosc Adv Surg Tech A 2007;17(6):793-8.

- Teruel C, Fernández-Real JM, Ricart W, Valent R, Vallés M. Prevalence of diabetic retinopathy in the region of Girona. Study of related factors. Arch Soc Esp Oftalmol. 2005 Feb;80(2):85-91.

- Thomas S, Schauer P. Bariatric surgery and the gut hormone response. Nutr Clin Pract 2010;25(2):175-82

- Toplak H, Ziegler O, Keller U, Hamann A, Godin C, Wittert G, et al. X-PERT: weight reduction with orlistat in obese subjects receiving a mildly or moderately reduced-energy diet. Early response to treatment predicts weight maintenance. Diab Obes Metabol 2005; 7: 699-708.

- Torgerson JS, Hauptman J, Boldrin MN, Sjöström L. Xenical in the prevention of diabetes in obese subjects (XENDOS) study: a randomized study of orlistat as an adjunct to lifestyle changes for the prevention of type 2 diabetes in obese patients. Diabetes Care 2004; 27: 155-61. 
- Torres JC, Oca CF, Garrison RN. Roux-en-Y gastrojejunostomy from the lesser curvature. South Med J 1983;76:1217-21.

- Tourrel C, Bailbe D, Lacorne M, Meile MJ, Kergoat M, Portha B. Persistent improvement of type 2 diabetes in the Goto-Kakizaki rat model by expansion of the beta-cell mass during the prediabetic period with glucagon-like peptide1 or exendin 4. Diabetes. 2002 May;51(5):1443-52.

- Trumper A, Trumper K, Horsch D. Mechanisms of mitogenic and antiapoptotic signaling by glucose-dependent insulinotropic polypeptide in (INS1)-cells. J Endocrinol 2002;174:233-246.

- Trumper A, Trumper K, Trusheim H, Arnold R, Goke B, Horsch D. Glucose dependent insulinotropic polypeptide is a growth factor for (INS-1) cells by pleiotropic signaling. Mol Endocrinol 2001;15:1559-1570.

- Tschoner A, Sturm W, Ress C, et al. Effect of weight loss on serum pigment epithelium-derived factor levels. Eur J Clin Invest 2011;41(9):937-42.

- Tunceli K, Bradley CJ, Nerenz D, Williams LK, Pladevall M, Elston Lafata J. The impact of diabetes on employment and work productivity. Diabetes Care. 2005; 28 (11):2662.

- Tuncman G, Erbay E, Hom X, et al. A genetic variant at the fatty acid-binding protein aP2 locus reduces the risk for hypertriglyceridemia, type 2 diabetes, and cardiovascular disease. Proc Natl Acad Sci USA 2006;103:6970-5.

- Tuomilehto J, Lindström J, Eriksson JG, Valle TT, Hämäläinen H, llanneParikka $P$, et al. Prevention of type 2 diabetes mellitus by changes in lifestyle among subjects with impaired glucose tolerance. Finnish Diabetes Prevention Study Group. N Engl J Med. 2001 May 3;344(18):1343-50.

- Uglioni B, Wolnerhanssen B, Peters T, et al. Midterm results of primary vs. secondary laparoscopic sleeve gastrectomy (LSG) as an isolated operation. Obes Surg 2009;19(4):401-46.

- UKPDS GROUP. Holman RR, Turner RC, Neil HA; United Kingdom Prospective Diabets Study Group. Effects of three months' diet after diagnosis of Type 2 diabetes on plasma lipids and lipoproteins (UKPDS 45). UK Prospective Diabetes Study Group. Diabet Med. 2000 Jul;17(7):518-23

- Unger $\mathrm{RH}$, Orci L. Glucagon and the A cell: physiology and pathophysiology (second of two parts). N Engl J Med. 1981 Jun 25;304(26):1575-80.

- Unger RH, Orci L. Glucagon and the A cell: physiology and pathophysiology (second of two parts). N Engl J Med. 1981 Jun 25;304(26):1575-80. 
- Urakami T, Kubota S, Nitadori Y, Harada K, Owada M, Kitagawa T. Annual incidence and clinical characteristics of type 2 diabetes in children as detected by urine glucose screening in the Tokyo metropolitan area. Diabetes Care. $2005 ; 28(8): 1876$.

- Vague J. The degree of masculine differentiation of obesities, a factor determining predisposition to diabetes, atherosclerosis, gout, and acid calculous disease. Am J Clin Nutr 1956;4:20-34

- Vague P, Selam JL, Skeie S, De Leeuw I, Elte JW, Haahr H, Kristensen A, Draeger $\mathrm{E}$. Insulin detemir is associated with more predictable glycemic control and reduced risk of hypoglycaemia than NPH insulin in patients with type 1 diabetes on a basal-bolus regimen with premeal insulin aspart. Diabetes Care. 2003 Mar;26(3):590-6.

- Van Hubbard S. Defining overweigth and obesity: what are the issues? Am J Clin Nutr 2000;72:1067-8.

- Vázquez C, Montagna C, Garriga M, Alcaraz F, Martín E, Botella Jl, et al. Dieta y ejercicio. Endocrinol Nutr. 2008;55:3-12.

- Velasco J, Cosína J; Maroto JM; Muñiza J; Casasnovasa JA; Plazaa I; Abadala LT. Guías de práctica clínica de la Sociedad Española de Cardiología en prevención cardiovascular y rehabilitación cardíaca. Rev Esp Cardiol. 2000;53:1095-120.

- Vidal J, Ibarzabal A, Romero F, et al. Type 2 diabetes mellitus and the metabolic syndrome following sleeve gastrectomy in severely obese subjects. Obes Surg 2008;18:1077-82.

- Vincent HK, Ben-David K, Cendan J, et al. Effects of bariatric surgery on joint pain: a review of emerging evidence. Surg Obes Relat Dis 2010;6(4):451-60.

- Wada M, Connolly CC, Tarumi C, Neal DW, Cherrington AD. Hepatic denervation does not significantly change the response of the liver to glucagon in conscious dogs. Am J Physiol. 1995;268(2 Pt 1):E194-203.

- Walker BR, Andrew R. Tissue production of cortisol by 11 beta-hydroxysteroid dehydrogenase type 1 and metabolic disease. Ann N Y Acad Sci 2006;1083: 165-84.

- Wang TT, Hu SY, Gao HD, Zhang GY, Liu CZ, Feng JB, Frezza EE. Ileal transposition controls diabetes as well as modified duodenal jejunal bypass with better lipid lowering in a nonobese rat model of type II diabetes by increasing GLP-1. Ann Surg. 2008 Jun;247(6):968-75. 
- Wang Y, Yan L, Jin Z, Xin X. Effects of sleeve gastrectomy in neonatally streptozotocin - induced diabetic rats. PLoS One. 2011 Jan 21;6(1):e16383.

- Wareham NJ. Epidemiology of type 2 diabetes. Endocrinol Nutr. 2009 Dec; 56S4:60-62.

- Webb GC, Akbar MS, Zhao C, Steiner DF. Expression profiling of pancreatic beta-cells: glucose regulation of secretory and metabolic pathway genes. Diabetes. 2001 Feb;50 Suppl 1:S135-6.

- Weiner RA. Surgical treatment of non-alcoholic steatohepatitis and nonalcoholic fatty liver disease. Dig Dis 2010;28(1):274-9.

- Weir GC, Marselli L, Marchetti P, Katsuta H, Jung MH, Bonner-Weir S. Towards better understanding of the contributions of overwork and glucotoxicity to the beta cell inadequacy of type 2 diabetes. Diabetes Obes Metab 2009; 11 (suppl 4): 82-90.

- Welsh M, Nielsen DA, MacKrell AJ, Steiner DF. Control of insulin gene expression in pancreatic beta-cells and in an insulin-producing cell line, RIN5F cells. II. Regulation of insulin mRNA stability. J Biol Chem. 1985 Nov 5;260(25):13590-4.

- Wickremesekera K, Miller G, Naotunne TD, Knowles G, Stubbs RS. Loss of insulin resistance after Roux-en-Y gastric bypass surgery: a time course study. Obes Surg 2005, 15:474-481.

- Wickremesekera K, Miller G, Naotunne TD, Knowles G. Loss of insulin resistance after Roux-en-Y gastric bypass surgery: a time course study. Obes Surg 2005, 15:474-481.

- Wild S, Roglic G, Green A, Sicree R, King H. Global prevalence of diabetes: estimates for the year 2000 and projections for 2030. Diabetes Care. 2004; 27:1047-53.

- Wilson PW. Estimating cardiovascular disease risk and the metabolic syndrome: a Framingham view. Endocrinol Metab Clin North Am 2004;33(3):467-81.

- World Health Organization Media centre. Obesity and overweight fact sheet. $\mathrm{N}^{\star} 311$; 2011.

- World Health Organization: Definition, Diagnosis, and Classification of Diabetes Mellitus and its Complications: Report of a WHO Consultation. Geneva, World Health Org., 1999 
- Wu L, Olverling A, Fransson L, Ortsäter H, Kappe C, Gao X, Sjöholm A. Early intervention with liraglutide improves glucose tolerance without affecting islet microcirculation in young Goto-Kakizaki rats. Regul Pept. 2012 Aug 20;177(13):92 6.

- Yang Q, Graham TE, Mody N, et al. Serum retinol binding protein 4 contributes to insulin resistance in obesity and type 2 diabetes. Nature 2005;436(7049): 356-62.

- Yki-Jarvinen H. Thiazolidinediones. N Engl J Med 2004; 351: 1106-18.

- Zalesin KC, Franklin BA, Miller WM, Peterson ED, McCullough PA. Impact of Obesity on Cardiovascular Disease. Med Clin N Am 2011;95: 919-937. 